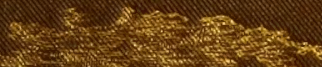

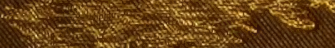

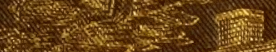

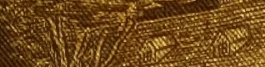

(1)

fil $x=2$.

M

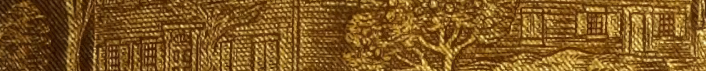

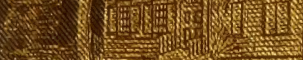

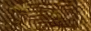

(1) $=0$

17.

\title{
Nin
}

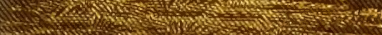

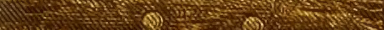

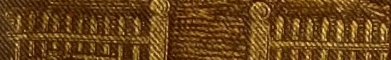

Hun

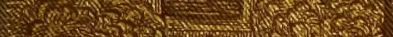

Q.
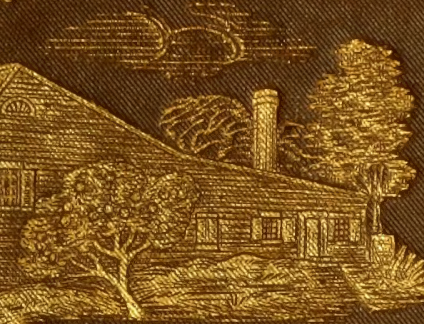

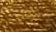
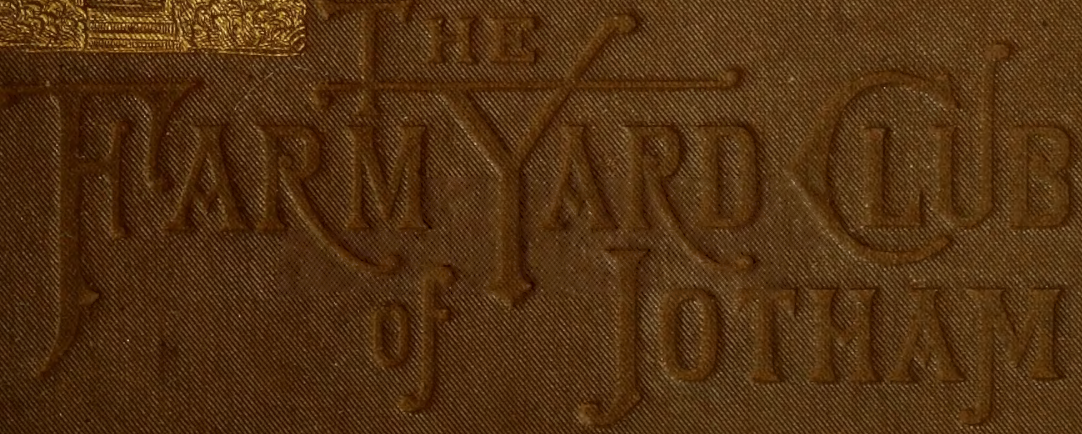

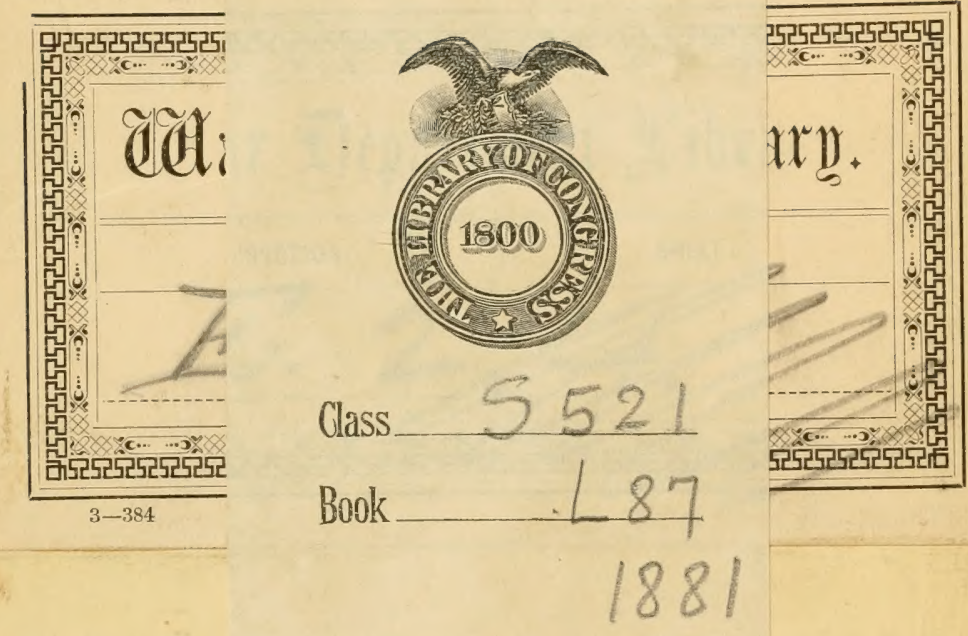


T H E

\section{FARM-YARD (LUB}

\section{OF JOTHAM :}

AN ACCOUNT OF THE FAMILIES AND FARMS OF THAT FAMOUS TOWN.

GEORGE B. LORING, United States Commissioner of Agriculture.
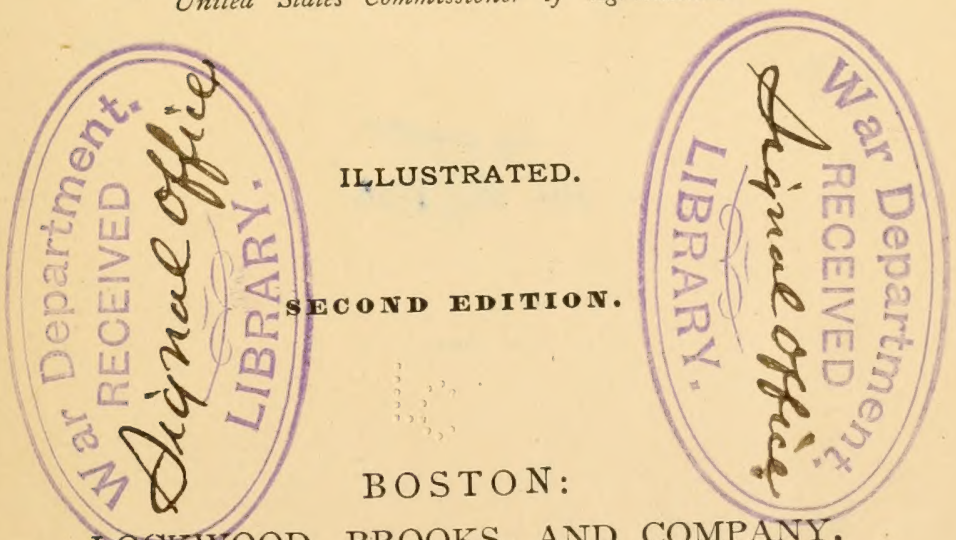

LOCKWOOD, BROOKS, AND COMPANY. I 88 I. 


\section{1 \\ 487 \\ 1881}

Copyright, 1876 .

BY LOCKWOOD, BROOKS, \& CO.

\section{by twesnator: \\ JUL 201916}




\section{E D I C A T I O N.}

To the sacred and blessed memory of her whose love warmed, and virtues elevated, and rare powers and attainments dignified, my home, and who encouraged and strengthened me in every worthy endeavor, during all the happy years of our life together; and to the daughter she left in my care, and who is the pride of my heart, I dedicate affectionately this volume.

G. B. L.

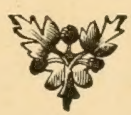





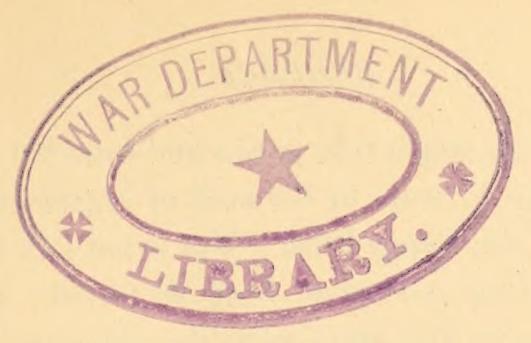

\section{PREFACE.}

$\mathrm{W}$

HEN I was induced to furnish the "Boston Globe" with a series of articles on agricultural subjects, I determined to present my views, if possible, in a form which would arrest the attention of every reader interested in the homes and farms and institutions and social habits of the American people. While I have called the practical farmers of an educated community, therefore, to the discussions, I have endeavored to portray the society in which they live, and the thoughts, character, and experience of their neighbors and friends, as well as of themselves; and I have done this with the hope that I might inspire a love of rural life, and also furnish some useful information upon rural pursuits. It is undoubtedly true, that, although the importance of agriculture as an industry can never be lost sight of, its delicate and intricate relations to society are in danger of being forgotten. The deliberate business of applying scientific rules to the cultivation of the earth, and the serious business of drawing a subsistence from her bosom, have wellnigh blinded us to the delightful associations and the natural beauty which belong to this primary and fundamental occupation. When the ancient Greeks organized their Olympian court, they gave almost the highest place to Demeter, the goddess of the cultivated and fruitful earth, of cornfields and vineyards, and at the same time the goddess of domestic 
joys, who not only taught men to sow and reap, but taught man ' and woman also to unite in the work of organizing a refined and cultivated and happy home. Not in our own day has this true and charming conception been destroyed; and I have endeavored to open the doors upon the refinement of thought and feeling which should naturally belong to our rural homes, and to give to the daily toil of the farmer in our Christian age the high and cultivated place assigned it by the most practical as well as the most poetical people of ancient times. It is not the mere possession of land which has, in all ages of the world, made an agricultural people strong and enduring; but it is the sturdy characteristics and ardent attachments growing out of such possession which constitute that vital force of a nation so much admired by the careful observer and student of history. And it has been left for us to prove that an independent and responsible community of small landholders, living in a land of social and civil equality, and tilling their own soil, stands foremost among those who are distinguished for intelligence and self-assertion, for devotion to human rights and progress, and for a lordly determination to preserve their own prerogatives. With this estimate of American agriculture I have written this book.

Lest the reader should be confused by any apparent anachronisms in the essays and discussions, I desire to state that all theories and statistics contained in the debates have been brought down to the present time, - an act of justice to the Club and of benefit to the public, for which I have no doubt both will be grateful.

THE AUTHOR. 


\section{CONTENTS.}

PREFACE PREFACE • • • • • • • • • • • INTRODUCTORY . . . . . . . . . . I I

The Town of Jotham. - The Hopkins Family. - The Old Farm and the New Barn.

\section{THE FIRST MEETING.}

Organization of the Club . . . . . . . .

The Thanksgiving. - Mr. Hopkins chosen President of the Club.

- His Speech of Acceptance.

\section{SECOND MEETING.}

Cattle

Mr. Howe and John Thomas commence their Labors. - Mr. Howe's Essay. - Mrs. Howe and Mrs. Thomas rejoice.

\section{THIRD MEETING.}

CATTLE (Continued)
Fanny Wright appears. - Dr. Parker comes upon the Stage and discourses on the Structure of Cattle.

\section{FOURTH MEETING.}

\section{Cattle (Continued)}

Dr. Parker continues. - His Opinion of Inherited Faculties and

Characteristics. - He soars aloft and rejects Evolution.

\section{FIFTH MEETING。}

\section{Cattle (Continued)}

How to cut and use Fire-wood. - John Thomas discusses Cattle Swedes. - Mangolds. - Fodder-Corn. - A Controversy. - Peter Ilsley shows his Temper. 


\section{SIXTH MEETING.}

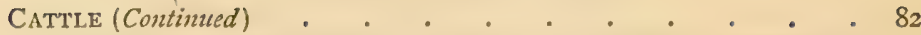

John Thomas and Huldah. - Family Jars. - Peace. - Modes of feeding Cattle. - Charles Ingalls appears.

\section{SEVENTH MEETING.}

CATTLE (Continued)

Spring opens. - A Northeast Storm. - Disease and Weakness in

Cows. - The Milk-mirror.

\section{EIGHTH · MEETING.}

FERTILIZERS

The District School, - An Educational Struggle.

\section{NINTH MEETING.}

Fertilizers (Continued)

The Drive to the Seaside. - Dr. Parker and Clara Bell. - An Exciting Time followed by Repose.

\section{TENTH MEETING.}

FERTILIZERs (Continued)

Charles Ingalls returns. - His Disappointment. - Mr. Howe dis142 cusses Fertilizers.

\section{ELEVENTH MEETING.}

\section{DRAINAGE}

President Hopkins speaks, and tells how he drained his Land.

TWELFTH MEETING.

The Hay Crop

The Trials of the Schoolmaster and Clara Bell. - Imaginary Trials the most difficult to overcome. - Mr. Hopkins delivers a Lecture on the Hay Crop.

\section{THIRTEENTH MEETING.}

THE HAY CROP (Continued)

Seeding Grass lands. - Peter Ilsley debates and wanders. - Dr. Parker loses his Temper. 


\section{FOURTEENTH MEETING.}

The Hay Crop (Continued)

A Social Breeze. - Mr. William Jones enlightens Mr. Howe.-

Mr. Hopkins defends Clara Bell, and gives Mr. Howe some good Advice.

FIFTEENTH MEETING.

Pasture lands . • • . . . . • • .

Squire Wright enters the Field. - Fanny returns a Widow. - The Western Life.

\section{SIXTEENTH MEETING.}

Pasture Lands (Continued)

Dr. Parker does not understand Clara Bell. - Charles Ingalls does.

- The Squire found to be fallible.

\section{SEVENTEENTH MEETING.}

Root CROPS .

Illness of the Boy. - His Recovery. - Silent Distress. - Charles Ingalls tells his Tale. - Clara listens. - Day breaks.

\section{EIGHTEENTH MEETING.}

RoOT Crops (Continued)

Sorrow vanishes. - Human Nature returns. - Fanny tells Dr.

Parker some Wholesome Truths. - He finds his Match.

\section{NINETEENTH MEETING.}

Grain Crops

Political Reform. - The Grocery. - Peter Ilsley shows himself. 274 John Thomas and his Family slandered.

\section{TWENTIETH MEETING.}

\section{GraIN Crops (Continued)}

John Thomas in Trouble. - His Character assailed. - Some Friends desert. - The Town-Meeting. - Charles Ingalls behaves like a Man. - Clara Bell shines. 


\section{TWENTY-FIRST MEETING.}

Grain Crops (Continued) . . . . . . . . .

Mr. Howe slow to believe. - William Jones talks about Oats and Horses. - Dr. Parker continues the Debate. - Mr. Hopkins proves the Integrity of John Thomas. - They all rejoice.

\section{TWENTY-SECOND MEETING.}

Market Gardening $\cdot$ Jim Bell's Sickness and Death. - Clara's Sorrow. - Sophronia
Jim

Seccomb's Letter. - Mrs. Sarah Bell desires Prayers.

\section{TWENTY-THIRD MEETING.}

Market Gardening (Continued) . . . . . . 340

Potatoes. - Insubordination. - Peter Ilsley wants Rotation. - Cooperate or quit. - Inside Reform.

\section{THE RECESS.}

A HOT SUNDAY • • • • • • • • • •

The Boy goes to Meeting. - Fanny's Suffering. - Dr. Parker consoles her. - The Walk to the Lake. - The Thunder-Storm. The Fire. - John Thomas and Huldah, the Christians.

\section{TWENTY-FOURTH MEETING.}

Market Gardening (Continued)

Mr. Howe likes a Town and a Club. - Mr. Hopkins begins to grow old. - The Club glad to meet again.

\section{TWENTY-FIFTH MEETING.}

Market Gardening (Continued)

Charles Ingalls as a Lawyer. - Classical Sketch of Perfidy. - John Thomas bewildered.

\section{TWENTY-SIXTH MEETING.}

\section{Superstitions and CranberRies}

Charles Ingalls puts up his Sign on Friday. - Its Removal. - A long List of Superstitions. - Joe Dole does the Business. 
TWENTY-SEVENTH MEETING.

Small Frutts and Flowers . . . . . . . . 416

Clara Bell and Fanny. - Clara's Ambition for Charles. - Her perturbed Soul. - Her Friends unequal to the Occasion.

TWENTY-EIGHTH MEETING.

Frutt Culture .
Charles Ingalls's Letter to Clara. - His City Life. - IBarnes tells all about Fruit-Trees. - Festus comes in.

TWENTY-NINTH MEETING.

Fruit Culture (Continued) •. . . . . .

Charles Ingalls returns from Boston. - A New Revelation to 447 Clara. - She is sorely troubled. - The Members of the Club philosophize.

\section{THIRTIETH MEETING.}

Grape Culture .

The Morning dawns. - Mrs. Bell steps in. - The Clouds vanish. 462

- Charles returns to his Law, and Clara to her Love.

\section{THIRTY-FIRST MEETING.}

IMPLEMENTS OF HUSBANDRY

Mr. Hopkins discusses Mowing-Machines, Ploughs, etc. - The Club disperses slowly.

\section{THIRTY-SECOND MEETING.}

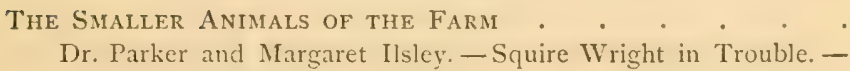
495 Fanny Undisturbed and Confident.

\section{THIRTY-THIRD MEETING.}

The Simaler Animals of the Farm (Continued).

John Thomas and Huldah discuss the Doctor, Nargaret, and Fanny, - The Old Sexton appears. - Dr. Parker and Fanny make an Evening Call. - The Wedding over. - Life is full of Promise. 
THIRTY-FOURTH MEETING.

The Smaller Animals of the Farm (Continued). • . . 532 Squire Wright's Intellectual Operations. - He discourses of Poultry.

\section{THIRTY-FIFTH MEETING.}

THE Horse • • . • . • . • . . . 549

Mrs. Howe's Death. - Mr. Howe's Trials and Submission. William Jones tells about Horses.

\section{THIRTY-SIXTH MEETING.}

THE Horse (Continued)

IVilliam Jones finishes reading the Essay of the young Medical 567 Student. - Remarks about Boys. - Feeding, Stabling, Driving. - The Last Meeting of the Club.

\section{SINCE THE ADJOURNMENT.}

Tree Planting. - Mr. Hopkins's Will . 584 John Thomas and Huldah tell their Story of Mr. Howe and themselves. - William Jones still drives. - Dr. Parker moralizes. I take my Record and depart.

INDEX . 


\section{L L USTRATIONS.}

\section{$\longrightarrow$ \\ CHARACTERS AND SCENERY.}

TITLE. DESIGNER. ENGRAVER. PAGE

The Village of Jo-

THAM.............. Lathrop...........Russell \& Richardson I

The Hopkins Mansion " " 4

President Hopkins... Katherine Peirson .......W. F. Dana....... I3

REv. Mr. Howe........ Rose Hazuthornte Lathrop.. Russell \& Richardson 16

MR. AND MRS. HowE .. " " " 26

FANny Wright ........ W. Champney........ Fohn Andrew so Son 39

Dr. PARKER......... " " "

President Hopkins AND

Dr. PARkER......... Katherine Peirson .......W. F. Dana...... 5 I

JOHN THOMAS AND

HuldaH........... W. Champney.......Russell So Richardson 83

Charles Ingalls..... " " A. C. Russell

Dairymaids............ Lathrop............ Fohn Andrezu \& Son 105

A HeRd of CatTle... " Henry Marsh..... III

THE DISTRICT SCHOOL-

House........... Katherine Peirson .......W. F. Dana....... II4 Clara Bell.......... W. Champney........ Fohn Andiew \& Son II9

A SEA View, BEACH, etc. " " Russell E Richardson I33

The Haymakers.....................W. F. Dana....... I74

Mr. William Jones...C. A. Barry.......... " 198

SQUIRE IVRIGHT........ F. W. Champney......... Russell \& Richardson $2 \mathrm{r} 2$

Squire IVRight's OfFice " " Fohn Andrew \&o Son 2 I3

A Western Town..... " W.

Hillside Pasture and

Catrle............ A. Barry.........W. F. Dana...... 233

Charles INGalls AND

Clara Beli.........Katherine Peirson...... " 250

THE GROCERY AND ITS

Habitués.......... IV. Champney........S. S. Kilburn...... 277 A CoRnfield........ " " Fohn Andrez E. Son 282

The Town-Meeting... " " Foln Filmer.......300 
TITLE.

DESIG.NER,

ENGRAVER.

PAGE

Jim LeLL'S Home...... Rose Hazuthorne Lathrop. Fohn Andrew \&o Son 325 FANNY AND THE DOC-

TOR BY THE LAKE.... F. W. Champrey.......

Clara Bell and her

HoME............ Rose Hinuthorne Lathrop. . Fohn Andrew \& Son 4I 7

The Orchard ......... W. Champney....... Foln Filmer....... 439

Dr. Parker and Mar-

GARET VIEIVING THE

RUins............. W. Champney........ " " 496 THe Old Sexton...... " "Russell \& Richardson 516 DR. PARKER's Wedding " Gohn Andrew \& Son 522 Funeral Procession. . Rose Hazethorne Lathrop. . IV. F. Dana ....... 549 THE HORSE AND HIS

RIDER, AFTER BEWICK.................. " " 568

DR. PARKER AT THE

LAKe ............. Rose Hazuthorne Lathrop. .

\section{A GRICULT URAL.}

A Shorthorn Bull............................. 32

SHORTHORN CoW.............................. 33

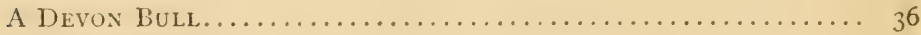

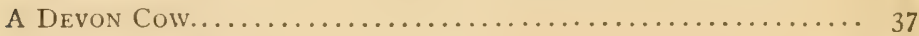

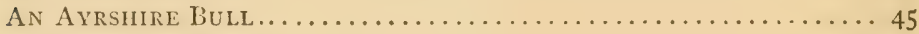

An Ayrshirf Cow ................................... 46

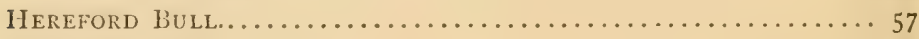

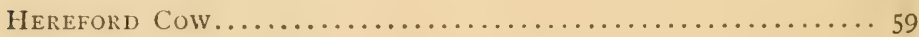

Jersey Bull. ................................. 62

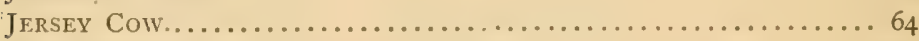

ToOls For Drainage........E. Forbes.......W. F. Dana....... 162

Drain TILE.............. " " "

A Hotbed............... " " " 380

Deep Tiller Sivivel. Plough ........................ 4 So

Telegrapit Plough ............................. 4 So

Eagle Plough................................. 48 I

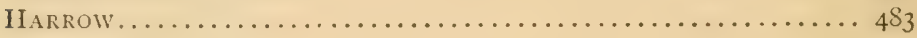

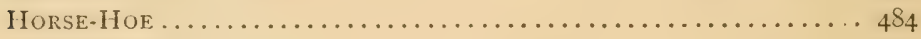

SEED-SUWER. . . . . . . . . . . . . . . . . . . . . . . . $48_{4}$

Expanning Cultivator .................................. 485

Wood's Eagle Mower..................W. F. Dana....... 487

HoRSE HAY-RAKE ................... " 489

Root-CutTER................................... 490

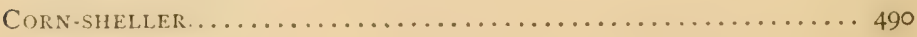

Cotswold Ram............E. Forbes.......W. F. Dama....... 506 
TITLE. DESIGNER, ENGRAVER, PAGE

Cotswold Ewe..............E. Fiorbes...... IV. F. Dana....... 506

Southdown Ram..........." " " 508

SOUTHDOWN EIVE..........." " "

Merino RaM............... " " 510

Merino EwE.............. " " " 510

Chester County Swine...... " " " 528

SUFFOLK SWINE............. " " " 529

Group of Asiatic Fowls......." "Russell G Richardson 535

Group of FrENCH AND ENGLISH

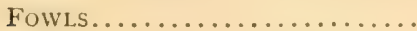

American Trotting Horse......

" $\quad$ " $\quad 539$

" W. $\quad$ F. Dana...... 557 

ple whose homes and farms occupy its shores. The village has hidden itself in one of the valleys between the hills, through which runs the meandering outlet of the lake; and here stand even now the old meeting-house, whose worshippers have never wandered away from the faith of the fathers; and the post-office, with a few letters waiting in the window "to be called for" ; and the stagetavern, with its piazza, once alive with travellers and drivers ; and the "store," whose well-worn floor and creaking counters could tell many a tale of sharp trade and hot debate; and the imposing dwelling of the prosperous physician, whose father and grandfather and great-grandfather were held as high authority throughout the region; and the not less imposing dwelling of the old minister, who, years and years ago, was settled for life, and who loved the fathers and mothers who are gone, and held through life a paternal relation to the children and grandchildren who remained; and the office of the "attorney-at-law"; and the academy, with its classic drill, which no high-school has yet elbowed out of the way; and the abodes of the prosperous mechanics, whose business it is to see that their neighbors are well housed and well clad, that their horses are well shod and their vehicles in sound and safe condition. It was a cheerful village, with its stately elms standing here and there as sentinels, and its orchards and gardens and reposing door-yards, and its highways running out countrywards between rows of maples and disappearing among the farms, and its sedate people, and its basking animals. In winter it was so clean and white, in summer it was so verdant, and in autumn so painted with all the hues of nature, and softened by the hazy twilight of the year, that it seemed to offer a retreat for all the weary wanderers who had become worn and exhausted on the hard highways of life. So charming was the spot that when the footsore Pilgrims reached and surveyed the land- 
scape of their future home, they exclaimed, "It is indeed the Perfection of the Lord." And so they called it Jotham.

One of the earliest settlers here was Israel Hopkins. He was called hither by those who, in obedience to the requirements of the act incorporating the town, had erected the first meeting-house and settled the first minister. He was a scholar and a theologian, who had seen enough of hard service to ripen his practical faculties, and to cultivate those talents which enabled him to get a living, and to give an intelligent sympathy to all about him who were engaged in the same useful occupation. He was settled for life, on a salary of twenty pounds sterling per year; and he was presented with a deed of a hundred acres of land, selected on that side of the village where the slopes were the warmest and the soil the most fertile, and the meadow on the river-bank the most luxuriant, - where the north wind was shut off, and the sweet south warmed and checred every living thing. On the most charming of these slopes the Rev. Mr. Hopkins built his house, a modest structure, two stories high in front and one story in the rear, turning its broad open face to the sunniest quarter of the heavens, and inviting all the sweetest influences of nature to fill it with cheer and comfort. As time went on and the parochial duties became familiar, and the surplus of the modest little salary accumulated, the farming began to increase. The fields were well enclosed and well tilled. The barn groaned replete with crops. The cattle multiplied and improved. The elm-tree, which had been planted at just a respectful distance in front of the house, began to look down upon the roof, and to sivay and toss its arms in the wild frenzy of the storm. The orchards grew into maturity and fruitfulness. The boys and girls reached that period of life when all New England boy's and girls toil and teach alternately. And the foundation 
was laid of that combination of theology and agriculture, that admirable domestic organization based on books and land, that union of intelligence and labor which made the

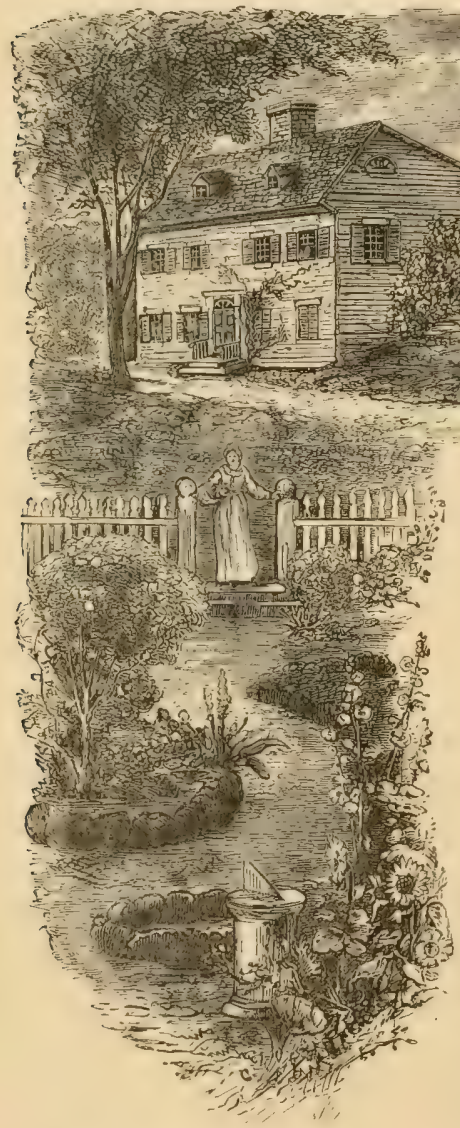

rural homes of the old New England clergy so charming in the early days, and made them, moreover, the nurseries of high moral and intellectual qualities, whose influence is not yet lost upon the country.

When Mr. Hopkins had faithfully discharged his duty for more than half a century he passed away, leaving a good parish to be presided over by one of his sons, his eldest, who had graduated at Harvard, and a good inherit-

THE HOPKINS MANSION. ance of land to his family. For fifty years more the same part was performed in parish and pulpit and farm by the new actor, under whose wise and prudent and faithful management the faith and fertility of the town improved 
in equal degree. But here the theological line ceased; and the faculties which had worked so well in the primitive colonial years for church and state alike turned in another direction; and from that old farm went forth a generation or two of strong and useful men into the business of the commercial world, connecting their names with all the great enterprises which gave wealth and power to the republic. During this latter period the old farm suffered. Sometimes it was the home of an inefficient son, a feeble link in the family, who served only to preserve the name and to continue the line of inheritance. Sometimes it fell into the hands of tenants and threatened to return to its primitive wildness; until, at last, it became deserted altogether, the undivided property of many heirs and the prey of many plunderers. How silent, now, were these once cheerful rooms! Where in years gone by the trampling of a busy multitude was muffled by the well-furnished and home-like apartments, the footfall of the solitary intruder now echoed and reëchoed along the dismal and deserted passages. The broad and massive front door, barred and bolted, seemed to have forgotten how to move. In one corner of the great rambling garret, whose rough-hewn, worm-eaten oak rafters told what a tough and powerful frame had there resisted the storms of two centuries, stood the narrow "pulpit orthodox" which had patiently endured the "apostolic blows and knocks" of the first ministerial Hopkins, and which had served as a sideboard since the old church had been torn down and the clerical cloth of the family had been laid aside. On the water-stained floor of this apartment were scattered some ancient papers:an old letter written long before by a newly-married daughter, Lois, from her far-off home in New Hampshire, to her "dearest mother," Eunice; a mouse-eaten sermon on the sin of profanity, by the second Hopkins; a battered copy of "Physiognomy," a poem, delivered before the Phi 
Beta Kappa Society of Harvard, in I799, by Joseph Bartlett; a Fourth of July oration in Boston, delivered in 1804 , by Dr. Danforth ; and a worm-eaten little pamphlet printed in Concord, in I793, entitled "The History of Jack Nips," in which Jack sets forth by announcing, "I cannot say that my father was a Hittite and my mother an Ammorite ; but my father was a Presbyterian, and my mother a highflying, separate New Light." Outwardly, the old house looked dingy enough. The untrodden door-stone had sunk into the earth, and had accumulated moss. The outbuildings were in decay. The barn was one piece of "ventilation gossamer," like Sam Weller's hat. But the sunny greensward before the door was as bright as ever, the landscape was as beautiful, and the ancient elm tree had grown into gigantic proportions, towering far above the great sloping roof, and rejoicing in a green and vigorous and commanding old age. As for the farm, it was in perfect repose; not a field was cultivated, not a wall was "laid up," not a pasture was occupied, not a fruit-tree was trimmed, not a drain was open.

It was in this condition when Timothy Hopkins left his counting-room at the foot of State Street, one morning in early spring, to visit the old homestead. He had hardly thought of it for years. He left it in early life, the brightest and bravest boy of that generation of Hopkinses, and erelong became absorbed in the business of the metropolis. He married Mary Johnson, the tall and graceful and beautiful daughter of a neighboring farmer, the girl whose rich voice had mingled with his own in singing-school and choir, and by whom all his rustic chivalry had been inspired, and his heart had been warmed on the bashful walk from evening meeting to her humble home. And for a few years the annual Thanksgiving had drawn them to the family meetings and the church choir at Jotham. But his own family was scattered, and the parent Johnsons had 
passed away; and there was no longer temptation for him in house or church, or on hillside, or on the bosom of the lake. His wife, too, was now gone to her rest; his two sons were established in business in remote cities; and he was alone bearing along that heavy and leaden weight, which the hard and inelastic routine of mercantile life lays upon the shoulders of its successful devotees. IIis fortune was made, and his health was gone. His old home was almost forgotten, when on this bright spring morning there came upon him a flood of memories of the past, that strange and unaccountable return of the pictures of early life, that irresistible charm of remembered youth, which outshines all mature success and obliterates all the toil and time which have bedimmed it; and he closed his books locked his counting-room, and started for that land of his fathers which was now the brightest spot to him on earth, for the hour at least.

It was long past high noon when Mr. Hopkins reached Jotham. He left the, train at a small station two or three miles from the village, this being the best railroad accommodation which the town had been able to secure. The beauty of the day tempted him to walk to his destination, and he set forth with unusual elasticity and vigor under the influence of his native air. The face of nature was rejoicing in the earliest touch of summer. The trees were clad in their first soft verdure, and the fields and pastures were already carpeted with green. The plough was busy on all the warm and early lands, and the fresh and healing smell of the newly upturned earth was like balm to his lungs, poisoned as they were by the heat and dust and pestilent air of the crowded city. The oxen moving slowly along the furrow, in the declining hours of a long and weary day, the lagging team toiling with its heavy load afield through the warm and hazy atmosphere, the chirp and hum of reviving animal life in the watercourses, the 
mingled songs of the spring birds, the momentary lull and silence, the familiar landscape, - all carried him back to the days when his young frame knew no weariness, and when the toil of this rural life was a pastime, and its pleasures were all he asked. He was restored as he walked to the scenes of his youth, and as the effects of a long life of intense labor fell from him, he found himself surrounded by that group of friends whom he knew and loved when he set forth in life.

As he reached his old home, now silent and deserted, he listened for a moment for those voices so long hushed, and seemed to hear the sweet tones which blessed that evening walk beneath the maples, when his broken words of confession were lifted into confidence and joy by the sweet and life-giving whisper of his first and only love. But he was at home, without father or mother or brother or sister or wife. The short dream was over; the man of business had returned to the realities, and before night had settled down upon the old farm he had determined to devote the remainder of his years to the rural calling of his fathers.

It is no easy matter to reorganize and restore a longneglected farm, and Mr. Hopkins knew it. But the same faculties which had enabled him to plan a new voyage, or rearrange an old one, when he was securing his fortune and placing himself foremost among the merchants of the day, served him most faithfully and usefully now that he had turned his attention to the land. His title to the estate was soon established; and before summer had fairly opened upon him he had found a competent and honest foreman, had made the old house habitable for a season at least, had purchased his cows and horses and oxen and implements of husbandry, had planted such lands as were available, had "topped" the walls for temporary safety, had repaired the sheds and outbuildings so that they might 
answer for a time, had torn down the old and worn-out barn, and had begun a new one, which he proposed to have ready for the hay crop, such as it might be, in the early part of July.

And now came his first perplexing question. It was easy enough to "top" the walls, and purchase cattle such as the market afforcled, and supply himself with tools, and seeds, and commercial fertilizers, and Suffolk pigs, and Plymouth Rock fowls, and brush up the old house, and plough and plant; but it was not so easy to build a barn. The whole neighborhood was interested. There were many model barns. His old friend Torrey had built an octagonal barn; but neither Torrey nor his friends seemed to like it, and $\mathrm{Mr}$. Hopkins certainly did not. His former legal adviser had erected a handsome, well-proportioned structure, large enough, it would seem, for a hundred-acre farm, but it had cost \$IO,OOO, and would hold but five horses, four cows, and the family carriages; and that did not seem to him like business. Jones, in an adjoining town, had built a long barn with one end against a hillside, so that he could drive in under the roof; but Hopkins thought there was a great deal of room wasted by this plan. His brother-in-law, Johnson, was very much opposed to barn cellars, but he thought this was a mere prejudice. Clark, the tavern-keeper, had so arranged his barn that the cattle and horses were kept in a sort of basement under ground, while all the building above the sills was devoted to hay and grain and tools and implements; but, he had observed that those cattle and horses were the most healthy and thrifty which were kept above ground, with good light and ventilation and a dry air; and he made up his mind that a cellar was no more a fit abode for his horse than for himself. The subject was largely discussed in the tavern, in the field, at church on Sunday, at the last quilting-party of the season, in the store, at the post-office; 
and the old farmers wisely observed that, "whichever way was best, Hopkins would probably build a gimcrack sort of a thing which would indicate that he had more money than wisdom."

But Mr. Hopkins had learned in his youth that a simple building, about forty-two feet wide and of such length as is required, with a driveway from one end to the other, is the most convenient design for a barn yet adopted. With this plan, the cattle may be supplied with plenty of room, and they may stand near the hay. Space is furnished for closets, stalls, etc., in convenient localities. Over the driveway can be constructed a movable scaffold, if desired. The building can be easily aired, and the frame can be provided with ease and economy. And so the barn was built, - an ample structure, with bands twelve feet in length, posts seventeen feet, driveway twelve feet wide, each band devoted to a specific purpose, and the entire length being seventy-two feet. On one side were stanchions for the cattle, - stanchions being the best mode of confining them. On the other side were pens, rooms, a compact stable occupying two bands, and stalls for oxen. Above all was the vast receptacle for hay, extending from the level of the mow-beams to the ridgepole; and under all was a well-enclosed cellar for manure, and a smaller cellar set apart for roots. Mr. Hopkins said he could make this barn as long as he wished, without injuring its symmetry or convenience, by additional bands. The barn was covered with rough clapboards, so that the walls might be comely without being too tight, and the whole was surmounted by a cupola. It was a barn which every thriving farmer could afford to build without drawing too much money from his active business. And Mr. Hopkins said he felt in duty bound to conduct his farm as a farmer should. If he were ornamenting an estate, he said, it would be one thing; but to manage a 
farm so as to set a good example to the agricultural community is another and a very different thing.

The first year of Mr. Hopkins on his farm was as prosperous as could be expected. His pastures did very well. His hay crop was large enough to feed two horses, a yoke of oxen, three cows, and two yearling heifers through the winter; not much, it is true, for a good hundred-acre farm, but pretty well for an exhausted and abandoned one. His crops were good. Three acres of corn gave him one hundred and sixty bushels; an acre of Swedes, five hundred bushels; and three acres of potatoes, seven hundred bushels.

He had made a beginning; had established satisfactory relations with his foreman; had set the old house in order, and had prepared to build a new one in the spring; had proved himself to be a good and neighborly citizen; and had so secured the confidence of his townsmen that when he proposed to organize for weekly meetings through the winter THE FARM-YARD CLUB OF JothaM, they readily joined him, took part in the discussion, and made up their minds to devote their brains as well as their hands to the business of farming. 


\section{THE FIRST MEETING.}

ORGANIZATION OF THE CLUB.

THE THANKSGIVING. - MR. HOPKINS CHOSEN PRESIDENT OF THE CLUB. - HIS SPEECH OF ACCEPTANCE.

THE first season of Mr. Hopkins's farming was fast drawing to a close. The harvest was past, and in the suspension of the active business of the farm, which followed the return of all the cattle to the barn for their winter quarters, and the completion of the fall ploughing, and the storing of the root crops and vegetables in the cellars, and the lively and efficient husking-party, at which the lanterns glimmered in the new barn, making the mysterious distances more mysterious still, and where the old grew young and the young grew radiant, his mind turned to his commercial duties once more and to his old haunts in the city. The counting-room had not been entirely deserted during the summer and autumn, it is true, but the visits had grown less and less frequent, and the old confidential clerk had learned that the business of the house was gradually closing up, and that he was slipping more and more into the position of a trustee and manager of the accumulated and invested property. But his old companions Mr. Hopkins had not forgotten, and he did long for one look at the Club, and a chat with the frequenters of the Exchange, and a morning walk "down town" with Lepine the banker and Frisbie the broker. He was pleased, moreover, with the thought that he would now appear among those old cronies as more or less of a hero, at any rate as a philos- 
opher and an intimate friend of Nature with all her mysteries. He knew they would joke him about his potatoes, and ask him how early in the morning he milked his cows. But then he also knew that there would be a little envy underneath the jibes, and he felt a natural American pride in his position as a landholder and tiller of the soil; and

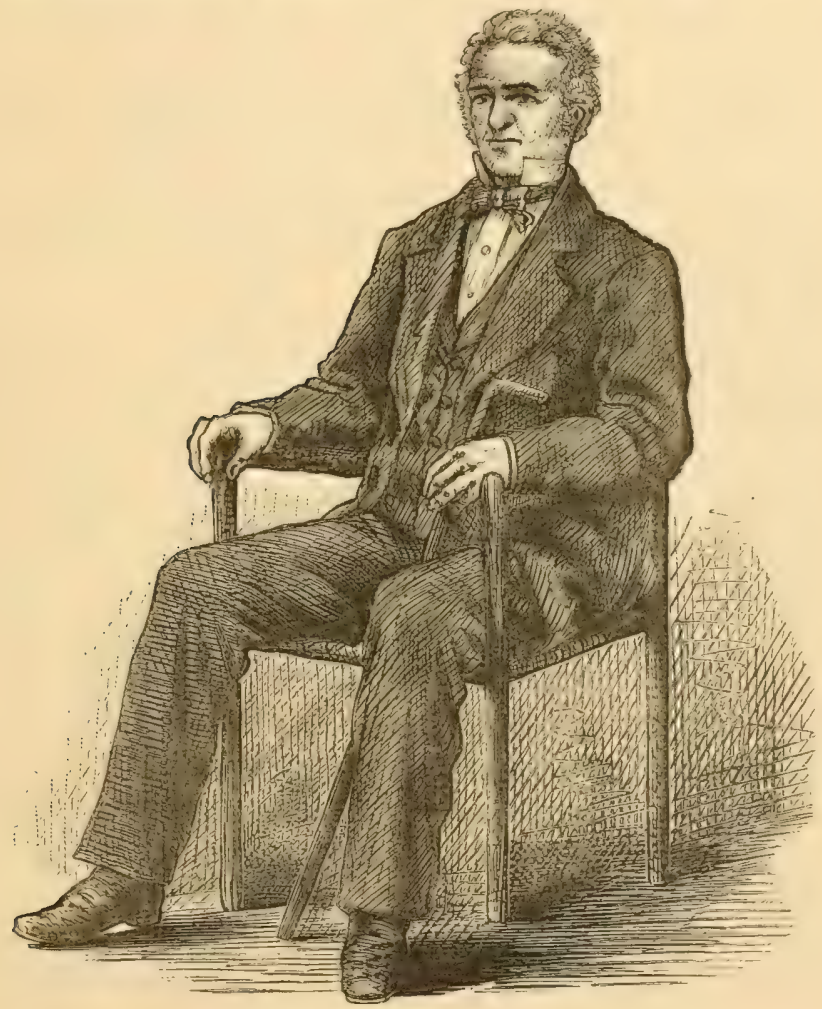

PRESIDENT HOPKINS.

so he went to the city, and the old clerk was glad to see him; and the soft-coal fire was pleasant in the countingroom grate; and the Club was social; and the deferential interest with which his account of his agricultural experi- 
ence was received by his old city-born mercantile companions was quite elevating to his mind and heart. But a few days satisfied him, and he longed to return to his farm, where the labors of the winter had already begun. Somehow or other, he had got up an interest in the cattle, and the spending of his crops, and the plans for his house, and the preparation for the fertilizing and planting of the next season. He thought of the wood-fire in the wide, open fireplace of the ancestral parlor. He sighed for the bracing air. So he invited Lepine and Frisbie and the venerable clerk to come down and spend Thanksgiving with him, summoned his two sons to join them, and turned his steps homeward.

The holiday season of the Puritan was over; that day of psalms and anthems, and family festivals, and joyful reality for the young, and sad memories for the old; that day, when all the sweet faces of the cleparted return and soften the domestic circle; that day, born of religious gratitude for even the small blessings which attended the hard and primitive life of the fathers; the only holiday known in New England for more than a century and a half; - the day was over, and the friends whom Mr. Hopkins had called to enjoy his rural hospitalities, and envy his rural treasures, were gone. Lepine had questioned the profits of the business ; Frisbie had repeatedly thanked Heaven that all men were not farmers; the two sons had wondered how much money the "old gentleman" would be likely to spend on the farm; the old clerk had valiantly approved of all he saw, and expressed his admiration of the wisdom of his employer: they had all strolled up and down the barn, charmed with the deer-like heads and mild eyes of the cows, and especially enamored of the long and sweeping tails of Jim and Billy, the two farm-horses; they had listened to the anthem, "Before Jehovah's Awful Throne," sung by a platoon of bass, four tenors, five coun- 
ters, and an angelic host of rosy trebles, accompanied by a clarionet, bass-viol, and bassoon; they had rejoiced in the dinner, rejoiced in the fireside evening-chat, rejoiced in the wood-fire, rejoiced in the comfortable beds, rejoiced in the winter landscape, rejoiced in the enthusiasm and sensible designs of their host, and had gone on their way rejoicing to the city, with its commonplace duties and glittering pleasures.

And now it was time to organize the Club. The Rev. Mr. Howe, the parish minister, had warmly urged it, and had even gone so far as to speak of Mr. Hopkins as one of the benefactors of the age for having suggested it. John Thomas, a shrewd, vigorous, inquiring, sagacious, and prosperous farmer on the north side of the pond, anticipated much benefit from its deliberations. Peter Ilsley, who sold milk from his farm, thought he should undoubtedly be enlightened by the discussions. William Jones, who had bred two or three good colts, and belicved a man night draw a prize every time in this business, if he only knew enough, was anxious to debate the "breeding and rearing of horses." Phineas Barnes, who divided his time between his blacksmith's shop and a little patch of strawberries and pear-trees, desired to know more about fruit. And they all agreed that, with weekly meetings for discussion in the houses of the members, and a few public lectures in the vestry, the Club might be made one of the most useful and interesting institutions in the town. Even the schoolmaster, a student from Dartmouth, who had left his father's farm to prepare himself for the law and public life, and was engaged for ten weeks to keep the "town school," requested the privilege of joining the association. And so he did.

On the Wednesday after Thanksgiving, at seven o'clock in the evening, those farmers who were desirous of joining the Club assembled at the house of Mr. Hopkins. There 
were twenty-two persons present, and they proceeded at once to organize the association. The Rev. Mr. Howe called the meeting to order, and remarked that he had been induced to appear on the occasion by his desire to encourage, in every way, the education of the people of the town. It was true that

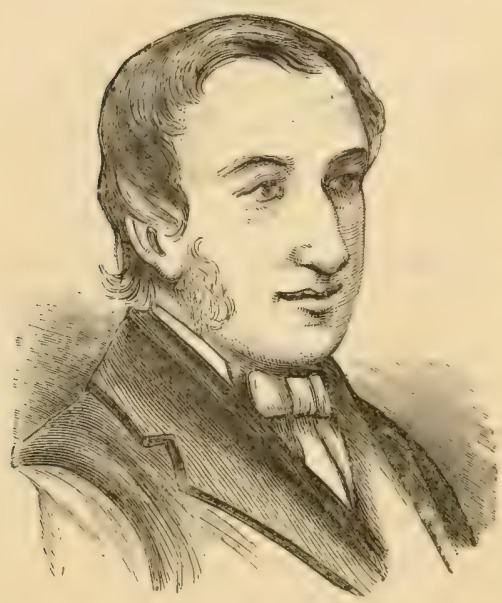

REV. MR. HOWE. his mind was led in a direction entirely different from that proposed by the practical men who had assembled there, but he felt assured that it was to an intelligent and thoughtful community, a community ready to apply their best intellectual forces to the practical business of life, and anxious to explore all the laws by which they were to be guided in their work, that he could most effectually appeal in his sacred calling. And he congratulated the farmers present that, while the manufacturer and the mechanic were obedient to a plan laid down for them by the ingenuity of others, the tiller of the soil explored his own paths, and was called upon for the continual exercise of his own wisdom and skill, in ascertaining and applying the best methods in his occupation. He said he felt confident that he expressed the unanimous sentiment of all the gentlemen present, when he thanked Mr. Hopkins for having returned to his ancestral acres, and having manifested such an earnest spirit of inquiry, and for having also displayed that warm hospitality which had opened his house for the first meeting of the Club. He thought 
an elaborate constitution and voluminous by-laws entirely unnecessary, and he would therefore suggest the following constitution, and leave the by-laws to the common sense of every member of the Club.

Article I. The Club shall be called the "Farm-yard Club of Jotham."

Article 2. 'The officers shall consist of a President and Secretary, whose cluties shall be such as are usually imposed upon these officers by similar associations.

The vote upon the adoption of the Constitution was unanimous. Mr. Howe said :-

And now, my friends, I take upon myself the pleasing duty of nominating as the presiding officer of this Club a gentleman who has brought into this community those qualities of mind and heart which have already endeared him to all who know him here. His name is connected with the most important events in our municipal history. His return among us inclicates the love which he bears for the high qualities of his ancestors, and gives assurance that his career here will be governed by those motives and springs of action which come from an appreciation of true merit, and a determination to preserve an honorable ancestral reputation, and to discharge faithfully the duties of life. He has taken his place in our midst, both as learner and teacher; and I am sure that he will be to all searchers after truth both a companion and a guide. I nominate, therefore, for the I'residency of this Club Timothy Hopkins, Esq., the progressive and inquiring farmer of Jotham.

The nomination of Mr. Hopkins was approved with a warm and significant murmur and rustle of applause ; and, on the suggestion of John Thomas, Esq., the Rev. Mr. Howe was as cordially and unanimously chosen Secretary. Mr. Howe kept a good horse, the best cow in the village, a flock of Brown Leghorns without a false feather, and raised his own vegetables. He was on this account con- 
sidered most worthy of filling the office to which he was so unexpectedly elected.

After an appropriate pause in which Mr. Hopkins seemed to be gathering strength for the occasion, and during which he manifested a becoming modesty, and a proper reluctance to assume the duties of the position assigned him, he proceeded to deliver his speech of acceptance.

\section{THE SPEECH OF PRESIDENT HOPKINS.}

Had I supposed, my neighbors and friends, that the duty of presiding over your meetings would be placed on myself, I should not have been so earnest for the organization of this Club. I am aware that it cannot be my knowledge of agriculture which has made me, in your minds, worthy of the position; for I am here rather to learn than to teach. If, however, prompt attention to the duties of the chair, a warm interest in your success, a desire to direct, so far as I may, your discussions into a useful and practical channel, and a determination not to wander off into mere theories, and not to be misled by prejudice and passion, will enable me to discharge my duties acceptably, I think I may assure myself and you of a fair measure of success. This shall be my share, at any rate, of our endearors after instruction: and I only ask of you, as your share, a clear presentation of those facts and a canclid elucidation of those theories upon which we hope to build up the business of agriculture here, and which, as practical and intelligent farmers, you can most profitably bestow upon me, an inquirer and learner, in return for the small service which I bestow upon you.

Not, however, for myself alone, nor for this community, have I been active in the formation of this Club. It seems to me that agriculture is in a sort of transition state. It has always held a well-understood relation to the business of every people, whose social and civil system has been based on social and civil classification. Where labor on the land has been doomed to a subordinate position, either of serfdom or slavery or tenantry, 
and the compensation for such labor has been small, the great questions of farming have been easily solved. Elihu Burritt tells us that in England, "men of skill and experience, who in America would conduct farms of their own, and could not be hired at any price, may be had in abundance for foremen at from I $2 s$. to I $6 s$, or from $\$ 3$ to $\$ 4$ a week, they boarding and lodging themselves." It is easy to see that uncler a state of things like this, agriculture simply means the cheapest possible production of a crop, with all the chances of finding a remunerative market, on the rule that "what is well bought is half sold." But when we are called on to decide the modes of farming best adapted to a free and intelligent body of landholders, whose wants are many, whose social and civil obligations and duties are great, whose expenses, public and private, are necessarily large, we enter upon a problem which requires all the wisdom man possesses for its solution. It is in this comnection that agriculture needs all the light and encouragement we can bestow upon it, and summons to its aid the school, the newspaper, the society, the club, all discussion, exhibitions, investigation by the scientist, inclorsement, approval, eulogy by the orator and the poet, examination by the statistician and publicist. It is a comparatively easy matter to decide how farming may be profitably carried on in India, China, France, Russia, and perhaps England. But tell the American landholder where he can best select his lands and how and for what purpose he can best cultivate them, and you have elevated agriculture at once out of a mere primitive occupation into the range of the highest enterprises to which an educated and self-governed people can devote themselves. No man doubts the importance of agriculture, or denies its charms. And yet it is found necessary to support and encourage it by every means in our power, simply because the effort to place it upon a sure foundation, a foundation enjoyed by more active callings, has not yet been crowned with success. The transition state between aboriginal agriculture and an accurate, scientific, and profitable cultivation of the earth is not yet passed through. And therefore for us I deem the first and most important question to be the selection and management of the farm. 
The first question is not, "Does farming pay?" for every man knows that it does pay everywhere. It pays in Massachusetts, and in New York, and in Ohio, and in Texas, in Germany, in Egypt, in Japan, in Califomia. It pays throughout the world. And so I think the question should be put thus: "Does farming pay whether you attend to it or not, and whether you understand it or not?" - a question so easily answered that it is unnecessary to waste time on it here. But behind all this lies the fundamental inquiry for us: "Where shall I select my farm, and how shall I. manage it?" And to this, it seems to me, there is but one answer. It is perfectly eviclent thit the agriculture which is profitable in this section, and is becoming more and more profitable throughout our country, is the cultivation of small farms for specific purposes, and with great care and skill, in the immediate neighborhood of a local market. The startling clecay of farms in the remote and sparsely settled sections of some of the New England States has led many to suppose that farming is on the decline here, and is gradually dying out. But if we will examine the statistics in the case, we shall find that, while these outlands have failed to support a profitable husbandry, the territory lying contiguous to the great centres of trade and manufactures has more than counterbalanced the loss to the State and the community. I know one county in this State where, while the amount of corn and hay and butter and cheese has declined, and the number of oxen and cows has diminished during the last ten years, the growth of market-garclen crops has largely increased, rising from $\$$ I 75,000 to more than $\$ 400,000$ a year in this period. And so the soil of this county, and of many another county, and many a State similarly situated, has never been a source of so much profit to the owner as it is to-day. The day of profitable hay and grazing farms in New England has undoubtedly passed away, and for the two reasons that they cannot compete with the grazing regions of the West, and that they have become exhausted by poor cultivation and constant cropping in this hard New Fngland climate of droughts and frosts. But, on the other hand, the day of careful cultivation 
and systematic management, and well-applied skill, has dawned for those who live near the larese towns and cities, or have convenient railroad communication, - a day of more accurate work and larerer protits. It is the application of art which pays in farming, as in every other occupation. Horace Greeley once said to me that the best places in the world for farming are those countries where there is no rainfall, and man is obliged to resort to irrigation, in applying which he becomes at once superior to the accidents and caprices of the clouds, a flood one day and a drought the next. And there is more wisdom in the statement than at first appears. It is where man can take matters into his own hands, and attend to them carefully aud systematically, that he stands the best chance to succeed.

And are you sure that such a necessity as this is not fortunate for a community like ours, whose vitality, permanency, and success depend on the intellectual activity and the moral sensibility of the people? That energetic and active and watchful farming which is required to produce a quick crop for a temporary market is undoubtedly the farming for an inquiring, debating, reading people like ourselves. The good effect even of the associations which go with it should not be forgotten. Isolation is not the law of modern society. The privileges and opportunities of a town with its libraries, amusements, friendly intercourse, schools, and churches are much more highly prized now than formerly, when the difference between the country village and the far off farm was less than it now is. The evils of widely scattered society have always been recognized, and never more than in our day. I do not forget that Jefferson declared that "great cities are great sores"; nor can I forget, moreover, that one of the dangers of every people is the intellectual and moral torpor which paralyzes those scattered communities which live only on the verge of society, and are threatened with that "barbarism" which one of our profoundest thinkers once declared to be "the first danger" of our colonial fathers. It is not with anxiety, therefore, that I witness the gradual gathering of our farmers around the towns, but 
rather with the assurance that it will work in every way for their prosperity and advancement. I congratulate myself that the farm which, on account of family associations and the memories of my youth, has drawn me hither is located within the reach of the social influences of this town, and also within easy access to a railroad and a market. I am confident that if I sucreed in bringing it hack to its early condition of prosperity, ir will be on account or its fortunate locatiol, and were $I$ to be asked by an enterprising young man just entering upon an agricultural career, and determined to devote himself to that as a means of subsistence, where he had better establish himself, whether on the prairies of the West or the cotton lands of the South or among the valleys of New England and the Middle States, I should advise him to choose his home as near an enterprising and thriving business community as possible, and to select his lands with reference to their evident capacity to produce what the market of that community might require. I have never known a man to fail who was guided by this principle. It has made the fortunes of hundreds and thousands around the great manufacturing centres of New England, and is rapidly enabling the Western farmer to find his market near home, and to escape the expense of long transportation and the fluctuations which always attend the great staples of trade.

Of the management of the farm it is more difficult to speak than of the selection. I remember reading, many years ago, that Eclmund Burke, after some years of unfortunate agricultural experience on his farm at Beaconsfield, declared that it required more judgment, foresight, and prudence to carry on a farm than to transact any other business on earth. Had he left his brilliant career as a statesman to engage in commerce or manufactures, he would undoubtedly have said the same thing of them. It is never easy to preserve the jutgment mbiased, and to keep the foresight undimmed, in the practical aftairs of life, where the promises and hopes are at work to elate and mislead. This is true of the merchant sending his ships to sea, of the manufacturer converting his raw material into a marketable fabric, and of the farmer committing his seed to the earth and waiting for 
the fulfilment of the promises. I always found in the business to which I have devoted most of my life, and in which I have been blessed with an unusual share of prosperity, that it was necessary for me to look at things just as they were and not as I wished them to be. I could never make a market, I could only occupy one already made. The only instance I remember of successful mercantile adventure against and in spite of the natural demands of a market, was the involce of warming-pan: to the West Indies by Lord Timothy Dexter, in which, by a sudden reversal of the natural law, the market met him, not he the market. I see no reason why the rule of life, which worked so well in the business of the city, should not also work well in the business of the country. I learned also to let non-essentials alone. I have known many a man to devote himself to statistics, and be swamped by figures, because he allowed them to shove his judgment and common-sense out of the way. Men of figures and marginal notes alone I am always wary of. And so I imagine that he who spends his time in analyzing the different effects of turnips and potatoes on the animal economy, well knowing that both are nutritious and palatable to cattle, and devotes himself to counting the curls around a cow's tail, unmindful of, and perhaps incapable of, comprehending the general outline and quality and thrift and structure of the animal, or the character in her eye, will hardly reach the point of being a great farmer; he may be a fussy one, but I do not think he will be a great one. I have also noticed that the exercise of mere taste and fancy alone is rarely profitable. In order to succeed you must be governed somewhat by the circumstances by which you are surrounded. It would undoubtedly be pleasant and sensational to send a steam-yacht on a fishing royage to the Grand Banks, but it would in all probability be highly unprofitable. I wish every farm in New England could carry Shorthorns, the most attractive of neat cattle, but I know they cannot. I think the fancy, then, should be controlled by surrounding circumstances and necessities; and that the capacity of the farm and the nature of the market should guide the taste of the owner and seller. And finally, I would urge a good- 
natured and careful observation of the experience of others. Nany a clollar have I made by catching at a hint dropped by some old and experienced merchant, with whom I happened to fall in on my morning walk to my counting-room. And I warn you all that when I meet with any obstacles in my farming, I shall always resort to the experience of those of you who, having met the same obstacles, have learned how to overcome them. I urge upon you an open-minded clisposition, a courteous confidence in each other, a love of debate, - not for the sake of controversy and wrangling, but for the purpose of ascertaining the truth, - and an avoidance of personality, from which nothing but evil can come. I am much obliged to you for listening to me so long and so patiently, considering how little practical linowledge I have to impart; and I trust our association in this Club will be of benefit to us all.

At the close of the President's speech there was a prolonged rumbling of applause, subdued by the fact that the meeting was held in a private house; but the satisfaction of the gentlemen present was too great to be concealed.

The Chair announced that the Secretary and John Thomas would prepare thenselves to open the discussion of the next meeting, and the Club adjourned.

"He talks pretty well, don't he?" said William Jones, as they went out.

"Yes," said Peter Ilsley, "but why did n't he tell us what breed of cows is the best, if he knows?" 


\title{
SECOND MEETING.
}

\author{
CATTLE.
}

MR. HOWE AND JOHN THOMAS COMMENCE THEIR LABORS. - MR. HOWE'S ESSAY. - MRS. HOWE AND MRS. THOMAS REJOICE.

THE selection of a subject for discussion by the Club seemed no easy task, either to the Rev. Mr. Howe, the Secretary, or to John Thomas, his assistant on the committee appointed for this purpose. Before they separated they agreed, therefore, to meet at the minister's house on the following evening, to decide upon the important matter submitted to them. They were both getting interested in the Club, and they felt how necessary it was to choose a topic for the first debate of which all the nembers would feel the importance. Peter Ilsley had shown which way his mind was drifting by his parting remark. When Mr. Thomas reached home that evening and recounted to Huldah, his wife, what he had seen and heard, the duty which had been imposed upon him, and his agreement to meet the minister at his own house, in order that a good way might be devised for performing that duty, he was quite surprised to witness the genuine and beaming enthusiasm with which she listened to what he had to say. She replenished the wood-fire before which she was sitting (for John Thomas owned a wood-lot, and insisted on having an open wood-fire in one room of his house at least), waked up the waning lamp on the table by her side, and plied her knitting-needles with renewed energy. It was evident that she anticipated with quiet and womanly 
instinct the enlivening influence which this little institution might have upon her own family circle, where, although everything was well-ordered and peaceful, there was yet, as she well knew, a slight want of intellectual elasticity, and the cheer which goes with it. She ventured to make a suggestion; and remembering that she was a good dairy-woman, and suddenly realizing what ? dismal place the farm would be to her without her cows, she asked John why he did not propose the subject of Cattle, and try to settle some of the questions with regard to feeding which she had heard him discuss so many times with his neighbors, without arriving at any conclusion.

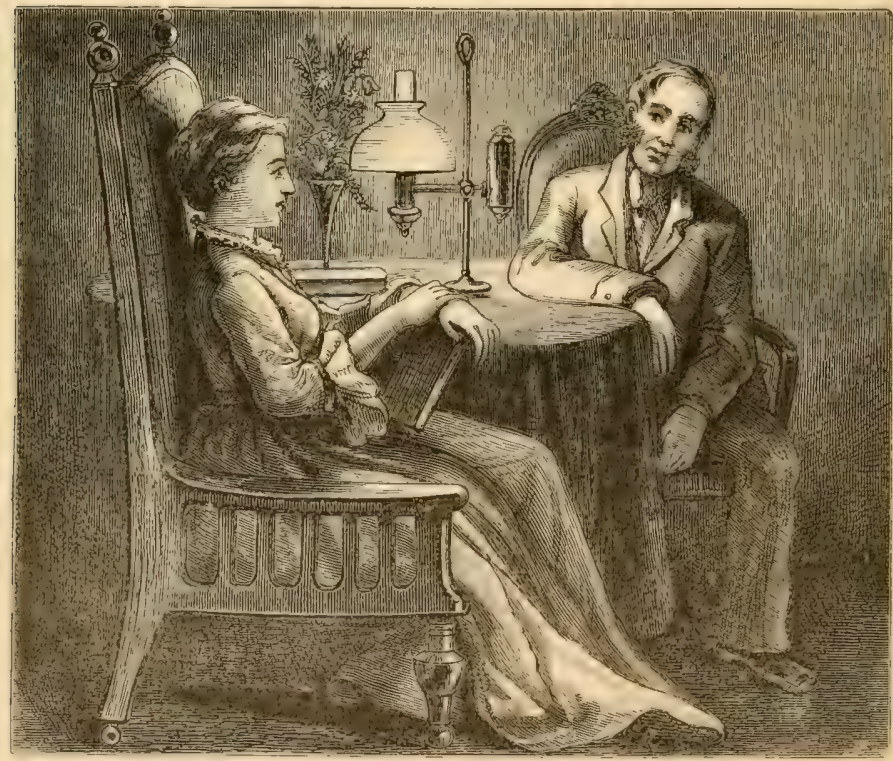

MR. AND MRS. HOWE.

The Rev. Mr. Howe, on his arrival home, found his wife also deeply interested in what was going on. She was a bright and refined and reposeful little woman, who having 
graduated at a normal school, notwithstanding the wealth of her family, was spiced and invigrorated with a flavor of authority, and of positive and undeniable views and information. She had just laid aside "The Life of Mary Ware" when Mr. Howe came in, and her mind was so aglow with the character of this heavenly woman and her divine husband, that she was only too glad of an opportunity to aid and encourage her own partner in all his endeavors to cultivate the little community into which they had been thrown. She listened to his account of the meeting at Mr. Hopkins's, applauded his opening speech, and wondered at the knowledge and wisdom displayed by the President in his elaborate address of acceptance; and she warmly and sympathizingly suggested that now and then she and her female friends would be glad to participate in the deliberations of the Club. She felt sure it would be a useful institution, and would bring the pastor into new and valuable and substantial relations to his people, in which both parties might be greatly benefited. And when she learned that Mr. Howe was Chairman of the committee appointed to select the subject for discussion, she too remembered what a debt of gratitude she owed to her dumb companions in her domestic economy, and she proposed that their management should receive the carliest attention of the agricultural investigators of Jotham. So far as the subject went, therefore, Mrs. Howe, Mrs. Thomas, and Peter Ilsley all seemed to agree.

It took but little time for the committee to decide upon their report. And when, on the following week, the Club met for a second time at the house of Mr. Hopkins, the following suggestions were unanimously adopted, viz.:

I. That the subject should be "Cattle: How to Select and How to Manage 'Them."

2. Inasmuch as a debate is always guided largely by the opening speech, and a well-prepared statement is very impor- 
tant, the Secretary shall take it upon himself to prepare and present an essay upon the subject under discussion.

3. 'That in all cases, wherever it is possible, the deliberations of the C'lub shall be opened with a paper upon some given subject, and that all attempts to wander away from the topic proposed shall be summarily checked by the Chair.

Mr. Hopkins had taken pains that his parlor should be as cheerful and engrging as possible, and the Club presented a most agreeable circle when he called it to order, and announced that the Secretary would open the business of the meeting by reading a paper which he had prepared, at the request of the committee, upon the subject of Cattle. Mr. Howe read the following

\section{OPENING ESSAY ON CATTLE.}

The subjugation of the animal kingdom to the wants and luxuries of man constitutes one of the most interesting chapters in the history of practical human advancement. In the beginning man was created "to have dominion over the fish of the sea, and over the fowl of the air, and over the cattle"; and when by his "first disobedience" he was obliged to resign the enjoyment of reaping the spontaneous productions of the earth for an unequal contest with thorns and thistles, no decree went forth to release "the beasts of the field" from their predestined bondage. The "bleating flocks" which welcomed the dawn of creation were sacrificed to furnish the first two human sinners with "coats of skin," after their expulsion from Eden into the chilling influences of the outer world, and we are told that the second born on the face of the earth occupied those primeval hours amid new and oriental luxuriance as a "keeper of sheep."

From that day to this the production and care of animals adipted to human wants has been one of the most important branches of industry; and we have been supplied with every variety of rule by which we can judge of a good cow, and every diversity of suggrestions with regard to her relations 
to agriculture. Columella tells us, and we are amazed and amused as we read it, that a good cow should be "a tall make, long, with very large belly, rery broad head, eyes black and open, horns graceful, smooth, and black, ears hairy, jaw straight, dew-lap and tail very large, hoofs and lecgs moderate." And turning from this to general principles, we learn and believe the old French proverb: "No cattle, no farming; few cattle, poor farming ; many cattle, good farming." We accept, moreover, the declaration of Cato, the wise and sagacious Roman, who when asked, "What is the most assured profit arising out of the land?" made answer, "To feed well"; being asked, "What next?" he answered, "To feed with moderation." IVe can imagine also the contrast which exists between the aboriginal production of food, which the sinewy savage practices, as he pursues the still more sinewy cattle across the plain, and even the first dawn of domestication in the management of animals, and the still greater contrast which exists between the wild and flying drover of the pampas and that calm and solid and impenetrable specimen of humanity who winds his placid way from the valley of the Tees to Smithfield Market, realizing as he follows his rolling and wallowing shorthorns the truth of the saying, "Who drives fat oxen should himself be fat." There is a long interval between "the five hundred yoke of oxen" of Job and the stupendous beeves which graze upon the fat pastures of England, bred and reared by rule into an exact estimate of each pound of flesh. And to you who are engaged in farming, among all the modem improvements it is a matter of special interest to know the processes by which the present breeds and races of cattle have been brought to their existing perfection, and how they can be preserved in their condition. An Ayrshire cow and a Shorthorn bullock are by no means the result of accident. They have been produced by the application of the highest and most intelligent skill, at the hands of the Bakewells and Parkeses and Mickles and Collings, under whose treatment, as has been truly said, "the longlegged, slab-sided, ill-bred oxen are metamorphosed into smallboned, quick-fattening Derons and Durhams" ; and the "lean, 
hurdle-backed Norfolk rams become beautiful firkin-bodied Southlowns." We in the United States have the advantage of the experience and profits of these distinguished and successful breeders; and it especially becomes us to inquire what advantage we can derive from all that they have done. We must have cattle adapted to our soil and climate, cattle which can be profitably fed, cattle which will make the best return for the labor and produce bestowed upon them.

I am aware that there is no breed of cattle universally adapted to the United States, or even to any one State. The valley of the Connecticut and the hills of Berkshire and Essex, in Massachusetts, differ almost as much as the valley of the Tees and the Highlands of Scotland. And we shall find that, in selecting a breed of cattle for each locality, we must be obedient to Nature, or Nature will take the matter into her own hands, and will bring about a certain conformity between herself and the animals she is to nourish. When I tell you that Shorthorns have not thriven well in some parts of the New England States, and that Ayrshires have shown too great a disposition to take on fat in the rich pastures of Maryland, you will understand what I mean by saying that Nature will have her own way in these things.

I find, also, that the necessities and the interests of every community generally control its industries. We may learn, from the statistics of cattle husbandry, to be found in the last census, what is most in demand in this branch of farming with which I am now dealing. In 1870 the number of cows in Massachusetts was I I 4,77I ; of working oxen, 24,430; of other cattle, 79,86r. In Michigan the number of cows was 250,859; of working oxen, 36,400 ; of other cattle, 260, I 7 I. In Mississippi the number of cows was 173,890 ; of working oxen, 58,145 ; of other cattle, 269,030 . In New York the number of cows was I,350,66I ; of working oxen, 64, I4I ; of other cattle, 630,522. In North Carolina the number of cows was I96,73I ; of working oxen, 45,408; of other cattle, 279,623. In Ohio the number of cows was 654,300 ; of working oxen, 23,696 ; of other cattle, 759,221. In Pennsylvania the number 
of cows was 706,437 ; of working oxen, 30,048 ; of other catttle, 608,066. In Kentucky the number of cows was $2+7,615$; of working oxen, 69,719 ; of other cattle, 382,993 . In Iowa the number of cows was 369,811 ; of working oxen, 23,058 ; of other cattle, $64+466$. In Illinois the number of cows was $640,32 x$; of working oxen, 19,756; of other cattle, 1,055,499. It will be seen from these figures how in many states the dairy cattle predominate, and how valuable they are even in the great grazing and beef-producing sections of the country. And in order to give still further proofs of the ralue of these animals let me submit the following figures, covering the whole country, and bearing also upon some of our most important productions: In I 870 the whole number of cows in the United States was $8,935,322$; of working oxen, I,3 I9,27I ; of other cattle, $13,566,095$. Of our dairy products cheese was estimated at $53,492,{ }_{53}$ pounds, butter at $51_{4}, 692,683$ pounds, and the number of gallons of milk sold was $235,500,599$. The value of the cheese was about \$ I 5,000,000; of butter, about $\$ 114,000,000$; and of milk sold, about $\$ 48,000,000$. On the other hand, the value of the animals slaughtered was $\$ 39 \$, 956,376$. The estimated value of the live stock of the country was $\$ 1,525,276,457$, as against $\$ 1,3 \$ 9,329,9 \mathbf{I}_{5}$ in $\mathbf{I} \$ 60$. It may be interesting for you to know that the value of the cotton goods produced in I $\$ 70$ was $\$ \mathbf{1} 68,457,353$, or $\$ 9,000,000$ less than the dairy; and of woollen goods, $\$ 151,298$, I 26 , or $\$ 26,000,000$ less than the dairy.

These figures show the universal importance of the dairy, while they also indicate those States in which distance from the market and the low price of pasture lands combine to render grazing the most convenient as well as the most profitable branch of farming. In the valleys of the West and South, and in some parts of New Fngland and the Middle States, beef is raised to a profit, every advantage being taken of a breed of cattle adapted to such a purpose. While, however, on the East and on the West, on the North and on the South, in every direction, at the fountain-head of our grain crops, before corn has been quadrupled on the original price of the product by long 
transportation and by speculation, where the rich valleys and prairies of the llest offer an abundant and a cheap sustenance for cattle, and where a propitious climate economizes food and labor, - while all about us beef is growing as it were spontaneously, we can never expect to adopt this as an extensive branch of farming.

It is the dairy, therefore, which occupies the attention of most of our farmers. Every man who owns land keeps a cow. The milk-pail is one of the first utensils provided for carrying on the domestic economy. 'The rich man is never satisfied until his table is furnished with milk and cream by his own animals. The poor man funds his establishment incomplete until he has added a shed for his cow ; and his farming is never perfected until he occupies the highway as a pasture, and gleans his winter's store of fodcler from the neighboring meadows. Every larger farm has its dairy proportioned to its size and cultivation. And as we look over the whole northern section of the United States it must be apparent to every intelligent farmer, that he will be a true benefactor to our farming community who will improve our dairy stock and bring it to as high a degree of uniformity as possible, making all due allowance for diversity of climate and locality.

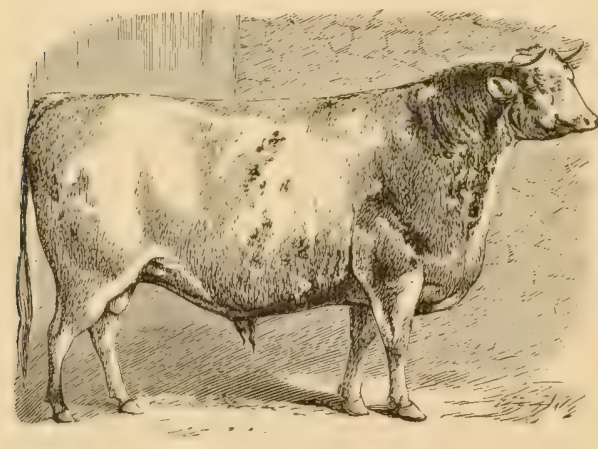

A SHORTHORN BULL.

Now, I have observed that, wherever in New England, or in fact in the United States, you may find a locality famous for good cattle, the high quality of that stock has come from some pure importation. More than sixty years ago Mr. John Vaughn, a liberal and intelligent gentleman, who conceived that England without Priestley was no place for a Christian to 
live in, followed that great philosopher and divine in his flight to our shores, and settled on the banks of the Kennebec. He imported the Durham cattle of that day, the improved Shorthorns of ours; and you may find to this dity, grazing in the valley of that river, a large, thrifty, quick-growing, solicl, massive breed of cattle, the indigenous Shorthorns of that region; indigenous, because they have become adapted through generations to that soil and climate, and are now among the most profitable products of the State. Go to Portsmouth and the surrounding towns, and you will find cattle of similar quality and description, the fruits of more recent importations; a native stock now, but possessing certain characteristics, which they lose neither in succeeding generations nor in various families. An im-

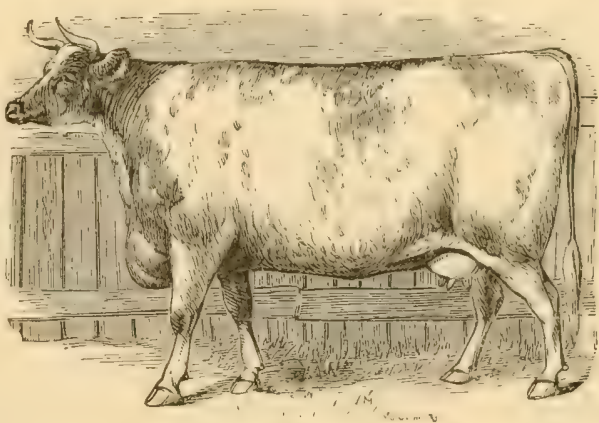

SHORTHORN COW. portation into the valley of the Connecticut by the late Mr. Williams has stamped the stock of that section with points of value seldom equalled. I had often been struck with the excellence of the cows in the Aroostook region, and thence to the Bay of Fundy, - a well-bred, hardy, dairy-looking race of animals ; and I soon discovered that some choice Ayrshires had been brought into that country. The oxen of Meredith Bridge and Lake Winnipiseogee, who has not admired their stately carriage, their rich color, their symmetry of form, their thrift, and their size and endurance? They are the modern Devon blood, mixed with the Shorthorn, and engrafted upon that soil, and brought to a high degree of perfection by judicious care. In an obscure town in Essex County, Mass., there was a remarkable cow, known of all men thereabouts, and distinguished for her outline, her dairy qualities, her beauty ; her owner said she 
was English; on inquiry I found that she descended from a herd of Ayrshires brought into the country many years ago, and now nearly extinct. There are certain sections where I can always furnish myself with a good cow; and I always find that some enterprising farmer has imported into those sections valuable animals, which have fixed the type there.

In calling your attention to the beneficial effects of introducing pure bred cattle of the various breeds into many sections of our country I trust I shall not be misunderstood. Do not suppose that all breeds are suited to one locality, or that all breeds will thrive indiscriminately in all places. I would not be understood, moreover, as advocating a foreign breed because it is foreign, aware as I am that there are many breeds of cattle that are no more worthy of importation into this country than the indigenous cattle of New Hampshire or Texas would be worthy of being imported into Europe.

With regard to the first of these propositions, I am confident that the New England farmer will find it especially important not to bring upon his farm any animal which will tend to deteriorate under his management and feeding, both in summer and winter, and under the climate to which the animal will be exposed. Nor should he introduce any animal into his herd which will not tend to improve it. We cannot afford to breed cattle for amusement only, or for simple experiment. And it especially becomes us, therefore, to ascertain what type of animal will be most likely to flourish under the rigors of our climate and on our short pastures. I will not undertake to designate the breeds which will thrive best here; that each farmer must decide for himself. But in order to show how important this rule is, you have only to turn to the immense value of the Shorthorn to the Western and Southwestern farmer and grazier. It would be difficult to estimate the wealth which has accrued to Ohio and Illinois and Kentucky from the early introduction of Shorthorns, and the constant attention to their increase and feeding. Calculate, if you can, the difference in the value of one hundred pounds of beef produced on those luxuriant pastures and at those groaning corn-cribs, in three 
years of growth, and one hundred pounds requiring four years for its production, and you will soon learn the value of a rapiclly maturing and large-growing animal like the Shorthorn over all other breeds of slower growth and smaller size. The value of the animals slaughtered in Illinois in $1 S_{70}$ was $\$ 56,718,944$. The growing of this amount of beef in three years secures the profit which the farmer makes on it. The necessity for occupying four years in growing the same amount on animals of less thrift and slower maturity would undoubtedly destroy all the profit, and very likely place the balance on the other side of the account. How fortunate is it for the Illinois farmer that he had the Shorthorn provided for him instead of other breeds, which I need not mention here. The Shorthorn flourishes in Illinois as no other animal does. The average of a herd will undoubtedly improve there, if brought from the North and East, and even from England. And the introduction of this blood into the more ordinary herds of the State is sure to be followed by marked improvement. That the New England farmer can find a breed of animals as well adapted to his dairy as the Shorthorn is to the pasture and stall of the Western beef-grower I cannot doubt. We need here a medium-sized, hardy, thrifty, well-organized and well-shaped cow, capable of producing a large amount of milk on a comparatively small amount of food, if we would feed animals to a profit. We can be indifferent to no single point in this business. Give a farmer in this town a coarse-made, delicately organized, unthrifty cow, with heavy head, light quarters, and capacious carcase, requiring thirty pounds of hay per day and two quarts of meal in addition to produce ten quarts of milk. Give him another cow of moderate size, well proportioned, of strong and hardy constitution, well-balanced and thrifty, and requiring twenty pounds of hay per day and one quart of meal, to produce fifteen quarts of milk. In the former there is loss; in the latter there is profit. Now let the dairy farmer learn that he cannot create this profitable animal out of every known breed, nor by an indiscriminate introduction of blood into his herd. The beef-grower has established his type, and he is slow to 
wander away from it. Let the dairy farmer fix his type, and let him preserve it with all the diligence and skill possible. I shall not undertake to say what that type is, for I am only engaged in laying down general rules. But I trust that before we abandon this subject some one, expert and wise in the busines. wi'l describe a profitable dairy cow, so that she will be recognized by her merit and not by her blood alone.

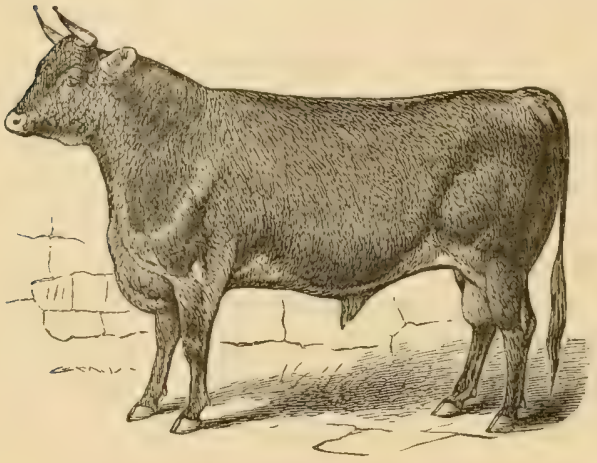

A DEVON BULL.

With regard to the second point, - that a breed may not always be considered valuable because it is foreign, - I urge upon you the most careful discrimination. Many socalled breeds of cattle have won a very fair reputation by their special adaptation to the locality in which they are found, and by their success there. They have apparently grown into this by obedience to nature about them rather than to any direction given them by man. The strong limbs and heavy muscles of the Swiss cattle, for instance, are undoubtedly the result of climbing the mountain heights, where the best pastures lie. The coarse, heary, and enervated physical organization of some of those breeds which have grown for generations on the fat lowland pastures, are a natural product of the soil and climate, under whose influence they and their ancestors have lived. And these animals are valuable, each in its own locality. But man, in such instances as these, has done but little work. He has made no imprint upon the breed, has by his skill engrafted upon it none of those faculties and qualities which are especially useful to him, and which he desires to transmit. It is the really artificial breeds, those which have been shaped and organized for speci- 
fic purposes by breeding and feeding which are most useful in themselves, and have the strongest power for improvement when mixed with others.

Of the best methods of preserving and transmitting these artificial and acquired faculties, when they have once been secured, of the best modes of selicing anima's for specific purposes, of the manner of feeding and the quality of food best adapted to develop the animals, young and old, for any particular purpose, I do not propose to speak this evening. These are questions which belong to the practical farmer, who can give his own experience, or to the scientist, who

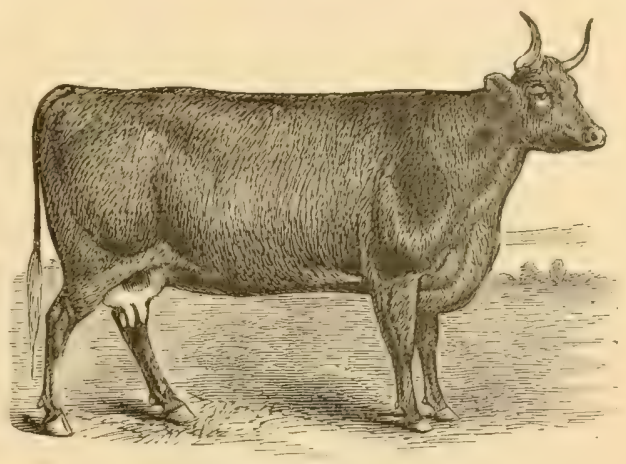

A DEVON CoW.

can point out the laws of the animal economy which the farmer must obey if he would succeed. I would recommend to the Club that these subjects be assigned to competent persons for their investigation, and that the results of their inquiries and observation be laid before us. With this introductory and general treatment of the question, I submit the matter to the Club.

When the Rev. Mr. Howe sat down Peter Ilsley arose, and in a most impressive manner asked the reverend gentleman if he would be kind enough to tell him "what was good for the garget."

Mr. Howe replied that he could not tell, and suggested that a question like that belonged to another stage of the debate.

"Mr. Chairman," said Moses Ferson, "I bought a cow, 
many years ago; she was a three-year-old when I bought her, had had one calf, and was coming in again in the spring. I bought her just after Thanksgiving, about this time of the year. I wintered her on run hay. I had n't any turnips, and meal was high. She wintered well, and calved about the middle of May. She was a line-backed cow, and I turned her out to grass about the Ist of June. I made up my mind that I would raise some millet for her, or some barley and oats mixed to be cut green, as I had heard of soiling, and I wanted the manure; so I thought I would try what I had seen recommended, and I sowed an acre - "

Here Mr. Hopkins reminded Mr. Ferson of the suggestion of the committee with regard to the speakers confining themselves to the subject under debate, and mildly endeavored to draw him back to the question.

"But the cow was breachy," said Mr. Ferson, "and I thought, perhaps, Parson Howe could tell me how to stop her."

Parson Howe made no reply; but, after a little more discussion, the President instructed the committee, who had the matter in hand, to provide for the next stage of the discussion on Cattle, and declared the meeting adjourned.

"Our friends evidently want facts and not theories," said Mr. Howe to Mr. Hopkins, as they separated, and the Club House was cleared for the night. 


\section{THIRD MEETING.}

\section{CATTLE (Continued).}

FANNY WRIGHT APPEARS. - DR. PARKER COMES UPON THE STAGE AND DISCOURSES ON THE SIRUCTURE OF CATTLE.

IT was several days before the committee on subjects for discussion had an opportunity to arrange matters preparatory to the next meeting of the Club. Mr. Howe had been unusually busy. There was a wedding at Squire IVright's, - his eldest and fairest daughter, Fanny, having been wooed and won by a thoughtful, earnest, and devout young minister, who had just graduated at a theological school, and who while yet a student had often tried his wings in Mr. Howe's pulpit, and found sweet consolation during the "interim" at the hospitable man-

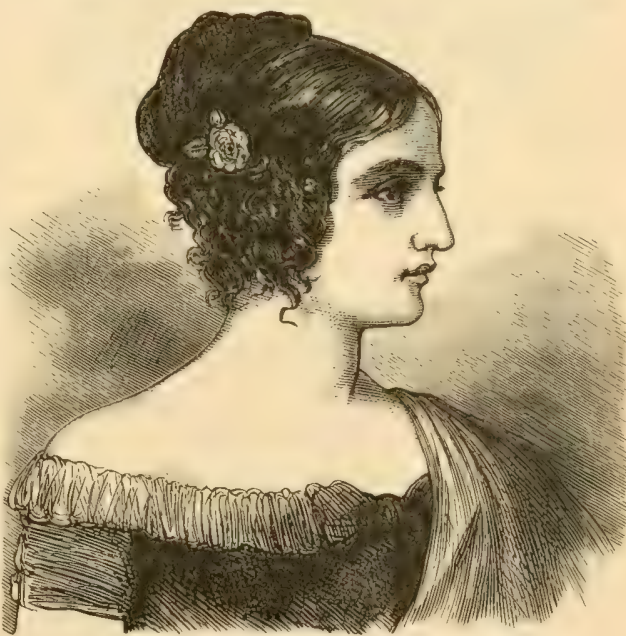

FANNY WRIGHT.

sion of the Squire. The excitement over this event was great ; for Fanny was a most efficient and energetic person, - sang splendidly in the choir, - had the best class in the 
Sunday School, - was the life of the sewing-circle, - carried cheer and light with her wherever she went, - entertained the brightest circle at the parties, with a soft and gentle vivacity so superior to the noise and tumult of so many of her rivals, that young and old hovered about her, - was tall and vigorous and superb with her crown of dark brown hair, - was so self-poised and well informed that she was never "forth-putting," and never awkward and abashed, and had, as her bachelor cousin said, always manifested great sense and judgment, until she followed the example set by so many of the finest and fairest, and fell in love with the young minister. Fanny had gone off in the blaze of a great wedding, and the darkness and silence which followed gave the village such a cheerless air that Mr. Howe felt quite oppressed and powerless. And then, too, an only son of a mother, and she a widow, had died, and all that sorrow had shut down around Mr. Howe, while the humble procession which wound along the hard highways on that gray, cold winter afternoon, and the dismal toll of the church-bell filling all the frigid air with wailing and woe, and the hard frozen grave in the bleak and unadorned churchyard had cast a heavy shadow over the half-frightened companions of the youth, and had softened the whole village into a tender feeling for the grief-stricken mother. But Mr. Howe and John Thomas did meet at length, and turned their thoughts to the duty assigned them.

Mr. Thomas entertained a little doubt with regard to the manner in which Mr. Howe had opened the debate, and he told him so. He had intended to plunge into an energetic and vigorous discussion of the comparative value of native cattle and pure imported breeds, the best way to feed, the best time to milk, the most profitable mode of feeding calves, and he was so dazed by the heavenly light into which Mr. Howe had borne him, that his only fear now was that too sudden a descent might utterly destroy both 
committee and club. And he was only too glad when Mr. Howe suggested to him that, in discussing the structure of cattle, their physiology and habits, the questions naturally next in order, they should call on Dr. Parker, the villare physician, and request him to join the Club, and to prepare a paper upon these subjects. Dr. Parker was a sort of mystery to the committee, as he was to the entire village, and to the people of the country lying within the large circuit of his practice. His father and grandfather had been physicians in

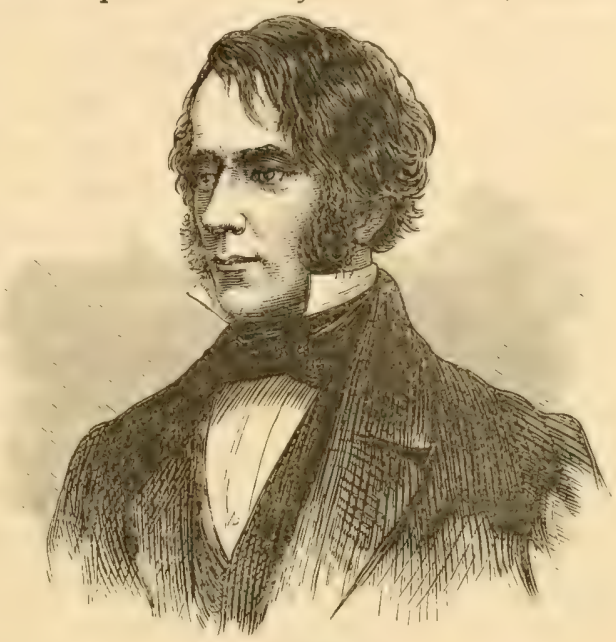

DR. PARKER.

Jotham and that region; and it was generally believed that he had in his possession an elaborate record of all the idiosyncrasies of every family which had submitted itself, from the cradle to the grave, to all these medical generations. He had the entire confidence of the community, not so much from what they did know as from what they did not know about him. The book was impressive enough, but Dr. Parker was more impressive still. He had been graduated at college while yet quite young; and before he had passed out of the unrecognized regions of boyhood into the settled and organized territory of youth and manhood, he had gone to the medical schools of Europe, from which he returned to step at once into his father's place, an accepted physician, without the exhaust- 
ing and withering delay of working into a practice. He had never been married; and it was said and believed that he never would be, and somehow it was desired at last that he never should be. His house was seldom entered except by himself and his housekeeper and servants, the "officedoor" constituting the boundary beyond which few people had been allowed to go. Everybody knew his sulky and each of his horses, but nobody seemed to know him, as all the village knew each other. That he was a victim to an uncontrollable appetite was silently and sadly recognized by all those who loved him, and confided in him, and believed in his skill and knowledge; and this fact in his life had driven him into a secret and hidden retreat, and had veiled him with an air of secretiveness and mystery which manifestly weighed him down, and, except for the practical duties of his profession, made him a self-imposed outcast among his fellow-men. And then, too, he was so learned. $\mathrm{He}$ had really been in Paris, and the people knew it ; and this fact in his life clothed him with just enough of the marvellous to satisfy that popular demand which usually seeks its gratification in quackery of every form. It was known, too, that he imported all newly discovered or newly combined drugs, and so there was no place there for patent medicines. It was announced in one of the daily papers at the time of his graduation at the medical school, that he had written the most elaborate treatise on "Phlebitis" that had ever been published. Whenever a stranger appeared in the village, bowed with study, and "sicklied o'er with the pale cast of thought," everybody knew that he was in search of Dr. Parker; and the postmaster could tell of many a letter addressed to the great Agassiz, or to Jeffries Wyman, or to Asa Gray, or to Dr. Deane of Greenfield, whose untimely death the world of science deplored; or to Dr. O. W. Holmes, or to Dr. Jacob Bigelow; and two or three college boys of the town said he must be versed in 
zoölogy and botany and geology, and must hare some bond of union with the brilliant scholars and explorers; otherwise he could never have such correspondents as these. And one morning it appeared in the "Boston Daily Advertiser," long, long before the "Globe" was establishecl, that Dr. Parker of Jotham had instituted some investigations into embryology among the flocks and herds of his native town, upon which Agassiz proposed to build his most important theories of animal life. What this all meant John Thomas did not exactly know, and he did not care; but he felt assured that such a man as this could either hold the Club up to the height to which Mr. Howe had brought it, or let it down so easily that no damage could possibly befall it.

Dr. Parker listened to the request of Mr. Howe and John Thomas that he would join the Club, and prepare for the next meeting a paper on the structure of cattle, with mingled amusement and surprise. He had never been asked before to join in any of the intellectual operations of the village, and he half wondered at the audacity which now proposed to invade his sanctuary, and drag him forth to the light of day and the popular gaze. His modesty bothered him a little at first, but the prospect of being brought into agreeable associations with his neighbors, and an unexpected and rising hope that there might be after all a humanizing and emancipating influence in this Club, took such strong hold on him for the moment, and opened such a new and unexpected vision of freedom from the secret chain which bound him, that before he knew it he had consented to all that the committee required. And when the Club met again in the pleasant parlor of President Hopkins, to the astonishment of all Dr. Parker appeared with the following paper upon 


\section{THE STRUCTURE OF CATTLE.}

I have been requested by your committee to continue the discussion so well opened at your last meeting by the Rev. Mr. Howe. I do not expect to present any views which will be especially new or attractive to the practical farmers composing this Club; and I assure you I have not the presumption to suppose that my attainments in science will enable me to attract the attention of the learned by any views or observations I may set forth. Perhaps this will be fortunate for us all, as I especially desire to confine myself, so far as possible, to what is familiar and practical. The structure of cattle, of which I shall treat, is interesting to every farmer who would recognize the importance of anatomical conditions as fitting the animal for specific purposes, and realizes as he should that certain physiological laws should be observed in feeding for any given object. It is true the wisest and most experienced and successful of you know well, now, how to feed your cattle for beef or for milk; and know, also, how to select them for each of those two objects. But all men are not wise or experienced or successful ; and it is for those who are not, as well as for my own gratification, that I have entered upon this discussion.

Now, nature has provided that a certain development of the bony structure, and a certain balance existing between it and the musculirr organization, shall indicate to a great extent the purpose to which an animal is best adapted, and also the effect upon the animal economy of various methods of feeding and of service. In a horse, for instance, sharp bony processes, finely grained bones properly balanced as to the weight of muscle, a rather pointed skeleton, indicate courage, high temper, endurance on the road, and great energy; while a frame of smoother make, with dull and blunt processes, with a skull without fine lines, with cannon bones of heary appearance and coarse fibre, is almost always attended with cluller faculties and less energy. So, too, of cattle. That lacteal system which makes a good cow is found in a frame remarkable for the prominence of its processes, the sharpness of its outline, the thinness of its 
edges, the looseness of its joints and articulations, and a certain bony keenness, so to speak, which every good famer recognizes almost by instinct; while on the other hand the slieleton of an animal whose tendency is to convert food into fat is duller, less angular, less finely organized, and intended more for repose than motion. With one frame goes the lacteal system of a good cow, and with the other go the fat-producing cells which are necessary for the rapid production of beef. To some extent the two may be combined ; but not in such a way as to render any one animal capable of reaching the highest standard in both classes at the same time.

Asking you to bear in mind this distinction which I have made, I will now give you what I consider to be the best points of a good cow. She should have heat of medium size, with a strong, well-marked bony structure, broad between and high above the eyes, with a capacious but not clumsy muzzle, full nostril, an eye full, mild, but not too prominent, jurvls thin and wide apart, homs small, well curved, clear, slightly turned upward, and with a calm and at the same

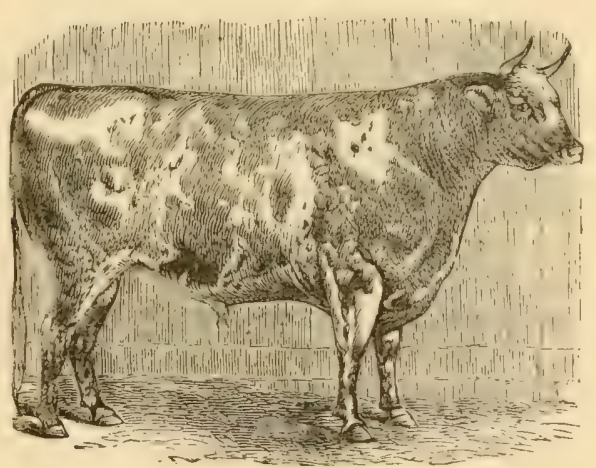

AN AYRSHIRE BUILL. time a strong and resolute expression, - an expression of good health and a strong constitution ; nck long, well-muscled, slender, tapering towards the head, with a little loose skin hanging below, and not dropping too much forward of the shoulders; shondlers thin and sharp at the top, and lying close to the chine, somewhat prominent, strong-muscled, and loose-jointed at the point (the head of the humerus), long from the point to the elbow; fore-yuartirs light and thin, with straight and slender fore-leg, broad knee, 
and broad, flat, capacious foot; carcase deep, round, and full, about the heart, and increasing in capacity towards the hindquarters; luck straight and loosely jointed, with sharp and well-opened spinous processes; pilitis wide over the hips, long, level, and supplied with strong muscles, - a long, level rump in all animals, usually indicating a good constitution and high quality; himd-yuarters broad, strong on the outside, and well cut out inside, with a strong hock and long, tapering foot; twil long and slender, strong at the roots, and set on in a line with the back; udder evenly divided into four quarters, extending well forward, filling the cavity between the thighs behind, not hung low, and with a large, long; and crooked milk-vein, - a superficial vein

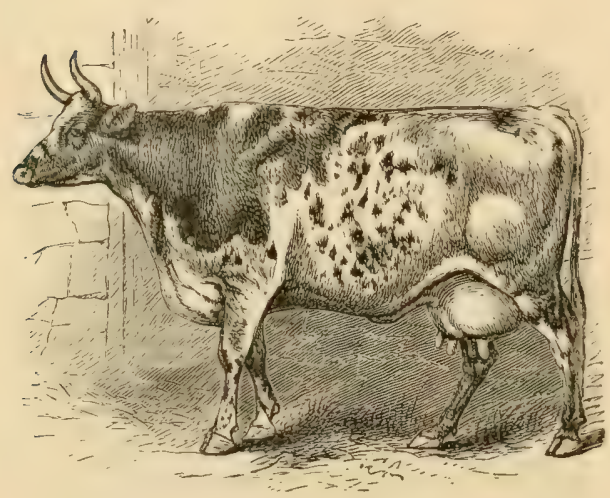

A: AYRSHIRE COW. on the belly indicating the character of the vascular system; teats set far apart and of medium size and length; skin loose and elastic, but not too thin; hair soft and silky, and of lively appearance; rilis broad, flat, thin, sharp-edged, and especially the last two widely separated. A yellowish color to the skin, especially that lining the ears and about the eye, is desirable.

These are the points which would, according to the best laws of physiology, indicate a great capacity to convert food into milk; and I have often noticed the rapidity and skill with which an expert will examine them, as he investigates a cow which he proposes to purchase. How rapidly he runs his hand along the back, to ascertain the structure of the spine and its processes; how quickly he thrusts his finger into the cup-like cavity at the point of the shoulder; how skilfully he follows 
and measures the milk-vein, from the udder to its passage into the great returning veins of the body; how adroitly he handles the skin; and with what a rapid glance he surveys the greneral outline and expression and character of the animal he is examining! No good anatomical point escapes him; not because he is an anatomist, but because he knows from experience the points of a good cow, and thus recognizes the truth taught by scientific investigation.

Now, by way of contrast, let me read to you a clescription which one of the best writers and observers in England gives of the animal which the English breeder has brought to the highest perfection for the purpose of producing beef. The difference will appear to you at once. He says: "The animal should have wide and deep girth about the heart and lungs; and not only about these, but above the whole of the ribs must we have both depth and roundness; the hoopid as well as the deep barrel is essential. The breast also should be ribbed home; there should be little space between the ribs and the hips. This is indispensable in the fattening ox, but a largeness and dropping of the belly is excusable in the cow. It leaves room for the udder, and, if it is accompanied by swelling milk-veins, it generally indicates her value in the dairy. 'This roundness and depth of barrel, however, is most advantageous in proportion as it is found behind the point of the elbow more than between the shoulders and legs; or low down between the legs than upward toward the withers; for it diminishes the heaviness before, and the comparative bulk of the coarser parts of the animal, which is always a very great consideration. The loins should be wide, for these are the prime arts; they should seem to extend far along the back; and although the belly should not hang down, the flanks should be round and cleep, the hips large, without being ragged, round rather than wide, and present when hancled plenty of muscle and fat; the thighs full and long, and when viewed from behind close together; the legs short, for there is an almost insepara-

- ble connection between the length of leg and propensity to fatten. The bones of the legs and of the frame generally 
should be small, but not too small, - small enough for the wellknown accompaniment, a propensity to fatten; small enough to please the consumer, but not so small as to indicate delicacy of constitution, and liability to disease. Finally, the hide, the most important thing of all, should be thin, but not so thin as to indicate that the animal can endure no hardships; movable, mellow, but not too loose, and particularly well-covered with fine and soft hair."

You will mark at once the difference between the two animals I have thus described; and I think there is no farmer here who expects to find in the round, dull, inexpressive bone of the beef animal the narrow, thick-edged rib, compact joints, and wellblunted processes, the frame of a good dairy cow. An expert would reject such an animal for dairy purposes at once.

Let us consider, at this point, the physiological conditions which attend these different structures. It is a comparatively easy matter to breed animals which, by their aptitucle to fatten, will remunerate the feeder. The qualities belonging to an animal structure, designed for this purpose, are very perceptible, are easily transmitted, and are easily preserved and improved by feeding. Mr. Bakewell learned almost the precise mechanism adlapted to his wants as a producer of size and fat, the form and quality of bone, the shape of the parts containing the vital organs, and the organs of nutrition, that "feel," which an expert understands, so that he may also be said to carry his eyes in his fingers' ends, capable of exploring the internal organization of every animal. And this bone, and shape of body, and texture of skin are easily preserved and transmitted. When Mr. Colling saw Hubback, he knew that his stomach and glandular system, and nervous and respiratory organization, all tended towards the development of fat; and he believed it would be easy to transplant such lethargic faculties as these. He did this on good soil ; and with proper care succeeded in making a creation of fat.

Mr. Aiton, however, one of the earliest breeders and founders of Ayrshire cattle, as I understand, and all his predecessors, had a very different and a much more troublesome task to per- 
form. That delicate organization which is called into operation when the food taken into the body is to be converted into milk is much more difficult to comprehend or control. 'There is a certain physical conformation indicative of a large capacity for secreting milk; but when we remember that this capacity depends upon a fortunate combination of many faculties, we can comprehend how many difficulties they labored under who, in Scotland, endeavored to establish a breed of milkers. 'They might secure the bony structure, the quality of skin, the shape of the muscle, the general outline, the form of udder most approved, and after all this there might be some deep defect in the process of assimilating the food, in the glandular system, in the nervous organization, which might entirely destroy the usefulness of the animal. This accounts for the wide differences which exist in individuals belonging to every well-known and long-established breed of milkers. Thousands of animals are driven from Shorthorn and Devon regions, so nearly alike in weight and size and shape, that the law of their reproduction seems to be as fixed as that which gives to the casting the shape of the mould, be it repeated times innumerable. But no one can find a race of milkers all brought up to a high standard, and all capable of unerringly transmitting that standard. We approach it, but are often vexed at the unexpected failures.

It would seem, therefore, that the great rule to be observed in the raising of dairy stock is, not to interfere with the delicate organization by the food furnished either early or late in life. Why cannot the system of a heifer be injured by food, so as to disorganize her glandular functions, as well as the system of a cow, which can be forced into diseased action with the greatest ease, - which, in fact, requires constant care, lest, in her business of manufacturing milk, she may take on disease? Why may we not, for instance, lay the foundation of garget long before the udder contains a drop of milk? We do not feed a milch cow as we do a fattening cow, unless we are willing to run the risk of ruining her. For the wholesale statement so often made, that what produces milk will also produce 
fat, and vice versa, is shown to be wholly unfounded by a comparison of the effect of rowen hay, brewers' grains, shorts and green food with corn-meal and oil-cake.

We are obliged to consider the different structures we are dealing with from infancy to maturity and decay, in all our endeavors to make the various classes and breeds of cattle profitable to us. That we may force the beef producers I have no doubt, for they are as well able in early life as later to discharge their duty of creating flesh, and their faculties do not seem to be injured by use. But with the structure and functions of a dairy cow we must be more patient and deliberate. Her powers mature slowly, and depend very much on the strength of her constitution. When this is impaired, either by feeding or breeding, her value is diminished. In establishing a dairy breed, therefore, early maturity, with its accompanying evils, is not desirable. On the contrary, it should be avoided, and that mode of feeding should be adopted which will be conducive to health in the individual and in the breed, and which will in no way exhaust the powers or shorten the life of the race.

I present these views, Mr. President, for the consideration of the Club, proposing at the next meeting to discuss more fully the effects of various kinds of food upon the animal structure. In doing this I shall not deem it necessary to resort to a microscopic investigation of animal tissue and fibre, because I think I can satisfy you that there are certain general rules so manifestly beneficial that all ought to follow them. And I trust that in this way we may discover the true relations which exist between science and practice, and may learn also how to record the facts which we obtain, and how to deduce from them the best laws to guide us in our work.

The speech of Dr. Parker was warmly received; and there was an universal look of satisfaction, when he announced that he would continue his remarks at the next meeting. Peter Ilsley said he should wait until the Doctor had finished his scientific views, before presenting what he 
himself had prepared of a practical character. The meeting, after considerable desultory debate, adjourned, leaving President Hopkins and Dr. Parker sitting for the first time together before the wood-fire, enjoying the dawning hours of a rapidly growing intimacy, and the solace of their cigars.

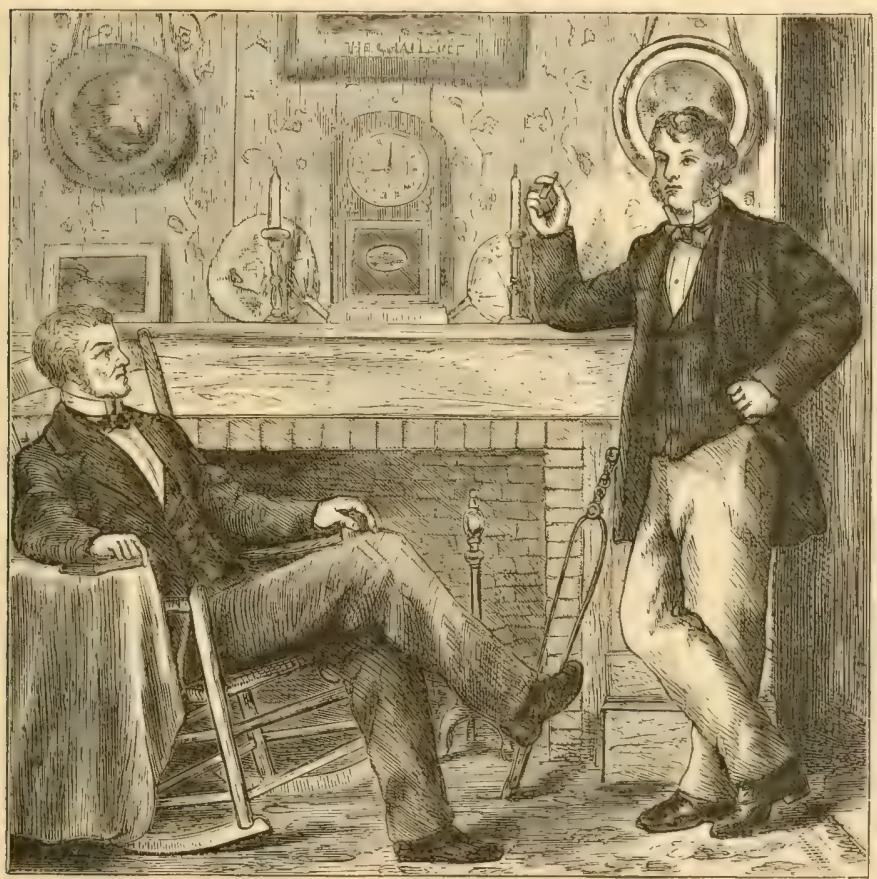

PRESIDENT HOPKINS AND DR. PARKER. 


\section{FOURTH MEETING.}

\section{CATTLE (Continued).}

DR. PARKER CONTINUES. - HIS OPINION OF INHERITED FACULTIES AND CHARACTERISTICS. - SOARS ALOFT AND REJECTS EVOLUTION.

WHEN the business of speeding the parting members of the Club was over, and President Hopkins found himself quietly and somewhat intimately sitting by his fireside with Dr. Parker, it became evident to both these gentlemen that there would be for many minutes a relief to their minds in the drowsy business of watching the curling smoke of their cigars. They had not known each other well, had not often met. They were reserved, too; the President, from the absorption and caution of a life of business; the physician, from the effect of his habits, his want of sympathizing companions, and the necessities of his profession. They were not of the talkative kind, and the closing business of the evening had been so wordy, so incirect, so confusing to a well-drilled mind, that the golden hues of silence seemed to have an unusual charm to them; and so for a short space of time the two new friends settled down and mused.

At last Dr. Parker turned to his companion and said, abruptly, "Do you like this ?"

"Yes, I do!" said the President, "as far as I have gone."

"Why?" said the Doctor.

"Well," replied Mr. Hopkins, "for a variety of reasons. I like the repose, to begin with; and so fond have I be- 
come of the calm and quiet life of this old farm and the village, that I look back with an involuntary shudder upon the excitement and strain of my many years of toilsome and successful business. When I recall how suspicious and secretive and watchful and sleepless I was, how blind to every want and deaf to every appeal I became when the object in view was trade and only trade, I must confess I am thankful that the work of making my fortune is over, and the work of using and enjoying it has begun. Then, too, my ancestors lived here, and I was born here, and I seem to have a sort of title to this spot which I have not to my wharf and warehouses, - a higher and finer right of possession. I like the people, moreover; like the minister, like the occupation of the place, the peculiarities of my neighbors, the defiant way in which they resist a theory and a theorist, the unshakable level of their minds, their sensible instincts, their honest impulse for what is right and humane in an emergency, their queer little selfishness when there is nothing of moment at issue, their sturdy individuality, their apparent torpor, their quick responsiveness, their keen understanding; their common-sense; and then, Doctor, to be President of a Farm-yard Club in your own town, and without a fight, and in your own house, with the gathered landholders about you; - I tell you, there is a feeling of satisfaction about it, which the ambitious who successfully walk more giddy heights may possibly feel, but I don 't believe it."

The Doctor, who had lived all his life in Jotham, and had come to look upon each family in the town as a pathological problem, and had had no ambitions, seemed hardly to understand all this; and yet there was something attractive about it to his mind, and he thought it might perhaps be well for him to follow President Hopkins into this new and airy field of investigation. And suddenly remembering that nothing binds men so firmly together 
as the consciousness of having the same blood in their veins, he said: "I believe, Mr. Hopkins, your great-grandmother was a Bradford."

"Yes," said Mr. Hopkins, "Eunice Bradford, a descendant of the old Plymouth family. She married Timothy Hopkins, my great-grandfather, from whom I get my name."

Dr. Parker, who had too long turned the cool eye of science upon his fellow-beings to be much interested in genealogy, was pleased, however, to remember that even before a Bradford had settled in Jotham, one of his ancestors had married in to that illustrious Pilgrim family, - and he instantly discovered the cause of a certain resemblance in motion, tone of voice, and slight peculiarities between Mr. Hopkins and an older brother of his own, who had long been dead, - a resemblance which had so attracted him that he had become restless to account for it, in order to determine in his own mind whether the finer traits are indigenous to a locality, or can only be preserved and transmitted through the channels of the blood. He had also seen and admired Mary Johnson, his far-off relative, when he was a mere child, and he was drawn still nearer to Mr. Hopkins, the husband of so kind and lovely a wife, and to his two sons who had such a charming mother. And as he went on and smoked and mused and chatted and remembered, he felt the currents of new and unusual emotions moving round his heart, and thought, on the whole, it was very wise in Mr. Hopkins to desire to end his days in his old home.

And so having settled the family question, he asked Mr. Hopkins, with an interest increased by the discovery of these ancestral ties between them, how he proposed to make his farming a matter of business, as he had his merchandise, and where he expected to find out what he wanted to know. 
"As to the business part of the matter," said the President, "I have not yet got at it ; my ship is n't launched ; when she is, I will engage to find a voyage for her. And as to information, I propose to call on my neighbors."

"Whom you are trying to teach in a club," said the Doctor.

"No," said the President, - "whom I am trying to encourage in the work of systematizing what they do know, so as to advance beyond the regions of mere tradition and experience. Peter Ilsley knows a good cow from a poor one, Doctor, better than you do; but put his knowledge and yours together and he won't make the odd mistakes he now does, and which he can't account for. And, by the way, Doctor, what do you say to all this talk about the origin of the species, and evolution, and man, and monkey?"

"O, pshaw!" said the Doctor, "nothing. Microscopically and chemically the fibre and tissue and fluids of a man may be the same as those of a dog. But man defies all laws. He is n't so strong as a horse, it is true, but what of disease or medicine will kill a horse twice harms him not at all. He is not physically powerful, but he is physically enduring, and, through the agency of his spirit, physically 'triumphant over space and time.' At a certain point he leaves the animal economy, and soars into the regions of a Divine power, lives and works in spite of disease, implants upon his race, through the agency of his soul, faculties, moral and intellectual, which become at last a part of his physical organization, and proclaims everywhere, and in every way, that he is not a beast. Reverently and devoutly I recognize the Divine power which manifested itself, not so much when it made the earth and the sea, as when it breathed into man an immortal spirit. And I reject with scorn and contempt the theory of evolution, as old Samuel Johnson did in his 
day the doctrines of Monboddo, with his ring-tailed humanity."

Mr. Hopkins was rather startled by the Doctor's sudden impetuosity, and, with a mild assent to his views, turned the conversation to local matters, and town traditions, and old memories, and the characteristics of the departed, and the labors of the living men and women, until the fire burned low, and the Doctor rose to depart, closing the conversation by abruptly and awkwardly asking the President if he knew Clara Bell, the miller's daughter.

"No, I do not," said Mr. Hopkins.

"I didn't know but you might have seen her," said the Doctor; and he was gone.

The Club gathered at its accustomed day and hour, and with more than its accustomed members, at the house of Mr. Hopkins, on its next meeting. Mr. Howe read the records of the last session, and announced that Dr. Parker would continue his discussion of animal structure, as he proposed at the end of the previous debate. The Doctor read the following essay on

\section{ANIMAL STRUCTURE.}

I endeavored in my last address to impress upon your minds the view that Nature has designed the various physical organizations for specific purposes, and that it is especially important for the farmer to discover the relations which exist between the structure of the animal and the service he is to perform or the object to which he is destined. In animals intended for the dairy this consideration should never be lost sight of ; and great regard should be had in raising and feeding dairy stock, to the effect which different kinds of food produce upon the animal economy. In order that I may impress this more strongly upon your minds, I will endeavor to lay before you as clearly and concisely as may be the different functions employed in the production of milk and of fat ; and I doubt not you will 
then see why it is that an animal cannot well engage in the production of both of these at the same time, and cammot siffely use for both the same kind of food; and I trust you will also see that the young animal destined for one service must be fed differently from the young animal destined for another service.

And now, in the first place, let us consider the organs and functions deroted to the production of fat. The fat cells, that tissue of the body in which adipose matter is deposited, are found in fat and lean animals alike, - the difference consisting in the amount of their contents and their number only. For the supply of fat, certain organs are provided which are capable of receiving all that excess of non-azotized compounds, such as starch, oil, etc., which is contained in the alimentary matter taken into the body. When there is a ready absorption of these compounds into the vessels fat is produced, especially if with this absorption there is combined a vigorous power to generate adipose tissue of the cells producing fat. When they are not absorbed, accumulations of fat do not take place; and when they are absorbed without being provided with adipose tissue, they would accumulate injuriously in the blood if not drawn off by the liver. Hence it is that in warm climates, where there is di-

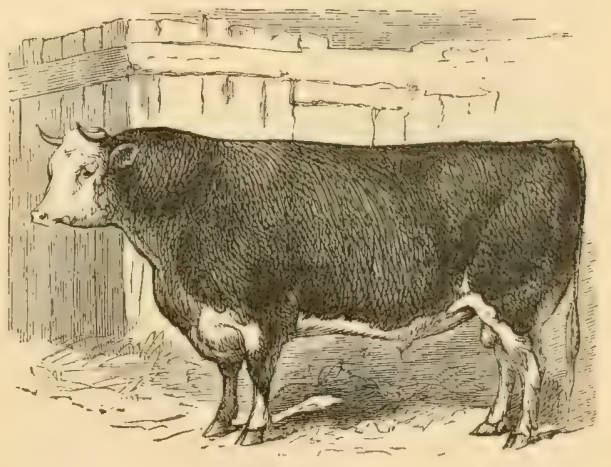

HEREFORD BULL. minished excretion through the lungs, and non-azotized matter is not got rid of by the respiratory process, the liver is overworked, its function becomes disordered from its inability to separate from the blood all that it should clraw off; and these injurious substances, accumulating in the blood, produce various symptoms that are known under the general term, bilious. Hence also 
some persons never become fat, however large the quantity of oily matter taken into the stomach; and it is in such persons that the tendency to disorder of the liver, from overwork, is most readily manifested; and they are necessarily obliged to abstain from the use of fat-producing articles of food. It is the power, therefore, of absorbing these fat-producing articles of food, and of generating adipose tissue for their reception, that saves the liver from being overtasked, and results in accumulations of fat. I have divelt upon the production of animal fat, and the organs engaged in its manufacture, in order to show how distinct a part of the animal economy it is, and how naturally the fat-producing functions can be transmitted, independently of all others, and may be cultivated at the expense of all others.

The secretion of milk, however, is a very different matter; and now, in the second place, I will discuss the organs and functions devoted to this part of the animal economy. This secretion is formed by glands, whose business it is rather " to elaborate from the blood certain products which are destined for special uses in the economy, than to eliminate matters whose retention in the circulating current would be injurious." These glands, called mammary glands, perform, as is supposed, the chief part of the work of elaborating the elements of milk; although it is not yet ascertained how much of this elaboration takes place in the blood during its circulation. Be this as it may, the production of milk is a very different business from the production of fat, and does not result from the combination of the same elements as are contained in the adipose tissue and fat cells.

It is well known, moreover, that the proportion of two at least of the principal ingredients of milk is liable to great variation with the circumstances which surround the animal. Dr. Playfair has ascertained "that the proportion of butter depends in part upon the quantity of oily matter in the food, and in part upon the amount of exercise which the animal takes and the warmth of the atmosphere in which it is kept. Exercise and cold, by increasing the respiration, eliminate part of the oily matter in the form of carbonic acid and water; while rest and 
warmth, by diminishing this drain, favor its passigre into the milk. The proportion of casein, on the other hand, is increased by exercise; which would seem to show that this ingredient is clerived from the disintegration of muscular tissue." "The experience of every farmer teaches him that an animal which has a large, heary, muscular development, and is thus furnished with the means of rapid locomotion, is seldom a good milker. Her digestive apparatus is more devoted to her fleshy fibre than to the preparation of milk. The same may be said of fat and bone. So true is this, that among cattle bred expressly for the stall the females often furnish hardly milk enough to sustain their own offspring; and in countries where the bone and muscle of the cow are developed by labor, her service in the dairy amounts to but little.

It would seem, therefore, from the explanation which I have given of the two duties to be performed by the animal economy, one for the dairy and the other for the stall, and of the ease with which either may be developed by feeding, that in raising animals for the dairy care should be taken that the young are not so fed as to develop a tenclency to great size, either inframe or in adipose tissue; nor so as to establish in the end a race which has

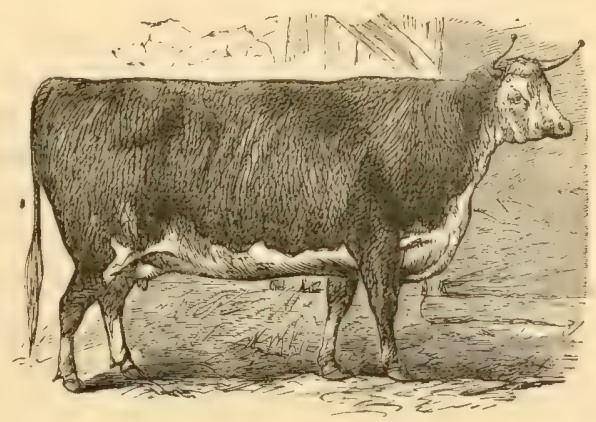

HEREFORD COW. every faculty except that of producing milk. We have all seen how high feeding of the young has in a few generations, and sometimes in one or two, removed from a family of vigorous, nervous, muscular and active horses all traces of those characteristics which have given them value. What they had acquired on the homely fare of their native hills they lost when brought and bred into greater prosperity. The hard and wiry tendon 
vanished, the elastic and well-defined muscle was rounded off into graceful effeminacy, the carcase and adipose tissue had gained the ascendency, through the aid of good living and a luxurious life from youth upward. Some of us have seen a promising heifer calf, the offspring of a good milker, pampered in its youth, and fed until it became anything but the dairy animal which its ancestry promised.

I would not advocate a deficiency of food for young dairy stock, but I would argue against an excess of articles of a highly stimulating quality. The plan of the Ayrshire farmers is undoubtedly a good one, - to take their calves early from the dams, feed them from the dish, and bring them to solid food or pasture as soon as the condition of the young stomach will allow. Instead of linseed meal, they use a great quantity of oatmeal, - an article of food much less predisposing to fat, and keeping up a vigorous growth. We have in New England the best quality of English hay as a basis for feeding; and after the calf is weaned, or after it has had milk enough to give it a fair introduction into life, hay in the form of hay tea, and afterwards of rowen, is undoubtedly the best food the young animal can have, especially when aided by a few turnips and a little oatmeal. In some cases milk is abandoned at a very early age, and skimmed milk is advantageously used as a substitute. I would not recommend the use of grain for young dairy stock, especially that containing a superabundance of oily matter, as Indian corn or cotton-seed or oil-cake. Perhaps corn-meal, sparingly, or barley-meal may be used in winter, should the animal seem not to thrive well. But a calf that is properly weaned, and properly fed after weaning, and, if dropped in early spring or in winter, furnished with a good pasture the first summer, will be carried through the first winter most satisfactorily on good sweet hay, especially rowen, with turnips and oatmeal. In this way can a uniform and wel'-balanced animal be produced, which when put to dairy service will not become coarse and rawboned in her appearance, nor take on flesh at the expense of the milk-pail.

Of course the views which I have advanced apply solely to 
dairy stock, and should be borne in mind mainly by the farmer who is engaged in raising cattle for this purpose. I have alluded, as you must have noticed, to the custom adopted by the Ayrshire farmers, and I have done this because on their farms the business of feeding and breeding for the dairy has been brought to the highest perfection. If, however, the object is the stall, an entirely different course should be pursued. The breeder and feeder of cattle especially adapted to beef may begin at the earliest age of his animal and force him into a rupid growth without injury to the animal and with benefit to himself. The fat-producing system can be constantly encouraged, and should never be checked by neglect or improper food. It is a system easily preserved, readily transmitted, and capable of bearing constant stimulus. While the Ayrshire breeder feels that he is liable to repeated failures on account of the delicacy and sensitiveness of the system he is to produce, the Shorthorn breeder may feel confident that he can arrive at uniformity, and sustain the type of animal he desires without great difficulty, and with small danger of being disappointed. He may therefore with great adrantage to himself pursue a course entirely different from that which I have recommended to the dairy farmer. His calves may be kept upon the cow until the third or fourth month, and when weaned they may be provided with the most stimulating and nutritious food. If at two years old they can be made to attain a size equal to that of ordinary animals at three or four, so much has been grained. And the feeder need have no fear that the physical organization of such an animal will be injured by this forcing process.

You, who are engaged in the practical business of feeding cattle for various purposes, and who undoubtedly know more from your own experience than I can from eren the best founded theory of my own, will allow me, I am sure, to suggest that the same rule applies to feeding dairy stock at maturity that applies to feeding the young animal. I have frequently met in my drives through this region cases of inflammatory clisease among cows, which I could almost always attribute to long- 
continued, excessive, or injudicious feeding. I suppose there can be no doubt that diseases of the udder, such as garget and swelling, which often terminate in ruining the cow, may be traced almost universally to the same cause. A sudden chill, or long-continued exposure to cold and wet, may produce this, but generally it is imprudent feeding. I should say that a liberal use of corn-meal and oil-cake and cotton-seed meal would produce this result. It may not come about in one year or two, but were I a cattle-feeder and a dairyman, I should just as much expect to find garget in my herd of milch cows if fed on oleaginous grains, as I should to find gout following a longcontinued use of Madeira wine, - and if not gout, something worse. If I am wrong in this, I shall be glad to be set right by those of you who have had experience in the business.

Now, I beg you to remember that I am considering what I deem to be for the best good of the animal, and most in accordance with the best physiological laws. It may be profitable for some of you to feed heavily, and force your cows up to their highest capacity by a liberal use of such food as I am condemning, and after a short period of time to turn your animal for beef. This point I do not propose to discuss. But 1

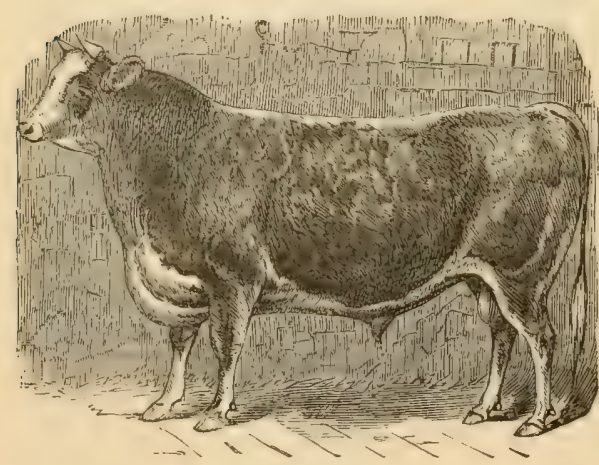

JERSEY BULL.

would ask you to consider the usual loss on a cow when she has finished her career in the dairy, and to calculate carefully whether it is not good economy to aroid the necessity for turning her for beef as long as possible. Cows do not mature at an early age, rarely before they are five or six years old, and from that age until they are ten or eleren they generally give their largest quantity of milk. I think this 
period cannot be shortened, without loss to the owner. And I am confident that such a mode of feeding as will enable a good cow to retain her faculties to a good old age is most profitable to her owner.

In addition to what I have suggested with regard to the food of clairy cows, you will pardon me if I make a few remarks upon their general treatment, - remarks which I shall base upon the structure of the animal, and not upon any experience of my own. The cow, it should be remembered, is not made for rapid and long-continued exercise. Her muscular system, if she is well-adapted to the dairy, is not powerfully developed; and her digestive organs are so constructed and constituted that she can preserve her health, even when kept in close confinement. Give her a good pasture, and she supplies herself with food from the smallest surface and in as short a time as possible, and then seeks a comfortable spot in which she can repose. It is quiet and rest and warmth which she requires, and he who attends most strictly and understandingly to her wants will see that she has all these, in addition to suitable food. A warm stable for your cows is indispensable, - a stable in which they can be carefully protected from cold and storms. Do not be deceived into the iclea that they need air and exercise. They do not - especially that which is found in a mid-winter day, by curling under the sunny lee of a barn and waiting impatiently for a chance to enter. Let your cows by all means have warmth, light, and repose. This is in every way comfortable to them and profitable to you.

You will hear much said about the necessity of providing a variety of food for your cattle. I think, however, you need give yourselves no uneasiness on this account. There is no great variety of grasses in our pastures; the grazing lands of California and the West, where cattle thrive and fatten with great rapidity, the blue-grass pastures of Kentucky, are not remarkable for variety, but for the quality of the grass which they produce. During six summer months in this climate, and throughout the year in the milder regions, the cattle graze without any other variety than that furnished by the few natu- 
ral grasses themselves, and they supply all the requirements of nature. The hay which is stored in our barns is made up of various kinds of our cultivated grasses, generally herds-grass, -red-top, and clover; and this of itself seems to be sufficient for the wants and tastes of our domestic animals. At any rate, good hay and grain, either corn-meal or shorts or oat-meal with a few turnips, can be fed day after day with manifest advantage to our cows and working oxen, as hay and oats can be to our horses. That a little green food in the shape of roots is useful for our cattle in the winter season, as is also a cessation from grain for two or three winter months in each year useful for our horses, I do not doubt, - in fact, it is reasonable and manifest. But there is no necessity for going beyond this, either to obey the law fixed by experience or to accommodate the structure of the animal.

In conclusion, let me remind you that cleanliness is really as indispensable to the comfort and health of the animal as are good food, warmth, and repose. This I urge as a preservative of health. As a remedy for diseases, except such as are local and require local remedies, and those which are considered epidemic, I would urge warmth and rest. Medicinal agents may, probably do, control the diseases of animals; but

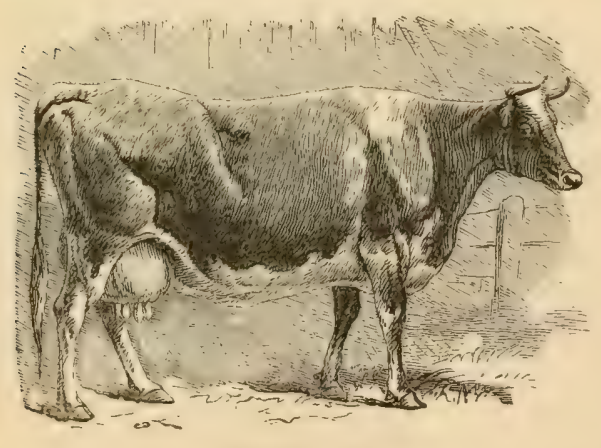

JERSEY COW.

I am confident that the effect of the remedy is as bad as the disease itself. Domestic animals are very sensitive to the effects of drugs, much more so than man. And while they bear disease with less impunity, they also bear medicines with less safety.

That medicinal agents must be resorted to I do not deny; but as a general thing the acute diseases of animals, if taken in 
season, will yield to good care, warmth, and repose. The difficulty is, we are unwilling to believe that our animals are ailing until they are almost past cure, and then the remedy is too late. Recognize the first symptom, attend to it, and the work is half accomplished.

I beg the Club to excuse the generalizing manner in which I hae presented my views; and I assure them that I shall be more happy to learn from their experience than I have been to set forth my own theories.

The Chair announced that debate was in order. Peter Ilsley rose and said: "Mr. President: I have heard the Doctor's lectures with a good deal of pleasure. I think he has helped me considerably. I have been bothered a good many times in buying cattle; and I have wondered how I got cheated as bad as I did. I can tell a good cow about every time, but when I thought a cow good and she turned out poor I never could tell exactly where I had been misled. Now I see what the bones and hide and head and horns all mean; and I believe as much as I do that the sun shines, that the Doctor is more than half right when he says one kind of a skeleton is not made for all kinds of business. I suppose a man can get whatever he wants among his cattle just as he can among his crops, if he only knows how to do it. But the trouble is to know how. I have seen in some places good cows, shaped just right, of good, nice size, neither too large nor too small, which had come by accident or chance, nobody knew how, and were the best in the farmer's barn. They had come from the rest of the herd not so good, and how they got there nobody could tell. Now I want to be able to make such cows to order; and somehow I think Dr. Parker has hinted a way. Now, before we go on discussing breeds and feeding, I want to offer a vote of thanks to the Doctor for his lectures, and I move that the thanks of the Club be given to Dr. Parker for his. kindness in coming in with 
his lecture and helping us out in our debate; and that his remarks be entered on the records of the Club."

John Thomas took the floor to second the motion. He was much obliged to Dr. Parker, also, for what he had said on the subject of cattle. For himself he was satisfied that all the difference between profitable and unprofitable farming, when a man kept a good many cattle, was to be found in the business of selecting and feeding. The first business is to buy good cattle, the next is to feed them with economy and skill. He had understood that the profits of a factory lay in the economy with which labor was applied to cotton and wool, to make the most of them at the lowest price. He thought the same law applied to a cow ; and he knew that if he could make fifteen quarts of milk out of a cow's daily food, he was better off than he would be if he made but ten. And so in crops. He had so applied labor and manure to land, properly chosen, as to get a hundred bushels of corn from an acre of land; and he had so applied them as to get only forty. There was profit in one and loss in the other. He should have something to say on feeding at the next meeting; and he should give his own experience and what his neighbors had done. He hoped the motion of Mr. Ilsley would be adopted.

The motion was unanimously adopted; and Dr. Parker felt, for the first time, the satisfaction of having done something for the public good of the community in which he lived. And when the Club adjourned he walked home with the crowd, a little anxious to know, and relishing more than he dared to tell, the kind things that the members said to him about his public endeavors. 


\section{FIFTH MEETING.}

\section{CATTLE (Continued).}

HOW TO CUT AND USE FIRE-WOOD. - JOHN THOMAS DISCUSSES CATTLE. - SWEDES. - MANGOLDS. - FODDER-CORN. - A CONTROVERSY.-PETER ILSLEY SHOWS HIS TEMPER.

THE mid-winter village life of Jotham was passing quietly away. The days had begun to lengthen, it is truc, but, in obedience to the recognized rule of the weather-wise, the cold began to strengthen, and those Arctic spasms which winter always indulges in just before it resigns its sceptre had driven man and beast into the shelter of house and byre, and had brought about the glittering and refulgent days and the starry nights which make this season so resplendent. The winter work was really over. In the door-yards of the most prosperous farmers, - those who had not yet abandoned their firesides for the stifling and gloomy warmth of air-tight and column stoves, whence come a thousand fatal ills to young and old, - the sledlength wood-piles lay, jagged and uneven, waiting for the second attack from the woodman's axe, which was to reduce them to a size fit for the brass andirons, whose polished heads had served as grotesque mirrors for the children of many a generation of gatherers around those hearth-stones. The people of Jotham still loved their wood-lots, and they knew as well how to supply themselves with fuel of the best description as they did how to gather their hay-crop at the best time, and in the best order. And so they cut and hauled their wood in January, cut and split it for use in March, exposed it for a couple of 
months in the open air, then placed it under cover where it could season properly, without losing its vitality. They had, moreover, learned the economy of burning a few green sticks with the dry ones, when the hard cold days rendered a steady and glowing fire necessary, hour after hour; and no such fires have ever been seen as those of Jotham, where the dry sticks of the previous season were commingled with the maple and walnut, just drawn from the forest, and laid with that skill which the sons and daughters of a wood-burning people alone understand and exercise. Into the far-off lots, the barn-yard manure had been hauled over the snow, and lay there in great heaps, waiting for the opening summer. Even now the barn-door fowls had begun to gather in the sunny corners of the open woodsheds, and to manifest, by their ruddy combs and busy air, that the time for their work had already arrived. A few stray hairs, flying thus early from the heavy winter coats of the cattle and horses, told also that the time was fast approaching when those warm garments, which nature had so bountifully provided, would be no longer needed. And all the farmers knew that they must seize the moments as they fly, and prepare for the active work of spring, or else lose those days which, once lost, can never be regained, even in the longest season and by the swiftest pursuit. It cannot be said that the village was very lively; for the cold still lay heavily upon it. It cannot be said that the church was very lively; for Fanny Wright was married and gone, and the bright star of the choir had dropped from the firmament. It cannot be said that society was very lively; for the social assemblies springing out of Thanksgiving and New-Year were over, and the sleighing-parties to Joppa ended, and the freshness of winter was gone. If you had visited the workshops and wagon-houses of the farmers, you would have found them putting their ploughs in order and tightening the harrow 
teeth, and overhauling the cart-wheels, or repairing the shovels and hoes, or painting the wagon-bodies and setting ready for spring work. These primitive mechanical establishments were busy enough. And the Club, as the objects of its deliberations came nearer and nearer to the minds of its practical members, and the field, with all its toil and its expected profits, began to have a more immediate interest, was filled with keener life and activity.

When the Club assembled once more in the parlor of $\mathrm{Mr}$. Hopkins, it was under the most favorable auspices. The usual entertainments of the village were over, and the details of the coming season had commenced. The members of the Club had, moreover, become more intimate with each other, less reserved, less awkward in the wellfurnished rooms of their President, more familiar with the locality, and they presented an unusually lively appearance as they gathered together in chatty groups throughout the room and discussed the news of the day, and a little theology and politics, the weather, past, present, and to come, and the troubles in the town school.

"Cattle wintering well?" said Peter Ilsley to John Thomas, as they met before the fire.

"Well, yes, fair, some of 'em," said Thomas; "the fact is, my yearlings and two-year-olds stayed out a little too late last fall; they got one grain pinched. When I got them up they had a little too much coat on, and were all ready for any trouble which might come in the barn. The first thing they did was to get the mange, which has tormented me these five years in one of my barns; and I have had to fight that with sulphur and lard outside, and meal and turnips inside. They are doing pretty well now, but then I have lost two months in feeding against disease, when I ought to have fed for growth. I don't think much of pasture-freezing in the fall. How have your cows done? Milk-market good?" 
"Done well," said Ilsley. "I gave them a good run at fall-feed, last fall, and began the winter with a little rowen, which kept them along until they got used to hay and grain. As for milk, I have made milk enough, but then I can't get anything for it ; the contractors and railroads kill everybody. Not as I want to market my own milk, but I do want to get pay for milking at any rate. There ain't no money in nothing, nowadays."

"How are ye, Peter," said William Jones, the horsebreeder; "been buying a new pasture, I see, over on Bear Hill. Good one? What did you pay for it?"

"Well, somewhere from twenty to thirty dollars an acre," replied Ilsley, rather unwilling to show his hand after his gloomy view of the milk business. "I kind o' wanted a place for dry cows, and I always liked the looks of that pasture."

"What'll you take in a couple of three-year-old colts for, next season?" said Jones.

"O, I don't exactly know; about a dollar a week apiece, if they ain't breachy; if they be, won't have them round at any price," was Peter's answer.

By this time Mr. Howe had arrived, and Mr. Hopkins had extended to all his genial hospitality; and the hour had come for calling the Club to order. This Mr. Hopkins did, and called for the reading of the records of the last meeting. This duty Mr. Howe performed in a most acceptable manner; and the debate opened once more on the subject of

\section{CATTLE.}

\section{John Thomas took the floor, and said:-}

Mr. I'Resinent: - The remarks of Dr. Parker have been so well arranged and so interesting, that I am more than half ashamed to try to follow him. But my old mother used to say that we could not have plum-pudding all the time; and so I 
offer what I can say as rather a common dish. I was pleased with the Doctor's description of a grood cow, but I was more pleased with what he said about the diseases of cattle and the mode of feeding them. He is right about sick cattle and horses; they need care and aid and protection. If there is an epidemic, the cheapest way is to stamp it out, as Massachusetts did years ago, and as I am told England and Holland have always been obliged to do. But when your cattle get cold, or lame, or have fever, or lose their appetite, the best way is to stop work and nurse them at once. Don't wait a minute. No animal is fit to labor unless he is in good health. Health and strength are all they have, and these must be taken care of. When I was a boy, I had a long attack of slow fever. My father sent for old Dr. James Jackson of Boston, who was very skilful, very famous, very kind, very sensible, and who had so many desperate cases put into his hands, as a last resort, that people used to think it was time to die when Dr. Jackson was called in. But he had great good sense; and he said to my mother, "Take good care of the boy ; that is the best medicine." And he was right. I remember, too, when my father had a violent sciatica, as it was called, the famous Dr. Waiker of Charlestown came, as an old friend, to see him, - they had been to the academy here together, when they were boys. And the I)octor talked and talked, and at last he said as he left, "Take good care of yourself, and eat baked apples, Thomas ; you will get along," And so he did. I lost the best cow I had, four years ago, of milk fever. When I found her, about twelve hours after calving, she was lying down, looking sort of wild about the eyes, and every now and then gritting her teeth, as cows always do in the beginning of this trouble. I spent half a day in getting a veterinary surgeon, and when I had got him I had lost my cow. Not long after I had the best one of my remaining cows attacked in the same way. The cause of the trouble I could not tell, and I never saw a man who could; but I thought that the softening influence of a warm bath could do her no harm, and might, possibly, relieve a certain rigid appearance which $I$ noticed in the animal. So 
I wrapped my cow in thick blankets wrung out with hot water, - covered her thoroughly from head to tail with many thicknesses, and bound the blankets on with cords. In a few hours there was an evident relief, and in a few days my cow had recovered. In addition to the warm bath I gave also warm drink and mashes, and I cared for that cow from the moment I discovered her illness until she was evidently getting better. I have not had for years a violently sick horse, except on a rented farm, where my tenant uses my horses and uses them carelessly. As soon as I discover that my horse is out of sorts I stop his work at once, and give him a warm, loose box or a pen. I do not allow him to exert himself at all when he is ill. I have seen so many valuable horses killed by exposure and effort after they were attacked by disease, that I macle up my mind to avoid all this, so far as my own are concerned, at least. A horse in health can be heated or chilled with impunity; but a horse not in health can bear neither. His strength is great under all circumstances, and will enable him to bear a great deal of suffering; but this same strength, when exerted by a frame laboring under disease, may be as destructive as the disease itself, and a mere exertion may kill. My neighbors work sick horses, and insist that it is good for them; and the horses die. I will not work my horses when they are sick, and they get well.

This is, I think, the only economical way of treating animal disease. We farmers cannot afford to lose our cattle and horses, and we ought, therefore, to be careful of them. We cannot afford to pay a doctor's bill of fifty dollars on a cow which at best is not worth over seventy-five dollars, and is not worth much of anything after going through a long fit of sickness and the doctor's hands. I have seen many a horse pronounced cured by a veterinary surgeon which was not worth the money the surgeon received for his care. Summary attention, therefore, and constant nursing seem to me to be the quickest and most economical mode of treating diseases in animals. This mode of treatment works well in pleurisy, pneumonia, rheumatism, and dysentery and inflammations; and, as for consumption and rabies 
and strangulation, the only remedy is getting rid of the cow; while foot-rot and mange and thrush and tumors are local affairs, and must be treated by local applications. So I think Dr. Parker is quite right when he says care and shelter and prompt attention and warmth are the best remedies for diseases in cattle.

And now I desire to say something with regard to feeding cattle. I believe all Dr. Parker has said about the fitness of certain kinds of food and unfitness of others. I have spoiled many a cow with oil-meal; and I have shortened the useful life of many another by too free a use of corn-meal. My neighbors complain of just the same trouble. 'The ill effects may not appear in one year, but they will in the end, in perhaps two or three years, and the loss is great. If you force a cow to give sixteen quarts of milk per day by oil-meal or corn-meal and ruin her in two years, how much clo you gain over what you would if you fed her on lighter food, and got only fourteen quarts a day, but got that until she began to fail from old age? I do not believe anything is really gained by forcing. You may gain good looks and a short period of superiority, but in the end there will be a loss.

The three kinds of food for cattle are hay, roots, and grain. Hay is the foundation, and if cut at a proper time and well cured, it will alone furnish nourishment for all ordinary purposes. I suppose if I should try now to tell how I make my hay, the President would stop me for not confining myself to the subject under discussion; so I will tell that at another time. But hay, English hay, herdsgrass, and recl-top, is the first thing needed for good healthy feeding. Meadow hay may answer for young cattle and stores, and so may salt hay, but these require the addition of grain or roots to make them equal to good English hay. Rowen for calves and milch cows is of course very valuable; but it is costly, does not spend well, and can only be considered an expensive luxury. I feed very regularly, and not often. I have always noticed that a cow turned out in the morning into a good pasture will fill herself as soon as possible, and then lie down and rest, and chew her cud, in the shacle, 
until into the afternoon. I suppose this plan is best suited to animals which chew the cud. Now I try to give my cows the same chance in the barn that they get in the pasture. And so in winter I begin to feed them with hay about six o'clock in the morning, and feed steadily for an hour and a half or two hours. About nine o'clock they are watered and have a feed of roots, Swedish turnips or mangolds, whichever I happen to have. At about four o'clock I begin to feed again, and feed for an hour and a half or two hours, as the cattle may seem to require, - for some will eat longer than others; and this ends the day. Cattle need watering but once a day, especially during the short days of winter; and I never turn mine out, except to drink. When cattle are fed in this way, they will lie down during the middle of the day, and keep perfectly quiet. My barn is a; still at noon as it is at midnight. Somebody has said, "The anim 1 l stomach is a very nice chronometer, and it is of the utmost importance to observe regular hours in feeding, cleaning, and milking." This is a point at which many farmers are at fault, - feecling whenever it happens to be convenient. The cattle are thus kept in a restless condition, constantly expecting food when the keeper enters the barn; while, if regular hours are strictly adhered to, they know exactly when they are to be fed, and they rest quietly until the time arrives. If one goes into any well-regulated dairy establishment an hour before feeding, scarcely an animal will rise to its feet; while, if it happens to be the hour of feeding, the whole herd will be likely to rise and seize their food with an avidity and relish not to be mistaken.

I like to feed my cattle myself, and they like to have me. I heard one of my boys, the other evening, reading poetry to his mother, and one line was,

\section{"Be not like dumb driven cattle";}

but I tell you dumb driven cattle are not so stupid after ail. They know "the hand that feeds them" as well as man does. And I can always save a large amount of fodder, and receive a large amount of thrift, by tending my cattle myself. They know me and I know them. And they look just as different 
when I ami about, from what they do when the boys take care of them, as my children do when I am with them and when they are with a stranger. All men can hoe and dig, but all men cammot keep cattle in good order. Kindness, system, order, a proper distribution of the food, knowledge of when to begin feeding and when to stop, a capacity to judge when an animal has had enough, all go to make a good feeder.

I have spoken of nothing but hay, dry hay, as an article of food thus far. It is the foundation of all feeding in this country; and I think we ought to be grateful that we have so nutritious and wholesome a kind of food for our cattle, and are not obliged to use straw and supply the nourishment with grain. When I have an abundance of grood sweet hay, I always save grain. But no matter how much straw I have, the cost in grain is always the same; for straw alone is poor stuff, but good hay is about equal to grain. Still, I like to vary. So I use roots, Swedish turnips, mangolds, a few carrots, some potatoes, corn-meal and shorts. To my milch cows I feed at the close of the morning foddering, a half-bushel of chopped feed, made of corn-stalks or coarse hay, or even good English hay, with a quart of meal and three quarts of shorts in it. I mix this a few hours before I use it; and if the feed is cornstalks, I mix it with hot water. At the beginning of the afternoon feeding I give three pecks of roots such as I have. When I give chopped feed and roots in this way, I feed of course less hay. For the young cattle and dry cows I use a few roots and no grain. Now and then 1 put a little salt into the chopped feed, or, if I can get it, I use a little salt hay or black grass, every day. And I like to keep my cows pretty full, not too much puffed out, in good flesh, and of even shape. It takes me about a fortnight when they first come to the barn to get their appetites regulated, and their bodies shaped to proper feeding, after the heavy supply they get in summer and fall in the pastures and fields. This is about all I know about feeding; and my cattle always look well, - go out in the spring in good order, and come up in the fall about the same, unless a drought has cut off all the feed. 
"What is a Swedish turnip?" said Sam Barker.

"A Swedish turnip," replied John Thomas, "is a rutabaga, a great, solid root, called, sometinıes, Skirving's King of the Swedes, or the Purple Top Swede. It is the great root of England; and a profitable root it is. You can raise it easier than any other root. It will grow best on a warm, rich, light loam, a little sandy, without clay. Grows well on newly ploughed sod. Plough in June, harrow lightly, roll a little, mark off the rows with a marker, two feet apart, and sow the seed in these rows. Sow about June 20 , so as to escape the fly and louse, which attack the young plant earlier. For manure, use about five cords of well-rotted manure to the acre, harrowed in ; and before you sow the seed sprinkle some superphosphate of lime in the rows, say about five hundred pounds to the acre. This root grows rapidly, especially in the month of September and a part of October, and will yield eight or nine hundred bushels to the acre. I have raised more. It can be cultivated easily with a horse-hoe, and will bear rough usage with the common hoe without being killed. Harvest it early in November. It can bear more frost than the mangold. When it is gathered, one man can take two rows, one in each hand, as he walks between them, and throw the roots together as he pulls them up. They are easily topped with a heavy knife or sickle, and should be piled in heaps in the field, covered with tops to keep off the frost, and suffered to lie two or three days before putting into the cellar, unless the weather is very cold. When carried to the cellar, they will keep better if they are dry and have a little earth clinging to them. The Swedish turnip is a first-rate root. It is the cheapest root in the world to raise. It is as good as the mangold-wurzel for milch cows, and if fed on a full stomach it does not affect the milk more than the mangold does, though you cannot make butter if you use either of them. For young cattle 
and stores the Swedish turnip is excellent; fed with coarse hay even it will carry them through the winter in good smooth condition. I feed my horses and colts on them. If William Jones will only try them on his colts, he will never use any other root. He buys carrots, I see, but they make his horses so soft that he cannot drive them without their being all of a lather; and they make his colts look sort of bloated, and their skins kind of mangy. I teach my horses to eat turnips early in life, for they will not take hold of them at first. And when I have once taught them, I give them about a peck a day from the middle of November to the middle of April. My colts grow like weeds on them, and their legs are as clean and cordy as a deer's. My horses will do moderate work on them, all winter, as well as they will on corn; and they will do all the better the next season for having this change from grain during the winter months. I have one horse which I raised; he is now twelve years old, and he has never eaten any grain in winter in his life, has never been lame, has never had his legs stocked, was never thin, and on turnip feed will do a ten-mile drive on the road, out and back, as well as any horse ought to. I learned the value of turnips for horses from two sources; one was a book on Irish farming, which said the farmers of Ireland always fed turnips to their horses when the ploughing in the spring began; the other source was an old man, Sawney Lowden, who used to raise English turnips to sell in the market. He raised them early and late, and he generally brought a thin, broken-down horse to haul his turnips to the market. The horse ate the surplus of the turnips for his provender. And Sawney's horse always grew so fat, in a few months, that he really looked like a new one. Sawney could make a new horse out of an old one in less than a year, and clear money enough on him to more than pay all the expenses of marketing his turnips. So I believe in Swedish turnips." 
"A pretty good turnip story," said Phineas Barnes; "but why do people raise carrots, if turnips are so much better?"

"Because their fathers did," answered Mr. Thomas, " just as they go to the same meeting, and keep a few flat-sided sheep, and feed farrow cows on meadow hay. I tell you a carrot is a hard and expensive root to raise, wants a good deal of manure, the best land, and careful weeding. It is a little troublesome thing to begin with, and it don't get over being a little troublesome thing until along into haying, and everybody is too busy to look after it; and then you have the tormenting little thing right in your way. It won't make milk, and it won't make much fat. I think it is about as good for the cattle and horses as brimstone and molasses used to be for the boys."

"Don't you like mangolds?" said Sam Barker.

"Yes, pretty well," said John Thomas. "They require better land, more manure, earlier sowing, and they will give a heavier crop. The seeds do not come up very well, and the plants feel the drought more than a turnip does. But with a good, strong, clayey loam and a moist season, and plenty of manure, with a good sprinkling of salt, you can raise a monstrous crop on an acre. They say Tom Payson raised seventy-five tons on one acre of land down at Deer Island. And I don't doubt he did, for he had an unlimited supply of manure and all the inmates of an almshouse to work the land."

"Now, one thing more," said Peter Ilsley; "what do you say to fodder-corn as a summer feed ?"

"I say," replied John Thomas, "that fodder-corn, as usually raised, is poor stuff. It will do pretty well if you sow it so thin that the plants will grow to some degree of maturity. A corn-plant with a spindle to it and an ear, no matter how small that ear may be, is a pretty good thing to give a cow. It seems to be mature and nourishing, and it 
is something like herdsgrass headed out, or millet with a seed-head to it, or like corn-stalks, which I think a gooul deal of as food for milch cows. But a corn-plant half grown, looking like a coarse flag or a rush, full of juices, and capable of being reduced to nothing by frost or by thorough drying, is utterly useless. I have tried it over and over again. I used to raise it just as all my neighbors did, by making a furrow, scattering some manure in it, and sowing the seed as thick as I conld. And I used to feed it to my cows. But the more I fed the less milk they gave. Ben Adams did the same. And one day he strolled over to my barn along late in August, and there were my cows working away at the fodder-corn, chewing and thrashing it up and clown and making a terrible fuss over it. 'John,' said he, 'this won't do. This kind of fodder-corn is n't good for anything. I would n't give a cent for a barnfull of it, green as this is, to make milk out of.' I knew Ben was right, but I did n't dare to say so; for everybody raised it, and I thought what everybody did must be right. At last, however, I got desperate, and I told Huldah that I had either got to get something better than that stuff to make milk out of, or she had got to shut up her dairy in the month of August, anyhow. But this would never do, and Huldah knew it, and said so; and in a moment of desperation she asked me why I did n't sow the corn thinner, or sow something else; and she said she would stand by me if I would do either. Well, it was no use to sow the corn thinner, because I could not get enough of a crop in that way, and I thought I must have the fodder whether it made milk or not. But at last I concluded that an acre of millet or Hungarian grass, all seeded out, and covering every half-inch of the land, would amount to something, and so I tried it. And I tell you, Mr. President, it works well, and I don't want any more fodder-corn to dry up my cows and increase my manure- 
heap. Corn-stalks I like. And after I have sold off my sweet-corn ears, in the market, I use the stalks and buts that remain, and like them. I can make milk in that way. But your reedy fodder-corn, half ripe, without any maturity in it, I look upon with perfect contempt."

At this point Peter Ilsley rose up in his wrath. He said he would not stand such an attack upon one of the great blessings of heaven. Fodder-corn, he thought, had been presented to man like manna in the desert; and if John Thomas did not find it good, it was because he did not know how to raise or use it. He had seen it fed on John Thomas's farm, fifty years before; cut up at noon, scattered about in the pasture, the cows waiting for it all the morning, and lying about all the afternoon digesting it, and making no milk. But that was n't the way to feed it. And John Thomas ought to know better than to condemn an article which he thought to be useless, because his father did not know how to use it. It was an outrage.

"But," said Thomas, with some heat, "I quit that plan long ago, and the thing don't work now."

"Well," said Ilsley, " that is your own fault, and I should advise you to leave your nonsense, if you ever expect to have any more influence in this town. If you don't quit your attack on fodder-corn, I will run you off the board of selectmen next year, or my name is n't Peter."

Mr. Hopkins found it was high time to interfere. He called Peter Ilsley to order, reminded him that an honest difference of opinion was always allowable, and mildly suggested that he had better try a few experiments in the millet and fodder-corn business, before he condemned his neighbor Thomas in such unmeasured terms. Here the debate ended. Everybody regretted the quarrel. The members of the Club dispersed, but not as joyfully as on former occasions; they withdrew rather stiffly from the house, and Mr. Hopkins and Mr. Howe were left alone to 
cheer themselves and remove the cloud, by conversing upon social life in America, and enlarging upon the vitalizing influence of free citizenship on the mind and heart. When they separated, the little strife was all forgotten by them. 


\section{SIXTH MEETING.}

\section{CATTLE (Continued).}

JOHN THOMAS AND HULDAH. - FAMILY JARS. - PEACE. - MODES OF FEEDING CATTLE. - CHARLES INGALLS APPEARS.

THE ill-feeling which manifested itself at the close of the last meeting of the Club did not readily pass away. John Thomas was very proud of his farming, and especially proud of his position as chairman of the board of selectmen, - an office which he had held many years, and which had been filled by his ancestors for many generations. Peter Ilsley was his old friend also, and it was by no means pleasant to have his official head threatened by one who had heretofore stood by him in all controversy, and had never allowed any charge against him to go unrebuked. Had he been told that he must be more discreet in his expressions or retire from the committee, he could have borne that with some degree of composure; but his official status was sacred to him, and he felt that, rather than jeopardize such a record and such an honor as he had won among his townsmen, he would quit the Club and all its associations. But then he remembered that he had many friends there who were always ready to support him, and whom he could not afford to offend. He was, moreover, beginning to enjoy the companionship of Mr. Howe and Mr. Hopkins; and his wife and Mrs. Howe were fast becoming very intimate, much to the comfort and delight and benefit of both, as he could easily see. Still, he was very angry; and when he had reached home and put up his horse, and had seated himself before the fire with 
Huldah, the cloud still hung heavily over his brow. II uldah could not imagine the cause of the trouble; she first thought of some loss in a bargain, then she looked about the room to see if the disturbing influence could be found in any disorder there; but at last she remembered to have heard something about "the proud man's contumely," and she began to suspect that Mr. Hopkins had been putting on airs unconsciously, and had manifested a little of that imperiousness which sometimes worked well enough on

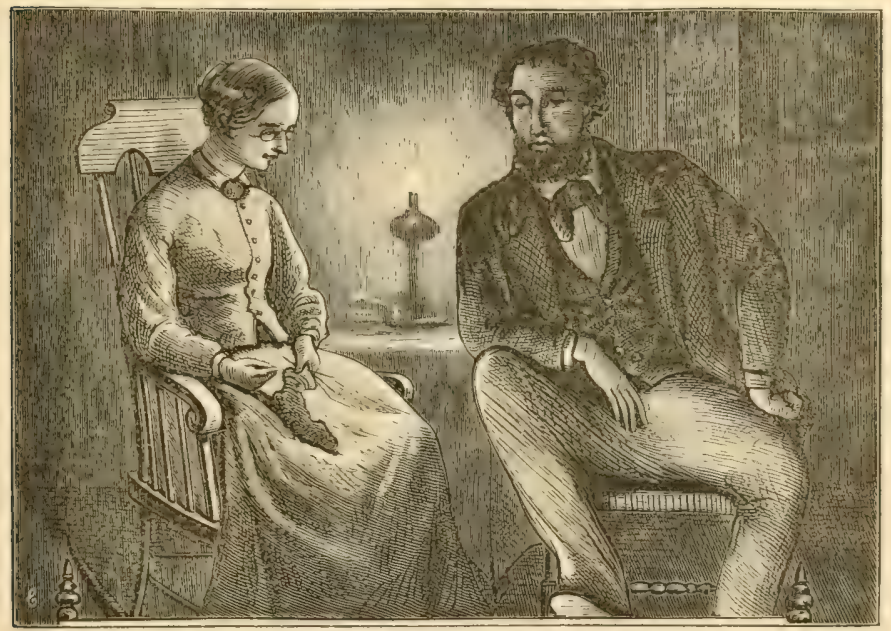

JOHN THOMAS AND HULDAH.

State Street, but would never be tolerated among the hills of Jotham. She knew it would be useless to ask John directly what was the matter; for she had lived long enough with him to know that he belonged to that class of men who always answer by indirection, or offset one question by asking another. She knew John was honest and fair-minded and honorable; but she also knew that he had great hereditary secretiveness, and considered it one qualification of a good business man to keep his own coun- 
sel, in small matters as well as in large, as many men begin by filing their important papers, and end by filing all they have, good, bad, and indifferent. So she began by asking if the night was cold, and John replied that it was. She then asked if the horse had got over his lameness, and she was told that he had. She inquired if the barn was in good order, and she learned that it was. She then expressed an interest in the health of Mr. Hopkins, and was told that he never seemed better, and that he had boasted of the invigorating influence of the air of Jotham upon himself. There was evidently no trouble with $\mathrm{Mr}$. Hopkins. She then got round to the debate, and she said she hoped John had succeeded in telling what he knew about feeding cattle, - for she felt quite proud of his skill and success in this branch of business. At this point John hitched his chair towards the fire, and said he had got along full as well as he expected; and here he paused, and Huldah knew that something had gone wrong in the discussion. She felt satisfied that this experience was so new to John, and that he was so sensitive with regard to it as a novel and untried duty, that if she let him alone he would open the subject himself. What he knew and was confident of he could keep; what was surrounded with doubt and left him groping in the dark he could not keep, and she knew it. So she stirred the fire, put on a good dry stick, picked up the lamp, and set to work with her needles.

"Going to sit up all night?" said John, somewhat tartly. "No," said she; " I thought you might want to get warm before going to bed; and I want to knit a few more rounds before I go; and wood is plenty."

At last John could stand it no longer, and he expressed a sudden and overwhelming wish that the Club had never been organized. He had had enough of it ; the only way to get along with people was to keep out of their company, 
he thought; the wisest thing to do was to do nothing, and keep still, and look wise; the safest thing to do was to throw the responsibility on other people's shoulders; and the shrewdest thing to do was to shove other men into a scrape and keep out yourself. In uttering these views he grew quite warm, and ended by relating the strife between himself and Peter Ilsley, whom he denounced as unfit for decent society and a nuisance to the Club.

"Now, John," said Huldah, gently and firmly, and in that subdued and monotonous tone which so often marks the woman who is mistress of her own house, and bears her part of the burdens of the farm, and knows and appreciates exactly the full measure of her authority, "you know better than all this. Peter Ilsley is a little rough, I know; but he is honest, and one of the truest friends you have got. He won't hurt a hair of your head. If Brindle were sick to-morrow, and he knew it, he would be over here to help take care of her. I have no doubt he would say you provoked him, and I am afraid you did. You know he raises fodder-corn, and always has, and he does n't want to try anything else, and does n't really believe there is anything better. Now, I heard you snap him up on this very thing, the other day, when you hardly knew it. He looked quite put down, and I could see that he was firmer than ever in his own way, through sheer temper, and a resolution to conceal his wounds. And I should n't wonder if you were a little pert with him in the Club. You were on a committee, and he was n't. You had been asked to read a piece, and he had n't. Now, don't you think, John, you were partly to blame; and that you expected him to stand from you what you would n't stand a minute from Mr. Hopkins or Mr. Howe or Dr. Parker?"

John began to relent, and to feel half ashamed of having lost his temper. And he made up his mind to say no 
more about the matter, but let it pass quietly; for a making-up scene he abhorred.

Peter Ilsley did not get along so well. He stumped vigorously and indignantly home alone, pulled off his cowhide boots, threw them violently behind the door, clamned John Thomas and his millet and turnips, and went to bed and went to sleep; and woke up the next morning, milked his cows, sent his milk to market, started for the mill with a grist, and was as good-natured as ever. He met Clara Bell on the way, as rosy and sweet as the dawn, and asked after the Doctor; and Clara blushed. And he told Jim Bell, the miller, that if he wanted music he had better join the Farmers' Club. "Why," said he, "you ought to see Cap'n John swing round, and hear the Doctor talk wise, and watch Major Phin. going to sleep, and see the Parson coo round Squire Hopkins, and see how stiff Deacon Bill sits up, and hear Bill Jones talk horse. I would n't miss the meetings for a farm down East. I pitched into Cap'n John, last night, like a bull through a gate. I go for him, you know, for anything; but he must n't set himself up. It is a bad thing to know too much, - or think you know everything."

Jim Bell agreed with him, and began to discuss the best way to pick his millstones, and to stop muskrats from digging holes in the mill-dam.

Mr. Howe knew well enough that "the beginning of strife is as when one letteth out water," and he determined to divert the current quietly and silently, and secure peace without allowing any man to be recognized as a peacemaker; knowing well that a meddling peacemaker is often a cause of more disturbance than a violent and noisy brawler. He sent, therefore, for John Thomas, and, without alluding to the trouble, he suggested to him that he should send the schoolmaster to Boston, the next day, to get the last volumes of Flint's Reports of the Massachusetts 
Board of Agriculture, and offer him five dollars to write an essay on Feeding, Steaming; and Soiling. And so he did. The schoolmaster, who was a farmer's boy, and had worked on his father's farm before he entered Dartmouth College, was delighted. He entered upon his work with great zeal, and before the next meeting reported to $\mathrm{Mr}$. Howe that his writing was a real pleasure to him, and he hoped he should not disappoint the gentlemen who had invited him to address the Club.

The schoolmaster had steadily attended all the meetings of the Club, and had made himself familiar with the mode of disputation which had been adopted. He was devoted to his business as a teacher, and kept his mind carefully prepared for every emergency which might arise in his school; and inasmuch as his father had at great personal sacrifice sent him to school and college, in order that he might prepare himself for the profession of the law, he felt in duty bound to neglect no opportunity, and he was determined to take a high stand in his class, and discharge his cluty faithfully

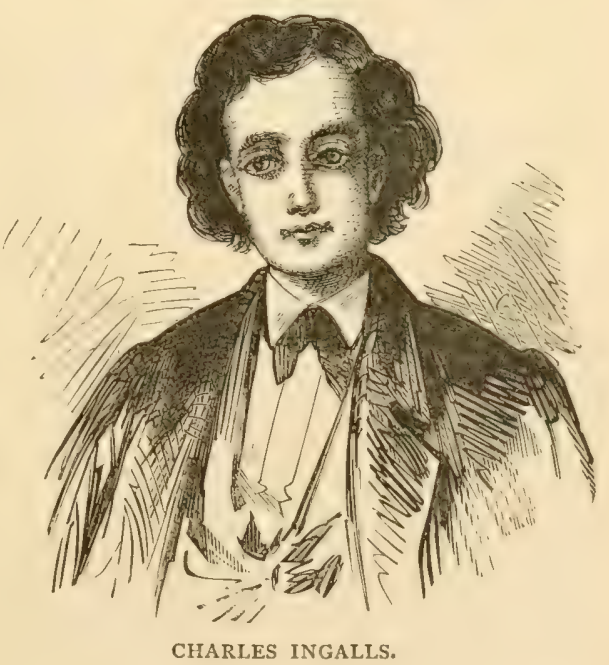
in the school-house. He was a tall, broad-shouldered youth, with a heary mass of black hair, a pale, solemn face, deepset eyes, and a broad and massive brow; thoughtful and 
somewhat taciturn, but full of humor, and possessing a sturdy strength of expression. He seemed to be full of great, powerful emotion; alluded often to his older brother, for whom he had evidently the most profound affection; had written a tale, which he was fond of reading to his intimate friends, and which was remarkable for the delicacy of its humor, its instinctive knowledge of the human heart, and for a style in which a grand and massive English phrase was inlaid with a wealth of Oriental imagery which colored it with peculiar charms. He was a youth of most profound repose, and with a glowing enthusiasm. The men who knew him wondered, and the women who knew him loved.

It was not until the very tick of half past seven that the members of the Club gathered at the house of Mr. Hopkins; and then they all came at once, and took their seats silently and in order.

Mr. Hopkins announced, "Our young friend, Charles Ingalls, the schoolmaster," who proceeded at once to read his essay on

\section{THE VARIOUS MODES OF FEEDING CATTLE.}

I have listened with profound pleasure to the practical wisdom which characterized the discourse of Mr. Thomas on the care of animals. His knowledge of and sympathy with cattle could not fail to impress the most careless listener ; and to myself, whose early and most intimate companions on my father's farm were the domestic animals, his words had a peculiar charm. I was especially struck with the simplicity of his plan. He has evidently reduced his work to the most convenient system; and I am sure he has been able to do this on account of the fortunate supply of forage crops with which we are provided in this country. We cannot be too grateful for this. When a prosperous farmer, drawing his wisclom from his own experience, can say, as Mr. Thomas did, that the foundation of 
all feeding is good English hay, and that grain and roots constitute the sum total of the variefy required by the health of the animal, he should realize how fortunately his lines have been drawn, and how simple his dairy farming is, when compared with that of other and, in this respect, less favored countries. I have just been reading the mode of feeding laid down by Mr. Horsfall, one of the most intelligent agricultural explorers and writers in England, and I am most forcibly struck with the intricacy of the plan which he deems needful for animal health, made intricate, as I think, by a necessary absence of good hay. He says: "My food for milch cows, after having undergone various modifications, for two seasons has consisted of rape-cake five pounds and bran two pounds, for each cow, mixed with a sufficient quantity of bean-straw, oat-straw, and shells of oats, in equal proportions, to supply them three times a day with as much as they will eat. The whole of the materials are moistened and blended together, and after being well steamed are given to the animal in a warm state. The attendant is allowed a pound to a pound and a half per cow, according to circumstances, of bean-meal, which he is charged to give to each cow in proportion to the yield of milk; those in full milk getting each two pounds per day, others but little. It is dry, and mixed with the steamed food on being dealt out separately. When this is eaten up, green food is given, consisting of cabbages from October to December, kohl rabi till February, and mangold till grass-time, with a view to nicety of flavor. I limit the quantity of green food to thirty or thirty-five pounds per day for each. After each feed, four pounds of meadow hay, or twelve pounds per day is given to each cow. They are allowed water twice a day, to the extent which they will drink."

A combination of bean-straw, rape-cake, linseed, cotton-seed, steamed shorts, and barley-straw is a formidable affair for a farmer in moderate circumstances to contemplate. And when to this is added the necessity of giving the cows a feed of this mixture morning and night, even during the good grass season of May, in order to get from twelve to sixteen quarts of milk per day, the labor becomes truly discouraging. Let the American farmer rejoice that no such trials surround him. 
Your minds must have been attracted by the frequent allusion to STEAMING food for cattle in the foreign treatises on the subject we are now considering. As near as I can ascertain, this artificial and somewhat expensive mode of feeding is practised in England, for the purpose of converting coarse and inferior articles of food into digestible and nutritious substances. For this object it is said to work well. On the celebrated Tiptree farm of Mr. Mechi it was introduced as a part of an intricate and extravagant mode of farming, which consist $=d$ of tanks, steam-engines, pipes, pumps, liquid manures, irrigation, and general machinery; and Mr. Mechi gives us assurances that he found the food prepared in this manner to be very nutritious for both cattle and horses. He only abandoned it when he found it impossible to make his foreman attend to its preparation. Experiments have been made in this country on a scale much less elaborate and expensive than that adopted by Mr. Mechi, it is true; but, except in cases where the surplus steam of a mill could be carried into the barns and stables and utilized there at a small cost, it has been generally abancloned. It has been found that the labor and fuel necessary to convert coarse fodder into useful articles of food bring the cost of the food thus prepared up to a point beyond the price of more nutritious and finer materials, which do not need the effects of steam. Good English hay, moreover, which can be used to advantage in chopped feed, is not improved by steaming. And corn-fodder and straw can be more economically prepared with hot water in a well-covered box in which the fodder, mixed with meal and shorts, is allowed to soak and soften for a few hours, than by the use of a steam-apparatus. Steaming, as a part of a pure system of farming, is rapidiy being abandoned in the preparation of chopped feed; and I learn from the Reports of the Highland Agricultural Society that it is unnecessary in the feeding of roots, it having been found that the roots, when raw, are more nutritious to cattle than when steamed. Six heifers and four steers, the former two, the latter four years old, were selected on the 20 th of February, 1833 , and fed on steamed and raw food alternately, weighed, and an accurate 
account kept of their cost, expenses, and condition. For the purpose of the experiment they were divided into two lots, the heifers three in each lot, and the steers two.

The heifers were allowed as many purple-topped Swedish turnips, topped, rooted, properly cleaned and cut into pieces, so that they could get them into their mouths, as they could consume, with three pounds of bruised beans and twenty pounds of potatoes, each beast per day, in adclition to the turnips, with seven pounds of straw each.

The steers were allowed as many of the same sort of turnips as they could eat, with four and a half pounds of bruised beans and thirty pounds of potatoes each beast per day, with seren pounds of straw each. That is to say, the food of the steers and heifers was the same, only with this difference, that the steers were allowed one and a half pounds of beans and ten pounds of potatoes more per beast than the heifers each day.

One lot of heifers and one of steers was put upon steamed, and the other lot of heifers and steers was put upon raw food.

Both lots, the cattle on steamed as well as raw food, were fed three times a day, at daybreak, at noon, and lastly an hour before sunset.

It was soon discovered that the cattle fed on steamed food consumed considerably more turnips than those fed on raw food; the steamed food being 94 cwt. 14 lbs. of turnips for twenty-eight days of two cattle, about 95 pounds per day ; and the raw food being $70 \mathrm{cwt}$. for the same time, about 140 pounds per day.

It was also found that the cost of keeping the three heifers for one week on steamed food was $\$ 4.93$, while the cost of keeping the same heifers on raw food for one week was $\$ 3.62$, giving an additional cost on the heifers fed on steamed food of \$I.3 I per week.

The estimates on the feeding of the steers arrive at similar results; the loss on one steer fed on steamed food being eighty-two cents, while the profit on one steer fed on raw food was $\$ 2.41$.

These facts are worthy of careful consideration, and should 
not be overlooked by the farmer in this country, where labor and fuel are so expensive that they cannot possibly be devoted to the work of increasing the amount of food consumed, with any hope or expectation of profit. They can only be used to advantage in reality when by them the amount can be reduced in quantity and improved in quality.

In examining the records of many agricultural societies which have been placed in my hands, and in reading the essays which have been prepared by enterprising farmers, both in this country and in England, I have been peculiarly impressed with the zeal with which the system of feeding cattle by soiling has been defended. The late Hon. Josiah Quincy has left on record some very careful experiments in this business, and he seems to have convinced himself that it is really profitable to the farmer and beneficial to the cattle. I think, however, in a country like ours, where pasturing is comparatively cheap, the weight of evidence is against it. It may answer pretty well for the feeding of cows near a milk market. But it seems to me it cannot be employed in the manufacture of butter and cheese, in which business we are obliged to compete with remote sections of the country where hay and pasturage can be obtained at a very moderate cost.

I submit the following estimate of the comparative expense of soiling and pasturing twenty cows from June ist to November I $5^{\text {th, }}$ - five and a half months, - which has been furnished me by an intelligent friend, who is deeply interested in the subject of agriculture.

In making this estimate he has taken seventeen acres of land, - the amount specified for this number of cows by the advocates of soiling. He has considered that land in condition to support these cattle would yield two tons of hay to the acre. He has estimated the price of pasture land at the average rates of good land of this description, and has allowed four acres of this land for the support of each cow. He has endeavored to take a fair expense of a man per month, including his board, and has allowed for the manure of the cattle all that is claimed for it. He considers that a good pasture will support cattle 
properly, and has omitted all comparisons of the health of animals confined and at large in the summer season, and of the quality of the milk yielded under the different circumstances. He has estimated the cost of pasturing rather above the average, and has charged no expense of litter against soiling. And here follows his estimate :-

Land required for soiling 20 cows from June I to November I 5 , $5 \frac{1}{2}$ months, 17 acres.

Value of hay which might be grown on this land, - thirty-four tons at $\$$ Io per ton, standing . . . . $\$ 340$ Labor of feeding, etc., one man at $\$ 30$ per month, including board

Aggregate expense of soiling . . . . . . . 505

Cr. by manure, as estimated . . . . . . 200

Net expense of soiling . . . . . . . . . 305

Pasture, 80 acres at $\$ 30$ per acre . . . . . . 2,400

Interest on cost of pasture . . . . . . . . I44

Annual repairs on fences . . . . . . . . 10

Expense of pasturing . . . . . . . . 154

Balance due on account of soiling over pasturing . . . I5I

He does not take into this account the interest on the cost of the 77 acres of land used in soiling, nor the loss of the land for the supply of winter forage, nor the expense of converting the droppings of the cows into $\$ 200$ worth of manure; neither does he calculate the expense of cultivating the 7 acres of land.

I cannot speak from experience, Mr. President, but I am satisfied from what I can learn by the experience of others that soiling, except for a small business and in a convenient spot, is no legitimate part of farming. It rather belongs to the luxuries, and seems to be an expensive luxury at best.

I suppose I shall be authorized to consider here the amount of food furnished by various crops as a part of the business I am now discussing. Without entering into any accurate calculation of the cost of keeping cattle on different kinds of foorl, I propose to make a short comparison of the amount of food fur- 
nished by the various crops used for feeding, from a given piece of ground.

Taking 2 tons of hay per acre as the basis of calculation, and as representing the kind of cultivation which is employed, we may concede that an acre of land will yield the following crops : hay 2 tons; Swedish turnips, 18 tons; mangold-wurzel, 20 tons; carrots, 25 tons; Indian corn, 70 bushels.

The practical value as obtained by experiments in feeding are: hay, Ioo pounds are equivalent to 300 pounds of Swedish turnips, 400 pounds of mangold wurzel, 250 pounds of carrots, and $5 \circ$ pounds of Indian corn.

Dividing the number of pounds of each of these crops on an acre, according to the estimates above, by the number of pounds representing the practical value of each for food, and we have, as results, figures which will express the comparative yield of each acre, according to the crop occupying it. For instance: hay, per acre, 4,000 pounds, divided by 100 equals 40 ; Swedish turnips, per acre, 36,000 pounds, divided by 300 equals I 20 ; mangold wurzel, per acre, 40,000 pounds, divided by 400 equals 100 ; carrots, per acre, $5 c, 000$ pounds, divided by 250 equals 200 ; com, per acre, 4,550 pounds, clivided by 52 equals $\delta_{7} ! .1$.

According to this table, an acre will yield three times as much food in turnips as in hay; two and one half times as much in mangolds as in hay; five times as much in carrots, as in hay; and about two and one fifth times as much in corn as in hay.

Now, in order to arrive at the cost of feeding the above articles to cattle, and at the comparative value of each as an article of food, we must be able to ascertain the prices which they bear in different localities, the advantages of the market, the cost of labor, and the kind and value of the cattle which are fed. I have furnished the figures for the benefit of those who desire to ascertain, if posible, the most economical and useful crops for cattle husbandry. There is no doubt that valuable as hay is, as an article of food, and universal as is its use here, there are crops which form a useful ally to it in the business of carrying cattle through the winter. The question is, which of these crops is the best for such a purpose, - the most economical and 
profitable? There are sections where the corn crop will not ripen, and where the cultivation of roots would do much toward enabling the farmer to support all the cattle in winter which his pastures will bear in summer, $\rightarrow$ a state of things which does not now exist. In some regions the hay crop is large, hay is cheap and labor scarce. The farmer there must judge for himself how far it will pay to devote himself to any other than the hay crop. Circumstances vary as localities vary, and it is they alone which can guide the intelligent farmer in the management of his land for his cattle, and can enable him to judge of the cost of feeding them, as well as to decicle upon the breed best adapted to his purpose.

If I have elaborated my remarks more than is deemed necessary by this Club, I can only ask to be excused on the ground that want of intimate knowledge has rendered it necessary for me to exprand and dilate where the practical farmer here might condense to a better purpose.

The schoolmaster had done well, they all said. Some of the gentlemen present thought he might perhaps have said less had he known more; and they hardly felt the necessity of discussing steaming and soiling, inasmuch as none of them intended to adopt either. But they had learned that such discussions were customary with all clubs, and they were determined that theirs should not be outdone by any others in the difficult work in which their minds were engaged. The sweeping sentences of the lecturer had had one effect at least, - they had borne the Club back to its original amiability and repose; and accepting the figures on corn and turnips, and believing in the estimates of the comparative value of different crops as food for cattle, they entered into a good-natured general conversation, in which William Jones remarked, without the slightest idea of being personal, that he did not see how it was that a man who felt himself to be unable to discuss other questions unless he was well-informed, felt 
entirely competent to discuss farming whether he knew anything about it or not.

"But then, the schoolmaster is a nice fellow," said Mr. Howe, as they dispersed; " and Mrs. Howe says he has written one little poem almost as good as Emerson's 'Humblebee." Enviable Charles Ingalls! 


\section{. SEVENTH MEETING.}

\section{CATTLE (Continued).}

SPRING OPENS - A NORTHEAST STORM. - DISEASE AND WEAKNESS IN COWS. - THE MILK-MIRROR.

BEFORE the Club met again, spring had blown its first soft warm breath over the hills and vales and waters of Jotham. In the deep shady hollows and in the dense woods small patches of dingy and departing snow might still be found; but the forests began to take on the soft pale green complexion of the just opening bud; the little whirls of dust marked where a sharp spring breeze struck suddenly on the winding highway; the lake rippled and sparkled in the sunlight, and seemed to laugh with joy at being released from its icy chains; the brooks ran like miniature torrents and roared through the channels where in midsummer they babbled; the hepatica came out clad in its furry coat ; the anemone danced forth into its airy life; the dog-tooth violet and the bloodroot were just peeping up; and the mayflower loaded with its perfume the languid air. The young cattle had already left the barns, and taken their first bite of the early spring grass, and were reposing in the warm, sheltered nooks, where they renewed their sweet intimacy with nature, rejoiced in the quickened life which flowed through their veins, and saluted with a steady and half-suspicious gaze their owners whom they had known so well in the stalls, but who suddenly became comparative strangers when nature invited its dumb children to return to their inborn allegiance. The domestic animals had not all left their winter quarters; but the farmers had. 
There was no more winter work for them ; no more preparation for the summer. The time had arrived when work meant work, and leisure meant leisure. The pleasant days were toilsome enough, but the stormy days were full of repose and rest, and seemed to give the earth new life and man new strength to cultivate it.

When the day of the Club meeting came round, a cold northeast storm had set in as an offset to a short season of almost summer warmth. As it rained and blew, the outer world seemed to be inspired with a new and wild life. The great trees swung their arms with huge force like giants at their exercise; the earth drank in the vitalizing waters; the peeping grass rejoiced in the gloom, and the living forces of the soil could almost be heard in their vigorous work. The grazing animals fled to the woods; the barns were closed and silent; the plough rested in the furrow where the storm had caught it; and the farmers of Jotham betook themselves to their newspapers and books, or to the neighborly shelter of the village store, or the postoffice, or the hospitable shops of the mechanics. It was a great day for the wheelwright and the blacksmith and the shoemaker and the postmaster and grocer. All questions known to the village were discussed, - the parson and his sermons, the politics of the time, the new bridge, Mr. Hopkins's farm, and the Club. The members of this new and vigorous institution were particularly active in discussing its merits and in overhauling each other. They had evidently grown quite familiar with the personal characteristics which came together at the meetings; and those who did not belong discovered in those who did a sort of confidential intimacy which was quite fascinating. Dr. Parker's theories were examined over and over again; Mr. Ilowe's agricultural zeal was expatiated upon; the schoolmaster's views on steaming and soiling were rehearsed and indorsed; and John Thomas would have received his 
share of the criticism had he not been foumd in the sroup) of critics.

"Sharp talk, I bear, in the Club, sometimes," saicl the grocer; "and now and then a little mixed, like Cap'" Joe's farming. Joe was a sea-captain; run a line from Boston to Havana. Joe was a first-rate sailor. I made one voyage with him, years ago. But he grot tired of the sea and took to farming. I knew his farm. Well, he bought a yoke of oxen and an old mare and some ploughs and things, and hired Sam Seaver, his old cabin-boy, to work for him. Sam was a good sailor too. So Cap'n Joe told Sam, one morning, to take the oxen and plough and old mare, and break up a little piece, back of the barn, for corn; and Sam went to work. Cap'n Joe went into the house. But Cap'n Joe had n't more 'n grot his pipe lighted before Sam rushed in. 'Look here, Cap'n,' said Sam, 'I am getting awfully mixed, out here. The starboard ox has got over on to the larboard side; and the larboard ox has got over on to the starboard side. The old mare is right athwart-ships; and as for the plough, God knows what has become of that. Jupiter, Cap'n Joe, come out and help a fellow. Things is awfully mixed.'

The grocer always told long stories, with a good deal of "says he" and "says I," and John Thomas thought he had got off quite well when the story ended, and the laugh came in. But as he had no responsive tale, not being given to story-telling, he slipped out at the door, left the talkers to discuss him, too, saying, as he went, "The Club is well enough," and strolled over to Mr. Howe's, to see what arrangements he had macie for the Club meeting, in the evening. He found the Parson at work on his sermon, and Mrs. Howe making butter. It was soon arranged that the debate in the Club should be general, and each member should tell his experience in the cattle business. John then started for Dr. Parker, and found 
him seeking shelter from the storm in Jim Bell's sittingroom, and discoursing with the lovely Clara. Mr. Hopkins he called on, and discovered him sitting before his fire, smoking his cigar and reading Stephens's Book of the Farm; and Mr. Hopkins was reminded of the meeting, and informed of the course proposed for the debate. When he reached home he found Huldah as cheerful and busy as ever, and he found his home a better "port in a storm" than the grocery or the blacksmith's shop or the postoffice.

In the evening the Club was crowded. The storm was still raging; but the members defied it for the sake of the cheering influences of that club-room which Mr. Hopkins had provided for them, all winter, where they knew they could escape from all that was dismal, and find in each other's society an exhilaration which they had not deemed possible until they had gathered together, time after time, for a common object, and that object the improvement of their minds.

Mr. Hopkins called the assembly to order with his usual promptness; and, without the formality of reading the record of the last meeting, he proceeded to review in a few words the ground which had been passed over, and to announce the plan of debate which had been adopted for the evening. "We have listened," he said, "to elaborate and carefully prepared essays upon cattle from the scientific, the educated, and the experienced; and it seems to me that, in a concise and condensed manner, we have explored the subject of cattle until every gentleman present ought to be able to select and feed and care for the best. I have certainly learned much of the animal structure best adapted to milk and to beef, and I think I understand the best mode of feeding and the best articles of food far better now than when I began. I doubt not, however, there are many valuable suggestions which you can make with 
regard to this interesting and important branch of husbandry. We have learned how to select and how to feed, and I shall be much obliged to the gentlemen present if they will, without introduction by the Chair, express their views upon such practical points as may occur to them."

Peter Ilsley was at once on his feet, and asked if anybody present could tell the cause of abortion in cows and suggest the remedy. "I have been bothered to death," said he, "twice within the last twenty years, by my cows losing their calves. Sometimes I have no trouble for three or four years, and then, perhaps, two or three cows out of my thirty will slip for a few seasons. This, I know, may be accidental, perhaps from one cause, perhaps from another; but when matters get to be so bad that for twelve montbs I don't have a single cow go her full time, as has happened to me twice since I began farming, it seems to be about time for something to be done. I suppose you can get rid of it by selling off your cows and buying new ones; but men who make milk for a living: can't stand that. And you can get what milk the cows will give after losing their calves in this way; but this will only be about half a mess; and how can a farmer hope to live in that way. Now, can anybody tell the remedy, or must we get on with it as we do with thunder and lightning, small-pox and measles?"

Dr. Parker replied that the causes of abortion, especially of what may be called contagious abortion, in a herd of cows, are many and various. Dr. Dalton, in his investigations in New York, found out this truth, and really nothing more. His observations and statistics proved that, as there is no common cause, so there is no common remedy. Isolated cases may be caused by sudden change of food, from hay to grass or from grass to hay. They may be caused by a change in the weather; by sudden and violent exertion; by food of a poor quality, bacl hay, musty 
grain; by starvation; by natural physical weakness. But all this is trivial when compared with that overwhelming disaster to which Mr. Ilsley refers. The cause of this remains undiscovered; and the evil, so far as we know, must be submitted to with the same patience that we exercise under any other trial. He happened to be consulted in a case very much like that presented by Mr. Ilsley. In a herd of fifty cows, not one escaped within a year. The disorder, if it can be called so, began in the autumn, just after the cows came to the barn for the winter, two or three cases occurring at first and attracting but little attention, but being followed by case after case, until the value of the herd was almost destroyed, and the business was almost broken up. No cause for this was ever discovered. The hay was examined, but it seemed to be in the same condition as all the other hay on adjoining farms. The grain, the water, the barn, all were explored to no purpose. And relief was only found in selling the cows and buying new ones. The cows that left the farm did well enough, and the cows that were newly brought to it also did well enough. The Doctor added, that if he were compelled to suggest a remedy for such a catastrophe, he should advise cleanliness; uniform temperature in the stable as far as possible; good ventilation, especially if the buildings are old and the accumulations of filth on and beneath the floor are great and of long standing; keeping the cows in uniformly good condition, and not allowing them to be abused. He said that if he found the difficulty occurring where the floor and walls of the stable were old, half rotten and dirty, he should advise laying a new floor and building new walls, on the idea that the musty exhalations from decaying and filthy wood might produce upon the system of the cow an influence similar to that produced upon the human system by imperceptible poisonous miasmas. 
"Much obliged, Doctor," said Wiliam Jones; "but I never could see the real value of submission, or "whatever is, is right,' or 'thankful for favors given, and patient when favors are denied,' and all that in the business of life, and as the result of science. I am willing to be resigned to my fate when the minister tells me to be; but I don't want that kind of advice from my doctor."

Dr. Parker quietly remarked that the profession of medicine required as much humility as the profession of divinity, and that intellectual arrogance was as unpardonable in one as in the other; adding that he was inclined to think, after all, that it required as much faith to get well as it does to get to heaven.

"IVell," said Hill John, "let us get out of this fog, anyhow. Can anybody here tell me what a milk-mirror is really good for?"

"Yes," said Peter Ilsley, "I believe I can. When the Frenchman came out with his theories about the significance of the various arrangements of the bair under a cow's tail and down along her udder, I set to work and examined my cows to find out whether he was right. I had the Frenchman's sixty-four varicties of mirrors or escutcheons, and I divided my cows into classes according to their marks. I found that cows which I had lately bought varied very much even when they had good mirrors, owing, I suppose, to the different ways in which they had been fed and taken care of before I got them. But among my old cows which I had fed myself for several years, and which had got used to me and my feed and barns, I found the really good ones had usually good mirrors. With a good mirror generally go a good rib and foot and udder and milk-vein and shoulder and head and hide, all necessary to make a good milker. But a good mirror does not take the place of any of these other good marks. And so I have found a poor mirror on a good cow which had all the other 
good points, and a good mirror on a poor cow which had but few other good points. If a man cannot select a good cow without examining her mirror, he cannot select her at all. For a mirror is by no means an unfailing sign. I read, the other day, that cows with a contracted and badly shaped mirror usually 'have large heads and a thick, hard hide ; being ordinarily in good condition. They are beautiful to look at, and seem to be well formed; many of them are nervous and restive and not easily approached.' Now, a cow like this does n't amount to much, mirror or no mirror, and so $I$ am in the habit of thinking that if you begin to examine a cow at the head and keep on you will find out whether she is a good one or not before you get as far as her tail. At the same time, if I were buying heifers which had never given milk, I should be careful to select those with good mirrors, expecting that I should stand a fair chance to get a good cow when they came to maturity, a fairer chance than I should without the mirror. But, after all, I 'd rather have a cow ready made, full grown. An old cow for milk and a young hen for eggs, is the true maxim."

"But I find that the best of cows can be spoiled by bad milking," said Mr. Barnes, the blacksmith.

"True enough," said John Thomas. "I have bought many a cow which did not promise remarkably well and did not do well the first season, and which, after a few months of careful feeding and regular milking, would come up beyoud all account. I generally milk my best cows myself; and I know a skilful milker can increase the milk. A cow half milked will soon go dry. And I am sure that one half the difficulty which cows have in their udders, on our great milk farms, arises from the irritation caused by the milk left in the smaller tubes of the bag by careless and shiftless milkers. I would rather have a poor teamster than a poor milker on my farm, - and both are bad enough." 
And now Mr. Hopkins spoke. "The cow is all very well," said he; "but when you have got your cow and your pasture and your barn and hay-mow, the trouble has just begun. The mystery of making good butter and cheese, who can tell it all? I admire the modern dairyrooms, the clean marble tables, the white glazed milk-pans, the neat and ingenious modern churn. But somehow the butter that came out of the old milk-room, with its wooden shelres and its windows slatted to keep the cats out, and its tin and old brown milk-pans, and more than all, that neat, maternal dairy-woman, has never been excelled. IVhy, I do not know; but so it is. I have read abuut globules, and deep milk-cans, and the value of jars to separate the cream from the milk, and the temperature of the churn, and the spatula and shaper. But they all sink into insignificance before the mysterious power of the female butter-makers of our boyhood and youth. A sweet pasture is a very good thing, but a sweet dairy-woman is much better. I remember Mr. Flint says: 'Many things, indeed, concur to produce the best results,

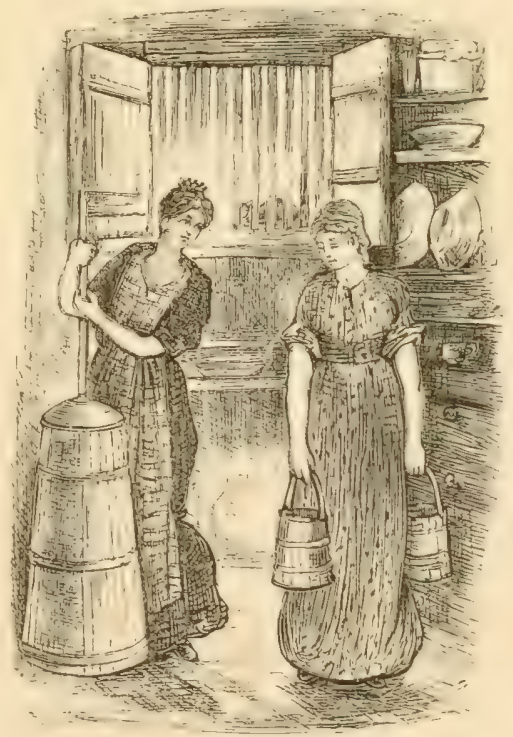

DAIRYMAIDS. and it would be useless to underrate the importance of any ; but with the best of cows to impart the proper color and consistency to butter, the sweetest feed and purest water to secure a delicate flavor, the utmost care must 
still be bestowed by the dairymaid upon every process of manufacture, or else the best of milk and cream will be spoiled, or produce an article which will bring only the lowest price in the market, when with greater skill it might have obtained the highest.' A dairy-room of uniform cool temperature, with clean, wooden shelves for the pans, good ventilation, removed from all odors (for butter absorbs odors with great ease), and arranged in a suitable corner of the cellar, is indispensable to every farm-house. Keep the temperature at about $60^{\circ}$. Use any churn you like; they are all good, the simplest the best. They say eight ounces of salt are enough for ten pounds of butter. But they also say that you may salt it as much as you please, and it will not keep unless the buttermilk is all worked out of it. And as with butter, so it is with cheese Everybody cannot make it well. I had an old friend who started out in farming just as I have done. He had good pastures, good water, good cows. Nancy, his clairy-ivoman, had a high reputation, - as lizg/ probably as a lived reputation could be. He had an excellent dairy-room, too; and he also had an ambition to get a premium for his cheese at the county cattle-show. He tried, and failed. His neighbor, Mrs. IVardwell, beat him - he knew not why. He listened to her advice, tried again, and again failed. He thought he had learned his lesson well, but somehow there was a failure. At last he bethought him that he had not used a thermometer, to ascertain whether or not the milk was of the right temperature to be converted by the rennet into curds. A thermometer he purchased with much trouble, hung it up in his cheese-room, consulted it, felt confident that his hour of triumph would soon come, and walked with an clastic step over to see Mrs. IVardwell and tell her of his good fortune. He found her making cheese, and, after some preliminary talk, he informed her that he had at last bought 
a thermometer, and thought he would now go on without further difficulty.

“"Bought a what?' said Mrs. Wardwell.

“' 'Bought a thermometer,' said my friend.

“'What's a 'mometer ?' exclaimed she.

" An instrument used to ascertain the temperature of air or liquids, and a very ingenious and useful instrument it is,' replied my friend. 'But, Mrs. Wardwell, what do you use to ascertain this important point in the manufacture of cheese? How do you find out, pray, whether the milk is warm enough or not?'

"'How do I find out!' said she. 'Why, Lord-a-massy, I put my finger into it.'

"It is this sensible skill, after all, which wins. But all have it not. And so we resort to books and instruments, and sometimes resort in vain. Hear what Mrs. Williams of Windsor, Mass, said nearly twenty years ago, about cheesemaking, - Mrs. Williams, who always reminded me of Mrs. Wardwell. She says: 'My cheese is made from one day's milk of twenty-nine cows. I strain the night's milk into a tub, skim it in the morning, and melt the cream in the morning's milk; I warm the night's milk, so that with the morning's milk, when mixed together, it will be at the temperature of ninety-six degrees; then add remnet sufficient to turn it in thirty minutes. Let it stand about half or three quarters of an hour ; then cross it off, and let it stand abrut thirty minutes, working upon it very carefully with a skimmer. W'hen the curd begins to settle, dip off the whey, and heat it up and pour it on again at the temperature of one hundred and two degrees. After draining off and cutting up, add a teacup of salt to fourteen pounds.' How well I remember this good lady's cheese, - as rich as Cheddar and as creamy as a Stilton.

"I feel sure that the time will come when Americans will consume more cheese than they now do. It is a most 
nutritious article of food, and I shall be glad when, instead of exporting six or seven millions of dollars' worth annually, we shall use it at home, and export cloths, hats, and shoes. Cheese is most valuable, both as an article of food and as an appetizer. It contains 3 I.O2 per cent of fleshforming substances, and 25.30 per cent of heat-producing substances; and it answers every purpose of meat in an economical and condensed form. So much for the dairy, my friends."

"And now," said Peter Ilsley, "will some one tell us which is the best breed of cattle?"

After a considerable pause, Juhn Thomas undertook to answer this question.

"I think," said he, "the Ayrshire, for all the ordinary business of the farm in New England, is the best cow that can be found. She has been bred, as I understand, for many years in Scotland, a country analogous to the northern portion of the United States, where the pastures are apt to be short and the winters long and cold. It is not easy to describe her in a way which will apply to all the individuals of a large herd or many herds; because while they resemble each other in certain prominent and important points, such as udder, milk-vein, rib, head, leg, foot, and back, they differ widely in color and size. An Ayrshire cow can best be described as a hardy, medium-sized cow, with a great capacity to live on short pastures in summer and hard fare in winter; and a capacity also to give the largest amount of milk on a moderate quantity of food. And this is what distinguishes her from all other cows. She comes nearer to the standard laid down by Dr. Parker in one of the early meetings of our Club than any other breed I have ever seen, and for steady profit on our farms in this region I have never seen her equal. Her milk is as good as the average quality of milk given by our common cows, and is especially well adapted to the manufacture of cheese. 
"The Jersey stands next, I think, as a dairy cow. She differs very much from the Ayrshire; is lighter, less hardy, somewhat delicate and tender, needs a warm stable, and good food and a plenty of it. She is not a heavy milker ; but she is a valuable animal to be used on a gentleman's estate, to furnish butter of the best quality for his table. I have been told that Jersey butter is not well adapted to the market, as it easily becomes rancid in hot weather; but for immediate consumption it is undoubtedly unequalled. A good Jersey cow, in a warm stable, with plenty of good food, and an independent purse, is a luxury, especially for the rich. For the milkman and the cheesemaker she will hardly answer. An infusion of her blood into a herd of natives, or even into good Ayrshires, often produces some of the most valuable of our cows.

"The Shorthorn, or, as called when I was a boy, the Durham, is a very valuable cow for the rich pastures of New York and the West. In New England, on the common farm, they have a tendency to diminish in size; and I have often seen them brought down almost to the size and shape of the Ayrshire. We cannot feed them to a profit on our pastures in Jotham. But where the grass is abundant, and the winters are comparatively mild, they are remarkable (unless bred according to the improved modern standard) for their capacity as milkers and their usefulness as dairy cows. We shall never see a finer beef-producing animal than the modern improved Shorthorn; and we shall not soon see a more admirable and profitable clairy cow than the old-fashioned Durham, where hay is cheap and pasturage luxuriant.

"From the three breeds which I have mentioned the farmer can supply himself with the best animals known, either pure or mixed one with another. The crossing of these breeds, in any manner, is almost sure to prove satisfactory; and I think no intelligent farmer, in selecting 
wisely from them and considering his farm and his market, can possibly go astray."

After this concise and practical description of the cows to which the dairy farmer should turn his attention, the members of the Club looked about with the feeling that the cattle question was about exhausted, and not a word was said until the Schoolmaster arose and remarked:-

I have listened with great interest, Mr. President, to the discussions of the Club on the subject of cattle, not only on account of their immediate connection with the profitable business of farming, but because they belong to one of the most pleasing branches of agriculture. I need not tell you how we all depend upon the dumb creatures which wait upon us during life, and at their death feed and clothe us. From valley and hill, from prairie and mountain, they come flocking in, the patient servants of their imperious master. They offer themselves a living sacrifice to the majesty of civilized man, suffering as he yields to poverty and hardship and barbarism, and rising with him as he rises into his conditions of luxury and ease and economy and fitness of purpose. The great community of cattle, who shall write its history? How it has been controlled by the social laws which make the world what it is ; how it enables the great community of man to dwell here on the face of the earth; how it stands the pedestal upon which a nobler fabric rests; how its condition tells the tale of races higher in the scale of being. That strange and mysterious relation between man and animal, everywhere recognized, everywhere felt; that mutual dependence, each upon the other; that intelligent appropriation and cultivation on the one hand, that unconscious and entire obedience and submission of all the great vital forces on the other, - who can tell it all ? And superior as we may be, powerful, controlling, and independent, can any man contemplate the magnitude of the change were the sovereignty of this great community of cattle to be asserted, and man's dominion be suddenly broken? From the feeding of armies and the sustaining of the busy throng who fill the 
places of power and trust, down to the nourishing drop which supports the feeble child in its first grasp upon life, it is

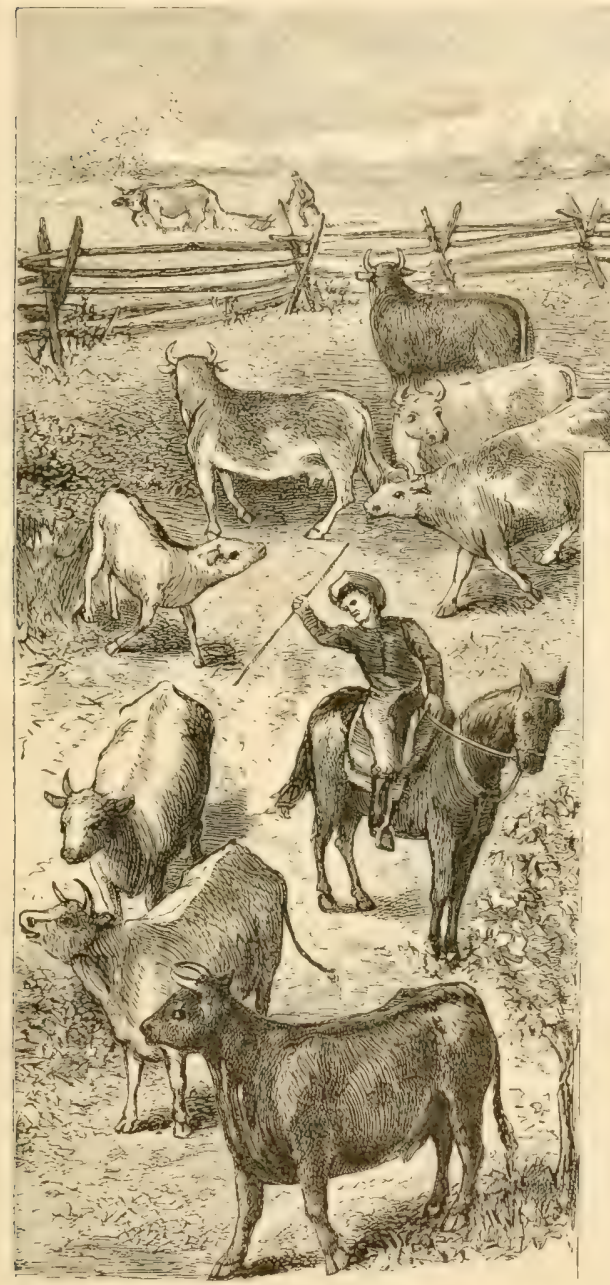

A HERD OF CATTLE.

the domestic animal which hears one long and constant human appeal, and never hesitates in its devoted and selfsacrificing reply. In parks, in meadows, before the cottage door, with an entire and unresisting submission to circumstances, there come to man, from his dumb ally, food and raiment and an unceasing claim upon his skill and his humanity. It is the animal kingdom which forms one of the liveliest charms of a cultivated landscape in motion or in repose. And man never succeeds in subduing the earth, and 
realizing its quiet domestic beauty, until he has enlisted those servants, without whose aid agriculture must fail, and whose value is commensurate with the progress made in the great business of applying all animate and inanimate nature to the necessities and adornments of civilized life.

The Schoolmaster's burst ended the long discussion of Cattle; and at its close the Club adjourned, and the members departed thoughtfully, and turned their steps homeward. 


\title{
EIGHTH MEETING.
}

\author{
FERTILIZERS
}

THE DISTRICT SCHOOL - AN EDUCATIONAL STRUGGLE

BEFORE the next meeting of the Club, the Schoolmaster had finished his labors and had left Jotham. His school had been successful. He came into town without very definite recommendations, and he had by the force of his character secured for himself great favor with the people. Not always had this been done by his predecessors in the school. The inhabitants of Jotham belicved in education, it is true; but they did not always believe in the schoolmaster, and not always in the school, when its expenses were added to the other town burdens in hard and unprosperous times. By law and custom, the rudiments of education had indeed been made a part of their social and civil system: and the every-day duties of life reminded them constantly of the importance of mental culture. But the air of the school-house was not attractive ; its memories were not agreeable; the trials and disappointments of their own school days, the tearful complaints of their children, the character of too many of the teachers, combined with the impression that school-keeping was an occupation taken up by those young men who were either unwilling to work or unable to get their subsistence in any other calling, all united to chafe and fret the practical and hard-working fathers, and to harden their hearts, and somewhat color their vision, towards the teacher and his calling. But. Charles Ingalls had overcome all this. He began his work, the Monday after Thanksgiving, in accordance with a cus- 
tom of New England as old as the festival itself, and he had succeeded so well that his term had been prolonged by a unanimous vote of the committee to more than twice its usual length. His experience had been interesting. He had been selected by his father as the college-boy of the family, and had received from that good old man all that could be possibly spared from his scanty income, even

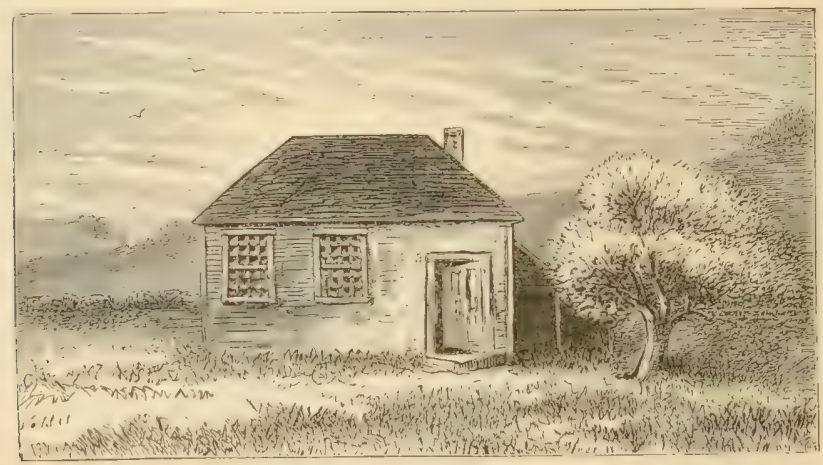

THE DISTRICT SCHOOL-HOUSE.

to the point of reducing his own wardrobe; and he had also had bestowed upon him a pittance from the meagre allowance of his fond mother, whose heart warmed towards him who was destined to carry the family name into some one of the learned professions, perhaps into the high public service of his country. He had fitted for college as best he could, in the spare hours given him by his father from the work of the farm, for every moment of which his brothers had received some just consideration; and he had received his final touches from the parish minister, who knew but little Latin and still less Greek, but who was quite. up to the college requirements of that day. He was now a Freshman in Dartmouth, had entered college when but sixteen years old, filled with good resolutions, and with a keen sense of his obligations to those self-sacrificing parents who had sent him there. This business of school- 
keeping was a part of the plan of getting through collenge, he knew ; but of its practical operation he unclerstuod but little. It was, therefore, with many misgivings and much anxiety that he turned the key of his simple and unattractive room in college, and started forth, conscious that before he returned to it his first step would be taken in the work of making his way through life, - a step which, however humble it might be, would indicate something of the amount of success or failure he was to meet with as he went on. It was the first time he had bent his bow, or thought of it; and now he was to learn the kecnness of his eye and the strength of his arm. As he approached his work his fears did not vanish. I Iis compensation was not large, - sixteen clollars a month; and he was to be expused, moreover, to new scrutiny and new associations every week in "boarding round" among the families composing the district.

When he reached the school-house the prospect was not cheering. It was a square, one-story building, with the remmants of an ancient coat of red paint clouded over its weather-worn walls, and with a plain heavy door which was scarred and battered by the bluws of more than a half-century of educational contest, in which now the teacher and now the pupils had been triumphant. As that door swung upon its rude hand-made strap hinges, on the first morning of his labors, and he entered the school-room, the sight which met his eyes by no means tended to cncourage his heart or strengthen his trembling knees. The centre of the room was occupied by a broad floor of worn and broken bricks, on which stood an enormous cast-iron box stove, with a red-hot spot in the middle of the door, flaming like a carbuncle, and the whole structure roaring with joy as the flames rushed up the quivering funnel. From the floor to the wall, on either hand, rose two rows of seats, the upper row facing the wall and the lower row facing 
the floor, - the upper for adults and the lower for children of tender years. Opposite the door stood the desk of the master, desk and seats worn, hacked, and dingy with long service.

The room was crowded with fifty scholars of all ages and sizes, from five years old to twenty-five. On the higher seats to the left, with their broad backs turned towards the school, sat a long row of well-grown sturdy youths, upon some of whom the duties of social and civil life had already descended; and opposite to these a row of taperwaisted young women, the pose and proportions of whose necks were as charming and attractive as that of the Fornarina in Raphaels great picture of the Ascension. When the master entered, the young women turned about to look upon him; the young men did not. The children looked demure.

It was a trying moment; but the reading of the first chapter of Genesis brought relief, and the school began. The day passed heavily. The young men seemed to be taking the measure of the master; the children recited their lessons in spelling with the vociferous tones which they had exercised among the hills all summer; the young women were silent and bashful, - and so was Charles. At the close of the day he ventured to read to the school the opening speech of the Captain in Dana's "Two Years before the Mast" (let every reader turn to it if he would know what it is), was a little surprised at his own audacity, dismissed the scholars, and, as they went out, one by one, not yet familiarized to the rushing exit which a few days brought about, his eye fell on the graceful form and sweet face of Clara Bell, at the sight of whom his heart leaped suddenly and his veins glowed with a man's courage for his work. His first day was over, - but he knew nobody, and nobody knew him.

It was not many days, however, before the fifty schol- 
ars and the master settled into their business. IVorcester's Geography, and Robinson's Arithmetic, and Murray's Grammar, and Walker's Dictionary were all called into play, and every form of line known to man was enlisted in the work of writing. Now and then a gentle murmur of revolt arose, but it soon died away. A half-dozen young gentlemen asked leave to sit " "p Galilee," and, on its being granted, they ascended to a gallery over the door, the object of which the master had until that moment been unable to imagine. And now the trials began. Galilee was in insurrection, and it was necessary that the diffculty should be suppressed at once, lest it should break out in Judaea also. The blood of his ancestors began to rise, and Charles Ingalls, true to the memory of those who had carried his name honorably through the old wars and the village struggles, marched single-handed into the revolted province. In an instant it was depopulated, its gates were closed, and its rebellious inhabitants were brought down in triumph to the lower regions, from which they had but recently risen.

This first contest settled the question of supremacy, until, as a sequel to the revolt of the young men, the young women arose, and a more complicated trouble at once began. It was not Clara Bell, but it was another young woman, who seated herself one morning near the master's desk, and, when requested, refused to rise and go to her place. What was to be done? Clara's eye was on him ; . he could not lay his hand on the form of one who reminded him of her, and his mother, too. He appealed in vain. There sat the obdurate female, deaf to all demands; and there, true to all his chivalrous instincts, true to a sense of genuine wisdom and sagacity, he left her, waiting for time to settle her case; and time did it.

Erelong a young gentleman arose and asked to be dismissed; the eyes of the reclining young woman turned at 
once upon him, and as he passed out at the great door, that repentant female silently and speedily arose and followed him. Charles was relieved. His school was in peace; his authority was preserved; and he had learned the valuable lesson that it is easier to lead the people by placing before them what they desire, than it is to force them into channels of your own creating. From that day the school prospered; the children liked the master and the master liked the children; all labored together, and when the winter months had rolled round, Charles Ingalls found himself the favorite of the village, loved by the young, respected by the old, the right-hand man of $\mathrm{Mr}$. Howe, the second tenor in the choir, the eloquent debater in the Club, and the friend of Dr. Parker, who had not yet discovered the blushing intimacy which had grown up between the schoolmaster and Clara Bell. And when the school had closed, and the time arrived for him to return to his college studies, old and young, Mr. Howe and the choir, Dr. Parker and the Club, regretted his departure, and only wished that he had been born in the delightful town of Jotham. For himself, he had no desire to go. He felt the movement of the great powers within him, and dreamed of his future greatness, but he was bound with an intimate and tender bond to the spot where his manhood first asserted itself, even in an humble sphere, and he felt as if those who had listened to his first utterances and -joined him in his first effort were bone of his bone and flesh of his flesh. He had begun to feel that he should reach a lofty goal, and he knew well that the memory of the people of Jotham would go with him, and their presence would attend him wherever his path might lead. So he bade good by to Mr: Hopkins and Mr. Howe and Dr. Parker and John Thomas, and strolled over to Jim Bell's, merely to tell Clara that he wished her a prosperous life, and to ask her to give his farewell to the scholars of the 
district school. Clara was radiant, and so was he. He was schoolmaster no longer; and the scholar had passed into the fascinating region of female companionship. They were indeed charming as they stood there in that humble home, conscious of the golden chain that bound them together, but ignorant of the trials which were to beset their path. The schoolmasterhad but little to-say, and Clara had less. But when

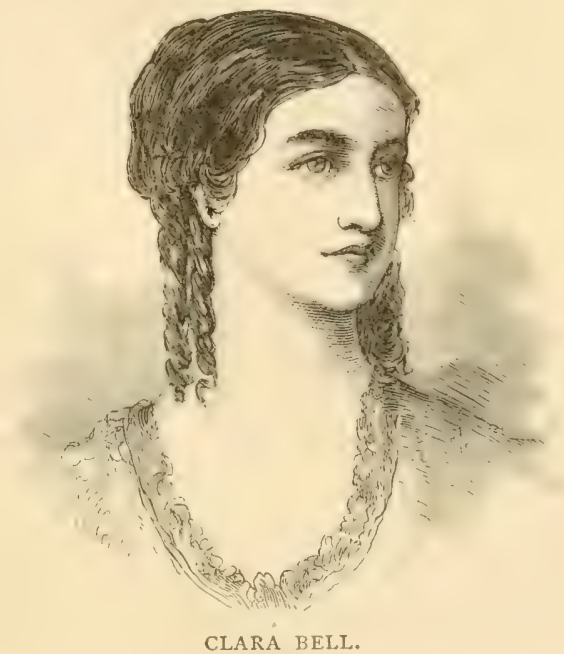
he suggested to her that he should always be happy to hear from her, and that a correspondence between master and pupil might be of mutual benefit to both, and she, as if brought sudkenly to a scnse of her obligations, assured him that she should write to him as often as Dr. I'arlier thought proper, he realized the trial which lay in wait for him, and watched to see her uprising consciousness of the sorrow which always springs from a double allegiance to duty and love. To both there came in an instant the sudden and blinding revelation, and they separated, with an inward consciousness that the time would come when the scales would fall from their eyes. What it all meant they hardly knew. But they realized that some one stood between them, and they had a vague dread of what time might unfold to them. And so they parted; and so they grew old and wise in an hour. 
When the school was closed and the schoolmaster was gone, John Thomas turned at once to the Club for mental relief, and, calling on Mr. Howe, arranged with him that a meeting should be called at once, and, as the season of planting was coming on, they agreed that the topic to be discussed should be Fertilizers and Fertilization. Mr. Hopkins called the meeting to order, and proceeded to discuss the question, -

\section{FERTILIZERS AND FERTILIZATION.}

I have been careful not to occupy an unreasonable share of the time of the Club in the debates which have thus far been carried on, and I feel, therefore, that I shall not be stepling beyond the bounds of reason, if I take an early opportunity to express my views on the subject now before us. I am sure we shall all agree that the question of fertilizers and fertilization is one of the most intricate and complex, as well as most important, with which we have to deal. Precisely what the soil wants it is difficult to tell, even after we have discovered, by the most careful chemical analysis, in what elements it is deficient. I am satisfied that fertilizers work in two ways : first, by directly feeding the plant; and secondly, by putting the soil in such condition that it can present to the plant, from itself, the food which it requires: and I am also satisfied that fertilizers operate both mechanially and chemically on the soils into which they are introduced. At the head of the list I would place properly composted and properly decomposed barn-yard manure, acting, as it does, as a direct food to the plant, through its soluble salts; as a stimulus to the soil to give forth all its nourishing properties, by means of its nitrogeneous qualities; and as a mechanical agent, both through the material with which it is composted, and through its natural supply of bulky inert matter which it mixes with the soil, and thus increases the amount of humus. The application of manures in which nitrogen abounds is always attencled with a great subsequent exhaustion, well known to 
those of our ancestors who in early times supplied the soil of some parts of New England with fish manure, and to those of more modern date who have burnt it up by the constant use of night-soil. Nitrogen is useful in its way; but in order that it may produce the best effect, it must be combined with more substantial and positive plant-food, - something which will enter into the plant itself. This combination is formed in barnyard manure to the highest degree of perfection. It contains a bountiful supply of that element which sets the soil at work, and it also provides all those soluble salts, phosphates, nitrates, etc., which give food directly to the plant. 'There is, indeed, no doubt that the animal excretions, properly prepared, provide us with all the constituents we need for the fertilization of the soil. Nature has provided these substances with the nitrogeneous compounds and the soluble salts in such form that they are peculiarly adapted to the soil in all its varieties; and with proper combinations they can be made our best fertilizing material.

I think you will all agree with me that two things are required to make this manure thoroughly effectual and valuable, namely, proper composting and complete dcomposition. Barn-yard manure can be made especially applicable to the soil by a careful and accurate choice of the materials with which it is composted. For this purpose, nature has supplied us with cheap, bulky substances of rarious descriptions. The straw and refuse hay, used as bedding for the animals on the farm, are very useful for this purpose; and the chemist will tell you how straw itself, decomposed, furnishes certain fertilizing materials acting chiefly mechanically, but chemically as well, on the soil. Muck also, when properly selected and properly cured, forms a valuable foundation for a compost-heap for certain soils. It belongs especially to those materials which nature has provided for the creation of a compost-heap; and it can be worked into a mass of barn-yard manure in such a way as to increase the fertilizing power of the mass of animal excrement, in the same way as straw, sand, and loam. In this connection, it is especially valuable as an absorbent. Having no direct fertilizing power of 
itself, it serves to extend and prepare those substances which have. But do not understand me that it is equally applicable to every variety of soil. It is not. It is adapted, in the compost-heap, to soils that are light and sandy, have an abundance of silica, and have soluble salts already provided, which the latent acids in the muck may possibly dissolve. Take a light, sandy soil, therefore, and if you have a sufficient supply of barn-yard manure which you wish to extend by the use of a composting material, you can use muck, with the assurance that the acids in the muck, even after it has been sweetened by sun and frost, will have a beneficial chemical effect on the soil, by aiding to dissolve, the soluble salts which go to nourish the plant. So I would use muck on sandy land for the purpose to which I have referred, and, if convenient, I would combine with the muck a small proportion of clay. But if I were preparing my manure for clayey land, I should use sand liberally in my compostheap and for bedding my cattle. I have seen many a heavy clay farm so overloaded with muck as to be almost worthless. Obedient to an old opinion which made muck a universal panacea for all the ills that land is heir to, the occupants and owners of that farm had literally filled it with this substance. For root crops and corn crops and grain crops and grass crops muck had been used in connection with barn-yard manure for more than half a century. The effect was painful enough. The root crops dwindled. The grass crop was so imperfect that hardly a field had a firm, compact, continuous sorl; but the grass was rooted in tufts and patches, with bare intermediate spaces occupying, in the aggregate, a large portion of the surface. A remedy for this condition of things was found in sand.

'The cattle were bedded with sand, so that the green manure heaps were half full of it. The compost-heaps were supplied with a large proportion of sandy loam, and, in due time, the mechanical condition of the soil was materially changed, and its chemical condition was so far improved that roots, corn, and grass were restored to that vigorous condition known to them before the heavy soil of that farm had been chilled and 
poisoned by an excessive use of muck. Compost, then, with muck for sandy landis, and with sand for clay lands. So much for composting.

And now for decomposing. I have not forgotten the old custom of hauling green barn-yard manure directly upon the land, and applying it in that condition to most of the crops usually raised on the farm. For some purposes this is well enough, I have no doubt. The best chemists will agree with me that the earth is a great and powerful laboratory. The capacity which the soil possesses of dissolving and dividing and decomposing and alisorbing what is put into it for its own purposes, is analogous to the capacity of the animal system to divide and use the food with which it is nourished. Hence I have no doubt that there are circumstances under which green barn-yard manure con be economically and profitably introduced into sme crops. This is undoubtedly the case with the com crop. Indeed, the best way to raise corn is to plant it on sod land, recently ploughed, with fresh barn-yard manure turned in and a small quantity of decomposed manure or some commercial fertilizer put into the hill. And the reason is obvious. During the "sixty days of hot corn weather," the earth and the heat are doing exactly what the farmer does in his compost-heap; and when the com requires the manure, the eurth, the sun, and the heated air are busy preparing this plant-food for its use. Experience has taught us that this mode of cultivating corn is a good one. But experience has also taught us, that for most crops wellcomposted and well-decomposed manure is by far the most useful.

In decomposing our animal manures, we should not forget that while the manure is largely diminished by decomposition, the furtilizing power of the manure is largely increased; and never until it is clecomposed is the manure fit for the food of the plant. Some of the most interesting experiments that have been made in modern times were made by Professor Voelcker and published by the Royal Agricultural Society of England, setting forth exactly how much barn-yard manure is increased in vilue by decomposition. The result of these careful experi- 
ments was this: that all the soluble salts of manure were larsely increased by decomposition; and that barn-yard manure that has been carried through the fermenting and heating process, although it has lost in weight, is largely increased in its fertilizing power, not only in soluble salts but in nitrogeneous compounds. The decomposition of manure, when properly composted, is therefore a very important consideration for the farmer, and should be conducted in the most economical and effective manner, - with muck for sandy lands, because they will not heat it sufficiently alone; with sand for clay lands, and with straw for grain crops, and with any component part which will increase its nitrogeneous quality, when you propose to raise cabbages, mangolds, or any other heavy-feeding plants.

And now, in connection with these views upon the various materials with which barn-yard manure may be profitably composted, let me call your attention to another fact with regard to fertilization which we ought not to overlook. The necessity for using fertilizers grows out of the fact that soils become exhausted by long cropping. This exhaustion can be remedied not only by applying different soils to each other in connection with the compost-heap, but also without combination with manures. I believe in mixing soils. If you have sandy land, for instance, you can increase its fertility by an admixture of muck or clay, or both, and vice versa. That the fertility of an exhausted soil can be largely enhanced by mixing other soils with it, I cannot doubt. There are many tracts of cold, heavy clay lands in Eastern Massachusetts, upon which an abundant and luxuriant crop of herdsgrass can be raised by a liberal covering of sand. And I have known many a sand-bill to be brought into luxuriance by a good supply of clay and muck. I trust the members of this Club will try experiments in this direction. Mix the various soils of the farm, and I am sure we shall find a mode of fertilization at once simple, true to nature, and fully as effectual as many of the more expensive and elaborate modes which are constantly brought to our attention. 
"It is all very well," said Phineas Barnes, when Mr. Hopkins had concluded his opening remarks, "for gentlemen who have large herds of cattle and plenty of money to talk about barn-yard manure as the foundation of all manure. But for one, I think it the most expensive material for enriching the soil that can be found. It costs a fortune in these days to feed cattle. If you buy stable manure it is as dear as gold-dust, and it costs another fortune to transport it. And I, for one, would like to find a good and reliable substitute."

"That you can't do," said John Thomas. "You may find something to use in its place, but there is nothing to fill that place. It costs money to manure the land, I know; but we have got to face the music or quit the business."

"What do you say about this, Captain Glass?" sail Mr. Hopkins to a fine old specimen of a maritime farmer, who had been brought into the Club by the grocer, whose cousin he was, and at whose house he was spending a few days.

"Well, I should say that Friend Thomas is right," said the Captain. "I farm near the sea, and we think well of compost-heaps, and not much of your snuff-box system of manuring. When I quit the sea, I bought a small farm, all run out; cut, the first year, five tons of hay; raised about thirty bushels of corn to the acre. We stood this one year, but we made up our minds not to be caught the next. And so we piled up kelp and manure and muck, about as much kelp as anything, for we had plenty of it, and we kept piling, all summer. Next year, we had a plenty of good well-rotted manure for grass and corn and potatoes; and we have had, every year, since. Now, I get thirty tons of hay, every season ; and we, that is, my boys and I, get as good a living off that farm as I ever got 
at sea, and don't run the risk of being cast away and drowned."

Here William Jones broke in, and said he had a high opinion of stable manure, of which he had a large quantity to sell.

"It don't compare with wood ashes," said Sam Smith the soap-maker.

"I think full as well of the sweepings of my hen-house as anything else," said John Jackson, the President of the Pierce County Poultry Association.

"Is n't lime about as good as anything?" said the grocer, who happened in at this meeting, and who had a large damaged lot of this article which he desired to get rid of.

"First-rate with muck, if you want to raise cornstalks, and don't expect any corn," said Peter Ilsley, who had been a patient listener thus far.

"What is all this talk about guano and potash and phosphates and so on ?" asked Mr. Howe.

And here begun a rambling talk about commercial fertilizers, so called, in which very hard words were used with regard to the manufacturers, and the most profound wisdom was manifested with regard to a protective law for the farmer, and a police force to carry it out; a talk which might have continued till this time, had not some one given a dismal account of the financial embarrassment which had fallen upon the farmers of one or two towns in the State, who had invested largely in guano and phosphates, relying on their onion and tobacco crops to help them out. This picture was by no means pleasing to the progressive members of the Club, who went for onions and tobacco, every time, as against corn and potatoes. And so one of them moved to adjourn. The motion was carried.

"Is there any end to fertilizing materials?" said Mr. Hopkins. 
"Not to receptive nature," replied Mr. Howe.

"To the willing soul all things are brought," remarked Dr. Parker. And then he thought of himself and Clara, and that fascinating schoolmaster, and he said, "Goud night," and went home. 


\section{NINTH MEETING.}

\section{FERTILIZERS (Continued).}

THE DRIVE TO THE SEASIDE.-DR. PARKER AND CLARA BELL. - AN EXCITING TIME FOLLOWED BY REPOSE.

"THE harvest is past, the summer is ended," and the Club, which had been suspended for months, began, through its committee, to show signs of life. The season had been refulgent. Never had the hills and valleys of Jotham been greener through the hot months, than in this period of genial warmth and frequent vitalizing showers. Never had the crops been better. Never had the farmers been more prosperous. The Rev. Mr. Howe had rejoiced with them in the goodness of Providence, whose smiles had been constant; and he performed this part of his parochial labor with unusual zeal and interest from his official connection with the Club, and the knowledge he had obtained through its deliberations. He had never been so much a pastor to his people as now ; and he found that the closer he stood by their sides on the earth, the easier it was to lead them on the path to Heaven. John Thomas had kept the varied business of his large farm in flourishing condition; his hay crop was ample and well cured; his corn had yielded well ; his potatoes had come almost up to the fabulous crops of his ancestors; his butter and cheese had found a good market; his swine had grown and fattened with unusual thrift; his young cattle had done well in the pastures; his poultry had been busy and prosperous; his two colts had grown into quite sizable horses; and somehow his general system of farming, carried on with good land, good sense, 
and a grood purse, had been as remuncrative as some of the more exact and modernized methods of his neighbors. Nobody secmed to know exactly how it was done, but they were all aware that John Thomas's farm alway's louked thrifty; his buildings were well painted; his walls were well laid ; his orchards were clean ; the borders of his fields were free from bushes; his cattle and horses had an air of comfort and happiness; his tools and implements were always in good order, and in their places when not in use. Peter Ilsley had never driven so lively a business in sellings milk, and had never tried so diligently to spruce up in his buildings and around his yards. IVilliam Jones had sold one three-year-old Morrill colt for eight hundred dollars, and a Mambrino for nine hundred; and he realized triumphantly the profits of breeding horses. Phineas Barnes had used his hammer and anvil faithfully, and had also derived a wonderful income from his little strawberry-beds and his vines and pear-trees. To Mr. Hopkins the agriculture of the summer had been a source of great delight. His drained lowlands had yielded most abundant grass crops. From his old cxhausted fields, upon which he had applied, with a liberal hand, every kind of manture and fertilizer which he thought to be adapted to their wants, he had secured crops of barley and corn, and potatoes, and turnips, and garden vegetables, which the first ministerial Hopkins, on the virgin soil, might have envied. His barn was well filled. The newness of his improvements was wearing off; and his entire homestead, house, barn, stalls, floors, yards, greensward, and paths had become humanized by use, and had taken on that domestic and civilized air which constitutes the chiefest charm of a well-ordered estate. He had added a dog-house to.his establishment, and he had provided this dog-house with a sedate and dignified St. Bernard dog called Bob, - a dog which seldom smiled. and had an impressive air of ownership about him. He 
had also supplied himself with a substantial pair of bay horses, and a well-built carryall, and an open beach-ivagon, feeling that a barouche or a Brougham was a little too much for country life and the outfit of a genuine farmer. And so the people of Jotham had all done well, and the season had been one which they could look back upon with supreme satisfaction.

The social enjoyments of Jotham, during this summer, had not been unusual or remarkable, nor had the disasters been great. Fourth of July had been noisily celebrated with clanging church-bell, and a few fire-crackers, and a musket or two; but it was all over long before the heat of high noon, and conded in a holiday of rest and rational repose; while as evening came on, the usual thunder-shower of the day rose lip with rattling fury, washed the roads, drenched the haycocks, and splintered the great elm on the common with a flash and a stumning report, which brought all Jotham to its feet with a subdued cry of alarm. The usual trials of the haying season had fallen upon those whose grass was standing as late as the 2oth of July, and was exposed to the drenching storms which then set in ; a lesson which they had been taught each year for a geiieration, and which each year had been forsotten. Here and there a root crop had been choked by the weeds, which had grown while the men slept, or were too busy to attend to them. Not every farm had made successful warfare on the caterpillar and the canker-worm ; and through the long season the blight of the insect remained to reproach the owner. A few cornfields had been damaged by cattle, because the farmers would neglect their fences. A bright and beautiful boy had been drowned while bathing in the lake; and another had been killed by the upsetting of an ox-cart. But these were the clouds which were apt to pass across the sky; and the people deemed that to be a fortu:ate season in which domestic peace had been preserved, 
and no startling manifestation of meanness or wickedncess had occurred within their borders.

The people of Jotham had mot in the midst of their cares and labors omitted the placid pleasures of country summer life. Their holidays and leisure hrours had been few, hut their simple out-elowr and in-door amusements had not been forgotten. The cloudy and showery days in the hay season had found the young men fishing in the ponds and streams, as the best business they could attend (1), until the heavens cleared up and the sun returned to his work as a hay-maker. To cheerful parties of young women, the hroad, half-wilel, undulating pastures, intersected by innumerable winclines com-paths, and fragrant with swect-fern and bayberry, and furnished with a living interest by the straying and browsing cattle, had presented most bounterus stores of those small fruits for which New England is famous, and whose delicacy of flavor has not yet been surpassed by the crops of the most cumning cultivator. The social gatherings of neighlors and friends had been unusually delightful; and the hospitality of the town hat been freely and corciially extended to a lons succession of the city friends of Mr. Hopkins, who rejoiced in his country home, and began to believe that agriculture was not so bad an occupation after all.

Among the customary annual entertainments of the prominent members of Mr. Howe's parish was an cxcusion, at the close of the haying season, to some convenient seaside resort, for a day's refreshment in the sea and the sea air. For years this trip had been taken, and some one of the primitive hotels, which then occupied the places now filled by the great establishments, looming along the northern shores of Massachusetts Bay, was always prepared for the annual visit from Jotham. The procession which left the town was always an interesting one. The clergyman with his one-horse chaise, the farmer with his 
family wagon, the mechanic with his light equipage, hired for the occasion, the lawyer and the physician, each with the vehicle used in his business on the circuit or in his practice, all started out in line to represent the active force of the place in holiday attire. In the summer just gone, this excursion had been arranged and carried out with unusual spirit. The animating influence of the Club was felt here as it was everywhere, and in all the public enterprises of the place. They who had wrestled with each other in hot debate during the winter, and who had been at work all summer applying their knowledge to the land, with more than common success, were extremely desirous of meeting now on a field free from all antagonism and dedicated to goodfellowship alone. And so Mr. and Mrs. Howe agreed to devote one day at least, perhaps more, to the enjoyment of the trip); and Dr. Parker grew interested in the matter and asked to be allowed to join; and John Thomas and Huldah spent a week in preparing for the holiday; and William Jones selected his best horse for the drive; and Phineas Barnes agreed to shoe Deacon Joe's mare, for the use of her on the journey, for the Deacon never joined in such frivolity; and Peter Ilsley brought out and washed the old yellow-wheeled family chaise, which had long since retired from active duty; and the grocer dedicated his store wagon to the dissipation of the hour. Jim Bell could not go; and he was gratified as well as astonished when Dr. Parker strolled round to his house and casually invited Clara to accompany him, - astonished that the Doctor should desire to go, and more than all astonished that he should invite Clara to go along with him.

It was a charming morning when the villagers drove out of town on their way to the sea. The sun was rising, and the air which just fanned the sparkling and dewy grass was fresh and invigorating. The drive was delightful, - 
not in hot haste, but slow and dignified and moderate, so deliberate, in fact, that the most practical farm-horse in the party, just from the furrow, had no difficulty in holding his own with the best. The halts were frequent, partly for a little interchange of ideas and a little mutual congratulation, and partly for the purpose of examining the well-known groves, and curious rocks, and the remarkable trees, which had for years formed the interesting landmarks of the drive, and partly also to catch a glimpse of some striking bit of landscape, whose beauty had been a topic of conversation eren with the old and practical for many, many summers. It should be remembered that, on

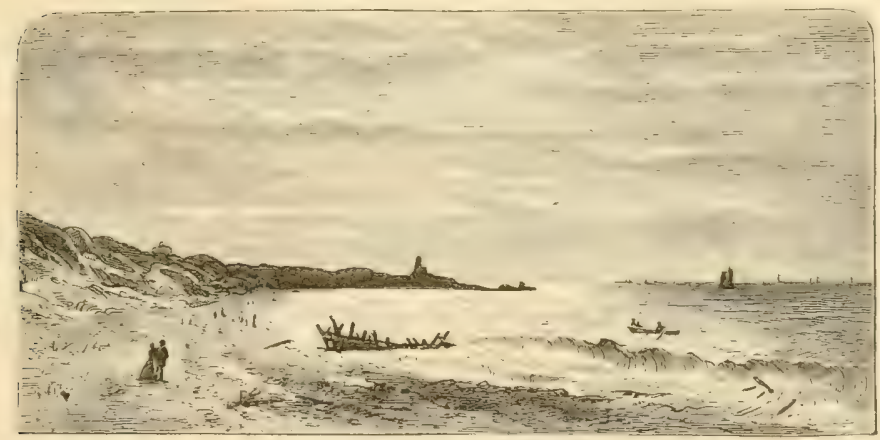

A SEA VIEIV, BEACH, ETC.

this annual drive, the persons engaged in it gathered together a store of pleasant little incidents for fireside discussion and asrecable chat, until the occasion came round again. And how they rejoiced at the first "uprising of the curtain before the sreat mystery of the sea," as they reached the summit of that familiar commanding hill, and found their old friend lying there, still in the bright sunlight, sparkling and grand in his boundless beauty, and submitting to no limits but the heavens themselves! The gathering at the little hotel, how cheerful it 
was! The stroll up and down the smooth sand beach, studdecl with that same array of shells which had greeted them so often, but which was even now as new and fascinating as ever, had the old charm still, as the rippling surf tinkled out its drowsy music, and seemed to lull all things to repose. It was entirely in order to discuss the natural curiosities which lay about them, and it was pleasant to see the inquiring groups, gathered around a bit of wreck, half covered with the sand, or a stray bone cast up by the tide, which had wrenched it from its bed to expose it to the gaze of the curious, or a new bowlder which the floating ice had tossed high up on the beach since the last excursion, or a new, but perhaps not very important shell, which had long since lost its occupant and seemed to be waiting now to be provided with a home of its own, as an ornament to the dressing-table of some fair one, who in her simple life depended on the bounty of nature for her outfit.

In these discussions Dr. Parker made himself useful and interesting. He had told Clara the name of every flower and tree which they had seen along the road on the drive; and now he discoursed upon the mollusks and seaurchins, upon the shore line and wandering rocks, upon the lessons of animal life taught by the lowest order of vitalized creation, and he became the delight of his associates, who wondered what had induced him to come, and wondered, also, at the extent of his knowledge, and the interesting and liberal way in which he spread it broadcast all around him. It was evident enough that he had found a new impulse; what it was they did not know, nor did they suspect, when, after having exhausted the topics proposed by the admiring group which surrounded him, he allowed them to scatter and then wandered away over the long beach with Clara, listening to the voice of the sea, stopping to examine every rosy-lipped shell, until they 
could hardly be seen in the dim distance. Not even on their return were they especially observed; for the hour of dinner had arrived and the excursionists gathered hastily into the familiar old dining-room, to enter upon the substantial joys of the occasion. Mr. Hopkins, who had driven over in his carryall later in the day, not having yet learned the delights of sumrise departures, and who had reached the seaside while the party was scattered along the beach, discovered a strange, tender light in Clara's eyes, a softer color in her cheek, a gentle tremor in her voice, a dreamy anxiety over her whole countenance, which he could not understand nor even attempt to account for, until he saw Dr. Parker's eye rest upon her, and saw also the nervous and uneasy manner of the usually calm Doctor, as he fidgeted about among the crowd. However, even Mr. Hopkins had come to the seaside for a day of recreation, and, as he found there "other fish to fry," he soon forgot Dr. Parker and Clara, amidst the bounties of the dinner, and the busy chat of his neighbors with regard to the incidents of the morning.

It was late in the afternoon when the procession was formed to return to Jotham. The day was delightful still, and all the long hours which had passed since the early morning departure had brought no weariness to the cheerful and busy party. One after another the wasons were brought to the door of the botel, their seats were filled, and they were driven away. Mr. Howe had joined the procession. Mr. Hoplins, having invited Mrs. Howe to a seat in his carryall, as more comfortable for her after the long day, had driven on. The last carriage to be brought up was Dr. Parker's; and it was with unusual elasticity that he assisted Clara into it, seated himself by her side, and turned his steps, as she supposed, homeward. It was natural that he should propose a little farewell drive on the beach; and so she rather rejoiced in one more oppor- 
tunity to listen to the surf, and to look upon that long curving line of solid, shining, sea-wet sand, which was now filled, to her, with the deepest and tenderest associations, and which she felt, half painfully, she knew not why, would never be obliterated from her memory. As the sun went down the scene was delightful. Everything around her, the memory of the day, the beauty of nature, a strange misgiving, the consciousness that she was not really returning home with her companions, a nervous sense of the new life into which she was entering, were more than she could bear, and a tear hung trembling in her eye, - to be dried there at its fountain, she hoped and prayed. Dr. Parker was silent; but Clara noticed that he was unusually active with his horse, and that that commonly quiet and wellbehaved animal seemed to be bewildered by his master, and to be growing quite impatient under his uncertain guidance and his spasmodic and unreasonable demands. She had never seen Dr. Parker whip his horse before. She had never known him to drive regardless of danger. And she was soon lifted out of her melting mood into a stern and positive feeling of anxiety and alarm for her personal safety. She suggested at last that perhaps they had better leave the beach and take the road to Jotham and join, if possible, the returning procession of their friends.

"So I say," said Dr. Parker. "But then, the sea, Clarry, is so fine.

'The sea, the sea, the open sea,

The blue, the fresh, the ever free';

we may never see the boundless abyss again, in which the leviathan play's therein, Clarry; where go the ships; the sea, 'without a mark, without a bound' ; 'I 'm on the sea,' Clarry, 'I ' $m$ on the sea'; and so art thee; this wild waste of waters all around us; how solemn! how sublime! What loes Hopkins know of this? Hopkins, the money-changer, 
who should be driven from this holy temple in which we have crected our altar, Clarry, and where I for one propose to worship until death do us part. What knows the minister of the meaning of this broad expanse of waters, typical of the mighty tickes which flow through the double human soul, - two souls in one, I mean, Clarry; two in one, — did n't we, Clarry?"

"I think we had better get off this beach on to the highroad as soon as possible," said Clara.

"High-road, so do I," said the Doctor. "High enough it is, Clarry."

The horse seemed to be of Clara's mind; and either because he had become accustomed to the accidents in the Doctor's life, and knew that his own instinct was his best guide under the circumstances, he turned his steps towards the path running from the beach, struck into the road leading to Jotham, and took a firm and steady gait for home, apparently unmindful of the eccentric management of his driver, who drove and talked with equal wildness. Clara possessed her soul in peace. The day which had dawned so brightly was heary and gloomy enough now. Her dream was over. Her profound respect for Dr. Parker, her admiration of his power, her faith in his.integrity and honor, were all gone: and in the midst of the ruin and darkness she saw the bright form of Charles Ingalls, who seemed to haunt, and reproach, and pity her, until she was wellnigh mad. It was a strange conflict for her; and the revelation which came out of it all blinded and bewildered her, who, until this hour, had not known where in a woman's heart respect ends and love begins. The evening drive home was dreadful to her. Dr. Parlier became quiet enough at last, - too quict. The silence was worse, if possible, than the noise. And as the horse pursued his steady course along the road, she pondered and pondered upon her sudden trial; hoped it was a dream; 
believed she could overcome it; determined to save him who had in the first radiant hour fallen so low before her; and resolved to wait for God to solve the mystery, and lift the veil, which she could not solve or lift herself. The silence became at last insupportable. She had learned her lesson; and now she must have relief even if it came through that human voice which she had suddenly learned to dread, but not yet to despise. The Doctor raised his head, and in a subdued and apparently shame-stricken voice said to his horse, -

"Go on, Jim."

This was enough for Clara. "How charming is the night!" said she, glad to know that he who could speak rationally to his horse might, possibly, speak rationally to her.

"It is, indeed," said Dr. Parker ; " are we near home?"

"Yes," said she; "I see the spire of the meeting-house in the moonlight, and we are just at the turn of the road leading through the maples into the village."

" IV ell," said the Doctor, hardly yet realizing what had occurred since leaving the hotel, "the drive has been very short, Clara, has it not? And I really hope you have enjoyed the day, and the walk on the beach, and the cheer of our party. But here we are, at your father's house."

He helped her out of the chaise and drove on, to realize, when he had reached his own home, what a cruel thing he had done, and how wickedly and thoughtlessly he had beclouded the life of that young girl. The night was horrible to him.

The kiss of Clara's old mother, who sat in the moonlight of the cottage window, waiting and watching for her, was indeed a gleam of Heaven; but it seemed only to intensify the gloom in her mind. And as she closed her chamber door, she shut out all the joy which belongs to youthful life, 
and found that sad and solemn relief which a determined resolve to discharge our duty faithfully, in all the events of life, will always brins, - that day of light without heat, at which all men shudder. The night to her was calm and peaceful.

The village was filled for weeks with pleasant talk about the excursion. Dr. Parker returned to his old exclusive ways, no one knew exactly why. Clara Bell became a companion of the matrons, a strong and wise woman, suddenly from brilliant girlhood; and nobody understood that. The summer waned. Winter came on. The Club resumed its meetings.

Mr. Howe and John Thomas, as soon as Thanksgiving was over, met to rencw their work as a committee to organize the meetings and provide topics of discussion for the Club. Mr. Hopkins had offered his parlors once more as a place of meeting; and notices were issued to the members, reminding them that the subject still under discussion was Fertilizers and Fertilization.

The members of the Club assembled with unusual alacrity and promptness. Mr. Hopkins called them to order, and, having sugrested that the first business was the election of officers for the year ensuing, was quite gratified with the action of Peter Ilsley, who rose and moved that the present officers be requested to serve another year, and supported his motion with remarks which really convinced Mr. Hopkins that he was more of a favorite in Jotham than any man had a right to expect to be, after two years of busy residence there. The motion having been carried unanimously, Mr. Hopkins expressed his thanks in a feeling manner for the compliment bestowed upon him. He reminded the Club of the valuable discussions which they had carried on the previous season, and expressed the opinion that not only intellectually but practically had the farmers of the town been benefited by the investigations. 
He had marked the course of his neighbors during the summer season which had just closed; and he felt proud to say that the cattle and crops of Jotham gave evidence of increasing zeal and intelligence in the farming community. For himself, the season had been one of great agricultural prosperity, and he found, as time went on, that his new occupation in life was becoming more and more dear to him, and he sincerely hoped his example would be more and more valuable to the community in which his lot had been so fortunately cast. He then announced the subject once more, and called on any member present to open the debate.

The debate which followed was exceedingly discursive, owing to the constant tendency of the members to divell upon their own experience during the summer, and to branch off into the incidents of their farms. It was voted, therefore, that Mr. Howe, the secretary, should condense as far as possible the remarks of the members into an opening paper for the next meeting, and that in this way the minds of the members should be brought into systematic operation for the further business of the session.

"Have not seen you for months," said Mr. Hopkins to Dr. Parker, as they and Mr. Howe lingered before the wood-fire, while the rest of the Club departed.

"No," said the Doctor, a little gloomily; "I have been overrum with business, and have been really too much worn out for even neighborly calls."

"Not since the drive to the beach have I set eyes on you except in your chaise," said Mr. Howe.

"I know," saicl the Doctor; and added with a sad and awkward smile, "that chaise will be the death of me, I fear."

"O no! I trust not," said Mr. Hopkins. "Sit down, Doctor, and take a cigar."

"I smoke but seklom, now," replied the Doctor. "Pray 
excusc me. I think I must sec Mrs. Jones to-night, who is very ill. So good night."

"He is odd, is n't he?" said Mr. Howe to Mr. Hopkins, as the Doctor vanished, and left these two worthies to watch the fading embers and muse themselves into a condition fit for sleep. 


\title{
TENTH MEETING.
}

\author{
FERTILIZERS (Continued).
}

CHARLES INGALLS RETURNS. - HIS DISAPPOINTMENT, - MR. HOWE DISCUSSES FERTILIZERS.

II HEN Charles Ingalls left Jotham at the close of his school, he promised the committee that if he found it necessary to teach at all during the next season, it should be in their service. The promise was not foryotten. The impression he left upon the community was so substantially good, that time only made it better; and when the day approached for the winter term to begin again, Mr. Howe was instructed to write at once to the schoolmaster, as he was now called, and remind him that the educational Monday would soon come round, and he would be expected to renew his labors in the old red school-house. To this the schoolmaster did not object. The compensation was small, it was true, and he might do better elsewhere. But elsewhere was not Jotham, - the town where he first tried his wings, the village with a Farmers' Club, the home of Mr. Hopkins, the birthplace of Clara Bell. He looked forward to another winter there with something more than delight, - with a feeling of pleasure so kieen that toil and compensation seemed to be entirely secondary. He returned, therefore, to his labor at the appointed time; not to the same labor, and the same town, and the same school and scholars, which he saw for the first time the year before; but to a well-known and familiar scene, to whose service he was now fitted by experience, and to whose locality he was now bound by the tenderest associations. He brought 
with hin also a maturer mind; for his clays in college had been devoted to the most diligent study, in which his powers had been quickened by a rague sense of the mark he might make in life. And when he entered that primitive school-room to begin again his labors there, he felt as if he were only returning home, stronger and wiser than ever before, with firmer ties and broader understanding and enlarged capacity. The room had not changed; the stove, and the brick floor, and the desk, and fialilee, and the mature young men and women, and the little chilelren were all there, just as they were on that first anxious and trembling morning. Is he cutered, he gave the schelars a general recognition, and procected at onec to his desk and began his labors by calling for the customary nating of a chapter in the Bible. Verse after verse was read by the pupils, and it seemed to him that the work in which he was engaged had only bectn suspended the day luefore. The voices were all familiar, and all came in the order to which he had become accustomed. And without exploring minutely the well-filled benches, - without exactly daring to rum his eye alone to sece if all the old familiar faces were present, - he waited for one voice, and waited in rain, until the last stumbling and hesitating and vociferous reader had finished his verse; and he learned that the voice of Clara Bell was not among them. To say that he was disappointed would be to sive utterance to what he would not say himself. And yet he felt that the zeal with which he had travelled over the long road in rough weather to Jotham, the readiness with which he had accepted another call to teach in that gloomy old schoolhouse, the enthusiasm with which he persuaded himself that he was actuated by a high sense of his duty to mankind, were all suddenly cooled before the realization that, after all, he was not eager to return to his labor, but to her. It was amazing how his courage was dashed; what 
a fecling of disgust seized upon him; what a sense came over him that he had sold himself; and with what an indifferent manner he proceeded to lay out for the scholars the work of the term. But then he remembered that he was in Jotham, and that in the ordinary routine of life, either at the singing-school, or at church, or at her father's house, in the regular orler of boarding round, he should erelong meet Clara; and he went to work with his usual determination, but with less of that elastic zeal than he had anticipated, before he discovered what a wretched place Eden must have been before Eve was born, and what a commonplace affair the world becomes when there is no one in it to love.

The schoolmaster had not, however, forgotten in the midst of all his devotion to the school-house and its associations the frequent meetings of the Club at the cheerful home of Mr. Hopkins; and when he was notified that he would be expected to take part in the deliberations of the coming season, as almost a public duty, he did not hesitate to declare that a duty like that belonged to the list of the most agreeable pleasures of the town. And he rather hoped he might have an opportunity to apply his rhetorical powers to some other interesting question before the Club, as he did so acceptably to the subject of Cattle. When the Club met, therefore, he was present. Dr. Parker was not.

The meeting was called to order, as usual, by Mr. Hopkins, who took special pains to congratulate the members and himself that the schoolmaster was once more among them, and who announced that Mr. Howe would, in accordance with a vote of the Club, present an opening paper on the subject of Fertilizers and Fertilization, - a subject which had occupied their attention at the last meeting, and which had increased in importance as the difficulties of agriculture had multiplied, and the demand for agricultural products had expanded. 
Mr. Howe modestly drew from his pocket the essay he had prepared, and with a slight ecclesiastical tone reasl bi: discourse upon

\section{FERTILIZERS AND FERTILIZATION.}

I have found it very difficult to discharge exactly the duty which has been assigned me. During the debate which was carried on at the last meeting of the Club, a great deal of valuable truth was enunciated and a great many facts were brought out, which it is impossible for me to re all and arranser to your satisfaction. I have been compelled, therefore, to present, in my own way, the views which were imprinted upon my mind by the debate to which I listened with so much pleasure and profit. I was extremely gratified to find that so many of our number had interested themselves in experiments upon the application of manures. It is not difficult, as I conceive, MIr. President, to find an abundance of fertilizing material. The earth is full of it; so full that we have only to stretch forth our hands and gather it together. The large amount of decaying animal matter to be found in slaughter-houses, and to be secured by accident and disease on the farm, should never be lost sight of. Blood, hair, and flesh can be composted in such a manner as to produce a most stimulating and valuable manure. Bones cannot be overestimated. I have seen so much benefit arise from the use of crushed bones, not bone meal, but whit the English call half-inch bone, combined with an expull bulk of barn-yard manure, and sufficient muck to make a compost-heap, that I urge it upon your most careful consideration. Mr. Barnes spoke highly of it for his pear orchard; but I can from observation speak highly of it as an application to com. turnips, grass land, in fact to any crop which requires strong and perminnent fertilizing. And I woul I most earnestly recom mend the use of bones in the way I have described, to every farmer who desires to cultivate his farm well. I do not believe in bone meal. I have found that the soil did not retain it well, and that it did not readily enter upon that heating pro- 
cess which is necessary to render all manure valuable. I have thought sometimes that the fine particles of the powder were washed away by the rains, and carried down into the earth leyond the reach of the atmospheric influences, and were thus rendered inoperative to the plant. But however this may be, crushed bones, half-inch bones, mixed, heated, composted, and used as I have described, are valuable to every cultivator; and I think they are fully as valuable as bones when reduced and broken up by the application of nitric acid. Used in the way I have suggested, the soil, the barn-yard manure, the muck, and the process of fermentation all combine to bring the bones into a soluble condition, - or if not to a soluble conditi n, to a condition peculiarly available to the plant. Fish also I would recommend, but always composted. The refuse left after the manufacture of fish-oil can be combined with muck and made a most valubble fertilizer, especially for the early stimulation of crops. It has been well said that fish in composts "should lie a year, that their oil may be dissolved and fitted for the nourishing of plants."

Strati, refuse hay, thatch, tanner's bark, leazes of deciduous trecs, fermented with other substances, as manures, may be used with great benefit on clayey and stiff soils, and generally with great advantage in the cultivation of potatoes.

II out-ashes are invaluable as a fertilizer, making a good topdressing on all kinds of lands, and being especially acceptable to corn when applied on the hill at the second hoeing, and to strawberry-vines. Ashes should always be applied on the surface of the soil. Liebig says: "A field which produced no clover can be made productive for a series of such crops by manuring with wood-ashes, which contain the same mineral matters as clover; in the Netherlands this manure is of the most general application for this purpose; and in Westphalia there is a proverb that 'he pays double who buy's no ashes.' It is a well-known fact that on strewing wood-ashes on a meadow, thousands of clover-plants make their appearance where they were not risible before." Buy all the ashes you can get, therefore, if you need more manure than you make from your cattle; 
if you cannot get inleached, buy leached, and apply to your corn, small fruits, orchards, grass lands, root crops, and you will meet with your reward.

Lime may in certain cases be used as a fertilizer and on certain crops. It has been well said by an old writer, that "lime acts as a manure by attracting and imbibing the oils and acids which are contained in the earth and atmosphere. It not only collects these ingredients of vegetable food, but so alters them as to fit them to enter the roots of plants. With the acids it forms a salt which by mixing with the oils becomes a saponaceous mucilage, which is the true pabulum for the nourishment of the plants. These changes cannot be made in the ingredients of which regetable food is composed without a considerable degree of fermentation. This fermentation breaks and mellows the soil, and so increases the pasture of plants that the roots can more freely extend themselves in quest of their food. Accordingly it is found that liming renders a soil very soft and open. And as lime when it is slaked is a very soft substance, I can see no reason to doubt of its containing a very considerable quantity of those impalpably small particles of earth which enter into plants and become a part of their subsistence. If so, it must be allowed that lime is to answer the intention of manure. . . L Lime may have an ill effect when it is injudiciously applied, or in too great quantities, or to an improper soil. Three cart-loads, or one hundred and twenty bushels, are allowed to be a sufficient dressing for an acre where it is cheap enough. This dressing enriches cold, stiff, clayey soils for many years after. If it force any soils too much it can only be those which are weak and sandy. The best time for applying lime as a manure is when land is newly broken up, or after lying a long time in grass. This may be ascribed to the plenty of roots in the soil which the lime soon dissolves and changes into food for plants. It may well be composted, and if mixed with a large proportion of clay, or with mud from the bottom of ponds or rivers, it may be applied to sandy and gravelly soils without danger, and to great advantage." 
I have seen an old book dedicated more than three quarters of a century ago to James Bowdoin, in which the writer calls attention to coal-ashes as top-dressing for coll, damp soils; to sea-plants, marl, sand, clay, to mix with the plough or barrow in sandy or gravelly soil ; to turfs, shells, scrapings of backyards for all kinds of soils; and also to an abundant supply of chips, shavings of wood, and sawdust for stiff soils; and to scrapings of streets, and urine and water which flows from compost-heaps mixed with muck or loam.

I have enumerated these articles to show you what a variety of materials the farmer can use for fertilization, if he will only exercise industry in collecting and judgment in applying them. I'erhap)s our renerable author has been too omnivorous in hin selection; but his list is, to say the least, interesting and suggestive.

But I referred to the experiments in fertilization which have been made among us cluring the last season; and they were so interesting to me that I have, as far as possible, made a record from memory of some of them. 'The experiment made by Peter Ilsley in top dressing grass lands is worthy of your careful consideration. Mr. Ilsley said, and he will correct me if I am wrong, he had been trying on one lot of land compost of manure and muck, on another leached ashes, on another green manure, on another wood-ashes, and on a fifth Peruvian gumo. Each lot of land contained I2,500 feet, and he began his experiment three years ago. He applied then on the first lot two cords of well-rotted manure, mixed with two cart-loads of muck; on the second, I 20 bushels of leached wood-ashes; on the third, two cords of green cow-manure; on the fourth, 80 bushels of unleached wood-ashes; and on the fifth, $25^{\circ}$ pounds of Peruvian guano. He weighed his hay, two crops for each of the three years; and the first year he got from the compost I, I 70 pounds of hay, from the leached ashes I, I 20 pounds, from the green manure $I, 600$ pounds, from the unleached ashes $\mathrm{I}, 45^{\circ}$ pounds, and from the Peruvian guano $\mathrm{I}, 67^{\circ}$ pounds. The second year he got from the compost 1,090 pounds, from the leached ashes 1,400 pounds, from the green 
cow-manure 1,750 prounds, from the unleatcher ashes 1 , sigo pounds, and from the gruano 870 pounds. The third year he got from the compost g65 pounds, from the leached ashes r, roo pounds, from the green manure i, 350 pounds, from the dry wood-ashes 1,230 pounds, and from the guano 550 pounds. 'The land selected'was a field free from shade, with a well-set sod three years old. In the three years the green manure produced 4,700 pounds, the unleached wood-ashes 4,570 pounds, the leached ashes 3,710 pounds, the compost manure 3,225 pounds, and the guano 3,000 pounds. I consider these experiments in top dressing very valuable.

I have secured the minutes of another experiment made by John Ray, who meets with us occasionally, and who, as you all know, is a careful and successful farmer. His experiment also rums over three years, and is intended to test the difierent modes of applying the manure, but not the kind of manure used. The land selected was a warm, rather light loam. It consisted of one and a half acres, divided into five equal parts. On four of the parts compost manure was applied at the rate of twenty cart-loads per acre. On the first lot the manure was ploughed in eight inches; on the second lot it was ploughed in four inches; on the third lot it was harrowed in; on the fourth lot it was spread on the surface after planting; and the fifth lot had no manure at all. The field was planted with corn. The first lot yielded twelve bushels; the second lot yielded ten bushels; the third lot yielded nine bushels and twenty-eight quarts ; the fourth lot yieided eight and a half bushels; and the fifth lot yielded seven bushels. The second year these lots of land were ploughed about eight inches deep, and som with wheat. The first lot, into which the manure was ploughed eight inches, yielded nearly fire busluels to the lot; the second lot, into which the manure was plougherl four inches, yielded four quarts less than the first; the third lot, into which the manure was harrowed, yielded the same as the second; the fourth lot, on the surface of which the manure was spread, yielded five bushels; and the fifth lot, which had no manure at all, vielded four bushels and two quarts. The third year the land was in grass, 
herdsgrass and clover. The first lot yielded $S_{25}$ pounds, the second 694 pounds, the third 643 pounds, the fourth 544 pounds, and the fifth 487 pounds. These experiments would indicate that manure must be applied to the land in different ways for different crops.

Now, I have no doubt much important information can be derived from the results at which these gentlemen have arrived; but we must remember that the application of manure to the soil is but a small part of the business of preparing land for a crop. It must be properly ploughed, properly harrowed, and at the right time; and it must be properly seeded with good seed if its full capacity is to be reached. Nanure is all-important; but the mode of dealing with the land is important also.

"What do you say to ploughing in green crops for manure?" said John Thomas.

"I have tried it," replied John Ray, who had rather a light farm, " and never could make much out of it. In the first place, it takes all summer to manure a piece of land in this way. If you sow your crop in the fall, even, you can't get at it until late in June; and if you sow it in the spring, it is n't fit to turn under till fall; and I have never seen the time in my farming when I could afford to wait that length of time, without getting something from the land to pay the bills. When you reckon the cost of ploughing and manuring for the green crop, and seeding, and add this to the delay and the loss of the land for so many months, it is evident that this is a pretty expensive way of enriching the soil. But more than all this, I have seen a piece of light land apparently poisoned by ploughing in a crop of green oats. It was done in July for the first time; another crop was sown, and when it was grown enough, was ploughed in also. This, as you will see, occupied the whole of one season. The next year the land was planted to corn, and it did not yield enough to pay for the seed. Why this is I do not know. But I have 
noticed that ploughing in a mass of clover stubble, which had been browsed and trampled on by the cattle, and which had reached some degree of maturity, will almost always benefit the land for the next season. I have no doubt that the acids contained in crude, immature vegetable matter are injurious to the soil, and contain no soluble salts which can in any way benefit the land. At any rate, I can't make anything out of ploughing in green crops in this part of the country, and I have never known anybody who could."

"I have heard a good deal said lately about artificial fertilizers. Cain anybody here tell us about them?" said the Schoolmaster.

" IV cll," said Mr. Hopkins, no one else seeming disposed to speak, "I suppose, as near as I can ascertain, they ought to be called stimulents rather than fertilizers. I undertook last summer to find out how far I could rely upon them in renewing some of my old worn-out ficles; and I was satisfied that they could not take the place of more bulky manures, which in themselves contain not only the humus which the soil requires, but all the chemical constituents which can be found in half a dozen artificial fertilizers combined. I learned a sreat deal about the value of guano, and the effect it had on the worn-out tobacco lands of Vircrinia, and the cotton-lands of the Gulf States. But I also learned that its effect is but temporary, and that it clid not supply the soil with those ingredients which had been taken from it by long cropping. And so of what they call superphosphates. They served in my trials, for I did use some of the most reliable, simply to stimulate for a time, and then the work was all over. And I found that in one good sliovelful of manure I had all the ammonia of guano and all the nitrogen of oil and all the soluble salts of phosphates; so I determined not to rely upon the artificial fertilizers with the expectation that 
I was to be carried by them through the season. I tried, moreover, an analysis of some of my soil, having been told that a skilful chemist could not only ascertain in what the soil is deficient, on account of the demands made by certain crops, but could also tell exactly how to supply that deficiency in exact proportion. But I found it would not work. The soil seemed to require something more than merely a condensed form of some salt, of which it had been deprived, - and that something I called humus, the inert matter of manure, which contains all the stimulating elements required by plants, and also the soil itself in which they are to take root. In my travels last summer I came upon a section of the State in which, for the sake of cultivating certain crops of a speculative value, the farmers had expended large sums of money in these commercial fertilizers. They had paid the highest market prices for guano and phosphates and fish pumice; and the result was that their farms were becoming impoverished and their crops would hardly suffice to pay for the expensive fertilizers applied to them. The agricultural experiment was a most disastrous one."

"Now, Mr. Hopkins," said William Jones, who was a constant reader of all the periodical literature of farming, "how is it that the English farmer can afford to ransack crery remote island, and dig into every mine for fertilizing material, like suano and potash, if they are so thin and feeting? An English farmer generally knows what he is about."

"So he does," replied Mr. Hopkins; "but he does not import these materials for application unaided to his land. He uses them to combine with more bulky and less active materials, in order to bring his plants forward with the more rapidity. Seldom does he use guano or potash salts alone. He resorts to straw, woody stems, leaves, weeds, beanstalks, all vegetable refuse which is prepared by fer- 
mentation in one way or another for application to the land; he uses oil-cake, the residuum of the starch-factory and the glue-factory, scraps, and the refuse of skin, hair, horn, and tendons, the refuse of the tallow-melter, shellmud from the sea-shore, and all animal excrements, and these he combines with each other, or makes them a basis for some of the imported fertilizers, to which I have alluded. Fertilization in England is almost as economically carried on as it is in Japan, and almost as thoroughly. And the English farmer exercises all his ingenuity to aroid the loss of any refuse material which, being returned to the soil, may bring forth a reward many fold in form of a profitable crop."

"And so an English merchant undertook to carry on a farm by steam, and filled the soil with iron pipes to convey liquid manure, and pumped the precious liquor over his acres with a steam-engine, and built great tanks to receive every form of decaying matter which could be dissolved and distributed. Did all this pay, too?" said the Schoolmaster, who had evidently been reading Mr. Mechi's book in addition to the regular college course, and had learned more of the farm at Tiptree than he had of his father's in New Hampshire.

"I doubt about that," replied Mr. Hopkins, who had always had the fear of Mr. Mechi before his eyes. "If such work can be carried on profitably in England, it is because labor is so cheap there that, as compared with America, it hardly enters into the account. Such an overwrought, artificial process may succeed for a time, but it must come to an end. Not one man in a thousand could conduct it eren for one day. And when Mr. Mechi pauses, I think no man can take up and carry on his work. I don't believe it pays him, and, if it does, it certainly will pay nobody else."

By this time Mr. Hopkins and the Schoolmaster had got 
a little beyond their own depth, for they began to talk about Liebigr and Boussingault; and the Schoolmaster, fresh from the laboratory at Dartmouth, was floundering about in carbonic acid and chlorine, and oxide of iron, and oxide of manganese, and alumina, until the two learned gentlemen had got very far beyond the depth of the Club, and had silenced everybody in the room but themselves.

Captain Glass, who was again a visitor in the town, and had been invited to be present, now broke in and brought matters back to their comprehensive level. "Yes," said he, "knowledge is a grood thing; it is a great thing; it's like baked halibut, - the more you eat the more you want." Nobody could deny this, and so the Club adjourned. 


\title{
ELEVENTH MEETING.
}

\author{
DRAINAGE.
}

PRESIDENT HOPKINS SPEAKS, AND TELLS HOW HE DRAINED HIS I.AND.

THE manner in which fertilizers and fertilization had been discussed at the last two meetings of the Club had brought the members to the conclusion that skill in the combination and application of the materials which abound on every hand is more important in the business of sup)plying an impoverished soil with food, and of preserving a good one, than an extravagant, indiscriminate, and costly use of many of the artificial fertilizers, which require more money than wit in those who use them. It appeared to be universally conceled that, with a fair supply of barnyard manure as a basis, most valuable composts might be made of this material, combined with muck or loam, and strengthened and extended with such condensed fertilizers as guano, fish, and bones in their original condition, secured before their cost has been increased and their value diminished by chemical combinations. The mixing of soils, too, for the purpose of rousing the latent qualities and creating new ones, was very favorably received. And it was determined, therefore, that the investigation had grone far enough for all practical purposes; and that further explanations belonged to the scientific explorer, who might pursue his experiments with the hope of arriving at some valuable fact and some new and useful law. The vital force of the soil, moreover, was not forgotten, - that force which sometimes fails when the chemical constituents 
remain, and the absence of which presents a problem to the explorer which the tests and analyses of his laboratory cannot solve.

The day after the adjoumment Mr. Howe and John Thomas met, as usual, to prepare for the next meeting. They realized fully the opinions entertained by the Club on the subject last under discussion, and they determined to let well enough alone, and take one more step in the long road of investigation upon which they had entered.

"I suggested the question of Fertilizers," said Mr. Howe, "as a proper subject to follow that of Cattle, because the two are so intimately connected, and to a certain extent the object of one is to supply the other. But I think we really ought to have considered the preparation of the soil for the reception of manures before considering the manures themselves. No doubt a great deal of labor and money is wasted on land which is unfit to bear a crop. The land may be too dry, and it may be too wet. When it is too clry, it had better be abandoned, except for crops requiring a hot, quick soil. When it is too wet, it should be thoroughly and properly drained ; for I consider stagnant water in the soil or subsoil as poisonous to vergetable life as it is to animal life; and $I$ should as soon think of finding a healthy community occupying a saturated miasmatic district, as of finding a vigorous vegetable growth in soil resting upon cold, stagnant pools. I clo not agree with some theorists, that all soils should be drained; nor do I agree with others, that soils which require drainage are the most valuable soils we have, when the water is once out of them. But many fields are so located that it is especially important to make them a productive portion of the farm; it is often very necessary that the farmer should reclaim lands lying near his homestead in order to avoid the expensive necessity of cultivating lands far removed from home. I think we had better announce Drainage as our next topic of discussion." 
"I agree with you," replied Thomas; "but there are so many wild and extravagant notions with regard to reclaiming low meadows, and tapping the springs on the hillsides, and underdraining light loams, that I am half afraid of a wild and bitter wranste over the subject; and IIeaven deliver me from another fodder-corn fight."

"But let it be Drainage," said Mr. Howe; “ and let us call on Mr. Hopkins to give us an account of the work he has already done in this direction. He has relaid old stone drains, and cleared out ditches, and planted tiles enough in his clay-ficlls, since he came into this town, to ruin an ordinary farmer. Perhaps he can tell us his experience."

And so they selected, as the next topic, Drainage, and Mr. Hopkins agreed to tell what he knew about it.

The Club assembled as usual, was called to order, the record of the last meeting was read, and the assembly settled down to listen to the statement of Mr. Itopkins, who spoke substantially as follows:-

\section{DRAINAGE.}

Gentlemen of the Club:- When I began the work of restoring this farm, to which I am so strongly attached, I realized, as the first step, the need of bringing the land immediately about my building into good condition for cultiration. I remembered how in my youth my father was compelled to select with great care the localities for his various crops, and how he was obliged to avoid for one crop the sandy knoll in the rear of the house, and for another crop the wet and springy meadow in front. I had seen grass crops lilled in one place by drought, and drowned in another when the season happened to be wet. And feeling that my most profitable lands would be those lying nearest home, I. determined to bring them into good condition as sonn as possible. I had read much on the subject of Drainage, a good deal of which commended itself to my judgment, and a 
good deal which did not. I was by no means disposed to accept the wholesale declaration so often made, that all land is too full of water and should be drained; and when I studied the elaborate accounts of the universal application of thorough drainage in England and Scotland, and saw the system recommended to us as of equal value in this country, I could not avoid observing the difference between the soil and climate of the United States and Great Britain ; and I had strong doubts whether in a somewhat porous soil, and under a bright and burning sky, it was as necessary to incur the expense of drainage, as under the almost constant rainfall of the British Islands, and on their heary clay soils. I recalled also the vast amount of time, labor, and money spent by one of my ancestors in attempting to reclaim that broad, boggy meadow lying near the outlet of Alder Brook towards the pond; and I made up my mind that I had better attend to my uplands rather than devote myself to removing the water from a bed of muck, whose tendency had always been to return to the wet and soggy condition natural to such localities, and to the wild grasses which grow there. It had been redeemed once in my day, and had returned to its original barbarism, and I concluded that I would not try that experiment again. I had also seen the same experiment fail elsewhere, and had learned in various ways that bog meadows make but poor farming land, at best. And then the great field of thirty acres lying near the source of Alder Brook, drained with stone drains, forty years ago, was, I noticed, in as bad a condition as ever, and the drains could be traced throughout its broad surface by the water-grasses winich grew all along their courses. So I became suspicious of stone drains in lands like that. But I had before me this broad level field, lying west of my house, a great bed of clay, usually unmanageable in spring, and unfit for the best farm crops. But it was near at hand, and promised to be most excellent land when thoroughly drained.

This land is, as you all know, nearly level, and in addition to the water falling upon it in form of rain and snow, it receives the drainage of a considerable extent of hillside and slope by 
which it is surrounder. The subsoil is a stiff, tenacious clay, without any strata of sand or gravel. The soil above this is a rich dark loam, from one foot to eighteen inches in depth. The field had been thoroughly and carefully cultivated in time past by some of the best farmers in this town. It was always a clifficult piece of land to till, owing to the surface water, and to its hardness in a dry season and its coldness in a wet one. some form of drainage had always been found necessary for its cultivation; and through its entire length rim a deep and wide open ditch, on each side of which the land was laid out in beds about forty feet wide, raised in the midclle as high as the plough could raise it, and divided by deep dead furrows.

This land I determined to drain with tiles, knowing it to be analogous to lands thus treated in the old country. The crop of my first year had been about a ton of hay to the acre, of a very poor quality. The land was filled with water-grasses and various aguatic weeds, and during the season to which I allude it was seldom free from stagnant surface water, collected in the hollows and dead furrows. In many portions of the field the cultivated grasses were entirely destroyed.

After the hay crop of that season was removed I ploughed the field, for the purpose of manuring and seeding again to grass, bit I found at once that such an operation would be utterly useless. The soil of a large portion was cold, stiff, and clammy, and in spite of the high manuring to which it had been subjected, it had still that slaty color which distinguishes a water-soaked earth from the rich brown of well-tilled and well-drained loam. It was evident that my manure and labor would be wasted, even in my attempt to raise a grass crop, exactly as manure and labor had previously been wasted there in the cultivation of corn and roots, on account of the disastrous effects of the water. I therefore abandoned my original plan; and as the field lies very near my barn-yard, in a convenient proximity to my manure-heap, and at such a distance from my farm-house that no time would be lost by the laborers in going to and from it, I concluded to devote it to constant cultivation; for I have always found that a farmer camnot 
afford to transport manure to the distant fields of his farm, while his grass lands lie at his threshold; neither can he afford to employ his laborers in long journeys from their meals to their libor.

The operation of draining the field began in Jecember. The open ditch was first cleared to a depth, at the head, of three feet, and sinking five feet eight inches at the outlet. In no place was the fall less than three inches in one hundred feet. Having thus prepared the ditch for the laying of the main drain, I directed sicle drains to be dug running at right angles with the main, begimning at a depth of two and one half feet and running to the depth required at the junction with the main. The side drains were about thirty feet from each other.

When the ditches were laid open throughout the field, I began at the upper portion to lay the tiles, taking care to keep the laying of the laterals and the main uniformly funished, as I advanced in the work. The main drain consists of two rows of four-inch tile laid contiguously. 'The laterals consist of two-inch tiles. I used mostly sole-tiles, and the chrains were filled as fast as the tiles were laid. The joints of the tiles.were snugly covered with wisps of meadow hay, laid compactly orer them, and the earth was packed as closely as possible around the tile throughout its entire length.

And now, having described the process, I desire to give the result. This field, which had long been almost incapable of cultivation, which was always flooded in the spring, and purched in dry, hot seasons, which was disfigured by an open ditch and by ridges and dead furrows, which had been for half a century a reproach to the adopted system of farming, began at once to improve in condition and appearance. Fren cluring the winter in which the drainage was completed the water was carried off from it in a way never known before ; and although it was by no means brought into perfect condition, still the ploughing the next spring and the cultivation during the next season were very materially improved over previous years. And, as you are well aware, my crops of corn and mangolds on that field were the admiration of you all cluring the last season. 
Since I began this business of thorough drainate I have often been asked whether it is profitable. 'This elepends rery' much on the location and quality of the land. Upon the location: the field which I have clescribed to you lies, as I have said, in one of the most convenient localities of my farm, and in almost indispensable to an ecomomical production of the crops s I need. I have other land lying near, but it is so occupied, or so broken by hills, that cultivation is either difficult or imposible. Here was a field, unoccupied, at my very door, almost useless, unfit for grain or roots, and unable to bear grass of a good quality and large quantity, for even a short series of years. It is a bed of clay, upholding a guality of soil which only required warmth and dryness a become highly fertile. Sicience and the experience of others taught me that such a substoil, once disintegrated, would become of the highest value for tillage, that droughts would not parch the crops, and that, in its bed, the growing plants would find an aloundance of nourishment. The superficial cultivation which it had received had produced no permanent benefit. The mante of fity seasons had increased the depth of the soil, but had not served to warm it. There it lay in that solid basin of cliy, inoperative, lifeless, and continually borne away by the streams which ran along the dead furrows and down the great open canal, into the highway, for the benefit of no man. I found that the expense of ploughing such land was too great. The open ditch was am obstacle, and the beds were troublesome. The process of ploughing wats slow and heavy, and the result was often attended with great uncertainty. A good farmer, who had once cultivated the field, said to me: "If I ploughed that field too early in the spring, I lost my crop; if I ploughed it too late, I could do nothing with it."

Now, without entering into a precise calculation of the return I have received for my investment in chraining, it is very easy to see that the crop of the present year alone, increased as it has been by the draining, would go far towards my remuneration. I have now a good field, whereas I formerly had a poor one. And it is hardly necessary to demonstrate to any farmer, that 
any reasonable expenditure for such a purpose and with such a result is not an extravagant or unprofitable outlay.

I would not be understood as saying that an indiscriminate application of thorough drainage to all soils is to be recommended. There are soils which do not require drainage. Heavy clay soils are a bane to the farmer without it, - a blessing with it. There is a large quantity of what is called cold, springy land, - land in which the water percolating from the hillsicles is caught and held, and in which the springs thus fed

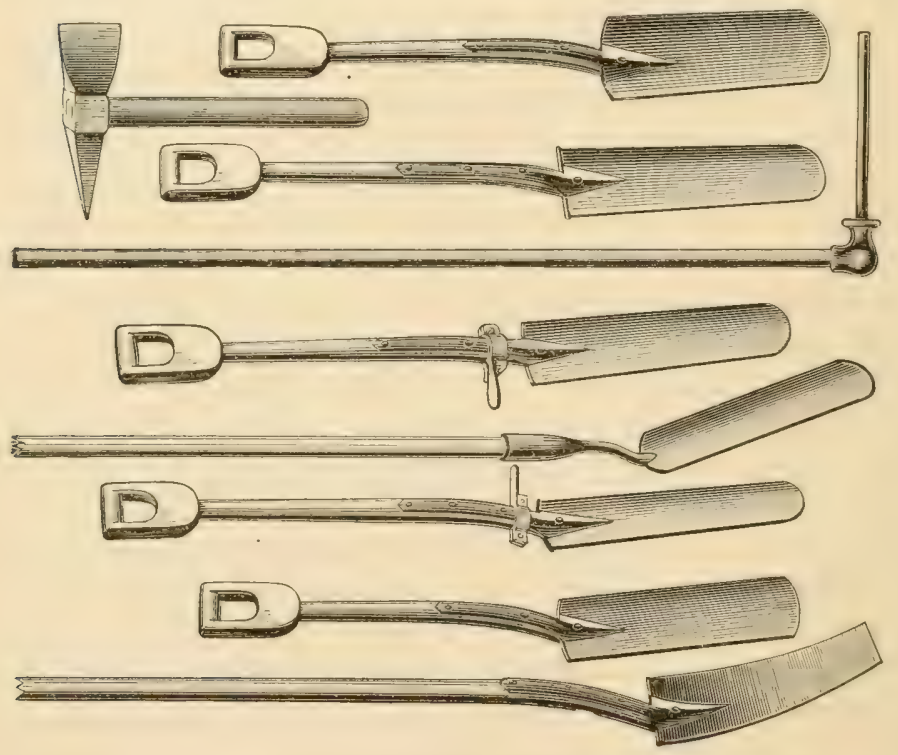

TOOLS FOR DRAINAGE.

are constantly seeking an outlet on the surface, for the want of any other mode of escape, - which would be made highly valuable by thorough drainage. I know many acres in this town, composed of a thin layer of loam and humus, upon a shallow bed of clay, beneath which is found a deep stratum of gravel. The clay is so tenacious that a great portion of the surface water never penetrates into the gravel filter beneath, but lies stagnant 
on the level places and flows down the slopes so that the valleys are constantly inundated. They yield but little, and they need only thorough drainage to become warm and fertile. Swamp lands require a different mode of drainage ; and although some may differ from me, I doubt if thorough drainage is applicalble to such land. A swamp is ustally composed of a collection of decayed vegetable matter, of greater or less depth, occupying what may once have been the bed of a lake or pond. 'Through it or from it usually flows a stream, and the land itself may amost be said to be afloat. The subsoil is very often below the reach of any ditching. The level of the water may be governed by the outlet. In its natural condition, the water is usually almost as high as the level of the land. 'This level of the water may be reduced in proportion to the fall which can be provicled at the outlet by digging, - seldom more than two or three feet below the surface of the

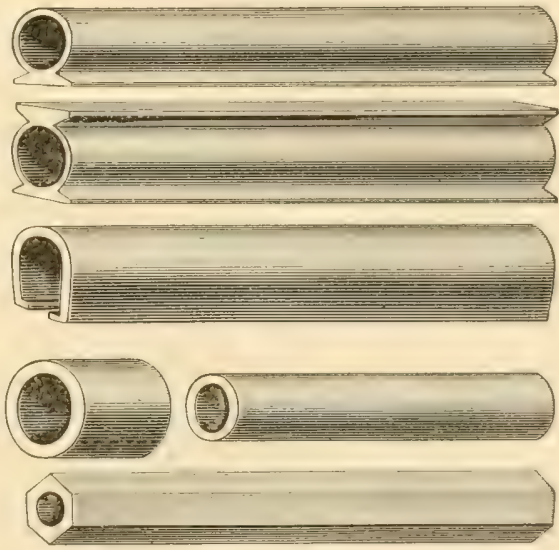

DRAIN-TILE.

\section{soil. If, therefore, by}

a proper arrangement of open ditches and a sufficient outlet, the water is caught as it flows from the hillsides and is conducted away from the swamp, you will have just as many feet in depth of a porous, peaty soil as you have reduced the level of the water; no more, perhaps less, on account of the settling of the swamp as the water is drawn off. This soil, composing islands, so to speak, between the open ditches in which the water stands, never loses its porosity; and it usually requires some application of gravel or sand or loam upon its surface, to bring it into condition for cultivation. It has no surface water, and it has no 
subsoil that has been reached. It is in reality arriculture afloat, and it must remain afloat so long as the reservoir if water beneath it is supplied and not emptied. I do not think tiles or blind drains in any form are applicable to such land; for I consider a firm subsoil as almost indispensable to the proper use of tiles, nut only on account of the solid basis upon which they ought to lie, but on account of their capacity for discharging water. I have found many a stone drain sunk in the swamps on my farm, carrying down many a dollar with them. If such spots are to be drained at all, let it be done as the Venetians drained the lagunes upon which they built their city, -.- by canals and not by sewers.

I am frequently told that the purchase of tiles is an unnecessary expense, inasmuch as nature has provided most of our farmers with materials for clraining close at hand, in the stones of their fields, and that they can be made to answer the purpose of tiles themselves. I am aware that it is a good plan to bury the stones which interfere with cultivation. But I doubt the economy of endeavoring to convert them into drains, except for the purpose of constructing a large free water-pas. sage, tapping a copious spring, or furnishing a culvert for it rapid stream. I should never expect to thorough-drain with stones; and I should consider it a misfortume to find enough in my land to tempt me to use them. Stone drains cannot be constructed as economically as tile drains. They require vastly more digging, and they are bulky and heavy to transport. They camnot be laid so as to prevent the particles of carth from entering their crevices; and their walls offer retreats for moles and mice too comfortable to be neglected. Owing to their liability to be obstructed, they are not permanent; and, except as conductors for rapid streams, I loubt if they are ever effectual. In the fields which I have described there are 7,562 feet of drains. The work required six men sixteen working-days. Let any one compute how long a time it would have taken to haul stones enough for these drains, even had they lain immediately about the field, and he will be able then to judge of the comparative economy of the two systems. And 
considering the character of the soil and the level of the field, I have no doubt that stone drains would have, ere this, been inoperative. I doubt if clay-beds can be drained by any such method. I have in my mind a beautiful meadow, which was drained, nearly thirty years ago, with stone drains, and brought for a time into fine grass land, but which is now rapidly returning to its original aquatic regetation. The drains are evidently obstructed. The work is evidently a failure. And why?

In answering this question I am brought to the consideration of a point frequently brought forward in all discussions upon thorough drainage with tiles. Place a tile in the hands of any man, or show him a tile drain laid and reacly for covering, and he will almost invariably ask you how the water enters the pipe. We are told that five hundred times as much water enters a drain at the crevices or joints as through the pores of the tile. This may be so. But one thing should be remembered,-- that no crevice should be large enough to admit particles of earth with the water, if the water-passage is to be kept free from obstruction. The great advantage of tiles over stones is that they strain the water out of the soil without admitting any earthy particles along with it, - an operation impossible in a stone drain; and unless the crevices or joints are close enough to perform this duty the drain must be a failure. Now, take any number of feet of two-inch pipe properly laid, with the joints carefully adjusted, and the space occupied by the crevices is rery small in comparison with the cubic inches of the bore. Yet from this pipe will be discharged at times a stream of its full capacity. Would not crevices large enough to admit this volume of water endanger the drain? I have no doubt that tiles act as strainers all along their course. The insinuating power of water in the soil is well known. It pursues its course in obedience to the laws of gravitation with a persistency almost unequalled. The clrop that falls upon a hillside begins at once a journey to its level, and nothing can stop it. No soil is so hard that the hidden vein may not be discovered, windins its way through it on its mysterious errand. It seeks the current that is to be.r. it on in the 
great circuit of the waters. The porous pipe which you lay in the earth becom-s at once a channel towards which the surrounding waters tend. The pressure is on every side. The law which propelled that drop towards myriads of capillary tubes, with an irresistible force, enables it to enter through the minutest passage into this artificial pathway, distilled, perhaps, but nevertheless driven there, as the fluids circulate through every living thing, animal or vegetable, not by visible tubes alone, but by chamnels which the microscope can hardly trace or discover. May not the very philosophy of tile-clraining with its strange success consist in this: that on every square inch of its surface are multituks of orifices draining the water aw from the adjacent soil and acting as outlets for the porous earth as the water is distilled away from it? Else how is a tile drain so much more effectual than any other drain ever invented? Crevices and joints do not account for this.

And now a few words with regard to the distance at which the side drains leading into the main should be laid from each other. It is impossible to fix any definite rule for this. But in land like my own where the clay is very stiff, and the accumulation of surface water very great, I think twenty-five feet would be a fair and economical rule to adopt. Thirty-five feet is the rule elsewhere. But as the rains in our country are very copious, and the work of relieving the soil of water is very greit. our drains should undoubtedly be more frequent than in a climate where rains are more after the order of a drizzle.

Next in order after the distance to be adopted between the drains comes the depth at which they should be laid. It is evidently indispensable that they should be laid below the reach of frost. Beyond this, opinions differ materially. It is now generally conceded, however, that deep drains work the best, discharge the most water, and most quickly and thoroughly drain the land in winter and spring. I think in this climate they shruld be laid at least three feet deep, and that when they are laid over five feet they lose a portion of their efficiency.

I trust that you will not forget that thorough drainage does not belong to pioneer farming. It is no part of the work of 
clearing the forests and expeiling the wild beasts. Neither dots it belong to what is called fancy farming alone. Every man in the region of this town and county, who cin afford to keep his farm through care and industry and thrift, can just as well afford to drain a portion of it as he can afforel to fence amel manure it. If he can afford to do the one, he can afford to do the other. If he applies his industry to one, he can better apply it to the other. For he may build the most substantial walls around fields loaded with manure, and yet find himself enclosing nothing but "vexation of spirit" and a reproatch to all his labor, because he has fated to lay the foundation of his agriculture on a well-drained soil. Every mechanic who oms his cottage and a few adjoining acres will do well to begin at the bottom of his soil if he hopes to reap the reward of the farming which he snatches from the bench and the workshop.

I have dwelt long on the subject of drainage, because it is really the fundamental business of arriculture, wherever special farming is accurately and profital)ly pursued. And I shall feel that I have done my duty faithfully and effectually, if I have laid down any rules or related any experience which will guide you in this important and intricate work.

The discourse of Mr. Hopkins, long and elaborate beyond the usual patience of the Club, was listened to with profound interest by a large majority of the members. Here and there one manifested a desire to enlarge upon the merits of stone drains and the value of reclaimed boss. But the general feelin was against him; and Mr. Hopkins found himself the undisputed master of the situation, at this time at least.

Dr. Parker and the Schoolmaster had listened attentively, - but evidently unconscious at times of the course of the argument. They knew enough, however, to go home when the Club adjourned, and not to linger together before Mr. Hopkins's glowing fire. And so the discussion of Drainage ended. 


\section{TWELFTH MEETING.}

\section{THE HAY CROP.}

THE TRIALS OF THE SCHOOLMASTER AND CLARA BELL. - IMAGINARY TRIALS THE MOST DIFFICULT TO OVERCOME. - MR. HOPKINS DELIVERS A LECTURE ON THE HAY CROP.

\section{THE schoolmaster could stand it no longer. He had now} reached the third week of his school, and he had never known three such weeks of dull, heavy, unalleviated toil. Jotham seemed to have changed in a twelvemonth from a cheerful, lively, sumny village to as gloomy and uninteresting a spot as could well be conceived of. Not that the various amusements and entertainments of the town had ceased, but that an impenetrable cloud seemed to hang over the whole scene, business and pleasure, church and school-house, club and post-office alike. John Thomas and Huldah had the same pleasant fireside, and there the Schoolmaster was always welcome. Mr. and Mrs. Howe were as bright and hospitalsle as ever, and managed, even on the small income of a country pastor in a small village, to get possession of every last new book of importance, and to learn the last bright thought, wafted to their receptive home as it were on the wings of the wind. Peter Ilsley had abated none of his sharp, genuine, somewhat rough wit and good sense; and sitting in his warm and ample kitchen, the Schoolmaster always felt as if he were moving among the familiar scenes of his own rural home. The sparks flew as brightly as ever from Phineas Barnes's forge, and Charles Ingalls found the same vigorous discussion going on in the old shop, that he had listened to with 
so much pleasure the previous winter. IVilliam Jones's horses were as proud and powerful as ever, and Charles rejoiced always when the rosy-cheeked and rich-roiced Jehu of Jotham took him into his sleigh, to whirl him over the snowy road to the school-house. Mr. Hopkins was unusually genial. The atmosphere of his native town had given him an air of renewed youth; and it really seemed as if he were ten years younger and twenty years more elastic and vigorous than he was when he left the cares of the city. Jim Bell was always at his mill, cheery and whistling, and chatty and dusty, ever ready to receive a visitor, and contented to listen hour after hour to the rumbling of his water-wheel and the grinding of his millstones. But Charles imagined he saw an air of mystery in the countenances of all these old friends ; and because they did not allude, innocently enough, no cloubt, to the subject nearest his heart, he worked himself into the belief that they were all combined against him, and were cruelly determined to blast the sweetest hopes of his life. Never were innocent people more thoroughly misunderstond. They knew no more about the (leep workings of the Schor)lmaster's heart than they did of the mysteries of Eleusis, of which they had not even heard. And they began at last to wonder what shadow had fallen upon their once unclouded teacher, and what uncasy demon had taken possession of him, once so elastic and agreeable and enlivening. Casually, and without any thought, the grocer called the attention of Dr. Parker to Charles's dreamy air, as they were about discussing a grlass of grin together in the remotest corner of the back office, - the Doctor and the grocer; and Dr. Parker suddenly set down his gin untasted, remarking, as he left the secluded spot, that "the Schoolmaster had an unbounded ambition, - enough for a dozen governors and half a dozen senators." Susan Grimes, a spinster of fifty, who took an interest in all the 
voung men, and watched with something more than, and very different from, a mother's interest, all the young women, said he was desperately in love with somebody, and she knew it. Clara Bell said nothing. She only wondered why Charles seemed to avoid her. She thought he must be angry with her for not having written to him as he had desired when he left her; but then what conld she, occupied by all the perplexities which Dr. Parker had woven around her, write to him who seemed to her to have no place in any spot which the Doctor claimed to occupy? She recalled the days spent by her under his tuition, and the day when they parted, and she realized a certain golden light around those hours, and a sort of morning cheerfulness which she could not entirely understand. She knew she herself had changed since that midnight drive from the seaside, and she began to believe that everybody knew it also, as well as she did. And although no allusion had ever been made to the events of that night, or to Dr. Parker, except with a significant look, which was intended to carry the idea of a thorough knowledge of all the sweet bonds between herself and him, she could not remove from her mind the thought that the whole village, Charles included, maintained a charitable silence with regard to that wretched drive, out of regard for her own feelings. She was but a young girl, too, and she supposed that such as she could not possibly occupy any place in the thoughts of great and busy village physicians, and the foremost scholars of great and distinguished universities; how little did she know of the heart of man, and who will take up her abode there in spite of him, and when he least knows it. She did not exactly understand herself nor anybody else, as it would appear. She had never thought of loving Dr. Parker, luut she somehow felt that he had a right of possession in her which she supposed she must submit to and recognize, a feeling which 10 misconduct of his had 
in any degree removed. She had never thought of being obedient to Charles Ingalls, nor dependent upon him even when his absence weighed upon her, and his presence was a joy to her, and the sudden thought of him would startle her with a thrilling emotion which she did not comprehend. Dr. Parker's conduct towards her had never changed. Before that summer excursion, it was a mixture of father and lover, and afterwards it was exactly the same. He never seemed to go out of his way to seek her companionship, but he met her everywhere with an unruffled air of divine right, and with an apparent consciousness of a kind of matter-of-course relation between them, which no fortunate circumstances could ever inflame, and which no irregularities could ever destroy. He loved her, and loved her with a depth of affection which he could not express, and dared not recognize, and felt bound to conceal, and which, after his wicked display of gross and unmanly selfindulgence, he had conscientiously endeavored to forget. And so the people of the village, and Dr. Parker, and Charles Ingalls, and Clara were all enveloped in a cloud, because not one of them knew apparently anything about another, or himself, beyond the events and emotions which made up the ordinary village life. The people, and calm Dr. Parker, and unconscious Clara might stand it, but the Schoolmaster could stand it no longer.

There are no problems so difficult to solve as those of our own creation. No combination and network of trouble and difficulty can be so intricate and so involved that the natural events of passing time will not solve and unravel them, and evolve all the right and justice which may for a time be buried and conccaled. It is we ourselves who, in the trying hour, ask the unanswerable questions. It is we ourselves who create the insurmountable obstacle. We too often beat against bars of our own construction ; and in our blindness and passion and anxiety we wear ourselves out 
against imaginary obstacles, which vanish at last before the actual reality when it becomes fairly presented and understood. So it was with Charles Ingalls the schoolmaster. His case was simple enough, but he had a thousand misgivings and doubts and fears, a thousand plans, a thousand expedients for securing his own peace and happiness, made necessary by his own imagination, and all weak and futile as compared with the power of strong faith, and manly assertion, and unflinching and unwavering endeavor. If he had told Clara Bell that he loved her, and had there left the matter, she would have found it out, and Dr. Parker would have found it out, and the people would have found it out; and then Clara Bell would have understood herself, and Dr. Parker would have become conscious of his situation, and would have retired, and all the people would have said amen, and to Charles Ingalls the way of life would have been open. But this is never done. Common-sense seldom lays out the road which is travelled by love. And he who is wise as a teacher, and a farmer, and a lawyer, and a merchant, and a minister, and a citizen, and calmly and sensibly disposes of the business obstacles of life, loses himself and is hopeessly entangled in that gentler service, which demands more faith, and more generous impulse, and keener insight than all other duties and designs of life. The field in which the Schoolmaster worked was not a broad onc, it is true, but its difficulties were just as great as if it had been broader. And he turned now to the church choir, now to the charm of a social evening party, now to the Club, and now to the hour when, in the natural order of boarding round, he might find himself domiciled in the family of Jim Bell, for an opportunity to restore the old light and joy which he had found in Jotham, to bless himself and to deliver a young life from the hell of being bound to a being so fixed, mature, and immovable, that all the power 
of gentle influences is lost, and obedience takes the place of love.

While this drama was groing on in the mind of Charles Ingalls, and he was toiling and struggrling with a desperate determination, which would have amazed his friculs and neighbors who looked at matters just as they were, could they have entered into his mind and heart, it is not to be supposed that the work of Jotham was in any way suspended. The farming and preaching and discussing and manufacturing went on as usual, and so (did the Club. And with a cool deliberation, amazing to the perturbed Schoolmaster, the committee met, selected the sulject for the next meeting, and urged a full and punctual attendance on all, Dr. Parker and the Schoolmaster included.

Glad was Mr. Hopkins when the members of the Club assembled at his house on that cold and hard December evening, and carried him back to the associations of the summer time and its most delightful arocations, by discussing the best mode of raising and curing

\section{THE HAY CROP.}

In opening the discussion, Mr. President Hopkins remarked that the importance and value of the hay crop would lead him into a consideration of the various modes of cutting and curing hay, leaving it for others to give their views with regard to preparing and seeding down the land, and the best time of year in which to do this, questions upon which he freely confessed that he was undecidec.

The best grasses known to us are undoubtedly timothy or herds-grass and redtop. (lover serves as a good introduction to better grasses, on land just laid down, nothing more. There are heary clay lands in some parts of the town, where redtop never appears, or at any rate never reaches maturity, even if 
the seed be carefully sown. On the lighter lands it is one of the most useful and beautiful of our grasses. Herds-grass or timothy is, however, our leading grass, - that grass which yields the largest burden of good hay on well-cultivated lands, and furnishes, when well cured, the best fodder for our cattle and horses.

It is very important, therefore, that we should ascertain, so far as may be, the best time for cutting and the best mode of curing this valuable grass, so that it may furnish the feeder with the largest amount of nourishment for his animals. I am not now considering the kind of hay which will make the most milk, or is best adapted to calves, colts, and young stock

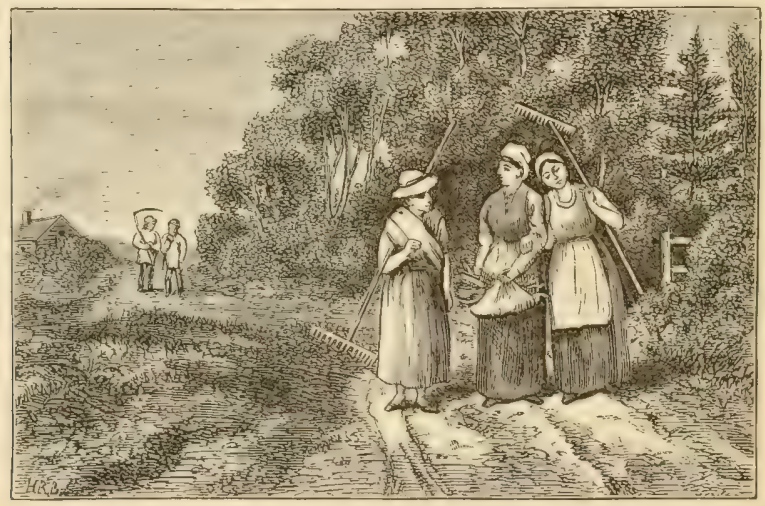

THE HAYMAKERS.

generally, or will be the permanent food of sheep. We clesire to learn, if possible, that condition of herds-grass hay which will supply the largest amount of those elements which make animal fibre, fat, bones, and muscle.

I do not think that hay which, when cured, bears a resemblance to rowen will do this. I have no doubt that animals fed on hay of this description will thrive well, especially when lavishly fed on it. I have do doubt that cattle fed on such hay have a larger reserved capacity for consuming corn and other grain than when fed on hay of a maturer quality. The capacity 
of cattle for consuming rowen seems to be unlimited. And it is generally understood that it is not a profitable or an economical kind of hay to feed; and that it requires a liberal supply of grain when it is used, if it ever is, in the business of stallfeeding.

The great object of the feeder should be to have his hay in such condition as to be able to avoid the necessity for an excessive amount of grain. The hay "that spends the best" is the most valuable. A hundred-weight of hay which will produce as much fat with a bushel of corn meal as a hundredweight of hay of different quality will with two bushels, is certainly the more profitable for the farmer, whether he feeds his animals for labor or fat. This no one will deny. That hay, moreover, which shrinks the least after cutting, and at the same time retains all its nutritive qualities, is the most profitable and desirable to all who would make the most of their hay crops.

I think there is a period in the growth of herds-grass when it reaches its maximum in this respect; when it contains all the nutritive elements it is capable of supplying the animal which consumes it. But this is not when it is half grown; when the head is half formed; when it has no well-organized fibre to give it strength and consistency. It is not when it is in blossom. For at both these periods it is deficient in starch and sugar and gluten, the most important of its nutritive elements; and it abounds with water. It is in fact immature, and is in the condition of any other plant or any root or fruit which is half grown and half organized.

I do not mean to contend that grass should be ripe before it is cut, for the change which takes place in the stalk of all grasses which bear seeds or grain when the seed becomes mature and fit for reproduction is such as to deprive it of a large portion of its nutritive elements, and to leave a large preponderance of woody, indigestible matter. The plant has then reached a period when its decay begins, and when its value consists very much in the seed which it has borne.

There is a period, however, when the seed is fully formed, and is yet "in the milk," as it is termed, during which grasses 
contain more nourishment, including that found in the stalk, leaves, and seeds, than at any other. This is the time when I think grass ought to be cut. It has then "more heart in it," to use a common farming expression; not only is the grass itself more thoroughly organized, but the seed, also, which in well-grown herds-grass is abundant, contains a large amount of nourishment, being equal in this respeet to grain of any kind, weight for weight. Experience has taught me that grass cut at this period of its growth, and properly cured, makes hay of the highest quality. Cattle that have been fatted with the smallest expense for grain have been fed on such hay. I have seen horses, performing constant service, in good, hard, muscular working condition, as if supplied with corn, fed on such hay alone.

I am aware that much of our grass stands too long, especially on large farms, where a great amount of hay is to be cut. This may render it necessary in some cases to begin cutting the grass before it is in proper condition. But eren in such cases it is not the earliest cut nor the latest which is the best. It is that which, when cured, has neither the succulent weakness of rowen, nor the hard and woody fibre of straw; but that which has the firmmess and consistency and color and quality which all m n understand, who know by necessary experience and observation what is the most nutritious and economical hay which they can purchase in the market.

I have not alluded to the commercial value of the hay crop, because I am aware that many of the comparisons instituted between it and the cotton, tobacco, and other staple crops of the country are entirely out of place: When hay is made an article of sale, and is shipped from the farm to a market, it is done at the expense of the locality in which it is cultivated. The most profitable mode of using this great crop is to consume it on the farm where it grows, constituting, as it does, the material from which the vital force of the farm is to be constantly renewed and retained. It is incleed the fuel used to move the machinery, and when it is withdrawn or exhausted the machinery must suffer. In a few fortunate localities, as on 
the seaboard, where kelp and other sea manure can le found in abundance, hay can be raised and sold ats a marlietalule cropl) : but not where the farmer depends upon his cattle for the fertilization of his farm. I wish it were otherwise. But not until the ingenuity of man has invented some conclensed fertiliser cipalble of taking the place of the natural manures, and comonically supplied, can we hope to convert our interior farms into hay farms for supplying the market. I trust this state of affaris will one day arrive. There are many valuable tracts of land lying in regions remote from railway communication which could be converted into profitable grass lands by the use of such a fertilizing material as I have alluded to. And I have no cloubt that the increasing demand for hay in all our large towns and cities, - a demand which increases more rapidly than the supply, - will render the restoration of these deserted lands absolutely necessary.

With these general remarks, I present the question for discussion, with the hope that the best method of seedling grass lands will receive the early and thorough investigation to which its importance entitles it.

John Thomas, being called upon by the Chair, no one indicating a readiness to speak, said :

I have for a long time been deeply interested in the growing of grass as a farm crop. I am not satisfied to cut from my ficlds a scanty supply, and am entirely unwilling to truvel over a large surface to get what hay ought to grow on a small one. I have read in one of Flint's reports a rery good collection of opinions from practical firmers on the subject of seeding wrass lands, and they agree so generally with my own, as drawn from experience on my farm, that I desire especially to read the passage to the Club.

"More than sixty years ago," the author says, "careful experiments were made in this State in hope of obtaining such information as would settle the question as to the best time of sowing grass-seed, and the practice of seeding down in the fall was then begum by a few individuals. At and before that time 
the practice of sowing in the spring was universal, and the same custom has very generally prevailed till within a very few years. Both the practice and opinion of the best practical farmers among us have changed to a considerable extent, and it is now commonly thought best to sow grass-seed in the fall, early in September if possible, mixing no grain or anything else with it, thou'h there are and always will be some cases where the practice of sowing in the spriig with grain is convenient and judicious. There can be no doubt that it is in most cases an injury to both crops to sow them together." I can hardly agree with this; for I have been very successful in seeding down land which had long been under the plough in the spring, using barley as the grain with which to sow my grass-seed. "The following statement of an expericnced and successful farmer will enable us to comprehend how the change was brought about, though others had tried the experiment long before him: 'More than twenty years ago we had several dry summers, in the springs of which I had sown grass-seed with rye, barley, and sometimes wheat, and lost most of my seed by the drought. I could scrape it up, the plants being dead and dry when small. Since that time I have universally ploughed after haying, and sowed timothy grass and redtop.'

"Other farmers probably experienced the same difficulty and came to the same conclusion. Our seasons differ greatly, to be sure, but it is now well understond that we must calculate on a drought in some part of the summer, and grass will suffer more from drought than from frost. Hence the propriety of fall sowing. There are some localities, undoubtedly, where spring sowing with grain is best, on the whole, as in the southeastern sections of the State, along the coast, where, on account of the proximity of the sea, the ground is often but slightly covered and protected with snow; yet, even there, some f.rmers say it is better to seed in August and September. Few general rules are of universal application in agriculture, and the farmer must carefully exercise sound judgment and common-sense. One practical farmer in Essex, in answer to our circular, says: 'I prefer August, because I think it less liable to winter-kill than to 
summer-kill. And another greater reason is that in fall secling I get rid of a crop of weeds, while in spring seeding my wround is seeded with them.' In experienced farmer of Hampshire writes: 'I rather prefer the last week in August for seeding rown land. The reason is that we frequently hate a summer drought which kills out the young grass.' ()ne of the best farmers in Micldlesex says: "When sown alone, I prefer from the zoth of August to the zoth of September. If sown sooner, the summer droughts are apt to injure the young blackes; if later, they do not have a chance to expand and arrive at that degree of maturity necessary for a good crop the ensuing season.' He says, also, that if in any case it is found necessiary to sow with grain, it should be in the spring and not in the fall. An experienced practical famer in Fssex County recommends "the latter part of August and the month of September for seeding down grass lind for mowing, unless that season be very dry ; in that case sow as soon after rain as may be. I do not think it advisable to sow grass-seed when the earth is very dry, as some of it may, by the moisture brought up in preparing the land, sprout, but not having continued moisture to support it will wither away, while some of the lighter seeds will, perhaps, swell by the moisture, but fail to sprout by a lack of nourishment, and consequently perish, while others will be blown away by the winds. The plant from seed sown in August and September, if the season is moist, will take deep root and be able to withstand the changes of weather in winter. Grass-seed sown with grain in the spring is liable to be killed in the hot days of July and August, about the time of cutting the grain, particularly on light, sandy, or gravelly lands. Clover should be sown in the spring, as soon as convenient after the frost is out of the ground, on land seeded down the preceding autumn, probably, rather than sooner in the autumn, as the winter is too severe for the tender roots. I have found March to be the best time for sowing clover-seed on those lands. I always sow on a light fall of snow in that month if there is one.' A farmer of Worcester County says: 'On moist land I prefer to turn over the greensward after laying with a 
Michigin plough, and seed in August, after spreading on a coat of manure to give the grass an early start.' A farmer of Franklin County writes: 'I consider the month of August as the best time to seed down land for mowing, with the exception of clover, and that I seed early in the spring:' Another from Hamplen: "I think Ausust or the early part of September is the hest time to seed down grass land, as in the fall of the year it will get root and not be burned up by the sun as it would be in the spring.' Another says: 'I sow from the middle of August to the midclle of september. If sown in spring with oats or other grim, the young grass is liable to be summer killed, either choked by the ranker growth of the grain, or scorched by the hot sun when the grain is taken off. If sown in spring without grain there is one season lost. This I never do unless I want my crop to be checked hopelessly by weeds.' A farmer on the Connecticut River states that 'if the season is not too dry, August is a good month to seed for mowing. I have had very good success in seeding with turnips or grass-seed alone, in August and September, to mow the next year; but the usual practice here is to seed with wheat or rye in September or October. Some seed in spring with oats, but generally it does not do well. Clover is more often sown in the spring, because it winter-kills.' A very successful farmer in Berkshire arlvises August or September. 'I have sown in October with good success. Seed sown in August obtains more root than when sown later, and consequently is not as liable to winter-kill. It also starts earlier the next spring, thereby keeping down the weeds. Much of our moist meadow land, too wet for hoed crops, and producing but light crops of grass, and that of an inferior quality, may be made to produce well by ploughing and seeding. Let it be ploughed deep in August or September, the surface well harrowed, and covered with a light coat of compost, ashes, or barn-yard manure, and seeded, and the next year the crop will pay all expense.' But, on the other hand, a practical farmer on the island of Martha's Vineyard says: 'I prefer seeding down land designed for mowing in April, for the reason that if sown in March the ground becomes so compact from the 
effect of heary rains that the seed clues not come up well, and if sown in August or September the grass does not attain that degree of miturity to enable it to withstand the frecuent freezing and thawing of the succeeling winter. We have usually but little snow to protect the young grass on this island. The objection to sowing grass-seed after linglish harrest will not probably apply to those places where the winters are less changable.' Another says: 'I have sown grass-seed in the months of March, April, Iay, August, September, and October. (On a rich, compact, retentive soil, seed has done well sown in April or May, but I prefer to seed my land of any description in August, or on a light snow in March. My reason is, that when I have seeded my ground in the spring, I have sown rye or oats with the grass-seed generally; if not, a crop of weeds would come up and usurp the plitee of the grasses and cholie the'm out, and a hot, dry July and August would exterminate what escaped the oats and weeds." ",

I have read this statement, wentlemen, because it gives the views of many practical farmers who are evidently interested in the question and hare experience in the work of raising grass crops. I wish they had been a little more definite; but still they are of great ralue. For myself, I prefer cultivating a piece of land with hoed crops three years after it is broken up, planting it to corn the last of the three years, and seeding it down the next spring with barley and grass-seed as early as the land and weather will permit. In this way I can clean my land of weeds, fill it with manure, subject it to proper manipulation, and succeed in the end in getting a firmer sod and a longer succession of grass crops than in any other way. I pursue this course always on warm, strong, loamy lands, from which I am almost sure to get a good hoed crop, - a crop of corn or potatoes or roots. My heary clay lands I plough, manure, and seed in August, as recommended by so many farmers whose statements I have read: but I am obliged to plough and sted again after this process sonner than I am where I aclopt the first one I have named. I never undertake to lay down my lands after a potato or a turnip crop. I can never get a good 
set of grass after either of these crops. Corn is the best crop, so far as my experience goes, to follow with grass. Give me good corn land, plenty of manure, barley to sow my grass-seed with, and I am almost certain of getting my land well laid down, and of getting a good crop for many years, unless I fall-feed it too heavily, or it is injured by drought or frost.

When John Thomas concluded, there were many who manifested a desire to speak; but the hour was late, and Mr. Hopkins announced that the subject would be continued at the next meeting. The members departed, leaving Mr. Howe and the Schoolmaster chatting with the President, who had lighted his cigar and had settled down for a talk. The absence of Dr. Parker was alluded to, and the two elderly gentlemen grew suddenly silent and mysterious. Charles Ingalls was bewildered again, fell into a brown-study, sat awhile, and then followed the rest. His companions remained to discuss Dr. Parker and Clara Bell, whose name he heard mentioned before he had closed the door. Ite derived little peace from that assembly; his walk home was gloomy and his night restless. 


\section{THIRTEENTH MEETING.}

\section{THE HAY CROP (Continued).}

SEEDING GRASS LANDS. - PETER ILSLEY DEBATES AND WANDERS. - DR. PARKER LOSES HIS TEMPER.

THE surface of Jotham was as smooth and unruffled as a glassy summer sea. Even the conversational monutone of a New England village was unbroken; the muscular repose which marks the countenance of the typical Ancrican was undisturbed the non-committal custom of answering one question by asking another was faithfully observed, and no one could have discovered by any outward manifestation that, within that placid suciety and in the simplicity of that rural people, the deep, hot mysteries of the human heart were rasing and glowing. And so, at the appointed hour, the members of the Farm-yard Club assembled at Mr. IIopkins's to continue the discussion on the Hay Crop.

I'resiclent Hopkins announced that the important (juestions of what grasses to select, how to seed down the land, the best time to cut srass, had already been thoroughly considered; and he felt confident that the views advanced on these points at the last meeting would be found to be advantageous to all who would apply them. Ife looked upon the amount of seed to be used, the selection of annual and perennial grasses, and the best method of making hay, as also questions of vital importance to the farmer; and he hoped they would be carefully discussed by the Club.

Mr. Howe expressed the opinion that on most lands a 
liberal use of seed was desirable. "I have examined many theories," said he, " and I find none better than that based on the practice of the best farmers $I$ have known in this section of the State. The object of seeding should be to occupy the land entirely with the crop of grass which you propose to raise. If the grass-seed is sown in the spring with barley, this grain will aid very materially in preventing the growth of weeds, which are liable to spring up in the carly summer months, and will also protect the tender grass through the hot months of July and August. But if grass-seed is sown in the autumn, the entire work of occupying the land so as to prevent the growing of the weeds will fall upon the grass alone. Whether, therefore, you sow in the spring with grain, and desire to prevent the great growth of weeds, or sow in the autumn and wish to provide against the injury from frost in winter, I think it best to use an abundant supply of seed. There is but little danger of the plants choking each other; and I am not sure that the stalks of grass, ilie the trees in the forest, do not protect each other. Good land, moreover, land in excellent tilth and well manured (and no other should be seeded to grass), requires a thick growth of plants in order to produce the largest crop of which it is capable. I should say, therefore, for the hay crop, give me good, strong land, plenty of manure, and a liberal supply of seed. What would be called a liberal supply, I leave it for those who come after me to indicate."

When Mr. Howe had concluded his little introduction, Peter Ilsley arose, with the air of one who is conscious of superior knowledge and experience, and delivered himself as follows :-

Mr. Moderator, - No man here can say that 1 have taken the time of this (lub in long speeches or in much discussion. I have heard the minister, and the doctor, and the schoolmaster, and the fancy farmer --.- excuse me, Mr. Moderator - all t 11 about 
the furm and the way to carry it on ; and I have n't said a word. Sometimes I have got in over my ears trying to follow these men, but I have generally managed to make out what the meant : and if I did n't, I have concluded that it was more their fault than mine. For I have always noticed that any man can tell other people what he thoroughly understands himself. Tht, howsomever, I linow grass, and hay, and grass-seed, and a good crop, and how to make hay while the sun shines. And I won't give up to any man in this part of farming. Now as to seeding. The minister is more than half right. You can put too many kernels of corn into a hill. lou can plant potiltoes too thick in a row: You can bother and pester mangolds and ruta-bagas to death, by having them too thick. But I like a gox d firm sod of griss, and even if the crop is fine because it stat.ds so thick, I would rather have it than coarser and heavier grass grow ing on land thinly seeded. I don't mean to say that yeu can seed every lind of land in the same way. Light, sandy lands camnot bear a heary growth of grass. 'They want every plant to have a chance by itself. Even if you manure them well, you must not exhaust them by giving them more seed than they can handle. But good, rich, strong land, land made for grass, should have a chance to bear all that can stand upon it. I never seed down sandy land. It don't pay. I want always a patch for melons, and-quashes, and curumbers, and early stuff for the market ; : o I lirep my sandy, light land for such crops as these. But I don't believe in trying to raise grass on land like this. Give me a heary, clayey loam, and I will get all the grass you can suing a scythe through, and all you can make on the ground. Grass grown thick on such land as this, and cut in grod season, will always make good hay. And if the season is a good one, and the land rich, you can get second crop enough to pay for a year's work and interest. This I call grass land. You can't get good corn off of it; you can't get good potatoes; you can't get good turnips; you can't get early crops ; but you can get good grass and enough of it. Now, such land as this I seed well. When I began I clid just as my father rlid before me, and sowed three pecks of herds-griss, a peck of redtop, an I four pounds of clover 
to the acre. But I soon quit that. I found that my crop was too thin." There were a good many little bare spots on the field. $\mathrm{Th} \geq$ grass grew too rank to be really good. The hay was coarse, but light. It did n't weigh well ; and because it did n't weigh well, it did n't feed out well. The cattle did n't thrive on it. It did n't spend well. I found that the finer grass, kind of run hiy, not exactly meadow hay, but fine soft grass that grows in the - dry runs, where there is not too much clay, went three times as far in feeding cattle and milch cows. A forkful was as heavy again as my coarse herds-grass, and so I made up my mind to sow my seed thicker. I used half a bushel of herds-grass, three pecks of redtop, and, if it was sown in the spring, seven pounds of clover, and I have had no trouble since. Sometimes where the land is very heavy I don't get much redtop. But I get a plenty of good fine herds-grass, and the first year a first-rate cut of clover. I have tried this way of seeding a good many years, and have found no reason to quit it. My hay is better tıan it was when I used less seed, and I am sure there is more of it.

But, Mr. Moderator (I meant Mr. President, - I thought I was in a town meeting), I raise some kinds of grass just as I do grain. If I am going to sell hay, I want herds-grass and redtop; and I don't want to try to sell to a man who knows anything, until my land has been in grass one year at least. The growth of the second year will do pretty well to buy. But the growth of the first year, if the land is strong, is not profitable to feed to horses or oxen or milch cows. It will do to work up into chopped feed ; but it is n't first-class hay, anyhow. But it is herds-grass and redtop that I want to raise for general use with my horses and oxen, and for the market. For my milch cows, for young stock, for horses that are not doing quite as well as they ought to, I raise Hungarian grass Somebody said it was poor stuff for horses; that it hurt them; that it made them broken-winded, and bloated their legs, and made them lose flesh when their food was changed. But I never found any such trouble as this with it. I have fed a young horse on it, in the fall of the year, not long after it was got into the barn, and he grew fat and strong faster than I have ever 
known horses to do on hay and grain. I have used it for working horses, and they did well on it. And I have fed it now and then to my working oxen, and they like it for a change at least. I raise it, however, mostly for my milch cows. It will make more milk than English hay. And when I have a good milk-market I always lay in for a good supply of Hungarian. This kind of grass I raise just as I do barley, or oats, or rye. It will grow but one year, and so you must plough and manure and seed every year if you want to get a crop. It will not grow on poor land. I see John Thomas looking at me, and I want to say to him that I am not talking about green food for cows in the summer season, - so he need n't think I am coming into his theory about fodder-corn. I am talking now about hay; so he can look the other way if he likes, and I will have no more fuss with him. I say I want good land for it. If I have had a piece in corn, and have manured it well, I like to. raise Hungarian on it. And first I plough early in the spring, as soon as the frost is out of the ground. I then let the land lie until about the first of June; give it about six cords of good well-rotted manure to the acre; plough it in shallow; then plough again; harrow as fine as I can; and then sow my seed. Half a bushel of Hungarian grass-seed to the acre is enough. If you sow more, the crop is apt to be short and too fine. It lacks firmness; and when it is cut and dried it withers away. The seed should be brushed in, or harrowed in with a very light harrow, and the land rolled. Now, if this is all done between the first and middle of June, when the weather is warm and the earth is beginning to feel the summer heat, you can get your seed started before the weeds spring up, and the chances are that you will get a good crop. If you sow earlier the weeds will get the start of you. If you sow later, the crop will not have time to grow before the summer haymaking weather is all over. The great trouble in raising Hungarian is the weeds ; and I have told you the best way to avoid them, because I have heard so much complaint that the crop is almost worthless and hardly worth raising on account of this nuisance. I'repare the land well, manure it well, sow the seed when the weather is 
really warm, - warm enough to bring up the corn and make it grow right along, and, my word for it, you will not be disappointed. You can get four tons or more of this kind of hay to the acre; it does not get damaged by being wet, as English hay loes; it will stand the effects of a storm about as well as corn-fodder; and it always spends well when fed to milch cows in the winter. I am talking about grass cut and made into hay; and I hope nobody will charge me with abandoning my fodkercorn, for I raise that still, to use in the dry summer weeks in August and September, before the fall feed comes. But I raise Hungarian, acres and acres of it, every season, for winter feed for my milch corvs. If it is rank, coarse, and heavy, I chop it and wet it with warm water, adding meal and shorts. And I am as sure as I am that I am alive, that no better food for cows can be founcl. I reckon that an acre of good Hungarian grass fed to good cows, cows that will gire fifteen quarts a day, and these are good enough, will bring $\$ 250$, besides the manure, and this is doing pretty well, when you consider that there is no hoeing to be done, and that the harresting is as easy as harvesting the hay crop. Do you doubt this? I see Barnes smiles. But reckon it up and see. Four tons of the hay, which will grow on one acre, will feed two cows six months. If they give fifteen quarts of milk a day each, and you sell your milk for six cents a quart, - and I calculate to get more, - you will receive in six months $\$ 360$. Allow $\$$ I 10 of this for grain for your coins, and you have $\$ 250$ as the result of that work, or my arithmetic is all wrong. I call this doing pretty well. And I am willing to raise Hungarian as long as I lieep cows, sell milk, and make manure. In reckoning my profits on an acre of Hungarian grass, I have said that I fed it to cows giving fifteen qual ts of milk a day. I don't expect a cow to give more in winter in a herd of thirty or forty, and I don't want one which will give less. I am very careful to have my cows begin to milk in the fall. If they must be fed all winter, I want them to pay for what they eat as well as they can. And I know that a ton of bay fed to a cow giving five quirts of milk a day will not bring me in as much money as if it were fed to a cow giving fifteen 
quarts. I like winter milch cows for profit. I like to feed them. It is like paying good wages to a first-rate man, - you will always get a new dollar for an old one, if you know how to set him at work. But to feed a drone, or a loafer, or a dry cow, - I cannot and I will not have that going on where I am, at any rate. John Thomas may do it for charity if he likes; but if I am going to give anything away, I want to give it away, and not squander it, - give it where it would amount to charity, and not waste it where it would be a premium on idleness. You might as well throw stones into an old well as to -

Here the President reminded Mr. Ilsley that the rules of the Club required every member to confine hinself to the subject under discussion, and he was especially desirous that clisturbing questions of religion, morals, and politics should be kept out of their deliberations. He expressed his sreat obligations to $\mathrm{Mr}$. Ilsley for the practical remarks which he had made, and hoped he would continue them, and excuse him for interrupting him in the current of his thourhts. For one, he would be glad to hear more of the processes of seeding grass lands, and he was particularly interested in the best mode of making hay, - a matter which had been much discussed, and on which he did not doubt that Mr. Ilsley had had large experience, and could present some useful and important views.

But the thread of Peter Ilsley's discourse was broken; he could not rally; he had gathered so much strength as he went on, that when he was checked, a sudden and unexpected exhaustion followed. He only remarked, there-fore, when the President closed his statement, that he must be excused for trying to imitate the wise men of the Club, much of whose talk belonged to one text just as well as to another, in his opinion, adding, "The old cock crows, and the young one learns." Upon this he sat down, and left the matter for others to discuss.

"Mr. President," said John Thomas, "my friend Ilsley 
has done well. He need n't have raked up the old quarrel about fodder-corm, it is true, for I understood what he was driving at just as well as he did himself. He was talking about hay, and I was thinking about it; and, when a thing is settled with me, it is settled."

"O, don't harp upon that old matter any more," said Ilsley; "I got at it by accident, just as half the great speakers do; and, when I had paddled in, I paddled out again as quick as I could. But I don't believe John Thomas is in order under the rules. Can't you bring him to, as you did me, Mr. President?"

The President reminded Mr. Thomas of the rule, and enlarged somewhat on the courtesies of debate and the weakness of personality in all discussion. Upon which the thrifty farmer of Jotham resumed his remarks.

"I have noticed a good deal of debate lately about the best methods of making hay, as well as of seeding the land and cutting the grass. It seems to be the opinion of many very sensible men and good farmers, that grass had better be cut in the morning, after the dew is off, and stacked or stored in the barn the same day. I do not know how this is, - but I have my doubts. Can any member of the Club give an account of this new process?"

No one replied, until the Schoolmaster, who had been silent the whole evening, as he had during many previous evenings, and who was always expected to know something about every question which involved considerable booklearning, rose and said :-

I do not think, Mr. President, that the plan to which Mr. Thomas alludes has been so generally adopted as to make it a matter important enough for cliscussion, or for any special experiment. A kind of hay known as brown hay has long been known in some parts of Europe; and of course its existence there is enough to make it an object of inquiry here. As near as I can learn, the mode of preparation which results in convert- 
ing grass into brown hay is confined manly to those sections of Europe where a fine hay-clay, with a clear air and a bright sun, is not often found. The grass is cut, as Mr. Johnson says, in the morning as soon as the dew is off, and if there is no rainfall during the midday, it is hauled into the barns or stacked in the field, as may be most convenient to the haymaker. We are told? that by this process, in which the grass is cured rather ly b ing cooked in packing than dried in the open air, a nutritious and palatable hay is produced; and that in this manner not only is time saved, but the risks of the weather, attendant on the usual long process of drying, are avoided. It is usual, in storing hay in this green state, to be sure that it is free from dew, and all external moisture caused by rain, and to fill the mow or complete the stack in which the hay is to be placed so as to avoid the necessity of giving it a num supply on any following diy. The top of the mow or stack is covered with a foot or two of straw or refuse hay, and the mass is left to dry and ripen. The steam and heat rising from the mass destroys the corcring entirely, or converts it into a pile, decayed and mouldy; while the hay itself goes through a change which makes it equal to the best hay prepared in the usual way, in the most auspicious weather. This plan, which is adopted perhaps from necessity in the dim and hazy sunlight of Northern Europe, has many advocates in this country. 'They are very earnest in defending their custom, and assure us that their hay is rastly superior to that of their neighbors, and to their own which they cure in the usual manner. I cannot learn, however, that they have many followers, or that the custom is very generally adopted. And I have been inclined to look upon the whole thing as largely a matter of experiment and speculation; and to believe that, in clescribing the process, many of the concurrent circumstances, such as the conclition of the grass, the amount yelded by the acre, the time of year when it was cut, have been omitted or lost sight of. That grass heary enough to make three tons of hay to the acre can be properly cured in this fashion, I dloubt. And I have found but few farmers who, either for their own use or the market, were willing to substitute hay cooked in the mow for that sweet-scented and 
nutritious fockler which is made from good English grass, cut when in good condition, and dried under a good hot American stun.

Dr. Parker, who was present, had been quite uneasy during the Schoolmaster's short clisquisition on brown hay. He was not overmuch gratified at his being called upon as the well-read gentleman of the Club; and he could not resist the temptation of presenting himself in opposition to a system of haymaking which he knew could not be acceptable to the farmers of Jotham, who had long been proud of their sweet and fragrant hay-mows, as had their ancestors before them. He knew very well that no cattlefeeder in that town would be willing to throw aside that delicious wisp of hay which he had twisted out of his mow, and applied to his nose with so much pleasure, scason after scason, and to substitute for it a dark-colored, dismal-looking, unfragrant handful of grass, cooked by self-generated heat, and barely escaped from spontaneous combustion. If he had any other reason for criticising the Schoolmaster's statement, he clid not allow bimself to recognize it, and he felt confident that the Schoolmaster himself was free from all suspicion. But, however this may be, he took the flonr and ammounced himself in favor of the old-fashioned method of making hay, as one which had stood the test of time, and which should never be displaced, in a favorable climate like ours, by any new-fangled notions got up by those who had to make their hay the best way they could. He continued:-

I see no necessity for adopting any new plan of haymaking, so long as we are or ought to be satisfied with the old one. It is all well enough for young men to be constantly exploring outof-the-way theories, to gratify their ambition, and to gratify the public, if possible, with a novelty. But every sensible and practical man must know, that a plan which has borne the test of 
time and has secured a good reputation to a community must be a gond one, and ought not to be laid asicle morely to gratify a whim or to test a theory. I am sure my old father understood how to make his hay, and the condition of his cattle and horses showed that he was right. How often have I taken part in that labor of the farm, and how well do I remember the beaty of that early morning scene, when a vigorous-band of young men cut their way through the dewy grass, and were ready for the noonday sun to do its share of the work! Haty cut thus early in the day, well dried until four o'clock, raked up and cocked, opened the next day as soon as the dew was off, and hauled into the barn during the heat of the early afternoon, was always sweet and fragrant and nutritious. It filled the barn with its delicious odor; and to the very last spire it was eaten by the cattle, who enjoyed it almost as much as they did the luxuriant grass in June. I leaned by observation in my early life, that such hay as this could not be made by storing the grass when half green, nor by allowing the hay to get wet with showers, nor by exposing it to the dew. I was told that dew was more injurious to hay than rain, and that hay should always be marle up into cocks long before the dews begin to fall. And I clo not doubt it. I know that hay thoroughly wet with dew is very liable to mildew; and I am sure that hay once mildewed can never be restored to its originally good condition. I think I can always judge of the slill and industry of a farmer, by examining his hay-fields towards evening. If the hay there is left in the swath, or is simply drawn together into windrow, to be exposed to the damp night-air, I doubt the thrift and knowledge of the owner. But if, on the other hand. I find the field studded with haycocks, carefully made up before the sun gets low in the heavens, I am confident that the work of that farm will be well done, and that when I wish to purchase good hay I can find it there. Now, during the last week in June and the first two weeks in July we have weather and length of days adapted to such a mode of curing hay as this. It is selclom that, in these weelis, we are visited with drenching rains. And when we consider that this is the time when most of our grass is best fitted 
to be cut, I think we ought to avail ourselves of this season to clo our haying in true American style, as we set apart certain days in autumn for harvesting our crop of roots and fruit.

I do not believe in abandoning the good old ways of our fathers, Mr. I'resident, until we can, at least, find better. I.et us, then, cut our hay in the morning, make it during the heat of the sun, cock it up thoroughly for the night, open it the next day when the ground is dry, put it into the barn while it is clry and warm, apply a little salt to it as it goes into the mow, and then invite erery advocate of the brown-hay system to delight in its frasrance, and to witness the avidity with which cattle will clevour it in the hard cold days of winter.

I am willing to recognize the value of the service of those young men who bring their book-knowlectge into our common schools, and engage in the useful occupation of teaching the youthful minds of this generation. But I would suggest that they stop there, and not rush into subjects which they do not fully understand, or interfere with the arrangements to which older and better men than they are devoting their minds and hearts.

The last sentence of his discourse Dr. Parker delivered with unusual emphasis, and with a fiery glow in his eye which disturbed those who knew him well, and surprised and astonished the cntire Club, and was understood by no one present, except himself and the Schoolmaster.

Charles Ingalls made no reply; but, as bad luck would have it, Jim Bell retorted upon the Doctor with unexpected spirit. He gave an account of the effect of heating in the mow, upon what is called black-grass, a kind of upland salt hay, which is not often wet by the tides; and he described how a large mass of such hay had been improved in quality, and made especially agreeable to cattle, by being accidentally stored before it was thoroughly cured, and by heating. It had been pitched over before the heating process had gone too far; and the effect was to increase the value of the hay to a very considerable extent. How it was done 
he could not tell, - whether by the development of sugar or starch, or what. But the improvement was manifest, and taught him that a certain amount of fermentation was valuable to some kinds of hay at least. He had often thought of this accidental experiment when he heard the brown-hay system denouncud. And while he still believed in the plan so well adopted by our fathers and so ardently advocated by Dr. Parker, and had no idea of trying any other himself, he still thought that the subject was worthy of investigation, and shoulu receive the most careful attention of the Club. He would furthermore suggest that learned men were the last men who should fall out with cach other, on account of their book-knowledge, and that from their good-natured discussions, and not from their wrangles, he had hepeel to derive as much information as from the details and statements of practical farmers themselves.

Jim Bell was the last man whom the Doctor expected to hear from in this fashion. He felt the force of his remarks, however; while the Club thought he had done remarkably: well, and Charles Ingalls deceived himself with the idea that Jim had rushed to his rescue because he was Clara's father. Here the debate ended, with the exception of that conversational rehearsal, with which such bodies always taper off their deliberations, and pass into a state of confusion which can be relieved only by adjournment.

Dr. Parker felt quite ashamed of his rudeness; and, what was worse, he feared that he had foolishly exposed himself to Charles Ingalls, and perhaps to others of the Club. As the rest dispersed, therefore, he lingered behind, sat down before the fire with Mr. Hopkins, and took a cigar with that worthy gentleman, hoping in this way to remove from his mind at least all unpleasant effects of the little disturbance. The hay-crop was soon forgotten, and with it the character of the debate. And never had Mr. Hopkins 
found his medical friend more agreeable and entertaining, as he cliscussed the schools of P'aris and the power which education gives a people to accomplish the great work of the world. He quite envied Dr. Parker's "fraternity of scholars," and made up his mind to "endow a college or a cat," so that he might be admitted to the sacred circle, and dine with the alumni on commencement days. 


\section{FOURTEENTH MEETING.}

\section{THE HAY CROP (Continned).}

A SOCIAL BREEZE. - MR. WILLIAM JONES ENLIGHTENS MR. HOWE. - MR. HOPKINS DEFENDS CLARA BELL, AND GIVES MR. HOWE SOME GOOD ADVICE.

THE Reverend Jonathan Howe, Secretary of the Farmyard Club, began to be perplexed and troubled. He was not accustomed to the controversies of public assemblies, and his own manners were so mild, his spirit so pure, and his conversation so gentle, that his presence usually subdued into propriety and decorum most of those persons who came in contact with him. It was a hardened sinner who would not be softened by Mr. Howe's melting and refining influences. He was, therefore, quite surprised and disturbed by Dr. Parker's conduct at the last mecting, and he was left in a bewildered state by the fierce energy with which the Doctor resented all interference with older and better men in their affairs of mind and heart. Mr. Howe saw, also, the Doctor's savage glance at the Schoolmaster as he uttered this sentiment, and the look, added to the words, quite dismayed him. He did not suspect the cause of the trouble: he only remembered what he had heard of Dr. Parker's habits. He had no disposition to linger after the adjournment; but his mind turned spontaneously to the little parlor at the parsonage, the well-chosen library, and the sweet and wise and cultivated Mrs. Howe; and for this cheering and invigorating scene he started at once. To Mr. Ilopkins he bade a speedy good-night, and, bowing to the rest, departed. He had 
barely left the threshold of the door, when he was joined by William Jones, whose keen eye had seen all, and whose worldly wits had already explored to his own satisfaction the field in which the saintly Mr. Howe was bewildered and lost.

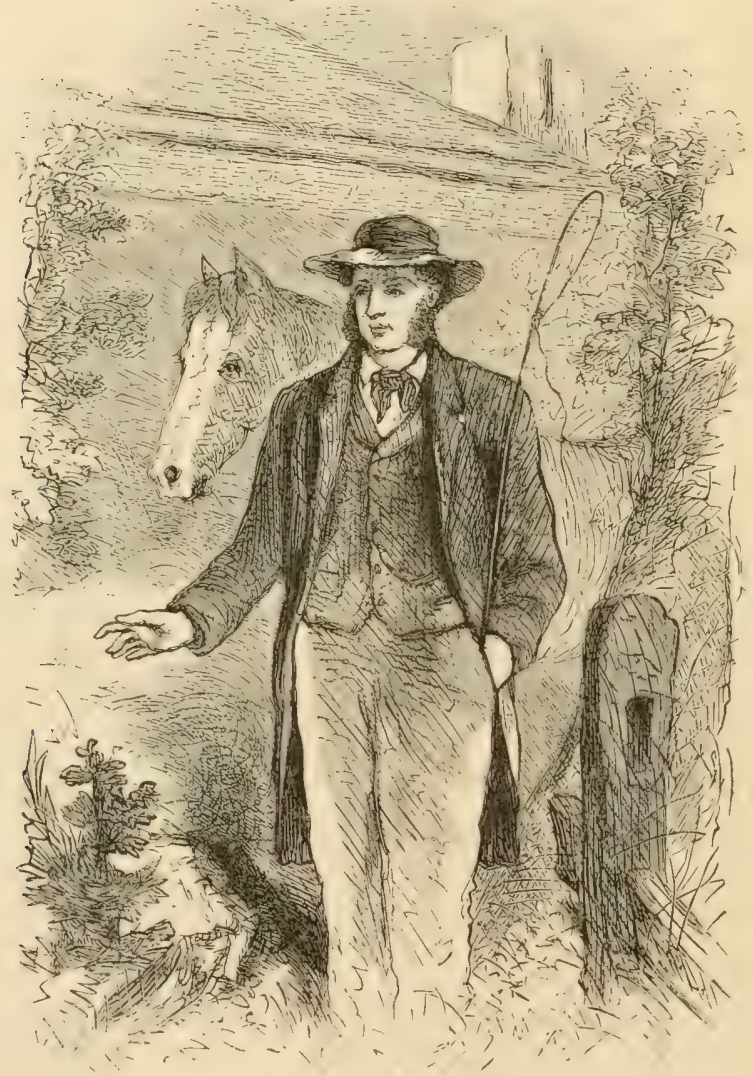

MR. WILLIAM JONES

"A little bit of a breeze, to-night," said Jones, as he stepped up to the minister, and they pursued their way homeward together. 
"Truly, I am amazed at Dr. Parker," said Mr. IIowe. "He evidently dislikes the Schoolmaster, deeply and bitterly, and why I cannot imagine, unless it be that from the point of his own unsuccessfil middle life he surveys with a jealous and envious eye the fine career which the young man's faculties are evidently destined to achieve."

"The fine what?" replied Mr. Jones.

"The fine career," said the minister ; "for that Charles Ingalls is made for influential and important service in the world, no one who knows him, as you and I do, can for a moment doubt."

"What do you suppose Dr. Parker cares for that?" said Jones. "He does all the business he wants to do here. He has all the country round about to himself. Nobody disputes him. He knows the people believe in him, and the doctors consult him. He is the biggest toad in the puddle here, and when he goes to Boston, once a year, to meet with his Society, he is as big a toad as there is in that pudclle there. He never has been on a track much, I suppose, but he can strike a two-forty gait on any road, and have speed enough left to astonish the best of ' $\mathrm{cm}$. IVhat do you suppose he cares for the chances of a colt, which may die or be dead lame before he gets anywhere near a fast record? Parker is smart, but he don't care to get anywhere. The old doctor always said IBill could beat anybody in the world if he would only try, but that he never would try. He writes to everybody, and talks to everybody, and knows everybody, and he don't care to be anybody; might have gone to the General Court, and would n't; might have been President of the Doctors' Society in this district, and would n't; might have been a professor in the college, and would n't; said he would n't go anywhere nor do anything with the rest of the people, because everybody was so 'damnably corrupt' that he did n't want to have anything to do with them. Excuse 
me, Mr. IIowe, but that's just what he said, one evening, this very winter, sitting on the counter over at the grocery. He said everybody out o' doors is corrupt; I don't think he included himself. I could n't help thinking of your text, last fall, the Sunday before election: 'I thank God I am not as other men are.' Wa' n't that it, Mr. Howe? No, sir, he don't care a red for the schoolmaster's career. There's a woman in the scrape, I think, Mr. Howe, and I should advise — "

By this time they had reached Mr. Howe's door, and he urged his friend Jones to come in ; the subject had become interesting, and he felt sure that even Mrs. Howe, who had been rather shy of Jones, and had wondered at her husband's fondness for him, would be glad to hear what was to be said on this dawning social scandal.

"A woman? Who? What? Come in, come in, Mr. Jones. Mrs. Howe will be glad to see you, I am sure. I should really be sorry to have the adjustment of domestic difficulties added to all my numerous and arduous parochial duties. But come in."

They entered the house and found Mrs. Howe in the cheerful and refined-looking little parlor, reading as usual. She had been revelling in the impassioned pages of Jane Eyre, and had been wrought by the experiences of that remarkable character into a sense of universal sympathy with every sentimental impulse in the world. She rvas glad to see her husband, but she was not quite so glad to see Mr. IVilliam Jones; and it was with considerable fear and trembling that she discovered the eager and earnest conference of the two gentlemen, and observed the corclial and somewhat deferential manner in which Mr. Howe ushered his companion into the room, and provided him with a chair. When they were all comfortably seated, and Mrs. Howe had made the usual inquiries with regard to the weather, the Club, and the people, Mr. Howe resumed 
the conversation which had been abruptly broken off by the arrival at his house. He gave his wife a little account of what had been going on ; of the curious manifestation of ill-feeling by Dr. Parker; of the Schoolmaster's selfpossession; of Mr. Jones's views of the Doctor's character, and of the idea of the case he was expressing just as they entered the house. Mrs. Howe found herself suddenly interested in the matter; and she forgot her instinctive dislike to Mr. Jones, as she listened to his spirited and graphic account of what he had seen for some months past, relating to Clara Bell and her two lovers. He had evidently been all eyes and ears in the matter; harl shrewdly observed the by-play on the drive to the seaside; had witnessed the Doctor's quict attentions; and had discovered the Schoolmaster's chagrin. His talk was certainly vigorous and expressive enough. It was quite remarkable how much this shrewd and observing man had seen. It was still more remarkable with what skill he made up what he had not seen, which could in any way complete his narrative or establish his theory. In his curious mingling of philosophy and common-sense, of icy observation and ardent feeling, of knowledge of the world and ignorance of those sensibilities which a wordy or a look may wound, he quite amazed Mr. Howe and quite modified the opinions of his wife with regard to himself. His description of Dr. Parker was so novel and unexpected, that Mrs. Howe became as interested in the Doctor as she had been in Rochester, whose masterly powers and majestic impulses had charmed Jane Eyre and herself. Mr. Howe could not conceive how so much fire could be pent up in so small a parish, and he was quite at a loss to comprehend how one of his lambs could be so torn and tossed as Mr. Jones represented Clara Bell to be, without seeking refuge in his bosom. He did not know how ignorant and how innocent Clara Bell was; and he took it for granted that she needed 
counsel and succor in the trying events and emotions through which he supposed she was passing. It was quite late when Mr. Jones left that little household, which was very much bewildered by his mixed talk on horse and humanity, and dazzled by his crude wit and his keen understanding. How he found out all he knew Mr. and Mrs. Howe could not imagine; and they were by no means averse to being trusted with the secrets of this important affair in the village; in fact, they were proud to feel that he could intrust them with matters of so great importance.

The silence which followed the departure of $\mathrm{Mr}$. Jones was oppressive and embarrassing. The story he had told had a dangerous charm, which the minister and his wife fully realized; and they were alternately sorry and glad that they had heard it. They really did not believe more than half of it, as it had been told them; yet it was such a charming incident in a quiet country village! Mr. Howe had become thoroughly accustomed to the commonplace rejoicings of weddings, and the gloomy and heart-breaking solemnity of funerals; and it must be confessed that he felt uncommonly quickened by the prospect of a complicated affair of the heart, in which the sweetest rose in his parochial garden was involved.

"This is a very remarkable story, and Mr. Jones is a very remarkable and interesting man," said Mr. Howe, breaking the silence.

"The story is curious, and Mr. Jones is a curiosity," said Mrs. Howe, who had already begun, in her own mind, to question the tale, and had a rising protest in her heart against receiving communications from such a source. She already hoped the matter would end here.

Mr. Howe slept uneasily under the weight of responsibility which Mr. Jones had put upon him. He discussed the matter no more, however, in his own house; but having set matters in order in the morning, he repaired to $\mathrm{Mr}$. 
Hopkins's, to arrange, as he said, for the next meeting of the Club. He found that gentleman having just risen from his breakfast-table, where he had endeavored to enjoy his solitary meal, and sitting before that never-fading woodfire, which cheered from morning till night that ample apartment, used now as both drawing-room and library, bedecked with his dressing-gown and slippers; for, since Mr. Hopkins had left the city with its courtesies and restraints, and had taken up his abode alone in the freedom of the country, he had introduced into his library, and even into his dining-room, these articles of dress, which are intended for the chamber and the dressing-room alone.

The President was glad to see the minister, offered him an easy-chair by the fire, and, as usual, extended to him the courtesy of a cigar. The President was reading a volume of the Diary and Letters of Madame d'Arblay, which had been sent from London by Mr. Everett to Mr. Webster, of whom Mr. Hopkins was a warm admirer and supporter; and who had forwarded the volume to his old friend in the country, "with the hope that its cheerful and chatty pages might enliven his agricultural hours." He had just reached that touching passage in which Mrs. IVilliams gives an account of the first attack of paralysis which fell upon the great Dr. Johnson. "It was about four o'clock in the morning; he found himself with a paralytic affection; he rose and composed in his own mind a Latin prayer to the Almighty, that whatever were the sufferings for which he must prepare himself, it would please him, through the grace and mediation of our blessed Saviour, to spare his intellect, and let them all fall upon his body. When he had composed this, internally, he endeavored to speak it aloud, but found his roice was gone." Mr. Hopkins was very much impressed by the majesty and repose of the great man in this trying hour; and he enlarged to Mr. Howe upon the value of a great faith and a 
consciousness of having lived a life of honest purpose, to support man in the last and most momentous scenc. He referred most tenderly to his wife and children who were gone, and brought out from their sacred seclusion the mementos which he had preserved of them, and with which for years he had held almost daily communion. His conversation was a surprise to the minister, who, having recently left the flippant and cumning talk of one man of business, was not prepared to hear such refined and elevated sentiments from another: It was by natural gradations that Mr. Hopkins passed from his family to his ancestors, from his ancestors to his farm, and from his farm to the Club. And the two gentlemen found themselves rehearsing the meeting of the evening previous, and discoursing especially on the curious conduct of Dr. Parker.

Mr. Hopkins had noticed it, but, with the caution and courtesy of a cultivated man of affairs, he had paid but little attention to it; had said nothing about it; and had set it aside as a matter with which he had no concern, and which he was not called upon to discuss. He sat back in his ample arm-chair, therefore, and dreamily smoked his cigar, while Mr. Howe repeated the story given him by IVilliam Jones. It interested Mr. Hopkins deeply. He recalled his own experience beneath the moonlight shadows of the groves about him even now, and the joys and sorrows of his life rushed over him as he listened to a simple tale of village love, and realized that all there is of human happiness was involved in the result. He did not exactly understand Mr. Howe's desperate and energetic determination in the matter, and he was quite surprised when the minister said to him :-

"I think it a duty I owe the members of my parish who are involved in this affair, which seems to threaten the happiness of one or all of them, to lead them through the 
dark path they are now traversing. Clara licll I have known too well to allow her to sacrifice herself to anybody. Dr. Parker I understand thoroughly, I think, and I am sure he ought not to jeopardize the happiness of any young person to gratify what must be a flecting passion on his part. Charles Ingalls is too young to decide such matters for himself, and ought to be warned that his promise is too brilliant to be endangered by a youthful alliance, of which, when he reaches distinction and fame, he may repent. The interesting account I have received from Mr. Jones has led me to feel strongly my duty in this matter; and I feel also that I must extricate these persons from the difficulty in which they are so unhappily involved. The sagacity of Mr. Jones in this matter has amazed me. While you and I, Mr. Hopkins, have blindly allowed these three friends of ours to wander into an almost inextricable maze of trouble, he has cliscovered all, and when the first and faintest ill effect shows itself, as it did in Dr. Parker's rudeness at the Club last night, he is ready with his warning, and really understands us and our duties better than we do ourselves. He is a wonderful man, this .Ir. Jones. Even Mrs. Howe, who disliked him exceedingly at first, has begun to discover his good qualities and his remarkable faculties. And I think you will agree with me, Mr. Hopkins, that I ought to follow his advice, and call upon the lovely Clara Bell to lean upon me in this hour of her trial, and to give Dr. Parker and the Schoolmaster that counsel and advice which they evidently need."

"Stop one minute," said Mr. Hopkins. "This affair will work itself out, Mr. Howe, if you will only let it alone. In the first place, I am satisfied that Clara Bell is entirely ignorant of the conflict going on between Dr. Parker and the Schoolmaster. I know her well, - have seen her almost every day since her father was taken sick and has 
depended upon us for aid, - and I know that she looks upon Dr. Parker as a guardian only whom she is bound to obey, and upon Charles Ingalls as more than a brother, but a brother still. I think I am right in this. Dr. Parker knows very well that he cannot and ought not to expose her to the trials of his eccentric life; but he is annoyed at the same time that any man should set his affections on her whom he considers to be quite his own. Charles Ingalls is fretting about nothing; and if he had half the sense in this matter that he has in the discharge of his duty, he would quietly return to his customary walks in this village, and treat the 13ell family as he does all others. You see, my dear friend, I have not been blind or unobservant as I have associated with my neighbors here. I know all about the seaside drive, last summer, - all about the follies and mistakes of Dr. Parker. But I have looked upon all this silently, and with that confirence in a good result which grows out of a capacity to consicler passing events at their precise significance, and not as the stock in tracle of a gossip or a mischicefmaker. I have seen as much as Jones, and have understood it better.

"And now a word with regard to Jones. You know what he is as well as I do, - a talkative, reckless, shrewd, unprincipled fellow, who makes himself agrecable and entertaining by his audacity, and wins his way by an apparent regard for all the superior persons with whom he associates. I have no prejudice against him, but I should not select him as a partner, or agent, or confidential clerk; and you ought not to select him as a companion in any respect. It must be that you are ignorant of the ways of the world, and of the immorality in it, or you would never admit to your confidence such men as you do. I remember well how my old grandfather, the last clergyman of our family in this parish, allowed himself to be misled by 
the apparent liberality and generosity of an unprincipled knave, whose very lineaments he would have thoroughly understood had he frequented the busy walks of life a littie more, and devoted himself to his library and his cluties with the families of his parish a little less. Iou may depend upon it, a rogue can have nothing worth conferring upon an honest man. The intimacy of a minister of the Church of Christ with a graccless and reckless man of the world is as unnatural as would be that of "Christ with Belial.' No good can possibly come of it. And I am amazed to see how you are charmed by certain glittering qualities, which with you mean chivalry and derotion, and with us mean a selfish and heartless display of impulse. I find no fault with this, because underneath it all I see a kind and forgiving spirit, a faith in humanity; a belief in the divine essence of man, an entire superiority to the low and grovelling designs of intriguers and deceivers, without which the clergyman would be so waywise and so worldly that we should assign him his place in the marliet, and not in the pulpit or at the bedside of the dying. I do not blame a pure-minded minister of the gospel for being deceived, but I do despise the knave who deceives him. Now, Jones is not a fit man for you to make a confidant of. He has neither your faith, nor your purity of purpose, nor your sentiment, nor your sense of honor, nor your appreciation of the mysterious workings of the human breast, nor your affection for the suffering heart of man; nor has he any knowledge of the relations established by a common belief, and a common love for divine truth. iv'hy, then, should you take him to your bosom? Ile may entertain you, but you should never submit yourself to him. John Thomas you can trust. His sturdy and homely qualities, which would prevent him from intruding upon your duties, are just the support which you need, - a support which, when real trouble comes, you will find of true value. 
So long as it is your business to rebuke evil, you cannot affiliate with it. You may forgive it, but you cannot make a refuge for it in your own sanctuary, without in the end destroying that holy place and demoralizing yourself. Look out for Jones, and take the advice of your wife.

"As for Jones's story, let us forget it. As I said in the beginning, this thing will work itself out, and we had better let it alone. Now, excuse this long sermon; tell Jones to hold his tongue; give my regards to Mrs. Howe; and let us prepare for the next meeting of the Club. I think we had better do a little raking after, and, if there are any points left, clean up what there is of the hay crop."

To this Mr. Howe agreed without further debate. He knew that Mr. Hopkins was right, and glad enough was he to drop the matter of social disturbance where the retired merchant left it, and return to the business of the Club.

At the next meeting, which assembled in full numbers at the usual place, the discussion opened with a general review of the points laid down by the speakers of the previous evening, and with a general agreement in the sentiments and opinions then expressed. In the course of the evening John Thomas said he hoped the time would come when we in this country would understand the stacking of hay better than we now do. He could not get a wellshaped and perfect stack on his farm, - a stack which looked well and shed the water thoroughly. "IVe compel ourselves," said he, "to use too much roofing in this country. And there is no reason why hay properly packed in stacks should not be kept in better order than when confined within the four walls of a building, and exposed to all the effluvia which gather there." He had been obliged to leave more than fifty tons of hay of various qualities out of doors for the last two or three years, and he would be glad to see as perfect a stack constructed in this country 
as can be found in the old country, where, he understond, the packing, ventilating, salting, and thatching of a haystack are brought to as great a elegrec of perfection as the erection of a building.

Peter Ilsley said: "I agree for once with all that John Thomas has said. I like a perfect haystack. It is an economical way of keeping hay; it saves a great deal of hauling in the haying season, if your mowing land is far away from your barns; and it looks as if the man who made it had an eyc to good farming, and a knowledge how to do it. So I go for stacks, and goocl-looking ones. I have lost a great deal of hay from bad stacking, and I should be glad to know that I should not be obliged to lose any more. But I want to say a word about salting hay. I learned from the English books on farming that the salting of hay at the time of packing has been largely practised there. Sinclair says: "The salt, particularly when applied to the second crop of clover, or when the crop has received much rain, checks the fermentation and prevents moulding. If straw be mixed with the hay the heating of the stack is still further prevented, by the straw imbibing the moisture. Cattie will eat not only such salted hay, but even the straw mixed with it, more eagerly than better hay not salted, and also thrive as well on it. The quantity recommended is a peck of ground rock salt to a ton of hay. In consequence of being thus treated, hay that has been flooded was preferred by cattle to the best hay that had not been salted.' I agree with this old Englishman, and like a little salt on my hay."

Phineas Barnes put in a plea for good haying machinery. He thought mowing and spreading and raking and cocking had never been so well done as when the scythe and fork and hand-rake were used by strong and skilful workmen. The mowing-machines, he was aware, were becoming very perfect, and they undoubtedly save not only the time of 
workmen, but considerable of the crop. But he had seen no such perfect hay, no such exact windrows and cocks, no such clean fields, as he used to see when the hand-rake and fork were in use. If had repaired a good many horse-rakes and tedders in his shop; and he thought there was great ground for improvement in them still.

John Thomas took the floor again, and called the attention of the Club to the fall-feeding of mowing lands. "I an sure," said he, "that I cannot lose my second crop of hay by letting it perish on the ground. I have read many essays and heard many remarks against the practice of fall-feeding; but I cannot carry on my farm without it. There are six or seven wecks in the fall of the year when I must feed my cattle somewhere. I cammot afford to feed out my hay at that time of the year, and I cannot find grass enough in my pastures to keep my cattle in good condition, or to keep my cows in milk. I feed my mowing lands, therefore, and cultivate them accordingly. I do not pretend that I can keep my fields in grass as many years when I feed them in the fall as when I do not. But I am willing to overcome this difficulty by more frequent ploughing and seeding, because I am sure that, in the long run, I make more than enough to pay the expense of this operation. I feed my mowing lands pretty close in the fall; and on this account $I$ make it a rule not to top-dress those lands. I am satisfied that you can top-dress lands which are not fed to advantage; but I am also satisfied that topdressing, applied to lands which are fed, is nearly wasted. The effect of the manure thus applied is not sufficient to counteract the destruction of the grass by the cattle. And the only proper and satisfactory mode of applying manure to lands thus fed is with frequent ploughing and seeding. If I were raising hay for the market, and had a supply of manure independent of my barn-yard, such as sea manure, fish composts, ashes, etc., I should never fall-feed. And I 
should expect in this way to get an ammual crop) of hay from my fielels for many successive years. I3ut I do not call this profitable farming, as a general rule, and believing as I do in cattle, I believe also in feeding them on our mowing lands in the autumn."

No one in the Club secmed disposed to question the soundness of Mr. Thomas's statement; and after a few general remarks on agriculture, and a lively talk upon town and State affairs generally, the Club adjourned in the best of humor, eviclently fecling that the dark cloud was overbluwn. Even Mr. Howe saw daylight, and rejoiced in the wisdom of Mrs. Howe and Mr. Hopkins. Meanwhile, the physician practised, the schoolmaster taught, and Clara took care of her father, "all unconscious of the mischief done." 


\section{FIFTEENTH MEETING.}

$$
\text { PASTURE LANDS. }
$$

SQUIRE WRIGHT ENTERS THE FIELD. - FANNY RETURNS A WIDOW. - THE WESTERN LIFE.

SQUIRE IVRIGHT had returned to Jotham. It was his modest and unadorned little office, standing beneath a towering elm on one side of the village green, which had been the resort of all those desiring and needing legal

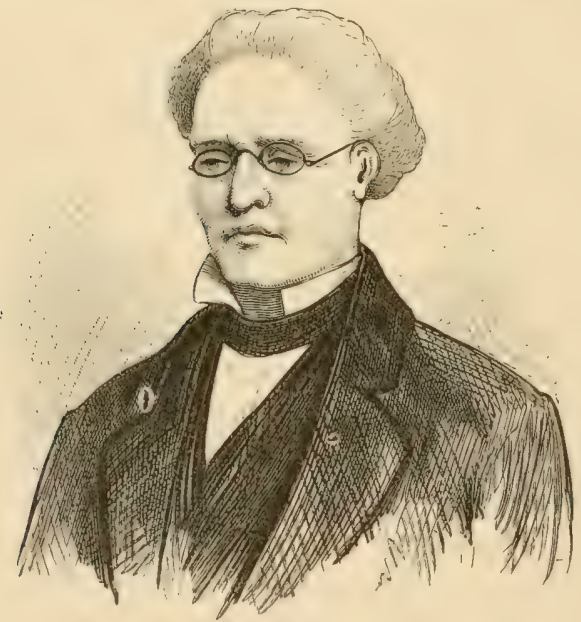

SQUIRE WRIGHT. advice for nearly forty years. "Henry Wright, Attorney at Law," over the front door, and " H. Wright's Office," round the corner, were the two signs which had been familiar to more than one generation of the people of the village, and had been read with interest by many succeeding crowds of wrathful litigants. The scanty library within contained all the legal lore necessary for that neighborhood; the overloaded and chaotic table was piled with the written documentary history of every 
variety of legal controversy; the worn and chipped and dilapidated wooden arm-chairs with well-shaped bottoms, and backs of just the height and angle, invited to long and lazy sittings; the old Franklin stove, with its cast-iron firedogs, and undisturbed bed of ashes, and polished and well-worn corners, told of many a tale of quiet and drowsy conference, with chairs atilt and feet aloft; and the dusty and uneven floor, swept only by the Squire himself, bade all incomers remember that no domestic tidiness was ever allowed to interfere with the official propricties of that

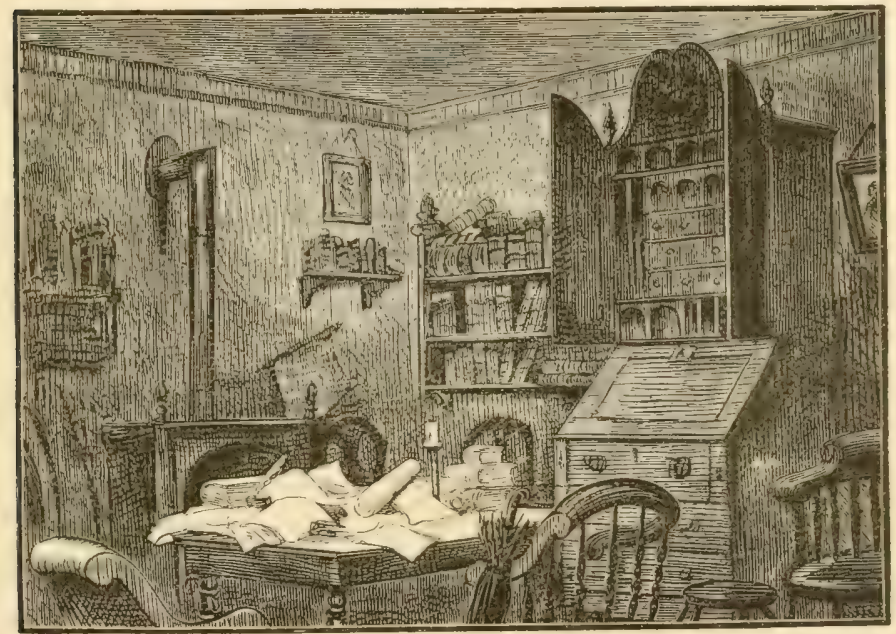

SQUIRE WRIGHT'S OFFICE.

sacred room. In winter, when the door was shut and the smoke was pouring from the chimney, all the uninitiated passers-by were filled with a bewitching idea of the comfort of that one-ideaed edifice; and in the warm summer days, when the door was open, they peered in upon the juclicial presence of that great legal authority seated within, and enrobed with a loose and flowing summer sown of calico, with a feeling of awe and veneration. The place 
was at all times such a charming temple of easy law and grenteel loafing, that even lawsuits had their bright side, and idleness was made respectable. The Squire was not a great jury lawyer, nor was he ingenious in the work of getting his clients into scrapes and then getting them out; but he was a great referee, a powerful pacificator. He was not a very busy man about the court-house, but the registry of deeds was full of titles accurately adjusted by him, and the registry of probate was full of wills which he had drawn up so that the testators were prevented from the sin and injustice of sratifying either ambition, or passion, or prejudice, in the final disposition of their estates, and went to heaven hand in hand with justice and fairness, at any rate, and with such recorded desire that the heirs understood each his exact right and proportion. Many a divorce case he heard sitting there "in chambers" ; and many a " united and happy family" went out from the hearings. Many a disputed account was adjusted there, and many a domestic broil was hushed, to break out no more. It was with peculiar respect and regard that Squire Wright was looked upon by the people. They said he had great sagacity, because he always avoided controversy. They sent him to the General Court, year after year, because he was libcral and cool-headed, and respected both parties, and never went to caucuses. They made him a county commissioner, because his honest purpose gave weight to his decisions and secured acquiescence even from the disappointed; they sent him to the State Senate, because he knew all about the wants of his district; they placed him on the Executive Council, because he was very much like the governor. He belonged to an era of good feeling, and was a useful magistrate in every sense of the word. And he always rejoiced that when violent and revolutionary questions arose, he could urge upon his people that they love their country and live together like brethren, confident 
that the great social and civil problems would settle themsches without his aid. He was evidently impressed with the idea that some kinds of people were born to rule, and other kinds were born to obey, although he never said so ; and he was somewhat in the habit of claiming for the former all the virtue, and ascribing to the latter all the wickedness of society. But he did not care to discuss this question. To him a woman was a woman, and a criminal was a criminal, and William Jones was William Jones: there was no door opening into his heart through which a rogue could pass, no amount of sentiment sufficient to make a mistake tolerable. He liked the Rer. Mr. Howe for his faith, and he wondered at his gentle weaknesses. He admired Dr. Parker for his knowledge, but he was vexed by his eccentric and self-indulgent habits. He fancied the Schoolmaster, because he was bright and inclustrious, and intended to be a lawyer. He respected Mr. Hopkins, because he was courtly and rich and honest.

Squire Wright had been absent from Jotham for many months. It so happened that about the time of Mr. Hopkins's return to his native town the Squire was employed by many of his neighbors who had invested a portion of their small capital in wild Western lands, and who were beginning to fear that both their investment and their titles were poor, to take the matter into his own hands, and extricate them from their difficulties. The work had been long and tedious, and month after month was the little office closed; no summer breeze stole in at the window and tossed the legal papers over the dusty floor; no smoke curled from the chimney on the hard winter mornings, to tell of the life and warmth and comfort below. In fact, Mr. IVright had been obliged to take up his abode in the remote IVest. He stationed himself in a new, muddy, sprawling, dismal Western town, where he worked for his clients and sighed for his neat New England home. It 
was to this town that his daughter Fanny went with the young minister whom she married; in fact, it was through Mr. Wright's influence that the parish was offered to Fanny's husband immediately on his graduation. The circumstances of the affair were all deemed fortunate, the investment of the people in those doubtful lands, the employment of Squire Wright in the investigation, the engagement of the lovely Fanny to the minister, the wants of that young and rising Western parish, the settlement, the chances which attended the growing town,

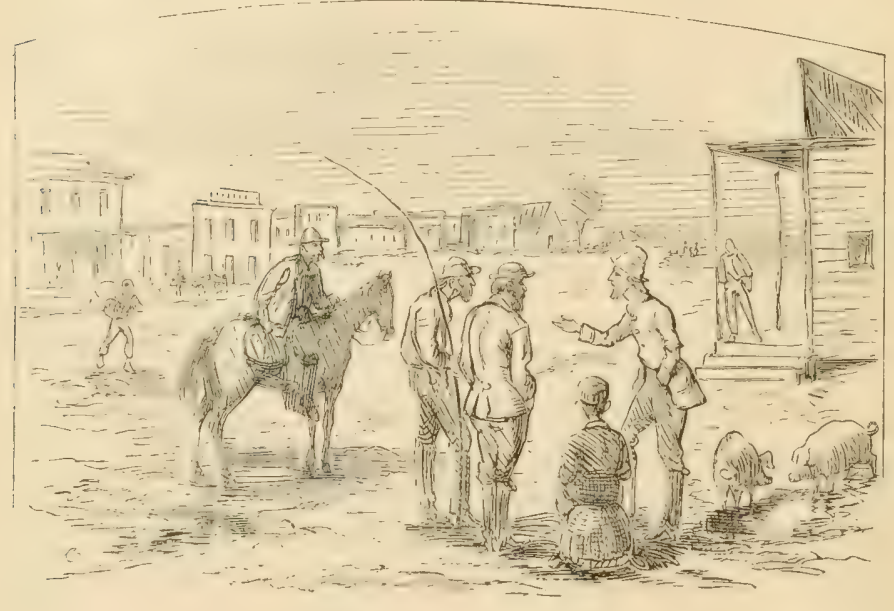

$\Lambda$ WESTERN TOWN.

- all seemed to conspire to give the family of the Squire unusual good fortune. But trouble and disappointment came apace. The young minister broke down under the influences of the climate; the malaria was too much for him; he was fretted by the ragged edge of socicty there; he was too sensitive for the rough vitality of border-life; and he died after a few months of exhausting and unsatisfactory toil. Fanny was shocked and broken-hearted by 
the sudden calamity; and when, the father being dead, loer boy was born, she felt that she had travelled the full circle of life, had grown old before her prime, and was left to toil for years along that road, which to the arged is but a step into the joy and repose of heaven. Her brother, a sturdy. lad, who had accompanied his father to the IVest, lost his health entircly through exposure in the forests and riverbottoms, which he was called on to explore; her mother grew rapidly old under the weight of care and anxiety, which she bore with sublime matronly courage; and her father, calm and self-possessed as he was, alone preserved nimself superior to all the adverse influences about him. It was in this condition of himself and his family that Squire Wright summarily finished the work given him by his clients, and returned to Jotham. It was midwinter, it is true, when he and his reached their old home; but it was a New England winter, with its clear, cold, invigorating atmosphere; it was a New England home, with its ample provisions for winter comfort and enjoyment; and it was upon Mrs. Wright, an accomplished New England matron and housckeeper, that the business of arranging that home for the various inmates fell. Under her direction the "best chamber" was soon ready for Fanny and her boy; a comfortable room was prepared for the languishing son; the parental bedroom was rapidly put in order; and a reinstated family looked about them, and from one to another, to see if the absence was a dream. The sorrow-stricken mother and the little child, and the pallid cheek of that once stalwart and ruddy boy, told the story. 13ut Mrs. Wright resumed her domestic duties, and the Squire unlocked his office, and the smoke rose from the little chimney. They were all back in Jotham.

"I do so want to see Fanny and her boy," said Clara Bell.

"I rejoice in Mrs. Wright's return," said Mrs. Howe. 
"Now, Fanny will take her place again in the choir and the Sunday school," said Mr. Howe.

"I shall be very glad to renew my old acquaintance with Mr. Wright. I have n't seen him for years," said Mr. Hopkins.

"I hope the Squire has forgotten that old horse case," said William Jones.

"I wonder whether Squire IVright will take a student into his office next autumn," said the Schoolmaster.

"We'll get the Squire to join the Club," said John Thomas.

"He used to know a good cow from a poor one," said Peter Ilsley.

"If he has brought back the money I wasted in those infernal Western lands, I'll shoe his horse for nothing as long as he lives," said Phineas Barnes.

It was in the midst of the rejoicings and congratulations and sympathy, on the return of Squire Wright and his family, that Mr. Howe and John Thomas sct themselves to work to prepare for the next meeting of the Club. They concluded that the hay crop had been cliscussed enough, and that all the theories about the value of meadow hay and salt hay had been settled long ago by the cattle themselves, both of which can be made to answer a very good purpose when accompanied by meal and turnips, and either of which, when fed alone, is mere "vanity and vexation of spirit." They determined, therefore, that next in importance to the winter feecling of animals is their supply of food in the pasture during the summer months; and they sent word to the President and the members of the Club that the next subject for discussion would be

\section{PASTURE LANDS.}

The hope and expectation of secing Squire Wright brought out a very full attendance at the Club, and when 
President Hopkins called it to order and announced the subject, he congratulated the assembly on the interest they manifested in the institution from which they had all derived so much pleasure and profit, and continued:-

It is possible that you have come in unusual numbers, this evening, hoping to see your old townsman who has been so long albsent from among you, and whose return is so welcome to us all. I have not had the pleasure of meeting Mr. Wright since I established myself here, his rleparture for the West having occurred about the time that I left $\mathrm{B}$ sston. But I am, of course, familiar with his standing and reputation in this community, and I rejoice with you that so valuable a citizen has returned to share with us the duties and responsibilities of society. I have noticed that mankind is naturally disposed to extend the right hand of fellowship to all, who, by reason of valuable service or prolonged separation, become objects of interest. It is no great matter, I know, for one of us to leave this town for business or pleasure. Nor is it any great matter when we return. But the ovation extended to a citizen of a free and independent municipality like ours, by those who are his equals in all things, his friends in prirate, his constituents in pulblic life, his rivals and competitors in the race for honors and pesition, has a significance and meaning not to be found in the prouler and more imposing ceremonies which are bestowed upon the great and the powerful. A fellow-citizen, in whom we have placed implicit confidence, whom we have intrusted with the creation of the laws under which we live, who has deroted himself to the care of all those institutions which constitute the foundation of free society, who has been our connsellor and friend, returns to resume his duties here. Not for his influence or his patronage, not for his power or distinction, not for his superior position in state and society, do we receive him with open arms and such manifestations of respect and esteem as lie in our power; but because he is one of us and represents in his person all the opportunity and position which every man here believes to be his right and privilege. 
A body of citizens receiving a fellow-citizen, - how in contrast with a body of tenants receiving a landlord, or of subjects receiving a ruler and master! For one, I like to be a member of a small community, knowing every man and known of all, my joys and sorrows made the common joys and sorrows of all. A fellow-feeling filling a whole community is a great thing to enjoy in an emergency, and grows out of a broad and generous humanity which can wade through seas of gossip and petty jealousy and come out dry shod on the other side, and ready for any event and trial. It gives me pleasure now to nominate Henry Wright, Esq., as a member of this Club, and unless objections are raised, I shall consider him unanimously elected, and I will announce to you that he will be with us towards the close of the evening. [Prolonged applause.]

And now for the subject we are called upon to consider. The committee has notified us that we would discuss the "Improvement of Pasture Lands," as part of the business of supporting our domestic animals on our farms. The importance of the question no man can doubt. From the middle of May to the middle of November, even in this northern latitude, we can feed our cattle upon grazing lands of one kind or another, and cluring these six months we can secure a large amount of the profit to be derived from cattle-husbandry, either in the dairy or in the stall. It is very necessary, therefore, that the lands used for this purpose should be economically purchased, economically preserved in good condition, and economically restored when run out and exhausted. It is usuilly calculated that it requires four acres of good pasture to feed a cow during the pasturing season. And I have no doubt this is a fair estimate. The price paid for such land, devoted to such a purpose. must necessarily be small, and the annual outlay upon it must be small also.

Now I must confess to you that, in reclaiming the farm which I now occupy, I have bcen more troubled by my pastures than by any other land which I possess. I have been able to restore the old cornfields by ploughing and fertilizing, and have conceived that I found my profit in an immediate crop. 
I hare brought up my exhausted mowing lands, from a yicld of half a ton to the acre to a yield of three tons, and $I$ am sure I found my reward in the increased crop. But when I turned my attention to the old pastures, overgrown with bushes and covered with moss, I must confess I began to despatir of ever accomplishing anything either creclitable or profitable, - anything which I could recommend as worthy of imitation. I began, of course, by cutting off the bushes : everybody does that. lut when they were gone, I had nothing but a poor starved pasture left, a pasture which long cropping and repeated growths of trees and shrubs had entirely imporerished and exhausted. Why I should have expected land upon which an oak or a pine tree would starve, to produce a good crop of pasture grass, I cannot tell. I certainly had no right to expect any such thing. I tried ploughing, but I soon found that ploughing poor land is poor bu-iness, and that it required more manure to fertilize an old worn-out pasture, acre for acre, than it clid to bring the barren tillage lands into a fair degree of fertility. I hare made my pastures look respectably, but I have not yet brought them into a satisfactory condition; and I shall be much obliged to the members of the Club if they will throw light upon this subject, either from their experience or their observation.

John Thomas, being called upon to follow the President, said: "I agree with Mr. Hopkins that the question before us is a hard one. It will never do to spend much money. on an acre of land used for pasturage. I have worked more or less on my pastures for many years, and I have come to the conclusion that time and patience are as valuable in this business as money, perhaps more so. I have learned that all useless plants should be cleared out of a pasture as the first step in its renovation. If the work cannot be done in one year, take two; and if two are not cnough, take three. At any rate, use the scythe and fire, year after year, until the work is done. Few vegetable growths can stand repeated attacks like these. The noxious plants will inevitably be destroyed; and when they 
are gone, the chances are ten to one that the nutritious grasses will grow and thrive. I have always believed that land would recuperate itself, if allowed to rest. And in this I have not yet been disappointed. When clearing my pastures, I have been very careful not to overstock them; and I have been surprised to see how rapidly the amount of grass would increase and how its quality would improve from year to year. This process is slow, I grant, but it is sure. And I can show you pastures capable of carrying a large cow on three acres through the season, which, ten years ago, would hardly carry such a cow on ten acres, if it would feed her at all. I keep my pastures clean, and I feed them moderately until they get a heary growth of grass, and then I increase my number of cattle, and for a year or two feed pretty close. I think pastures may be injured by too little as well as too much feeding, for I have often noticed that short, sweet grass is more nutritious, as well as more palatable, than that which is rank and heavy; and I am sure, also, that unless properly fed, pastures may become filled with useless grasses which the cattle will not eat, and which drive out the better grasses, and are more difficult to get rid of than barberry-bushes or Canada thistles."

Peter Ilsley had no doubt that the plan of John Thomas was a good one for his land. "But," said he, "I find that I cannot bring my pastures to with time and patience at all. I have no 'ferns,' or 'brakes,' or barberry-bushes, or Canada thistles to fight. I am not troubled with huckleberry-bushes or bayberry. Trees don't grow on my pastures. They are smooth enough, Heaven knows. And I never have to feed them close to keep out the poor grasses. But they are covered with a dry, crackling moss, which takes the place of grass, bushes, and everything else. Now it is of no use to wait for this stuff to gro off; for it will not go of its own accord. And so I am obliged to stir 
up the land somehow or other, and make the grass grow where the moss has got possession. Land may recuperate itself, as Mr. Thomas says; but I think that land which will grow but little grass and no busbes, and a great deal of moss, has lost the power of recuperating itself, and needs help of some kind. Such land as this needs manure of some sort, and must have it. You must fertilize it with something, and in some way, if you ever expect to make a decent pasture vut of it. You must either plough and manure it or top dress it. Now, I am not much in favor of ploughing a pasture. If ploughed at all, it should be for the purpose of cropping and cultivating for corn or potatoes or grain or root crops; and then it passes out of the list of pasture land and becomes tillage land, and should be so classed and used. If the pasture is large, and is so far away as to make it fit for pasturage only, you cannot plough it with profit or adrantage. For instance, I have a fifty-acre pasture, a mile from my house, - a hill pasture, free from bushes, with hardly a tree in it. It is useless for me to try to plough such a pasture as this. It cannot be done. And if it could, I am not sure that this is the best way to improve it. Mr. Thomas is right when he says the natural grasses should be brought in if you can do it. Now this cannot be done by ploughing. You can get them out with the plough, but you cannot get them in. For when you have ploughed, and manured, and seeded, you have only the artificial grasses, such as herds-grass, which hard croppings and frost will always kill in the long run, and redtop, which easily dies out, and clover, which will not last more than two or three years at the longest. And so I have seen a small pasture lot ploughed and manured and cropped, and seeded to various kinds of grasses, but the crops were poor and the grasses which were seeded into it did not come to much. It made a poor pasture, after all, and it never approached being a good one until 
the natural grasses had come in and driven the artificial grasses out. I have two pieces of land, several miles away, which I use for pasturage. One of them has been cultivated for many years; the other has never been cultivated at all. The cultivated lot has, every year, the most grass; but the other has the best feed, and my cattle and horses always thrive best there. Why this is I cannot tell. But the cattle know it, and that is enough. I do not think, therefore, we can ever expect to make good pasture lands by using the plough. On a large scale we cannot afford to do it; and on a small one, even, we cannot always depend upon it. And so, I suppose, we must use top-dressing; and use such as we find most useful for the land we would restore.

"Now, for me, plaster is the best top-dressing that I can use. I have used it freely for thirty years, and where I have used it most my pastures are the best. I do not think it works very well on light sandy lands or on gravelly knolls; but on all the clayey hills and springy lands on my farm I can use plaster with great benefit. It scems to warm and sweeten the land, and brings into it a great deal of white clover. Where plaster does not answer, we must resort to something else, always remembering that top-dressing is the best thing to do. Let me read what a gentleman in Franklin County did with one of his pastures. He says: "In the first place, I removed all obnoxious vegetation; I made a clean thing of it. It cost me a good deal of labor, but when it was brushed over it looked very smooth. I then took twenty bushels of ashes (the pasture covered fourteen acres), three quarters of a ton of plaster, and eight bushels of hen manure, and composted them together. It lay some two or three weeks, and then I scattered it round the fourteen acres, broadcast. It had a very wonderful effect. I have continued the same dressing up to the present time. I began this operation seven years 
ago, when the pasture could only carry two cows ; and the season before the last I put in seven cows and three carly spring calves, and had a very fine pasture. The last season I put in the same, but, in consequence of the severity of the drought, I removed two of the animals. But from the experience I have had with this tract of land I think, if I am permitted to live three ycars, I can keep ten cows on this pasture, and that they will be able to fill themselves in two hours and lie down. I find that plaster alone will not answer my purpose on this land.' But, Mr. President, I am taking more than my share of the time."

The Schoolmaster here took up the subject, and asked if the experiment of dressing the land with different soils and earths had ever been tried by any of the gentlemen present. He said he knew one instance in which a dry and somewhat gravelly pasture had been brought into fine condition by the use of muck. He had seen it the year before, and the growth of grass upon it was abundant. He had also known of the application of clay to land covered with moss, and the effect was wonderful. It seemed to him that the rule was "almost anything for a change"; and he suggested that clay, coal-ashe's, wood-ashes, fish-guano, plaster, and lime should be used as a top-dressing on pasture lands which had been overfed and exhausted. That pastures should be kept free from bushes he could not doubt. Ife believed that some kinds of trees, such as the red-cedar and the locust, might be scattered over a pasture without harm, but not the bushes which usually spring up when the wood is cut off. But he would as soon expect to get a valuable crop from a weedy ficld as a good supply of sweet grass from a bushy pasture.

At this point Squire IVright came in, and the Club acljourned. He was most cordially and kindly received, and it was noticed that, while all his dignity remained, he had evidently been softened by the hard experience tinrough 
which he had passed. He had lost none of the soundness of his head, while he had increased the warmth about his heart; and he was pleased to say to Mr. Hopkins, at the close of the collation given by that gentleman in honor of his return, that he thought his presence in Jotham had vastly improved the character of the town. "At any rate," said he, "the place was wise and kind when I left it; but now it is as warm and cordial as my old mother's hearthstone." Mr. Hopkins, however, as he bade him "good night," thought the change was in him. 


\section{SIXTEENTH MEETING.}

\section{PASTURE LANDS (Continued).}

DR. PARKER DOES NOT UNDERSTAND CLARA BELL. - CHARLES INGALLS DOES. - THE SQUIRE FOUND TO BE FALLIBLE.

IF a family of strangers had moved into Jotham, they would not have been more an object of interest to the people there than were Squire Wright and his wife, his children and grandchild, on their return from the WVest, and their occupancy of the old mansion. In many respects they were themselves strangers, indeed; for the subdued and sorrow-stricken and enfeebled, who had come back, were by no means the conficlent and vigorous group who went out. Fanny IVright (for nobody seemed to realize that she was Mrs. Ransom now) was remembered only as a tall and stately girl, erect as a forest pine, and so full of a sort of "lofty cheer," that she seemed to elevate and inspire all about her. She had married the young and delicate and handsome Rev. Perez Ransom, without any special knowledge of the "ecstasy of love," but because it seemed natural that any good girl should be glad to marry a minister, and because the bearing of the inexperienced pastor towards her, even in the rosiest hours of their betrothal, was more that of a shepherd to one of the lambs of his flock, than of an impassioned lover to the object of his love. She had gone the entire radiant and glowing round of mistress, wife, and mother, without knowing either the wisclom or the sweet delirium of love, and without realizing that there is any other motive than a sense of duty either on earth or in heaven. It had all 
been done before the village knew that it was fairly intended; the few well-written sermons, some Sunday evening interviews, a sudden engagement, a marriage unexpected, and the clean and proper young minister and his bright and beauteous bride were gone. What wonder, then, that Fanny's old companions, who were not a day older in spirit, and but little more than a twelvemonth in reality, should find it difficult to realize that she had returned a mother and a widow, - a mother whose first warm and glowing sentiment ever felt was for her child, a widow who remembered with the greatest pleasure the pious attributes of her departed husband? What wonder that she herself was obliged to pause, now and then, and explain to herself how it was that her mother had become her intimate companion also, sharing with her a new and deeper life, and traversing with her profounder paths of knowledge; why it was that she had left the sweet little chamber of her grirlhood, and had become worthy to occupy the most well-ordered and imposing room of the house; how it was that her father had added to his natural affection for her the tender veneration which he felt for the mother of his grandchild? Mrs. Ransom was, indeed, a stranger in Jotham; a stranger to those who had known Fanny Wright; a stranger to herself, who did not understand how she had reached such maturity and exuberance of life, considering the road she had travelled.

Squire IVright, too, found his condition materially changed from what it was before he had passed through his recent experiences. The people had at last discovered that he was mortal like themselves. They retained all their respect for his integrity and sound judgment, but they felt that he was now more than ever one of themselves. They had been half inclined to think that whenever he uttered his decree even the wind and sea would obey him ; but now that he had been shattered by the storm, they 
held out one hand to help him, while they crended the other to receive from him their accustomed aid. It wals observed that in his intercourse with his neighbors and friends, he had now not only a judicial word, but a gentle onc; and they who had been in the habit of watching the expression of his countenance discovered a gentler and more kindly light playing over his features, where before those sterner qualities which men call reliable had held their sway. It is barely possible that his magisterial grandeur had been somewhat dimmed; but his humanity had expanded, until he included within the circle of his interest not those engaged in the business of life alone, but all who needed a sympathizing look and tone as well as sound advice. Mr. Howe consulted him with regard to the affairs of the parish; Mrs. Howe asked his opinion with regard to investing the surplus funds of the Female Charitable Society; he encouraged the Schoolmaster to discuss with him the best method of managing the school; he even bestowed upon IVilliam Jones, who sought his advice about some doubtful trade, such genuine and impressive counsel, that he materially mended his ways; and he took the affairs of Jim Bell, the miller, who was gradually declining and fading away, into his special care and keeping, for the benefit of his family when he was "dead and gone." Clara Bell, who, although intimate with Fanny and a favorite of Mrs. Wright, had never dared to approach the reserved and dignified old lawyer, found now in him the sweetest comfort and consolation; and haunted as she was by the restless and fitful spirit of Dr. Parker, and continually and painfully conscious of the Schoolmaster's unuttered and unhappy affection, she was especially grateful for that picture of domestic happiness and repose which always presented itself in Fanny's chamber, when her boy nestled to his grandfather's heart, and warmed and irradiated the evening of his day, with a glow which even the 
bright morning had not known. The Squire until now had not known himself, nor had he been truly known by his townsmen.

The condition of Charles Wright, the son whose health had been broken at the IVest, was such as to require frequent visits from Dr. Parker. "The boy," too, as he was familiarly known, needed looking after ; and Fanny's.chamber became a constant resort of the Doctor, who, notwithstanding his peculiarities, had a genuine love for whatever was gentle and refined. He had discovered, too, the affection which was renewed in stronger and deeper form between Fanny and Clara Bell, and the constant presence of the latter in that cheerful and domestic room invested it with a peculiar charm to himself. And here he was especially bright and fascinating. He had great respect for the ability and information of the Squire, whom he often met there; and he was deeply moved by the strange and inspiring influence which these two young women had upon each other, to invigorate their finest faculties, and to create a harmonious whole which can seldom be reached by the individual alone; these two young women, so unlike and yet so fitted to each other, the one having reached the highest experience of life without knowledge of the way, the other already harassed and distressed by conflicting love and duty, even before the path of life was fairly opened; the one having shaped her mind and heart according to the demands of true regard, the other having witnessed nothing thus far but the intensity of passion; the one having learned the end without knowledge of the beginning, the other tossed and tried by the conflict of an impassioned beginning without thought or knowledge of the end; both sincere and earnest and gentle and fair, the palm-tree and the pine of true womanly beauty. Dr. Parker had never seen Clara so charming as when under the influence of this association. That girlishness, which 
he had always before witnessed with some degree of impatience, vanished here, and her fine womanly qualities, her good sense, and her intelligence displayed themselves to his surprise and admiration. He realized, too, more fully than he had ever done before, how grossly he had insulted and trifled with her on that unfortunate drive from the seaside. He learned what a fine womanly nature he had shocked, and, as his affection for her increased, he grew also more and more ambitious to win the object of his love, as a triumph over the obstacles which he felt his folly and wickedness had thrown in his way. He had sayacity cnough to see that Clara had not forgotten that event, and that it prevented her from stepping beyond that recrion of kind consideration, which she had been taught to feel for him from her clildhood, into the higher region of love. $\mathrm{He}$ could see that she was no longer obedient. And he felt, moreover, that as her intimacy with Fanny went on, her knowledge of herself would increase, until her own nature, and not the nature imposed upon her by others, would assert itself. He knew that she loved Charles Ingalls, and that nothing would prevent her from being obedient to that love, except her belief in the bonds which had bound her to the will of her father and to himself, as her father's friend and her protector; and he trembled when he thought upon the possibility of revolt and self-assertion, and the liberty which must follow. He could not speak to her upon a subject which, in an hour of prostration and abasement, he had referred to in language bordering on buffoonery and folly. The stars of heaven looked down upon him, and told him that, with a drunken leer, he had compared her eyes to themselves. The sweet tones of her voice reminded him of her trembling farewell on that unhappy midnight. And he knew also that before her stood continually the pure and honest and manly form of Charles Ingalls, whose gentle deference told the feeling within, 
whose deportment was so exemplary, whose purpose was so honest, whose soul was so spotless, whose mind was so eager to enter upon the work of life for her sake, and between whom and her heart of hearts stood nothing but his own long-established authority, clothed by her with a little affection. But he knew, moreover, and he never ceased to remember it, that Fanny Wright had married the young minister from a sense of duty alone, and without the slightest iclea of the law of love; and he hoped and believed that her experience might still be considered a law unto Clara, and that she might be led to believe that wisdom and prudence and thrift are a better guide than love itself. But he forgot that he, in his mad moments, had taught this young girl the lesson he would now have her forget, and that when he babbled of his own love he pointed the way for her to something purer and holier. Neither did he know that love had already sprung up in her heart, and that the path which Fanny Wright had trod was impossible to her. There was no such thing now for Clara Bell as Fanny Vright's marriage with the minister; and Dr. Parker ought to have known it. The Schoolmaster did, and possessed his soul in peace.

It was while Dr. Parker was considering, in his own mind, how he could best extricate himself from the difficulties which surrounded him, and was enjoying his daily visits to this charming circle, that the time arrived for another meeting of the Club. The Doctor was not sorry for this. He hoped to meet Squire Wright there, and he thought it possible that he might produce a favorable impression on that gentleman's mind, which he might convey to Fanny and Clara. He hoped, too, that he might meet the Schoolmaster, and learn the condition of his mind, under the knowledge of his own frequent and long-continued visits at the Squire's.

The meeting of the Club was unusually agreeable. The 
old parlor never looked more inviting and hospitable; the fire was never brighter; the members never nore courteous and spirited.

Mr. Hopkins announced the subject under debate to be

\section{RECLAIMING PASTURES,}

and called on John Thomas to lay before the Club such information as he had secured since the last meeting. Mr. Thomas said : -

Mr. PRESIDENT, - I can add but little to what was said at the last meeting upon the subject of renovating pasture lands. I

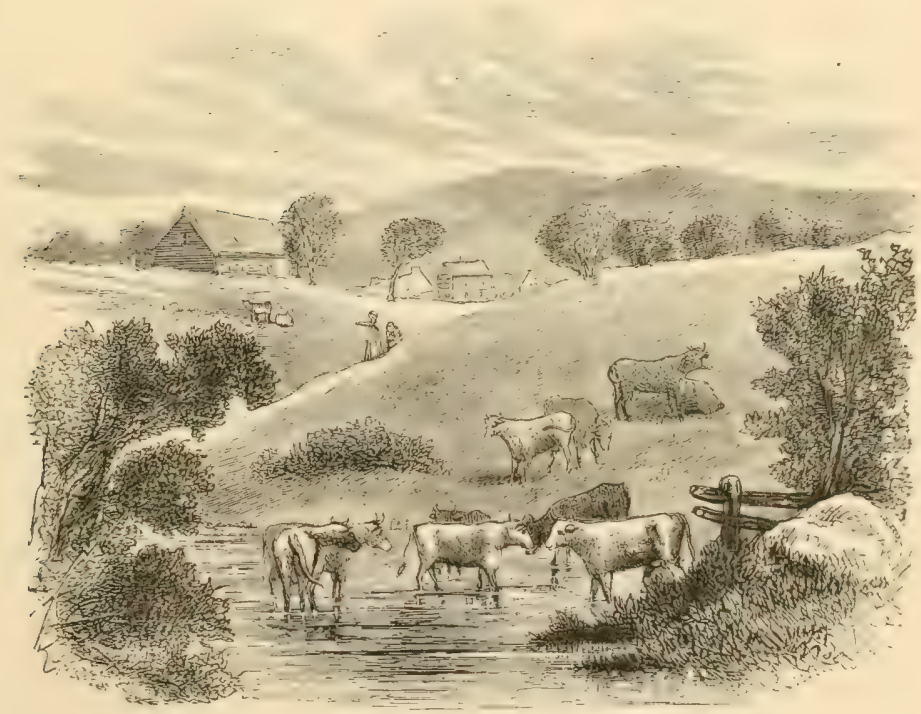

HILLSIDE PASTURF, ANI) CATTLE.

think we have but little raluable information upon the matter, beyond the statements made at that time. It is undoubtedly a good pian to keep pastures free from bushes, and to stock them 
lightly, if we would preserve them in good condition; and the same plan will apply to renovating them when they are overrun and exhausted, except that in this latter case you must apply some kind of fertilizer. I have looked over the statements which have been made on this subject, from time to time, in reports and essays, and they all agree in the views expressed here. Not many years ago the Board of Agriculture in Massachusetts issued a circular to the farmers of that State, making inquiries upon the very question now before us; and, from the statements made in reply, they recorded the following conclusions, which I take the liberty of reading from one of the annual reports of that body:

"It is known to all who have investigated this subject, they say, that all pastures which have been constantly and closely cropped for many years, without receiving suitable returns, must of necessity be greatly exhausted of those substances which, in the economy of nature, are appropriated to the growth and support of bone and muscle and to the production of milk; and that thorough renovation can be effected only by restoring these substances to the soil. Different modes of restoring these properties have been practised; but it matters little how the effect is produced, provided it shall be thorough and at saving cost.

"In every ten gallons of milk there is about half a pound of bone earth; hence a cow that gives twenty quarts of milk a day takes from the soil about two pounds of superphosphate of lime every week; and to restore this, three pounds of bone-clust are necessary. IBone-dust and sulphuric acid, mixed in equal parts by weight and left until the acid has decomposed the substance of the bones, have been applied with satisfactory results. By this process the substances of which the bones are composed are very minutely divided, and are thus more readily taken up by the roots of the plants. This preparation may be conveniently applied by mixing it with plaster, loam, powdered charcoal, etc., or to this mixture may be added thirty times its bulk of water, and applied in a liquid state.

"Bones are best suited to dry or well-drained land, and may take the place of a part or the whole of the farm-yard manure. 
When thus used it will be well to combine them with wordashes.

"Ploughing exhausted pastures will be of little avail, except to destroy weeds and bushes, without a suitable application of manure, as ploughing will restore nothing of which the soil has been deprived by long and close feeding. Manure in suitable quantitics is indispensible; but any kind that will produce grood crops of timothy and clover will answer the purpose.

"It is the opinion of the committer, formed upon some experience, that old pastures may in many instances be renovated by turning them over smoothly late in the autumn, applying with a harrow a liberal quantity of manure in the spring, and seeding with redtop, timothy, and clover, with or without a crop of wheat, barley, or other small grain. If the season continuts dry, after the crop of grain, if there is any, has been removed, the young plants will languish, and they must be protected from close feeding; if the season should be wet, a heavy growth will follow, and admit of pasturing freely.

"It may be, and probably is, a better and more thorough mode of operation to plant with corn or potatoes the first year, and seed the next, applying a second dressing of manure. Buth modes may be tested at pleasure.

"The production of these grasses may be greatly promoted, and the latter, in moderate quantities, inclefinitely continued, by occasionally top-dressing them with from one to two bushels of plaster per acre, or twenty-five bu-hels of wood-ashes per acre, when plaster refuses to operate. Irrigation, with slight manuring in many places, produces favorable results.

"The committee learn, both from experiment and inquiry, that pastures deroted exclusively to the fattening of cattle seldom deteriorate, clearly because they are not cropped to the extent of all they produce, and the cattle remain upon them both day and night.

"The committee would suggest the following plan for the renovation of such pasture lands as may be ploughed:-

"Set apart four or five lots of convenient size; plough and plant No. I with corn, applying manure enough to produce a 
good crop. The next year sow the same with wheat or barley, and stock down to grass. Plant and treat No. 2 in the same manner, and so continue, planting one lot and stocking down one lot each year, until all are stocked down to grass. At the end of six years the five lots will have been completely renoratud, and the same course commenced a second time. Thus the system may be indefinitely continued, yiclding an unbroken succession of remunerating grain crops and pasturage of the finest quality.

"In a single instance which came to the notice of one of the committee, the quantity of grass produced by this mode of cultivation was, he believes, nearly quadrupled, while the quality was improved in a much greater ratio.

"The committee are aware that many experienced cultivators, whose opinions are entitled to the highest respect, are strongly opposed to the practice of pasturing renovated lands until the third year after seeding; and they seriously question whether any advantage results from ploughing such lands for the purpose of renovation. It is hoped that valuable information will be derived from the experiment on the application of manures, which will probably be made by the county societses under the direction of this board.

"If it should be proved by the proposed experiment that manures applied to the surface are of equal efficacy with those harrowed or ploughed in, and thus incorporated with the soil, then the plan abore suggested may readily give place to the system of surface manuring."

I have read this report, Mr. President, because I once knew the author, and I had great respect for his intelligence, honesty, and grod judgment, and because I desired to show that eren from such a source we could derive nothing very positive or definite on the question before us. The experiment proposed by this committee could not possibly be applied to remote or hilly or rocky pastures with any chance of success, on account of the enormous cost which would attend it. You cannot apply to a pasture the same mode of cultivation which you apply to a piece of mowing land, unless you are willing to add very largely 
to the cost of the 1.nul, without expectines an ample or eren a real. sonable reward. I agree, therefore, with the conclusions we reached at the last meeting, namely, rest, destroying bushes and weeds, and the application of fertilizers to the surface. I can show you, to-day, a piece of pasture land of about twenty acres, level, casily ploughed, free from stones, and just such land as can be casily and economically handled whether for pasturing or tillage. Three years ago one half of this pasture was ploughed, planted one year to com, manured reasonalbly, and seeded the next. Since that time it has been feel down by milch cows. The other lialf has been let alone, the owner not having yet got ready to extend the ploughing and cultivating. Now, if you will visit that pasture any day in the months of June or July, when the feed ought to be as good as the land will yielel, you will find the cultivated land to be still broken, the sod uneven and not uniform, the grass scinty, weeds springing up here and there, and the amount of feed quite small. On the half which has not been ploughed there is a firm, compact sod, a fair supply of feed, and a smooth and eren surface thickly and uniformly covered. I renture to say that there is more than twice the amount of feed on the latter half that there is on the former. And I think every member of this Club would agree with me that upon the unploughed piece there is a vastly better chance to use with advantage plister or ashes or any other fertilizer, than there is upon the piece which has been ploughed, cultirated, and manured. I know I am repeating somewhat the remarks of the last meeting; but the question is one of so much importance, and one also on which we have still so much to learn, or unlearn, and I don't know exactly which, that I trust the gentlemen present will excuse me for travelling over ground with which they are already familiar.

Mr. Howe took the floor at this point, and said :-

I have listened with great interest to the remarks made at . the last meeting of the Club, and to the report read this evening by Mr. Thomas, with valuable comments of his own, upon the management of pastures. I can easily see that the minds 
of those who have discussed the question are occupied by the best methods to be applied to large, remote, outlying lands which, unless pastured, would either be lying waste, or growing up to wood. I grant that the difficulties surrounding the management and renovation of lands like these are very great. But I have in my mind some smaller farms, so situated that a portion of them must be used for pasturing, where I think a more elaborate system than has been proposed here may be adopted with great benefit. More than fifty years ago my father, who, as you well know, was a clergyman, who divided his time, as all his contemporaries dicl, between his parish and his land, purchased an estate of ten acres for his homestead. It was a strong, somewhat heary piece of land, seven acres of which was a level elevated plain, and three acres of which occupied the slope of a hill. None of the land was in good condition, and it was thought best to sulject the whole to a uniform system of renovation, before dividing it into such lots as might be needed for the various purposes of a small farm. When the buildings had been erectech, and the walls and fences completed, the entire ten acres were put uncler the course of cultivation in fashion at that time. The crops, with the exception of a small patch for a garden, were corn and putatoes and grass in the common rotation. The hillside was the least promising and most troublesome part of the farm, being uneven, springy, and covered in many places with brake-roots and hassocks But these were all removed, and the land yielded great crops of potatoes, as I well remember, excellent corn, a fair crop of barley, and very heavy crops of grass, to which the lot seemed to be especially adapted. In the course of four or five years after the clearing and renovating process was becrun, it was cletermined to devote this hillside to pasturage. Remember, it had never been exhausted ; it had never been pastured or cropped to the point of being rum out; it had simply lain rough and idle for years. It was fenced off, and the business for which it was designed commenced. There are three acres of it ; and from that time to this it has carried two cows, sometimes, for a few weeks, three, often a yearling heifer in adclition, and by the application 
of a few bushels of plaster, every four or five years, it has retained its value as a pasture to this day. Care has been taken, it is true, that it should be kept free from brush and noxious weeds; hardhack has been cut down as soon as it appeared; thistles, which have sprung up now and then, have been carefully mowed while in blossom, and a little coarse salt has been applied to each root, as a sure eradicator of this pest; and the droppings of the cows have been scattered orer the grass early in the spring for many years. This pasture, thus reclaimed, has been very convenient to that little farm for a long time, to say the least 'of it. It has, as I think, been very profitable; for here were three acres of land, well located, easily fenced and walled, carrying season after season as many cows as twelve acres of common pasturage would have carried, uncler ordinary circumstances. I do not mean to say that this could be done in all cases. I only know that it was done in this case, and that every practical observer was satisfied that this division of the ten-acre farm was much better than it would have been to purchase a pasture elsewhere, and devote the original purchase to crops alone.

Mr. Howe's statement was received with evident satisfaction; and in the farther corner of the room Solomon Eaton, the thin and feeble and white-haired old man long past eighty, lifted up his piping little voice for the first time in the Club, and bore his testimony to the importance of scattering the manure of last year over the grass in spring. "I have made it my special business for many" years," said he, "and I have had the same maul to do it with for more than twenty-fire years, and mean to use it twenty-five years longer."

The old man's little speech silenced everybody for a few minutes; it was so unexpected, so flavored with a childish enthusiasm, such a momentary waking up of all the old forces, such an evidence that even in the frosty winter of his old age the opening spring-time of nature was as full of delightful warmth and cheer as ever; it struck like a far-off 
knell. And in the silent moment that followed every man there saw a vision of a lifetime, from the dawn of the morning to the last feeble ray of the setting sum.

Villiam Jones, however, was not the man to bear such kind of silence long; and so he remarked that "pasturing was dear enough, anyhow, without ploughing and manuring," and he hoped the simpler method of cleaning and delay would be adopted by the Club.

"So say we all of us," chimed in Peter Ilsley. And at nine o'clock the Club adjourned.

Old Mr. Eaton tottered out, and was followed by Jones and Ilsley and most of the members of the Club, who were evidently anxious to get home before the snow-storm, which had now set in, became severe. Dr. Parker, who had sat unusually silent during the discussion, and had only changed his attitude to turn now and then a half-dreamy gaze upon Squire IVright, and to avoid the Schoolmaster, went out also. The Squire and the Schoolmaster lingered behind. There was no special purpose in their delay; but they happened to come together as the assembly dispersed, and they paused before the fire to pay each other those usual civilities which are so useful in preparing the way for intimacy, and which are so convenient to occupy the time while the preliminary survey is going on. It was evident that these two gentlemen had already taken a fancy to each other, and it was evident to the Schoolmaster that somehow the Squire had alreacly gained more knowledge of him than is usual with a stranger or a new acquaintance. At any rate, so it seemed to him. And as he stood there engaged in careless conversation with that old man, he felt assured that the problem which troubled him would be solved to his satisfaction, if he would only conduct himself in such a way as to secure the respect of this venerable lawyer, and the esteem of this subdued and softened gentleman. 
"Ah : my friends," cxclaimed Mr. IJopkins, as he chesed his front door and returned to his parlor, "I am glad to see you together. Charles Ingalls, Mr. Mright, is a most estimable young man, I am halply to say. I commend him to you. Ife has tatught our school most acceptathly; this is now the second winter; and he has done well, - done well in the school-house, and in the Club, and in the chureh, and in our houses. I hope the day will come when we shall find him in your office. You will study law, Mr. Ingalls, of course?"

The Schoolmaster hardly knew what to reply, but he hesitatingly answered that pussibly he might. He had sometimes thought of medicine.

"Not at all, not at all!" said Mr. Hopkins. "Medicine is a very sooul profession, lute it is not the sphere for you. You may think you would enjoy the work of relieving human suffering, and of becoming a part of every household in town; but I know better. You may not succeed anywhere, but you may be sure you never will as a physician. And I advise you to school your mind from this hour to the business of clearly and calmly examining whatever comes before you, and to a rapid application of some fixed law with which you are familiar to such matters as are submited to your investigation. Above all things, cultivate your memory, that your judgment may not be lecl astray. Tou must be a lawyer, and a good one. IThat de you say to it, Mr. Wright?"

"I am inclined to think you are right, Mr. Hopkins," replied the Squire. "Mr. Ingalls has a little more fullicity" about him than is absolutely necessary for a doctor. I guess he'd better try the law."

They chatted awhile, and separated. And Charles Ingalls pondered upon the good fortune of his two old friends. 


\title{
SEVENTEENTH MEETING.
}

\author{
ROOT CROPS.
}

ILLNESS OF THE BOY. - HIS RECOVERY. - SILENT DISTRESS. CHARLES INGALLS TELLS HIS TALE. - CLARA LISTENS. - DAY BREAKS.

"ThE Boy" had been ill for many days. A heavy, gloomy cloud had hung over the house. Hour after hour, through day and night, the child lay there, weighed down by the oppressive load of disease, unconscious of the drooping sadness all around him, and of the desperate struggle for life going on within him. The attentions of Dr. Parker were constant and devoted; he made an almost impatient appeal to the science he loved so well to manifest its power, or surrender its claims to the confidence and respect of mankind; and he realized the restless and exhausting anxicty which, more than toil itself, wears out and kills the faithful and conscientious physician. The Squire was bewildered and lost. The storm had struck him when he least expected it, and he wandered from his house to his office, and from his office to the bedside of the little sufferer, where alone he found a momentary repose. He prayed for the child's life; he waited and watched in silence; he looked and longed for one encouraging word from Dr. Parker, but dared not ask for information; he tried over and over again to ask his good wife, the patient and cheerful and self-possessed grandmother, whose calm trust and great faith held up, as with a strong arm, the suffering household, if it was well with the child, but the words choked him and his tears blinded him; and often and often 
did he put his great, strong arm around Fanny, his daughter, the broken-hearted young mother, and clraw her to him in the sad, oppressive silence of that chamber, as his expression of love and sympathy. It was in the companionship of Mr. Howe alone that he found comfort, and to Mr. Howe alone was it that he unburdened his aching heart, asking him to pray with him ; "for," said he, "if the child lives, I shall owe all the joy to God; and, if it dies, I shall surely need all His support." In all the great trial Fanny never faltered, it is true, but she went about her duty half bewildered and stunned by the swift calamity. To her the daylight was all gone. She passed, mechanically, from place to place; diligent in all offices for the child, and $O$, so weary, and so broken-hearted by the presence of the simple little arrangements she had made for the comfort and happiness of her boy. The sight of his idle toys killed her. A little picture, hanging on the wall, placed there to please his eye, blinded her. All she had done for him seemed poor and weak; its very poverty was touching, now that he walked with her on the confines of the dark valley. And as the depths of her heart were revealed to her, she learned for the first time the sacredness of her being, and realized what that love is which binds with a holy bond. The world, indeed, seemed to mock her as it went upon its accustomed way, while her own life was so torn and convulsed. And as she learned how sorrow, as well as joy, belongs to the wise design of the Great Father, she recalled the tender lines which Charles Ingalls once read to herself and Clara:-

"Its inmost bitterness, the heart

In its recesses knoweth ;

Yet, ne'ertheless, the spring-flowers start,

The mild spring-wind still bloweth";

and she felt how over all the heavens were spread with the equal blessing of sunlight and cloud. And then the 
hours were so heavy, and the fountains of her tears were so dry, anci her lip was so parched and feverish, and the gloom was so solemn, and man was so powerless, that she longed to lie down by the side of the child, and wait for death to come.

It was very long, as long as eternity it seemed, before the darkness broke and day began to dawn. But the hour came, and when to all that band of mourners it seemed as if the shades of death were coming on, and that little life was about to close, Dr. Parker amnounced that the severity of the discase was passed, and that "nature," as he modestly remarked, "had triumphed." And "joy cometh with the morning:" The light of that house returned. The Squire once more drew Fanny to him, whispered his gratitude, and then retired to the loneliness of his office, to muse over the smouldering embers on his hearth upon the great and surpassing grodness which had averted the trial. The patient and long-suffering and cheerful grandmother wiped away the one tear which trickled out of the corner of her eye, and pursued her accustomed way of usefulness and self-control. Clara Bell, who had constantly bestowed her sweet and gentle aid, prured out all her heart in one abounding liss to Fanny, and fled to her own humble home to tell all there in a food of grateful tears. The worn and drooping mother was still; too thankful for words, and too much bowed down to feel and realize that the joy of her life had retmmed. Iicfore her eyes there passed continually a new vision of the life she had lived; her short and sad experience had a new meaning; she had learned all those powers of the human heart which belong to the sphere of wife and mother. She thanked God for her child, and she pondered with a new and tenderer love upon the memory of the child's father.

The care which Dr. Parker bestowed upon Fanny's child, during its long and severe illness, was tender and touching. 
Ite had done all that his learning and skill could dictate to wercome the discase, but, more than this, he had chone all that a watehful and intelligent nurse could have done to bear the child over the depressing moments, when the powers of life seem to be more endangered by weariness than by the discase itself. IIe had so deroted himself to this work, that a marked change in his general deportment was manifest to all who knew him. II had evidently put himself on his grool behavior; and cren the minister and the Squire felt that the umpleasant shade of recklessness, hardly visible, it is true, which colored his life ordinarily, had passed away. If carried with him so manifestly the influence of the anxious family, that the people of Jotham, with whom he was in constant intercourse, felt a deep and universal sympathy for the sufferers, and rejoiced most thoroughly and warmly with them when the trial was over. It really seemed as if the character of the village had changed, - so great is the effect of even one prominent and controlling "individual upon the community in which he lives. Jotham, with a purified and softened Dr. Parker, was a vast improvement upon Jotham with the mysterious and incongruous Dr. I'arker of the library, and the laboratory, and the grocer's counter, and the periodical indulgence. And not in the village alone did this temporary change in Dr. Parker have an effect. It was not in accordance with nature that he shoukl go hand in hand through all that trial in Squire Wright's family, and not establish a new and better relation there. The respect ancl admiration felt for him by the Squire and Mrs. Wright were unbounded. Fanny was filled with a warm and almost affectionate gratitude to him, and he was now received by her with emotion as well as with regard and civility. Clara Bell's face, which for months had been so passive in his presence, seemed now to be filled with a light almost tender whenever she met him. And so 
charming was all this to him that, deeply conscious as he was of his weaknesses and defects, he felt at times that his regeneration had begun. He knew at least that his relations to mankind about him had materially changed.

During the many weeks of "the Boy's" illness the people of Jotham had been remarkably quiet. Mr. Howe had been obliged to give special attention to the poor and suffering of his parish. Mr. Hopkins had been called to Boston oftener than usual on matters of business. The "singing-master" had been so clisabled by a cold that his school had been suspended. John Thomas had been confined to his house by an accident which befell him while he was at work in the woods. Peter Ilsley had been knocked down by his bull, and so bruised that he could hardly get to the barn to fodder his cattle; and William Jones had been constantly occupied in taking care of a favorite horse, which had been unaccountably attacked with cerebrospinal meningitis. Not a social tea-drinking had occurred for weeks; and even the Club had been obliged to postpone its meetings. In the midst of all this trouble and general suspension the Schoolmaster stood alone. Day after day he discharged his duty in the school-room; but when that duty was over he found himself deprived of all those enjoyments which had made Jotham so fascinating to him the previous year. He had but little opportunity for pleasure; and amidst the sorrows of his friends he had no heart for what there was. In common with all those about him, he felt also a deep sympathy for Fanny and her boy ; and it was perfectly natural he should abandon his usual haunts, and turn his steps towards the new objects of interest. While, therefore, Dr. Parker was devoting himself to his professional services, and Mr. Hopkins was in Boston, and Squire IVright was mournfully waiting for the relief which came, Charles Ingalls found himself occupying his leisure hours in various attentions to Jim Bell. He 
had forgotten all the imaginary barriers between himself and Clara; and, without awkwardness or hesitation, he began his devotion to her father, whose feebleness increased day by day, and whose useful friends were too largely withdrawn by the illnesses and accidents which have already been recounted. There were the newspapers to be read, and he read them. There was the village gossip to recite, and he recited it. There was an old account to be found and examined, and he found and examined it. From Clara, too, he could get daily reports of the illness of "the Boy"; and so, the way being open, he walked in it without effort or delay.

His hours with Clara were not all rosy and unclouded. He had not forgotten that early allusion of hers to the authority of Dr. Parker, and while he felt inwardly sure of her regard for him, he conscientiously observed the obligations which he felt her sense of duty imposed upon her. The moments spent with her were sweet enough, it is true, for all around the books which they read together, and the bits of song and story which he prepared for her, and the pictures of his future life and career which he drew with her, there was a warm and glowing atmosphere, whose lifegiving influences they both recognized and felt. The little room in which they sat so often Clara had adorned with a simple and graceful taste, and never in palace or garden was there found a sweeter retreat than that humble spot, where these two lovers tried to conceal their love from each other, and where the bonds which bound them together strengthened and strengthened until nothing but death could break them.

"Thank God, 'the Boy' is better," said Clara, one evening, as she came in from the Squire's and found Charles waiting for her return, to read to her Whittier's "SnowBound." "I am so glad for Fanny; the poor child has suffered until she is almost crazy." 
Charles saw the tears of gratitude spring into Clara's eyes as she said this and sat down to listen to his reading; and so, out of regard for the thoughts which were evidently uppermost in her mind, he laid aside his book, and said: "The Squire, too, must be himsclf again. I have never seen an old man suffer as he has on account of the illness of a child. How fortunate it is that old age dulls the kicen edge of grief, -old age $t$ ) which scparation is inevitable and ncar, in obedience to the laws of nature."

"Why, Charles," said Clara, "does old age chill our affections?"

"I hardly know about that," said Charles; "for I shall never for set the youthful glow with which the old Squire declared to me in his office, one afternoon, that he did not believe there was anything sweeter in life than the reviving affiection of an old man for his wife. But I suppose the consciousness that a separation must naturally be short makes it the more endurable; and the nearer man approaches heaven, the less valuable does earth appear."

"I don't believe," saicl Clara, thoughtfully, "a woman knows anything about what you and the Squire call reviving love. I think she loves right on if she begins to love at all."

"And allows nobody to interfere?" asked Charles, eagerly.

"Nobody," answered Clara. "I mean love, and not duty. I am but a young girl, Charles, and know but little ; but I have seen how, through these long weeks of sorrow and anxiety, Fanny's heart has been awakened, and she has learned at last what her affections are. She is very different now from what she was before she had learned that her child might clie."

"What do you mean?" asked Charles.

"Why, she used to tell me what a fine parish she lost when Mr. Ransom clied; and how sad it was to be checked 
in early life, and how important it was that every youms woman should start well. I asked her, one day, if she meant that every young girl shall set her affection on a young man of good character and high principle, and not be deceived by the more superficial qualities, and she said she did n't mean exactly that; but some time she would tell me what she did mean. And then she spoke about Dr. Parker and his position and fortune. But she tallis a great deal now about the power of love alone to carry us through the trials of life."

"Do you think she loves Dr. Parker?" said Charles, with a faint tremor in his voice.

"O no," saicl Clara, innocently ; "I don't think a woman is apt to fall in love with her cloctor, when he is trying to save the life of her child; I think gratitude takes the place of love."

"Did she think you had better continue your love, then, for Dr. Parker ?" said Charles.

"My love for Dr. Parker!" said Clara; and the tears came into her eyes, and she suppressed the rising sob with that effort which, in a woman, is more touching than an uncontrolled outburst of grief.

Charles felt so ashamed of himself for having endeavored to wring a confession from an honest and loving heart by a mean inmuendo, that he sat in silence, feeling that he had cast a shadow over the brightest moment of his life. He was suddenly overwhelmed with the thought that he was not worthy of a person so fair and ingenuous as Clara; and he covered his face with his hands, and sobbed aloud.

"Charles!" said Clara, in a tone softened and enriched by the emotion which was swelling in her throat; and Charles Ingalls uncovered his face to behold fixed upon himself the warm and tearful gaze of the radiant and beautiful woman whom he loved. In an instant his sky was 
cleared. The evil passions which had tormented him fell away. He was no longer angry with Dr. Parker; no longer oppressed with the burden of concealment; no longer discontented with his lot. But the future all opened before him full of promise; the path of life seemed bright,

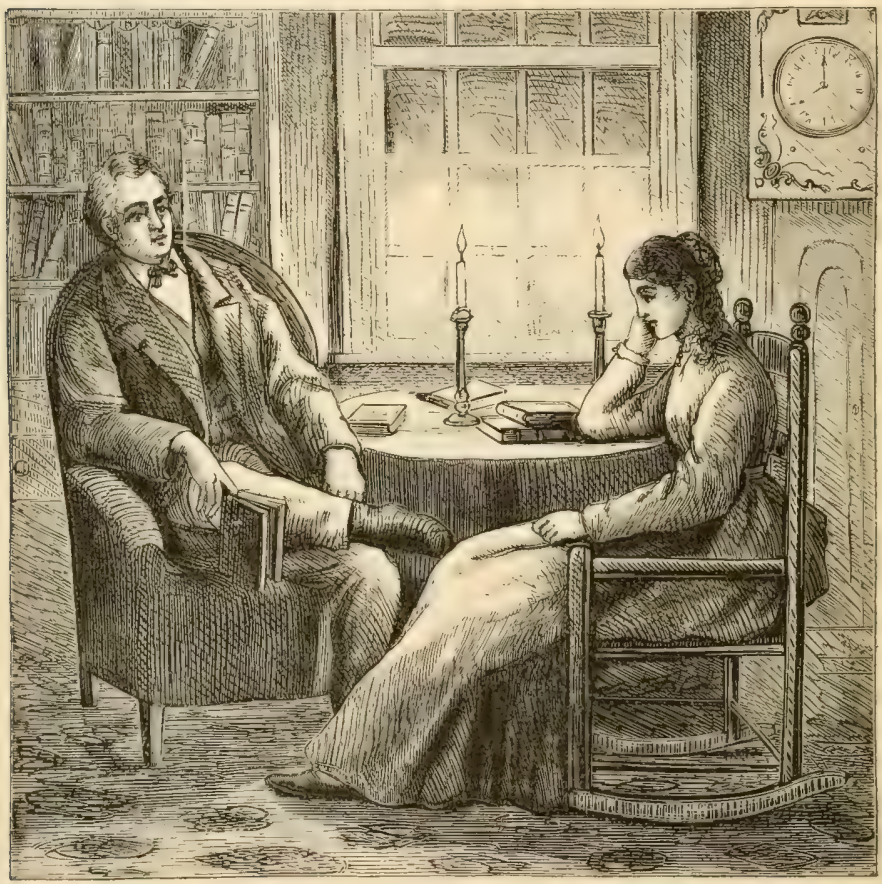

CHARLES INGALLS AND CLARA BELL.

and open to the highest and best accomplishment. More than ever now was he overwhelmed, his joy simply intensifying the emotion which was awakened by his shame and distress. With a half-smothered cry he exclaimed, "Clara!" And, falling on his knees at her feet, he buried his face in her lap, and wept like a child. 
As when the clouds break and roll away from the summer sky the sunlight pours forth all its glory and beauty upon the earth and the heavens, and the gilded canopy above seems to rejoice in the landscape sparkling with raindrops, so the darkness passed away from these two heares, and for them there was the radiance of a life of joy and love. The sweet stillness that surrounded them was not soon broken; but there in silence they gave their pledges, and felt that life had now begun. When Charles left, "Snow-Bound" was lying unopened on the table.

Mr. Hopkins had returned; Mr. Howe was at leisure; John Thomas was at work again; Peter Ilsley had recovered; William Jones's horse was dead; and all seemed desirous of a meeting of the Club. The meeting was therefore called by the committee, and the subject selected was

\section{ROOT CROPS.}

When the Club assembled, Mr. Hopkins warmly congratulated those present on the good fortune which had brought them once more together. He alluded to the difficulties in business which he had been obliged to overcome, on account of his son, since they last met, and rejoiced that, after having discharged his duty to the best of his ability to save his name from even a shadow of financial dishonor, he had been enabled to return to the quiet associations of Jotham, and to renew the discussions of those interesting topics which belonged to the Club. He had a sympathizing word for John Thomas, and Peter Ilsley, and William Jones; inquired kindly after Jim Bell, and turning to the Squire he asked with special interest after Fanny and "the Boy," and was inexpressibly grateful that the trial was over. To the Schoolmaster he was unusually cordial; and as he took him by the hand he felt that for some reason there was a new and more elastic force in the 
young man's blood, and he saw a rare exaltation in the young man's face.

"The subject under discussion," said he, "is one which has attracted great attention in modern days, and has been carefully investigated in all the best agricultural countries of the northern latitudes. There has been a strong prejudice against the cultivation and use of roots in this country, I am aware; and the abundance and cheapness of Indian corn, one of the most healthful and nutritious of all grain products, have led many to believe that such roots as mangolds, Swedish turnips, and carrots are unnecessary and superfuous. In England, where corn is not cultivated and the crop is unknown, the Swedish turnip has long been held in high favor; and in our own country, at last, in spite of opposition, the swede and mangold are now considered as valuable adjuncts to the common articles which are used as food for cattle. I have seen many herds which had been well fed during the winter on hay and corn-meal, and which indicated in the spring a want of some greater variety of food in order to preserve their health and good condition. I have also seen herds which have had a reduced amount of meal, with a daily feed of roots, and came out in the spring in the finest condition, and ready to receive the highest benefit from a run at grass during the following summer. Those of you who are familiar with Mr. Webster's views on agriculture, as expressed publicly and privately, cannot have forgotten the enthusiasm with which he dwelt on the value of the turnip crop to the agricultural resources of Great Britain. He was undoubtedly correct; and it is now generaliy conceded that the introduction of the turnip into the great field crops of England has wrought a happy revolution in the whole system of farming there.

"I am aware that, during our discussion of the subject of cattle, in one of our early meetings of the Club, some 
interesting remarks were made with regard to manefolds, swedes, and carrots, and the best methods of cultivatines them; but it has been deemed well to consider these matters more carefully; and I will now call on Mr. Johnson to give his experience in root culture."

"Mr. President," said Mr. Johnson, "I have for many years devoted a portion of my land to root culture, and I think I have found it profitable. I formerly confined myself to grain of various descriptions, in addition to hay, in feeding my dairy cow's; but I became satisfied that they suffered for the want of green food of some lind during the winter, and I began on the use of mangolds for my cows, and turnips for my young cattle and steers. For these last, I can only say that they will be kept in fine thriving conclition on hay of a very orclinary quality, if they get in addition a peck of turnips, even four or five times a week. The health of all my cattle has vastly improved since I began this mode of feedingr. In orcler that I may present noy plan of raising the mangold and the Swedish tumip, I lave brought to the Club statements which I made years ago to our agricultural socicty, and which contain my present views generally.

"Alangold-Ithat. - The crop of mangold-wurzel, which I enter for premium, was raised on one acre and wne cichth of land. The soil is a heary, clavey loam (and that is best for mancrolds), has leen many years under cuitivation, and is a portion of the field which I drained with tile's and have heretofore described. For threc years after drainage it was devoted to grass crops, having heen laid down to grass the year before it was chained. Last year it was manured on the sod, twenty-five loads, or a little more than cight cords, to the acre, and was ploughed with a Michigan plough. May 23 it was harrowed, furrowed, and planted to corn with superphosphate in the hill. Early in November following it was fall-ploughed. 
"Early in May of this year it was manured with eight cords of barn-yard manure to the acre, ploughed again, and left until May 20. It was then ploughed again, harrowed, and drilled. Seven cords of manure, a compost of barn-yard manure with sand and muck, were applied in the drills.

"The seed was soaked thirty-six hours in water poured hot upon it. The tops of the drills were carefully raked. An implement made of plank, four inches wide and three feet long, from the bottom of which projected pins two inches long and an inch and a quarter in thickness, and seven inches apart, and on the top of which was fastened a frame handle, made by nailing narrow strips of board, two and one half feet long, to the ends of the plank, and fastened together at the top by a short strip a foot and a half long, was used for making holes into which the seed was to be dropped. The latter process was also done by hand, and the seed was covered with the hoe. In this way I secured an even crop, and avoided the necessity of thinning, which attends the use of a seed-sower. The crop was hoed twice, and, later in the season, was cleared of weeds by hand. The varieties were the long red and the yellow globe. The crop was, by measurement (sixty pounds to the bushel), I, 800 bushels. The account with the crop stands as follows:-

To manure (fifteen cords at $\$ 5$ per cord) . . . $\$ 75.00$

To hauling manure . . . . . . . 8.00

To ploughing twice . . . . . . . 4.00

To harrowing . . . . . . . . . 1.00

To sowing the seed . . . . . . . 6.00

To two hoeings . . . . . . . . 16.00

To clearing . . . . . . . . 5.00

To harvesting . . . . . . . 20.00

Total.

Cr. by $\mathrm{r}, 800$ bushels of mangolds. 
"The cost of these roots, nine and a half cents a bushel, is certainly not extravagant, considering their value as food and their usual market price. They ustally sell for $\$ 7$ (now more generally $\$ 15$ ), of sixty pounds to the bushel, or about thirty-four bushels to the ton; and at this rate bring twenty cents and a fraction per bushel.

"According to analysis and experiment, 400 pounds of mangold-wurzel are equivalent to 100 pounds of English hay. At sixty pounds to the bushel the crop weighed 96,000 pounds, or forty-eight tons, - equivalent to twelve tons of hay, taking the estimate that four tons of mangolds are equal to one ton of hay. For the production of milk, I have no cloubt that the forty-eight tons of mangolds are worth more than thirteen tons of hay."

"Do you sow by hand and in drills now?" asked Mr. Hopkins.

"No, I do not," replied Mr. Johnson. "I sow with a machine and on a flat surface; but I cannot get quite so large a crop, and the work of thinning is much greater."

"I will now read my statement of the Swedish turnip, or ruta-baga crop, which I made the same year," said Mr. Johnson.

"Ruta-Bagas. - I enter also a crop of ruta-bagas, raised on two and a half acres of land.

"The land was an elevated knoll, rising out of a bed of clay, and bounded on one side by a salt marsh. The top of the knoll is somewhat gravelly and light, but, as it inclines towards the low land surrounding it, is a warm loam.

"The piece has been in grass for many years, and yielded last year a poor crop, - less than half a ton of hay to the acre. It was ploughed June 20 , with a Michigan plough, and manure at the rate of fifteen ox-cart loads to the acre was spread upon it, and harrowed in. It was then harrowed again with a light harrow, and the loose sods were 
turned over with the hoe. Lines were drawn with a marking rake, containing three long; heavy teeth, twenty inches apart, drawn by one man and held by another. In the small furrows thus made a small quantity of superphosphate was sprinkled. The seed was then sown in these furrows with a sower. The seed used was Skirving's King of the Swedes. The planting was finished in June.

"The land was hoed twice, and the plants were thinned out, leaving spaces of six inches in the rows. The crop was harvested by four men and two teams, in four and a half days. The amount of the crop is one thousand eight hundred and seventy-six bushels at sixty pounds to the bushel; and the account is as follows :-

To twelve days' ploughing .

. $\$ 12.00$

To three days' seeding .

3.00

'To twenty-four days' hoeing and thinning . . . 24.00

To ten cords of barn-yard manure and hauling . . 50.00

To I,000 pounds of super-phosphate . . . . 20.00

To twenty-seven days' harvesting . . . . $\quad 27.00$

Total . . . . . . . . \$ . . . . . . .

Cr. by 1,876 bushels of roots.

"The market price of ruta-bagas varies materially in different seasons. Last autumn they sold for fifty cents per barrel. Last spring and this autumn they sold for one dollar per barrel. At these prices it is easy to calculate the cash value of the above crop.

"As food for cattle, ruta-bagas bear the relation to English hay which three hundred bears to one hundred. At sixty pounds to the hushel the crop weighed one hundred and twelve thousand five hundred and sixty pounds, or fifty-six and one third tons, equivalent to eighteen and seren ninths tons of hay, taking the estimate that three tons of rutabagas are equivalent to one ton of hay.

"There is no doubt that ruta-bagas, or Sivedish turnips, 
are easily cultivated on light warm land; and I am satisfied from experience that they are the most useful root the farmer can raise for store and fattening cattle."

"Full of water, ain't they?" said Sam Barker. "Ninety" per cent water. Who wants to haul this round?"

"A man, or a turnip, or a forked raclish is ninety per cent water. You are, Sam. So is most of the food we eat. But water in certain combinations nourishes. And I think a Swedish turnip is one of them," said Mr. Thomas.

A conversational debate on these two roots followed, until " the clock tolled the hour for retiring," and the Club dispersed.

The Schoolmaster had been cheerfully silent. Dr. Parker was not present. The subject was not exhausted. 


\title{
EIGHTEENTH MEETING.
}

\author{
ROOT CROPS (Continued).
}

SORROW VANISHES. - HUMAN NATURE REIURNS. - FANNY TELLS DR. PARKER SOME WHOLESOME TRUTHS. - HE FINDS HIS MATCH.

THE family of Squire Wright had returned to their accustomed course. "The Boy" had recovered his health almost entirely, and had come back to his cheery and enlivening spirits, which infused themselves through the household like the sunbeams of opening summer. The gratitude and joy which welled over and filled to perfect fulness the hearts of all that family, when the shadow passed away, had become so much a matter of custom that now and then, in an unwary moment, a little roughness would return or a momentary passion would break forth, and astonish that just now chastened and purified group. The spirit of evil seldom closes his eyes in sleep. No matter how long and how well the citadel may have been guarded, he stands ready to enter at the first unwary moment. And no sooner do we return to the joys of earth, after having been raised by sorrow to the sacred regions of heaven, than we are beset on every hand by his busy and untiring efforts to seize and lead us astray; and his very presence indicates the departure of trial and sadness, and the return of the careless and comfortable and real joys of earth. All this had come upon the Squire's family, who, while they were so happy, had become so human, and who wondered how a breeze could ever spring up in a calm so heavenly as that which followed the long days and nights 
of anxiety and distress. The little irritations were very small and feeble and short-lived, and, as they showed that the child was safe and that the danger was past, they were all right. At any rate, so thought the Squire, when be recovered courage enough to snap up a stupid and annoying client, and suddenly realized that he had gained strength enough to do it; so thought the grandmother when she petulantly wondered how Fanny "could let that boy pull her best lace collar in pieces"; so thought Fanny when she found that she herself and the Squire, and the grandmother, and the boy had all returned to the common ways of life, and to that companionship whose waywardness and error often add flavor to its virtues, and give a brighter coloring to its beauties and charms.

Dr. Parker still continued his daily calls. IIe was a creature of habit, and it was never easy for him to leave a familiar and long-travelled path. His mind and his heart were obedient to the same law. A train of thought he did not easily abandon; a sentiment in his heart, without being warm, was not easily changed. And so he jogged on, asked every morning after the health of the boy, advised Fanny to take a little more air and exercise, bade " a very good morning" to the grandmother, and inquired after Clara Bell, how she was, if she had lately been seen, and what she appeared to be interested in. To Fanny he was especially confiding. IIe laid before her any new discovery to which his attention might have been called by his scientific correspondents; he submitted to her every new theory; he told her the uneventful but odd and curious story of his life; he even deplored to her his weakness, and with a strange combination of anxiety to reform and pious pride in making his confession, he dwelt upon his folly and boasted at the same time of his humility and his wisdom.

It was during one of these conversations that Dr. Parker, with that confidence which an unmarried man is very apt 
to repose in a married woman, described, with a small degree of weak sentimentality quite usual on such occasions, his lonely and single life. He told Fanny how he had been shut out from female society in his youth, by the early death of his mother, and by his father's ambition that he should avoid all social amusements and devote himself to his books alone. He described one after another the phantoms of delight which had appeared for a time upon his vision and then vanished, leaving his life all the darker for the sudden and flashing illumination. He gave an account in touching phrase of his present loneliness, and bemoaned that hard lot which seemed to shut him away from the world, and close as a sealed volume the joys of life to his eye.

"I cannot tell you, Fanny," said he, "how poor and mean all my attainments and prosperity seem before the one unfulfilled desire. I have been proud of my intimatc relations, with the learned and the great; I have rejoiced in the society of my books; I have felt that I had won my way by hard and constant study into the most cultivated associations; and I have created for myself a world of my own, where I can feel that I am superior to those around me. But I have long felt that heaven without sun or star is no heaven at all; and I have learned that no man can possibly fill his place in society until he has first established those relations without which society could not exist. Do you think Clara Bell loves me?"

"Why, my clear Dr. Parker," said Fanny, "what are you talking about? Clara Bell, you know perfectly well, is a warm-hearted, generous, affectionate creature, who could not understand that sentiment which is tempered and fashioned by thrift and duty. She could fall in love with a boy, but not with a deliberate and calculating man. I don't think Clara will marry either a profession or an occupation. And then, more than all this, she is afraid of you." 
"What makes you think so?" asked Dr. Parker.

"Well," replied Fanny, "I have heard her, cluring the many days we have spent together these last few months, discuss almost everybody in Jotham, in her fresh, bright, and sparkling way, - the Schoolmaster, and Mr. Howe, and Mr. Hopkins, and Ruth Johnson, and Mrs. Howe, and you; and all but you without restraint. But when I asked her what she thought of you, she always hesitated, and looked confused and troubled and bewildered."

"You ought to know the cause of that, Mistress Fanny," saicl Dr. Parker. "Don't you know that maidens always speak tremblingly of those whom they love?"

"Softly," said Fanny, "but not always tremblingly. And what makes you suppose Clara loves you?"

"What makes you suppose she does not?" replied the Doctor. "How can a girl like her help admiring the character and position of a man like myself? You must be mistaken, Fanny. Clara is n't a fool ; and her father can't live long, and she is n't going to waste herself on a nobody."

"No, I do not think she is," said Fanny; "nor is she going to waste herself on anybody. Clara is not a person to play the cipher for any man's arithmetic. Her lofty look is enough to inspire any one of your sex with respect, unless he has lost all power to respect anything; and the kind of infuence which she would naturally exert would almost make a man out of a mouse. Why, my beloved old father says she is the most sensible companion he ever knew ; and, of course, all the wisdom comes from himself."

"And do you really mean to tell me, Fanny, that this young woman, with her bright faculties and affectionate heart, is not to be influenced by superior culture, and by the kindness and courtesy which a man like myself can bestow on herself and her friends?"

"Not by superior culture," said Fanny, "but by superior 
faculties; not by an act of kindness, but by the impress of affection."

"But I have been so long devoted to her," groaned out Dr. Parker.

"O, that is all well enough to talk about," added Fanny; "but you can't worry nor coax a woman like Clara into either love or obedience. You may call upon her to exercise all her patience under your annoyance, but you can never rouse her to love by persistent and tormenting attention."

"But clo you really mean to tell me that this miller's daughter is going to defy me?" asked the Doctor; and his countenance assumed such an air of eager ferocity that even Fanny, who was not easily startled, began to be alarmed.

"I don't think she will surrender to you," said Fanny, calmly ; "for I think another has surrendered to her."

"The Schoolmaster?" asked Dr. Parker, pale with chagrin and disappointment and jealous rage.

"Now, Doctor," said Fanny, "I beg you to be reasonable. You expect this young girl to love you when, as you allow, you have made a monster of yourself in her presence, and have done nothing to elevate either herself or you above the ordinary sphere and associations of life. And you ought not to trifle with her. She never told me she loved the Schoolmaster; but I ask you to judge for yourself how you would stand beside such a clear young life as his. You know how strong he is in all the attributes which make a superior and admirable man. And do you suppose for a moment that any temptation of position or wealth could interfere with the natural and spontancous affection which a noble young girl would feel for such an one as he? You ought to be grateful that Clara has found such peace. You think you have conceived what it is; then rejoice with her that she has reached it. I know 
what life is without it, and with the commonplace relations which duty and judgment can create; and I thank Goxl that no such trial lies before her. I have never heard her say she loved the Schoolmaster; but I know she ought not to love you."

Dr. Parker listened to Famny's calm and unruffled expression of opinion upon a subject vital to him with astonishment. He was not prepared for a positive and judicial view of the case from a young woman whom he had been in the habit of looking upon as a child; and it was a revelation to him that a woman could be anything but a bundle of impulses and sentiments and "latent evolutions." He was fretted and exasperated by the humane and kindly sagacity manifested by Fanny, and he struggled in erery direction to escape from the toils with which she had insensibly surrounded him. He had discovered that what he had supposed to be a deep and vital attachment was in her eyes nothing but a freak; and when he examined it under the light she shed upon it, he arrived at about the same conclusion himself. His pride was deeply wounded, too. He had made a bungling confession to a mediator from whom he had received no comfort; he had destroyed all the chance he ever had with Clara herself, by calling a third person into his councils; he had betrayed his weakness and temper; and he had measured lances with a mere girl, as he called her, and had been beaten in the contest. To stop where he was would be to leave matters in a very bad position. To find his way out was not an easy matter. And there he was, - an accomplished, cultivated, inteljectual scholar, - groping about where he had no business to be, and baffled at every turn, because he was endearoring to explore with the powers of his mind what he should have submitted to the impulses of his heart. And so he revolved and raged, until he reached a condition of mind and body similar to that into which he had sometimes been 
thrown by a long-continued debauch, - a tendency to which under any form of excitement had undoubtedly been produced by his habits of life. At last he grew violent, paced the room, muttered some very hard language, and, suddenly turning on Fanny, exclaimed: "My God! I can't and I won't bear this; there is one way out at least."

"Not for you to travel, however," said Fanny, coolly, who began to be alarmed lest her own room should be the scene of a sudden and unexpected tragedy, and who had been told often by William Jones that the best way to prevent or remove a horse's terror is not to be terrified yourself.

"Now, Fanny," said the Doctor, "this is cruel. Suddenly and unexpectedly my weakness and ignorance have dawned upon me, and all my little dream has vanished. But then that damned Schoolmaster, - excuse me, Fanny, - that he, with nothing but his untrained natural endowments, should have outstripped myself, with my attainments, - this is intolerable. I don't believe he has outstripped me, Fanny, do you? What do you know about it, anyhow? But let the babies go; the Schoolmaster and the silly girl. She may be well enough, for anything I know, but

'If she be not fair for me,

What care I how fair she be?'

And now, Fanny, let us drop these young and inexperienced persons; and leaving them to their fate, let us walk hand in hand along the path of life. My bewildered brain is restoring itself, and the dark and dreadful design which just now possessed it is gradually passing away. There is a heaven open still for us, I am sure. And may we not rise together above the sorrows and disappointments of life, and console and sustain each other? Fanny, 
I must have a home. Will you not join me, and fill that place made vacant by the wayward and wandering Clara? I will be a father to that boy; and I will be a - "

"O doctor," said Fanny, "stop; pray do! This is a little too much. But eight months a widow; what would the people say? And then, to take Clara's place, - why, that would be ridiculous. Come, now ; don't be childish. You are well enough off as you are. Think of the scientific correspondence, and the turtles and the books and the Medical Society, and the library and the patients and the Club ; could man have more? Come, my dear old gallipot, clear up and cheer up, and don't despair, with the blessings of Heaven all around you."

Dr. Parker was more bewildered than ever. Fanny had literally driven him off the ground. He was enraged, ashamed, and disgusted, and, seizing his hat, he rushed from the house and made his way home.

"I guess the Doctor's wuss 'n ever," said Peter Ilsley, as he reached home toward evening, after a long day in the woods. "I see him, this arternoon, driving like fury away down towards Pilfershire; did n't seem to see anybody; head down ; mare goin' like a shot out of a gun."

"I do wish he 'd let Clara Bell alone," said Mrs. Ilsley.

"So do I," said Peter; "and I wish he'd keep away from the Club, too. He don't say much, but he kind o' roiles up the whole concern when he's there. I wish I knew what the devil ails him."

The repose of the village was in no way broken by the domestic inciclents of the Doctor and the Schoolmaster and the two charming young women. Charles Ingalls was bound to keep his secret, and Clara did keep hers. And as for Dr. Parker and Fanny, there was no temptation for them to divulge their strange and weak experience to anybody; and so the affair found not its way into the ordinary current of village gossip. 
When, therefore, the Club was called together again at Mr. Hopkins's, every member came in his usual condition, and with his understanding of his associates unchanged. It was on a disagreeable, drizzling, thawy evening that the Association assembled, and the warm welcome of $\mathrm{Mr}$. Hopkins was especially agreeable. He had settled back into his country ways after his city experience, and rubbing his hands before his fire he inquired of Jones about his horses, and Ilsley about his cows, and Barnes after the fruit-bucls, and old Mr. Eaton about his maul and the opening of spring for the pastures. And when all were seated he announced that the schoolmaster, Mr. Charles Ingalls, would open the discussion with an essay on

\section{ROOT CROPS.}

The subject of Root Crops, Gentlemen, occupied so much of our attention at the last meeting, that there is but little left to discuss at the present time. We indeed considered the two most important roots which the farmer can cultivate,- the turnip and the mangold,-- leaving but little to be said for such other crops as are included under this head. At this I am not surprised. I look upon the cultivation of the turnip as the most important branch of this business, - a branch which, if properly pursued, may remove the necessity of all others. Were I called on to select that root which could least be spared from the long list of farm crops, I should select the turnip. It is easily cultivated, and is useful as food to all our graminivorous domestic animals. So important is it in England, that even the history of its introduction is interesting. We are told that "according to the name given to the plant in England, the Swedes are natives of Sweden; the Italian name Noroni de Laponia intimates an origin in Lapland; and the French names Chou de Lafonc, Chou de Sucic, would indicate an uncertain origin." Sir John Sinclair says: "I am informed that the Swedes were first introduced into Scotland in $172 \mathrm{I}-22$, on the recommendation 
of Mr. Knox, a mative of East Lothian, who had settled at Got tenburg, whence he sent some of the seeds to Mr. Mamilton. There is no doubt they were first introduced into Sicotland from Sweden, but I believe their introduction was prior to the date mentioned. The late Mr. Airth, Mains of I)umn, Forfarshire, informed me that his fither was the first farmer who cultivated Swedes in Scotland, from seeds sent him ly his eldest son, then settled in Cottenburg, when my informant, the youngest son of a large family, was a boy of about ten years of age. This would make the date of their introduction 1777 ; and this date is corroborated by the silence preserved by Mr. Wight regurding the culture of such a crop by Mr. Airth's father when he undertook the survey of the state of lusbandry in Scotland, in 1773 , at the request of the Commissioners of the Annexed Estates, and when he would not have failed to notice so remarkible a circumstance as the culture of the Swede. Mr. Airth sowed the first portion of the seed he received in the garden in beds, and transplanted the plants in rows in the field, and thus succected in raising a good crop for years before sowing the seed directly in the fields. I have not been able to trace the history of the yellow turnip; but it is probable that it originated as supposed by Professor Low, in a cross between a white and the Swede, and, as the name implies, this may have been in Aberdeenshire. All the white varieties of field turnips obtained at first the name of 'Norfolk Whites,' from the circumstance of their having been cuitivated to any extent in that county by Lord Townshend, who, on coming home from being Ambassaclor to the StatesGeneral, in $173^{\circ}$, paid great attention to their culture, and for which service he obtained the appellation of 'Turnip Townshend.' It is rather remarkable that no turnips should have been raised in England in the fields until the end of the serenteenth century, when it was lauded as a field-root as long ago as Columelia, and in his time even the Gauls fed their cattle on them in winter. The Romans were so well acquainted with turnips that Pliny mentions having raised them of forty pounds' weight. 'Turnips were cultivated in the gardens in England at the time of Henry VIII. Dale's hybrid originated in a few 
ounces of a hybridal seed being sent in 1822 or 1823 by the late Mr. Sheriff of Bastlericlge, Berwickshire, to Mr. Robert Dale, Libberton, West Mains, near Edinburgh, who, by repeated selection and impregnation, brought it to what it is, a good yellow turnip, and now pretty generally cultivated. The Lawtown hybricl originated about eight or ten years ago by Captain Irright of Lawtown, in Forfarshire, crossing the green-topped white with the green-topped Swede, to harden the white, which object proved successful, but its culture has not been pushed. By sowing the Swede beside the white Lawtown, the latter has been converted into a yellow turnip, possessing the properties of the Swede; and were the cross still further pushed I have no doubt that a distinct variety of the Swede would be obtained. A rariety of Swedes was brought into notice about four or five years ago by Mr. Laing, Daddo, Northumberland, who found it among his ordinary Swedes, and observed it by its remarkably elegant form of leaf, which is much notched near the base. It is getting into use, and possesses the valuable property of resisting the effects of spring for at least a fortnight longer than the common varieties, as I had a favorable opportunity of observing in Berwickshire, late in the spring of $\mathrm{r} 84 \mathrm{I}$, and on this account may be stored and kept in a fresh state to a very late period of the season."

I have given this long and elaborate sketch of the introduction of the Swede into Fngland, because I estimate its value very highly, and I am anxious to interest you in its cultivation. I have seen those who were ignorant of the meaning of the rery name Swede, and often confounded it with some form of beet. The personal sketch I have given of this root will, I hope, serve to remove this confusion. The care with which the Swecle has been cultivated, and the skill displayed in crossing the different varieties in order to obtian the best, the heaviest, and least perishable, will satisfy any inquiring mind that where it is best known it is marked at its highest value. I trust I may be allowed, therefore, to urge once more its cultivation by the members of this Club, and by the large and enterprising community of farmers in this vicinity. 
Next in importance to the tumip and the mangold stands the carrot. I have not learned that this root is maintaining its reputation in the farming community, although it is still very generally cultivated, inasmuch as it commands a good price in the market, and is by some still considered a valuable food for horses. Dut the Swede is rapidly taking its place, as a root more easily cultivated, and more useful for all purposes of feeding cattle and horses. The carrot is said to produce an unhealthy condition of the secretory functions of the horse, when it is fed liberally and for any length of time. It often brings on a cutaneous clisease, not very severe in its character, but enough to indicate an unhealthy conclition of the system; it excites the kidneys to such undue action as to weaken the animal, and creates a tendency to swelling in the legs. It seems to be less thought of than formerly as food for cattle. It is not now claimed for it that it increases the flow of milk, or is useful for the purposes of fattening. At any rate, on these two points it stands far below the Swede, and it is mainly prized by those who use it as food for their dairy cows, that it improves the color of the butter and perhaps enhances the quality of the milk.

The cultivation of carrots is not easy work. The land on which they are sown should be a rich, warm, somewhat sandy loam, well and rleeply ploughed, and pulverized as finely as can be clone with the best harrow. In fact, for the best cultivation the land should be ploughed with a Michigan plough, and each furrow raked fine and smooth as fast as made. In this way the field can be brought to the best condition for receiving the seed. This preparation should be made as early in the season as possible, as soon as the frost is entirely out of the ground, and the subsoil has become freed from any excess of water. This condition of the soil will generally occur from the Ioth to the I 5 th of May, and then is the time for sowing the carrot.

Carrots require a great deal of manure. The best cultivators use from eight to ten cords to the acre, spread broadcast, ploughed in at the first ploughing, eight cords being about twenty-four cart-loads of forty bushels each. The manure 
should be thoroughly decomposed, the use of green manure causing a tendency in the root to clivide and grow with great irregularity. Barn-yard manure will answer a very good purpose, but if kelp and mussel-bed and ashes can be obtained they will be found very ustful. The manure, whatever it is, should be very fine and thoroughly incorporated with the soil.

The seed should be sown with a reliable seed-sower in rows about fourteen inches apart; and the plants should be thinned in the rows so as to stand about two inches apart. From the first appearance of the plant until it is quite weil grown it needs watching. No crop suffers more from weeds than the carrot, and at no time should these pests be allowed to accumulate, or attain any considerable size. The first hoeing and weeding will always be a difficult job. The seeds germinate slowly, and the young plants are so small that great attention is necessary to bring forward the crop in thriving condiition. Usually an early hoeing with the wheel-hoe, followed by three or four hoeings with either the wheel or common hoe, and then weedings with the hand, will carry the crop beyond the danger of weeds. But the work is at all times difficult and requires young and strong backs, nimble fingers, and tough and wellarmed knees. It is a species of horizontal agriculture which I would not urge upon the considerate or judicious farmer.

The carrot on well-prepared and suitable soil yiclds a large crop. The root has great power for penetrating the soil, and it has been known to reach the depth of two or three fuet when grown on trenched land. Colonel Timothy Pickering reports a crop of 6so bushels to th: acre, raised in his diay and in his neighbo:hood. I find reports of $25 \mathrm{I}$ bushels on forty-three and one half rods of land, 290 pounds to the square rod, $318 \frac{1}{2}$ pounds to the square rod, and 103 bushels from one eighth of an acre. Six hundred bushels to the acre is evidently a good crop.

The harvesting of the carrot is a comparatively easy business. The tops can be cut from them as they stand in the rows with a sharp hoe; a plough can be used to turn them up out of the ground, and with a five-tined manure-fork they can be taken 
from the loosened earth. They should be harvested about the 2oth of ()ctober, and in no case should they be exposed to freezing. It is a good plan to pile them in heaps in the fickl, cover them with rops, and leave them for a day before carting into the cellar. So much for the carrot.

I have found a disposition in some quarters to recommend the parsnip as a field crop. I do not think this juclicious. The parsnip is a difficult root to raise; it is apt to wilt in the cellar, and seldom yields a crop large enough to compete in any decree with either the Swede or the mangold, or even with the carrot. I have, however, before me one intelligent and well-drawn statement of its cultivation, which I submit, and leave you to jurlge of its value. It is given by Mr. Willard Howe of I)anvers, Mass. He says :-

"The half-acre of land on which the parsnips were grown is a light sandy loam and has been previously used (eighteen or twenty years) for onions. It was sown one of these years onehalf to carrots and the other half to onions. The onions failed; it was then set with cabbages. The yield of parsnips on the half where cabbages grew was seventeen bushels, the land and manure being equal.

"The manure used was composed of equal parts of stable manure, night-soil, and spent tan ; well-mixed and fermented manure spread and ploughed in, and fitted as for carrots or onions.

"Seed sown I 7 th of May with a machine; the rows seventeen inches apart, and the plants thinned to about three inches.

"Harrested by ploughing two furrows away from the row, with the side-hill plough, the last furrow deep and close to the row, - with two horses; then they are dug easily with spade or shovel. In all, 3 I 3 bushels of 45 pounds each, 299 of nearly eren size fit for family use. They will be for sale in February and March, and we hope to obtain the same price as last year, - \$1.50 per barrel.

"In calculating the expense of the crop, I have charged $\$$ I.25 for men, \$1.50 for horse per day, and what it costs for boys" labor. 
"Expense of crop:-

Hauling manure and spreading and ploughing $\quad \$ 55.25$

Hoeing and weeding . . . . . . 5.75

4 cords of manure at $\$ 7$ per cord . . . 28.00

Land rent . . . . . . . . 6.00

$\mathrm{I} \frac{1}{2}$ pounds of seed . . . . . . . 1.25

Harvesting, eight days . . . . . . I0.00

Total . . . . . . $\$ 56.25$

Credit by 100 barrels at $\$$ I.50 per barrel . . \$ $\$ 50.00$

I4 bushels at twenty cents per bushel . . . 2.80

$\$ 152.80$

Balance in favor of crop . . . . . \$96.55."

You can judge from this statement whether the parsnip is a profitable field crop and one which ought to receive your attention.

I have occupied too much of your time, Gentlemen, in cliscussing the question assigned me; and I can only hope that I have presented facts which will provoke debate and will lead to still more important investigation.

"Mr. President," said Peter Ilsley, "I think the Schoolmaster has told us all we want to know about root crops. Yqu can go too far with 'em. When grain is cheap, you don't want to go too deep into the root business. Just enough for the bealth of your cattle, is my maxim. And now I don't believe I would discuss root crops any more, Mr. President, would ye? or would ye ?"

"I move we adjourn," piped old Mr. Eaton.

And so the Club adjourned, and each man went his way. "The Schoolmaster wears well, does n't he?" said Mr. Howe to $\mathrm{Mr}$. Hopkins, as they lingered after the assembly had dispersed.

"Very well," replied Mr. Hopkins. "He will make his mark, I am convinced. But pray tell me, where is Dr. Parker? I have not seen him for many dajs." 
"I don't exactly know," said Mr. Howe; "but somehow I have an idea that he is at the crisis of his life; and whether he will go up or down, no man can tell. God help him!"

And the two gentlemen parted. 


\title{
NINETEENTH MEETING.
}

\author{
GRAIN CROPS. \\ POLITICAL REFORM. - THE GROCERY. - PETER ILSLEY SHOWS HIM- \\ SELF, - JOHN THOMAS AND HIS FAMILY SLANDERED. \\ "The stormy March has come at last, \\ With wind, and cloud, and changing skies: \\ I hear the rushing of the blast, \\ Which through the snowy valley flies."
}

AS the spring approached, an unexpected public difficulty arose in Jotham, which for a time suspended the meetings of the Club, and threatened not only the peace and happiness of the community, but the very existence of the Club itself. The municipal month of New England, the "stormy March," the month of tempests and town-meetings, was approaching. In Jotham the annual town election had never been exciting; the appropriations were always small; the schools were not expensive; the highways were kept in repair by the citizens, who "worked out their taxes," and "mended the roads" as soon as seed-time was over, by ploughing the roadsides and shovelling the broken sods and loam with great unevenness into the carriage-path; there were no destructive and swelling mountain streams to bridge; there was no town-hall to repair, the meetinghouse being used for this purpose; there were no official salaries to provicle for. The municipality was a model of harmony and economy, and had been so for years. The line of town clerks did not number over half a dozen from the beginning of the record. To three or four families had been intrusted the duties of the Board of Selectmen, and 
the members of the board had changed only with the changing generations. A political excitement in the town was almost unknown, except at a Presidential election, or during a great party revolution in the State, in which the issues were made up outside, and brought into the town by the self-sacrificing gentlemen who were busy in introclucing them into public affairs, and laying upon them their own foundations.

But this political repose was not to continue forever. Peter Ilsley had long looked with envious eye upon the calm and substantial prosperity of John Thomas, who was the Chairman of the Board of Selectmen, as his father and grandfather had been before him; and he had also watched with that eternal vigilance, without which popular freedom is always lost, the air of inborn authority which had settled down upon this heir to the chief magistracy of the town. He remembered, too, the irritating and chafing discussions he had held with him in the Club. He surveyed the well-proportioned and well-painted farm-buildings, the neat fences, the well-ordered fields, the thrifty orchards, the sleek and well-fed cattle, which gave a peculiar charm to John Thomas's home; and as he could not account for all this satisfactory scene so in contrast, as it was, with his own disorderly premises and unprofitable farming, on any apparent grounds of heavier crops or better markets, he began to entertain the thought that somewhere and somehow, and at some time, the Thomas family had secured by some questionable practice an ample property, and had concealed it where the eye of the tax-gatherer had not yet reached it. He had heard of rings and jobs, and how could he be assured that a long possession of power, even in Jotham, would not lead to profitable corruption? He knew by observation that "miller's hogs are always fat"; and so he forgot that prosperity and thrift, with the substantial qualities which attend them, are very 
often the cause of official prominence, and are not always the consequence. He was satisfied that the public service clemanded a change, and that the career of John Thomas must be checked. And so for a time he forgot the Club, and Dr. Parker's eccentricities, Clara Bell, and the Schoolmaster, and all their associations, and turned his attention to the work of public reform.

But Peter Ilsley was not recognized as a reformer in Jotham. That he was honest as this world goes, and gave good measure, and had a rough sense of justice, nobody doubted. But he was oftener found salting his cattle in his pastures on Sunday morning than listening to the sermons of $\mathrm{Mr}$. Howe; he always led the rough and dissatisfied element, if there was any, at town-meeting; he had even been heard to swear in the presence of the minister; he was fond of arguing on finance with Mr. Hopkins, and on theology with $\mathrm{Mr}$. Howe, and on law with Squire Wright, whom, in his own mind, he left dead on the field; he quoted Jefferson a good deal and Tom Paine a little; he had strong passions and prejudices, and ardent opinions, in obedience to which he often wandered away into new and untried paths, and formed new and not always congenial associations; he was bright enough to be a most excellent member of society, but he was not bright enough to know that the community could weigh his motives, and could distinguish between an imperious spirit and a reformatory spirit, - between high tone and high temper. It was very easy for this man to clamor about public corruption; he knew that the good men would approve, and that the bad men would join him in the cry ; and he knew that one public man was just as good as another for a victim, if any advantage was to be derived from his downfall.

Peter Ilsley was one of the regular evening visitors at the village grocery. The motley crowd who gathered there after the labor of the day was over always welcomed 
his coming as a signal for some lively talk upon the current topics of the day. One old man sat apart in a remote corner, his chair tipped back against the wall, his hat drawn

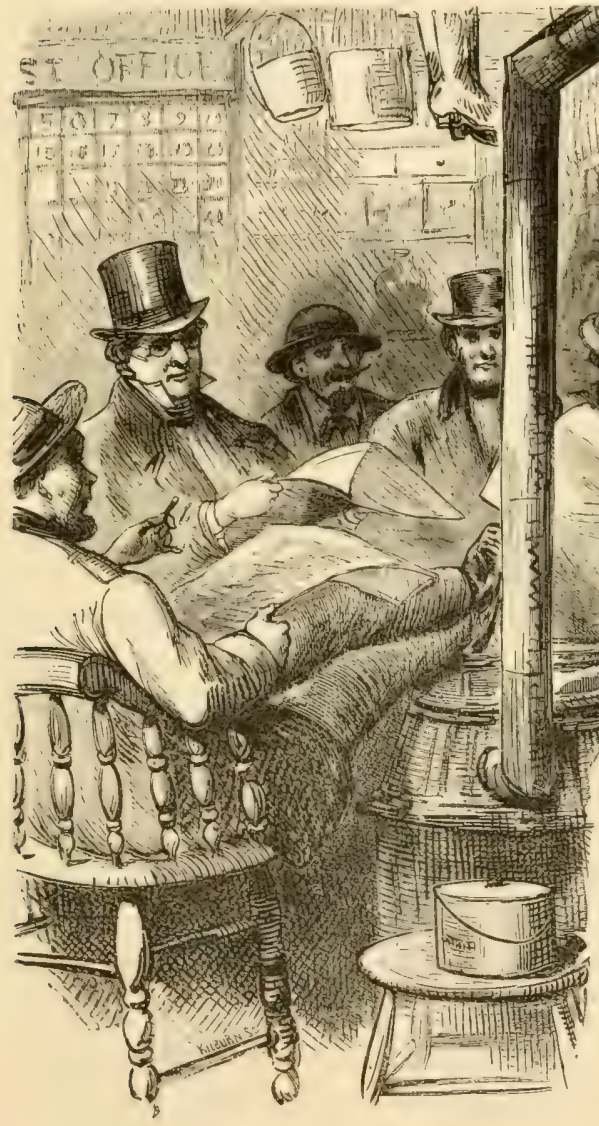

THE GRUCERY AND ITS HAIITUÉS.

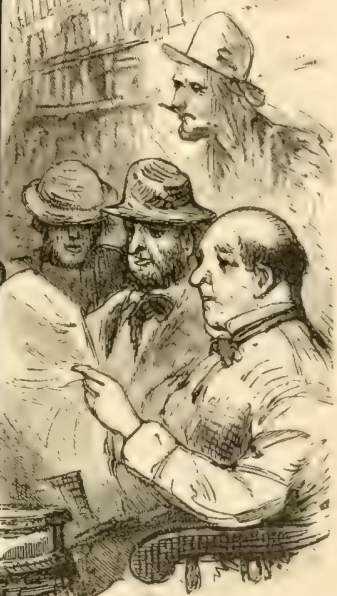

over hiseycs; he was oracular. Another, who had once represented the town in the General Court, was never wearied with reciting the personal events of the session, and the intimacy which he formed with the distinguished men of the Commonwealth, in whose ranks he felt that he could be counted; he was a bore. Another was full of anecdotes of the old clergymen of the county, and could give long quotations from their occa- 
sional sermons; he was considered as one of the pillars of the church. Another remembered the Oakes cow, and he was especially learned in his discussion of the various breeds of cattle, and especially tedious in his story of a calf which he raised when a boy, and whose early life was so full of incidents, that the biographer had never found an evening long enough to reach that period of life when the calf stopped and the cow began; the fact that he had owned a cow made him tolerable. One was authority on hogs, another on horses, another on the domestic affairs of the town, and another on the most highly flavored scandal of the day. No one of them was given to very hard labor, although they all had small estates in various parts of the town, from which they procured a meagre subsistence, with the help of what they could earn by hoeing and haying and chopping wood and laying stone-wall. They were looked upon as useful men in their way; they held a respectable enough position in the town, had places assigned them among the various town offices, were listened to in town-meeting, were considered as a part of the society of the place, and maintained such friendly and equal relations with their more prominent neighbors, that no feeling of dissatisfaction or jealousy had ever entered their hearts, and no iclea of asserting their rights had ever entered their minds. They were by no means the dull and unintellectual portion of the community. They had a fine opportunity to waylay the newspapers which came to the postoffice, - a primitive affair kept behind the grocery counter, - and they read their contents with rapidity and eagerness before they were distributed among the subscribers. In fact, the old grocery was the reading-room of the town, as well as the resort of the liveliest debating-club; and while the cheerful parlor of Mr. Hopkins had great charms, and the organization which assembled there had great wisdom, it was in the dingy little "store" that all important ques- 
tions were discussed; and the sharp sayings were perhaps too freely circulated by the independent assemblies scattered about its dimly lighted corners and its dilapidated counters.

"A gallon of West India molasses and a pound of tea," said John Thomas to the grocer, one stormy winter evening, after he had stamped the snow from his boots at the door, and paid his respects to the assembly already gathered for the usual evening services.

Had he been less occupied with his business he would have noticed an awkward stillness among his friends as he joined them, and a little difficulty in renewing the conversation, which was going briskly on when he entered the room. But his stay was short, his molasses and tea were soon provided for him, and he left a good word behind, and started for his bright home and the thrifty and busy Huldah.

"The devil is always near when you 're talking about him," said Peter Ilsley, as John Thomas vanished. "But what is it about the boy, Uncle Josh?"

The oracular gentleman in the corner, with his hat pulled over his eyes, replied deliberately: "Well, I don't know. But they used to say, and they do say now, that the old man, John's grandsir, was a pretty violent old customer. He was a captain ; I just remember him. In the Revolutionary war he lived through and fought through every campaign. It was he who footed it home from Valley Forge, and drove back a load of provisions which his neighbors here sent to the soldiers. John has got the head-stall now, which the old man made out of damaged knapsacks when he lost his own in the camp. He was tough and smart; was a good farmer, always had money, and built the $\mathrm{L}$ part of the house that John now lives in. He had a temper like a tiger, and was as strong as a moose. No man ever got him down in the wrestling- 
ring, town-meeting days; and there was n't a man within a hundred miles of this place whom he could not lay on his back in a minute. As much as seventy years ago he had a boy bound to him, - a Purvis boy, born down in the woods at the foot of Bald Hill, - a kind of a clever boy, not very smart and not very bad. All at once, along about the middle of June, the boy was missed. The last time he was seen, he was going down into the field on the edge of the pond, with his hoe on his shoulder; and neither boy nor hoe was ever seen again. The old Captain said he guessed he had run away, and gone home to Bald Hill. But he did n't turn up there; and then he said he must be drowned in the pond. At last it began to be suspected that in a passion the Captain had struck the boy and killed him. And stories were told for many years of an old well in a back pasture which had been filled up, — nobody knew when; and nobody knew exactly where the well was to be found. Two or three times the people turned out to find it, and I remember when I was a little fellow following a crowd on this business. This was after the Captain died. They dug and dug, and cut down trees, and tore up bushes, until John's father, who then owned the farm, ordered them to quit, and threatened to sue them for trespass if they did not. No well, nor any sign of a well, was ever found; no boy, and no hoe. But somehow the old folks believed the story ; and once good old Minister Hopkins seriously asked the Captain if, in a moment of passion, he did not really strike the boy dead. The Captain looked at the minister, looked on the ground, said nothing, and went away. And I believe everybody in town was sure he was guilty, for nobody had ever failed before that time to tell Minister Hopkins the truth, the whole truth, and nothing but the truth, when asked. I don't know how all this may be, but I 'm glad enough that old Captain Thomas was n't my grandfather." 
The story was not new, but it seemed to have new force, and as it came in slow and deliberate measure from the lazy lips of the oracular old man, it seemed to produce an unusual effect upon the audience.

"Rather bad blood," said Peter Ilsley; "and they do say that "what is bred in the bone will come out at the skin." "

"They used to say old Squire Sam, John's father, was no saint," added the ex-representative. "And when I was in the General Court I used to hear about Squire Sam's vote making a governor, and about the pay he got for it, - a commission as sheriff or justice of the peace."

"He was a sheriff one while," said the grocer; "and they say the good, round fees used to roll into his pocket like dropping stones into an old well."

"John 's honest," said Peter Ilsley, scrutinizing the little crowd, to see how the remark took.

"I don't know about that," replied the biographer of the Oakes cow; "he stuck me like sixty once on a cow trade; put me a farrow cow, and a breachy one at that, with a calf three weeks old by her side, and a bag as big as a Shaker bucket; had n't been milked for two days. He said he sold her just as he bought her, and he was so awful smooth about it that I never could get anything out of him."

"Now, this won't do," said the pillar of the church, "John Thomas is as honest a man as lives in Jotham. He always goes to meeting, sencls his children to the Sunday school, has the minister to tea Thanksgiving day's, and pays what he owes. If John Thomas is n't a good citizen, there are n't any.'

"How about that poor beef and bad butter that he sent to the poorhouse last spring?" asked the cow-dealer.

"I have no cloubt that Thomas is honest enough," said Peter Ilsley. "He has a stiff way about him that I don't 
like, and then he has made the minister and Squire Wright and Dr. Parker and the Schoolmaster all believe in him, and that 's enough. But I think it would be a pretty good

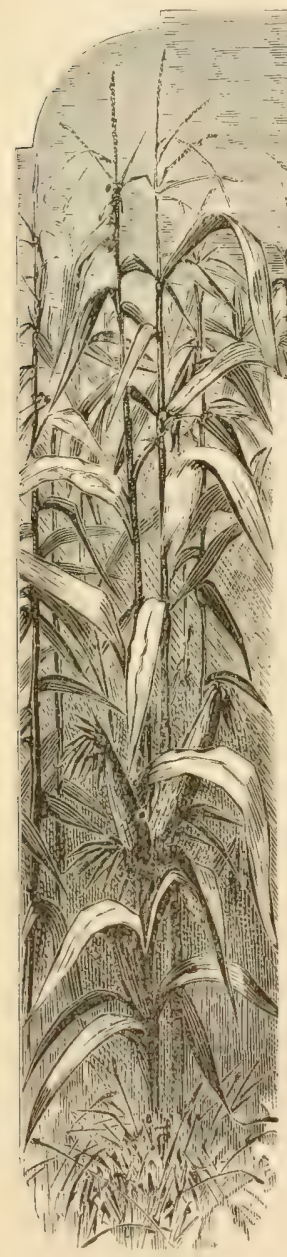

A CORNHIELD.

plan to inquire into the doings of the selectmen for the last few years. I know when I was on the board, five years ago, we were full easy enough about the poorhouse bills. Nobody ever asked where the provisions came from, or who supplied the lumber, or how much the labor-bills were. Bill Stevens the keeper said it was all right, and Thomas said Stevens was right, and the rest of us had nothing to say about it. I never exactly dared to say that Thomas and Stevens divided, but I never could swear that they did n't. At the same time, I suppose I might have found out when I was on the board. But then, I thought if Thomas wanted to get into a scrape, it was none of my business. We did n't any of us attend to our duty over and above well."

"Look here, Peter," said the grocer, "I think you have gone about far enough on that line. 
John Thomas always said you were a first-rate officer, and looked out sharp for the town expenses, and saw that all the vouchers were properly examined and filed. Now, if you are going to black yourself for the sake of blacking him, it seems to me that you'll come out at the little end of the horn."

" Well, I don't know but I shall," said P'eter; "but how many days' work of his cattle on the road did Thomas charge for last summer? For one, I think these things had better be overhauled, let the blow fall where it may."

The loungers around the "store" now began to gather themselves up to depart. They folt a little ashamed of the turn their talk had taken, and they felt annoyed at Peter Ilsley, and a little disgusted with the spirit he had manifested. They were glad that it was not daylight when they went forth; and they rejoiced that under the cover of darkness they could reach their homes without meeting John Thomas, or Mr. Howe, or Mr. Hopkins, or their wives and daughters. They wondered how far this thing was going, - and they hastened home to bed.

Neanwhile Mr. Howe and John Thomas had made up their minds that it was time for another meeting of the Club. They therefore issued a call for the following week, and selected as a subject for debate, Grain Crops.

The Club assembled with great promptness, and with an evident feeling of satisfaction that its interests were not to be neglected, nor its existence endangered, by any outside controversies. Mr. Hopkins received the members with unusual cordiality, and manifested a marked kindness to John Thomas, the reason for which that gentleman could not imagine, ignorant as he was of the trial he was to meet at the hands of Peter Ilsley and his followers. The discussion was opened by the President, who selected Indian corn as the most important grain for the consideration of the American farmer. 


\section{MR. HOPKINS ON INDIAN CORN.}

Maize, or Indian corn, is perhaps the most important crop raised in America. Adapted to local wants and immediate consumption, it occupies also an important place in our domestic and foreign commerce; and, while cotton brings us to the great manufacturing countries of the world, and lies at the foundation of that export trade upon which our financial prosperity depends, corn enters so largely into our domestic economy as food for both men and animals, that it may properly be called the corner-stone of our agriculture. Colonel Taylor, a sagacious and intelligent Virginia farmer, once said: "Indian corn may be correctly called meal, meadow, and manure; it produces more food for man, beast, and the earth than any other farinaceous plant. And so valuable is it, that if the discovery of America had done no more than to bring this plant to light and introduce it into the list of great farm crops, this of itself would be sufficient to immortalize Columbus and his adventurous companions. From America it has spread everywhere, - into all latitudes where the summer sun gives even sixty days of warm weather, and where a quick and rich soil feeds the rapidly growing plant. Eridently tropical in its nature, it accommodates itself to Canada and Georgia alike. It has taken so high a rank among the crops of Turkey that on the continent of Europe it is called Ble de Turgue, and I have found it the common food of the Neapolitan peasant, under the name of Grana dol Tiurco. In Germany I have seen it cultivated as a house plant and admired as a rare and beautiful product of the Southern soil."

The question whether corn can be profitably raised in New England I do not propose to discuss at length. Here it may be counted, I cloubt not, rather as an attendant than as a staple crop. Considering the usual market price of corn coming from the Western cornfields, with which the farmer can fill his granary, it would be idle to devote land suited both by quality and location to market gardening and root crops, to the growing of corn. But on remote lands, on farms somewhat removed from the market, corn may properly be male one of the standard crops. 
As part of a rotation also, which is to end in grass, the corn crop is most valuable, especially if it immediately precedes the sowing of the grass.

The soil best adapted to corn is a warm loam. I say a warm loam, for although corn will accommodate itself to a cold soil and a cold climate, it is a plant which especially requires heat for its highest perfection. It will not even vegetate in soil whose temperature is less than $55^{\circ}$. And if it is exposed to the malign influences of a cold and wet soil, it will never recover, no matter how favorable the season may be. A corn crop may be injured as much by the effects of a cold soil upon the seed as by an early autumnal frost. Corn should nerer be planted, therefore, until the atmosphere has been tempered by summer heat and the soil has been well warmed by the early summer sun. It should be planted at such a time and in such a soil that it will germinate at once, and start forth in life with a strong and healthy green color. A yellow and stunted growth in the corn crop is never followed by a vigorous and profitable maturity. It is heat, then, which corn requires, - a warm soil and warm weather. It is only uncler fortunate circumstances like these that a great crop can be raised; and it is only by the observance of this law that the average yield of corn in any locality can be brought to the highest degree.

The preparation of the soil for corn planting is simple, and similar to that required by the other common field crops. If stubble land is to be used it should be thoroughly pulverized by one early and one later spring ploughing. If, however, sodland is to be used, it should be ploughed immediately before the planting, and the furrow set at an angle of forty-five degrees, in order to secure a proper and necessary circulation of the air through the soil during the early growing of the corn, and in order to provide for the most effective application of manure, to which I shall allude hereafter. The land should not be ploughed in the autumn with any idea that this will be a substitute for spring ploughing, but only in heary stubble land as a valuable preliminary to the cultivation of the next year. Nor should the manure be applied in the autumn unless you are willing to lose 
one half of that stimulating power which corn especially demands of its fertilizers.

Corn is one of the crops to which green, undecayed barn-yard manure can be profitably applied. I have spoken of the use of sod-land for the corn crop ; and it is to land of this description that green manure may be applied with great advantage. If you will spread the manure broadcast upon the land just before ploughing, and turn your sod upon it, not flat, but at the angle I have designated, you will prepare for the most rapid and sudden decomposition during those very weeks in which the corn grows most vigorously. The bed which you have thus prepared for rootlets when they are engaged in their busiest operation is the best that can be conceived of. The heat of the active decomposition, the fortunate combination of decaying vegetable matter and manure, and the texture of the crumbling sod, all combine to make this mode of fertilizing especially applicable to the corn crop. It should be borne in mind that, in addition to the manure ploughed under the sod, some form of fertilizer should be applied in the hill at the time of ploughing, in order to give the seed an early start; or to the plant itself at the first hoeing. Half a shovelful of well-rotted manure in the hill is, I doubt not, the best fertilizer that can be used for this purpose. Plaster has been used, but it is too wet for this crop. Bones prepared as laid down in the early clebates of this Club are very useful. Half a gill of guano or a gill of superphosphate may be applied with adrantage. The droppings of poultry composted with a small quantity of muck, and well decomposed, have great effect. Lime is of no value, unless you prefer a large amount of forlder to a good crop of grain. Ashes applied on the surface at the first hoeing not only stimulate the plant, but they tend to destroy and drive away many of the insects and worms which are injurious to the crop.

I have found a record of a corn crop kept by a reliable citizen of this State, which contains so many valuable hints with regard to cultivation, and so many interesting calculations, that I will take the liberty of reading it as a part of my statement. 
"The field of corn entered by me for premium contains two acres; the soil is a black loam generally, and part of it is a mixture of gravel. The condition of the field was poor; it wals sowed down to grass in the fall of 1846 without any manure; it has been in grass ever since until September, i $S_{72}$, when I had it broken up about ten inches deep. Allow me to say that it had better have been ploughed in the spring following, just before planting. The manure used on this field was a compost macke entirely between the isth of November, I $S_{52}$, and the last of April, $1 \$ 53$, from one horse, one cow, and sods taken from the above field and composted in my barn cellar by my hogs. As the bulk of the mamure was taken from the same field to which it was returned, I shall only estimate the value of the horse and cow manure, the use of the hogs for composting, and the carting of the sods into the cellar, as that was the only cost to me. The compost was carted directly from the barn cellar, without turning over, about the last of April, and spread as even over the whole field as it could well be, and immediately ploughed in. The quantity spread in this way was about sixteen cords to the field, or eight cords to the acre; it was then harrowed and furrowed both ways, three feet four inches one way and three feet the other. There were about two cords of the scrapings of the cellar put in the hill. On the roth and It th of May I planted it with Plymouth County corn, putting six or eight kernels in each hill ; cultivated and hoed it twice, taking out all but five, and sometimes four stalls at hoeingtime.

"On the rsth of October, the committee, after examining the whole field, selected two places, in separate parts of the field, and measured one square rod in each, which they considered to be a fair average of the whole. 'They measured from the centre between two rows, and gathered, shelled, and weighed each rod separately; the first rod weighed $4+\frac{1}{4}$ pounds, the second $+6 \frac{1}{4}$ pounds, making the average $45 \frac{1}{4}$ pounds to the rod ; reckoning 56 pounds to the bushel, as per rule of the society; it gires me I 29 bushels to the acre. The corn was well ripened, and I begân on the same day to harvest it. 
"Debt and credit on the above field :-

Interest on land valued at $\$ 225$ per acre . . . . $\$ 27.00$

Taxes on the land . . . . . . . 2.56

Ploughing in September, 1852 . . . . . 5.00

Carting sods into barn cellar at sundry times . . . I0.00

Manure of horse and cow, $5 \frac{1}{2}$ months . . . . 8.00

Use of hogs to work over sods and composting . . 10.00

Aplylying manure, $\$ 10.00$; ploughing and harrowing and fur-

rowing, $\$ 6$. . . . . . 16.00

Seed corn and planting, $\$ 3.50$; cultivating and hoeing, $\$ 6.00 \quad 9.50$

Cutting stalks and harvesting . . . . . . 16.00

Total . . . . . . \$104.06

Value of crop : -

Stalks and husks . . . . . . . . 30.00

$258 \frac{1}{7}$ bushels shelled corn, at 90 cents . . . . 232.20

Increased value of land from manuring . . . 14.00

Total

$\$ 276.20$

Profit . . . . . . . . \$I72.I4

This statement I consider interesting and valuable, with the exception of the time of ploughing in the fall, and the date of planting. The Ioth of May, in ordinary seasons, is too early to plant corn. The last of May is better. It is unnecessary for me to add that thorough hoeing and cultivation are indispensable to a good crop. Opinions differ with regard to the best method of harvesting corn. The advocates of cutting and stocking when the corn is glazed claim that more fodder is saved and a greater weight of corn secured in this way than in any other. Of this I am not sure. The fodder when cut has reached a clegree of maturity which makes it tough and woody. It is exposed to all the storms of autumn, which camnot certainly improve it. The corn itself may not be evenly ripened throughout the field; and the green corn may heat and mildew in the shoot. These are manifest objections. On the other hand, stalks cut when green and properly cured are palatable and nutritious. The corn left standing, after having been topped, has the full benefit of the last hour of ripening; it is exposed to no heating process, and has every opportunity to make a dry 
and sound liencl. I may be mistalien about this, but I strongly incline to the opinion that where the crop is not so larere ats to make it expensive, the mode of harvesting by cutting and curing the stallis and allowing the corn to stand and rijen in the fielel is the most satisfactory.

I fear I have occupicel so much of your time that debate will be cut off ; but you know I am always glad to receive the ('lut) at my house, and I trust we shall soon have another opportunity to continue the discussion.

After Mr. Hopkins had finished his paper there was indeed not much debate. The minds of the members seemed to be prenceupied, and there was an evident desire to adjourn and join in general conversation. It was noticed that Peter Ilsley and IVilliam Jones, with two or three of the lesser lights, gathered in a cormer of the room and opened a guarded talk. Mr. Hopkins, Mr. Howe, and Charles Ingalls met in front of the fire and stood about and looked at each other, making but few remarks. The other members of the Club grouped thenselves according to their tastes. But there was an awkward mystery hanging over the room; and it was found that in no one of the groups had John Thomas a place, and that at his approach the conversation ceased. Gradually they separated; and John Thomas was glad to go home and sit clown before his own fire with Huldah. He did not know the reason why, but as he reached his house he noticed that he had been walking on alone. A week of inmuendoes started at the grocery had surrounded John Thomas with a dangerous complicated network of which he was as yet ignorant, and from which he was not easily to be extricated. 


\section{TWENTIETH MEETING.}

\section{GRAIN CROPS (Continued).}

JOHN THOMAS IN TROUBLE. - HIS CHARACTER ASSAILED. - SOME FRIENDS DESERT. - THE TOWN-MEETING. - CHARLES INGALLS BEHAVES LIKE A MAN. - CLARA BELL SHINES.

THE evil and ungenerous sentiments and suspicions which were aroused by the conversation at the grocery soon filled the air of Jotham and beclouded it, as the testdrop of the chemist casts its opaque and dingy shadow through the crystal pool. The ordinary village gossip had always had its share of scandal and flying abuse; enough to season but not enough to poison the tone of society. I3ut now matters assumed a serious aspect. A citizen in whom the community had reposed entire confidence, and who had been intrusted with the affairs of the town without hesitation or doubt, was enrolled in the list of those who are a reproach to society, and whose restraint and punishment are among the painful duties of a well-ordered state. Nobody pretended to say that John Thomas was dishonest; nobody suspected him of being a rascal. But perhaps Stevens, the keeper of the almshouse, had overreached him, and the sagacity of a public official should place him beyond the reach of fraud; how otherwise could the state be safe? John Thomas, the citizen and farmer, might be cheated every day of his life; but John Thomas, the Selectman, never. He might be weak and mortal in his own affairs, but not in the affairs of the town. They felt by a sort of perverted instinct that official infirmity was no better than official wickedness; and one ancient 
maiden alluded in an undertone to Caesar's wife, while many an ambitious moralizer referred to spots on the sun.

"I am sorely perplexed by this affair of John Thomas's," said the Rev. Mr. Howe to his wite, as they sat tregether on Sunday evening, discussing the services of the day and the condition of the parish. "He is under a heavy cloud, and when it is to clear off I cannot tell. He may be a victim of a lofty and perhaps imperious demand for official honesty, which is a natural characteristic of a free people. From the days of Washington until this hour, every man in high place in this country has been charged with corruption and dishonest designs; and it is encouraging to feel that the people have always set their stanclard so high, and have always been so uncompromising in their demands. I glory in this keen and watchful public eye."

"Is n't there something a little green in that eyc now and then?" said Mr. Hopkins, who had walked in to make his usual Sunday evening call on the minister, and had heard the latter part of his little discourse.

"It may be so," said Mr. Howe; "men may be envious and jealous of success in every form, but I think they feel so deeply the importance of honesty as the corner-stone of republican government, that they may sometimes be hard in their demands. A mind filled with deep convictions, and a heart fixed on high purposes, are apt to be merciless. If men will aspire to high places they must pay the price. It were better that even a righteous man should suffer, rather than that wrong should fall upon the community:"

"It is so hard that popular injustice should be necessary to preserve the purity of popular institutions," said Mrs. Howe, in a gentle tone.

"Not popular injustice," said Mr. Howe; "but popular integrity, which must be heard, though the heavens fall, and which should no more be checked in its career than 
the workings of an all-wise Providence. If John Thomas must be sacrificed for the good of the community, and in obedience to the high demands of popular integrity, he must bow with resignation, and we, his friends, must submit with patience."

"But if he is innocent?" interposed Mrs. Howe.

“That he must prove," said Mr. Howe; “and be held guilty until he does."

"If I were a man, I should be very slow to pay such a price as this for the highest office in the gift of the people," replied the perplexed and sympathizing Mrs. Howe.

"My dear," said the minister, warming to his subject, " nothing but a fearful accountability, rigorously impressed, can keep society, or the state, or the church, or party, pure. Let it be understood that the character of the church is created by the sinners it should save, that the state is no better than the criminal it should punish, that society is controlled by the corrupt, and that a party is always as bad as the worst men in it, and state and society and church and the party will purify themselves, even if it be done by fire."

"But are you sure this is true?" asked Mr. Hopkins, who began to grow restless under a doctrine which threatened to tarnish his mercantile honor. "I am sure men must have a higher motive, and a more enlightened sense than this. Injustice never worked out a reform. I do not know that I should feel called on to save an innocent man from its operations, in the face of popular clamor. I fear I should not feel called on to sacrifice myself in any such conflict. But I must say that if ever there was a theory out of which conspirators and hypocrites and Pharisees could be born, this is one. I am for honest men every time and in every walk in life; and I know no way to get them but by encouraging honesty and punishing dishonesty with justice and keen discrimination; and I would punish a conspirator quicker than I would a thief. This wholesale 
denunciation and condemnation of public men will fill our high places with cowards and time-scrvers and imbeciles, - men who escape condemmation by aroiding all responsibility. But remember, I clon't say this to shield or excuse John Thomas, or to stand between him and an indignant people. No man shall ever charge me with having winked at or tolerated official wrong. I do hope and pray that I shall never be tempted to take office."

"No office higher than the Presidency of the Farm-yard Club, I suppose," quietly remarked Mr. Howe.

At this moment Squire IVright entered, and, after having saluted those present with his usual courtesy and urbanity, and enlarged upon the bright and beautiful weather which had marked the day, and discussed the manner in which "St Martin's" and "Dundee" had been sung by the choir and the audience combined, he turned his attention to the case of John Thomas as the all-absorbing topic of the village.

"If he were alone in this trouble, I should have great compassion for him," said the Squire; "but everybody is exposed to this same attack, and he has had a long career of power, and must now take the torment."

"But his poor wife!" whispered Mrs. Howe.

"Before the severe demands of public conscience," continued the Squire, "I am always unwilling to listen to the calls of mercy. Society is gentle enough with the criminal, and holds him innocent until he is proved guilty. With its servants, however, it should be unsparing. The necessity for official service is bad enough; the existence of public servants, large and small, is discouraging enough; let them, then, go to the rear. I hold that every man who is engaged in the service of the state should be bowed down with humility and should feel that the day of his distinction has arrived when he retires to private life. If, in order to preserve the national integrity, we must subdue public servants, so be it ; it is the sacrifice we offer 
for the good of our country. This may be hard; but while as a friend I deplore it, as a citizen I acquiesce in it. I would hold every public organization accountable for the sins of its members; and I would declare an unending war of purification. Now, take this case of John Thomas. If, during his administration, Stevens has defrauded the town in supplies to the almshouse, he, Thomas, has scandalized this community; and, hard as it may seem, the career of John Thomas must be held up as a warning to all officials. As a friend, I admire him; as a citizen, I respect him; as a reliable business man, I trust him; as a member of society, I value him highly; as a trustee, I should have confidence in him; as a referee, I should rely on his judgment; but as a selectman of Jotham, I cannot approve his course or commend the example he has set his townsmen."

"But do you think he has really been dishonest?" asked Mrs. Howe.

"No, not exactly," said the Squire. "But that is of minor importance. For, pray tell me how we can fight the great army of public plunderers if we allow even a suspected person to escape? No party could afford to do that."

"We were not considering party, if you will allow me to interrupt you," said Mr. Hopkins. "And I am sure that party must be weak which is obliged to sacrifice innocent men in order to relieve itself of the odium of the guilty."

"O no, Squire, this is not a party question!" said Mr. Howe. "I agree with you in allowing the public demand for honesty to be carried on to a point of unreasonableness and the sternest justice. I would never check it. I pity John Thomas; but I cannot meddle with his public career. But it is not a party question with me. It is a question of public and general importance."

"It is a question of equal and exact justice," said Mrs. Howe, who had no idea of popular indignation, and for whom the cirimm ardor praic jubcutium had no terrors. 
The evening had now passed away, and the company separated, not by any means satisfied with the way in which they had met the question of John Thomas's delinquency. They felt that somehow the justice and manliness and courage and humanity had been with Mrs. Howe.

And now the town became thoroughly engaged in the business of discussing this unfortunate malfeasance; and John Thomas, who had led an inconspicuous life of honest drudgery and steady, commonplace duty, found hinself an object of disagreeable interest, and surrounded by a painful isolation. The path into this umpleasant complication had been so concealed, and the journey had been so gradual, that he hardly knew how he had arrived at the strange complication of difficulties which beset him on every hand. He had never examined himself on the point of integrity, had made no good resolutions in this direction, had never raised a doubt in his own mind with regard to the reputation which he had for a long life enjoyed among his neighbors, - to ascertain whether it was well founded or not. He had always passed for an honest man, and he tonk it for granted that he was so. But now the people said he was not, and he was naturally inclined to accept patiently and submissively their verdict, as he had heretofore accepted their approval and their good opinion. Ite had been so long ranked among good men by spontancous public accord, that it took him a long time to realize the situation into which he was forced by being conclemned as a bad one. The whole affair was in his mind either a farce or a dream; and he could hardly tell which, until passing events, trifling in themselves but significant, brought the reality home to him in a startlings and amazing manner.

Huldah became silent and anxious and abstracted. She had never been what is called a person of high spirit.: 
But she had been such a cheerful and busy and contented wife to John Thomas, such a tender and watchful and eren-tempered mother, that her house had been as cloudless as a soft and sunny October afternoon for more than twenty-five years. In all that time she had never been either elated or bowed down. She was now, however, eviclently oppressed by a deep and heavy sorrow which she could not conceal, and which she was unwilling to impart to her husband, lest by so doing she should indicate her belief in his gruilt. Once, as they gathered around the table in the morning, John saw a tear stealing down her cheek; but he had been so long accustomed to living with her in a mutual joy that he could neither understand nor manage a mutual sorrow. And so he too was silent and awkward, and at last heavy and oppressed. His home was darkened.

His children felt the depressing influence of this domestic mystery, and grew shy and half frightened. And his favorite boy, John, his namesake and his counterpart in all his sturdy and manly qualities, overwhelmed him with grief and astonishment by inquiring of him what the boys at school meant by asking him if he lived on poorhouse beef and pauper butter at home.

Dr. Parker called to pay a bill, and when the amount was settled, John vainly endeavored to lead him into general conversation; and when he proposed to take their usual look into the barns and among the horses and cattle, he was perplexed and disappointed by the Doctor's silence and his readiness to depart. Even his barns looked gloomy, and his pride in his animals was turned into shame and distress, as he stood there alone in an atmosphere chilled by the frigid civility and avoidance of an old friend. He even thought the Doctor had paid the bill with unusual promptness as a reproach to him.

In the grocery he did not meet with even silent courtesy. 
IIe had never been in the habit of spending an evening hour in this village ' Change; but now he felt an irresistible desire to mingle with his neighbors who congregated there, partly in expectation of a friendly word, partly to relieve his mind with idle and familiar talk, and partly in hopes that his presence might lead his accusers away from their object. But he got small comfort there. The conversation did not flow with its usual ease and rapility; and when it did go on, it was far from agrecable or satisfactory to him.

"Damn a ring, anyhow," said Peter Ilsley, as they closed a discussion of Biddle and his Bank.

"I see no occasion for swearing about it, Peter," said John, putting in a word to place himself right on the moral side of the question, and to rebuke Ilsley for his rudeness.

"Well, I do," said Peter. "Common words don't begin in a time like this."

"I don't believe three scamps ever got together, that one of 'em dicl n't let out on the others," said the ex-representative, looking at Peter, and remembering that he was a selectman turning state's evidence.

Peter squirmed, and said nothing. John laughed with a hoarse spasm, and departed. He had begun to realize the trouble which surrounded him; and he had begun, also, to feel the importance of a bold and manly and candid declaration in an hour like this. And more than all, he felt how through inexperience he lacked the wisclom and courage to meet this crisis as it should be met. He was a silent sufferer, because he had never learned how to take or give advice; had never dealt in expressions of sympathy; had never been taught that there are times when defiant selfassertion is necessary as an act of justice to ourselves and our friends.

It was in the midst of this unhappiness, suspicion, and ill-feeling, that the time arrived for holding the annual election of town officers in Jotham. The March meeting, 
as it was called, had come. The usual warrant had been nailed up in the church entry the number of days required by law, and the inhabitants had read and pondered upon the various articles, both before and after divine service. Some of them seemed to read with unusual care, as if they expected to find an unwonted article there, - perhaps to inquire into the conduct of the selectmen, - but they found nothing; and so they said nothing. And so, on the first Monday of March, at I o'clock, P. M., the old bell sounded out its summons, as it had done for years, and the people assembled to discharge their duty as citizens of the town. The meeting was opened with prayer by Mr. Howe; the warrant was read by the Town Clerk; and in accordance with the first article, providing for the choice of a Moderator, Squire Wright was elected to that high and imperial office, which the law has clothed with such supreme power. The Moderator was stationed on the low platform in front of the pulpit, while the voters were scattered about in groups, some gathered near the desk, some loitering up and down the broad aisle, some assembled in the porch, and some of the old and fecble sitting quictly in the square, high-backed perws. The choice of Town Clerk attracted but little attention, the few votes which were cast being for Silas Savary, who was declared to be duly elected. The article providing for the choice of three Selectmen was read, and the voters present were called upon to deposit their ballots for these high officials. At once there was a stir, and the scattered groups began to sather about the pulpit, not actively, but with real or assumed reluctance. The ballot-box stood open, the Town Clerk was seated behind his check-list, but no man advanced to vote. There was evidently an unusual movement to be made, - so unusual that the mover hesitated, and hardly knew how or where to begin. At last Sam Barker addressed the chair and asked if debate was in order. 
"Debate is always in order," said the Moderator, "unless the question is being taken, or the meeting has adopted and applied a rule to suppress it."

"Then, Mr. Moderator," said Mr. Barker, "I want to say to this meeting that I find the name of John Thomas on a ballot here for Sulectman, and in my opinion he ought not to by elected to the office. He may be an honest man, but there are those who do not believe it. I- " Cries of order arose from all parts of the house; and the Moderator reminded Mr. Barker that such a personal discussion of the merits of a candidate could not be allowed at that time. “Let him go on," said John Thomas; "I suppose I might as well meet it now as any time." And he really appeared to be gathering courage for a contest, although his voice had but little of resolution in its subdued and muffled tones.

Sam Barker began again, and was proceeding with much vehemence to call in question John Thomas's fitness for the office, alluding to the damaging traditions with regard to his grandfather, denouncing his father, and amid great confusion clamoring for an almshouse investigation, until a feeling of remorse and sorrow seemed to be settling down upon the whole assembly. In the midst of the disturbance, a young woman was noticed to enter the church, and make her way to Charles Ingalls, who sat alone in a wall pew, watching the strange and to him novel scene. It was the first time a woman had ever been seen in a townmeeting at Jotham; the first time that it had ever occurred to any man there, that a woman could have voice or interest in public affairs. They all thought they knew how beautiful Clara Bell was, -- but they had no iclea, until that moment, of the startling beauty with which the discharge of what seemed to be a great duty could irradiate her face, nor of the determined enersy which could inspire her form with new grace and power. Charles Ingalls was amazed as she approached him, and still more amazed 
when she exclaimed: "Charles, I know it all! Remember your mother, your own honor, and be a man! John Thomas has a wife and children and a reputation. IIe may be wrong, but he is entitled to justice. Now speak!"

This unexpected appearance of Clara Bell had produced profound silence in the meeting. Squire Wright, as Mod-

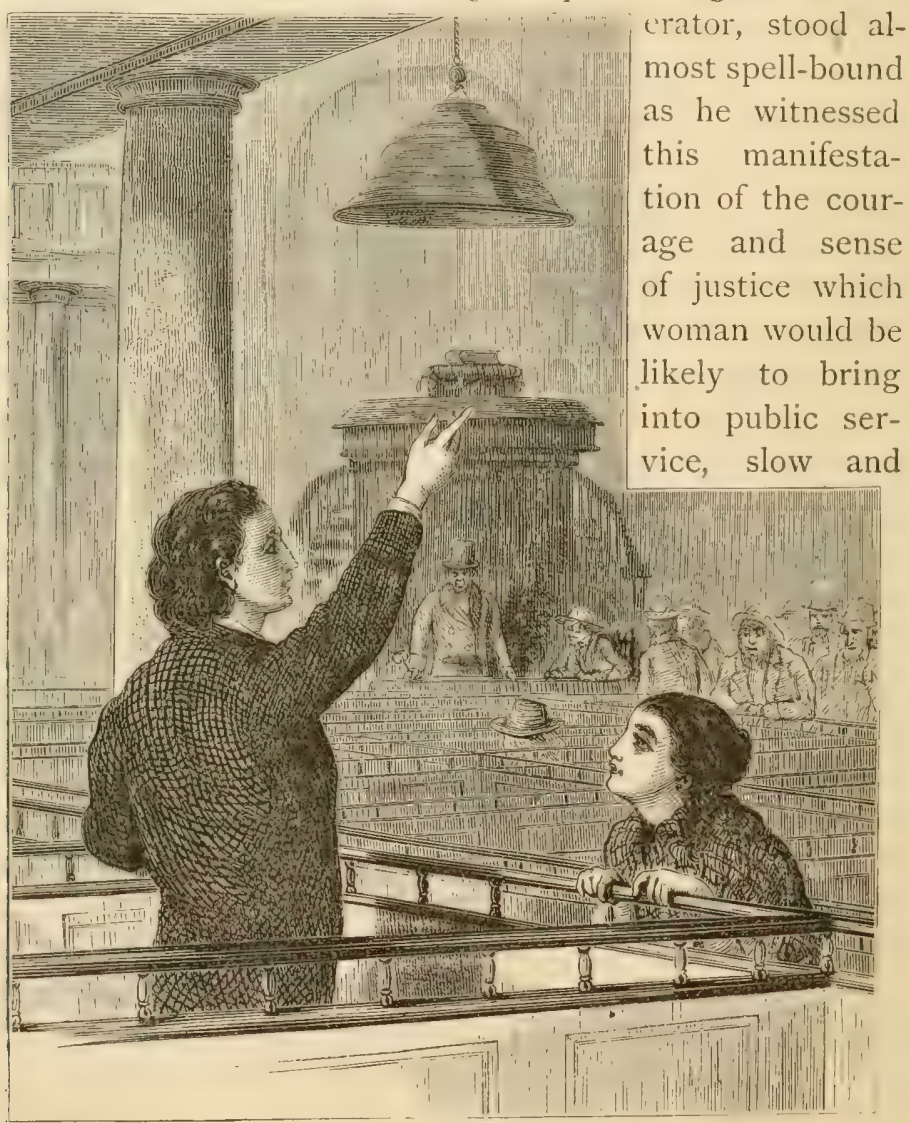

THE TOWN-MEETING.

reluctant as he was to acknowledge it, and unwilling to recognize anything as superior to the rigorous justice of 
the law. Sam Barker harl lost the thread of his philipulic, and was dumb. John Thomas lifted up his bowed head and secmed filled with new courage. Charles Ingalls rosi and addressed the chair, while Clara stood leaning against the side of the pew, and looking into his face with a countenance slowing with confidence and expectation.

\section{SPEECH OF CHARLES INGALLS.}

Mr. Moderator, - I am but just a voter in this town, am unused to public assemblies like this, and am entirely ignorant of the course of debate which would be considered at this time in order. I have, however, but a few words to say, and I beg the indulgence of this meeting of intelligent and responsible citizens while I say them. I know, sir, as you clo, and all here do, that the reputation of one of our most respected citizens has been so successfully assailed that he funds among us but few defenders. I know and feel the danger of appearing here as an apologint for his alleged offences. But I know, also, that there is a litent sense of justice in every community which will not allow any man to be condemned unheard. We are told that Mr. Thomas has been guilty of neglect of official duty at least, and probably of corrupt practices, while in charge of the interests of the town. The origin and olject of the complaint are by this time well understood, I doubt not; and my desire is that before going further we should remind ourselves of the precise nature of the accusation, the character of the accused, and the fact that he has had no opportunity to be heard by his townsmen. I appreciate the deep and solemn importance of integrity and fidelity in the official service of a country like ours. The corruption of a despotism may be concealed and tolerated, perhaps, and its power remain unshaken. But in a community where all power springs from the governed, the fountain and stream must both be pure, or swift destruction is sure to follow. It is the honesty of private life which must lie at the foundation of honesty in public life here. I would, therefore, place society and the state on the same footing, and I 
would employ the same means to suppress crime in the one that I would in the other.

Now, sir, let me suggest to the gentlemen here present that a clamor for reform for mere political party purposes is poor business; and that an attack on a man's character for similar purposes is poorer business still. The motive is a demoralizing one, and the result is simply to degrade public life and to deter good men from taking any part in it. I would remind you, moreover, that an inquisition is not an investigation. There are tortures more severe and cruel than the thumbscrew or the wheel, which may drive men either into callous insensibility or into clespair. I.et us, as sensible and honest men, aroid such cruelty as this. I warn you, too, against public professions of purity and integrity. The corners of the streets exist to-day just as they did in the time when the Great Teacher denounced the Pharisees and hypocrites, who met there to display their piety and their purple robes. While, then, we make a stern demand for high-minded and honest and honorable servants, let us avoid a wholesale denunciation of public service on the one hand, which is self-righteousness, and political design on the other, which is demoralization. For one, I like neither the time nor the manner in which Mr. Thomas is accused. The chief accuser has not approached his business like a man. He has waited for his opportunity. He seems to have had a hand in the very business of which he complains. Honesty is a good thing every month in the year and on all occasions, in the autumn as well as in the spring; just before Thanksgiving as well as just before town-meeting. And I trust, sir, we shall manifest as much anxiety to escape political injustice as we do to unearth a rascal. I hope and pray, moreover, that we shall never be brought to the point of denouncing church and state and society, and all associations, or even party, because bad men will seek shelter where they think they can find security and plunder.

Allow me, Mr. Moderator, in closing, to relate a striking personal incident illustrative of my argument, - an incident which I found recorded in a French newspaper filed in the reading- 
room of the college library, and which I happened to read just before I left old I bartmouth for this town, at the begrimning of the last winter. During the later years of the reign of Lomis Philippe in France, the eminent and powerful thinker and writer, Sainte-Beure, began to attract the attention of the literary and political world, and as a recognition of his genius and accomplishments he was appointed by M. Cousin a keeper of the Mazarin Library. For his convenience, and as a part of his emoluments, he occupied the rooms provided for the librarian at the Institute, and there diligently pursued his studies and faithfully discharged the cluties of his office. In ()ctober, 1847 , finding a defect in the chimney of his room, he sent for a workman to repair it, and on ascertaining that the government was responsible for work done on public buildings, he made application for authority to order the repairs, which was granted, and the workman was paid out of the public treasury one hundred francs. In February, I $\$$ \& $\$$, Louis Philippe fled to Englind, and a republican govermment was founded. The upholders of the new order of government proceeded at once to denounce and expose the crimes of the Ministry who had served the displaced monarch as well as those of all their friends, and to publish the names of all persons who receired bribes from the ministers of the Crown. In due time the name of Sainte-Beuve, a man who had enjoyed a high reputation for courage and honesty, and was counted as a friend of the republic, was published to an astonished community as one who had yielded to temptation, and had played the part of hypocrite and thief at the same time. Sainte-Beuve at first looked upon the accusation as a joke, clenied it, and treated it with contempt. But he at last became conscious that the charge was looked upon as well founded by some of his best friends and most respected acquaintances, and he proceeded at once to deny it in a long, elaborate, and carefully written letter addressed to the public of Paris, declaring that he had had no communication whaterer with King or Ministry or the House of Orleans, and that he had conscientiously refused all honors at their hands. Notwithstanding this explicit denial that he had drawn money from 
the ciril list of Louis l'hilippe, his friends and the public were not wholly convinced of his purity; and feeling it impossible to hold a post under a goremment which regarcled him as corruptible and corrupted, he ceased at his own request to be a keeper of the Mazarin Library. He was at once invited by $M$. Charles Rogier, Belgian Minister of the Interior, to become Professor of French Literature in the University of Liege; and when he accepted the invitation and left Paris, his enemies declared that he had fled from the capital orerwhelmed with guilt and fear. 'The account continues, sir, that "while he was the victim of charges which it was hard to bear, and of insinuations which it was impossible to silence, Sainte-Beuve left no stone unturned in order to discover the source of what he felt to be an atrocious calumny. He wrote to the ex-ministers of the fallen monarchy, requesting them to give him all the information in their power, and they replied that the matter was a mystery to which they could supply no clew. Some time clapsed before the publication of the paper in which his name was said to have been entered as the recipient of a large sum from the civil list; when the paper appeared there was the following entry in it: 'Sainte-Beuve, roo francs.' 'This represented not only the amount charged, but the actual payment which had been made for the repair of the chimney on the roof of the rooms at the Institute. The outlay had been incurred too late in the year to be included in the Budget, and had been entered among the extraordinary expenses. To him, then, a smoky chimney had really proved one of life's. greatest plagues. It had made him the object of such suspicion and attack, that he had resigned a post to which he was attached, had accepted another not to his taste, had become for a time a voluntary exile from France, which he strongly. loved, and from Paris, which was his favorite place of abode."

Can you conceive, sir, the wretchedness of this man's life? Can you imagine a burden more grievous to be borne than the long and weary hours of unjust punishment for unfounded accusation? That such injustice and wrong should arise from an unfortunate chain of evidence, whose error and weakness no legal 
invertigation can discover, is hard and discouraging cough ; but as the result of political excitement, or rancor, or design, it becomes intolerable, and should receive a public condemmation a thousind times more severe than the pun shment which society would inflict on the criminal. I tust no such wrong will be committed in Jotham. Heaven knows that we desire to be honest here, and I believe we shall let the world know that we scom to be bitter, persecuting, or unjust.

I hope, Mr. Moderator, the balloting will proceed, and that we shall rise above passion and prejudice, and deposit our rotes; for those whom we respect, and in whom we have confidence, resardless of personal ambition, and guded by the same rule that would govern us in the ordinary business of life. I have said more than I ought in the presence of my elders and supe riors; but I have been keenly reminded, as you see here, that the tenderest relations in life and the sweetest happiness may he involved when we would hardly expect it. I know I have fecbly and imperfectly performed an unexpected dluty, but I have done it sincerely and honestly. I have done it in obedience to my conscience, and to the warmest appeal man can know on earth.

When the young schoolmaster had finished his speech he passed out of the meeting-house with Clara, pale and trembling from his effort, and knowing little more than her approving pressure on his arm as they walked rapidly on towards her home. "You will never be ashamed of that speech, Charles," said Clara, sweetly and gently, as they cntered the house, and he flung himself into an ample easy-chair and buried his face in his hands. The eye of the Moderator, his old friend and teacher, was on him still. He saw the wondering gaze of Mr. Hopkins, whom he respected so much, and of Mr. Howe, whom he loved. And he saw also the half-contemptuous look of the hundred men assembled there, as they listened with a sort of unespected silence, but not with true deference to the fine-spun theories of the beardless youth. And he felt that his life 
in Jotham was ended, and that his character for wisdom and sagacity and perhaps stern integrity was damaged at the very threshold of life. But he knew he had done what he conceived to be his duty; he looked up and saw Clara's approving face, and he had faith that the Squire and Mr. IIopkins and Mr. Howe would approve also ; and that even the less sensitive might not condemn.

When Charles and Clara had left the meeting, not a word was said by those who remained behind. The question had evidently gone beyond the reach of their discussion. A few whispers were heard about, "A pretty good gait for a colt," "His modesty 'll never hurt him," "He's got a good deal to learn yet," and so on ; but, without further comment, Peter Ilsley proceeded to cast his rote for selectmen, and the rest of the multitude followed his example.

The whole number of votes cast was . $\quad$ r 50

Necessary for a choice . . . . 76

Peter Ilsley had . . . . . . 76

John Brown . . . . . . 149

Phineas Barnes. . . . . I50

And they were elected.

John Thomas had seventy-five, and was not elected. In the midst of his speech and his excitement Charles Ingalls had forgotten to vote.

The various articles in the warrant were disposed of, and the meeting adjourned.

"Well, John, it is all over," said Huldah, as John Thomas hung his hat and coat in the entry and sat down before the cheerful fire and near her clean and tidy table.

"Yes," said John, " and I am glad I have got my conscience left, and I suppose that is enough. As I listened to Charles Ingalls, I felt sure all would come out right in the end; and for your sake and the children's I trust it 
will. If this is a stain, I must bear it, and I know you will help me. If it is not, why, all right."

Huldah gave John a sly kiss, - they had been married more than a quarter of a century, - cheerfully arranged the table, called the children, and with John's customayy invocation of the Divine blessing, they sat down to tea. The cloud had blown over; how and why, they did not exactly understand.

The business of the Club was next in order. Mr. Howe consulted with Mr. Hopkins as to the best time to call it together, and they determined that, without troubling John Thomas in the matter, they had better call the meeting at the earliest possible date, and continue the discussion of grain crops.

Mr. Hopkins remarked that he should extend an invitation to the wives of the members of the Club, and that he should be especially happy to see Clara Bell on the occasion.

The Club met at the usual hour, and was called to order by Mr. Hopkins, who announced the subject, and then proceeded to speak some kind words upon the importance of having, above all things else, a peaceful and happy community in Jotham. He said he had come among them to enjoy the repose of his ancestral home, and to escape the jealousies and conflicts which attend the busier scenes of life. He urged upon them the necessity of charity and kindness and fair dealing, assuring them that next to integrity came obedience to the law of doing unto others as we would that they should do unto us. He thought perhaps they had better postpone the discussion until the next evening; and he announced that he had invited the wires of the members in order that they might have a quiet social entertainment and become better acquainted with each other. With this little introduction he left the chair, and taking Mr. and Mrs. Thomas by the hand he gave 
them a warm and cordial welcome to his home. To Charles and Clara he was especially attentive, - so attentive to Clara that the ladies exchanged expressive glances with each other as the interview went on. And so peace and confidence were restored in Jotham.

Peter Ilsley was not present at the meeting. 


\title{
TWENTY-FIRST MEETING.
}

\author{
GRAIN CROPS (Continued).
}

MR. HOWE SLOW TO BELIEVE. - WILLIAM JONES TALKS ABOUT OATS AND HORSES. - DR. PARKER CONTINUES THE DEBATE. MR. HOPKINS PROVES THE INTEGRITY OF JOHN THOMAS. - IHEY ALL REJOICE.

MANY days passed before Mr. Howe met John Thomas for the purpose of arranging another meeting of the Club. The minister was not entirely convinced and satisfied with regard to charges which had been preferred against his associate on the committee; he could not exactly understand how a universal belief in a man's guilt could be entertained to-day, and almost as universal an assurance of his innocence be felt to-morrow, without a careful and satisfactory investigation; and he was half inclined to look upon the whole matter of John Thomas's guilt as based on suspicion, and of his acquittal as the result of a popular freak. And he found it difficult to bring his ministerial mind into such an easy estimate of error, and his ministerial heart into such an unfounded and impulsive forgiveness of sin, as he had witnessed in the events of the town meeting and the Club. But he had great faith in his people, and he entertained no doubt that they had the best of reasons for the course they had pursued. When he met John Thomas, therefore, he tried to feel as everybody else appeared to feel, - satisfied and confident, and full of restored esteem and kindness. He was quite unwilling that his faith should make him less ready to forgive than the rest of mankind about him, - even while he was 
disposed to believe that his conscience was more enlightened, and more keen in its demands, through the influence of theological thought. He made up his mind to acquiesce in the views and sentiments of his people, and to wait patiently for such satisfaction as he might derive from future developments. It was without effort, therefore, that he met Mr. Thomas with his usual cordiality, and made arrangements for issuing notice of the next meeting of the Club, and for the continued discussion of the subject of

\section{GRAIN CROPS.}

When Mr. Hopkins called the Club to order, he found his parlor somewhat crowded by the members, who were present in full force, and who manifested the liveliest interest in the welfare of the organization. It had evidently become the institution of the town, and was destined to control to a great degree the public opinion and to direct the public councils. He looked about with a good deal of satisfaction, announced the subject, and called upon those present to express their views freely, and to give their own experience in the raising of those crops which are of importance to the very existence of man and beast.

William Jones opened the discussion immediately by calling attention to oats as one of the most important grain crops of the North.

"Oats," said he, "have a peculiar interest to my mind, on account of their connection with the health and vigor of one of the most valuable of our domestic animals, the horse. I am of opinion that they are the only grain which can be safely and properly fed to this animal; and that, were they produced in larger quantities, and sold at lower prices, the use of corn, in any form, for horses would be entirely abandoned. I have been obliged, for the sake of economy, to use corn-meal in what is usually called 
chopped feed; but I have always found that it produced a tendency to disease in my horses, either in their digestive organs or in their heads and legs, and I have been grlad to quit it. If you want a fat, round, bloated horse, with greased heels and loose bowels and a stupid brain, feed him on chopped feed, or give him a heavy supply of cracked corn, three times a day. I have often wondered how the great mass of livery and stage horses can possibly perform their work on such a diet; and I have no manner of doubt that three quarters of the cripples which we see in our stables, and tottering along the roads, are burnt up by corn. Poor hay and sour meal mixed together are enough to kill the strongest horse ever born.

"And then I have noticed, Mr. Chairman, that our stables are beginning to be filled in the spring of the year with young, overgrown IVestern horses, which have had all the corn they could eat from the day they were weaned until they were sent here for sale. They have been provided with corn just as IVestern hogs and cattle are, - by throwing a plenty of ears for them to nibble into the yard where they are confined; and they grow up very much after the fashion of swine and short-horn steers, whose only merit is their fat. They come into our market half broken, used perhaps to a little double harness-work, but wholly unfit for private single driving, and about as safe as a panicstricken reindeer. Their bodies are out of all proportion to their legs. Their lungs have never been expanded by exercise over rough and hilly pastures. In summer they have been overfed with the rank grass of Western pastures, and in winter they have been stuffed with a surplus of Western corn. And so when they are put to work on the road or on the farm, or in the heavy drays and wagons of the city, they soon begin to tumble to pieces, have all the diseases that are going round, get lame, and for a year at least are pretty nearly worthless. I think it would be better 
for these horses and better for their owners, if they were half starved in winter at a straw-stack, than to be fed as they are. It seems to me that half the civilized world might be supplied with horses from the West to the great profit of the breeders there, and to the great advantage of the purchasers also, if they were only bred and fed in the right way."

"Uncler our rules, I must remind $\mathrm{Mr}$. Jones that the subject under discussion is the oat crop," said the President.

"O yes," said Mr. Jones, who had wandered away into his usual horse-talk with remarkable fluency. "I hope you will excuse me, but oats and horses go together so much and belong to each other so entirely, that I can never think of one without talking about the other; and I was going on to say that if we would raise good horses, and keep them in good health, and give them long lives, we must use more oats and less corn. That is all, Mr. President,"

Dr. Parker, who had been listening with evident interest to what Jones had said about the effect of corn on the constitution of the horse, took up the subject where he left it, and remarked that he had never yet seen any good reason why oats did not enter into the list of articles of fooc consumed by man more largely than they do. He remembered that Dr. Johnson, in order to manifest his dislike to Scotchmen, gave as a definition to the word oats, "A grain which in England is generally given to horses, but in Scotland supports the people" ; but he had alway's thought that the old lexicographer had unwittingly testified to the superior wisclom of the people whom he hated so thoroughly. Oatmeal for the young animal and for man is especially nutritious. It has less starch than wheat flour, it is true; but it has more gluten, more sugar, more gum, and more fatty matter, and it is more digestible. No food gives the young animal so good a growth of bone 
and such a healthy organization as oatmeal, unless it be Swedish turnips. I do not imagine it could enter into the preparation of fine bread and cake as wheat flour does; but while such food as this may and often does impair the digestion, the common preparations of oatmeal are palatable and easily digested. The great loss is in the large amount of woody fibre which is furnished by oats, being twenty-one in one hundred parts, while that of wheat is hardly more than one tenth of this. On the score of economy as a crop, he had nothing to say; but as an article of food he could not speak too highly of this grain, and he had no doubt that $\mathrm{Mr}$. Jones was right in his estimate of their value in the feeding of horses for growth while young, and for the road and draught when matured.

“Mr. President," said John Thomas, "I think we all agree as to the value of oats as an article of food, but it seems to me that it is the business of this Club to cliscuss, first of all, the best mode of raising the crop. I find that oats differ very much from wheat, with which we have heard them compared this evening, in being more liable to be influenced by soil and climate. Wheat grows almost everywhere, and on almost all good strong soils. Oats grow best in the colder latitudes and on lighter soils. When the Scotchman ate more oats than wheat, he did it because he could raise them more easily. And I have always found that on new land and in high latitudes the crop is large and profitable. For myself, I am sorry to say that my land has lost its faculty of producing a good, plump, heavy crop of oats, unless the season happens to be very favorable. I have tried every variety, Norway oats and Surprise oats and New Brunswick oats, but they are all, on my land, an uncertain crop; and I have not yet found out any way to manure my land so as to make the crop sure. In the western part of the State, where the land is newer and the country more mountainous and the air 
cooler, enormous crops of oats are raised by the good cultivation practised by the farmers there. I think oats require a larger proportion of mineral fertilizers than most of our grain crops. Heavy manuring with nitrogeneous barn-yard manures is hardly the thing for them. Bones, superphosphates, ashes harrowed in with the seed, will be more likely to produce a good crop, and will give the straw more ability to stand up, should it grow heavy, as it must, in orcler to yield an abundant supply of grain. I should not select heavy clay lands for oats, so far as my experience goes.

"The sowing of the seed-oats should be done in early spring, - as soon as the frost is out, and the land sufficiently settled for the plough. The soil should be thoroughly pulverized with the harrow, and about ten cords of well-decomposed barn-yard manure should be applied to the surface; or, what is better, some bones or ashes combined with less manure. Three bushels of seed are required to the acre in order to secure an abundant crop. In yield, no grain varies so much as this. Twenty-five bushels to the acre is in some places considered a fair crop. We are assured, however, that some new varieties will yield seventy-five bushels, and the premium crops of one section of this State have been reported as more than a hundred. It is not advisable to sow grass-seed with oats, as the catch is liable to be injured."

\section{WHEAT.}

"And now," said Mr. Howe, "let me call the attention of the Club to the wheat crop, having, as I think, exhausted the subject of oats. I have no doubt of the value of oats as an article of food; but I cannot conceive of the highest form of civilization without an ample supply of wheat. It seems to me to be the universal grain; and if it is provided 
with less sugar and gluten and gum than oats, it has as a fair offset a large preponderance of starch, which makes it applicable to all the nicer varieties of artificial food known to man. I have studied the wheat problem with the greatest interest, and I should consider it an evidence of advancing agriculture if I could see every farmer in New England, who now supplies his table with flour from Western mills, devote a small patch of his farm to the production of wheat for his own family use. I am sure it would be good economy for him to do this, and would avoid the necessity for that enormous outlay of money to which, as a people, we are subjected, because we will insist upon it that we can buy cheaper than we can raise it.

"I suppose every good farm in New England has soil adapted to the growth of wheat, - strong; clayey land, supplied with silica enough to make a bright, firm, and stiff straw and a well-filled grain. Wheat, I know, will grow on a great variety of soils, but best on that which I have described. It is land like this which is most readily brought into good condition for wheat by the use of marl, or ashes, or decomposed barn-yard manure, or bones, or clover hay ploughed in, or superphosphates. I have no doubt that barn-yard manure composted with sand, and well fermented and rotted, would be found to be peculiarly applicable to the wheat crop. The addition of salt to the manure, to the extent of about three bushels to the acre, would undoubtedly largely increase its value. In adclition to this process of fertilizing the land, Boressingault says: 'Farmers are wont, before putting their seed-wheat into the ground, to prepare it in various ways, with a view to destroying the germs of certain parasites which are believed to adhere to it externally. The process is generally called pickling, or liming, because milk of lime, in which the seeds are put to steep for twelve hours, is often employed in its course. Means that are said to be more 
efficacious have also been recommended; some make use of alum, others of sulphate of iron, sulphate of zinc, sulphate of copper, sulphate of soda, and even white oxide of arsenic. All these means appear to conduce to the same result.'

"Wheat should be sown the last of August or the first of September; and the seed should be covered about two inches. On most soils two bushels of seed will be required to the acre. The seed on all the great wheat-fields is sown with a drill, broadcast sowing with the hand being now entirely confined to the small fields and to lands whose unevenness prevents the use of the drill. When sown in season, and well started in the winter, the wheat may be superficially harrowed in the spring with a fine-toothed harrow, for the purpose of stimulating the growth of the plants and of removing from the soil those weeds which will, if not checked, interfere with the crop. The wheat plant grows very rapidly in the spring, and will, if properly cultivated, outstrip the weeds and keep possession of the soil throughout the season.

"If it happens to be necessary or convenient to sow spring wheat, let it be sown as early in the spring as possible; always remembering to prepare the ground for this, as for all spring crops, at the time of seeding. Even if your land is ploughed in the autumn, plough it again in the spring just before sowing, and in all cases apply your fertilizers in the spring months. Harvest your crop as soon as the seed is firmly formed, and as soon as the straw, by turning yellow on the upper joint, indicates that the growth of the plant has ceased and the process of ripening has begun. The wheat should be bound and shocked as fast as it is cut, whether by a reaper or with the cradle. The importance of proper shocking and stacking cannot be overestimated; and as in our discussion upon the hay crop we were told to learn as rapidly as possible how to 
make a good haystack, so I would urge upon you the importance of a skilful and accurate construction of a wheat-stack if you would make the most of your crop. The selection of the variety of seed I would leave to the judgment of each farmer. For, surrounded as we are with advocates of Oregon, and Diehl, and Pedigree, and IVceks, and White Mediterrancan, and Red Andriola, and Golden Straw, and Red Chaff Amber, and Witter, for winter wheats, and with Black Sea, and Canada Club, and Rio Grande, and Fife, and China Tea, for spring wheats, the wise farmer need have no fear that he can fail in fincling a variety suited to his soil. .

"Mr. Dickerman well says: "Smut is the great enemy of the wheat crop, and the only help for it is in brining the seed. The most convenient method is the following: cut a cider-barrel or oil-tierce in two in the middle, or use two large wash-tubs; make a strong brine, strong enough to bear an egg, and if used hot all the better; put the brine into one of the tubs and turn the wheat into it; stir it up two or three times and skim off the chess, chaff, and light wheat which will come to the surface; then shovel it out into a basket and let it drain over the other tub; turn it on the floor, and sift slackened lime upon it slowly, stirring it with a rake until it will not stick together; sow as soon as possible. Rust is another foe the wheatgrower is obliged to encounter; the remedy for this disease is simply to supply the soil at once with ashes and sand, in addition to the careful selection and preservation of seed, as before described. If the farmer continues to sow his seed without this care in raising and preserving it, he will continue to have musty and smutty wheat. The only remedy for the insect enemies - the midge, the fly, the worm, and the climate bug - are careful selection and thorough tillage. Make the wheat grow so luxuriantly: that the little which the insects consume will not be missed nor the growtli checked." 
"And now I should like to be informed whether chess, one of the pests of our wheat-fields, is a specific plant, belonging to its own class and order, or wheat degenerated by a cold soil and bad cultivation."

"I am satisfied," said Dr. Parker, "that chess is a specific plant, which springs up on cold lands when wheat fails, just as charlock comes into a fecble barley-field, and the mistletoe finds its home on the oak and apple tree. It evidently does not belong to the same genus or species with wheat; and I have no idea that any mode or degree of cultivation would ever convert it into mature and perfect wheat, which would undoubtedly be the case were it in any degree a diseased form of that grain. The old idea of Pliny that both wheat and barley had a tendency to degenerate into oats, with which he classed chess, seems to have been accepted so far as wheat is concerned, until it has become a popular prejudice; and the conversion of wheat into chess is generally believed in our day, as the conversion of wheat and barley into oats, a form of chess, was believed in the days of Pliny. But I accept no such theory. Plants do not break away from the class to which nature assigned them any more than animals leave the species to which they belong and join another at will."

\section{BARLEY.}

"I have found a very fair profit from barley," said John Thomas. "It grows well on strong land, and can be raised to great advantage on soil which is well prepared for seeding down to grass. In this connection, and for this purpose, it is the best of all the grains, - grass never catching so well as when sowed in the spring with barley. The amount of manure, moreover, which should be used in preparing the land thoroughly for a good grass crop, is also well suited to produce a good crop of barley. On 
strong land, well prepared, after crops of potatoes and corn, ploughed in the autumn and cross-ploughed as early. as possible in the spring, I have harvested fifty bushels of barley to the acre. I prepare my land as I would for any other crop requiring a fertile soil, and sow two bushels and a half to the acre. The manure used should be wellrotted barn-yard manure, composted with sand or sandy loam if it is to be applied to clay land. Barley is excellent food for fowls and swine; and in small quantities, and for a short period, is bencficial to horses as a change. I have tried it on my milch cows, using barley-meal as a substitute for corn-meal; but I have been obliged to abandon it, on account of the effect it produced on the milk. It generally commands a fair price for malting, but the market is so variable that it is hardly safe to raise it for this purpose alone. The straw is excellent food for cattle, better than the straw of any other grain. On the whole, Mr. President, were it not so useful to sow in the spring with grass-seed for the purpose of laying down grass lands, I think I should abandon barley entirely. I have often combined oats and barley, equal parts of each, and sowed them for fodder, with a very good result. I think the two united make a much more valuable winter food than either alone."

\section{RYE.}

"Which do you prefer, spring or winter rye?" asked Mr. Hopkins of the Club generally.

"I have land," said Moses Fierson in reply, "just suited to rye, light, somewhat stony, and warm. I find I can get a better crop of winter rye than I can of that sowed in the spring. I have manured this kind of land heavily, say with nine or ten cords of good barn-yard manure, and have secured what is called a large crop, - thirty-five busheis to the acre. But I have seldom found it remunerative, 
even with the price usually paid for the straw. I am sure I could have made more money from my manure, had I applied it to different land and some other crop. I use for my rye crop, therefore, lands which are not well adapted to anything else, lands too light for corn or barley or grass; and with a moderate supply of manure I get a crop that pays pretty well. If I had no such land as this, I should probably raise but little rye. On light land like this, I use about two bushels of seed to the acre. I look upon rye as a luxury in my house, and on rye straw as a luxury in my stable. That is all."

"Does anybody raise buckwheat?" asked Mr Hopkins.

"Yes," replied Ben Adams, "I do; I always raise a little on an out-of-the-way lot, the flowers for my bees, the grain for my hens and pigeons and my breakfast-table, and the straw for nothing. I should not call it much of a crop, anyway."

"I think," said Mr. Hopkins, "this completes the list of grain crops, and that we have given them a fair discussion, and I hope a profitable one. Before adjourning the Club I desire, however, to bring to a satisfactory conclusion in the mind of every gentleman present a circumstance which has given rise to some unpleasantness here, and to great anxiety throughout the town. I refer to the charges made against Mr. John Thomas as a public officer in this place. You observed, I doubt not, that while the excitement was at its height, I refrained from expressing an opinion on the subject. Perhaps I was over-cautious, but I was really at a loss what to do or say. The events came upon me so rapidly, and rumors thickened so fast, that I could not immediately bring order out of the chaos into which my mind was thrown; and I therefore silently watched the current of events as they passed before me. Had I been as young and inexperienced as the Schoolmaster, or as fervid and positive as Clara Bell, I might 
have done better. It must have been noticed by you all that when the matter had arrived at a sort of conclusion and had brought about the defeat of Mr. Thomas as a Selectman of this town, I accepted his statement of his innocence, and gave him a cordial welcome to my house, at the last meeting of the Club. Now, I did this just as a large majority of the people of this town clid it, - from our instinctive conviction that he bad been wronged, and a natural feeling that even an appearance of injustice should be summarily atoned for by a gencrous people. This is natural. It always occurs in similar cases. It may not always be wise, and we may sometimes forgive and restore a rogue. But it is natural: and it is a curious illustration of the desire we have to grive every man the benefit of a cloubt, most especially after we have pronounced his condemnation.

"But to my mind, in the case of Mr. Thomas there was more than this. He had the benefit of an unspotted character. He had borne himself well here during a long life, and he was entitled to the advantage to be derived from long, faithful, and honest public service, and private good deportment. I think a moral character well established should be favorable evidence for every man, and the most positive evidence should alone destroy it. Against all intricacy of testimony, against all conflicting statements on the part of the accused, against all apparent inconsistency, this should stand as unimpeached testimony, until all entangling circumstances are weighed, and the overwhelming and confusing statements which surround the accused are thoroughly understood. The advantage of all this I gave Mr. Thomas. And now I am happy to say to you all, that this spontaneous acquittal, this natural tribute to the character of $\mathrm{Mr}$. Thomas, has been confirmed by examinations made since our last meeting. Those of us who, from a desire that public morals should in no way be 
outraged or offended, allowed the storm to rage unheeded, are now satisfied; and I have learned that there is a higher guide to judgment than a mere accumulation of charges and statements alone. The accounts of the almshouse show that no irregularity whatever existed there during the administration of John Thomas; and the record of the Board of Selectmen shows that, on all occasions, he was the first man to examine all doubtful matters, and to provide a remedy for all wrong. Of this the present board are entirely satisfied, after the most careful investigation. And in justice to Mr. Thomas, I must say it appears that on one occasion, an irregularity on the part of the keeper of the almshouse was exposed by him, against the expressed wishes of Mr. Ilsley, at that time his associate on the board. It seems, moreover, that the charge so freely made by one of our townsmen, that Mr. Thomas had grossly cheated him in the sale of a cow, is wholly unfounded, the animal having been bought in the market by Thomas and resold to the complainant, at his special desire, without removing her from the ground. She really never came into Thomas's possession, and he knew no more about her when he sold her than when he bought her. I state this now as an act of justice to a valuable member of this Club, and as a warning to us all never to condemn a man unheard. The evil of such a course is incalculable; and the fact that such an act of injustice may be committed without its merited punishment encourages all intriguers, slanderers, and villains to do their dirty work. I congratulate you that this is all over now. I congratulate John Thomas on his restored reputation in this town. And I shall congratulate the town when it manifests to him a determination to bestow on him once more her confidence, and avail herself of his valuable services."

"And now I breathe freely," said Mr. Howe; "and all 
my doubts are removed. The power of character is great, but the power of undoubted testimony is after all supreme in the mind of a guardian and gride of public morals and religion."

"I never believed a word of the stuff," said William Jones.

Dr. Parker thought the diagnosis was bad in the beginning. Squire Wright respected the sentiment and recognized the value of character; but he still leaned upon the legal power of the evidence. The Schoolmaster said nothing; his face told plainly enough what his feelings were. John Thomas, too, was silent, and quietly withdrew, hastening home to Huldah and his fireside. All rejoiced that the war was over. Peter Ilsley wished it had never begun. The Club dispersed, and every man went to his own home, ready now to apply the lesson of justice and charity which the last few weeks had taught. 


\title{
TWENTY-SECOND MEETING.
}

\author{
MARKET GARDENING.
}

JIM DELL'S SICKNESS AND DEATH. - CLARA'S SORROW. - SOPHRONIA SECCOMB'S LETTER. - MRS. SARAH BELL DESIRES PRAYERS.

JIM BELL was evidently growing weaker day by day. He had been confined to his house almost all winter, with what in more primitive days was called consumption of the blood, but what is known in our day - when the refinement of science occupies one end of society and the ingenuity and audacity of quackery occupy the other as follicular atrophy. For months he had been quiet, patient, submissive, and declining. It was enough for him to sit at the southwest window of his sumny little sitting-room, and watch the rise and fall of winter, - the spasmodic approach of arctic cold reigning a few hours and then retiring, until his sway was established in days and nights of hard and biting frost, - the white and shining fields, the twigs beciecked with crystals and brilliants, the raging storms, the lengthening days, the embrowned and departing snowbanks, the dark patches of reappearing earth in mid-field, the lingering mists of the great thaw, the breaking clouds, the sudden return of the frost king from his cold blue chambers in the northwest, and his reluctant surrender to the sweet south; it was enough for him to watch all this, and as he passed on, leave his little world - the mill, the club, the church, the town - behind. As spring approached, and the sun tempted him abroad, he crept feebly forth to listen to the hum of his wheel once more; and he found consolation in the promise which the roaring brook, just 
freed from wintry bonds, and the clattering kingfisher, just returned to his summer quarters, gave of the bounty and beauty of the opening scason. But his interviews with nature were short; his home was his only place of repose,

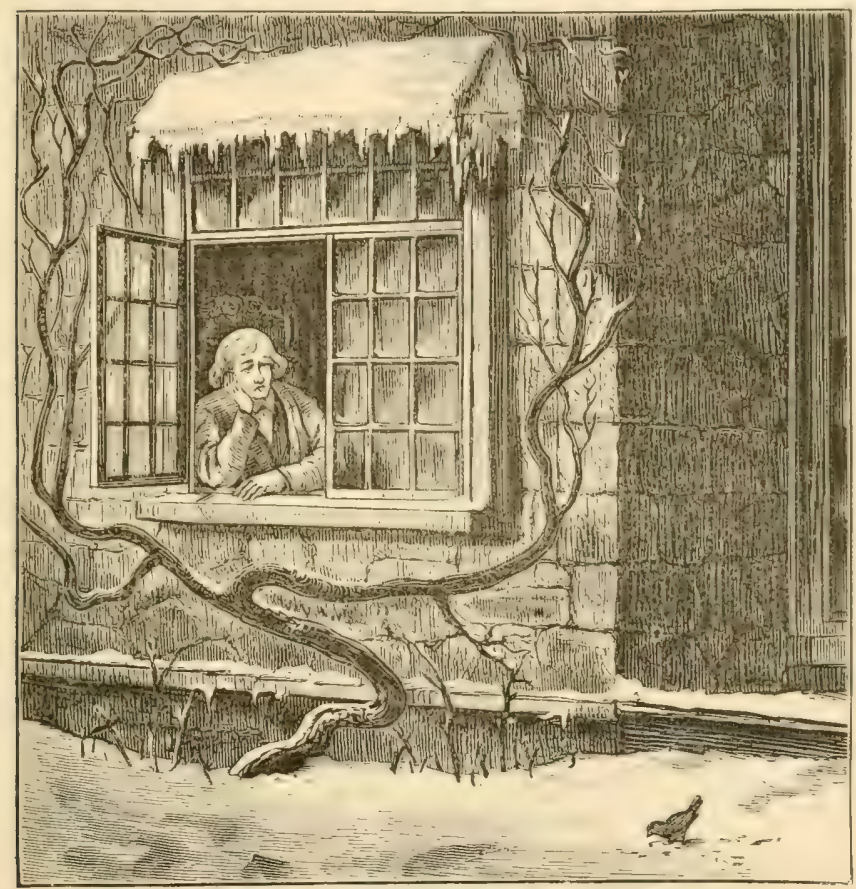

JIM BELL'S HOME.

his only sunlight was the cheerful radiance of Clara's face; his sweetest music was the sound of her voice. And so he waited and watched.

And there in the stillness of those country hours a feeble and uneventful life grew fainter and fainter. Jim Bell was not an old man, and he had never been a young one. The measure of his life had always been small, as small as maturity in youth and immaturity in old age 
could make it. His years were not many, and his circuit was narrow. He had neither been a vigrorous sinner nor an ardent saint. And in the midst of his commonplace cheerfulness and his mild and slender activity, his sad and impenetrable silence was oppressive and bewildering. In all demonstrative powers Mrs. Bell was far his superior. She was hearty and prompt, and strong and positive, as well as truly good-hearted. She was a bouncing girl when Jim married her, and as time went on she seemed to gain all that he lost, to expand as he shrank, to absorb every vital force and energy which left him, to grow as he declined; and so when he had become prematurely old and was ready to return to the dust, she was just entering upon an affuent and well-established maturity. In her youth she was redundant, and having passed through all the trials of middle life, she was redundant still ; while in the atmosphere of her plenitude poor Jim had faded away to nothing. It was touching to see how exhausted and how utterly submissive he was, as in the midst of abounding life and the refulgence of opening spring he was patiently passing away. He never murmured, but he became more and more childlike, until in the early hours of a soft May morning, with the sunlight irradiating his room where he lay, and the southwest wind bearing through his open wiudow the sweet perfume of the budding earth, his sun was darkened and his breath was hushed. The scene was so peaceful and so natural, that the mourners almost forgot to mourn, even as they who watch the setting sun accept the darkness and repose of the evening hours, and turn their eyes with faith and confidence to the breaking light of the new-born day. No hum of busy industry disturbed the repose; no cloud of disappointed ambition cast its shadow there. The only pang was the pang of parting.

During all these months of sickness and sorrow Charles Ingalls had taken up his abode in Jim Bell's house, - not 
exactly in accordance with modern propricties, but entirely in accordance with Clara's comfort and happiness. His work as a teacher was ended, and his work as a law student had begun. And as his mind toiled on through the opening studies of the great profession he had chosen, he found infinite strength and satisfaction in his association with Clara, who not only encomagged him with her quick thought in the path he was pursuing, but led him away into the refreshment of those springs of knowledge which are more tasteful and sparkling, and which belong especially to woman and to the feminine side of man. His presence was moreover of material benefit to the miller's family, whose income had never been great, and was now cut off entirely. Prematurely introduced to the necessities and responsibilities of life, he and Clara could not shut their eyes to that practical wisdom which makes life peaceful and happy, and gives a substantial foundation to all the highest aspirations and deepest sentiments. They learned to live and grieve together, as well as to love and rejoice. And they learned also how to use best their slender means for the cultivation of those faculties which adorn and beautify the hard and practical walks of life.

"What a new life death is!" said Clara, as she sat looking sadly orer the familiar landscape, towards sunset of the day when the simple funeral of her father took place. "My father never appeared so truly himself to me as now. He never bore the world well; and somehow he knew that I knew it. And now that there is no world to him, I can see him as he really was, unbent by any burden. How slad he must be to rest from his labors! Don't you enry such rest, Charles?"

"Why, Clara, do you?" said Charles Ingalls. "Life is a great blessing to me now. When I rest, I want to rest from my labors. I do not desire to resign my joys or lose my opportunity. I think, Clara, death is a new life only when this life is worn out." 
Clara was lost in thought as the vision of her father, released and purified, absorbed her on the one hand, and her love for Charles bound her on the other. She envied the repose of the one because she did not realize what it really meant, and she rejoiced in the vigorous and abounding life of the other, because she felt that her own being was involved in it. While she was occupied and lost in this conflict she was suddenly brought to her senses by her mother, who broke in with all her vital force, and dispelled every imaginary charm by announcing that tea was ready.

"Come, children, come to supper!" exclaimed the thrifty lacly, who on all occasions was "cumbered about much serving."

Charles started up, and Clara followed him, rejoicing still in her spiritual exaltation. But the realities of life soon overcame her, - the vacant place at the table, the newly arranged room where her father died, the manifest preparation already made to go on through life without him, brought her to a realization of her loss, and she was driven to her own little room in a paroxysm of grief. Her philosophy was all gone; and she felt that there was at least one sorrow which she must bear through life.

When Charles returned to the place where he and Clara had entered upon the great problem of life and death, he found her there before birn, softened and clrooping, as if a tempest had passed over her. She had taken her sorrow to herself, for a time at least, and she turned her conversation to the topics in which they were mutually interested. Charles spoke of the fervid beauty of Mr. Howe's prayer at the funeral; but she turned at once from that and inquired about the last meeting of the Club; and as she enlarged upon the members of that active and useful institution, she came naturally upon the trials and troubles of John Thomas. 
"By the way, Charles," said she, "I received a letter yesterday which I am sure you would be slad to hear, relating to the town-meeting. I had entirely forgotten it. I hardly understand it; but perhaps you will tell me what it means."

She brought the letter, and read as follows :-

BERRYTON, April 24, IS-.

My DEAR Miss BeLL:- I have just heard with supreme delight of the noble stand taken by you at a recent townmeeting in Jotham. I address you as Miss Bell, because I have observed that married women are generally too much subdued by the discipline of life to be able to rise above its consentionalities, and make public ansertion of the great principles which unclerlie state and society in a republic like ours. I congratulate you on your domestic condition, therefore, which has left you free to arrive untrammelled at that maturity of female life and thought which I assure you has enabled me to look calmly on while the great strife is raging, out of which is to come emancipated humanity. I know not how far this strife is to be carried, - no finite mind can know. But when I behold a defiant spirit like yours, bravely entering the field of conflict, my heart takes courage, and I feel assured that the day of redemption draweth nigh. If every woman in the land would take upon herself the duty of regulating and controlling one member of the opposite sex, as firmly and successfully as you controlled the young man whom you inspired to speak for the right in that rude town-meeting. the trials which we suffer under the operation of the law would soon cease. I trust and pray that this may soon be done. The great female over-soul must and will be heard, pouring its soft but potent appeal into the ear of every man, as the still, small voice of the Lord was heard above the raging elements, and gave inspiration and power to the prophet. I rejoice that you have been saved in your passage through the frivolous path of youth, and afe now ready to dedicate your mature powers to the great cause. The work is hardly yet begun, I know ; but I 
feel assured it will go on until every avenue of life will be open to us, and our rights and privileges will be confirmed for our own elevation, and for the mental and moral benefit of man, whom we are now compelled to obey. I may not live to witness this triumph; but I cannot doubt that the day of social and civil unification will soon clawn, in which all artificial distinctions will be swept away. Pray write me and give me an account of those experiences in life which have brought you to your lofty and defiant position.

Truly yours in all aspiration,

Miss Clara Bell, Jotham, Mass.

Sophronia Seccomb.

"There," said Clara, "what do you make of that? I don't exactly understand what Miss Seccomb means. I hope I have done nothing which does not belong to a young girl whom God has blessed with the proudest and sweetest love that a young girl ever dreamed of." And her face glowed with a radiant affection, which brought herself and Charles to that mutual ecstasy which has never yet found expression in words, and probably never will, so long as the silent and more effective substitute shall endure.

"Why, Clara," said Charles, "Miss Seccomb means well enough undoubtedly. She believes, as I do, that society needs reforming in many matters relating to women. If she had known you were governed by a generous sentiment alone, and not by any well-defined doctrine, I think she would have written a better letter than she has. If she could see you now, my precious beauty, I am sure she would learn that disappointment is not necessary to raise woman up to the standard of assertion and moral heroism. But don't be troubled, my dear. I understand the direction of your mind better than you do, and I cannot be too grateful for that natural inclination which enabled you to lead me up to my highest duty fearlessly and without de- 
lay. I don't think I was ever made for a reformer; I am too much inclined to analyze and defend. But I accept naturally all reformatory thought; and while I live, I mean that in high stations and in low my voice shall always be raised in elefence of the wronged and the oppressed, and in response to the stern demands of those who insist upon the right though the heavens fall. But you and I don't want to discuss these things now. I can trust you, and I hope you can trust me, to accept and maintain the best thought as time goes on. I wish we knew Miss Seccomb. Don't you think our joy would do her good?"

Clara made no answer to this long speech. What the wrongs were she did not exactly know; but she felt assured that she could meet them when she did know, and that instead of leading Charles, it would be only necessary to go hand in hand with him in obedience to their mutual recognition of truth and justice. She felt, therefore, at perfect liberty to drop the subject, and to abandon all metaphysical speculation until the time came for them to act. Somchow she felt disinclined to devote any more of the rosy hours to disquisitions upon state and socicty. And so as the soft summer night shut down over her, she reclined her head on Charles's shoulder and gave herself up to sweeter visions, in which the spirit of her father hovered over her, and the future opened with all the brilliant promises which love and courage always make. That day this young girl had travelled with her lover far on the journey of life.

The death of Jim Bell did not long occupy the thought of Jotham; death and misfortune seldom dlo, anywhere. He had been respected during life for his honesty and good behavior. He had received the kind attention of his neighbors during his last sickness, and they had all attended his funeral with courteous solemnity. On the 
Sunday after his burial Mrs. Bell had attended church with the usual propriety, and had presented to Mr. Howe the note customary on such occasions at that day in Jotham ; to wit:-

Nirs. Sarah Bell desires prayers that the death of her husband may be sanctified to herself and her family for their spiritual and everlasting good.

And Mr. Howe had made this now abandoned and almost forgotten custom the text for a fervid passage in the long prayer, and a strong paragraph on a good life and immortality in his sermon.

This was all over now, and the work of the village went on as usual. The mill which Jim Bell had tended so many years, and which was indispensable to the people, was rented to competent parties for the accommodation of the town and the benefit of Mrs. Bell; and John Thomas was called in to advise and arrange matters for the future welfare of the bereaved family. Of course in this work Mr. Howe was his counsellor, and when they had accomplished this service they turned their attention to the Club, of which they were still the executive committee. They determined upon a meeting, issued their notice, and selected, as a subject for discussion,

\section{MARKET GARDENING.}

Mr. Hopkins called the meeting to order with his usual promptness and courtesy, and proceeded to open the subject in a general way as introductory to a discussion of each individual crop which forms a part of the business of market gardening. "The application of labor," said he, " to small parcels of land for the purpose of raising a crop suitable to a local market, and commanding a price fixed by local demands, constitutes what I conceive to be the law of the best American agriculture. When we devote 
ourselves to the business of growing the staples which enter into the markets of the world, we submit our industry to the hands of those who enjoy every atvantage over us. As I have often reminded you, it is not easy to compete with the wool-growers of Texas and California, who enjoy almost unlimited pastures and a climate so mild that shelter in the winter season is unnecessary. The farmer of these sections, where land commands a high price, cannot furnish grain to the market in competition with those who occupy the broad and cheap and fertile prairies of the IVest. And even the IVestern grain-grower finds himself often crippled by the producers of countries where labor commands but a nominal price in comparison with his own. As land advances in value and the wages of labor increase, the farmer must, if possible, escape from that competition which can be brought against him by more primitive forms of society, and by those who hold lands at the settlers' rates. I think this is the great lesson which we must learn in this country, as it has already been learned elsewhere. Go with me to those nations whose population is deroted in any degree to agriculture as an industry, and you will find that it is the special farmers who are the most prosperous. It is not the hempgrowers of Russia nor the grain-growers of Hungary and the Black Sea who constitute the most prosperous farmers of the old countries. The careful cultivators in Germany and Holland, the market-gardeners around London and Paris, the men engaged in supplying the local markets with the necessaries of life and with the fruits and vegetables which are called luxuries, are the men who hold in their hands the agricultural prosperity of those sections of the earth. And so it is in our own country. There is a shifting and uncertain prosperity, sometimes very great, which attends the growing of staples for the commerce of the world. But as I look around to ascertain where 
the long-continued and permanent prosperity lies, I find it among those who, obedient to an inevitable law, gather around the great aggregations of population and supply them with food, or devote themselves to some one branch of cultivation which is especially adapted to the quality of the land which they occupy.

"Of the first, the supplying of local markets here in contradistinction to general husbandry, I call to mind one notable illustration: I was led at one time to believe that one county in our State was declining in an agricultural point of view from year to year, until I feared that this industry would be entirely destroyed within its limits. I found that as time went on the cattle of the county were diminishing; the corn crop was reduced more than one half; the grain crops were dwindling continually; the products of the dairy, butter and cheese, were becoming smaller and smaller; the hay crop grew less from year to year; and it seemed to me that the assertion that agriculture was dying out was literally true. But when I found that the sale of milk at large prices was constantly increasing, and the production of market-garden crops more than supplied the deficiency in the other crops, I discovered that the farmers of this county had learned the law which should govern their business, and that they were guided by the same rule as the manufacturer and merchant adopt in order to secure their prosperity. An attempt to supply a market with inappropriate commodities must, in accordance with every human law, fail. I think there is but one successful violation of this law known in the history of American commerce. When Lord Timothy Dexter sent a cargo of warming-pans to the West Indies, he laid the foundation of a disastrous commercial enterprise, which would have ended as it ought to have done, had not the ingenuity of man converted them into molasses ladles, and thus forced them into an applicability which the exporter had never 
anticipated. Of the second, the derotion of land to crops to which it is especially adapted, the encouraging instances are numerous. It would hardly have occurred to the casual observer that the peat-bogs of Cape Cod could be converted into some of the most profitable agricultural acres of the State. And yet so it is. When it was found that under the comparatively mild climate of the Cape "the cranberry grew with great luxuriance on the meadows there,' the application of skill and judgment in clearing those lands and controlling the flowage of the waters secured to the farmer who occupied that section a golden opportunity for prosperous labor. The use of the light and warm and rich lands of Massachusetts and Connecticut for the onion crop has been a source of large income to those States. It would not be easy to estimate the profits which have been derived from the cultivation of choice vegetables on lands and in localities adapted to them. And I urge this mode of farming upon those who enjoy the advantages which lie all around you here. It must not be supposed, however, that this business can be transacted without diligent and careful attention. When Burke declared that farming required more judgment and foresight for its successful prosecution than any other business on earth, he uttered an undeniable truth. If he had applied the remark to market gardening especially, he would have stated a truth still stronger. And this is one great advantage of this mode of farming above all others. It not only brings the farmer into the immediate association of populous sections with all their social advantages, but it also appeals at once to his most energetic faculties to enter upon their work. We admire in this country the intelligence which is roused to action by all commercial and manufacturing associations. In special agriculture as I have described it we may find the same opportunity. It is the active and civilized mode of farming to which the American should 
naturally tend, attended as it is by all the privileges and opportunities which belong to cultivated life.

"There is also the advantage which the farming community may derive from a more general use of the products of the garden as articles of food, and which should never be forgotten. I think there can be no doubt that the health of our people suffers materially for the want of that vegetable diet which is so freely used elsewhere. The use of salted meats in this country has undoubtedly been and is now a great source of ill health, and perhaps of active disease. We have a tendency here to an unusual development of bony structure, and a deficient supply of muscle and tissue. This is especially true on our thin and our limestone soils. We need more of that rotundity and constitutional affluence which are to be found in lower and more humid countries, and among those people whose diet is largely composed of vegetable products. The rural population of Holland and Denmark and Germany and many parts of France can teach us a lesson in this direction. And I trust that for the health of our people, if for nothing else, we shall turn our attention to the growth of vegetables on our farms. We are improving our buildings; we are learning to adorn our highways; we are ormamenting our homes with plants and flowers; we are manifesting an improving taste everywhere. Let us not then forget our gardens, in which we can gratify the eye and from which we can draw an ample supply of most nutritious and healthful food. I trust you will now discuss the various crops which come within the range of the branch of agriculture which I have been discussing."

POTATOES.

"Mr. President," said Dr. Parker, "I am inclined to introduce the potato into that class of crops which are 
considered to belong to the business of market grartening It is so difficult to raise, has been so cut oif by discase, and is so profitable when carefully cultivated as an early crop, that I think it is entitled to our most careful consideration. The land best suited to the potato is undoubtedly that which is best supplied with carbon. The manures best adapted to it are those which have the largest supply of the same material. And so I would select new lands, or such as are well supplied with peat and vegetable mould. In new lands, which have not been exhausted by long cultivation, or which have not been overloaded with nitrogeneous manures, the mode of cultivating the potato is comparatively simple. But in lands which have been long cultivated, and where the potato crop must be raised as a market-garden crop, the utmost care is necessary in order to secure even a reasonable return for seed, manure, and labor applied.

"I remember listening to a long and interesting discussion of potato culture in Maine, and I came to the conclusion that nitrogeneous manures were generally injurious to the potato. There were many modes of cultivation described, but that which seemed to meet with the largest favor and to secure the most ample reward, was described by a farmer from Aroostook County, who ploughed his land as early in spring as possible, cross-ploughed it and pulverized it well, and then laid it up into deep drills. Into these drills he placed an ample supply of strawy manure taken from his stables, - manure in which was a small proportion of stable manure from cattle and horses, and an abundance of straw. In this manure the potatoes were planted, and the furrows were turned back upon them, and lightly rolled. The crop was described as large and of excellent quality. The universal testimony was that green manure was unsuited to this crop; and the rough surface of many potatoes was ascribed to the use of such 
manure as this, and especially to the use of heated and mouldy or fire-fanged horse-manure.

"I am aware that the potato cannot be raised here as it can in newer countries, or in newer sections of this country. But I am confident that as an early crop it is most valuable, and as a nutritious vegetable it is entitled to our utmost care.

"The land best adapted to potatoes can be properly manured with muck as a basis of the compost-heap. Thus combined, almost all well-rotted and decomposed manures are useful. Plaster thrown into the hill is always a valuable adjunct, and I doubt not that ashes applied superficially may be highly valuable. The potato secms not to be a gross feeder, but to be dainty in its choice of food. While it will seldom grow well in rich, heavy, fat soils, with an abundance of nitrogeneous manures, I have seen it flourishing to the highest degree, and producing an abundance of tubers, in heaps of coal-ashes, which were manured with a little decomposed manure in the hill.

"I do not know that the potato will ever be restored to its former value as a field crop; but I am confident that its yield may be largely increased by judicious fertilizing and careful cultivation."

The points presented by Dr. Parker were enlarged upon by the members present, who entered into a conversational mode of treating the subject, until the hour arrived for adjournment.

When the Club had scattered itself about the room, preparatory to bidding Mr. Hopkins good night, Dr. Parker was observed to approach Charles Ingalls with a degree of cordiality which had not been seen for months, and which indicated that the Doctor had recovered entirely from his old irritation.

"I hope you enjoy the study of law," said he to Charles, "and that Miss Clara is reconciled to your being obedient 
to its requirements. Tell her to remember that a proper combination of the audacity of the reformer with the sobriety of the jurist is what makes men great."

"I have reminded her of that already," replied Charles; "but I am afraid she has not yet advanced beyond the homely truth contained in the familiar line,

'But only great as I an good." "

"A first-rate beginning," said the Doctor; "and the foundation of more happiness and of more real worldly success than we are apt to suppose. But I think I can risk you both."

And Dr. Parker and Squire Wright walked home together, while Charles Ingalls pursued his way thoughtfully alone. 


\section{TWENTY-THIRD MEETING.}

\section{MARKET GARDENING (Continued).}

POTATOES. - INSUBORDINATION. - PETER ILSLEY IVANTS ROTATION. -CO-OPERATE OR QUIT. - INSIDE REFORM.

THE spring was now advancing rapidly, and the farmers of Jotham found themselves obliged to turn from the theory to the active and vigorous practice of agriculture. The best of them had followed the example of Mr. Hopkins, and had hauled the great manure-heaps into the fields where they were to be used before the frost had begun to leave the ground. They had made haste to collect the year's supply of wood while the snow lay deep in the forests; and hardly had the banks melted from the walls where they had been piled by the wintry gales, when the energetic husbandmen relaid and topped them, wherever the heaving frost and the wandering hunters had thrown them lown. The farm work of Jotham was, therefore, well up; and it was found necessary to suspend the sessions of the Club during the active spring and summer months. It was deemed best, however, to have one more meeting before the final adjournment for the season, and an urgent call was issued to assemble at the house of the President, Mr. Hopkins, for the purpose of discussing the best mode of cultivating the potato, both as a garden and a field crop. "The potato," said Mr. Hopkins, after having called the Club to order, "will be the topic of discussion this evening, and I shall be happy to hear the views of the gentlemen present, in addition to those which they expressed at our last meeting." 
"Mr. President," said Peter Ilsley, "I have tried for the last few years to raise early potatoes for the market, and have had poor success. The crop is so uncertain that I cannot depend upon it at all. One year I used nearly all the barn-yard manure I had upon a large field near my barn, which I planted early in the season, expecting to reap a large reward. The crop started well cnough, but the season was warm and wet, and I lost my crop entirely: Not a bushel of potatoes did I get from that field: and had I not raised a good supply of flat turnips after the potato-tops had been removed, I should have lost my: manure, my labor, and the use of my land for that year at least. I have never dared to run such a risk since. I am afraid the day of potatoes as a field crop in this region is over. What I raise for sale now, I get from a small patch of ground, the cultivation of which I can afford to lose if the crop fails. I have no doubt we may be benefited by a careful selection of manure and a frequent change of seed. But I find it poor business to spend my time over a crop which at best is small, and which belongs to the things that are dying out. Sickness and old age are bad enough among ourselves; but when it comes to fruits and vegetables, I think we want youth and vigor. If any section of the country is suited to potato-growing, I move that that section have the privilege, and the profit, if there is any. I used to rank my potato crop as the first in value on my farm; now I rank it as the last. Some years it pays and some years it does not. I can count it in with other crops, but I can't depend upon it for a living."

"I don't blame Peter Ilsley for being discouraged about potatoes," said Sam Barker. "I have had a hard time with them myself, but I can't help raising them in spite of all my trouble, and I think we can do pretty well with them still, if we will be careful in choosing seed, soil, and manure. I find the soil has a great effect on them. I 
have raised first-rate Jackson Whites in one field and most miserable ones in another on my farm the same season. In old times it seemed as if all kinds of land would procluce potatoes; now, it seems as if hardly any land would do it. So we must make our choice of soils. Potatoes grow rank and coarse in heavy soils, and they grow scabby in gravelly soils, especially if you use green manure. In a dry, fresh, and fine loam, moderately rich, they will grow well. What Dr. Parker said at our last meeting about the manure fit for potatoes is true. I plant my potatoes in hills, just as my father did. I think a potato needs a good, loose, well-pulverized bed of earth to grow in. I shall never forget how, when I was a boy, we prepared our soil with good ploughing, fixed the hills three feet and a half apart, put in a plenty of light rotten manure, hoed and cultivated twice, and made of each hill a good warm bed, in which the potatoes could grow without being troubled. And such hills! Why, I have seen four of them fill a bushel basket. I don't know as it was the hills; but it was something, and I don't find such a great growth or even a chance for it, to my mind, in the drill fashion of these days."

"What Mr. Barker says is more than half true," said John Thomas. "I like to try to raise potatoes just as he does. And I must confess that I like the old-fashioned hill, though nobody uses it now, - and everybody says you can get a larger crop from drills. I think, as those who have spoken before me do, that much depends on soil and manure in raising this crop. But I am sure that a great deal also depends on the choice of seed. I change my seed often. I am obliged to do this. Potatoes grow smaller in size and less in crops in this region, unless you renew your seed by getting that which grows where the potato is comparatively strong and healthy. If I have a good variety which originated in the new lands of Maine and it holds 
its own there, I get my seed each year from the farmers in that State. Then I am very careful what I get and how I plant it. I avoid an overgrown potato, - one which is coarse and heavy, as overgrown ones are apt to be, on the ground that it is not in a vigorous and healthy condition. I avoid a small potato also, on the ground that it is immature and is not fit to continue the species. I select a medium-sized, firm, well-shaped potato, with a smooth, healthy skin, and with a substance which indicates a good quality. I would have every seed potato the best cooking potato I can find in my heap. It is seldom that I cut a potato when I have selected it as I have just described. I may be mistaken, but I think the vigor of our potato crop has been greatly reduced by the habit of cutting out each eye and planting it separately, or by quartering the potato and planting quarters. I have found the crop degenerating most rapidly in those sections where the poverty of the people induced them to plant the eyes alone and use the balance of the tubers for food. And I am not alone in this observation. Is it unreasonable to suppose that nature combined in each individual potato all the elements necessary for reproduction, and that all the eyes belonging to each tuber are required to make a healthy and strong and fruitful cluster of plants? This is my idea, at any rate. And I am opposed, therefore, to gouging out the eyes of a potato for the purpose of extending its supply of seed, and with the expectation that the vigor of the potato will not be lost by the process. I do not doubt that the potato crop is subject to a destructive disease. I know it is, but I feel confident that it would have retained its vigor to this day had proper care been taken in selecting healthy seed and in placing it in a natural condition, with all its powers unimpaired, into soil well adapted to it and well prepared with plough and manure. It was found long ago that you could not 
raise a strong and vigorous cluster of vines from the crown of the potato with its numerous eyes. And I believe it would also be found, if proper observation were made, that the eyes scattered over the body of the tuber would produce more fruitful vines if regulated by the force which lies in the crown, - that part which has been considered comparatively useless. I do not know what the experience of others may be, but this is mine so far as the selection and planting of the seed is concerned."

"It is very curious and interesting," said Mr. Howe, "to see how man struggles to restore what is decaying, and how he values that which he is most in danger of losing. The wandering lamb always receives more care and more esteem than 'the ninety and nine which went not astray.' So while we have every variety of root crop, and soils adapted to each, and can have an abundance of turnips and beets and carrots and parsnips, all with comparatively easy cultivation, we struggle for the potato still; and I must confess that the discussion which this diseasestricken plant has brought out is, after all, the most interesting we have had. In offering my contribution to the debate, I recall a statement made not many years ago by a careful and sensible observer, who made investigations into the agriculture of one of the best counties of this Commonwealth. He says in that portion of his report which treats of the potato crop:-

" As respects the cultivation of this very useful and profitable root, many experiments have been made and various suggestions offered. The experiment made by a member of the committee is to seed with whole potatoes instead of cuttings, and the result was a large per cent above those that were cut, - rows standing side by side in the same field. Another member has also tried the experiment, only, however, to a limited extent, by cutting off the seed end, or the part having the greater number of eyes, 
and planting the other section, - that is, the smooth part, - and found these potatoes superior both in quantity and quality, the cultivation being the same. Doubtless the best-flavored potatoes are grown upon old pasture land, or lands that have never been cultivated, using a light dressing of plaster. The climate, also, has much to do with the potato crop: Probably the potatoes grown in the North of Ireland are superior to those raised in any other quarter of the world, while the same crop cultivated in France or Spain is very insipid. The northern counties of Scotland, it is said, produce this crop to much greater perfection than the south of England and Wales. So also those grown in Maine, New Hampshire, and V'ermont are preferred to those cultivated as far south as forty degrees north latitude, or in Massachusetts even, - all of which may be attributed to different degrees of climate. Hence the location best adapted to this plant is between forty-five and fifty-five degrees north latitude.

"Now the potato, it is well known, is a native of the high table-lands of South America. The soil of these regions is composed of vegetable substances, shell, and lime; and on accomnt of its elevation is well drained and dry. From this point the potato has been carried in every direction, into every latitude, into every climate, hot and cold, and into every variety of soil. It has also been cultivated in accordance with the methods adopted in each one of these various sections. Small potatoes and large, eyes, and mutilated bits have all been used for the purposes of propagation, and we are now surprised that a plant thus trifled with is beginning to show signs of exhaustion. That all this violence is the cause of the various diseases which attack the potato I feel very confident; and I am confident, also, that for all this no remedy will be found until by care and proper cultivation the plant is restored as nearly as possible to its natural health and strength. 
Insects and fungi will always attack a feeble vegetable growth; and so around the potato, enfeebled as it is, the rot, the curled leaf, the rust, and the bug gather for their prey. The causes of this weakness are numerous. What ought we to expect of a potato crop, if we will insist on planting small, half-ripe tubers, deficient not only in health, but also in that element of starch which, being converted into sugar by fermentation, furnishes food for the young plant, and the absence of which must result in a feeble crop? How can we hope to get a strong plant from a sprout which has been cut away in its very infancy from the mother-tuber which is intended to furnish it food through all its early life? Why should we encourage ourselves with the idea that we can produce strong and vigorous generations of plant-life if we will persist in using the seed which comes from diseased plants, and will refuse to renew our seed when it is evident that in no other way can our crop be restored? With what expectation of reward can we insist on planting our potatoes in soil manifestly unsuited to them? Why should we continue to weaken the potato, and then expect to secure a crop? Why should we, in a word, overfeed this plant with an excess of stimulating fertilizers, and then hope to retain its strength? It has been well said that plants which are subjected to high cultivation do not ripen and consolidate their tissues so thoroughly as those of more moderate growth. Fruit trees cultivated in rich gardens, and making a large growth of wood, are certainly not capable of enduring so great climatic changes without injury as those which grow in poorer soils. The case is the same with the potato. The tubers are inflated and watery in consequence of a deficiency of starch, which should have been elaborated in the leaves and properly prepared for plantgrowth; the organs are overworked and overcharged with stagnant matter, and the whole plant feels the debilitating 
influence. This effect may not appear in the first or the second year, or indeed in many years; but like the abuse of the human system by excesses of any kind, it will surely appear at some time. This anxiety to raise large crops, and to work the plant beyond its capacity by excessive stimulus, is very injurious, and will in the end destroy it. Moderate stimulus produces a firm texture and vigorous constitution. If, then, we will mutilate the plant and overfeed it, we must expect to be tormented with all these diseases which seize upon a plant whose constitution is enfeebled, - immaturity, decay, and fungi.'

"I repeat, therefore, use healthy, sound and unmutilated seed; select high, elevated lands for your potato ground, where the heats are not burning, and where the rains and dews do not chill; avoid nitrogeneous manures, which are fruitful of fungi, and use wood-ashes, plaster, lime, salt, sulphur, which are fatal to the parasitic fungi wherever they reach them. I think a little scientific observation and a little common-sense may yet restore our potato crop to the respectable position which it held on these farms when they were new and their products were abundant."

"I suppose potatoes are nutritious to all our animals," said Mr. Hopkins. "How should they be fed out?"

"To cattle," said John Thomas, -- "cows and oxen and young cattle, - they should be fed raw. Experience teaches this, and the experiment to which we listened in the early days of our Club, in feeding roots raw and steamed, may also teach us a lesson with regard to potatoes."

"If I fed them at all to horses, I should feed them raw," said William Jones, "though I must confess I consider them quite inferior to Swedish turnips for horses, young or old, and I seldom feed them unless it be for a change."

"For poultry and swine," remarked Peter Ilsley, "they" should be cooked, undoubtedly; and if they are combined 
with meal or shorts in proper proportion, so much the better for the hens and the hogs."

"And now," said Mr. Hopkins, "I think we have sufficiently discussed the subject before us; and with the hope that such of you as desire will remain for a little social conversation after this meeting is dissolved, I propose that the Club adjourn to such time as may be deemed best by the committee, when our summer and autumn labors are over and winter is again upon us."

And so, in accordance with this suggestion, and on motion of Mr. Howe, the Club adjourned for the season.

The practical farmers who had gathered there to take counsel together with regard to the great industry in which they were all vitally interested, had come from the toil of a long spring day, and they were quite ready to return to their homes when the meeting broke up. The darkness of evening came on so slowly that it was quite late when the assembly was called to order, and its deliberations were correspondingly late in coming to a close, so late that these hard-worked citizens were glad to find repose. But the evening was raw and chilly, and there were those who were glad to linger around Mr. Hopkins's fire, which he had lighted to drive away the dampness and to cast its genial glow over the gathering of his friends. The brass andirons of ancient and sturdy pattern shone so brightly, the polished fender reflected the company so honestly, the strong figures on the rug came out so vividly in the firelight, that you could easily imagine that Winter was still howling about the house and roaring through the valleys with his hard and blustering sway. It was with that evident satisfaction that comes with the possession of pleasures a little out of season, that the less busy and toiling gentlemen present remained and drew around the fire for a sort of final chat. Mr. Hopkins lighted his cigar and took his ample arm-chair at the right of the fire, and 
in the row stretching round to the opposite corner sat Dr. Parker, dark, keen, and rotund, unmarked as yet by age; Squire Wright, white-haired, strong, angular, and somewhat formal and oracular; the Rev. Mr. Howe, sedate and proper, and at the same time filled with humor and common-sense; John Thomas, calm, reserved, stiff, and honest ; Charles Ingalls, young and vigorous, impelled by great forces, and as simple as he was powerful, broad-browed, dark-eyed, and meditative; Peter Ilsley, strong, rude, rough, and designing; William Jones, cumning, adroit, airy, stylish, full of the accomplishments of him who lives by the mysteries wrapped up in what he calls a "harse"; and Sam Barker, who debated everything, always had his own way, and never so exhausted himself by labor as to become unfit for such social and intellectual recreation as came within his reach. The cream of the Club was there. Some smoked, others did not. Mr. Howe and Charles Ingalls did not.

"Well, gentlemen, the Club has flourished this last winter," said Mr. Hopkins.

"Yes," said Squire Wright, "and I see no reason why it should not become a most valuable institution in our town. It ought to control public sentiment here, and dethrone the grocery and shoemaker's shop, which have ruled here for years."

"And so it would," said Dr. Parker, "if it were not organized. Our people arm themselves against an organization, no matter whether its object is good or back. It is not easy to see how great objects are to be accomplished here, if this spirit of hostility to associated bodies is to continue. Each man among us has such an uncontrollable tendency 'to fight it out on his own hook,' like the soldier in the Revolution, that it seems as if a good cause even would die if supported by an association."

"Not so," said the Schoolmaster. "Men believe, as I 
think, in association. Some defy it when they despise the object for which it is organized. Some shun it, when they cannot rule. Some hate it, because it is too strong for them. Some denounce it, because they cannot control it. All recognize its power, and all admire it so long as it serves their purposes."

"There are those who never come together," said Dr. Parker. "Animals herd, but they seldom have a common cause. They gather together, and sometimes recognize a leader, whose superior strength secures the power to rule; but they never organize, they never help each other. The existence of an animal is an individual existence in every sense of the word. A hundred wolves or a hundred horses are independent wolves and horses, and never unite except because led in a common direction for individual plunder or subsistence. No one gives another a lift. So in certain conditions of the human race. Lunatics never combine or organize. If they did, who could control them in our insane asylums? It is not often that confined criminals combine. If they did, who would undertake to manage a crowded jail? The rascals have not conficlence enough in each other to make an extensive organization. No man carr tell the power of the depraved and the demented, if they retained that capacity to associate and work in harmony which belongs to those who, actuated by high motives, are engaged in a good cause."

"Harmony," said Mr Howe, "is a good word to introduce in this connection. If association meant harmonious action, it would all be well enough. But so far as I know, it means rivalry and jealousy and designs and consequent deceit, and, too often, treachery."

"Why, my dearly beloved pastor," replied the Doctor, " are n't you a little hard on human nature? I know men quarrel, - I suppose a sense of self-preservation drives them to this; perhaps, also, a sense of self-aggrandize- 
ment. But because bad men exist it is no reason there should be 'no more cakes and ale.' The quarrels of associations are not the prominent and most distinguishing characteristics which they possess. Sewing-circles gossip, but they are not all gossip. Temperance societies wrangle, but they do not omit the weightier matters of the law. Parties are rent by contending factions, but they work in one direction for a common cause. Men carry their own individual characters into associated life, I know; but it is not the bad characteristics which prevail. They torment and confuse and trouble, and drive men into making asses of themselves, but they seldom rule. And I have often noticed that in large associations and small the mean and quarrelsome men seldom succeed. They may make mischief, but they are seldom called into power."

"Now and then they win," said Peter Ilsley, inadvertently, and then shrank away, remembering the last townmeeting, and wondering how in the world he could have blundered into such an unfortunate remark.

"Yes, they do," said Mr. Hopkins, somewhat sharply, " but their power seldom lasts long. I have lived a life of reasonable length and of a good deal of activity, and I have never seen the time when somebody was not abusing every kind of association that I ever heard of. They abuse secret societies, - which certainly have the merit of keeping their quarrels to themselves, - because they cannot get into them I suppose; they abuse corporations, because they are too improvident to secure any of the rewards of this combination of capital; they abuse religious societies, because they are not the deacons; they abuse parties, because they cannot lead their councils. But the striking feature of these complainers is that they agree as little with each other as with society in all its organizations. A consenting mind is a good thing, - ' a unanimous mind,' as somebody has called it, - not a subservient or an obedient mind, 
but a reasonable one; just and good-tempered as well as uncompromising. I always liked the Quakers, - following a high standard, advocating and toiling for human freedom, encouraging temperance, virtue, honesty, peace, and never wrangling over their work. I see no reason why a reformer should be the worst-tempered man in the world, or make himself disagreeable to everybody about him. The best of them do not. Luther did not; Mr. Garrison does not; some of the little ones do. But this complaining is no argument against associated effort. They say societies and parties are selfish and corrupt. That may be; then let the purifiers take the matter in hand. The good men can rule if they will, - rule within an associated organization, if they will only attend to the business; rule if they will begin at the beginning and not dash in at the middle; rule just as well without ruin as with it, almost always better. I suppose it indicates a lofty sense of independence to step out of the ranks and fight for a while, like a boomerang, dangerous to everybody, friend and foe, and fighter included; but I do not think it indicates wisdom, or a clear understanding of results, or is in accordance with the best ideas of progressive action, or shows a capacity to lead. Your own house may not always be the abode of peace and comfort and happiness, or domestic felicity, but it is poor business to get outside and stone the windows, for all that. If you cannot live in your house, why not quit it, and let some one else manage it, and say nothing about it?"

"Do you suppose it would harmonize matters if every member of an associated and organized body knew that he would have his chance to lead?" asked Charles Ingalls.

"I guess it would!" exclaimed Peter Ilsley, with another unfortunate slip, which ought to have settled him for the rest of the evening.

"I have no doubt," said Mr. Hopkins, "this would do 
much to kecp the peace. Man is ambitious, - more ambitions oftentimes than sagacious and wise. Man's ambition is often disappointed beause he does not know enomgh to gratify it, - does not know how to conduct himsilf in such a way as to secure public conficlence, and this often when he has cvery qualification, and is a model of grood conduct, and might be a moklel of usefulness. Man often exhausts himself, too, in reaching after what he cannot set; and I sometimes think he grows desperate in his efforts, because he rcally fecls that his efforts will be in vain. I3ut let it be understood that under a system of rapid rotation every man will have his chance, and my word for it the trouble would soon be over. There is an inherent love of power in man, even when he lives in a state of perfect social and civil equality; and he will strive for it all the more when he knows that it is within his reach, and is not confined to a fortunate class or family. He will obey if he knows he is obliged to, but he wants to rule if he knows the chance is open to him."

"Do you suppose anybody wants Mr. Hopkins's place in this Club?" asked William Jones.

"I don't know about that," blundered out Peter Ilsley again, and then lost himself in hopeless confusion, while Mr. Hopkins looked steadily into the fire for a moment, with an unusual expression of anxiety and surprise casting a fleeting shadow over his calm and benevolent countenance.

"Well," said Dr. Parker, "I think this promises to be a fruitful season." And everybody thanked him silently for changing the subject, even Peter Ilsley, who could not tell when he might be caught again.

"Yes," said John Thomas; "the fruit buds are strong and abundant, and my winter rye and fall-sowed grass never looked as well as they do now."

"The land has settled fairly and rapidly," said Squire 
Wright. "My garden never started earlier than it has this season ; potatoes and peas starting already."

"And may we have a peaceful, fruitful, and prosperous season," added Mr. Howe in a ministerial tone. And the group began to move.

Mr. Hopkins stood at the door musing after they had all passed out; and, wondering whether he was really in anybody's way, and whether the Club had roused any jealousies, and whether it could be possible that his labors to improve the town were set down to ambition, and whether the community was ungrateful, he closed the door, and drew into his old home, with all its memories and associations, and assurances of confidence and love. 


\section{THE RECESS.}

A HOT SUNDAY. - THE BOY GOES TO MEETING. - FANNY'S SUFFERING. - DR. PARKER CONSOLES HER. - THE WALK TO THE LAKE.THE THUNDER-STORM. - THE FIRE.-JOHN THOMAS AND HULDAH, THE CHRISTIANS.

AND now the hush and hum and stillness and sweetness of summer reigned among the hills and valleys of Jotham. Nature entered promptly upon her business. Darkness fled away; and the sum, mounting higher and higher, sent its rays through the long summer days into all the seclusion which winter had shrouded with impenetrable gloom, until the dingy corners were filled with light and life. The frosty breath was withdrawn, and over everything moved gently and softly the life-giving air, which fans the earth into its new existence year by year. To this genial summons the response came as readily now as it had for ages; and in all the secret places of the earth the forces of life moved mysteriously and irresistibly. The soil itself seemed vital. The living forces rushed through myriads of channels from the bosom of the carth, into the swelling leaf and flower, until the green and growing garment was complete, and the floral crown sat with all its beauty upon the brow of Summer. Life was everywhere. IVith a bound the cattle left their winter confinement, took one wild circuit of the old familiar pasture, and settled at once into their new intimacy with nature. The air itself was vocal; the songsters had returned as by magric. Insect life burst out, busy, noisy, happy. Even man himself resigned the cramped and shivering ways of winter, and strode forth to his toil with the very 
lordliness of the land inspiring all his energy. Through the open doors and windows of his dwelling the soft air entered, the winter home was gone, the fireside vanished, and the family circle now gathered on the old green around the threshold. The mode of life was changed; the pleasures and the toils were all new; the hard battles of life were softened; the happy paths were happier; to the new-born there was a glad reception; even death itself seemed gentler. The week-days were made for toil, the Sundays were made for rest.

"Fanny," said Squire Wright, "the boy had better go to meeting to-day. He'll crow a little I doubt not, but he will learn, now or never, to know the real difference between a meeting-house and a dwelling-house, between Sunday and any other day in the seven."

Fanny looked a little disturbed at this proposition from her father. She was very young still, and she felt quite uneasy under the thought that she might be exposed to a scene with her boy, who evidently had a will of his own, and might be obliged to exercise her maternal authority before the assembled congregation. Besides all this, since her return a young widow from the West, she had been known as Fanny at home and abroad, until the fact that she was Mrs. Ransom was almost forgotten. It must be acknowledged that this was not disagreeable to her, much as she respected and loved the memory of her departed ministerial husband; and why should she be compelled to proclaim her widowhood - she, a bright and blooming young girl - to the whole community of Jotham, by a contest with her first-born amidst the solemnity of divine worship? But the Squire was inexorable, and to all his household his will had always been law. He had not much faith in human strength, and in man's power to support himself by the Divine spirit, through all the trials of life. He had not much faith in religious sentiment un- 
inspired by the presence of material symbols. Ite hardly beliered that man was wicked, but he felt confident that he was weak; and he felt keenly the importance of habituating him, in the very morning of life, to those scenes and customs which belong to the religious organization of the world. He was not a bigot, nor was he indifferent to the value of a well-grounded faith. He seemed to have a most exalted iclea of the impression produced upon the mind by association and mere external influences. He often said that the lofty gaze of the mountaineer and the peering glance of the sailor were admirable illustrations of the controlling force of circumstances upon man's physical expression; and he felt confident that in the same way permanent impressions might be produced upon the mind and heart. When he urged upon Fanny the importance of graceful and vigorous phrase in her talk with the boy, he did it because he knew well how quick young ears are to catch passing utterances, and how ready young lips are to repeat them. When he advised her to familiarize him with cheerful and attractive books, and to make these books his most acceptable companions, instead of the instruments used in the daily drudgery of the school, he knew that this taste once acquired was never lost. And it was easy to see that in all his intercourse with his family he carefully preserved all that courtesy which had given him large influence in the community; for the especial benefit of the young who belonged to his domestic circle. He seldom moralized, seldom made tedious appeals or gave commonplace warnings to the disobedient, never dealt in cant; but his manner told at once the profound contempt he had for waywardness and sin. If he had been asked what he thought would be the consequences of crime and misdemeanor, in this world and the next, he would probably have found it difficult to give an answer: if he had been called on to define his faith, he could not have 
done it; if he had been requested to give the text of the sermon he had just listened to, he would have failed to answer: nor could he have told definitely even the subject itself. But he said a sermon always did him good; so did the prayer; so did the singing of the choir. He always treated the minister with deference, was charitable towards his defects, and enlarged upon his merits; never treated him as a dependant, but always saw that his wants were supplied; and gave him a foremost place in his family circle and a cordial attention at the fireside talk. He respected him because he was a minister, and felt that it was his duty to encourage him in that difficult task which the pastor of a people imposes upon himself when he undertakes to accommodate himself to all their tastes, and to remove their fears, and to relieve their sorrows and share their joys, and to subordinate all his feelings and characteristics to theirs, in a service which sharpens his sensibilities and tends to aggravate his peculiarities. He was a faithful and useful parishioner. Of his religion he never boasted. He had made up his mind that in his weakness and his strength, in his wants and necessities, in his tastes and views, in his sentiments and associations and feelings and prejudices, he represented the average of well-behaved humanity; and as he supported himself in this mental and moral condition by a proper observance of all decent customs, and by a constant recognition of social propriety, he was earnest in his desire that "the Boy" should start well in life, and carry with him precepts and memories which would make all good ordinances as dear to him as the face of his mother, and of the grandparents who idolized him as if he were a child of their own.

And so the boy was taken to meeting for the first time. It was just past midsummer, and the heat of the morning was intense. Mr. Howe was as wise as ever in his sermon; the choir sang with its usual fervor; and the sum- 
mer breeze which was wafted through the open windows fanned as orderly a congregation as ever gathered in an old-fashioned Puritan meeting-house. But neither the wisdom of Mr. Howe, nor the power of the multitudinous choir, nor the solemnity of the congregation could sustain itself under the riotous conduct of the boy. He was simply intolerable. Even the Squire grew uneasy under his various demonstrations, and repented that he had insisted on introducing his grandson to public life in such hot and fretful weather.

"He is a hard one to break," whispered William Jones from the adjoining pew, and the Squire agreed with him. But the battle was to be fought, and everybody behaved as well as everybody could while the contest lasted. Poor Fanny was wretched. She felt that the position she had held as a superior and controlling power in society was gone. The boy had taught the people that she had one master at least, and she returned to her home, at the close of the services, so subdued and chagrined that she seemed to have entered upon a new life. The disobedient little boy clung to her amidst the surrounding indignation, with an air of grief and defiance commingled, and gave her a new idea of the tender relations which grow up between a mother and a son, in which the maternal rule is broken by maternal tenderness, and the filial obedience is sometimes disturbed by the filial manhood. But there was nothing to be said; and gradually the boy returned to his accustomed ways, with a little shyness added, perhaps; and Fanny tried to become a girl again; and the Squire and Mrs. Wright read their Bibles with more than common devotion.

The Sunday afternoon passed away; Mr. Howe preached the second sermon of the day, as all ministers of his time did; the Squire and Mrs. Wright were among the hearers ; Fanny had been allowed to remain at home after the 
exhausting exercises of the morning; the meeting-house doors were closed, and the declining hours of a hot midsummer Sabbath were as still as the sultry eventide of the tropics. The sun in its going down had met, long before it reached the horizon, a heavy bank of clouds, and had tipped the moving and shifting edse with a golden radiance, which seemed to add an unusual glow to the heat of the evening. The widespread valley which stretched away from the Squire's threshold was basking mistily in the liquid heat. And it was with unbounded gratitude that the exhausted villagers welcomed the first puff of a westerly brecze which came up to cool the approaching night. Fanny was sitting alone at the open front door, pondering upon the trials of the day, and listening now and then for an expected call from the little sleeping personage who had caused all the trouble, when Dr. Parker appeared on his customary Sunday evening call.

"Well, Fanny, it has been a hard day, has n't it?" said Dr. Parker as he seated himself on the threshold at Fanny's feet, and tossed his hat away, as if impatient that anything should interpose itself between the evening air and his heated brow.

"Yes," said Fanny, "it has been very hot, and I have had a hard trial of my patience. But then it is the boy, you know; and he will so constantly remind me that I am a girl no longer. And then to tell it to the whole congregation! But why should n't he?"

"O," said the Doctor, "never mind that. The boy is well enough; but you must not allow him to quench the impulses of youth. He can pass for a companion or a brother."

Fanny sighed, and thought how little, after all, this wise and learned Doctor knew. She stepped out into the approaching twilight, and, joined by Dr. Parker, strolled down the grassy and shaded lane which led to the lake. 
The air which now came up the little valley was delicious, tempered as it was by the coolness which it caught up as it passed over the bosom of the waters. Fanny, subclued and chastened by the little experience of the day, had lost the sharpness of her wit, and, almost for the first time in her life, felt like leaning upon a kind and strong arm for support. She had borne domestic sorrow with great fortitude and courage, and had nerved herself up to the capacity of carrying her friends bravely on through the agony of impending calamity. But it was a mutual sorrow which she bore and shared so well; and it was a calamity which threatened to fall as heavily on her father and mother as on herself. Now she had commenced upon a work which she alone could conduct. That an hour of childish mischief in a meeting-house should have so sunk into the soul of this young woman was almost inexplicable; to herself it was unaccountable. But there was a revelation about it which weighed upon her mind and heart, and brought her to a solemn consciousness of the relation which existed between herself and her boy, and between the two and the world. She had learned in public, and hac? declared there, that she was the guide and controller of young forces which, if successful in the world, must exercise strong and well-regulated faculties, and that in her hands rested the guidance of a being who was born for good or for evil, perhaps in accordance with the skill and wisclom with which she directed his early footsteps. Dr. Parker was struck with her gentleness and thoughtfulness. Since the day that she convinced him with her sharp shrewd commonsense that Clara Bell had no love for him, and had tossed lim from herself with the ease of a magician throwing his bubbles into the air, he had never dared to approach the region of sentiment in her presence, and he had never conceived for a moment that she entertained for him any stronger feeling than a common regard. From that time, 
now many months ago, he had exercised an unwonted self-control, and had unconsciously laid aside a large share of his self-conceit and his indifference to the opinions of those about him. The discovery that Clara Bell's feeling toward him was fear and not love, and the audacity which Fanny displayed in bantering him out of his weak delusion, had done him great good. What the advice of wise men and the example of good men and the taunts of bad men could not cure, the natural treatment of two young women had removed, for a time at least. And as his recklessness vanished his sensibility returned, and insomuch as he felt worthy of confidence and esteem, he desired to obtain it. It was in this mood that he and Fanny walked on. But for their experiences in life, they would have loved each other as lovers do. What the feeling was which brought them nearer and nearer to each other they could hardly tell; but they seemed to have stepped out of the ordinary walks of life into a calm and quiet atmosphere where they could at least escape all meanness and annoyance. It was not as in the brightness of sunlight that they walked, but as in the mild and silvery refulgence of the full-orbed moon. They strolled on in silence. Fanny leaned on the Doctor's arm. They wandered down to the shore of the lake and sat upon the grassy bank, listening to the ripples which came dancing up the beach to die there. They heard the lashing note of the whippoorwill in the dark hemlock grove across the waters. They heard, too, the beating of the distant oar, and the ringing laughter of the rowers. The soft hum of summer evening was all around them. The memories of the past came rushing into their minds, and compelled them to silence. The tale which trembled on the Doctor's lips he had once told with a mumbling frenzy, and the shame of that hour made a coward of him, and lay like a mountain in his path now that his brighter and better day had come. The mild and passionless journey of life upon 
which Fanny had entered with the young minister was by no means forgotten by her; and now she found that in spite of herself his subduing influence was around her

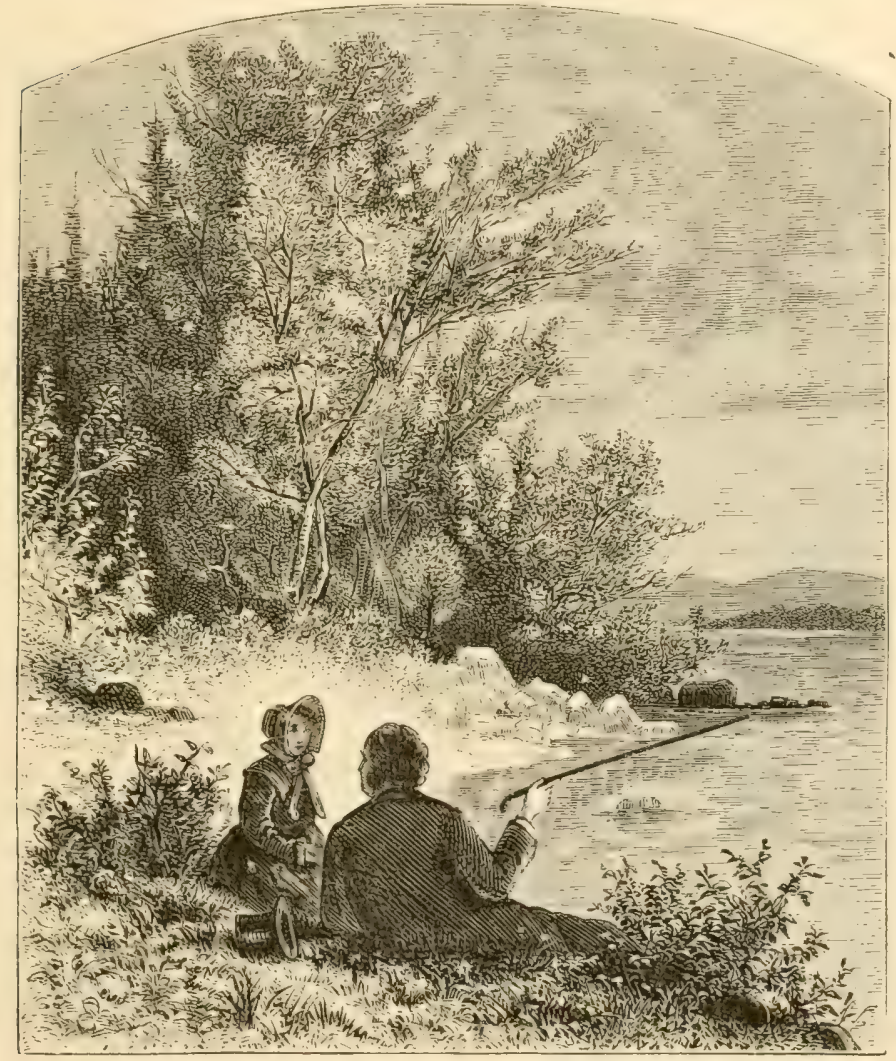

FANNY AND THE DOCTOR BY THE LAKE.

still. And so they sat there in silence, listening to the confused and drowsy music about them. The hours were sweet enough, but there were no words to tell the tale, there was no power with both combined to throw off the influences of the past. They left the shore of the lake, 
and wandered back arm in arm towards the house. As the darkness gathered thicker and thicker about them, they felt that Nature in her sympathy had provided for them a deep and sacred retirement in which, unseen even by each other, they might make their sacred declaration. But even the darkness was not enough for them, and they stood at the very threshold of Fanny's home, unconscious that their journey was quite ended, and without having uttered a word in their strange, mysterious walk.

"O, how are they to be envied," said the Doctor, as they stepped into the dimly lighted parlor, "whose lives were fortunate in the beginning. The drifting clouds of noonday soon vanish and leave not even a shadow behind. But a cloudy morning foretells a fitful day, at least, if not a heavy onc. The mists that shroud the sun at its rising seldom roll entirely away. If the young would only learn this from those of us who have passed through the trials and chances of early life, how many would escape the dangers by which they are surrounded."

Fanny thought of the boy, and prayed that he might look back upon a wiscly directed childhood and a fortunate youth. She knew too well, however, the thoughts which were passing through the Doctor's mind; and she felt somewhat disposed to give expression to her natural pride by suggesting that for herself she had nothing to regret or repent of, and that however applicable his reflections were to himself they belonged not to her. But fortunately for her, and for them both, the opportunity to make this chilling statement was suddenly lost, and it never returned. In their silent and thoughtful and palpitating walk they had been so absorbed that they were entirely unmindful of the fact that the heavens had become overcast with thick and heavy masses of clouds, and that already the dim flashes and distant mutterings told of an approaching storm. The bank into which the sun had sunk had risen 
and taken possession of the hearens. And before ranny had found time to reply to the reflections of the Doctor, a rivid and blinding flash of lightning, followed instantly by a deafening peal of thunder, was the signal of a wild and terrifying storm which burst upon the lands and homes of Jotham. Fanny shuddered, drew closer to the Doctor, forgot at once her mischievous design, and sat with him on the sofa in the rear of the room, away from danger, as she hoped. Mr. and Mrs. Wright were heard moving about and closing their windows. The boy slept peacefully. The storm seemed to fill the whole heavens and to threaten the very foundations of the earth. The lightning was incessant, not distant and lurid, but sharp, near, a visible pathway of flame, keen and swift and flashing; it seemed to rush from window to window on a flaming track; it did leap from cloud to cloud in great masses of fire. The thunder never ceased. Before one roar had begun to die away, another, heavy, sullen, crashing, burst upon the ear with new fury and new terror. It was a storm which was never forgotten by those who witnessed it. Hour after hour it went on in its might and majesty. People trembled in their beds beneath its rolling, roaring; blinding fury, and there sat Fanny and Dr. Parker, hand in hand, and silent still, waiting for the terrific conflict to cease. The long-continued cannonade paused for an instant, to be followed by a blazing, blinding flash, and the hissing and screeching explosion which announces that the lightning is engaged in its work of destruction, - and all was still. The rain began to cease. The wind lulled. The two lovers, for they had reached that point at last, left the sofa and approached a window to look forth into the subsiding storm. As they stood there watching the dim and distant flashes, and listening to the far-off muttering of the departing storm, they saw gleaming through the dripping branches of the trees a steady and increasing light shining from the 
western side of the town. Dr. Parker saw in a moment that the final flash had done its work, and that the most awful calamity that can befall. a country village had come upon their neighbors in some one of the farm-houses of that neighborhood. A dwelling-house was evidently in flames, and the work of destruction was rapidly going on unchecked.

Dr. Parker started forth at once to alarm the people and to join in their attempts to subdue the conflagration, or to save what they could from destruction, leaving Fanny to rouse her father and urge him to follow. The rain was over, and the great, broken masses of clouds were rolling away, now concealing and now disclosing the moon, which was wading through them on her nightly path. The saturated earth and the drenched trees had a mournful look as the Doctor rushed on, calling out all whose houses the passed on his way to the fire, and succeeding in rallying and joining an excited crowd of villagers who were bewildered by the unusual scene before them. The old churchbell now joined in sounding the alarm, the first time since it had hung in that ancient belfry. Guided by the light which began to dart up to the heavens amidst great volumes of smoke, the hurrying multitude soon discovered that the farm-buildings of Peter Ilsley were enveloped in flames, the lightning having apparently blown its fiery breath through house and barn and shed at once, and laid everything there beneath its destructive force. Through roof and window the flames were bursting when the villagers arrived. Within and about the house not a soul was to be seen. The few cows, which had evidently been lying in the barn-yard, had broken through the gateway in terror, and were standing in mid-field, gazing upon the scene with eyes in which the glow of the fire was vividly reflected. The people were helpless and dumb. They had no means of subduing the devouring element; they 
had no courage to rush to the rescue even were that possible. As they stood there terror-stricken and paralyzed, the Squire bemoaning the sudden and serious loss of property, Mr. Howe distressed at the thought that a human being might possibly be perishing there, Dr. Parker stunned by the weight of the calamity before him, John Thomas lamenting silently that his strength and determination were of no avail, there suddenly appeared at an open lower window of the house a little child crying for help.

The fire had not yet reached that corner, although the child's form was enveloped in the thick volume of smoke, which was pouring through the window where she stood. In an instant the vigorous men rushed to her rescue and brought the little thing out of danger, half blinded and bewildered, and crying and sobbing and begging that they would save her father too. "The entry! The entry!" she cricd in her agony; and it was evident that in the mass of smoke and flame which now rolled along this passageway Peter Ilsley would be found cxhausted, insensible, perishing. But who was the man to brave that danger, or to lead in a charge for which not a soul there was prepared? At this moment John Thomas, roused now to a sense of duty and of indignation at the powerlessmess of the multitude, called on those about him to follow, and rushed to the front door of the house. In a moment he had beaten down the panel and frame, and had found his way into the burning hall. His companions attempted to follow him, feeling that their chief duty would be to save him from sivift destruction. But almost before they had reached the threshold, John Thomas appeared, scorched and blackened and half blinded, dragging the burned and senseless form of Peter Ilsley just out upon the open green, and falling there by the side of him whom he had rescued. A groan of terror and admiration burst from the 
crowd around. The two prostrate men were instantly borne out beyond the scorching influence of the flames, Peter Ilsley a mangled and disfigured form, barely retaining the breath of life, and John Thomas badly burned, but regaining at once his consciousness, and calling on his companions to save also those who still remained in the house, - the wile and children, and the hired men of the farm, all of whom were perishing in the flames. But this was all in vain. Nothing more was to be saved from that destruction, neither man nor animal, - only a little sobbing, half-crazed child and a disfigured and dying father. And even while the people gazed there and consulted together what they should do with the sufferers, the blazing buildings fell with a crash and the great flames rolled trimphantly up to heaven. It was all over. Of that house nothing was now left but the burning timbers, beneath which lay the ashes of those who but just now had been full of life and happiness; and the multitude shuddered and turned away, while a suppressed sob of horror broke from the crowd of women who stood afar off and witnessed the dreadful scene.

But the old man and the child; what was to be done for them? No one seemed disposed to assume the care and trouble of providing for them in his own household, and it was suggested that they be carried at once to the almshouse, where every comfort could be provided for them, and where Peter Ilsley had a sort of right, from his official position in town. The little girl, Margaret, stood there sobbing as if her heart would break, and calling in piteous tones upon her father for help and recognition. Unused as they were to such touching scenes, the people standing by scemed to be stunned rather than roused to a sense of their obligation. To Dr. Parker the public institutions of the town seemed to be the most natural resort for the sufferers. Mr. Howe could do noth- 
ing, and hardly dared to make a suggestion. Mr. IIopkins knew no other course to pursue, his house being rather a house than a home. At this moment two or three of the women approached, apparently anxious to learn the extent of the disaster, and perhaps suspecting that there might be work for them to do. Among them was Mrs. Thomas, who now learned for the first time the danger to which her husband had exposed himself, the narrow escape he had had, and the distressing fate which had fallen upon the family of Peter Ilsley. John sat there on a rude seat provided for him, evidently suffering severely, and so disfigured by the fire as to be scarcely recognizable. He had hardly taken in the entire situation himself, and it was not until he saw Huldah and heard her voice that he began to realize what he had done, or to understand what he was to do in the future.

"Thank God, John, you are safe," said Huldah, with her seclate monotone unbroken, even while her heart was swelling with emotion.

John looked up as she took his hand, and said calmly in his good, manly tones, "Thank God, Huldah, you are here. But what is it, and what is to be done?"

"You are hurt, John," said she, "and must be taken home at once. Peter Ilsley is here, dying, and must be cared for. His little Margaret is here, too, alone in the world, and must be comforted. We have a great house, John, and you will soon be well, and Peter ought not to go to the poorhouse, and the little girl, - who knows but she may be a comfort to us by and by? John and Susan are wellnigh grown up."

John Thomas turned toward his wife with amazement. The anxious weeks and months he had passed on account of Peter Ilsley's injustice, the blow this man had struck at his good name, rushed at once into his mind, and he paused for a moment, gathered together his wandering 
faculties, and simply answered, "Huldah, you always were an angel!"

At the suggestion of Mrs. Thomas, John was sent home as quickly as possible; the poor mutilated form of Peter Ilsley was placed in a comfortable wagon and borne to her house, while she herself, consoling little Margaret, took her by the hand and led her by the side of her father to that home in which his last moments were to be made as comfortable as possible, and where she was to pass a portion of her life and grow into the affections of those who were for a time to fill the places of the departed. The villagers looked on in astonishment. Mr. Howe thought how often he had preached about the good Samaritan, and how seldom he had practised it. Mr. Hoplins felt as if a new revelation had dawned upon him; and he resolved that that child should not want, so long as his own substance might last. Dr. Parker, apparently lost in thought, and evidently wrung by a deep and silent grief, fixed his eyes on the sobbing child and followed her passively to her new abode. It was a curious and mournful and touching procession which passed out from the group that lingered behind to watch the last dying embers of that destroyed home. And as the morning dawned, the early light streamed into the comfortable room which Huldah had provided for the dying man, and illumined her own apartment, in one corner of which the little deserted and lonely child lay sleeping and exhausted, while John was resting opposite on his own bed, arranged by her skilful and affectionate hand.

Peter Ilsley died and was buried, - unconscious of his trials and ignorant of his benefactors. Margaret wandered up and down, calling for her father and mother and brothers, and her sister and companion, and wondering why none of them came to her, until the kindness of Mrs. Thomas had penetrated her whole existence, and 
Susan had become to her an older sister and a wiser companion. John soon recovered, and returned to his work, bearing through life the scars and the memory of that awful night. He learned to love the little child, and he never ceased to be grateful to Huldah for having lifted him above the ungenerous impulse which was making its way into his heart, when he first realized that his persecutor appealed to his kindness and charity.

Charles Ingalls thought it would take many semons to teach what John Thomas had taught by this one act of his life; and Clara Bell prayed that she might be as good a woman as Huldah.

The affairs of Jotham went on as usual. The summer passed away and the harvest-time came on. The annual excursion to the sea-shore was omitted. The rains feli upon the ashes of Peter Ilsley's house, from which a few charred bones had been raked and buried with him; the winds passed over them, and when autumn came Nature had already begun to obliterate the marks of her own destructive work.

The recess ended, and the time came round when the meetings of the Club were to be resumed and the investigations were to be continued. 


\title{
TWENTY-FOURTH MEETING.
}

\author{
MARKET GARDENING (Continued).
}

MR. HOWE LIKES A TOWN AND A CLUB. - MR. HOPKINS BEGINS TO GROW OLD. - THE CLUB GLAD TO MEET AGAIN.

IT was earlier in the winter than usual that the Club was called together to begin the intellectual campaign of the season. Indeed, the autumn had hardly passed away before the lengthening evenings had created a desire on the part of the members to enjoy the hospitality of Mr. Hopkins once more. The sudden and startling blow which had fallen upon the town during the summer had brought the community into a more intimate relation, and had cemented those who had once looked with indifference upon each other in the sunshine of prosperity. They were inclined to be more charitable and genial than they were before almost an entire family had been swept away from their midst, and it was evident that the chastening had quickened their better faculties, and had infused a kindly spirit into their hearts. The town had a clubable tendency always, as Mr. Hopkins found when he first called his neighbors together. But as the life of the town increased in interest, and its events multiplied, its sociability increased also. The apathy of an uneventful community passed away. The return of Mr. Hopkins, the emigration and return of Squire Wright, the formation of the Club, the experience of Dr. Parker, the energy of the Schoolmaster, the tragical death of Peter Ilsley, all tended to create a mutual interest which could only be satisfied by association. The injunction pressed upon the mind of Dr. 
Parker when he became a member of the Hasty P'ulding Club in college, and was told in hollow and heavy tones by the presiding officer, "Sociability, sir, is a source of the most delightful pleasures," grew more and more valuable and real to him as the incidents of life around him increased in importance. The closer his hold became on society, the more he desired to see of it. He knew perfectly well that he had fallen away into periodical dissipation because he had isolated himself, and had forgotten that he was a member of the human family. He began to realize that a community without clubs is no community at all. Even Mr. Howe, who had depended largely for his associated influence and enjoyment, through the early part of his ministry, on evening meetings and sewing-circles, realized the value of a broader organization, as the Club made itself felt, and held out more and more its support and entertainment to those who had joined it.

"For the first time in my life I am glad to see winter approaching," said Mr. Howe to Dr. Parker, as they met accidentally on their way to the first meeting. "I hope to forget the hardships of the summer."

Dr. Parker said nothing in reply, but silently recalled the summer and autumn months, and wondered what Mr. Howe meant. He remembered the "hot Sunday," and the thunder-storm, and the fire, and the destruction of human life; but, then, he also remembered the walk to the pond, and the sweet revelations which followed, and the gradual growth of his attachment to Fanny, and her affectionate response; and the summer did not seem to him overladen with hardships. And he did not easily comprehend the view which $\mathrm{Mr}$. Howe was taking of what had been to him anything but a gloomy season.

"I am just in that state of mind," added Mr. Howe, "which enables me to appreciate the companionship of my fellow-men where 'face answereth unto face.' Just now, I 
find the light of the countenance sweeter than the light of the sun."

"Ah! now I understand," said the Doctor; "you like, then, a town the whole of which can be included in a club."

"Yes," said Mr. Howe, "I think I do. The older I grow the more I value human sympathy. If I sprain my ankle or lose my dog, I like to be asked about it; I like to feel that everybody has heard of my misfortune, and hopes I shall soon be restored or find the dog. I know there is a good deal of gossip belonging to this kind of life; but to my mind, personal gossip is based on personal interest. It is man's prerogative to discuss his fellow-man; if he does it fairly and generously, it does him good ; if he does not do it at all, he grows as hard as an iceberg, and as cold. What a gossip Charles Lamb was; and Boswell, and Scott, and Horace Walpole; what rich personal talk they had about their friends and acquaintances! I should be in utter despair if I thought I was never discussed here in Jotham. A town where you know everybody and everybody knows you, or a town so huge that you can make your own community in the midst of it, and fill that and be thoroughly known by it, - one or the other of these I consider the only fit place to live in."

"Now," said the Doctor, "I don't know about this. I am afraic the interest which manifests itself in gossip and in anxiety about your ankle and your dog, is a pretty fleeting affair, after all. I think the bond must be stronger and more vital if it is going to amount to much. We expect the members of a family to be interested in each other in accordance with the most natural impulse and instinct; and we arlmire this for what it is worth. But who ever heard of the immortal friendship of a dozen men? We have never yet got beyond two at a time. David and Jonathan, and Damon and Pythias, are the only two distinguished 
pairs that I can remember. And I know not how it is, but I have seldom found a wide-extending sympathy, except under fortunate circumstances. Great prosperity certainly creates more jealousy than sympathy. Great powers stimulate more ambition than affection. Great adversity begets selfishness. Great opportunities establish all sorts of rivalry. I have found that college classmates wondered how the fellows got along so well, much oftener than they rejoiced over their successes. I have heard a hundred men express pricle that they were in the same class with some distinguished scholar or statesman, where I have heard one rejoice warmly over the eminence which his early companions had reached. I agree that it is a good plan to have 'tears for others' woes,' but I suspect it is more important to have 'patience for my own.' I suppose, however, there is a middle ground somewhere, in which may be found 'neither poverty nor riches,' and in which the sympathetic feelings are kept alive. But, after all, I think man is rather inclined to go alone, - or, perhaps, properly mated." And this last suggestion was dropped in as the Doctor thought of Fanny.

"Not so," said Mr. Howe. "Man is just as gregarious as all the rest of the animals. He may be full of petty passions, - I am sorry to say I think he is : and I am also sorry to be compelled to believe that he feels authorized to ride rough-shod over his rivals and adversaries, and that he is often governed by the most contemptible motives. But still I think he is fond of society, fond of sympathy, fond of friendship; would rather believe all men to be saints and heroes than knaves and cowards; and on the whole has a pretty healthy and generous feeling about his fellow-mortals, unless somebody has diligently poisoned him."

"I know men get together," said the Doctor, "always have got together, and probably always will ; and the more 
they know the better they will like it. I have always wished I could have looked in on the Kit Cat Club, and the Beefsteak Club; but I don't believe there was much affection in this, after all. It was a kind of intellectual ring, - but then it must have been delightful. And then a courteous interest must grow out of such associations if nothing else, and that is worth a grood deal in such a rough world as this. But I have seldom found that in the height of prosperity or in the depths of adversity men paused long to 'rejoice with those who do rejoice, or weep with those who weep.' Anxious and struggling society I look on as a pretty cool place, after all, - a good deal of an ice-house. I am told, for instance, that such a thing as political friendship was never heard of."

"I don't know how that is," said Mr. Howe; "and I never desire to. I shall never forget the way in which poor Ilsley came back on his friend, Thomas; and I, too, am told that the desertion of professed friends is the dark side of political association. All that, I suppose, is a part of the scramble; and well enough, too, perhaps, inasmuch as a man in public life should be compelled to sustain himself on principles and convictions, and not on personal attachment or a mere personal followings. And I have no doubt the same frigid necessity which guides and governs such a man guides and governs all men who are engaged in the hard service of life. Perhaps it is sad that it is so. But I more than half suspect that the attachments of both business and politics are sweet enough to more than counterbalance the wounds inflicted by deserters and time-servers and camp-followers and waiters on Providence.

"I think all this makes it necessary for a man to learn where to draw the line of his friendships. Still, I do believe in the real value of companionship. I like a little town, after all. I likic a club. I have never forgotten one sentence 
of an old English writer, which I read when I was in college :-

". 'When men are knit together by a love of society and not a spirit of faction, and do not meet to censure or annoy those that are absent, but to enjoy one another; when they are thus combined for their own improvement, or for the good of others, or at least to relax themselves from the business of the day by an imnocent and cheerful conversation, there may be something very useful in these little institutions and establishments."

"Yes," said the Doctor, "and they can go beyond this, if they desire, into an intellectual companionship, half thought and half gossip, which might be as refreshing as the loctes Ambrosiance, or the Leges Conriziales of Ben Jonson. But what do you suppose is the reason that women never have clubs?"

"For the same reason that they don't combine for their rights, I suppose," said Mr. Howe; "and I suppose it is fortunate for us that they do not."

"I am glad they don't," said Dr. Parker, as he thought of Fanny combining with anybody but himself.

By this time the two gentlemen had reached the house of Mr. Hopkins, and they entered to find most of the members of the Club already assembled. It is difficult to realize the fact that the leading citizens of a small town like Jotham should only have met casually during the recess of the Club, but so it was. They had encountered each other at the fire; they had sat together as part of a congregation in the meeting-house; they had saluted each other on the road; they had transacted business with each other whenever it had been necessary; but they had not come together as companions and friends. And they met now as young men meet who have reassembled after a college racation, and wonder why it is that they feel such a momentary interest in each other's welfare. Per- 
haps an indifferent observer would have noticed but little change in the appearance of the assembly cluring the period of its separation. But Charles Ingalls saw that Mr. Hopkins had grown older, -- age had evidently touched him; and he saw also that John Thomas had taken on a kinder look, and that Squire Wright was on very confidential terms with Dr. Parker, and that Mr. Howe was unusually corlial to himself. There was a good deal of demonstrative handshaking, and friendly inquiry, and warm congratulation, and mutual admiration, and pleasant compliment to the host and his wood-fire and his cheerful room, before the little rap was given which brought the Club to order.

Mr. Hopkins announced that the subject selected for discussion was

\section{MARKET GARDENING,}

and he proceeded to speak upon it as follows :-

You will remember, Gentlemen, that our last meeting was occupied by a discussion upon the potato, as a crop standing half-way between a field crop and a market-garden crop, and partaking of the nature of both. We now propose to examine the various plants which enter most essentially into the business of gardening, and which require careful and accurate cultivation in order to be produced with any degree of profit. To my mind, this is not only the most remunerative, but the most agreeable branch of farming. The first steps in its operations being taken long before the sun has reached the remal equinox, it seems to remind us of the approaching mildness which is to take the place of the hard and cheerless days of winter. I never see the preparations for my hotbeds going on without feeling a pleasing assurance that winter is really passing away, and that the toil of summer has begun; and you all know that to thorough and profitable market gardening a cold-frame or hotbed belongs. By the last of February this work should begin. If the frame, 
which may be conomically made of rough planks set edgewise into a pit or trench about four feet wide and two feet deep, and cirried above the edge of the trench about eighteen inches, has been open during the winter, place the sashes into the frames for a few days for the purpose of thawing the earth beneath. This having been clone, remove the heating manure of list year, and fill the trench with horse-manure and leaves well heated in a compost-heap at the time of using. Pack the manure as firmly as possible in the trench, and cover it with six or seven inches of fine rich loam. Put on your sashes, and in a sunny day or two the bed will be in condition to receive the seed. The beds should face to the south, and should be protected in the rear by a light board fence. Straw mats made in frames which can be raised and lowered on hinges should be used to cover the sash, in order to protect the bed from the chill of night and cold diys, and from the too great heat of the sun, as the season advances. A bed like this every farmer should have who intends to supply the market with early vegetables; and as a matter of taste and pleasure I will defy any man to show me a warmer and more cheerful spot on an early spring day than the sumny side of a hotbed, with the timid and unseasonable vegetation just starting under its encouraging influences.

These beds may he used merely to start the plants for early transplanting, or, skilfully managed, they may be occupied with a permanent crop which is to be brought to early maturity. Large quantities of lettuce and cucumbers are raised in this way, and are brought to a full growth long before it would be safe to remove them from the protection of the glass. But if not deroted to such permanent cultiration as this, they may be employed to furnish early plants of lettuce, tomatoes, cabbages, egrg-plants, celery, cauliflower, etc., which require this preliminary aid in order to be grown in good season.

The hotbed, then, is a most useful structure to be employed in this branch of farming, and next to it in point of usefulness stancls the manure-heap. Profitable crops for the market cannot be raised without an abundance of manure ; and in preparing the compost-heap for this purpose every variety of fertilizing 
material should be used which the various crops may demand, -for the Brassicuceous plants, such as the cabbage, cauliflower, kohl-rabi, and brocoli, nitrogeneous manures; for leguminous plants, such as peas and beans, a liberal supply of well-rotted phosphatic manures. In orcler to illustrate the importance of manure and enough of it in this work, I will read what Henderson so well says on this point. He says: "It is a grave blunder to attempt to grow vegetable crops without the use of manures of the various kinds in about the proportions I have named.

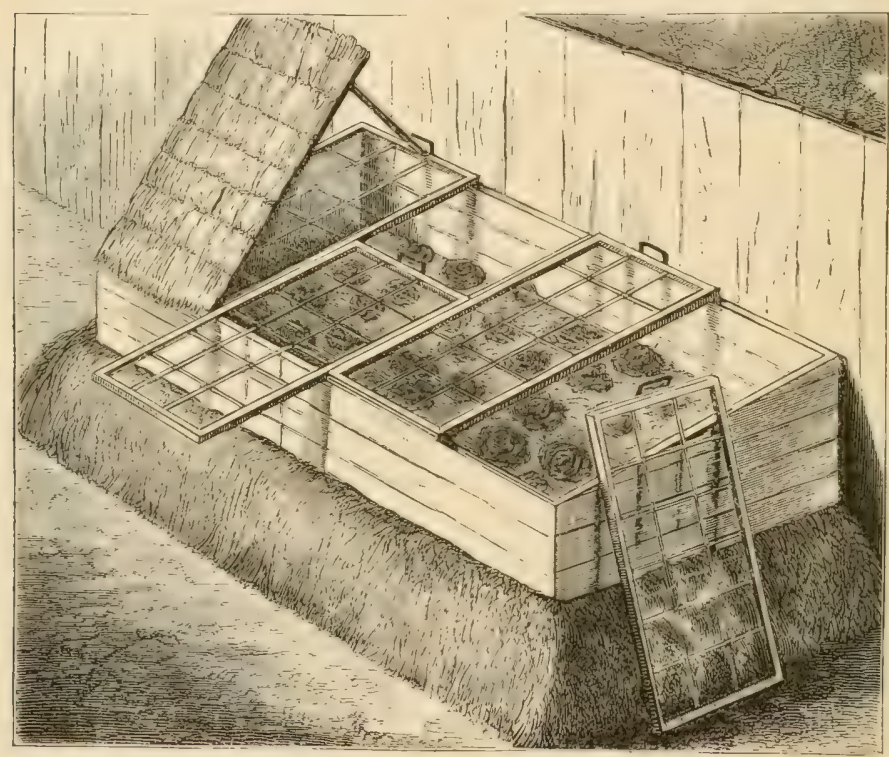

A HOTBED.

I never yet saw soil of any kind that had borne a crop of vegetables that would produce a good crop the next year without the use of manure, no matter how rich the soil may be thought to be. An illustration of this came uncler my observation last season: one of my neighbors, a market-gardener of twenty years' experience, and whose grounds have always been a model of productiveness, had it in prospect to run a sixty-feet street 
through his gromels. Thinking his land sufficiently rich to carry through a crop of cablages without manure, he thought it useless to waste moncy by using guano on that portion where the street was to run, but on each side sowed guano at the rate of twelve hundred pounds per acre, and planted the whole with early cabbages. The effect was the most marked I ever saw,that portion upon which guano had been used selling off readily at twelve dollars per hundred, or about fourteen hundred dollars per acre, the other hardly averaged three dollars per hundred. The street occupied fully an acre of ground, so that my friend actually lost over $\$ 1000$ in crop by withholding $\$ 60$ for manure."

Hotbecls, manure, industry, and skill are what the marketgarclener needs, - always including propitious weither and a favorable market. Of the various crops which are most profitably raised I would leave each farmer to judge for himself ; for I have always found that every good cultivator seems to have some one crop to the cultivation of which he is especially adapted. Let him stick to this.

"And yet," said John Thomas, "the list of crops which belong directly or indirectly to this business of marketgardening is very long, longer a good deal than Ben Tyler's list of his boys. Why, to begin with, there are beets, carrots, turnips, parsnips, radishes, lettuce, celery, asparagus, tomatoes, peppers, rhubarb, sweet corn, peas, beans, squashes, melons, cucumbers, cabbages, onions, thyme, summer savory, sage, sweet marjoram, and Heaven knows how many more. There is a certain degree of similarity of cultivation belonging to all these, such as a good, fertile, well-manured, well-pulverized, clean soil. But I suppose we ought to deal with each one of these which I have enumerated, and others in proper order, for the perfection at least of our discussion, if not for our own edification. If the Club will excuse me, I will begin with those to the cultivation of which I am most accustomed. 


\section{THE ONION.}

"I have raised onions, more or less, for many years. I always select for them a warm, mellow, loamy soil; and I use the same plot of ground for this crop year after year. The manure which I have used largely is mussel-bed, or kelp composted with manure, if I could procure it cheaply from the seaside. If I could not, I have resorted to barnyard manure and night-soil, well decomposed and mixed. I have used of this ten or twelve cords to the acre to advantage. I prepare the land as early in spring as possible, ploughing deeply and raking into a smooth and even surface. I sow the seed, also, as early as possible, using about three pounds to the acre. I sow in rows, with a seed-sower, about fifteen inches apart and half an inch deep. Great care should be taken to keep the crop free from weeds from the beginning. The young plants, once choked, never fully recover. Repeated hoeings during the early part of the season with a common wheel-hoe are also very beneficial, though great care should be taken not to pile up the earth about the growing bulbs. The plants should be thinned to about two inches apart in the rows. An onion crop grows rapidly, and reaches maturity about the first of September. It may then be gathered, if the tops are completely dead and dry, with a common gardenrake; and the windrows into which they are gathered should be dried for a few days on the ground before being taken into shelter. As a general rule, an carly sale of the crop is the wisest. The fluctuations in the market are great. The crop is liable to decay if packed in barrels and stored, and it is impossible to move it with safety in the cold, hard weather of winter. Of the best varieties, it is claimed that from five hundred to a thousand bushels may be raised to the acre. I have raised eight hundred and fifty myself, and Peter Ilsley claimed, before he died, 
that year before last he raised nine hundred and seventyfive.

"It may be well to know how I raise my seed; for I always raise my own, being unwilling to depend upon the seedsmen, who often charge exorbitant prices, and do not always furnish that which is reliable. I always select my largest, ripest and best-shaped bulbs; keep them with great care during the winter, and in April, if the weather and soil permit, I plant them in rows two fiet and a half apart, and about nine inches from each other in the rows. It may be necessary to support the stalks as the heads grow and increase in weight. The heads should be gathered in August, as soon as they turn brown; and the seed, after being threshed out, should be thoroughly dried in the sun to prevent its heating and losing its vitality.

"The varieties which I have found to be the best are the Yellow, the Silver-skin, the Large Red, and the Danvers. The last is a globular onion, the result, as I have been told, of a careful selection of bulbs for seeds by the farmers of that town, which has for many years been famous for this crop. It is a free grower, and yields a great crop; but it is said to be better adapted to the home market than for transportation, from its liability to heat on account of its size and its softer consistency.

"Of course the fly threatens to destroy my crop every year, as it does that of all the rest of you. And I am tormented by stumpy necks, as everybody is. The remedy for these evils I have not yet discovered, although I do think in these, as in other difficulties with our crops, good cultivation and vigorous plants may generally be relied on as the best preventive to what cannot easily be cured."

"I think onions are a very risky crop," said Ben Adams. "You are exposed to all sorts of destruction: if the crop is small, you can never make up the loss; if it is large, you are very apt to find a heavy market; if you cannot 
sell it, you can do nothing with it; neither cattle nor horses nor sheep nor swine will eat it; and on the whole I think it is about like the tobacco crop; if it sells well, you are prosperous and happy; if it does not, you are of all men most miserable."

"But," said John Thomas, "a great many men have made a good deal of money raising onions; and I am willing to take a small risk every year. I must confess, however, I like to raise crops which I can feed to my cattle, if I camnot find a market for them in any other way. And now let me call your attention to

\section{THE CABBAGE.}

"Cabbages are a favorite crop with me. They usually sell well, are easily cultivated, and are valuable as food for cattle in case the market is not remunerative. Not that I would raise them for cattle as some recommend, for I can use my land for this much more profitably with Swedes or mangolds. But there is no necessity for wasting cabbages if you are obliged to keep them on hand, and hence I like them. My early cabbages I always start in a hotbed and transplant; my late crop I always raise from seed planted in the hill.

"Cabbages require a strong, heavy, clayey land, warmed by an abundance of nitrogeneous manures. Night-soil is very useful in cultivating this crop. At any rate, whatever manure you use do not use it sparingly. It is a good plan to apply ashes either to the plant when transplanted or when it first starts in the hill, as a terror to the maggot, which is always threatening the life of the young cabbage. I have found it necessary to change my soil each year for this crop. Whenever I have raised it two successive years on the same land I have found that it was in danger of being stump-footed. I seldom raise my seed, but always 
get that which is raised in America and by the most reliable men.

"The profit of a cabbage crop is often great. I have sold the late varieties, such as the Champion of America, the Marblehead Mammoth Drumbead, the Stonc-Mason, and others, standing in the field, to be gathered and hauled by the purchaser, for two hundred and ninety dollars an acre; and on this a fair profit was made. With the carly varieties, such as the Early York, the Early Wakeficld, and the Early Nonpareil, much larger profits can be made if they are brought early to the market.

"There are so many varieties of cabbage that it seems as if cultivators had taxed their ingenuity to produce as many as possible. For myself, I prefer the Early York for one end of the season and the Marblebead Mammoth Drumhead for the other.

\section{THE CAULIFLOIVER.}

"In the line of the cabbage I have endeavored to cultivate the cauliflower, but not with great success. What the difficulty is I cannot tell. I have often suspected that I did not select my land well. I once got a good crop on land that had not been long under cultivation, and which was deep, rich, and strong. That the most stimulating manures should be used there is no doubt. It is said that lime and sulphur are very valuable fertilizers for this crop, and that salt combined with the manure is very beneficial. It undoubtedly requires the same kind of fertilization as the cabbage, perhaps more liberally applied.

"The cauliffower should be sown in a hotbed early in March, and transplanted into favorable soil and under favorable circumstances late in May. If the weather is dry, the plants should be liberally watered in order to produce a large and well-developed head. The plants should 
be set in rows like the cabbage and cultivated in the same manner. The crop is an uncertain one, but is highly remunerative when it succeeds.

"The plants are fit for the table in October, and they may be kept for early winter by hanging them in a dry cellar with the heads downwards, or for later winter by taking them up in the fall with an abundance of earth and roots, and resetting them in the cellar, or in an outbuilding where they will be safe from frost. In this way they can be kept long into the winter.

"The varieties of the cauliflower are numcrous, and among the best stand the Wellington and the large Adriatic."

"Mr. President," said Phineas Barnes, "I have listened with great pleasure to $\mathrm{Mr}$. Thomas's descriptions of these market-garden crops, which he knows so much about, and I move that the subject of Market Gardening be referred to him and Charles Ingalls as a committee, with instructions to report on the remaining crops as fast as possible at future meetings."

The motion was unanimously carried, and the Club adjourned. As the members separated, Mr. Howe quietly asked Mr. Hopkins if he did not think Dr. Parker had quite abandoned his bad habits. "He has never appeared so well to me as he now does," said the minister. "I am sure he has had a change of heart, and I am half inclined to think that Squire Wright has had a hand in it, from the air of intimacy which envelops them."

"I think you are right about the Doctor," said Mr. Hopkins; "but whether the work has been done by the Squire or the Squire's heifer, with which he seems to be ploughing, I cannot tell."

"What!" said the minister, "another lamb in trouble?" And he rushed home to confer with Mrs. Howe. 


\section{TWENTY-FIFTH MEETING.}

\section{MARKET GARDENING (Continued).}

CHARLES INGALLS AS A LAWYER. - CLASSICAL SKETCH OF PERFIDY. - JOHN THOMAS BEWILDERED.

THE day after the last meeting of the Club John Thomas, upon whom devolved the work of discussing the many remaining crops which belong to the business of market gardening, finished his morning's work as rapidly as possible, and sought out Charles Ingalls as the most competent person in town to aid him in his investigations. He found Charles deep in his books in Squire Wright's office, occupying the green old roundabout chair which had been for so many years the Squire's throne. Charles was now both student and practitioner. His old teacher had begun to withdraw from the business of the office, and merely resorted thither an hour or two in the morning for the purpose of hearing the news, or attending to his own private duties. It had already been discovered that Squire Ingalls, as many of the litigants had begun to call him, had shrewdness and good judgment enough to make him a good counsellor, and knowledge enough of law to make him a safe adviser. He preserved, moreover, the original condition of the office unimpaired and unchanged, - and this was set down largely to his credit by those who had become familiar with its dusty and dingy precincts. And it was observed by the old habitués of that office and the county courts, that many of those cases which had remained on the docket for years and had become important parts of the legal history of the Commonwealth were 
readily managed by the young squire; that he had, with quick instinct, adopted the ways of the old one; and that his application of the law was the same. Charles did learn with great rapidity. His mind grasped with great power the general principles of the law, and recognizing it as a "solemn expression of the legislative will," he read Blackstone with the avidity of a novel-reader, and grew as familiar with Justinian and Grotius and Mansfield as he was with the Constitution of the United States and with the judges and lawyers whom he met in the court-house. His perceptions were keen, his comprehension great, his memory tenacious. He had also an honest mind, - a mind which no tempting sophistry could mislead, and whose clear understanding enabled him to clothe his thoughts in unmistakable language, and enabled him also to discover the truth and consistently adhere to it; a mind promptly obedient to the best sentiments, and strong cnough to maintain a position once taken. The persons who came to the office for advice were not long in discovering the remarkable powers of this young man, and they soon learned to accept his opinion in the adjustment of their controversies and to rely upon his law as their best guide. And not his intellectual and moral qualities alone secured their confidence. His mien and bearing were such that those who approached him were filled with respect. He was just now entering on a somewhat premature mental and physical maturity, - a maturity which had been hastened by the necessities and responsibilities and labors of his early life. To all, his appearance was engaging. His face, which when he first came to Jotham as a schoolmaster was a trifle too sharp and pale to indicate power, and formed too strong a contrast to the dark and heavy luxuriance of hair which crowned his smooth and ample brow, had become fuller and more ruddy, while his chin had grown firmer, his mouth more resolute, his nose more 
prominent and vital, and his eye calmer and more penetrating. He was six feet in height, with strong and wellformed limbs, and a chest which indicated grcat powcr and endurance. No young man could be better proportioned than he. His carriage was erect, firm, and casy; and he presented a specimen of manly beauty rarely seen in these later days of heated and exhausting civilization. The tones of his voice were strong and melodious, and admirably adapted to convey, in all the variety required by persuasive oratory, the well-matured thoughts which he always endeavored to clothe with the simplest and most appropriate language, and to adorn with the most natural imagery. The people began to foretell a great career for him as he developed before them day by day, and there were mingled desires and expectations, spontaneously formed, that he would avoid all the temptations of narrow official position, and accept only that service in which his powers might find their highest development, and his life might be commanding and useful. They hoped and expected that he would at any rate rely on himself and not lean upon others.

When John Thomas entered the office he found Charles busily engaged in studying the law of contracts, and so absorbed was he in his endeavors to establish in his mind the true distinctions between express and implied obligations of this sort, that he began to doubt whether a contract was really a concurrence of mincls in reference to any given object, and not an attempt to conceal a natural divergence for the sake of a mere temporary understanding. As he lifted his eyes from his book he felt a sudden sense of relief at fincling so trustworthy and honest and sensible a companion as John before him.

"My dear old friend, how do you do?" said he. "Sit down and tell me, if you can, why men can't do as they agree to in this world." 
Mr. Thomas had no answer ready. His mind was full of the arrangements of the Club, and he had nothing to say on either law or philosophy. "Don't know?" said Charles. "IVell, I am satisfied one half fail from ignorance and the other half from wickedness. The hardest work in this world is to make men understand each other, - next to making yourself understood. What language was intended for I can hardly conceive. State a proposition to your neighbor to-day, and he will understand it just the other way to-morrow. Write it down, and he will read it just as you do not. And so I am obliged to pore over page after page of most tedious matter, to find law enough to compel men to keep their engagements. Stupidity and subterfuge make great mischief. Evasion through wit and evasion through ignorance cause one half the trouble in life. I shall never forget how well an old Secretary of the Treasury, steeped in old-fashioned classics, stated it, when called upon to give his opinion of the treaty between the United States and the Netherlands relating to a drawback on coffee. He says: 'Equivocation and subtilty to evade the spirit and intent of a treaty is odious and justly condemned by all civilized nations. The cxamples of Mahomet, Emperor of the Turks, who promised a man at the siege of Negropont to spare his head, yet afterwards caused him to be cut into two parts through the middle of the body, and of Tamerlane, who at the siege of Sebaskia induced the city to capitulate upon his promise to shed no blood, yet caused all the soldiers of the garrison to be buried alive, were gross subterfuges which, as observed by Cicero, aggravated the fraud, but did not absolve the perfidy. The spirit of a treaty is to be observed rather than adhering to the letter. Therefore the actings of the Roman general, Q. Fabius Fabes, who agreed with Antiochus to restore him half of his fleet, yet caused each of the ships before the delivery to be sawed in 
two; and of Cleomenes, who, having concluded a truce for a certain number of days with the people of Argos, and finding them on the third night asleep, in reliance upon the faith of the treaty, fell upon them, killed a part and made the rest prisoners, under pretenee that nights were not comprehended in the time, - have been stigmatized as scandalous subterfuges and breaches of good faith : and well they might be.' And yet the world is full of Mahomets and Tamerlanes and Fabii and Cleomeneses and contractors and violators and knaves and fools. Don't you think so, Mr. Thomas?"

John Thomas stared and made no answer. He was unprepared for such an outpouring of letters and indignation from Charles Ingalls, whom he had always taken for the mildest of young men; and he attributed much of his excitement to the excessive application of the young law student to his books. He recalled no glaring breach of faith in the town; and as he never allowed himself to be excited over any imaginary evil, he could not understand how Charles could possibly have talked himself into so much feeling over the weakness and folly of mankind in general, simply because legal ingenuity exhausted itself in the work of controlling it. And so he said nothing.

Charles soon recovered, and brought himself back to the realities of life before him. "It was a good piece of grandiloquence, though, in the fine old secretary, as he considered the treaty and the coffee-bags, was n't it, Mr. 'Thomas?"

"I have no doubt it was," said John. "And, now you have put me in mind of it, I am afraid that an inability to do as we agree is man's besetting weakness, and an unwillingness to do so is man's besetting sin. But we blunder a good deal in this world, Charles, and I always have this consolation, that so long as we can pay a minister to tell us what we ought to do, and a lawyer to tell us what we 
will be allowed to do, the world will get along pretty well ; and every man will have a chance to get a living, notwithstanding the confusion created by our blunders and mistakes, and our folly and stupidity."

Charles looked a moment at John Thomas, and quietly said, "I do like a man who never gets tangled up."

"I called," said John, "to see about the Club, and not about contracts or what you call classics. I want to finish up Market Gardening at the next meeting; and I thought you might be willing to help me in going through the long list of vergetables which belong to this business. If we could only meet here some evening I think we might get along very well."

To this Charles agreed, and the next evening the two investigators drew up to the old office table, each provided with a tallow-dip, having closed the shutters, replenished the fire, and looked around the dimly lighted room with a sense of veneration for the ancient wisdom which was gathered within its walls; and seated there they continued their work on Market Gardening.

"Gentlemen," said Mr. Hopkins, as he called the Club to order on the evening appointed for its next meeting, "I ask you to give your attention to the paper which has been prepared by $\mathrm{Mr}$. Thomas, on the crops belonging to the market-garden and the proper mode of cultivating them."

"The statement which the young squire and I have prepared," said John Thomas, "is as short as we could make it; and I hope it covers the whole ground. I will read it."

\section{MARKET GARDENING.}

Mr. Presinent, - In continuing the discussion of Market Gardening, I have concluded to consider the following important crops, namely :- 
Asparagris. - It is raised from seed; sown in the antumn or very early spring, in drills fourteen inches apart. 'Thin out the plants to about four inches; cultivate them well, and cover them lightly in winter with straw. Transplant these roots when they are two years old into a deep, rich, warm soil, avoiding a clay subsoil if possible. Trench the ground before transplanting, two feet and a half in depth, and mix with it liberally an abundance of well-decomposed manure and salt. Lay out the land in beds, and set the roots in trenches dug deep enough to cover the crown of the plant three inches below the surface of the soil when the trench is filled. Set the plants one foot apart each way. When the plants are set be careful to spread the roots out thoroughly over the soil. Keep the bed free from weeds, cut down the tops in the autumn, and cover the beds with two or three inches of well-composted manure. Rale orer the becls early in the next spring, being careful not to disturb the roots, and treat the plants in every way just as you did the year previous. Follow the same plan the third year, and on the fourth year you can cut freely from the beds. Enrich your asparagusbed every autumn with loam mixed with a good supply of we'lrotted manure, and salt to the amount of three quarts to a square rol. The best time to cut asparagus is when the plants are about four inches abore the ground. Begin cutting as early as you please, and cease cutting on the 2 oth of June.

There are many good varieties of asparagus, all worthy of cultivation; and so worthy that a proper selection of soil is found to be more important than a choice of plants; the same variety growing in one locality tough and slender, and in another large, tender, and succulent.

Celir. - Celery has become one of the most profitable of all garden regetables. It is propagated by seed, sown in a hotbed in March, on well-pulverized soil, and covered very thinly near the surface, which may be pressed smooth with the back of a spade. When the plants are three inches high transplant them into a bed well enriched and worked very fine, where they should be allowed to grow until the middle of July, when they should be again transplanted into trenches fifteen inches deep and a 
foot wide, laying the trenches five feet apart and piling the earth compactly between them. Supply the trench with a good quantity of well-rotted manure, without which the celery will not flourish. As the plants grow up, fill in the earth around the stems for the purpose of blanching them, keeping "the stalks of the outside leares close up, to prevent the earth getting between the stems of the outside leaves and the inner ones; for if it does this it will check the growth of the plant. Keep the plants well earthed up as they grow ; and by the beginning of October they will be fit for use."

"Some allow the plants to make a natural growth," says Burr, "and earth up at once, about three weeks before being required for use. When so treated the stalks are of remarkable whiteness, crisp and tender, and less liable to russet-brown spots than when the plants are blanched by the more common method."

When the crop is gathered it should be packed in the cellar in moist sand, without covering the ends of the leaves.

The best variety for general use is undoubtedly the Boston Market.

Littuce is largely cultivated, and is extensively used in almost every market and in almost every season of the year. It is a hardy plant, grows easily on soil adapted to it, and comes to perfection equally well under glass and in the open air. It grows most luxuriantly in rich, strong soil, and during the cooler months of summer. A light, gravelly soil is wholly unfit for it ; and the warmer and richer the soil the larger and more tender will the heads become. The seeds should be sown in a hotbed for the earliest plants, and in the open air as early as March and early April, in well-pulverized soil, and covered not more than a quarter of an inch; it can also be sown for successive crops until September. It can be sown broadcast or in clrills, as is most convenient. The plants should be transplanted when two or three inches high; and if in a hotbed, they should be frequently watered, and the glass should be covered with matting during the cold and frosty nights. They should be set about ten inches apart, if a large, well-formed head is desired. 
Of all the varieties the Green Curled is undoubtedly the best. of the small early varicties the best are the Hardy-Hammersmith and the Early Curled Simpson.

Lettuce is, when properly cultivated, one of the most profitable crops riised; and, as a salad-plant, is so healthful that no well-ordered farm should be without it.

Cucumbers undoubtedly stand next to lettuce in profit as a hotbed product or as an open-air crop. The plant is tender and delicate, the growth of tropical climes. It grows best on warm, light, rich, loamy land, without clay, and in warm and dry weather. If raised in a greenhouse, as cucumbers often are for a very early market, they can be planted in early winter; if in the open air, they should not be planted until the ground is warm and the weather is beyond the danger of frost. The hills in which the seeds are planted should be a foot and a half in diameter and a foot deep, and filled with well-rotted manure to within four inches of the top, and then with three or four inches of warm, rich loam. In the hill thus prepared the seeds, about twenty in number, should be sown and covered firmly about half an inch deep. When the plants have become strong and the time for bugs and worms is over, thin out the plants to about four in the hill. The fruit should all be gathered as soon as it reaches a suitable size, if you would preserve the productiveness of the vines. To raise cucumbers for pickling, select warm, rich land, prepare it well, and plant the seed about the last of June. These should also be picked as soon as they have reached the proper size, if you would preserve the productiveness of the vine also. The yield is very great, as many as a hundred and twenty-five thousand being sometimes grown on an acre.

The best variety for table use is undoubtedly the Early Frame. The White-Spined is also very good.

The Squash is a valuable field or garden crop. It should be planted when the land is warm and the weather is beyond the danger of frost. The land should be a warm, rich loam, the hills should be eight inches deep and two feet in diameter, and filled within three inches of the top with well-rotted manure, 
which should be covered with about four inches of fine, warm loam. Plant about a dozen seeds in the hill, and if the variety has a running vine place the hills about six feet apart. Leave three good plants in a hill. The squash should not be twice raised on the same land, but should be changed each year to aroid the striped bug and cut-worm. For the striped bug the remedy is slacked lime sifted on the vines at noond.ı, with a common bale-basket. For the cut-worm the remedy is as yet unknown.

Squashes degenerate rapidly. The best varieties are: for summer the Bush Summer Warted Crookneck, the Early Yellow Bush Scalloped and the Early White Bush Scalloped ; for autumn and winter, the Autumnal Marrow, the Canada Crookneck, the Hubbard, the Turban, and the Winter Crookneck. It is usually an uncertain crop, and does not always find a ready market.

The Nilun. - The cultivation of the melon is very much like that of the squash, the same quality of soil being required for both, and the preparation of the hills being the same.

'The varieties of muskmelons which are entitled to consideration are the Early Cantaloupe, the Black Rock Cantaloupe, Monro's Green Flesh, and the Nutmeg. The long, yellow muskmelon is hardly worth raising. The best varieties of watermelons are the Carolina, the Black Spanish, which matures early in the northern latitudes, and the Mountain Sweet, a.variety especially adapted to the Middle States.

The Tomato is raised from seeds planted in a hotbed in March, - the plants to be set as early in May as possible. Burr tells us that the French mode of raising tomatoes is as follows: "As soon as a cluster of flowers is visible, they top the stem down to the cluster, so that the flowers terminate the stem. The effect is that the sap is immediately impelled into the two buds next below the cluster, which soon push strongly and produce another cluster of flowers each. When these are visible, the branch to which they belong is also topped down to their level; and this is done five times successively. By this means the plants become stout dwarf bushes, not above eighteen inches high. In order to prevent their falling over, sticks or 
strings are stretched horizontally along the rows, so as to keep the plants erect. In addition to this, all laterals that have no flowers, and, after the fifth topping, all laterals whatever are nipped off. In this way the ripe sap is directed into the fruit, which acquires a beauty, size, and excellence unattininable by other means.

There are many varieties, all good except the white and yellow.

R/ubarl, a hardy perennial plant, has become very common as a profitable market-garden product. It is propagated by a division of the roots, and grows best in a deep, rich, strong soil.

The plants should be set in row's five feet apart, and three feet apart in the rows. "For the first year the ground between the rows may be cropped with lettuce, turnips, beans, or similar low-growing crops; but after the s-cond year the leaves will cover the whole space, and require it also for their full development."

Keep the soil clear and well manured, and break down the flower-stalks as soon as they are formed.

In gathering the crop break the leaf-stems off clear to the base, as cutting leaves the stalk in a condition for a free flow of the sap.

This plant is sometimes blanched, but this is done at the expense of its quality and flavor.

The best variety is the Early Prince Imperial.

The Pea is a very common crop, but it is not always well grown; in fact, it is considered so common and so easy to raise, that it is often injured by neglect. It should be planted in light, rich soil, about three and a half inches below the surface, in rows, and manured with well-rotted manure, composted if possible with leaf mould. Warm and stimulating fertilizers, such as guano or hen-manure, may be advantageously added to the compost. For all the dwarf varieties the soil should be lil)erally enriched. The rows should be about two and a half feet apart. Sometimes they are planted in double rows twelre inches apart, and when so planted all the dwarf varieties will support each other. But when the taller varieties are grown 
a greater yield will be secured by sticking the plants, which should be done when they are three or four inches high. The sticks should be in the form of a neat, well-trimmed bush. When peas are hoed, the earth should be drawn up about the roots.

Peas are liable to mildew, and on this point Knight says: "The secondary and immediate cause of this clisease is want of a sufficient supply of moisture from the soil, with excess of humidity in the air, particularly if the plants be exposed to a temperature below that to which they have been accustomed. If damp and cloudy weather succeed that which has been warm and bright, without the intervention of sufficient rain to moisten the ground to some depth, the crop is generally much injured by mildew." Plentiful watering is said to prevent this disease. Sulphur is said to cure it. The varicties of peas are almost innumerable. The Dan O'Rourke and Dwarf Marrow are good enough for the small varieties, and the Champion of England and the Marrowfat for the large varieties. But you can hardly go amiss, and it may be an amusement to change the variety each succeeding year.

The $B a m$ is one of the best esculents grown. It is thrifty and prolific, and when used in the pod is very palatable, and when shelled is highly nutritious. It should not be planted until the weather is warm, as it is very liable to be injured by the frost. Plant the dwarf varieties in drills, placing the drills about eighteen inches apart, and the seed about four inches apart in the drills. Plant the running varicties in hills three fect apart one way and two feet the other, leaving four plants in a hill, unless the plants are small, when you can double the number. The soil should be warm, rich, and well manured.

You can plant the Bagnolet for a string-bean, and for a shelled dwarf bean the Dwarf Horticultural, the Golden Cranberry, the Mohawk, and White's Farly; and for a shelled pole-bean, the Horticultural, the Mottled Case-knife, the Red Cranberry, and almost any one of the twenty varieties which the seedsmen like to sell.

Beans, whether dwarf or pole, or white or turtle, or string or 
shelled, are a profitable crop, and so nutritious that no farm should be without them.

The Turnip, although a plant easily cultivated, is especially sensitive with regard to the soil on which it grows. I warm, light, sunny loam, entirely free from clay, is best suiterl to its growth; and the manure used in its cultivation should be well rotted and composted with a warm loam. The use of nitrogencous manures, such as night-soil and green barn-yard manure, is apt to make the root tough and corky, and rough on the surface. The turnip should be sown as early as the ground is ready to receive it. The early part of the season is best adipted to its growth, and the great and chief profit in this crop is ob. tained by supplying an early market. The seed should lue sown in rows about fifteen inches ap.ırt, and the plants my be allowed to stand pretty thickly in the rows, proximity not appe.r. ing to injure them at all. 'Turnips, both spring sown and fall sown, are easily and somewhat roughly cultivated. An excess of hard labor upon them is therefore wasted. They can be gathered as they are required, either for market or the table, until the first of November, when they should be harvested and stored.

The garden turnip is usually one of the flat varieties, such as the early flat Dutch, the Golden Ball, the Green-top Filat, and the Purple-top Strap-leaved. The flesh of the best table varieties is white. 'The long varieties, such as the Cow-Horn, are not so delicate in their flavor, and are more useful as a fall crop, to be sown after early peas and potatoes, and fed to cattle during the winter. I am not sure that the Cow-Horn is not as profitable a crop as the Sivede.

T'ice Bict. - The table beet, commonly known as the Red Beet, requires a soil somewhat like that which is favorable to the growth of the tumip, except that a mingling of cling is generally beneficial. The fertilizers which the beet requires also differ from those needed by the turnip. Strong, well-rotted manure, in which there is a reasonable admixture of salt and portion of night-soil gives a good growth to the beet. It feeds well on nitrogen.

The beet can well be sown in the autumn for an early spring 
crop; and for summer and autumn use they should be sown as early in May as possible. The seed of the bect does not germinate readily, and great care should be taken in the sowing. Some cultivators soak the seed in warm water twenty-four hours before sowing, but I doubt the benefit of this process.

Beets should always be harvested before they are touched by the frost. They will, if properly harvested and prop rly stored, retain their sweetness through the entire winter. Medium-sized roots rapidly grown are the best for table use.

The varielies of the beet are numerous; the best early varieties being Cattell's Dwarf Blood, Early Flat Bassano, Early Llood Turnip-rooted, and the Half-long klood for a later variety.

The Club will bear in mind that in considering the beet and turnip as a market-garden crop, I have not included the rutabaga or Swede, nor the mangel-wurzel, which are field crops alone, and are intended for an entirely different purpose.

The Carrot. - The carrot is a moderately valuable root, whether in the field or in the garden. It flourishes well in a warm, light, deeply-tilled loam, well enriched with thoroughly decomposed barn-yard manure. The ground shou'd be well prepared, finely worked, and raked smooth before sowilg. The seed should be sown in rows about fifteen inches apart, and the crop should be kept clean from the start. The carrot should be harvested before it is touched by the frost, and when kept for table use it should be packed in sand in the cellar. As I do not believe in it as a field crop for cattle and horses, I shall consider it as a market-garden crop alone. The best varieties are the Early Horn, the Early Half Long Scarlet, and the Early Frame. The larger varietics are apt to be coarse and fibrous.

The Parsnip is rapidly coming into more general use than formerly. It is not an easy root to cultivate, and it should be sown in early spring in warm, rich, deep land. It will not grow well in gravelly, shallow, or clayey soil. This crop is unfit for use until late in th: autumn, and is vastly improved as an article of food for the table by being allowed to remain in the earth all winter. Parsnips are apt to wilt in the cellar if placed there in the autumn. They may, however, be packed in sand in the 
spring, and kept fresh and firm until late in June. The parsinip is a luxury, but it is one which every farmer can afford to cultivate.

I have considered the principal crops which enter into the business of market gardening, and which, if not essential in all cases to the farmer's business, are at least uscful for his table. A long list might be added, I am aware, such as the Artichoke, Cress, Curasin, Oyster-plant, Chickory, Chive, Colewort, sweet Corn, which is grown as a field crop, Egg-plant, Endives, Fennel, Garlic, Lavender, Leek, Radishes, Nushrooms, Nasturtiums, Okra, Parsley, Peppers, Martyneas, Gherkins, Sage, Spinach, Sweet Marjoram, Thyme, Summer Sarory, and many others which may be cultivated as a matter of taste, and sometimes, under fortunate circumstances, as a matter of profit. I have dealt with the most important crops, and I now leave the subject for general discussion.

The elaborate discourse of John Thomas was followed by some interesting talk upon the minor cletails of market gardening, in which the members of the Club related some interesting experiences in the cultivation of unusual crops, and the profit often derived from an accidental market. The meeting adjourned at a late hour.

As the gentlemen passed out, after bidding Mr. Hopkins good night, Charles Ingalls joined John Thomas, and strolled along toward home with him, their paths lying in the same direction. As they walked on, Charles returned to their old discussion of man's fidelity and reliability. "I think," said he, "I was a little severe on human nature when we last met. On reflection, I have come to the conclusion that the intricacies of artificial life, of state and of society, of property and of education, are a little too much for man who has made them. I am disposed to think, after all, man is more overloaded than vicious, especially since-I talked with Clara about it."

"I don't know but you are right," said John Thomas, thoughtfully. And they parted. 


\section{TWENTY-SIXTH MEETING.}

\section{SUPERSTITIONS AND CRANBERRIES.}

CHARLES INGALLS PUTS UP HIS SIGN ON FRIDAY. - ITS REMOVAL. - A LONG LIST OF SUPERSTITIONS. - JOE DOLE DOES THE BUSINESS.

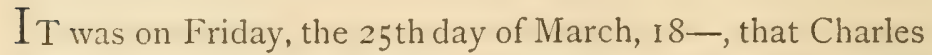
Ingalls put up his sign as "Attorney at Law," beneath that of Squire Wright, on the front door of the little office in the village of Jotham. He had progressed so rapidly in his profession that the neighborhood had already, by common consent, installed him in the position of legal adviser; and by the same consent he had been admitted to the bar, in the county court, where, without much formality, his attainments were considered of more importance than the time which he had spent in his law studies. The people knew no reason why he should longer delay entering formally into his profession, and the lawyers who examined him could find none. Squire Wright, too, was quite willing to encourage the premature operation; and when it was over, he was also quite willing to establish the young lawyer in his own office, and to allow the name of "CHARLES Ingalls, Attorney at Law," to be placed beneath his own, which had adorned the walls of the primitive building for so many years. There was but little consultation between the old Squire and the young one with regard to the terms upon which they should enjoy the joint occupancy of the office, and none whatever on the time when the public announcement of the fact should be made by the plainly lettered sign on the front of the building. 
Charles Ingalls had risen early on the eventful morning, and before the people of the village were stirring, he had nailed his name to the wall, and was diligently engaged in examining a case which had been placed in his hands the day before. Of course he expected the congratulations of his friends on this first step on the real highway of life. But in this he was doomed to disappointment. One after another they came in, "passed the time of day," attended to their business and departed, without an allusion to the important event. It was evident to him that they were perfectly aware of the public announcement that he was a lawyer in good standing, and an associate with the best of the fraternity; but it was also evident that they were determined to say nothing about it, and that they entertained moreover a feeling of doubt with regard to the result. He grew perplexed and disappointed as the day wore on; and he began to feel that nothing was so effectual to harden the heart of man as the prosperity of his fellows. It was nearly noon when Squire Wright made his daily call at the office. He entered with a busy and somewhat nervous air, stood a few minutes before the fire, examined an old file of letters with apparent interest, walked to the window and looked out, and inquired of Charles how he was getting on with his case. He clid not seem to be much interested in the answer, and he did not wait to receive it; but as he passed along towards the door and went out, he said in a hurried tone quite unusual to him, "Good morning, Charles. Sign out, I see. Don't you know that Friday is hangman's day?"

Charles had no time to answer ; the old Squire was gone ; and now Charles's disappointment was double, and a painful suspicion that perhaps he had made an unlucky beginning of life added greatly to his disquietude. He was sensible enough and free from all superstition; but it began to dawn upon him that he had violated a deep-rooted sen- 
timent of the community in which he lived, and he made up his mind that whether it was right or wrong he would have been wise to recognize it. There was nothing to be done, however, and so he laughed a little nervous laugh, thought upon the popular follies with a slight scorn, half wished that he had remembered what day it was when he put up that vexatious sign, and returned to his home in the evening to be unusually courteous to the widow Bell, and especially kind and fascinating to Miss Clara. The day which he had entered upon with so much elastic hope and promise had become clouded before it was high noon, and he was grieved to feel that its refulgence had been bedimmed by an accident, and tarnished by what was to his own mind a foolish whim, but by what became a source of nervous uneasiness to him when it rose to the magnitude of a popular belief and a recognized superstition. Clara made the evening of that day delightful, and painted with almost girlish enthusiasm the future of the young lawyer who had just now set forth on his high career. But somehow Charles wished that the day could be blotted out, and that he could begin again, and under new auspices; and Clara wondered that, as she babbled on, he had no story to tell of the friendly congratulations he had received from his friends, whom she knew he must have seen during the day, and who she was sure would share with her the pleasure she felt over his starting forth in life.

It was barely sunrise the next morning, when Charles Ingalls returned to his office to commence the labors of the day, impelled by a youthful zeal to press on in his work, and stirred also by that morbid impulse which forces us back to the contemplation of a painful and unwelcome truth, which we should be glad to expel from our sight forever. As he approached the office, he turned his eyes to the unlucky sign, expecting to enjoy the delicious pain of finding his tormentor there still, with its dismal prophecy 
of an unfortunate future. He looked at first with a haif stolen grlance, but with that he only saw the name of "Henry IVrigiti, Attorney at Law." He looked again with a full gaze, and still he saw only the name of his old master. His own sign was gone; and as he realized the fact that his name had been torn from that wall, that fate had been thwarted, and that he had really a chance to begin again, and begin in a way which would remove all the doubts created by popular superstition, and would restore him to the solid promise of popular confidence, he laughed at himself; at the place which once knew his sign and now knew it no more; at the people; at his luck; and with a keen sense of the absurdity of his position, he tittered along towards the office door, opened it, and entered. As he swung back the door, he saw upon the floor, at the threshold, a soiled and dingy bit of paper folded in form of a note and addressed to himself. He opened it, and read as follows:-

jotham, Mar. 25, 18-

deer Sur: if you don't kno beter than too begin yure life friclay you ought to hav yure eer; cuffed. you may bee smart but i am smarter. The Cock will crow twelve o'clock at night in five minuits and then it will be too late; but I have gut the sine down. You'll find it under the stepps of Joppa skulehous. go and git it. nail it up agin tomorrer. All rite now. you are too good a feller to be killed afore you start.

$$
\text { Yr frend }
$$

JoE Dole.

Charles read and re-read, laughed and re-laughed. He made his fire on the old brass andirons, made a pretence of sweeping up the hearth, and sat down to his books profoundly amused and impressed by the evidence of wit and folly which he had before him, quite rejoiced at his escape, and waiting for the coming of some friend to whom he might impart his information, and who might join him in his trip to Joppa school-house in search for the lost sign. 
He realized the fact, moreover, that the community, which had been dismayed at his mistake, was entitled to the full benefit of the remedy which Joe Dole had so kindly and so gallantly offered; and for this reason, also, he waited for a companion to aid him in rescuing the sign and giving publicity to its restoration and his own redemption. It was not long before Dr. Parker appeared on his early return from the house of a patient with whom he had spent half the night, and expressing surprise at the way in which Charles had taken time by the forelock, entered the office and sat down before the fire, rejoicing in the cheering, glowing heat which radiated from the burning sticks, and poured over and into him a warmth which was peculiarly grateful to one who, enfeebled by long watching in the night, had stepped out into the chilling air of an early spring morning.

Dr. Parker heard Charles's story, and read Joe Dole's letter with great glee. He leaned over the fire, rubbed his hands, chafed himself into a genial glow, and expanded with deep, internal, chuckling laughter.

"This is too good," said he. "The demons are abroad still. Simon Magus and Appollonius of Tyana, and the witches of Macbeth may be dead, but their disciples still live; and I believe they will live until the world comes to an end. Good for Joe Dole. He evidently believes in a devil, and rejoices to head him off in his devilish designs. Now, Charles, let us start."

The walk to Joppa school-house was a long one. But the two friends set out with vigor and energy, amused, elated, and stirred by a faint and lurking ecstasy which a ghostly mystery will often infuse into the heart of the sturdiest and boldest. They reached the school-house, found the sign under the doorstep, and in the bright sunlight of that spring morning, when the villagers were all abroad, they restored it to its place on the office wall. 
The people were at rest, and Charles entered once more upon his labors, this time, as they believed, with the favoring gales of fortune.

It cannot be denied that Mr. Howe and Mr. Hopkins and John Thomas, and all the calm and sensible citizens rejoiced that Charles had escaped the dangers of the unlucky day. They believed nothing in it themselves; but everybody else did believe that the day was a bad one in which to begin, and that was enough. And it was with a real sense of relief and satisfaction that these three gentlemen arranged for the next meeting of the Club, feeling confident that not only agriculture, but popular notions and whims also, would be vigorously discussed.

And so it proved. As the members of the Club gathered together on that breezy March night, in which the windtossed branches of the old elms rocked and creaked in the fitful light of the moon, which was in mid-heaven wading through the fleeting clouds, it was evident that they were not to be brought easily to order.

"That was a narrow escape for the young squire," said William Jones.

"You don't believe in all that nonsense, Bill Jones?" said Sam Rarker, in a tone which indicated that, notwithstanding his bravado, he was not sure that the devil would not put his paw upon him the next moment.

"Don't I though?" replied Jones. "Why, how many times I have heard my dear old mother warn me against Friday. 'Don't get married Friday,' she always said. 'Don't start on a journey. Don't begin a job of work.' And I have heard her many a time sing the old lines:-

"Friday night's dreams on the Saturday told Are sure to come true, be they never so old." "

"O, well," said Ben Adams, "there's more in this than you think there is. This is a queer old world, after all. 
Why, I was told years and years ago, by my grandmother, that pigs can see the wind; that hairy people are born to be rich; and that people born in the night never see spirits ; and I believe it. Why should n't it be so?"

"You might just as well tell me that if a cat sneezes or coughs every person in the house will have a cold," said Moses Ferson, boldly.

"And so I do," replied Phineas Barnes. "And let me tell you, for I know it, that if in the morning, without intending it or knowing it, you put on your stockings the wrong side outwards, you will have good luck all day. And stockings hung cornerwise at the foot of the bed with a pin stuck in them will keep off the nightmare."

"I have learned to be mighty careful what I do when I am among folks," said Sam Barker; "for I remember that once when I was talking thoughtlessly with a good woman I carelessly turned a chair around two or three times; she was offended, and said it was a sign we should quarrel; and so it proved, for she never spoke friendly to me afterwards."

"I have heard," said Squire Wright, "that when your cheek burns it is a sign some one is talking about you; when your ears tingle lies are being told about you; when your nose itches you will be vexed; when your right eye itches it is a sign of good luck; or your left eye, of bad luck; but

\section{' Left or right}

Brings good at night.'"

"It 's unlucky to pare your nails on Sunday," remarked Mr. Howe.

"I have been told," said Mr. Hopkins, "that when you pass under a ladder you must spit through it, two or three times afterwards, if you want good luck. Do you believe this, Captain Glass?"

"I don't know about that," said the Captain, who hap- 
pened to be in town on that evening; "but I do believe that a spark in a canclle is a sign of a letter coming; that bubbles in tea denote kisses; and that birds' egg's hung in a house are unlucky."

"They used to tell me when I was a boy," said John Thomas, "that if I did n't have something new on New Year's day, I should n't get anything new through the year."

"Now let me give you some remedies," remarked Dr. Parker :-

"To cure corns, steal a piece of beef, bury it in the ground; and as it decays the corns will go away. To cure whooping-cough, pass the child three times before breakfast under a blackberry-bush, both ends of which grow into the ground; or take advice from a man riding on a piebald horse, if you can possibly meet one on the road. They used to tell me in England that these remedies are infallible, and I have heard so in this country. I don't doubt they are as infallible as anything else."

"Keep in your purse a bent coin or one with a hole in it, and you will always have plenty of money," said the thrifty Mr. Hopkins.

"How often have I heard the young girls in England singing, in the moonlight evenings," said Dr. Parker, -

" 'New moon, new moon, I hail thee

By all the virtues in thy body.

Grant this night that I may see

He who my true-love is to be." "

"And I remember an old plan of discovering and catching a thief," said Mr. Hopkins. "I went into a house in England many years ago, in which the good man of the house had lost a shirt. The thief, I believe, was suspected. And so they took a Bible and a key out of the house, and bound the key to the Bible against the Ist chapter of 
Ruth, I 7th verse: 'The Lord do so to me and more also!' Then with great silence and gravity they called on a boy and girl to place their left hands behind their backs, the middle fingers of their right hands balancing the key. The wife of the person who had lost his shirt then said: 'The Lord do so to me and more also. Has he got my husband's shirt?' naming all the persons in the house. And when the right name was reached, down went the Bible and the key, and the thief was discovered."

"Yes," said Squire Wright, "and the day of the week on which the I4th of May falls will be unlucky through the year."

"Now," said Captain Glass, "let me give you some of the best signs of the weather:-

"When the raven soars round and round at a great height in the morning and croaks loudly, the day will be fine.

"The loud clamor of ducks and geese is a sign of rain.

"Before rain, swine are uneasy; rub in the dust, as do also the cocks and hens.

"Cows and sheep gather into the corner of a field before a storm.

"The presence of sea-gulls inland denotes a storm.

"In fine weather the bat continues flying until late in the evening.

"Flies bite and gnats sting in the autumn before rain.

"The clamorous croaking of frogs indicates rainy weather.

"Beetles flying about in the evening indicate that the next day will be fair.

"Dogs are sleepy or lie before the fire when rain is coming.

"Moles throw up the earth before rain.

"Spiders crawling on the wall denote that rain will ensue. 
"When trees and hedges are full of berries it inclicates a hard winter.

"It is a sign of rain when the pigeons return slowly to the dove-houses.

"Before rain the guinea fowls squall more than usual, and so do the peacocks.

"When dew lies plenteously on the grass in the evening, the next day will be fine. When there is no dew, the next day will be wet.

"If the sun sets clear on Friday night

It 's a sign of rain before Monday night."

"And now," said William Jones, with a sanctimonious air and a nasal twang, "let me tell you, finally, that the howling of dogs foretells death; and dogs can see death enter a house."

"And let me tell you," said Dr. Parker, "that if children do not cry at christening they will not live long, and $\mathrm{Mr}$. Howe knows it."

"And let me tell you," added Mr. Howe, impressively, "that some persons carry in their pockets a piece of a coffin to keep away the cramp; and to prevent dreaming about a dead body you must touch it."

"Come, come," said Charles Ingalls, "we have had enough of this. My 'individual' hairs begin to 'stand on end, like quills upon the fretful porcupine!' I am glad Joe Dole, wherever he is, took down my sign, and told me where to find it, and how to restore it. I suppose, my friends, you are now all satisfied with that job. But while I am perfectly willing to do anything to pacify your minds, I must remind you that there is a difference between observing the laws based on natural events and the mysteries of the supernatural. I am willing to believe that bats and beetles and dogs and frogs can foretell rain; but I am not willing to believe in the power of a chip from a coffin, or 
the communications of a ghost, or in those made by pretended spirits. I am willing to believe that firiday is an unlucky day; but I am not willing to believe that good wit and good wisdom do not mean more than good luck in the working out of that plan which God has committed to his children on earth."

"A pretty good sermon," hastily interposed Mr. Howe, who thought this conversation had gone far enough. "I trust we shall now lay aside our discussion of superstitions and turn to the discussion of the Cranberry, the subject proposed by the committee. Upon this, Mr. Hopkins called the Club to order with unusual energy. Each man took his seat, and Charles Ingalls presented the report which he had prepared upon the subject of

\section{THE CULTIVATION OF THE CRANBERRY.}

Mr. President, - I have undertaken the work assigned me for this evening, conscious of my inability to speak upon it from the standpoint of experience. The cultivation of the cranberry has not come under my own eyes, and the transfer of this delicious fruit from the cold and wet localities in which it grows spontaneously into systematic and well-arranged heds, where it can develop itself as plants and animals may under the fostering hand of man, is a business whose details I have been obliged to obtain from those who are familiar with the work. For what I shall say I am indebted to an intelligent and observing friencl, Mr. Stephen N. Gifford, of Duxbury, who while occupying his time there as a teacher of youth, and a good one too, has also found leisure to bring some of the peat-bogs of that town into the most profitable production of the fruit which we have under consicleration. Older than I am by many years, he has extended to me the kindest sympathy in that profession to which we both belonged before I entered upon the law, and now he has kindly and patiently bestowed upon me that information upon this practical question of agriculture, without which all I could say to you this evening would be of no value what- 
soever.* I think Mr. (iifford's instructions contain all that is to be known, or, at any rate, all that is worth knowing, with regard to the practical business before us. He advises us to select a piece of swamp land with a peat bottom, through which runs a brook capable, if clammed, of flowing the land with ease and rapidity. It is found that land of this description is better than a meadow, so called, covered with grass, and producing as a natural growth what is termed meadow hay, because it is more easily cleared for the purpose of cultivating cranberries, and is more likely when cleared to remain free from grass, which is the especial obstacle in the way of raining this crop. A meadow, however, can be used if it is absolutely necessary.

Having selected the bog, pare it clean as far down as the peat, remoring all grass roots if possible, and all rushes and bushes. When this is done, level the bog. Lay it out in beds thiry feet wide, cutting clitches through to the main channel of the water, and crowning each bed in the centre, so that the water will readily flow off, - stagnant water being very injurious to the vines. Will up the ditches with boards laid along the edges, a d rumning down into the ditch about a foot. Then drive stakes down into the ditches to which the boards can be fastened, and support the stakes with braces nailed to the top and across the ditch.

Cover the bog now with sand, clear, pure sand, without any admixture of loam, to the depth of three inches at least, and not over five. The object of sanding is to prevent the peat from dring and cracking, and to prevent the vines from growing rank; medium-sized and slow-growing vines being the most fiuitul. The sand also aids the cultivator in keeping the weeds out of his crop. If the vine grows too vigorously, it sends up fiwer fruit-bearing stalks from the joints.

* The reader will recognize in this amiable teacher in Duxbury, who so readily furnished his young friend many years ago the information he needed with regard to cranberry culture, the present worthy and venerable Clerk of the Massachusetts Senate, who brought from the school-house to the Senate chanber all those qualities which make him an admirable officer and a courteous gentleman. 
Vines for planting should be selected with reference to the quality of fruit they bear. They may be cut from a common cranberry meadow with the scyth , or pulled up by the roots. The new rines may be propagated from cuttings or from roots, the latter securing the earliest maturity, the former being the most expeditious method. In setting, take a cluster of eight or ten cuttings, make a hole in the sand with a dibble or stick, and place the cluster deep enough to reach the moisture of the bog. Some persons sow the cuttings in drills. The plants can be taken up from May ist to July ist, and set out immediately. Set the clusters in rows eighteen inches each way. Keep the land free from weeds and rushes and meadow grasses.

The meadow is now planted. 'The vines will bear fruit lightly the year after setting, if they are set early in the spring; if they are set in the autumn you will get no fruit the next season. The berries will increase in amount from year to year until the fourth or fifth year; and on the latter year you will probably get a full crop. A fair crop is from fifty to seventy-five barrels to the acre; worth in the market from $\$ 8.50$ to $\$$ II per barrel, according to the quality.

A meadow is good for nothing, and should have no money spent upon it, unless it has a liberal stream of water controlled at all times fur the purposes of flowage. A reservoir is useful if the size of the meadow or bog will warrant it. Dam the stream securely at the outlet of the bog. Flow according to necessity. If the cranberry patch is a new one, set in the spring, it is important to flow it early in the autumn, before the frost has a chance to touch it; say about October ist. This should be clone if you can cover the meadow at once with water; in fact, a meadow which comnot be flowed rapidly should not be set in the autumn, lut early in the spring. Retain the water on the mexdow from the middle to the last of May. Draw it oif then, and leave the meadow to the action of sun and air.

The two cnemies of the cranberry are the fire-worm or webworm, and the fruit-worm. The former attacks the vine about the first of August, - the fruit-worm attacks it about the same time, or when the fruit is two thirds grown. The origin of these 
pests is immaterial. The remedy is flowage, and as the time of their attacks is midsummer, it is important to have a reservoir to draw from, in case the stream should be low. It is unsale to keep the water on in summer more than twenty-four hours; and it should be on at night, if possible. Sometimes flowing in June will prevent the derelopment of the imperious insects; but this should be done with great care. It is a good plan to keep the water-level of the bog within three or four inches of the surface, if possible, in order that the roots of the vine may always have an abundance of moisture. The fruit when thoroughly formed should never be flowed; and at this time the water should be lowered in the bog.

The crop should be gathered by hand, a cranberry-rake being injurious to the berry. The fruit is injured by handling, and should be picked so clean from the vines thit it can be packed at once. The fruit should never be put into a bag for fear of its being crushed; but it can be placed with advantage in boxes or barrels on the meadow where it is picked. The best form of a package is a box capable of holding about a bushel and a half, and slatted on two sides and the top, or on two sides and the bottom, according to your taste. When the boxes are filled they should be left open until it becomes necessary to close them up for market. And if purchased and to be kept in the boxes all winter, the fruit should be uncovered.

Cranberries should be kept in a cool, dry place, with the thermometer at about $40^{\circ}$.

Charles Ingalls closed his essay and answered the questions put to him as well as he could. The members were grateful to him for his investigations, and voted the thanks of the Club to his friend Gifford for his practical instruction. But their minds naturally returned with rapidity to the supernatural channel in which they had been running, and many a member went home that night through the darkness startled by every howling dog, and sensitive to the point of folly with regard to the signs of the times. 


\section{TWENTY-SEVENTH MEETING.}

\section{SMALL FRUITS AND FLOWERS.}

CLARA BELL AND FANNY. - CLARA'S AMBITION FOR CHARLES.HER PERTURBED SOUL. - HER FRIENDS UNEQUAL TO THE OC. CASION.

CLARA BELL, around whom all the circumstances of life were simple and undemanding and bright, became perplexed and troubled. Her experience had been small, it is true; but her personal beauty had drawn about her a circle of admirers whose intellectual capacity appealed to her pride and called forth all her mental powers. She was but a school-girl when she found a companion in Dr. Parker and an accepted lover in Charles Ingalls, and when she became the object of the admiration of $\mathrm{Mr}$. Howe and Mr. Hopkins and of the old Squire. But she was a bright school-girl, and she could by no means be satisfied with the attentions bestowed upon her for her physical charms alone. She was indeed beautiful, - so beautiful that all the village was proud of her. Born to no position which could in any way excite the envy of her companions, she took her place in the uniform and indiscriminate society about her with a right as natural and as recognized as that given to the proudest and stateliest tree in the forest. She had not left her girlhood entirely behind her; and yet she had advanced far enough into the maturity of womanhood to arrest and command those whose intellectual demands had been sharpened by age and experience. She was tall, and as graceful as a palm-tree. Her well-shaped and wellbalanced head, crowned with a luxuriance of rich brown 


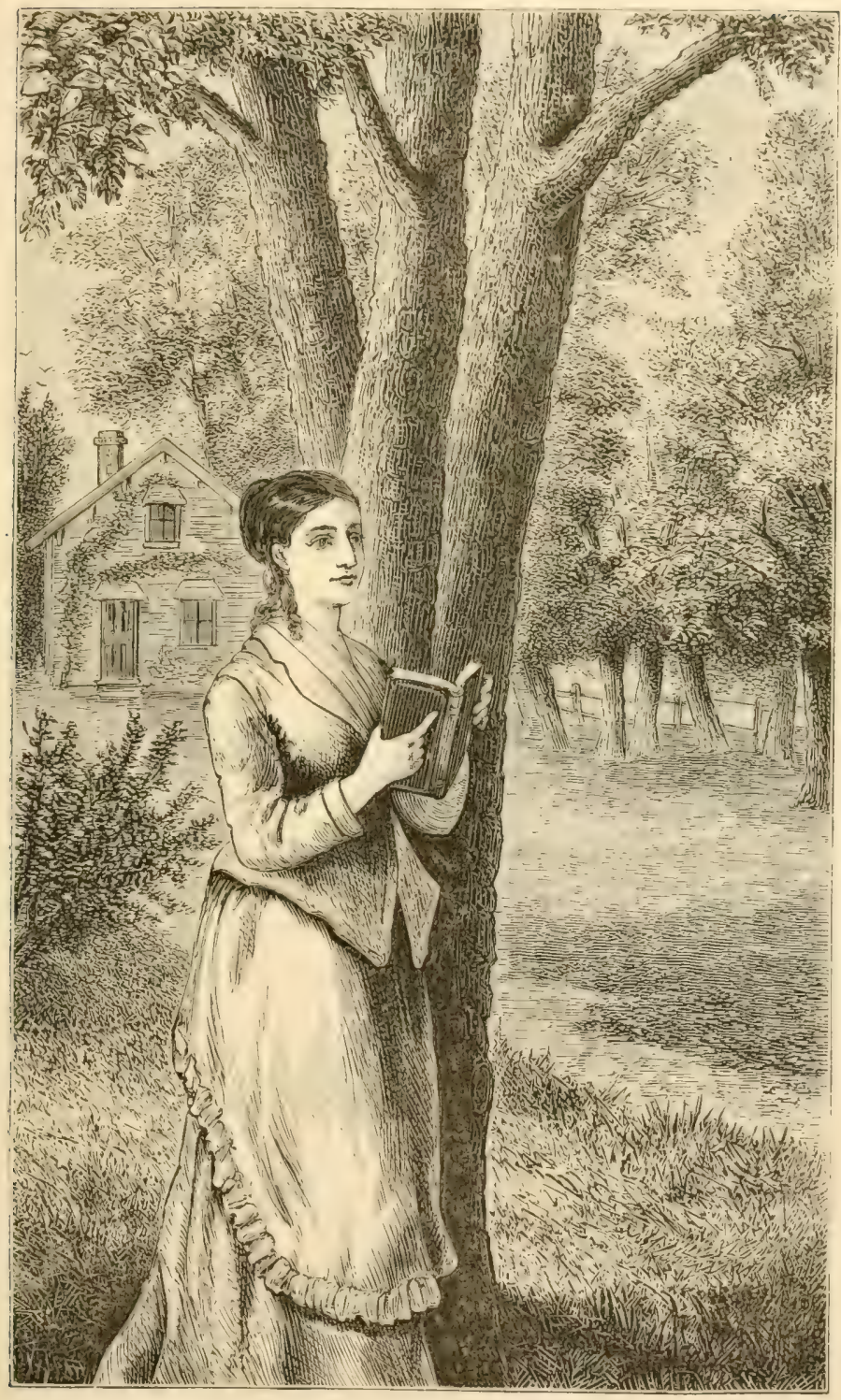

CLARA BELL AND HER HOME. 
silken hair, over which the slanting rays of the sun threw a warm and golden light, and whose wavy lines never degenerated to a curl, seemed to be the natural abode of power and fervor combined. Her calm and steady blue eye was full of wisdom and affection, expressive of unconscious confidence in herself and tender deference towards those whom she loved. Her nose, with its well-arched bridge and thin and plastic nostrils; her firm, graceful, and luxuriant lips; her well-rounded and well-set chin ; her blooming cheeks, whose oval lines had resigned a little of their uniformity to make way for the facial angles drawn by sentiment and thought, gave her an expression of warmth and brightness and vigor which seemed to illuminate the very air she breathed; and she bore her head upon a neck not too full nor too much rounded, as the lily is borne upon its stem. Nature never made a fairer or more graceful form than hers, and while her height made her slightly conspicuous among her companions, her movements displayed such elasticity and poise that her very walk through the streets was a public benediction. In the eyes of all the people of Jotham Fanny Wright had been beautiful enough, and as Mrs. Ransom she was looked upon as the impersonation of fascinating widowhood; but her hair was a shade too black, her eye was a little too hard, her face was slightly too firm and positive, and her motions just a bit too determined and decided to win all to love, even while they might compel all to obedience. The sharper and more ringing tones of Fanny's voice were quite in contrast, too, with the mellow notes which flowed so luxuriantly from Clara's throat; as the crisp assertions of the one seemed harsh when compared with the generous and kindly and sensible expressions of the other. Seldom has a town been adorned and cheered by two such radiant flowers, - Fanny as fair as earth can bear, and Clara graced with the finer charm of light and air from heaven. Doubt- 
less Fanny's experience in life had endowed her with a maturer cast of worldly wisdom; but to Clara there naturally belonged a broad and impressive sagacity and a steadiness and quickness of comprehension which inspired great confidence and respect even for one so young. For both, country life and the customs of rural society had done much towards developing that commanding and superior position which woman has secured to herself in the quiet scenes of life, without laying aside the affection of the daughter or the gentleness of the mother or the kind attention of the wife. Those who have witnessed the calm and reposeful and superior air of the American woman in country life will understand thoroughly what I mean. It is not an offensive assumption, but a half-shy, half-determined, and entirely unequivocal manifestation of matronly authority, displayed by a mistress towards her lover and a wife towards her husband.

That Clara was conscious of her beauty there is no reason to doubt; every beautiful woman is. But it is not every woman endowed by nature as she was who understands the responsibilities which a fair and fascinating form imposes upon the intellect which inhabits it. She had felt this in her intercourse with Dr. Parker and Squire IVright, and especially when she was brought in contact with the kindly and at the same time way-wise scrutiny of Mr. Hopkins. With Charles Ingalls she felt it more heavily still, until at last she was possessed by a morbid anxiety lest in the rapid development of his intellectual powers she might be left by him far in the rear, and might become merely a pretty companion for him in his leisure hours. She had wit enough to see that his relations to the men about him were changing, as he was made their confidant and adviser in their most important matters of business; that his understanding of men was quickened and modified continually; and that his capacity to com- 
prehend his own duties and their necessities was continually strengthened. She began to realize, moreover, that Jotham was no place for him, and that the time would soon come when, in a wider sphere, she would be obliged to exert all her powers to fill the measure of his demands upon her, who was to be his constant companion and friend. She even forgot what a gentle and forgiving master a lover ought to be; and she entirely lost sight of the fact that her own blind adoration of Charles might be the reason of his blind adoration of herself. And so she grew anxious and perplexed. Visions of his future greatness filled her mind, - though what this greatness meant she did not exactly understand. Her humble little home, whose charms seemed to be sufficient for Charles himself, seemed to grow more and more insignificant daily to her eye; and she turned almost mournfully upon her mother, as she fancied the troubles which their future splendor might strew along the path of her who was so ill prepared for any other life than that she now led. Clara did not realize it, - she probably misunderstood herself so thoroughly, - but she was in reality filled with an ambition for her lover which quite outshone her love. And not this alone. Her ambition for herself was evidently roused, and she began to be filled with a painful dread lest the time should arrive when to herself and to her world it would be evident that in faculties and attainments Charles had far outgrown her. And so out of the very plenitude of her organization, and out of the abounding good fortune of her life, there spread over her heavens a dark and heavy cloud which filled her young heart with gloom and despair. It was with an unexpected weight of sorrow, mingled with pride, therefore, that she saw the increase of Charles's duties and responsibilities, and learned that he might at any time be called away from Jotham, for a season at least, on business which would introduce him 
at once to a broader ficld, and would call for the exercise of all his highest faculties. And so it was. Squire IVright had been employed in an intricate and difficult contest over the title to certain lands in Jotham, in which the town itself was involved. The case in hand was not of large amount, but its decision was likely to be followed by long and expensive litigation should the existing titles be set aside, and the ownership of the land should be found not to vest in the present occupants. The old Squire felt too infirm, or too indolent, or too doubtful of his capacity to manage the case in the higher courts of the Commonwealth, and he was quite willing, therefore, to instruct Charles in all the law and the facts, and then to send him forth to try his powers among the magnates of his profession. And Charles was glad to undertake the task.

It was with a great fluttering of pride and anxicty that Clara helped Charles pack his little carpet-bag, which she had made for him, and into which his brief was carefully stowed, and saw him start for Boston. The parting was not very painful, nor was it very demonstrative; for it was to be but for a few days at the longest, and the event itself was so full of interest that this alone occupied most of their thoughts and feelings. But when Charles was gone, this young girl, whom he had left behind in a state of unwonted excitement and intensity, began a survey of her present life, and a look into the future, which were by no means conducive to her happiness or her repose. The village life in which she moved, even her clear old home itseif, lost for an hour their accustomed charm, and she began to chafe and fret under her limitations. The domestic duties which she habitually attended to with great care grew tedious and irksome; the opening spring landscape looked cheerless and dismal; the school-house, far off on the hillside, had a lonely look; the village spire, which 
had been through her life her type of architectural aspiration, began to grow dwarfish and insignificant. She had companions and friends in abundance, but none to whom she could turn in her present state of mind. Mrs. Ransom, her refuge in all times of trouble, and her more than sister in all the enjoyments of lite, and in all that mutual exploration of the flowery fields of love through which two young confiding female hearts are so happy to walk hand in hand, was not just the person for the present occasion. Mrs. Ransom's experience with one somewhat inferior husband, and her opening promise of another, whose course in life had left him slightly tarnished for high, ambitious prospects and designs, had by no means prepared her for a grenuine sympathy with a fresh young girl who knew as yet nothing of blighted hopes, or of the ugly scars which evil habits will always leare, to remind us that even when laid aside they lie in ambush to return at any unfortunate moment to the attack. To lay her heart open to her mother was impossible. That estimable woman had carried a feeble partner in her arms through life, and had laid him down to rest, and neither the labor of the past, nor the conmparative ease of the present, nor the dull current of her life from the besinning, made her a very fit adviser or a very warm sympathizer for a young girl, whose aspirations would have appeared to her somewhat stiffened and work-worn mind as the height of folly. She knew how kind Mr. Hopkins was, but she knew, also, that he had no ears for a story like hers. Mr. Howe might be a good enough spiritual adviser, but not a remarkable counsellor in trials like hers; and Mrs. Howe was too much devoted to the inculcation of humility and obedience, as the two great Christian virtues, to rise with her to that height whence she could survey all the kingdoms of the world and the glory of them. As she recalled the spirit of the village 
life about her, and the modes of life and thought by which she had been surrounded from her childhoud, she was surprised to find how unequal to her wants they were. She could not analyze this feeling, - she was not well enough informed to understand it, but she was sensible and lieen enough to know and feel that somewhere in the world there must be a sphere in which her restless mind could find room for action, and in which her heart could find a response. The associations and teachings of the church had heretofore been a source of great pleasure and strength and consolation to her, - a heavenly retreat in which, even as a child, she had found a gentle and mysterious clevation. But now she remembered the severity of the theology she had heard there, and the cold formality with which the ordinances had been administered, and she hid her face in her hands, and pressed her eyes into total darkness, with a fecling of despair that eren the glory of that sacred tabernacle was departing. 13eneath the gentle devotion of the place she now discerned a severe dogmatic belief, and a shadow of uncharitableness, which wounded instead of soothing her ; and she wondered whither the humanity which she needed now had fled. She pictured to herself the amount of taste and culture by which she was surrounded, and she wondered why it was that the adormments of life and its accomplishments there seemed so commonplace. That there was a better theology and a more elegant association somewhere, she now felt confident; not because she was familiar with either, but because her aspirations and ambition demanded something more than she now possessed. That all this was unwise, and even weak and foolish, she felt inwardly conscious; but she could not avoid it, and so she toiled on until she became uneasy and clissatisfied and discontented through ignorance and false desires. Had she known more of the world she would have risen "superior to her pain." Had 
she traversed the paths which promised her so much peace, she would have understood how thorny they often are. Had she been more familiar with all the various circumstances of life, she would have realized how indifferent a triumphant soul must be to surrounding accidents, and of how little value to a struggling heart are the material comforts and embellishments of life. But all this she did not know. And so during Charles's absence she made herself quite unhappy, as many a maiden had done before over imaginary evils and trials which time and the experiences of life would surely remove from her mind.

While Clara was groping about alone in this dark and dismal reveric, Mr. Hopkins was preparing for an unusually interesting assembly at his house, under the auspices of the Club. He found that the interest of the women of the village was increasing in the discussions, and he found also that the usual curiosity of the wives and daughters about the proceedings in the conclaves of husbands and fathers was beginning to be severely exercised; and, as he was not one of those who believe that every step that woman takes towards practical service in life, and her share of social and civil duties and rights and responsibilities, is a step towards anarchy and her own destruction, he made up his mind to request every member of the Club to bring his wife or daughter to the next meeting, while he reserved to himself the pleasure of inviting those who had no husbands, and such daughters as had no fathers. It was therefore at a novel and peculiarly agreeable assembling of the Club, in which the members seemed to have brushed and arranged themselves with unusual care, as if conscious of the decorous deportment which woman had a right to claim of them, that John Thomas announced for discussion the subject of 


\section{S.MALL FRUITS.}

Mr. Hopkins being determined that the female portion of his audience should listen under his own roof to his own voice, before they had an opportunity to open their ears to the wisclom of any of his associates, proceeded to draw from his desk what he declared were the manuscript sheets of a work known as "The Farmer's Book," which he said some of his young agricultural friends were preparing for future publication, and to read therefrom some excellent remarks upon the cultivation of small fruits.

"The Strawbiry," said the writer, "is the most delicious and widely cultivated of the small fruits, and is not only desirable in every garden, but can be profitably raised for market in the vicinity of every village, borough, or city. It flourishes naturally on sincly loam, but any soil can be made suitable for it. Muck and peat mixed with a clay soil and enriched with manure will make a good soil for most varieties. The soil, whatever it is, should be deeply trenched and manured liberally. The roots of the strawberry are fine, and the soil should be thoroughly pulverized and the manure mingled with the soil. The same manures and composts recommended for other crops are required for this, and should be applied without stint.

"North of New York we think spring planting is preferable, but where fall planting will succeed it is better. The time to plant is just after the crop is gathered. If the plants are to be immediately replanted, and a portion of the earth removed with them, the work can be clone in the fall. When plants are taken up in the spring, the dead leaves should be removed. When the roots are bared, it is well to clip off one half their length with shears before planting. It is also well to puddle the roots in such cases. This is done by mixing earth and water and dipping in the roots. When the earth is taken up with the plants of course a hole must be made large enough to receive earth and all; the roots are thus left in their natural position; but when the roots are bare they can be forced into a very small hole, and will often grow in it. But a much more certain 
and profitable course is to make a hole large enough to spread out the roots. In either case the crown of the plant should never be set below the level of the surface. A cloudy day is the best for planting. The systems of cultivation and renewal are various. The first is the shiftless system, by which the plants are set out and allowed to grow until the ground is covered with vines, weeds, and grass, with no fruit.

"The alternate strip system is on some accounts the very best. Strike out rows three feet apart and set the plants about a foot apart in the row. Let all the runners on one side of the rows grow and take root, while all on the other side are cut off. Thus every alternate strip of three feet will be covered with vines which will give a crop of berries, while the bare strip will serve as an alley for the pickers. After the crop is orer clig up the alley, and the next season allow the runners to cover and take root in it. After this season's crop is gathered, dig in the old plants, and so on, digging up on one side each year. At the time of setting the plants, and at each anmull digging, a liberal coating of manure should be dug in.

"The licminil system has of late years been popular, and consists in planting in becls, three rows, eighteen inches apart each way, and paths two feet wide. Hoe the plants, weed faithfully, let the rumners grow, and after the bed has produced two crops dig or plough it up, and plant in a new place.

"The ammual system is the same, except that the plants are put a little nearer together, cultivated the first season, bear the second, and are then ploughed or dug under. When pistillate varieties are planted, some other varieties must be planted in alternate rows to fertilize them. One row of staminate to four of pistillate is sufficient. In most parts of the country north of New York City winter protection is beneficial.

"The most successful cultivators cover their plants. Straw, hay, or leavis to the depth of two inches is sufficient. Spent hops, pine leaves, and salt meadow hay are still better. A portion of the mulch may be left on in the spring, which will sharle the roots, retain the moisture, and keep the fruit clean.

"Mulching of some sort through the fruiting season is a great advantage." 
"And," said Mr. Hopkins, "I have found that a topdressing of ashes in the spring will increase the quantity and improve the quality of the fruit."

"The varieties we recommend for cultivation are the Agrirulturist, Boston P'ine, Brookilyn Scarlet, Crimon Cone, Horey"s seedling, Larly Finger, Lennig's White, IIc Avoy's Superior, New Jersey Scarlet, Wilson's Albany, and the Triomphe de Gand.

"Riusplervics and Blucklierries are mostly propagated by suckers or shoots growing from the roots. A rich, moist soil is lesst; if too dry or sandly, apply swamp muck; but a full crop of the rasplerry every season cannot be expected from a gravelly or sandy soil. If the soil be deeply trenched when first planted, a flantation of either of these berries will continue in bearing five or six years, when they should be renewed, if the crop begins to be diminished. I'runing should be done early in the spring, or in the fall immedintely after fruiting. It consists in cutting out the old wood, leaving only the last season's growth, and cutting that back three or four feet and fastening to stakes or trellis. The suckers should all be taken up, whether wanted for planting or not. When the vines grow rigorously, summer pruning becomes necessary. The terminal shoots should be pincined off about the last of August, and if they continue to grow should be pinched off again when they have grown twelve inches more. Winter protection is often given with great advantage. Bend down the canes, throw on dirt enough to hold them, then go through with a plough on each side, and turn a furrow slice over them. An acre can be covered at an expense of not more than sixteen dollars. The Philadelphia, Black Cap, American Black, American White Cap, Surprise, and the Antwerp are among the tried varieties of the raspberry; and the Iawton, Kittaming, I)rchester. New Rochelle, and Wilson's Early are hardy, productive, and marketable blackberries.

"The cultivation of these fruits in the vicinity of large cities will never fail to be profitable.

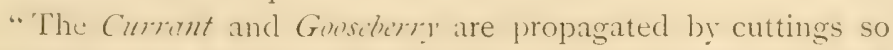
readily that no other mode will be described. Cuttings should be of ripe wood, of recent growth, cut off in the fall. Make 
the cuttings six inches long, cutting smooth just at the base of a bud, and planted as in the case of grape cuttings. The currant had best be planted in the fall, and the gooseberry in the spring. A deep, rich soil, deeply trenched and heavily manured, is necessary if the most profitable crop is desired. The bushes will grow almost anywhere, but will not produce regular and abundant crops of the largest and best fruit unless manured and kept free from weeds, and the ground kept mellow or mulched through the summer. These remarlis apply equally well to the blackberry and raspberry.

"The most common mode of pruning and training is none at all; but a more profitalse morle is to cut out all dead wood, all wood that has borne for two or three years, and all shoots and suckers that crowd the growth. Six large, vigorous shoots will produce more and larger fruit than double that number of weak and slender ones. The black currant is trained as an upright with an open head. The gooseberry is also sometimes trained in this manner; it is accomplished by rubbing off the lower buds on the stem. The most successful varieties of the currant are the Deseret, American Black, Buist's, Cherry, Dana's White, Red Dutch, Victoria, White Grape, White Dutch, and White Florence. 'The Cluster, Mountain Seedling, Downing, and Houghton's seedling are the only varieties of the gooseberry proved to be worthy of cultivation."

"And now," said Mr. Hopkins, "having read what of this manuscript relates to small fruits, allow me to read as appropriate to that portion of my audience who have for the first time, and I trust not for the last, honored us with their presence this evening, some additional remarks upon the subject of Flower Culture."

"Flower culture," this writer observes, "will be confined to the farmer's wife and family; but the farmer, if he be a true lover of nature, will be always ready to lend a patch of ground and an occasional hour with the hoe or spade to the flowergarden; himself and his family will be better for the sight of flowers, and they will be more closely attached to the home 
thus beautified. We can grive but a few bricf plain directions for flower culture.

"The best soil for the cultivation of flowers is a mixture of loam, peat, leaf-mould, and sand. If peat cannot be had, decayed turf can be used in its stead. Leaf-mould can always be had in the country by covering a pile of leaves with earth in the fall, and letting them rot for a year. Prepare a pile every fall, and you will have a constant supply of the most valuable manure for your flower-garden, vineyard, or nursery. The children should be encouraged to gather all the leaves possible in the fall for these purposes.

"So small a space an is occupied by the flower-garden should be spaded, hoed, and raked, until it is thoroughly pulverized to the depth of eighteen to twenty-four inches. Flower-seeds should not be planted until the earth begins to be warm. If the soil tends to be too cold and heavy, add sand to it. One great mistake in planting flower-seeds is to plant too early and too deep, so that the seeds nerer feel the warmth of the sun, and decay without germinating. No definite rule can be given with regard to the depth of planting all seeds, but the very small seeds should be som on the surface, and a little finely pulverized earth sifted over them and pressed gently with a board. Seerls of the size of the coxcomb and amaranth should be planted a little deeper; balsams, asters, etc., from one quarter to a half an inch in depth; sweet-peas, four-o'clocks, lupines, morning-glories, etc, from one half to one inch deep. The ground should be kept moist by light sprinklings, and as soon as the tender plants appear they should be shaded from the direct rays of the midday sun until they are well rooted. All plants should be kept clear of weeds, and the ground frequently stirred about their roots. First on the list of flowers stands the rose. To produce the most perfect roses, prepare a trench, or, if for one vine, a hole two and a half feet deep, filling the bottom with broken bricks, crockery, etc., for drainage, and the balance with an even mixture of earth and manure. Roses are best planted in the fall, but as far north as the New England states the planting of all tender varieties must be 
delayed until spring. New plants are obtained by layering, as directed for the grape, or by cuttings; or, as in many cases, by taking up and dividing the roots of a growing plant. In planting, the nicest care should be observed in placing the roots. When planted in the fall they will usually be benefited by a winter covering of leaves or stable litter. Cut out all old and decayed wood in the spring. One gardener of our acquaintance recommends two hundred different varieties of the rose for general cultivation. The only remark we shall make in regard to its selection is, select a succession of varieties that will bloom through several months, and as far as may be select different colors, from that most beautiful of all roses, the white rose, to the dark purple, sometimes called the black rose.

"The flowering almond is a hardy shrub, loaded in blossoming time with pretty pink flowers ; it is easily cultivated from suckers or layers. The syringa should be grown in every yard, both for its pure white blossoms and its fragrance. It will grow from cuttings in any good garden soil. The lilac, spirea, woodbine, and honeysuckle are all worthy of general cultivation, which can readily he done, as they require but little care if properly planted in the heginning. The gladiolus, dahlia, tulip, and like flowers require more care, as the bullus must be taken up in the fall and replanted in the spring; but their beauty warrants the use of some time that might otherwise be wasted. The bulbs are taken up as soon as the frost touches the plant, and kept dry on a shelf in a cool place, or by packing in dry sand; and about the first of May should be brought out and sprouted in a warm spot, when the tubers should be divided. Each tuber that has a bud will bear a plant. They should be planted out in groups three and a half inches deep, and a stake driven beside them to which they should be trained.

"The peony is hardy, and requires only to be covered with straw during the winter to put forth vigorously on the first approach of spring. The althea, or hollyhock, is a neglected but beautiful plant, - we think more desirable than the dahlia. The seed should be sown in May, one half an inch deep, and when the plants have put ont five or six leaves they should be 
transplanted. Dy sowing and planting the seed of the double varieties, a mass of beautiful flowers of many colors is produced every season. China-asters are to be highly recommended. The ground for these, as well as for all flowers, should be dug deep and well manured. They are sown in beds from the Ist to the roth of May, and come into bloom in August. The verbena is the most beautiful of all garden-flowers for massing in beds ; it is, however, difficult to leep through the winter. We can only name a few of the many plants included in the lists of nursery-men and florists; but it is well not to be deceived by highsounding names into buying common and inferior plants. There are enough well-known plants like those we have mentioned to make a little paradise around every home."

Mr. Hopkins concluded his reading, and the conversation became general. Clara had watched the faces of the crowd, all her friends and neighbors, and as they brightened under the description of the familiar flowers, known since their childhood, she wondered how she could possibly have been for a moment estranged from any one of them. They all seemed sufficient for her now ! The tears came into her eyes as she remembered all their kindnesses to her in her humble home, and to those whom she had loved there. And she hid her face to hide her emotion, as Mr. Hopkins enumerated those flowers which she had seen around her father's door, - the white rose whose budding forth he had watched with such childlike interest day by day in the spring-time, until his eye closed in death, and he left the buds just opening there for her to love and watch, - the sweet-pea and the mignonette which her mother planted for her, and which Charles bestowed upon her as his sweetest and most appropriate gift, - and the flaunting peony and the dainty hollyhock, and the dahlia in its autumnal pride. And as the last words of Mr. Hopkins, "to make a little paradise around every home," reached her ears, she slid quietly out at the door, and, re- 
joicing in the darkness which enveloped her, sobbed along the pathway to that spot which it seemed now as if no prosperity could eclipse and no misfortune could destroy. Glad was she to find herself there a child once more; and, falling on her linees by the side of her pure white bed, she thanked God for that home, for the memory of her father, for the affection of her mother, for the love of him who was more to her than father or mother combined, and prayed that never again might she dream that life had any joys brighter than those which all the endearments of home can give, and no promises more radiant than those which are made by the God and Father who meets us there. And she fell asleep to dream of him who was far away.

"She went home to look after her mother," said Mrs. Thomas, as the Club adjourned, and Mr. Hopkins found that Clara had vanished. 


\section{TWENTY-EIGHTH MEETING.}

\section{FRUIT CULTURE.}

CHARLES INGALLS'S LETTER TO CLARA. - HIS CITY LIFE. - BARNES TELLS ALL ABOUT FRUIT-TREES. - FESTUS COMES IN.

THE proverbial delays of the law had detained Charles Ingalls in the city much longer than he had anticipated, and really much longer than he desired. Not that time hung heavy on his hands, for he had a power of concentrating his mind upon the work in which it was engaged with such intensity that the hours flew by more rapidly than they could be counted; but city life was somewhat irksome to him, accustomed as he was to the ease and quietness of the country; and the showy and brilliant entertainments which were offered to him on every hand, as the relaxation of his leisure moments, seemed very cold and tasteless when compared with the sweet and rosy society which he found in the humble abode of the Widow Bell. He was not fond of letter-writing, but there is still in existence a letter which he wrote to Clara during his absence, which sets forth so well his course of life and his mental condition, that I am glad to be able to insert it here. It is as follows:-

Boston, April 13, 18-.

My DEAREST Clara: I have now been many days away, and, although intensely nccupied by my work, I cannot longer bear the thought that I have not, as yet, cledicated an hour of my absence to one good. long, elaborate, and affectionate letter to you. I know you will not attribute this to indifference, but to that desperate way I have of plunging into any work 
which is on my hands, and forgetting that I love anybody or that anybody loves me. I have thoroughly enjoyed myself in this new sphere to which I have been introduced by the business placed in my hands by Squire Wright. You know I cannot pretend to be a lawyer of extensive reading; but I have man ged in spite of this to secure a considerable reputation by my thorough and intimate knowledge of the matter in which I am employed. I have not yet forgotten a fact, nor have I broken down on any point of law involved in the case. Of all other law I take great pains to preserve a dignified silence. With the associations into which I am brought by my profession on this broader field I am delighted. The mean men in the law are too mean for endurance, and they find it so impossible to conceal their meanness in the profession which they have chosen, that everybody lnows and sees it; but the great and magnanimous ones are splendid enough to make one forget the bad, and remember only the good. Mr. Fenton, to whom Syuire Wright gave me letters of introduction, and with whom I am associated, stands at the head of his profession here, and a delightful man he is ; as familiar with the law and all its great principles as I am with a mere point of discussion in our Club, and as thoroughly informed on all the thought and literature of the times as if he were a roving scholar. He is very kind to me; takes me to his house to dine, and he has a lovely daughter; has introduced me to his club, a body of the best-educated gentlemen in the city: has offered me the use of his library on all occasions; has invited some of the young members of the b.ur to meet me at his house; and suggested the other day that perhops I might like to enter into a partnership with him, should I ever determine to come to the city for a permanent settlement. Miss Mary, who heard the suggestion, remarked that she thought her father would be very fortunate to secure such assistance. You may be sure, Clara, I blushed.

The excitement of city life, its temptations and its promises, have already led me to consider in an anxious manner the path which I am to travel through life. It has never occurred to me until now that anything more than a rural life with its repose and its limitations would ever come within my reach. 
Tut my success in this my first attempt to perform my part ir: the midst of active and condensed and vigorous life has led me to believe that I may possibly accomplish something f r my own honor and for the benefit of mankind. I hope you will agree with me in this, and that your intelligent sympathy and generous encouragement will go with me in all my endeavors in this direction. I do not approach or contemplate the work with confidence or assurance. And I assure you my mind dwells continually on the little office sheltered under the trees of Jotham, on the lake and the hillside, on the shady and gransgrown lanes, on the broad farms and hospitable farm-houses, on the placid faces of John 'Thomas and his wife, on the tracric and awful fate of l'eter Ilsley, on the old school-house, the meeting-house with its rolling choruses of sacred music, and its sermons filled with pious faith, and on the abounding personal interest which makes society in Jotham a brotherhood if men. And I am sure that no success, amidst the trials of active life, will ever wean us awa from the charming scenes in which you and I have walked together, and whose memory always ontlives the artificial charms which man creates to make the course of life desirable, and its close quiet and peaceful.

But why should I be anxious or complain. I have been provided with a wealth of early association given to but few. The morning thus far has been radiant, and I must be brave and thankful. As I wandered through the delightful and fascinating library of Mr. Fenton, the other dity, my eye fell upon that charming poem of which you and I have heard so much, in which the story of Festus and his Clara is so sweetly and divinely told. And I opened to that rosy scene in the garden and read how Clara says :-

\section{"Shall we ever live}

And love as now?"

Festus. "Ay, live I fear we must."

CLARA. "And love; because we then are happiest.

We shall lack nothing, having love; and we,

We must be happy everywhere ; we two."

And I was filled with hope and courage for my opening life, 
which I pray may be preserved from temptation, and guided by Divine light through all trial and darkness, and led by a Divine hand along all the dizzy heights of worldly prosperity.

How gladly, my dear Clara, would I return home. And so I send love to your mother, and the old Squire, and Mr. Hopkins, and Mr. Howe, and Dr. Parker, and the Club, and Fanny, and am

Your own affectionate

CHARLES.

Clara read this letter over and over again, sometimes with doubt and fear, but in the end with hope and confidence. It was not exactly such a letter as she expected from Charles. There was more of it, and less of it, than she anticipated. She was not prepared for quite so much wisdom, and she hoped for a little more about love. The evident satisfaction with which Charles was moving among his new acquaintances was a source of slight annoyance to her; and the praises bestowed by him on Mr. Fenton's lovely daughter Mary caused a momentary pang in her heart, which was not entirely removed until the closing sentences of the letter restored her faith and conficlence. She came to the conclusion that Jotham without Charles was a very stupid place, and that Boston was a very dangerous place for a young man like him. She wrote in reply to his delightful letter, congratulating him on his success, and begging him to return home as soon as possible.

Charles's absence from Jotham was by no means agreeable to the inhabitants of that cheerful and neighborly community, but it was not quite fatal to their enjoyments. The singing-parties, and the quilting-bees, and the teafights, and sewing-circles went on as usual, and the Club held its regular meeting and tried to get on without the aid of the young lawyer, whose intelligence in discussing agricultural questions was quite surprising to those who 
had no faith ia any information except that derived from experience and observation. The subject selected for debate was Fruit Culture, and it was opened by I'hineas Barnes, who had thus far occupied but little time of the Club, and whose orchard, runming far away in the rear of his blacksmith's shop, was the admiration of all beholders, and was sometimes claimed to be a source of great profit by the owner. He had evidently prepared his essay with great care.

\section{MR. BARNES'S ESSAY ON FRUIT.}

The raising of fruit has become a difficult, uncertain, and troublesome busincss. The obstateles lying in the way of the fruit-grower have increased rery rapiclly within the last few years. I have not forgotten the thrifty orchards of my childhood and youth. Apples grew almost without cultivation, and were so abundant, that, but for the large manufacture of, and the general demand for cider, we should have been unable to dispose of one half our crop. Peaches were large and luscious. Pears were not common, and had reached no degree of perfection. But plums were as easily grown as potatoes; and the plum-tree was a common ornament in the rear of the house, around the ash-heap and the sink-spout. But now ererything of this lind has changed. The apple has lost its size and shape, and attractive appearance, in this region at least; the peach hardly reaches maturity; the plum is almost unknown; and the pear alone seems to defy all adverse influences, and to increase in quantity, size, and variety. The uncertainty which attends fruit-growing has led me to doubt sometimes, in spite of myself, with regard to the profit of its cultivation. And I have been half inclined to advise my fellow-farmers to wait until the diseases and injurious insects had vanished, before entering upon a new era of planting orcharils of any kind. At any rate, I have become satisfied that the most conrenient and fertile lnuds of the farm should not be devoted to this business. In former days the fields adjoining the farm-buildings were usually occu- 
pied by fruit-trees, and it was believed, and perhaps with good reason, that they could not be used for a better purpose.

But it is not so now. Almost every crop known to the farmer, such as grain, roots, grass, and garden vegetables, is more profitable year after year than fruit. And we have all discovered that, for convenience, economy, and profit, the lands lying near the stable and the manure heap are those to which we should apply our most careful cultivation; while the farther removed, lighter, and less accessible lands can be used for the orchard and the nursery and the fruit-garden. It is well known to you here that I have devoted a great deal of time to my orchard, and that its condition is much admired. But it has, I am sorry to say, not been steadily profitable. I set it out twenty years ago, and hare found the care of it a very good employment for my leisure hours. Besides, I coukl not cultivate the land for any other purpose. My trade keeps me busy, and I have had my orchard for an amusement. To raise market crops or common farm crops was to me impossible. I had no time for this. But I found I could take care of trees, and so I planted them. In all this twenty years I have had but one year of a good crop, and at no time have I been able to raise any other crop on the land for fear of spoiling the trees. The conflict I have had with canker-worms and caterpillars has been tremendous. I have not been cliscouraged, however, and have rather enjoyed the excrcise; but I have had but little fruit and small pay.

If we will plant orchards, the question of lociality is one of great importance. A sheltered spot is usually the best. Fruittrees do not bear well the effects of high winds, and should be protected against them. I.ow lands, which are liable to late spring and carly autumnal frosts, should also be avoided; and as a general rule an clevated spot with a clry, firm soil should be s-lected, - a soil especially free from stagnant water. The branches of a fruit-tree are to be protected from frosts and violent winds; but still more should the roots be protected from a cold, wet subsoil. I suppose the best soil for orchards, the locality being farorable, is a sandy loam with a sandy clay sub:;oil ; or a shelly spot filled with clisintegrated rock. The fruit- 
aree requires a slow growth, in which every jart is well matured, and in which the tendency should rather be to fruithulness than to wood and foliage. For an apple orchard the soil I have described is especially adipted and appropriate. And it is fortumate, both for the tree and the cultivator, that such snil is very

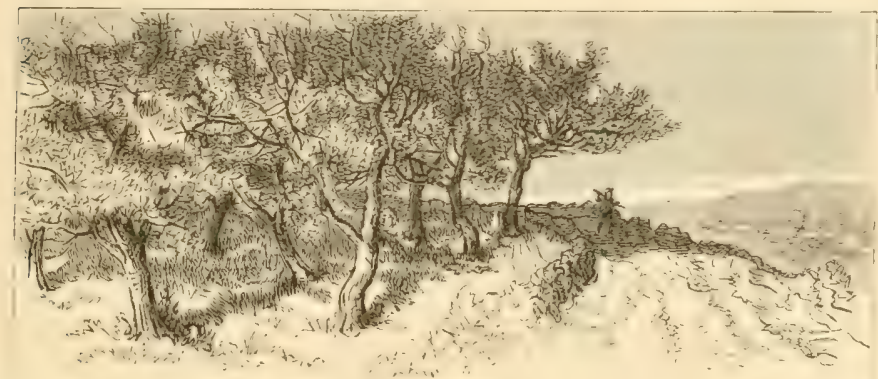

THE OKCHARD.

commonly found among ledges or on hillsides, where the cultivation of farm crops would be difficult, and in some cases impossible. I would advise taking such outlying land as I have described for orchardi, and keeping the good and inlying lancis for grain, roots, grass, and market-garden crops. Soil abouncling in lime is always well adipted to the growing of fruit.

As a general rule, the soil in which the apple thrives is congenial to the pear and the peach. The plum and the quince, however, require a stiffer, more clayey, and moister soil. The soil, when selected, should be thoroughly drained if it appears necessary, and thoroughly ploughed and subsoiled the season before the trees are planted. The land should be fertilized with well-rotted barn-yard manure, mixed with the soil at the rate of about six cords to the acre. This manure may be composted with muck to advantage. Apply, just before setting the trees, an abundance of wood-ashes, say a hundred bushels to the acre, or fifty bushels of oyster-shell lime if ashes cannot be readily obtainel. After this aroid the use of heary nitrogenots manures, and, confuning yourself to bones and ashes, apply 
your fertilizers to the surface of the soil. A light top-dressing of salt will be useful. A good advicer at this point says: "Your trees once set (and he who sets twenty trees per day as they should be set, with each root in its natural position, and the earth pressed firmly around its trunk, but no higher than as it originally grew, is a faitlıful, efficient worker), I would cultivate the land for the trees' silie, growing crops successively of rutabigas, carrots, beets, and early pitatoes, but no grain whatever, for six or seven years, disturbing the roots of the trees as little as may be, and guarding their trunks from tug or trace or whiffletree, by three stakes set firmly in the ground, about each tree, not so near as to preclucle constant cultivation with the hoe, inside as well as outside of the stakes, so as to let no weed mature in the field. Apply from year to year well-rotted compost to the field, in quantity sufficient fully to counterbalance the annual abstraction of your crops. Make it a law inflexible and relentless that no animal shall be let into this orchard to forage, or for any purpose whatever but to draw on manures, to till the soil, or to draw away the crops. Thus until the first blossoms begin to appear on the trees; then lay down to grass without grain, unless it be a crop of rye or oats to be cut and carried off for feed when not more than half grown, leaving the ground to the young grass. Let the grass be mowed for the next two or three years, and thenceforward devote it to the pasturage of swine; mowing over it with a scythe once or twice each summer to clear it of weeds, and taking out the swine a few days before beginning to gather the aplles, but putting them back again the day after the harvest is completed. Let the swine be sufficiently numerous and hungry to eat every apple that falls within a few hours after it is clropped, and to insure their rooting out every grub or worm that burrows in the earth beneath the trees, ready to spring up and apply himself to mischief at the very season when you could best excuse his absence. I do not commend this as all, or nearly all, that should be clone in resistance to the pest of insect ravage; but I begin with the hog, as the orchardist's readiest, cheapest, most effective ally or servitor in the warfare he 
is doomed unceasingly to urge against the spoilers of his leritage."

I have found that trees should be set about twenty-five feet apart. This will not allow them to reach a great growth or perhaps to live a long life. But we should remember that an apple-tree is of no real value when it begins to decay, and that it camnot be expected to bear a profitable crop through a long series of years. One of the best orchards I liave ever seen stands on a hillside exposed to all the winds which blow across Like Champlain, and standing so thickly together that the sunlight never reaches the ground beneath the branches. The trees appear to protect and nurse each other. I do not suppose they will reacin a great age; but this is not desirable when we remember that a fruit-tree, an apple-tree at least, seldom bears any amount of fruit after it is forty years old. I am in favor, then, of thickly planted, well-cultirated, short-lived orchards. Never attempt to rejuvenate an old orchard. It is time and money wasted. The greatest care should be takin in both top and root pruning. The shape of an apple-tree should be like that of a rase, and the inside of the tree should be kept as open as possible. The lower limbs should be about six feet from the ground. and the upper limbs should not be allowed to stretch high up into the air, where they will be exposed to all the racking and wrenching of the winds. The pruning of the roots should only be adopted when the growth of wood is too luxuriant, and the tree is clisinclined to bear fruit. The best mocle of performing this is to dig a trench around the tree about as far from the trunk as the branches extend, or if the trees are thickly planted, dig cross trenches between the rows, cutting off all the small roots that appear, and filling the trench with well-ro:ted and composted mamure, or with muck with a large mixture of lime. In this way, a barren orchard can often be brought into most luxuriant bearing.

I have thus spoken of the selection and preparation of the soil for an orchard, the planting and pruning and fertilizing of the trees, and of the liest mode of securing an ample yield of fruit. I do not think it necessary to consider the modes of 
grafting, - for I have always found that no description of this work was adequate to make an expert in the business. Practice alone will make a perfect grafter ; and practice alone will teach a grafter what is the best method of setting the scion and covering the end of the limb into which it is inserted.

Many attempts have been made to bring barren and worthless trees into bearing. One of the best is thus clescribed by R. L. Pell, Esq., a most experienced and successful fruit-grower. He says: "For several years past I have been experimenting at the apple, having an orchard of 2,000 bearing Newtown Pippin trees. Three years ago, in April, I scraped all the rough bark from the stems, washed all the trunks and limbs within reach with soft soap, and trimmed out all the branches that crossed each other. In the latter part of June I slit the bark by running a sharp pointed knife from the ground to the first set of limbs. In July I placed one peck of oyster-shell lime under each tree, leaving it piled about the trunk until November, when it was dug in thoroughly. The following year I collected from these trees 1,700 barrels of fruit for the market, besides cider apples. The trees were then manured with stable manure, composted, and the succeeding autumn they were again loaded with fruit, while the trees not so treated were quite barren."

With regard to pruning, one careful observer tells me that "every apple-tree should be pruned each year of its life; that is, it should be carefully examined, with intent to prune if that be found necessary. It should be pruned with a careful eye to giving it the proper shape, which, from the point where it first forks upward, should be that of a teacup, very nearly. I have seen young trees so malformed that they could rarely, if ever, bear fruit enough to render them profitable. And the pruning should be so carefully, and judiciously done from the outset that no wood two years old should be ever cut away. With old, malformed, diseased, worm-eaten, decaying trees, the best must be done that can be; but he who, pruning a tree that he set and has hitherto cared for, finds himself obliged to cut off a limb thicker than his thumb, may justly suspect himself of lacking a mastery of the art of fruit-growing:" 
The gathering of the apples is p urt of the business of orcharel culture which should nerer be carelessly or roushly done. Mr. Copeland has laid down some excellent directions for this business, which I will read to the Club. He says: "The first of the month (o)tober) overhaul the stock of barrels, and if the number is cleficient purchase some at once; be sure there are enough heals and hoops. When all is ready bergin to gather the fruit as soon as ripe, and by no means wait until hard frosts set in ; the slightest slim of ice on standing water should stimulate the greatest exertions. It is very true that the leaves of the trees protect the fruit against the frost, but it is not all protected in this way, and if frozen, however slightly; it is libely to decay very rapidly. Apples when ripe rearlily come off in the hand if gently turned round, and should be left on the tree until they will do so, mless the near approach of winter renders immediate gathering necessary. When the fruit is ready for picking, carry ladders of different lengths into the orchard, so as to prevent any necessity for beating or shaking off the fruit. Clear some place on the ground large enough for a heap which will fill sereral barrels; cover this space with clry straw or old hay. Fasten a hook of iron or wood to the handle of each basket, that it may be hung on the tree or ladder, so as to leave both hands free. Let your pickers understand that it is a fixed law that erery apple, small or large, is to be picked by hand. Every basket as it is filled must be carefully emptied at the appointed place, by being laid on its side and slowly turned that no apple may be bruised. It facilitates this labor and insures greater care in handling to have one person with an extra basket constantly employed in exchancing the full baskets of the pickers for the empty ones. When one pile of fruit is large enough make another. There will probably be a small portion of the fruit which cannot be reached by the hand : this must be shaken down after the hand-gathering is done, piled separately, and used or sold as soon as possible. When the day's work is drawing to a close, cover the heaps with straw, hay, or hay-covers for the night, and do the same on wet days. Leave the fruit for several days, according to the weather, to 
cool and dry. When dried enough, have the barre's carried into the fields and the inples put into them by hand, carefully assorted, according to quality. Let one man fill the barrels as full as possible without crowding, and lay on the heads, which another person should fasten in firmly. When this is clone, the carts are to be sent out and the barrels lifted into them. Roll them as little as possible; carry them into the fruit-room, where they may stand on end or be piled on each other. If they must be left out through the night or in wet weather, lay them on their sides, and pile them up so as to shed rain, and corer the upper ones with boards."

I know you will ask me, Mr. Presiclent, what varieties I prefer and what I have in my orchard. If I were raising apples solely for the marliet, I should find out the apple best suited to my soil and locality, and I should confine myself to that, whether it be the Baldwin, the Spitzenburg, the Hubbardston, or the Russet. By so cloing you make a reputation and secure a market. But usually I should select sereral varieties, such as will give me a supply through the many months during which the apple comes to maturity, and can be kept. Of the early varieties the best are the Early Harvest, Red Astrachan, Golden Sweet, Williams' Favorite, Sops o' Wine, Porter, and Early Joe. Later in the season I should select the Gravenstein, Fall Pippin, Osgood's Farorite or Lyscom, and the Hubbardston. For early winter apples I prefer the Spitzenburg, the Northern Spy, the Fameuse, the Mother, Tallman's Sweet, Seek No Further, and the Ribston Pippin; and the Rhode Island Greening, the Baldwin, and the Golden Russet for the late winter and early spring months.

I have no doubt, Mr. Presiclent, that much more might be said concerning the cultivation of the apple, but I hare occupied enough of your time this evening, and I have laid down all the directions I deem necessary for the proper management of the orchard. I could tell how much I have become attached to my trees, and how much each one seems now like an old friend or acquaintance, whose shape and countenance I should rerognize among ten thousand. Each tree in my orchard seems to 
have a character of its own, and I assure you I pass many pleasint hours among my friends whom I planted, and who hase grown up under my cye, all as different as the members of my own family, and all reminding me of the cheerful days I hate passed in their care and cultivation.

"A most excellent piece for our friend the blacksmith," whispered Dr. Parker to the old Squire, who sat with him in the corner next the brightest side of the wood-fire. "It is a good thing to have a bright daughter at a grood school," replied the Squire.

"I have heard Mr. Barnes's account of his trees with pleasure," said Mr. Howe. "I agree with him that a period seems to have arrived in the cultivation of the apple, like that which has reached the potato and the buttonwood tree, and which awaits almost every variety of vegetation to which the skill and science of man are applied. Plants transferred from a natural state to a highly artificial state are liable, I think, to limitations; and I trust science will one day discover the mode by which such a difficulty can be overcome. While the trouble lasts I would curtail the extent of our apple orchards, give the whole family a restingspell, and wait for the time when Nature in this region is once more ready to pursue her work in this direction. I should not allow my old orchards to encumber the soil longer, and I should be sparing in the planting of new trees, and very economical and careful in selecting land for this purpose."

"Don't abandon the apple," said Dr. Parker. "I know we are obliged to contend with all sorts of diseases and insects and adverse winds and storms; but the usefulness of an orchard, the associations which surround it, the place which the apple has held in our clomestic economy, the cheer it gives the evening firesicle, the rosy crown of our Thanksgiving table, the representative fruit of New England, appeal to us for care and consideration; and I hope 
our farms will continue to have the beauty of the orchard even if the days of its profit are gone. What would the girls and boys do without it? IVhat would become of the charming Galateas of modern days who pelt us with apples still? What - "

The end of the Doctor's sentence was inaudible; and some of the practical gentlemen began to wonder whether he had "stepped aside" once more. But the Squire understood it all, and only indulged in a little internal laugh over the poetic wanderings of even the coolest, when fanned by the wings of the busy and ardent little god.

"The West is interfering largely with our apple-trade," remarked Mr. Hopkins.

"Yes," said John Thomas; " and so I have reduced the raising of apples on my farm to the wants of my family, and if there is a surplus I convert it into cider, as the best and only way of disposing of it."

"And the cider into vinegar. I suppose," said the Rev. Mr. Howe:

At this remark Sam Barker's ruddy face grew redder still, and he coughed a profound and wheezy cough in response.

The subject was becoming intricate and difficult to manage in all its bearings, commercial, moral, physical, and agricultural, and with a suggestion that Phineas Barnes continue the discussion of Fruit Culture at the next meeting, and tell what he knew about the cultivation of the pear, the Club adjourned. 


\section{TWENTY-NINTH MEETING.}

\section{FRUIT CULTURE (Continued).}

CHARLES INGALLS RETURNS FROM BOSTON. - A NEW REVEIAATION TO CLARA. - SHE IS SORELY TROUBLED. - THE MEMBERS OF THF CIUB PHILOSOPHIZE.

THERE is no doubt that even during the absence of Charles Ingalls from Jotham a full-grown drama was performed in every family of that delightful and quaint town, as often as once a day at least. The outward events may not have been great, but the passions and motives and impulses and emotions, the intricate workings of the human mind, and the eccentric and unaccountable beatings of the human heart, so often find room enough to display themselves, even on the narrowest stage of life, that the great, secret, hidden story has not yet found a chronicler capable of comprehending or telling it all. It is not always on the most imposing field that the grandest events are enacted; but in the obscure regions of society, the sudden impulse, the burning passion, the adroit design, the cunning endeavor, may all find room and opportunity for the exercise of all these natural faculties, in obedience to a divine law which the mind of man has not been able to conceive. The tragedy of a cottage may be as great as the tragedy of a palace. God works everywhere. And so in Jotham the play of life was going on like the kingdom of God, which cometh not with observation. Clara thought the place was unusually dull; but to all the rest of the people there was no perceptible change. The executive committee of the Club, even though expecting Charles's 
return, and although anxious for it, still determined to call their meeting, and encourage Phineas Barnes to continue the discussion of Fruit Culture.

It was under the usually agreeable circumstances, over which no cloud had fallen, that $\mathrm{Mr}$. Barnes drew forth his paper and proceeded with his work.

\section{FRUIT CULTURE.}

I have determined to give my views on the cultivation of the pear and the quince, and perhips of the peach. I had prepared myself carefully for this when my attention was called to the admirable views written out for the Farmer's Book, a work to which allusion has before been made at our meetings, and I think I cannot do better than to read them here. "Pears require," says this work, "nearly the same soils and situations as the apple, but more porous. Different varieties require different soils. All require lime, and if it be not naturally in the soil, it should be supplied. The following list shows the soils in which a few of the standard vari ties clo the best. In clayey soils : -

"Andrews, Bartlett, Beurre d'Anjou, Beurre Superfine, Beurre Langalier, Brandywine, Belle Lucrative, Buffum, Doyenne, Bussock, Howell, Louise Bonne de Jersey, Iawrence, Merriam, Onondaga, Rostiezer, Seckel, Vicar of Winkfield, and Winter Nelis.

"All the above varieties, except the last, the Winter Nelis, are benefited by a large admixture of sand in the soil. The following varieties grow best in a sandy soil without clay :-

"Beurre d'Aremburg, Beurre Bosc, Beurre Diel, Dearborn's See.iling, Duchesse d'Angouleme, Flemish Beauty, Glout Morceau, Uıbaniste.

"Whatever the soil, it should be thoroughly and well cultivated. The pear on its own roots will not bear transplanting after three or four years of age, unless it is root-pruned every year or at lenst the year before transplanting; but on the quince it may be transplanted at almost any age. But though in gardens and 
market culture the pear is usually grown on the quince as a dwat tree, for the purposes of the ordinary farmer, to whom we speak, we advise budding on pear stocks. At three years from the bud they should be removed to the orchard. The early autumm is the best time for this, and if done before the fall of the leaf, the leaves should be stripped of. When transplanted great care should be tiken to retain as many as possible of the small fibrous rootlets, as these furnish life to the tree. The same directions given for transplanting the apple apply to the pear, except that the trees should not be more than twelve feet apart, which will allow five hundred trees to an acre. Every farmer can find at least one fourth of an acre to devote to the culture of the pear, which will allow for one hundred and twentyfive trees, and which will be a source of enjoyment and profit. One need not now waste a lifetime in order to obtain the fruit, for six years from planting the seed is ample time for the first crop of this delicious fruit, and we know of thousands of peartrees that have borne for over fifty years. We once knew a tree three years from the bud to set over four hundrell pears; all but about twenty-five were picked off, but this shows how quickly the fruit will mature if treated properly. Pear-trees set twelve feet apart and pruned to a pyramidal form will have plenty of room for a number of years, and as they become too thick the poorest trees can be thinned out. 'The pyramidal form is one very easily obtained if the trees are kept down, as the pear should be, to within twelve feet in height. In the pear orchard no calculation should be made for horse cultivation, and the lowest branches should not be more than four or five feet from the ground. I) warf pears on quince stocks should be cultitirated much lower. All agree that the pyramidal is the best shape for the pear, and each pruning should have reference to this shape. No grass or grain should ever be allowed in the pear orchard, but ail root crops are beneficial, as for the apple. A small strip can be ploughed by the use of the short whiffletree, but most of the cultivation must be done with the spade, digging-fork, and the hoe. The pear must not be allowed to bear too early or too profusely. It requires a great deal of 
courage to pick off half the young fruit from a tree, but that which matures will be larger and finer, and the exhaustion to the tree not so great, even if the weight of the fruit is the same. The tree is exhausted, not by the amount of fruit in weight that it bears, but by the number of specimens in which it perfects the seed. Fruit-growers will do well to bear this in mind. For market or the kitchen-gardens the pear should usually be cultivated on quince stocks. The quince is a valuable tree of itself, but as a stock for the pear it is of the greatest importance. It is usually propagated by layers when cultivated for its fruit. The soil for the quince should be deep and rich and well cultivated. The common method of setting the bush and letting it talie care of itself is just as ridiculous as for the farmer to leave his corn in the same way. They should be pruned generally, and never allowed to grow bushy. As they are usually near the house, they should be treated to frequent doses of soap-suds, and the soil about their roots kept mellow. Quince-trees treated in this way will yield enormous crops in proportion to the size of the tree. The Orange Qunce is the farorite for the garden. For stocks for the pear a different mode of propagation is practised, namely, root-grafting, which is extensively practised by nurserymen upon apple and quince stocks, as it can be clone in the house in the winter. The seedlings or cuttings that are to be root-grafted are taken from their winter bed, if few at a time, grafted, and at once returned. 'The stem is cut off at the collar, or the point where it emerges from the ground, and the graft inserted in the same manner as upon the stock. Pears on quince stocks will usually have to be obtained from the nursery, and we advise purchasing only of reliable nurserymen, and obtaining assurances that they are not on the common quince, which is worthless for stocks, but on the Angers Quince. Thy the best that are to be had, - a few cents mike but little difference here, but will make a vast difference in the final results. "If, however, the attempt is made to grow your own stocks, select to bud on the quince only such as have proved successful when thus grown. Many pears will not grow on the quince. The standard varieties that are best adapted to the quince are: 
Bergamotte, Beurre d'. Injou, Beure Superfune, Beure Iniel, Beure (ifford, Brandywine, Belle Lucrative, Inchesse d’Angouleme, Liaster Beurre, Flemish beauty, Glout Morceau, Louise Jonne de Jersy, Rostiezer, Urbaniste, Vicar of Winkfield.

"In the Southern States the Madeleine, Julienne, White I)oyemne. I awrence, S.ckel, and 'yson can be added to the above list; and for the Western States, the Tyson, Seckel, Kirtland, Nouveau, Poiteau, Doyenne Ette, and Bloodgood.

"The pear on the quince should be planted with the collar from two to four inches beneath the surface, for the quince serves as a root, never as a stem. Here has been the cause of the failure of tens of thousands of dwarf pears. If the quince stock is above the ground, it is more liable to be attacked by inse ts; it is liable to be broken off by high winds at the joint, and the pear, growing more vigorously, produces a deformity; while if placed two or three inches below the surface, it is strong, healthy, free from borers, while the pear itself will in time take root beneath the surface and grow upon its own roots. Lnder proper treatment it comes into bearing on the quince in one half the time needed on its own roots, can be more readily trimmed to a pyramid form, so desirable in the pear, and we think is just as long-lived. We at least know of trees on quince stocks that hive been in bearing over forty years. Twelve feet apart is ample space for planting these trees; and when ground is scarce, if it is sure to be thoroughly cultivated, annu.illy manured, properly prumed, and the young trees thinned of their first crops, six feet apart in the rows and rows twelve feet apart will answer. In summer pinching off the terminal buds is the best method of pruning these trees. If the leader shoots up too vigorously pinch it off; if any of the upper shoots get as long as the lower ones, pinch them off; if bucls appeat where you clo not want limbs to grow, pinch them. This is much better than waiting until the rood is matured and pruning must be done with a knife; but, if you leave it until then, be sure your knife is like a razor. Cut just above a bud. Prune in the spring those branches you wish to have grow vigorously, and in summer those whose growth you wish to check. When trees are 
slow to come into bearing, prune in the spring, pinch through the summer, and root-prune early in the autumn.

"The pear, unlike other fruits, bears from a permanent spur; after the fruit has been picked, if this spur is cut back new fruitbuds will start at its base. 'The germs of these buds can be seen at the time of gathering the fruit. The wood-buds are readily distinguished from the fruit-buds, as the latter are full and plump, while the former are usually pointed. IVood-buds can be converted into fruit-buds by bending down or breaking off the shoot just above the bud. This distinction between wood and fruit buds should be kept constantly in mind when pruning the tree. Old pear-trees are reinvigorated by the same process of grafting the tops already described for the apple.

"Thinning the fruit, as we have hinted, is often necessary. Says Thomas W. Field, a successful cultivator of the pear: 'Good soils, fine cultivation, healthy and vigorous trees, and all the other requisites of pear-growing will often fail of producing fine fruit, if all that sets is allowed to remain on the tree. The fruit of the Bartlett, Dearborn's Seedling, Louise Bonne de Jersey, and many other varieties will set in such quantities that if thinning is neglected not one half will reach the full size or acquire their best flavor. Besides, these varieties yield fruit so early that the trees will be ruined by this precocious fruitfulness. Two years after planting these varieties will begin bearing, and not more than a dozen specimens should be allowed to ripen annually the two first years of bearing. The period for thinning is when the pears are from a half to three quarters of an inch in diameter; for, as many fall soon after forming, it is not until then the perfect ones can be distinguished. Not more than one half the thinning should be done at once, and the others may be allowed to remain until we can ascertain the imperfect fruit to be removed.

" "There are but few of the finer varieties that are not improved by gathering before they are fully ripe. Not a few have been discarded as unworthy of cultivation, which by early picking improve so as to rank among the first in excellence. Several varieties rot at the core when left upon the tree until fully ripe, 
which will keep for weeks if picked eallier. Among these are the filemish lieatuty, Isemre I )iel, and Louise Bome de Jersey. The true test of the proper condition for githering is the clearing of the stem from the spur when slightly raised. Some varieties should not be left even so long as this. The fruit should never be picked early in the morning, while the dew is on, or in a wet or cloudy day. When it is necessary to pick it in such weather, it should be exposed to light and air until it is completely dry. Pears picked in the middle of a sumny day are superior in flaror, and keep better. Early gathering applies only to the summer and autumn rarietles; late-keeping, winter kinds should be allowed to hang as long as the frosts will permit. A dry, cool room should be used for the storage and ripening of fruits, and there should be nothing in the room from which the fruit can absorb flavor." "

Mr. Copeland says the success of pear culture depends on plenty of moisture, plenty of manure, and on thinning the fruit; and $I$ agree with him entirely.

And now let me say a few words with regard to the peach. The best stocks for the peach, as well as for all stone fruit, are raised from the seeds; and they grow best on thir own stocks, which should be selected, in the case of peaches especially, from the late varieties as the most hardy: They should be planted in rows three feet apart, and eighteen inches apart in the rows; and in this form they should stand until they are two years old. When they have reached this age, in the month of September they should be budcled. The following year they can be set in the orchard, for which the soil should be prepared and manured with the same care as has been recommended for apples and pears. It is not easy to keep a peach-tree in shape. It has a tendency to grow in a rambling, scraggy manner, and can only be kept in order by early and persistent pruning. A yearling tree should be cut back within two or three fect of the ground in the spring; and durmg the following year it should be allowed to retain only three of its shoots, which will form the branches of a later growth and will determine the shape of the tree. Every other shoot besides these three should be remored 
during the season. Cut back these three shoots half their length the following spring, and when the wood-buds appear upon them, rub off all but two or three on each shoot, and so on year by year, until the tree has received a proper form. On the fourth or fifth year the tree will begin to bear, and will soon bring forth fruit abundantly. The fruit should be properly thinned in order that it may reach the highest degree of perfection.

The peach-tree in these days is peculiarly liable to disease. The Yellows and the borer are its most dangerous enemies. For the former the only remedy I know is the selection of a warm, dry soil, a plentiful supply of ashes and bone-manure, and patience and submission when the disease breaks out. For the borer the author of "Ten Acres Enough" gires the following effective remedy: "Ten well-grown bearing trees which I found in the garden were harboring one hundred and ninety worms among them when I unclertook the work of extermination. I bared the collar and roots of each tree as far as I could track a worm and cut him out. I then scrubbed the whole of the exposed part with soap suds and a regular scrubbing brush, after which I left them exposed for a weck. If any worms had been overlooked, the chips thrown out by their operations would be plainly visible on the clean surface at the week's encl. Having tracked and cut them out also, I felt sure the enemy was exterminated, and covered up the roots, but first using a swab of common tar, applying it all around the collar and some distance up."

Trees attacked by the borer may be restored to liberal fruitfulness in this way, and if they are in a nursery, they can in the same way be kept free from these destructive pests.

Of the varieties I prefer the freestone, white-meated, medium early. The very early kinds are apt to be deficient in flavor and firmess; and the very late varieties are ofien coarse, harsh, and litter. The Cambridge Belle and Morris White do very well in our climate, and are very delicious. The Crawfords, both early and late, being yellow-fl shed, have never stood high on my list. 'They are beiter to raise and sell than to consume. 
I think it is unnecessary for me to occupy your time in cliscussing the apricot, which is a fancy fruit intencled for the garden, and merely ats an attractive variety. It sichom yields well, and cannot be profitably raised for the market.

I doubt not I have omitted many important matters in this statement, which I have drawn purtly from my own experience, and partly,from the best authority and the most concise, methodical, and agreedble writers. If I have at last done anything for the benefit of the (lub), I congratulate myself upon it ; and I feel more grateful than I can express for the patient attention I have received. I trust the subject with which I have dealt will be carefully discussed by the members of the Club, and I shall be happy to receive any suggestions by which I shall be able to perfect my orchard, to whi.h I have devoted so much time, and to which I am so warmly attached.

"I should say the raising of pears and peaches was rather fancy work, after all," said Sam Barker.

"Not cxactly," replied John Thomas. "I don't think it is quite as steady-going and substantial as raising corn and potatoes; but these nice fruits require care and attention, and that never does any man harm; they are always a luxury, and that looks well on any man's table; they often sell well, and that encourages a man's pocket. It don't do to carry them too far. But they will do to civilize the men-folks, just as flowers civilize the womenfolks. I have a few trees, a few pears and peaches, and I nurse them, and look them over, and trim them, and diground them, and like to know that they belong to the farm. They make it kind o' human."

"It don't do a man any harm to have a choice thing round," said Ben Adams.

"As it is in fruit culture so is it in every other branch of farming," said Mr. Howe, who noticed the good influence of the discussions of the Club on those who had attended its meetings. "An attempt to reach and main- 
tain a high standard will always improve a man's whole life, whether he makes his effort on the land or in the library."

At this moment Charles Ingalls entered, as if to confirm the truth of Mr. Howe's last sentence; and a welcome guest he was. He had finished his business in Boston, and with the promptness of a good lawyer and a faithful lover he had made the best of his way back to Jotham and the modest mansion of the Widow Bell. His arrival was unexpected to Clara, who supposed from the tenor of his last letter that he would necessarily be absent a week longer. She was not exactly prepared to meet him. She had been loving a schoolmaster and a law student so long, that she was a little abashed in the prescnce of a professional gentleman who had stepped at once into a good reputation and into association with those whose socicty is an indorsement of ability and character. She was getting ready to meet Charles, and he had come before she had completed her preparations; and as the fine speech died away on her tongue, and as the resolve she had made to impress him with her progress and development as much as he would undoubtedly impress her with his own faded and died away from her heart, she felt abashed and awkward, and stood there before her lover the poorest picture of herself which could be imagined, and in striking contrast with the self-possessed and polished women, young and old, whom he had met during his absence; nor did she recover at once. In endeavoring to play her part well, she had lost all her natural force, and she became disappointed in herself, ashamed of herself, and half afraid of Charles. And Charles, too, was disappointed. He had left Boston gladly, and had hastened homeward with growing anticipations of the abounding joy which awaited him there. He did not exactly realize how humble that home was. He had partially forgotten what a 
simple and unadorned person Clara was. And when he found himself suddenly transported from the sulid comfort and thorough culture of the city to the uncxpected awkwarlness of a starled country girl, and the bare simplicity of her country home, he was stumned and astonished, and at last distressed. He did not get along at all ; nor did Clara. Poor Mrs. Bell did n't understand the chilliness of the atmosphere in her usually bright and sunny home. Charles tried to be cheerful, and told of his success; tried to be kind, and told how in the midst of all the gayeties of his journey he had longed for the easy companionship of his friends in Jotham; tried to be affectionate, and told Clara how much more dear to him were the warm and genial rays of her home, adorned as she adorned it, than was the luxurious abole of Mary Fenton, made graceful by her studied and polished presence. But he failed to be either cheerful or kind or affectionate; and, without losing his temper, he sat awhile, after sipping his cup of tea which Mrs. Bell had provided for him, in a painful silence, and at last, saying that he really ought to go to the Club, he strolled out in a state of misery, disappointment, and disgust. He was wretched and bewildered. How gladly would he have returned and thrown his arms around Clara in an ecstasy of reconciliation and warm and thorough understanding! But she was not the Clara whom he had left but a few short weeks before, and he stared out into the darkness until his eyes were near to bursting, in hopes that he might see the light and beauty which he had failed to find where he confidently expected it. His experience in the city grew hateful to him; and in an agony he cried to God that he would restore himself and Clara to the sweet and happy home which was once so unclouded to them both. And through the stillness of the night there came floating and panting to his ear a bursting sob of passionate distress and hopelessness which told him how decply a 
young heart might be buried by the despair of disappointed love. But he returned not, - why, he could not tell. And so he entered the checrful parlor of Mr. Hopkins to be cordially welcomed by his old associates there. Clara laid her aching head upon her pillow, disappointed, broken-hearted, and bewildered by her own conduct as well as by the conduct of her lover.

When Charles appeared in the Club the debate was just drawing to a close. Mr. Hopkins declared the meeting to be adjourned, and the members gathered around the young lawyer with stich cordiality and unaffected warmth that his spirits rebounded, and he began to feel that he had really found his home and his friends after all. He told his experience rapidly to one group after another, and received their congratulations on his success with that feeling of manly pride and independence which sometimes passes for youthful vanity and complacency. One after another, at last, the members withdrew, and left a little assembly consisting of Mr. Ilopkins, Mr. Iowe, Dr. Parker, Squire Wright, and John Thomas, who drew up their chairs before the hearth, and called Charles into the circle to give an account of himself. He had witnessed no more cheering scene than that in any house which he had entered during his absence, and he had fallen into no stronger, more manly and intelligent and independent group than that which he now joined. Mr. Hopkins, Dr. Parker, and Squire Wright lighted their cigars, while Mr. Howe looked on with an air of serene superiority to such questionable taste, and John Thomas contemplated the glowing backlog with apparent indifference to the habits and opinions of his companions.

"Well, Charles, we are glad to see you home at last," said Squire Wright, when his cigar was thoroughly lighted; "and we think you have done your work well."

"Yes," said Mr. Hopkins, "and I have been thinking it 
would n't be a bad plan, Squire, for you to have an office in lioston, and locate Charles there. He is going to make a first-rate commercial lawyer, I am satisfied."

Charles thought of Clara, and shuddered.

"I don't know about that," said Dr. Parker. " I cannot conceive anything so bad for our country towns as drawing away from them all the young activity and talent, and pouring it into the large cities. Why, what a misfortune it would be to our State and the country to destroy all the dignity and independence and power of the country, Squire. Don't suggest such a thing."

"But," said Mr. Howe, who had begun to dream of a city pulpit, " ambitious young men and young men of talent must find a sphere where they can fulfil their mission."

"O Parson, don't for Heaven's sake talk about spheres and missions!" exclaimed Dr. Parker. "Jotham is enough for me, and may be for any man who knows the difference between a reality and a sham."

"Your old father always said you had no ambition, Doctor," said John Thomas, bluntly.

"If you want to make your mark among men, you must go where men are," said Mr. Hopkins.

"The merchant is right," said the old Squire; "and let me tell you man can't afford to avoid his fellow-men. If he cloes he must pay the price for it in mind, body, and estate. I have great respect for my profession. Excuse me, Parson, but I think it is the great sphere for the exercise of man's highest powers. The creation of a state has always received the achmiration of the world; the creation of a code, as the foundation of a state, is one of the most difficult tasks ever undertaken by man. And I have always connected my profession with such labor as this, because I know no way in which man can approach the work of creative statesmanship except through the avenues of the law. There is certainly no service on earth in 
which man can apply all his powers of mind as he can in this. I may be hardened and narrowed myself by severe work in the practice of law, I know, but I cannot tell how highly I appreciate the character of a sound, wise, progressive lawyer, - a lawyer who understands what the law is, and also knows how to interpret it in accordance with the best spirit of the age and country in which he lives, and how to reform and modify it in accordance with the necessities of the times. I may be told that the business of a lawyer is to conserve, and hold back, and apply. But I think differently. A knowledge of the law should not make a man an obstruction, even if the practice of the law has that tendency. I do not forget that out of the legal philosophy with which he had stored his mind, Jefferson drew the doctrines of the Declaration of Independence; and I cannot be too grateful to those great legal minds which, during the opening scenes of the Revolution, taught the American people the firm foundations upon which to build the Republic, - Adams, and Otis, and Quincy, and Randolph, and Lee. And I have always admired the comrage with which the great freedom-loving lawyers of our own times have defied the decisions of the courts, have led the people on in the paths of progress and freedom and humanity, and have bent the law to their great doctrines of right. Now, Charles, my day is over; and let me beg you, guided as I am by the light of experience and long observation, to be a sound and wise lawyer, if you would be useful in your profession, and a humane, progressive, bold, reformatory lawyer, setting higher value on principles than on precedents, on doctrines than on rules, if you would be useful to mankind. And let me warn you that inasmuch as you fail in this latter service, so much will you fail in accomplishing all that the profession you have chosen offers you in a republic like ours." 
The Squire finished his harangue and his cigar at the same time. There was no more to be said. He looked exalted, and his audience looked thoughtful. And they sat there and watched the dying embers, and smoked, and dropped in a remark here and there, until a nod from John Thomas reminded them that it was time to depart. And so they did.

Charles Ingalls took care to separate himself from his companions and make his way home alone. He had found temporary relicf in the excitement of the Club, and in the fireside talk which followed; but this was exhausted, and he was now compelled to turn to himself and to bear the full force of the disappointment and pain which sensitiveness and ambition had brought upon himself and Clara. He felt ashamed of his own weakness, and sick at heart that he had not, in a manly and generous way, lifted her who loved him so deeply out of her trouble, and restored her at once to an abiding faith in her own superiority and his affection. One kind word, one gentle look, would have done it all; and in this he had failed. And now his selfreproach was bitter, and his young and lordly head was bowed in shame and regret, as he realized that he had in the very morning of life inflicted a wound which might never be entirely healed, and remembered how dangerous it is to disappoint a woman's love in the beginning. As he approached his humble home he saw a faint light in Clara's window, and his heart sank within him. He entered the house, and all there was still. He crept to his room and to a night of repentance, and sorrow, and new resolutions, and restored devoted love. 


\title{
THIRTIETH MEETING.
}

\author{
GRAPE CULTURE.
}

THE MORNING DAWNS. - MRS. BELL SIEPS IN. - THE CLOUDS VANISH.-CHARLES RETURNS TO HIS LAW, AND CLARA TO HER LOVE.

THE dawn of the morning clothed Jotham with its splendors, and the breath of the morning filled it with sweetness and life. The stars of heaven retired from their nightly vigils before the rising illumination, and all the feeble, flickering candles which had watched during the heavy hours of night by the bedside of pain and sorrow made way for the consoling and invigorating light of the new day. The sad and the joyful realities took the place of those spectres which assume a material shape in the night watches, and fill the soul with a painful ecstasy or with overwhelming dread and apprehension. The distressing intensity of darkness was over, and the healthful infuences of the sumlight were felt in mind, soul, and body, as well as in the awakening forces of the natural world. To Charles and Clara the daylight was especially grateful. They had passed a slecpless night, surveying with distress and terror the great gulf which seemed suddenly fixed between them, exaggerating the trials of the present and magnifying the gloomy prospects of the future. The mystery of the situation neither of them seemed to understand. For herself, Clara felt that she had been brought to her trying situation by an ambitious clesire to appear well in the eyes of her lover; and why such a worthy endeavor should be rewarded with such profound sorrow, and such a painful 
distuption and misunderstanding, she could not comprehencl. At times she was disposed to be angry with Charles for his apparent disregard of her feelings, and his incapacity to understand the embarrassment into which she secmed to herself to be naturally thrown. For himself, Charles had a more difficult task still. His conscience smote him when he recalled the emotions which rushed upon him as he returned to his home, and found it smaller and less demonstrative than he had anticipated; and he was not ready to forgive himself for having been tempted by the more imposing attractions of the outer world. He could not be angry; but he could be ashamed, then penitent, then anxious for the hour to come when he could ask forgiveness, and in a manly way return to the sweet companionship of her whom he loved, and enjoy once more her affection and confidence. While he had no idea of the cause of Clara's apparent indifference, and was so puzzled in his endeavors to attribute it to any rational motive, that he at last convinced himself that it was scarcely more than momentary and accidental awkwardness, he had no such excuse for himself; and he had an idea, all too vivid, of the weakness and almost wickedness of his own which had beclouted their heavens. It was he, therefore, who arrived first at the point of thorough reconciliation.

It is not an easy matter to be equal to a peaceful adjustment of our difficulties, or to return to the abodes of confidence and love after having wandered away from them. Charles felt this keenly as he hastened to meet Clara in the early morning hour and knew not whether by confession or appeal or by natural impulse, he was to be restored to his home in her heart. Clara felt it more keenly still, because it seemed to her that nothing short of desperate estrangement could have brought Charles to his frigid and repulsive deportment. When they met, therefore, - Clara more fascinating than ever, a drooping lily, beautified and 
spiritualized by the sudden sorrow, her pale face still bedewed with grief, and her steady and loving eye depressed by the storm; her whole form softened with an air of doubt and hesitation, and sustained by an evident capacity to bear the trial if it must come, - and Charles freed from every ignoble sentiment, and elevated to a strong and manly determination that no cloud should hang over that loving heart again, so long as he held his place of light and heat in its heaven, conscious of his power when true to her whom he loved, and of his weakness when false, when they met, the heavens were cleared at once, and the doubt and trial were all in an instant forgotten. Charles's radiance brought strength and peace to Clara; and Clara's shrinking and touching sorrow brought generosity and courage to Charles. There was no occasion there for explanation, none for forgiveness, none for words. To each the situation revealed itself; and before the great vision which broke upon their eyes, all the annoying events sank into insignificance, and all doubts vanished. The cloud had passed from Charles's brow, and as, glowing with a manly radiance, he drew Clara to his loving heart, and in a gentle and tearful tone exclaimed, "Thank God, my darling, I am here at last," her spirit rose within her, and her heart found its sweet peace once more, as she laid her head upon his breast and whispered: "O Charles, may God bless us evermore! I can bear death, but not cloubt and fear." And on that bright, fresh spring morning, with opening nature as a witness, there went up to Heaven from those two young hearts a vow which was never broken, and a still and fervent prayer which was heard and answered.

"Why, Charles, it does seem so good to see you back again," exclaimed the Widow Bell, who now appeared upon the scene. "Clara's been so kind o' lost and moping, that I didn't know what to make of her. Why, 
when I was young, afore I was married, my poor critter used to go away and be gone all summer a-fishing to the lianks, 'cause he was kind o' feeble like; he never had no health, you see; looked real delicate, just like Clara, only not so smart as she looks; I never took on, nor thought much on 't, anyhow. But then folks differs. But I'm so slad to see you home. And Clara looks better a'ready."

"Why, my dear good woman," said Charles, "what an awful time you must have had! But let me tell you that I have no idea of going a-fishing, or leaving you, or quitting Jotham for the present, or allowing Clara to go alone in the world, or giving her a chance to let me go alone. And now a cup of your excellent coffee, Mrs. Bell, before I start for the office and all the labor of the day."

Mrs. Bell vanished, leaving the two lovers to recount to each other what had occurred of mutual interest during their separation. Clara was anxious to hear about Mr. Fenton and the Courts, and inquired about Mary Fenton, . how she looked, what she did, and what she knew. The library was a matter of great interest to her, and she asked Charles to advise Mr. Howe to purchase "Festus" for the book-club as soon as possible, - unconscious as she was of the startling theology which the good parson would find in the fervid pages of that defiant book. The story of the village was soon told by Clara in return; and before Mrs. Bell had prepared her breakfast, the way of life was running smoothly for her family, as it had been for herself.

Charles reached his office in good season, and had it and his papers in good order long before Squire IVright appeared, to receive an account of the precise condition of the business which had called Charles to Boston. The examination of the papers, which was commenced by the sagacious old lawyer as soon as he arrived, proved to be 
eminently satisfactory, and the decision of the Court was found to sustain all the points for which he had contended from the very beginning of the difficult case. And then camc a long list of those matters which always accumulate in the office of a country lawyer. William Jones had inadvertently sold a spavined horse to Deacon Morrill, of an adjoining town, and the irate deacon had left the case in the hands of Squire Wright; Charles was directed to call Jones's attention to the matter, - but in any event not to get into a "horse-case." Sam Barker and his brother Phineas had lived together for twenty years on the undivicled estate of their father. Phineas had died, and now his heirs called on Sam to divide and settle. Sam thought this a hardship, and had put himself into the hands of Squire Wright. Dr. Parker had left a long account against the railroad for services in the great accident where ten passengers were killed and twenty badly wounded; and he hoped the account would be pressed to an immediate settlement. The grocer who had just died had boarded with Ben Adams twenty-five years, and during all that rime there had been no settlement between them, so that there was an interminable grocery bill on one side, and as interminable a board bill on the other; and Ben Adams, who was indignant at the demands of the creditors of the grocer for a settlement, and who feared it, had put himself, too, into the hands of Squire Wright. John Thomas had been talking about making a will, and had left some minutes in the hands of Squire Wright, which the Squire now turned over to Charles, to be put by him into shape. And Charles began to think that the law business of Boston was nothing when compared with that tide which poured into the humble little office in Jotham. Into all this work, therefore, he fell, and he devoted himself to it so diligently that he forgot everything else about him, and everybody but Clara, and was quite astonished to find 
that the time had arrived for a meeting of the Club, at which he was expected to read a paper upon the subject of

\section{GRAPE CLLTLRE.}

The meeting having been called to order, and the subject having been announced by the President, Charles Ingalls discoursed as follows:

Mr. Presinent, - The cultivation of the grape is one of the most difficult and doubtful operations of all that are undertaken by the farmer in this latitude. 'The grape is especially attached to its congenial soil and climate, and is not readily adapted to a new one. "It is," says Deaman, "extremely fastidious in its selection of the soil and temperature suited to its growth, and its after development is so slow that for six years it bears no fruit at all, and does not yield a full crop before the fifteenth seison. It thrives best on the southem shores of the gulfs of Corinth and Lepanto, and on ancient Peloponnesus. The only other places where it will grow are three of the most fertile of the Ionian Islands, for it resists every attempt at transplanting to other countries of similar temperature or latitude. In Sicily and Malta the cuttings passed into the orclinary grape, and in Spain they would not take root at all. Even at so short a distince as thens, recent similar and perserering attempts signally failed ; yet the fertile and lovely island of Zante is nearly. buried in the profusion of innumerable plantations." Gripes grow nowhere so well as in their native land, and hence it is that the greatest improvement in this fruit has thus far been marle by using the indigenous varieties as the foundation of new stock. It is very difficult to establish the vineyard in all the northern and central portions of New England and the corresponding latitudes west, where it can be relied on year after year for a well-developed and well-ripened crop; but yet every farmer, every horticulturist at least, is ambitious to add this to the other products from which he is to reap a reward for tilling his soil ; and the persistent efforts to cultivate the grape in a latitude unsuited to it are continued. In the unkindly regions 
great care should be taken in selecting the soil and the location. A warm, southerly slope should be secured if possible, and in this way the climate should be brought as near as may be to the temperature required by this plant. Avoid an exposed hill, on account of the blisting winds; and avoid a low valley, on account of the early frosts. 'The quality of the soil should be a warm, sandy loam, with a gravelly subsoil if possible, and entirely free, either by nature or art, from stagnant water. And inasmuch as the roots of the grape are not disposed to penetrate deeply into the soil, but prefer to confine themselves to the warm surface, the soil should not be ploughed to a greater clepth than five or six inches, nor should the manure be so buried as to attract the fibrous roots into the cold strata. It is argued by some very successful grape-growers that the sod ploughed under is peculiarly grateful to the grape, and they consider the decaying grass and roots thus buried to be a most valuable fertilizer for this crop. The soil should not be thin and poverty-stricken, nor should it be strong and heavy. A warm and light and substantial loam is what is most required. Nor should the manure be of a strong nitrogeneous character. The wood of the grapevine will generally grow rapiclly enough uncler any circumstances; and the object in cultivating the vine, therefore, is to encourage especially the growth of fruit. For this purpose avoid barn-yard manure and deep tillage. Fertilize the surface with phosphates, ashes, and bones.

In selecting the vines for transplanting choose the strongest and healthiest which are one year old and have been properly cultivated. Vines older than this are not easily transplanted, and do not begin so readily the business of bearing fruit. In a young vine you generally get the best roots for transplanting, - roots of such a size and organization that they take readily to their new becl. The best time to transplant vines is early in the autumn, if you can get them: not late in the autumn, lest the hard cold of winter should be too severe for them; but early enough for them to get slightly rooted, so that they can resist this exposure successfully. If it is impossible to transplant them in the autumn, set them as early in the spring as the condition of the land will allow. 
Select your vines with care, endearoring always to obtuin those which have a smonth healthy look, with a groocl cluster of fibrous roots, and those which have made the best supply of wood the first season. Be careful not to set the vines too decply; five inches are enough, at which depth you secure all the warmth of the sum and atmosphere, and escape the drought. If set at a greater depth than this, a new system of roots is apt to start out above the old ones, and to perform the whole work of feecling the plant, learing the original roots to clie and decay. The result of this is a feeble-rooted and short-lived vine. If surface roots happen to grow the first year, they should be carefully removed with the knife.

Duing the first year after transplanting the vine may generally be lift to itself. By confining the first year's growth to a single cane you produce a tendency in the root to grow in a similar manmer. If, on the contrary, you encourage by neglect. or in any other way, a multitude of shoots, you encourage also a mass of fibrous and branching roots, which is best adapted to nourishing the vine when it reaches maturity enough to procluce fruit. If the cluster of canes grown on the let-alone principle becomes inconvenient in the work of cultirating the soil, it can be bound to a stake and compelled to occupy but little more space than a single canc. In cultivating the soil in a vineyard great care should be observed to cultivate frequently, but never deeper than an inch and a half, to avoid injuring the roots. For this purpose a light cultivator or a small common harrow with stout teeth will be found convenient: By this process the soil can be kept in a light, porous condition, and the weeds will be most effectually killed.

In setting the rines the best cultivators have found that the space required for each vine is about forty-eight square feet; the rows being eight feet apart and the vines six feet apart in the rows. Says Dr. Fisher in his admirable essay: "The rows should run north and south, and for these reasons: If a row runs north and south, the morning sun shines upon the easterly side, and the afternoon sun shines upon the westerly side; every leaf gets the sunlight in the course of the clay. If the 
rows run east and west, the sun shines all day upon the south side, and the leaves on the north side always make an effort to turn round toward the sun. They get all they can. They get, perhaps, nearly as much sun in the aggregate with the rows in this direction as the other. But the great difference is this: when it comes september, about the time of ripening, if the rows run north and south, the sum shines directly upon the ground for three or four hours during the micldle of the day, and it warms up the soil, and that soil holds the heat during the night and radiates it. The temperature of a vineyard will thus be some degrees warmer than otherwise. If, on the contrary, the rows run east and west, the vines shade the entire ground, and hence you lose part of the heat. The moment the sun disappears you have no stored-up heat to carry your vines through the night. This, in the time of frost, is sometimes very important."

Vines should be pruned in the autumn of the year, and each vine should be cut down within two buds of the earth. In this way we have a strong, well-organized root, capable of nourishing the small vine which remains with its two buds; and a strong healthy growth will follow. Give the vine a free growth the second year, as you did the first, confining its abundant growth to a strong stake, and prune it again in the autumn, cutting it down to two buds from the root, and unless the vines are unusually strong, they should be pruned down the third year also; if very vigorous they may be allowed this year to fruit a little.

During the third year it is necessary for the vine to be furnished with a trellis erected as follows, according to the authority of Dr. Fisher. The posts should be made of twoinch-square chestnut, or some other hard, durable wood. "The posts should be set six feet apart through the whole rineyard, one post for each vine; they are set two feet and a half in and five feet and a half out, being eight feet long. My custom is to set the end post right by the side of the first vine, which makes it nine feet from the next one. The others are six feet apart. I put a brace in at the end, bracing the outside post to the foot of the next one, which brace is set into a little shoulder 
just sufficient to hold it. Then upon these posts the wires are stretched. I have used various kinds, but the last was No. ${ }_{5}$ galianized iron wire, which I am inclined to think will give better satisfaction than anything else. 'The lower wire is placed twenty inches above the ground, a little higher than I used to put it, for the purpose of keeping the grapes on the lower part of the trellis out of the dirt. A year ago this last autumn there were heary rains through the month of September, that spattered a great deal of soil upon the grapes, and it was ve:y difficult to get it off. It troubled me so much that I decided that the lower wire should be raised to about twenty inclies from the ground. The next wire I put fifteen inches above that. You will see the utility of that by and by. The next wire is fourteen inches above the second, and the next onc is fifteen inches above that.

"At the beginning of the third year allow but one cane to grow from each vine. Lead this cane of the second vine up to the first wire and let it grow along the wire during the season. Carry the next cane up to the third wire and let that run along the wire also. Lead the next cane up to the first wire and train in the same way. And so on alternately through the entire row. If laterals start from these canes, pinch them off to one leaf from the cane, being careful not to injure the leading shoot, nor nip it off until it reaches a height of six feet. Prune the vines in the autumn of the third year, by simply cutting off the superfluous laterals. And if the cane is not strong enough to bear fruit the next season, cut it back to within tỵo buds of its origin, and so continue to do until the wond becomes strong enough to hold the fruit, and rigorous enough to produce it. Thus managed, vines should begin to bear the fourth year.

"During the fourth year we shall find a shoot starting from each one of the buds, and these shoots should not be allowed to grow beyond a cluster and two or three leaves beyond; this will suppress the growth of wood. Meanwhile the shoots are allowed to progress for a little time, and when they become firm enough and long enough they can be tied to the second 
wire above them. If laterals start out on these upright shoots aluring the season, they must be nipped off as the laterals were during the first year. When the tops of the laterals are pinched off, the surplus gripes should be pinched off also. This must be done in orcier that the vines may not be exhausted. A vine, it is said, cannot bear more than six pounds of grapes successfully and without injury to itself, and it should not be called on to do more. The shoots, at this period of the life of the vine, should bear but one cluster apiece. The cluster nearest the arm will usually be found to be the largest and the best, and should be preserved.

"It will be found easy, on the plan I have thus laid down, to get the first crop the third or fourth year. But when you begin to lay your plans for the succeeding crop the difficulty begins. In oreler to secure this, select a strong shoot from the main stem and train it up to and along the wire in a direction opposite to the canes that are bearing. In the autumn cut away all of the vine that has already borne fruit and turn your attention to this new cane, upon which you are to depend for your future supply. You will in this way find yourself with but one arm, as was the case at the close of the fourth year; but the arm turns in the other direction. One year all the arms will run towards the south; the next year they will all run towards the north; the next year towards the south again. That is, the bearing arms grow one way and the growing arms the other; they change places. The arm that has borne your crop being cut away, the remaining arm will bear the crop the next year, and you grow a new one on the other side for the succeeding year. You have one cane bearing a crop, and you have another cane that grows six feet for the crop of the next year. Vines managed in this way can be kept in bearing a great many years, especially if they are allowed at no time to bear more than a reasonable amount of fruit in any one season."

The preservation of the grape is more difficult than its cultivation. In a good season almost every cultivator can get a good crop; but it is seldom that the best cultivator knows how tn keep his crop. The best plan is undoubtedly to place the 
grapes on movable shelies in a cool fruit-house liept as near the tumperature of forty degrees as possible. Some rarieties lecep much better than others, but the plan I have sugresested will apply to almost all the varieties that are worth raising. It is unquestionably wise to market your grapes as early as possible after gathering; and it is also wise, as I think, in New England to waste no time in endeavoring to convert the juice of the grape into wine. I good wine grape does not wrow here. Neither the soil nor the climate is adapted to the production of such varieties of grapes as produce the delicate wines of the Rhine, or the substantial and fruity juices of Spain and the south sicle of Madeira, or even of ()hio, Pleasant Valley, and Califormia. Nor is there skill here in the manipulation of the grape for this purpose. I shall not discuss the rarious methods of wine-making, for the reason that the dictails of the art can only be learned by experience, and an elaborate discussion of the subject during the space and time allowed me is impossible. Ibut some statistics of the wine crop of several countries may be interesting to you, and I therefore venture to submit them. The wine product of the United States was in 1870 nearly $S, 000,000$ gallons; California alone making, as long ago as I 865 , quite 2,000,000 gallons. In France, whose population does not much exceed that of our own country, the arerage production of wine is $\$ S_{4}, 000,000$ gallons, worth at the press twenty-five cents a gallon, or \$221,000,000 for the whole crop. The aggregate number of acres devoted to the grape in all Eurnpe is $12,2 \$ 5,780$ : the aggregate annulal crop is $3,107,039,000$ gallons, and the aggregate value of the crop is $\$ 76_{3}, 733.500$, this last-named magnificent sum being the amount received by the producer, and it is safe to believe the value is cloubled in the hands of the wine merchant.

The insects and diseases which trouble the vine are numerous and not easily overcome. The modes of getting rid of the insects are attracting the parent moths to their fate in early summer by building bonfires in the vineyards, destroying at the first pruning all nests, webs, etc., and dusting the rines with sulphur-lime throughout the season; and, as is necessary with 
the rose-bug, gathering them in sheets spread for the purpose, and then destroying them with fire or hot water. For the vine hopper, clust the leaves in June when the bug appears, with sulphur and caustic lime, early in the morning. The same application when the dew is on will destroy the aphis, or louse. For the diseaves which attack the vine a remedy may be found, or a prevention rather, in a dry, warm soil, proper pruning, and proper cultivation. The fungoid diseases can be removed by sulphur and lime, and so may the black rot.

Mr. Dickerman in his lifetime gave us fourteen cautions in grape culture, as follows: "(I) Against using green manure, either in the preparation of the soil or after culture; (2) against working the soil when wet, either in preparation or after culture; (3) against planting vines too shallow in light or gravelly soils, or too deep in heavy ones; ( $t$ ) against allowing secondary roots to grow from the stem, above the original roots; (5) against cutting any of the main roots in any of the operations of culture; (6) against covering the vines in the winter wholly with straw or barn-yard litter ; $(7)$ against too late spring pruning after the salp has started: (8) against putting down too long horizontal arms when the plants are not vigorous; (9) against allowing young rines to bear beyond their ability; (ro) against letting laterals grow too long befure pinching; (I I) against letting the canes from the horizontal arms grow too long; (12) agrainst allowing one cane to grow higher than another, unless the growth of wood is too rank, when one or two canes may be allowed near the main stem as safety-valves; (I3) against tying the vines too tightly; (If) against applying manure, except in the fall. If applied in the spring or summer it will produce a rank growth of wond which will not ripen before winter."

It seems hardly necessary that I should give you a list of the desirable varieties of the grape when so many are constantly brought to your attention by all dealers, propagators, and speculators in vines. The Adirondack, Allen's Hybrid, Concord, Clinton, Colamba, Delaware, Diana, Hartford Prolific, Iona, Isabella, Rogers' Hybrid, and the many farorites which the skill 
of man and various soils and climates have produced, will furnish all the opportunities that can possibly be (lesired of sup)plying ourselves with this delicious fruit and of adding to the grace and culture of our farms. To you all, then, let me commend a reasonable culture of the grape.

The address of Charles Ingalls seemed to be highly acceptable to the Club, who, while they had but little knowledge of the subject, were nevertheless interested in the cliscussion of a branch of agriculture, or horticulture, which employed so many laborers and absorbed such a large amount of capital. The grape, too, had a sort of poetic interest to them, connected as it was with many familiar events in history, ancient and modern, and festooning the trees which fringed the warm and sunny meadows with a tempting luxuriance of fruit, of which every boy claimed his inalienable share.

"What a dreadful wine-drinking world this is!" moralized Moses Ferson, as he pondered on the figures which Charles had given of the manufacture and traffic in the juice of the grape.

"Yes," said Dr. Parker, " and I learn there are those who look upon the trade as a great moral agent."

"A great moral humbug;" exclaimed Mr. Howe with unusual warmth, and turning to the Doctor to see if his resolution still remained firm. The Doctor looked wholly unconscious, and simply turned to Squire Wright and suggested an adjournment and a walk home together. He seemed to think Fanny might expect them, and in this he was not far from right. An adjournment was voted, and as one by one the members of the Club departed, Mr. Hopkins beckoned to Charles Ingalls to remain, and sitting there long into the night, the old merchant told the tale of his early life in Jotham, and retraced with Charles the steps he had taken so often along the busy highways 
of trade in the great metropolis, hoping to hear from the young Squire, who had just grown familiar with its men and manners, something of this old friend and that whom he had not seen for so long a time, and about whom he dared not ask any questions, for fear that they might have entered upon the dark, mysterious journey. And as they sat there, the old man seemed to rejoice in the strength of his young friend, and in his own gently fading powers. When Charles left, Mr. Hopkins sent his love to Clara. 


\section{THIRTY-FIRST MEETING.}

\section{IMPLEMENTS OF HUSBANDRY:}

IIR. HOPKINS DISCUSSES MOWING-MACHINES, PLOUGHS, ETC. - THE CLUB DISPERSES SLOWLY.

THE agricultural prosperity of Jotham was evidently increasing, either under the influence of the Club or under the stimulus given it by the progressive and well-endowed operations of Mr. Hopkins, and the excellent market he had opened by his intimate relations with the business men of the neishboring city. The farm-buildings of the town were now kept in good repair, their conveniences were greatly increased, and they were adorned with many articles of taste which gave them a cheerful and home-like appearance. And not only the buildings, but the tools and implements used by the farmers in their business, had improved in so marked a manner that it was deemed wise to set apart an evening for the discussion of the best mode of equipping a farm, and the economical care of those things which enter into the equipment. It was found to be a more difficult task than was anticipated; and the committec, therefore, requested Mr. Hopkins to prepare an opening statement, relying on his judgment for advice in the selection of tools and machines, and on his honesty and independence to guide him to wise and just conclusions with regard to their comparative merit.

When the Club assembled, and had been called to order, Mr. Hopkins announced the task he had undertaken, and proceeded at once to read his report, as he called it, upon the subject which had been referred to him. 
MR. HOPKINS'S REPORT ON THE IMPLEMENTS OF HUSBANDRY.

I am aware of the importance of the work which I have undertaken, and of my inability to perform it in a manner satisfactory to those whose practical experience in handling the tools of the farm is so much greater than my own. The strong and vigorous husbandman, engaged in the hard toil of primitive agriculture, may be somewhat indifferent to the form and weight of those implements which are placed in his hands. His strength and skill may be superior to all inventions, and regardless of all the graces of construction. But in our day, when every hour of toil must be turned to a good account in orcler to make that toil profitable, it becomes absolu:ely necessary that man's physical forces should be strengthened, and his skill should be aided and encouraged by the application of the best mechanical laws to the instruments which he applies to his business. We have discussed almost all the practical operations of the farm, the methods of fertilization, the preparation of the land, the care and harvesting of the crops, and I think we can now with the highest propriety consider the implements with which these operations are carried on.

Plingrhs. - The most significant and the most important implement used by the husbandman is the plough. In the earliest diays of agriculture it was simply a pole shod with iron, and bent at its lower extremity at an angle which would enable it to grub up the earth in a rude and simple way, for rude and simple cultivation. The earliest plough used in this country was hardly better than this; and the ploughs used in Northern Italy to-day are so little in advance of it, that, were Virgil to reappear upon the earth, he would recognize in that land of the vine and the olive the same instrument which he describes so well in the Georgics. The progress of civilization, and of agriculture at least, may in fact be marked by the attempted and actual improvements made in the plough. And while it is the point upon which mechanical skill and ingenuity as applied to agriculture have failed more than on any other, it is still one 
on which such manifest improvenents have been marle that it may truly be said to be the representative implement of the world.

I wish, gentlemen, I could say more for it than I can. IVe boast of the style and strength of our molem mould-boards, beams, land-sides and coulter; but we have been thus far unable to lay aside the primitive design of the rudest plough, and we have not yet been able to surpass, with all our mechanical slill, many individual specimens of a simpler and ruder construction. I wish I could say that we had left the general principle of the plough as a pulverizer of the earth behind us, and had secured for ourselies a more complete and competent implement, one capable of cloing vastly more work than the plough can do with the same amount of power, and one the quality of whose performance does not depend on the skill and strength of him who guides it. The working of the plough depends to-day, as it always has, upon the skill of the ploughman. This should not be. We should be provided with an implement of pulverization which will work as well in my feeble and inexperienced hands as in the hands of a strong and ablebodied expert, who can overcome in a trial of ploughs because his arm is stronger, and his back is broader, and his step firmer than mine, and not because his plough is better. I doubt not that by the application of the best mechanical laws the plough as at present constructed has been brought to a high degree of excellence, - perhaps it may be nearly perfect. But it is excellent and perfect as a plough, and not as an implement of husbandry which has its own independent merit, and is valuable as a rapid and economical pulverizer, because it is not a plough, and is constructed upon a new and better principle.

The premium ploughing of our agricultural fairs to-day is no better than it was fifty years ago. It may be that the superior skill and inferior implement of the olden time are able to accomplish just what superior implements and inferior skill can perform in our day, and that in this way the balance is preserved. But this is not all. The plough itself was in some respects capable of duing as good work ats any of its modern and improved 
descendants. 'The best ploughman I ever knew lived in this town a half-century ago; and I think he owned the best plough I ever saw, - a long, low, rakish plough, with a wooden mouldboard, and a broad land-side, so constructed that it held its place in the furrow, and so substantially founded that it could
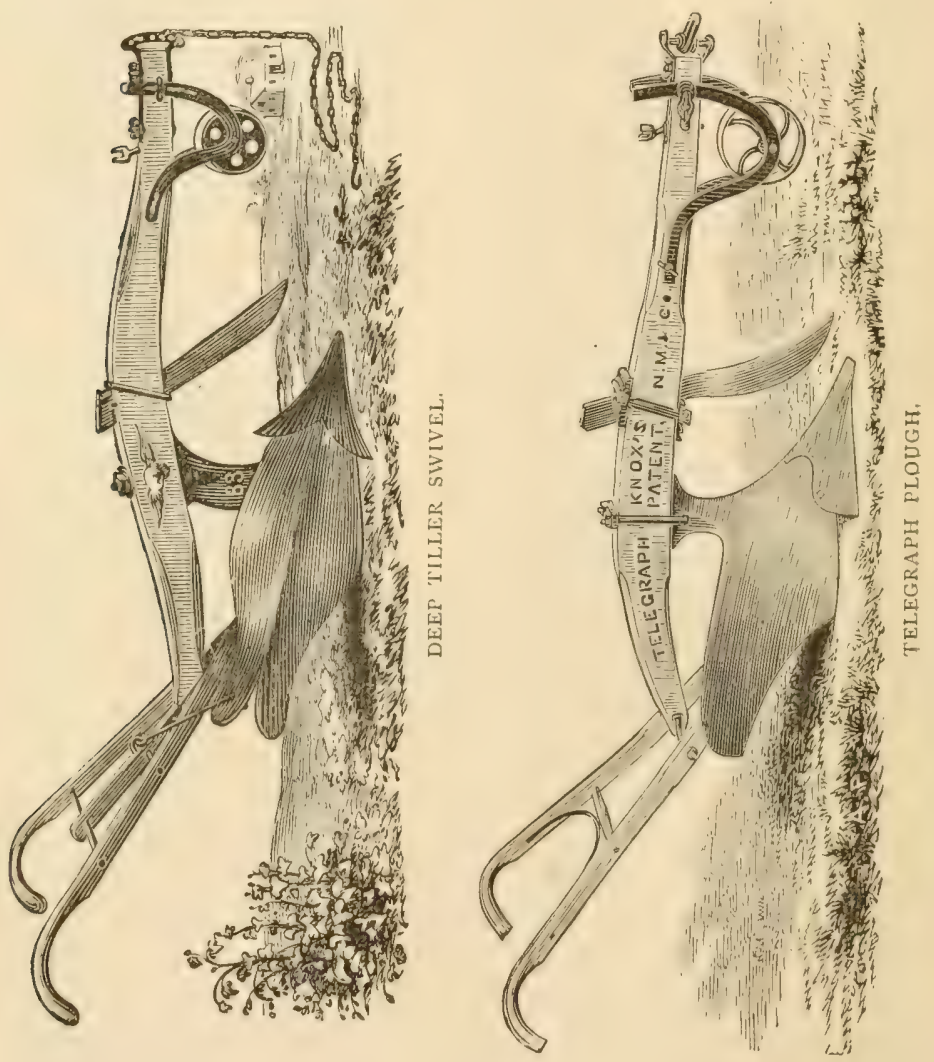

lift its furrow-slice without calling in the aid of him who followed it. This plough may have been an accident; and so are many of the improved ploughs of our own day. The ploughman may have been an accident also; and so are many of those 
whom we now know. And is it not evident to you all that we shoukl have gone beyond the range of accident in these dias if mechanical improvement, and have reached the fixed and established fact?

Now if we are to be compelled to confine ourselves to the plough as an implement of pulverization, is there no definite law of construction which will give us a plough good in all soils and in all hands? There ought to be. And yet this whole question of construction is so involved that no two ingenious inventors agree. One will tell you that you cannot get a plough properly through the land except on the principle of the concave. Another will tell you that the best pulverizing plough in the world is built upon the principle of the convex. And it is a curious and striking fact that two plougbs, one eminently concave and the other eminently convex, working in the same soil will produce precisely the same results and will be attended by precisely the same defects. One inventor devotes himself to the land-side, another to the mould-board, another to the angle of the

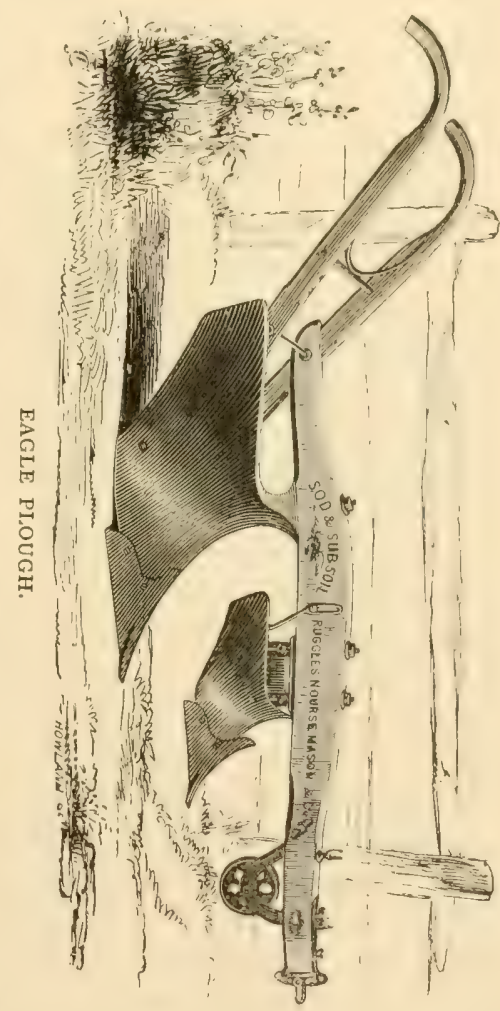
hanclles, another to the centre-draught; and while all their ploughs differ, they all agree in this, that they will all work in the same manner, and that they all depend on the skill of the holder. 
Not a plough but has its advocates; not a plough but has its admirers.

Now is there no such thing as an exact and proper balance between the two sides of the plough, the land-side and the mould-board? Is there no such thing as a land-side which will enable a feeble-backed man to keep his plough at work properly and prevent the necessity of his holding a great solid furrow, say twelve by twelve, wholly by the strength of his loins? Is there no mould-board which bears a well-balanced relation to a land-side like this? Cannot the advocates of these two important points of the plough learn of each other, and so make their combination as to provide us with the perfect implement? Preserve, then, the balance, and remembering that the draught is not increased by the length and breadth of the land-side, make this portion of the plough the foundation upon which the entire structure may rest. Then may you adopt the concave or the convex form of the mould-board as suits your taste, confident that either, when properly combined, will do its work well. I have examined most of the popular ploughs, and I have found that all those which were most widely esteemed have this characteristic. There may be ploughs with short and imperfect land-sicles which will work well in certain localities, but their sphere is usually circumscribed. And whether it be the Telegraph or the Doe Plough, or Allen's Cylinder Plough, or the Deep Tiller, or the Conical Plough of Mead, or the Lion, or the Eagle, or Holbrook's Ploughs, the plough which satisfies the most ploughmen and does the best work is that which is held steadily in the soil by a capacious mould-board.

Of gang-ploughs and steam-ploughs I shall say nothing, because they are inapplicable to our work and are yet in an imperfect conclition, except for the broad work of the plantation and the prairie. That I can say nothing also of spaders I most sincerely regret, for we have no implement of this kind which is entitled to consideration. If any inventor therefore would immortalize his name and be hailed as a public benefactor, let him invent a spader which will turn up and pulverize six or seven acres a clay to the depth of eight inches, and can be drawn by a 
pair of farm horses. His fortune and renown would be estab. lished at once.

Herrars, - The harrow is an implement which has received many modifications, and not many improvements. The triangular harrow, of various sizes, has for many years been sufficient for all the purjoses of the farm, and has, almost from time immemorial, finished the work of pulverization begun by the plough in all its varieties. Recently some improvements have been introduced. Gecldes's harrows, consisting of two halves hinged upon each other, is very convenient for uneven land, and as usually constructed is of a size well suited to horses. It is armed with the common, straight, iron harrow-tooth. This, and in fact all straight-toothed harrows, are adapted to the work required on welltilled and pulverized land, free from sod; and they may

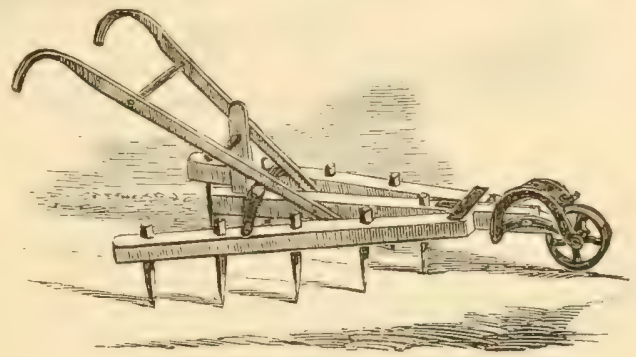

HARROW.

be used with advantage in preparing such land for root crops and for the sowing of grain and grass-seed in the spring. For sod-land, however, the harrow known as Shares's is to be preferrecl. Armed as it is with a series of coulters so inclined as to aroid all clogging with grass-roots and sods, it pulverizes the surface most admirably, and at the same time levels the sod which has been upturned by the plough. For seeding lands in the autumn, and for preparing new corn land in the spring, this harrow is invaluable.

My opinion is that all straight-toothed harrows should be so light as to be easily drawn by horses. The slow motion of oxen is unfit for work of this description unless it be when applied to Shares's harrow for the preparation of new land. Harrowing, to be effectual, should be clone lightly and rapidly. Hurse-Hocs and Cultitators are numerous and generally con- 
venient and useful. I have on my farm a Scotch implement of this kind, sent me by a friend in the old country, which is provided with a set of hoes and also a set of weeders, and which I have found very useful in cleansing the land and in cultivating

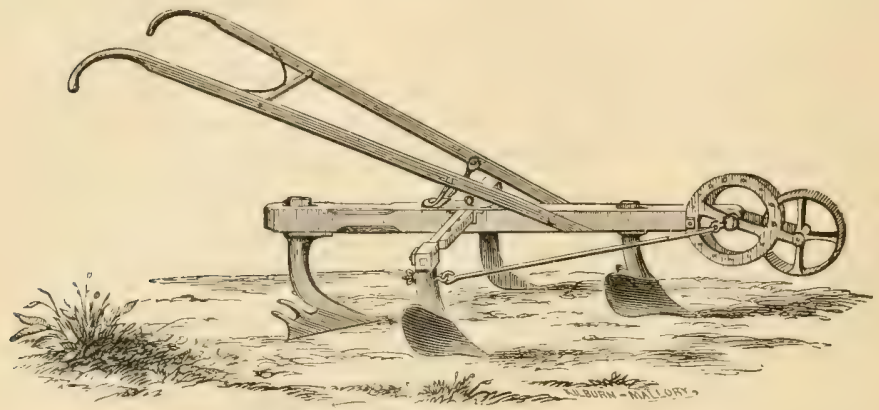

HORSE-HOE.

root crops and the crops of the garden. I use my cultivators frequently among all my hoed crops, and both they and myself find it to be of great advantage.

In my search for seed-sowers and weeding-hoes I have found a great variety and many good ones. The simplest I have

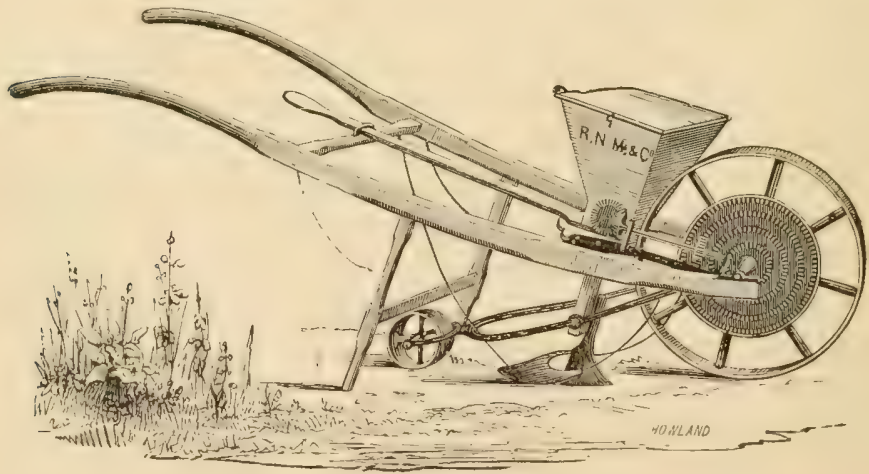

SEED-SOWER.

found to be the best; and with this rule you can hardly go amiss in your purchases. In fact, I find the hand implements 
of the farm so well, so economically made now, that I congratulate myself and you upon the great advantage we enjoy over our ancestors, who were obliged to content themselves with rude, heary, home-made implements, and with the hard labor which went with them. This was when it was by no means easy to equip a farm with strong, useful, and convenient tools at any price. But now shovels, and manure-forks, and hay-forks, and rakes, and spacles, and yokes, and chains, and crowbars, and pickaxes, of the best quality, are easily and cheaply obtained.

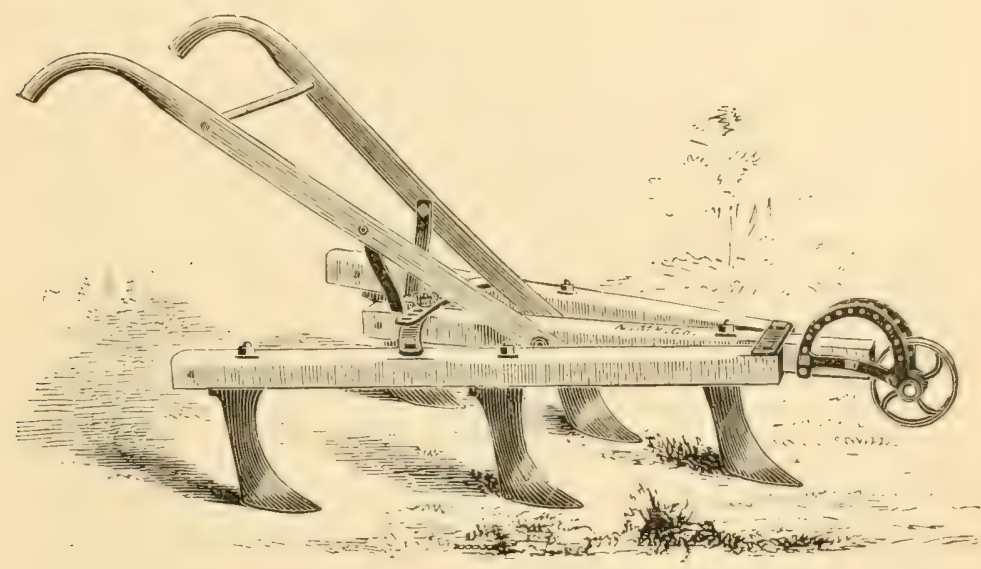

EXPANDING CULTIVATOR.

But it is in construction of machinery for the heavy work of the farm that we in our day especially excel. The invention of the mowing-machine marks as important an era in the world of agriculture as the printing-press did in the world of letters. Introduced into this country but a quarter of a century ago, and brought to a reasonable degree of perfection less than fifteen years ago, it has become an indispensable part of the machinery of every well-organized farm. Rude and imperfect in the beginning, it has been improved and strengthened, until at last it has reached a degree of perfection which makes it as compact and trustworthy and well organized as a steam-engine. 
For this we are indebted to some of the best mechanics in our country. Beginning with Ketchum's mower, in 1850 , a machine of such doubtful value that few farmers were induced to lay aside their scythes and adopt it, the work of inventing, improving, and constructing has gone on until it would be difficult to enumerate the valuable machines with which the marliet is crowded. The scarcity and high cost of labor, and the increasing amount of hay cut and consumed throughout the country, created an imperative necessity for a reliable mower, until in $\mathbf{1} S 55$ the spirit of invention was fairly aroused and machines began to multiply. Ketchum and McCormick were almost forgotten, and the leading agricultural societies in our country began to offer such liberal rewards, that the number of inventions increased with great rapidity. At the great trial instituted by the New York Agricultural Society, in I $8_{57}$, at Syracuse, more than forty mowers and reapers were brought together, all giving evilence of vast improvement in the work of cutting both grain and coarse and fine grass, over all predecessors. At the second trial of this society at Auburn in 1866 , the number of machines was largely increased, and their value was found to have largely multiplied. The principle upon which a machine could be made to cut grass systematically; thoroughly, and stcadily had evidently been discovered; and when, in I 869 , the New England Agricultural Society organized its great trial at Amherst, Massachusetts, it was found impossible to determine the relative value of the machines, except by dividing them into groups. The Buckeye here retained the high position it won at Syracuse and Auburn, and found strong competitors in the same class with itself, in the American, the Clipper, and the Kniffen. Since that time these machines have been greatly improved; and their light, compact, ornamented frames form not only a useful but an ornamental object in the hay-field. At home and abroad has the value of American mowers and reapers been recognized; and while on our own shores an army of inventors has won an honorable clistinction in this work, the names of McCormick and Walter A. Wood are remembered still in foreign lands for 
the admirable machinery which they exhibited and for the high prizes which they bore away.

As with the movers, so has it been with the reapers. Reilizing the importance of providing for the harvesting of nearly $200,000,000$ bushels of wheat annually in a rupid and economical manner, the same ingenuity as was applied to the mower

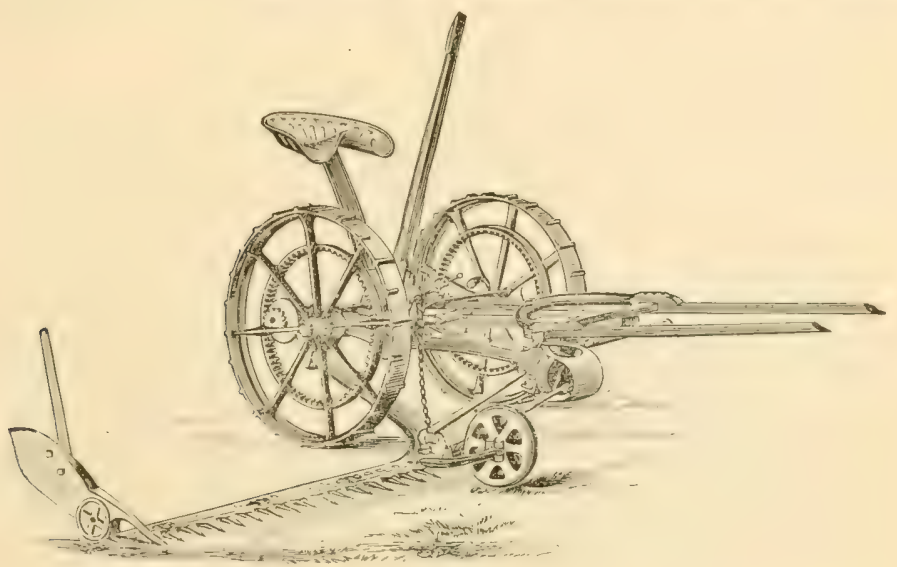

A MOIVING-MACHINE.

was applied also to the reaper, and the work of cutting and harresting the grain is as easy as driving a pair of horses on a smooth highway.

As a rule, buy a mower which cuts a swath four feet in width, - a wider swath racks the machine and exhausts the moving power; and buy a reaper which cuts five and a half feet.

Dickerman lays down the following rules for the purchase, care, and use of mowers and reapers, namely:-

(1) Buy the best. It will be the cheapest in the end.

(2) Buy it early, so as to be sure you have the one you wish, and not find, just as you are ready to begin, that you cannot get the one you intended to buy.

(3) When attaching the horses, see that the knives are in a horizontal postion, neither pointed up or down. This secures a smooth, even stubble. 
(4) See that the nuts are all turned tight. The manufacturers are often obliged to finish a part of their machines some months before the time for using them, and all wood is liable to shrink a little.

(5) Buy the very best sperm oil, if possible. Poor oil will be sure to grum up. If you cannot get sperm oil, kerosene and castor oil mixed, one third of the former and two thirds of the latter, will answer a good purpose.

(6) Keep the bearings well oiled, also the buttons which hold the knives down to the plates in the fingers.

(7) Keep the knives sharp all the time. Take both scythes into the field sharp, and once an hour or so rub the edges with a sharp gritted whetstone; this saves sweating your horses, and the wear upon the machine, and leaves the field looking as if you understood your business. Use the scythes about equally, as they fit and work the better for it.

(8) Keep the buttons down as close to the cutter as possible, and have the scythes play easily. They are made of malleable iron and will bear pounding, but in long use they are apt to wear loose. Examine them frequently, and as they wear, rap them down with a hammer, so as to keep the edge of the cutters in close contact with the elge of the steel plates in the fingers. You might as well expect to cut wet paper with a dull, loose-jointed pair of scissors as to cut grass with dull scythes not in their proper position.

(9) When the cutters become worn to a point, and begin to grow shorter, have new ones put on ; it is the poorest economy to use them so; like using a worn-out plough-point.

(Io) Examine your machine carefully as soon as haying or reaping is over, and if it needs any repairs send it at once to the manufacturer, unless you can replace the parts wanted yourself. He has time in the fall, before beginning to turn out machines for the next season, to attend to it faithfully, and you save much vexation, and perhaps loss, which might occur if this is neglected till spring.

(II) If the machine needs no repairing, take out the knives, wipe them clean, and then rub them over with an oily rag to prevent rusting. Oil the fingers and remove the pole and bar, put the bar and scythe in a dry place, clean your machine thoroughly, and keep it dry and clean through the winter.

If these suggestions are not heeded, do not blame the manufacturer if your machine wears out.

Of Tidilers, Horse-Rakes and Horse-Forks it is hardly neces- 
sary for me to cliscourse at any length. The tedeler, an implement originally introduced from lingland, has been modified and improved until it has become quite convenient and useful ; and when properly applied it facilitates the work of hay-making to a very great degree. The American hay-tedder is a valuable machine. Horse-rakes abound, and since they have all adopted the spring tooth they vary but little in point of excellence, and

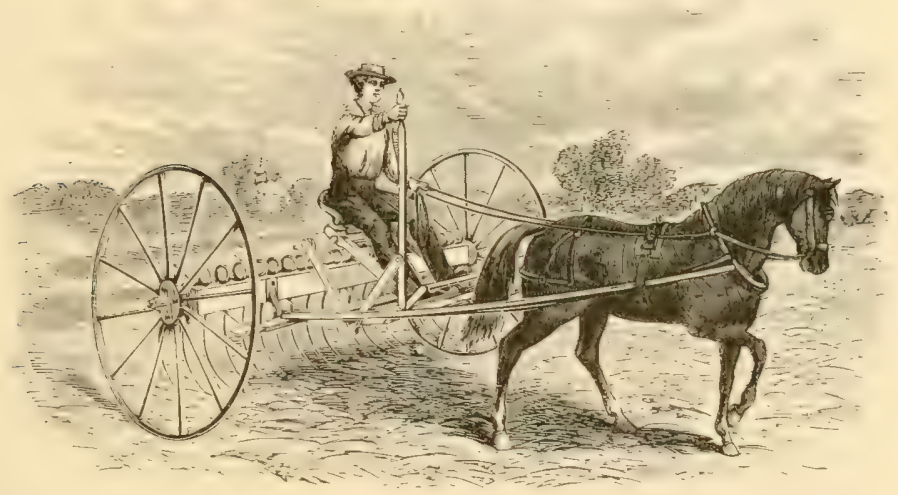

HORSE IIAY-RAKE.

are all open to the objection to which this form of tooth is open. I hope we shall one day see a better plan of construction throughout. Of the numerous Horsi-Forks, by means of which hay can be rapidly unloaded in the barn, I can only say that after having used several, with all the arrangements of hooks in the rafters, and pulleys and ropes along the barn floor, and an obedient horse at the end of the rope, I have found that my men much preferred unloading my hay by hand. They may be mistaken ; but each one of you can try the experiment for himself, and learn which process he would prefer.

In selecting Threshing-Machines, Corn-Shellers, Hay-Cutters, and Root-Cutters take the advice of an honest and trustworthy dealer in whose capacity to select you can have entire confidence. 
The care of the tools, implements, and vehicles of a farm is

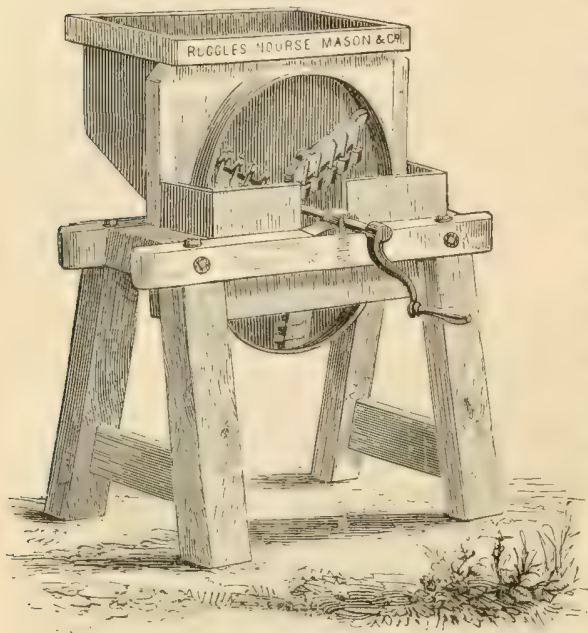

RUOT-CUT'TER. an important part of the business of the farmer. A tool-house or a convenient toolroom every farmer should have so arranged that the light tools can be hung upon the walls, and the heavier implements can be conveniently located along the floor. Have a place for everything and everything in its place. Once a year give your carts, ploughs, harrows, mowing - machines, hand implements of every description, tedders, horse-rakes, and your yokes and harnesses, a thorough examination ; and start in the spring with all these things in good order. And remember that a small supply of carpenter's tools, with a few blacksmith's hammers, wrenches, and pincers, will enable you to save a great deal of time and expense in the necessary repairs of vehicles, implements, and farmbuildings. A finely cul. tivated field is a delight to my eyes; but a well-

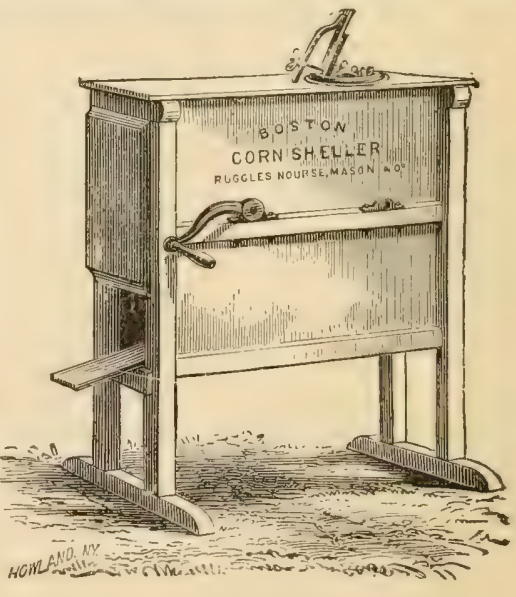

CORN-SHELLER.

ordered collection of the implements of every description re- 
qquired on a farm indicates a capacity for managing and arranging the operations there which commands my respect.

before closing my remarks I desire to call your attention to the interesting history of the establishment of agricultural warehouses for the sille of tools, implements, and ser ds in this country. In 1845 there died in the town of Chelsea, in Massachusetts, Mr. Churles Willis, who is entitled to the credit of having founded this branch of business here, and perhaps in the world. It was he who in 1820 joined with Mr. Joseph R. Newhall in orgmizing a warehouse of this description in North Marlet Street, Boston. Of this enterprise, and of Mr. Willis, Mr. Charles P'. Bosson, one of the brightest agricultural writers in our day, says: "The business was new and untried; in the minds of many chimerical, and there were many prejudicus to overcome. But, as we have before intimated, Mr. Willis was just the man to meet and grapple with those prejudices, and to carry out what was then but an experiment to a trimphant issue. This was the first agricultural warehouse established in the country, if not in the world. Certainly nothing like it had ever before been heard of in Great Britain or in France. It was established for the sale of improved agricultural implements and machines, and for the sale of improved seeds. Its success, small at first, speedily increased. It gave a wonderful impetus to the inventive genius of our countrymen in the direction of agricultural machines. The Boston agricultural warehouse was quoted the country over. It was one of the curiosities of the city, and was by many regarded as the most interesting exhibition the city afforded. Eminent men from abroad risited it; many came expressly to see it. General Jackson, Clay, the celebrated Dary (Crockett, and others of less note paid special visits to it. And the writer of this sketch distinctly remembers to have heard the old hero of New Orleans address Mr. Willis in language of high and flattering eulogy on the success he had achiered in conclucting an institution so important to the great interest of the country to such a pitch of prosperity. Alluding in this connection to his own military career, he said: 'Mr. Willis, peace hath her triumphs no less than war, and this is 
one of them. They who are devoting their lives to the advancement of the great cause of agriculture, as you are doing, deserve the gratitude of their country.' And Mr. Bosson also tells us that Colonel Pickering, Thomas Green Fessenden, the Hon. Joln Lowell, Gorham Parsons, General H. A. S. Dearborn, and others like them high in civil and military life, all friends of agriculture and lovers of the soil, were his warm friends and patrons in this useful and honorable enterprise."

I beg your parclon, Gentlemen, for having occupied your time with so long and dull an essay on a dry and somewhat uninteresting subject. I must confess to a certain fondness for all those implements which are employed in the business of farming, and to a certain respect for them, as we survey with admiration the very tools themselves of him who excels in any art in life. If I am not a great farmer I can at least respect those who are, and I may be reminded by the instruments which they use of the pleasures and profits and honors of their occupation. I gaze with delight upon the camp equipage of a great commander; and I turn also with delight to the contemplation of those implements which a great farmer employs in his calling. I am sure you will bear, therefore, with my prolonged, perhaps tedious, perhaps even garrulous remarks; for, in addition to my sense of the importance of the subject, I have a feeling that having explored with you almost all the topics which can occupy the mind of an intelligent farmer in the conduct of his affairs, at least all the topics upon which I have any information, I shall not again arldress you so elaborately as I have done this evening. I shall undoubtedly leave the discussion of future questions to others, and shall be obliged, as the hand of Time presses more and more heavily upon me, to listen to the talk of those into whose care and keeping I shall intrust the interests of the Club when I am gone.

When Mr. Hopkins had finished bis speech there was no inclination to discuss the subject which he had apparently exhausted. John Thomas would gladly have enlarged on the theory of the plough and the attempts made to 
improve it by such eminent men as Thomas Jefferson, Colonel Knox, and Governor Holbrook of Vermont ; Sam Barker had a long story to tell about the profits of a peripatetic threshing-machine; William Jones would have expressed his opinion upon the merits of a self-sharpening hay-cutter for stable use ; and Moses Ferson had a strong desire to call up the glories of the hay-field, whose platoons of mowers armed with the scythe, and the music of whose rifles had been the delight of his boyhood, and had furnished a sphere of action for the power of his manly muscle. But they were all hushed by the closing remarks of President Hopkins, who by his liberality and kindness and good sense had won his way into all their hearts, and who evidently felt as they did when they contemplated his shrinking form, that old age and the cares and anxieties of his early life were at last telling upon the powers once so vigorous and strong.

John Thomas moved an adjournment, which was carried, but which did not disperse the members. They lingered about the room conversing with each other, evidently reluctant to leave the spot where they had enjoyed so much bright hospitality, and where they had learned the value of courtesy and kindness in cheering and smoothing the path of life. The warning that the association with their venerable President must erelong cease oppressed them. Not a man there but could recall a kind word or deed of him whose very name reminded them of the best personal history of the town, and whose presence had called up before their minds the high precepts of life which had been taught them and their fathers by a worthy and pious line of spiritual teachers and guides, known from the earliest days as the Lord's anointed. And it was not with heavy and saddened, but with purified and exalted hearts that they bade the President good night and departed. Mr. Howe returned to his home with new faith 
to cheer the path of her whose health was now failing under her patient and wearing performance of the cluties of a minister's wife. John Thomas sought his Huldah with new devotion and a warmer determination to discharge his duty well. William Jones strode solemnly home with honest resolutions filling his mind and heart. Charles Ingalls returned rejoicing to Clara and his humble abode and his books, and it was as when the mild spring wind bloweth upon the earth and the soft and vernal life moves therein with its beauty and its strength, that the warning words of the old man roused, as to a new existence, the gentle and tender qualities which slumbered in the hearts of his companions. 


\title{
THIRTY-SECOND MEETING.
}

\author{
THE SWALLER ANIMALS OF THE FARM.
}

DR. PARKER AND MARGARET ILSLEY. - SQUIRE WRIGHT IN TROUILE. - FANNY UNDISTURBED AND CONFIDENT.

"FANNY," said Squire Wright, as he took his seat at the tea-table, at the close of a mild and sunny day in early April, a day full of spring-time promise, "has Dr. Parker been here to-day?"

"No," replied Fanny, with an anxious look. "I have n't seen him for two or three days. When he was last here he seemed to be in trouble; and he said, as he left, late at night, that he was going early in the morning to meet Dr. Frost in consultation, nine or ten miles away. I don't remember exactly where."

"O, he finished that long ago," said the Squire. "Jones saw him, day before yesterday, over at the old Ilsley place, standing looking at the few relics of the fire still left, in a sort of brown-study, his horse tied to the fence, and that little girl, Margaret, whom John Thomas adopted that horrid night when the house was burned, holding fast to his hand and crying as if her heart would break."

"Why, I thought the child was as happy as possible," said Fanny. "But Dr. Parker has never forgotten that fire. It seems to haunt him. The thought that almost an entire family was struck out of existence in an instant has apparently held painful possession of his mind ever since the event happened. I never knew he had any special interest in Peter Ilsley; but certain it is that 
Peter's death and Margaret's life are always in his memory. He was n't related to the family, was he, papa?"

"Not in any way to speak of, I think," said the Squire; and Fanny felt his eye fixed on her with a gaze which she did not understand, and which was so quickly withdrawn that she hardly felt sure that it was a gaze at all.

"The child is very bright, I hear," said Fanny.

"Yes," said the Squire, "and very inscrutable. John Thomas told me the other day that she was the most

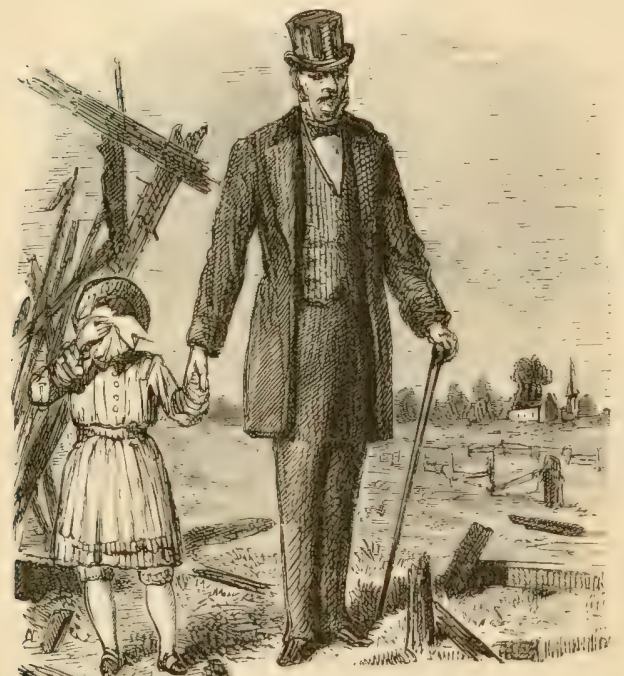

DR. PARKER AND MARGARET VIEIVING THE RUINS. mysterious person he ever knew. He says she is always obedient, - obeys in an instant; but always seems as if she had a right to take command. She never lies, but you always feel that she tells no more than she means to. She is affectionate, but not as a child is affectionate; is kind to those who are kind to her, but never demonstrates. Thomas says she knows no such thing as fear; wanders away in the dark, as if she loved its solitude. And while she has a half-ivild and uncultivated side, is at the same time filled with a spirit and bearing and natural grace which evidently belong to an educated line. It is evident that neither Thomas nor his wife understands the child, and that they are both afraid of her." 
"What was her mother's name?" asked Fanny.

"Margaret," replied the Squire.

"Margaret what?" asked Fanny, with a sharp and sudden energy.

"Nargaret Munro," answered the Squire. And Fanmy" turned away with an air of indifference, and with a clesperate purpose to conceal all appearance of cmotion.

"Did you know her, papa?" asked Fanny.

"O yes," said the Squire; "very well. She was very handsome when she first came to Jotham to teach the summer school in the Pond District. I don't remember where she came from. She taught here awhile, just before young Parker went to Europe to study medicine, and married Peter Ilsley while he was gone, and for what, nobody knew; for we all thought she might have done better. But so it was. The old doctor never seemed quite easy about that marriage."

"Does this child, Margaret, look like her mother?" asked Fanny.

"Yes, very much," said the Squire. "Margaret MIunroe had blue eyes, as blue as the sky, and light hair. The child has eyes colder and a little less bluc, with fair hair and the mother's expression, only the mother had a face full of ardent affection, which the child has not. The mother had - "

"Did she look like that?" eascrly asked Fanny, as she drew from her bosom a little worn daguerrentype, and thrust it with startling emphasis into the face of her father.

"Like that!" cxclaimed the Squire, seizing the rude and dingy miniature, and acljusting his eyes after the confusion into which they had been thrown by Fanny's impetuosity. "Like that! When? How? What is this? Margaret Munroe, as I live; but where on earth dicl you get it?" 
"I picked it up on the floor, papa, the other night, after Dr. Parker had left: and see here, what a delightful memento it is," said Fanny, as she opened the back of the case and disclosed a little locket of intertwined hair, light and brown, confined there in loving embrace, and surrounded by a thin gold band, on which were inscribed the letters M. and W.

"Confound the little telltale thing;" said the Squire, with a sharp, hissing laugh of disappointment and disgust.

"O no, not so, papa," said Fanny, with her rich and ringing voice tuned now to an expression of determination, mingled with deep chagrin and a little anger. "Dr. Parker has told one half the story, and this little memento has only told the rest. But, papa, not a word; I can work out of this; but not a word. I can bear the thing itself, but I cannot bear the public knowledge of it. Do you think the people know Dr. Parker as well as you and I do, papa?"

"Know what, my dear?" said the Squire. "Dr. Parker has his ins and his outs, I suppose, and is in good order one day, and in bad order the next. But I believe he behaves very well now; and I think he is quite an ornament to the town. Mr. Howe thinks very well of him ; Deacon Thomas has a very high opinion of him ; and, in fact, I have n't heard a word against him for years. In one respect I know he is thoroughly reformed. And a very good citizen he is, I am sure."

"But, papa, all this won't do," said Fanny. "A man with a history and a daguerreotype is no man for me. 'Better is a dinner of herbs where love is, than a stalled ox and hatred therewith.' I am glad you think so well of Dr. Parker. I hope he 'll be a father to poor little Margaret. Then he will have his little girl, and I will have my little boy. But more than this, - I do not 
want to think of it. And then you know, papa, I am very happy with you, and mamma, and the boy. I don't think I have very good luck in this world; do you, papa?"

The Squire was quite uneasy under the random fire of Fanny, who was in a state of intense excitement over her sudden realization of the complicated condition of Dr. Parker, and of her own failure to reach that sphere of thought and feeling without which woman's life grows cold and hard and commonplace and unsatisfactory. She was roused to a consciousness of her blessed possibilities, just in time, as she thought, to see them vanish beyond her reach; and she rushed from the presence of her father, who had simply tormented her with respectable sugges. tions and icy compliments, when she needed assurances of fidelity and love. She fled to her own room, and there recalled her life, its weaknesses, its disappointments; wondered whether these were due to her own character or to accidental circumstances; began to realize the difference between an impulse and an inspiration, between the great reality of love and the emptiness of a desire for station and home; thought upon the wide-spread heaven in which Clara Bell seemed to be passing her life, and the narrow and artificial structure in which she was passing her own; and prayed in her agony and despair for a new and loftier nature to support her in her trials, to solve the difficult problems of her life, and to elevate and purify those who were brought under her influence, and him who claimed a place in her heart. She rose from her struggle more of a woman than she had ever yet been; more of a mother; and with a more thorough understanding of the tone and spirit with which a woman must surround herself, in order to be true to herself and able to discharge her duties to those who depend upon her care and affection. Her life passed rapidly before her, and when she remembered her 
own mistakes she became more ready to forgive the mistakes of her friends; and as she studied now the imperative demands of her own heart, she learned also the mistakes and failures which may fall upon those whose sensitive and loving natures require response and support. She found that she could hate no one for his wayward affections; and she was filled with inexpressible tenderness, not all love alone, toward Dr. Parker, as she recalled the incidents of his life, which pointed to a great, warm, manly heart, beating with the full-flowing ticles of intense life bencath that calm and subdued exterior. Even the miniature which had roused her to such sudden passion she now began to contemplate with a tender regard; and she pondered with peculiar emotion upon the bond which existed between the disappointed lover and the child who alone remained to remind him of the rosy hours of his early life. And it was not until her mother returned home with "the boy," whom she had accompanied to a neighbor's for a long afternoon's visit and a tea-drinking, that Fanny came back to her actual life, and with deeper knowledge of herself and him whom she loved. She even turned a kindly thought toward the little Margaret. And she wondered more and more at the slumbering secrets of the mysterious Dr. Parker.

Squire IVright was sorely perplexed. He was an old man now, and had all an old man's chilled and withered views of the path of human life. He had long since forgotten the blooming Margaret, who taught the district school and married Peter Ilsley so many years ago. He had forgotten that Dr. Parker ever knew her, until his eye fell upon the dingy little daguerreotype; and he was suddenly frightened into a defence of Dr. Parker when he necded no defence at all. He came to the conclusion that the workings of a young woman's mind and heart are too much for an old man to comprehend, and in his confusion 
and perplexity he betook himself to his office, - a thing he had not clone before in the evening hours for many months, - with the hope that by rummaging among his law books he might turn his mind from a subject which had long ago become unfamiliar to him.

When he reached his office he found that Charles Ingalls had not yet left it; and that he was engaged, after a long clay of hard work, in preparing himself for an intricate and difficult case which was coming on at the next term of the court. Charles was greatly surprised at seeing the Squire; and the Squire was evidently surprised at finding Charles at work there at so late an hour.

"Well, young man," said he, "this is the usual hour for play; and I know you have temptations enough elsewhere."

"I work first," said Charles, " and then I turn my attention to what you call 'play' and 'temptations elsewhere.' But Dr. Parker has kept me here longer than usual this evening. He was in a curious frame of mind, and asked me to draw up papers of adoption for himself and little Margaret Ilsley, who was saved from the fire and has been so kindly cared for by John and Mrs. Thomas. I asked him what he was going to do with her, and he flamed up like a volcano, and said he was going to take care of her. I have never seen him so restless, not even in the worst days of his worst habits. He said something about the world deserting him, and his disappointments, and about going to Europe to lay his bones. Something lias stirred his depths fearfully."

"O, it must be the morbid effects of his profession," said the Squire, "in which the more you know the less you know, and in which the student finds every disease of mind and body in himself. It is bad enough to be a physician; but to be a bright one, with doubtful and uncertain 
habits, in a country village, without a wife and family, must be worse than being in hell itself."

Charles did not see this exactly, and he began to think that Squire iVright was in as unsettled a mental condition as the Doctor. But he ventured to suggest, by way of consolation and encouragement to the Squire, that the Doctor would undoubtedly soon find his way out of one part of his dilemma at least; "although," said he, "the Doctor did hint at the impossibility of his ever being married, and of mustering courage enough to go through the trying ceremony."

"Heaven help poor Fanny if he is going to behave in that way!" said the Squire. "But this adoption business I don't know about. What can the Doctor expect to do with such a mysterious child? He 'll find the boy is all he can manage."

"Now, Squire," said Charles, "I think I would have nothing to do with that matter, if I were you. You will pardon me for being frank about it. But the Doctor and Fanny are of age, and ought to know what they are doing. Besides, love makes its own channels, and asks for no outside aid. I do pity them both. They have started badly on the journey. Still, they will come out right, I dare say."

"You're a young philosopher," said the Squire.

"Clara is my philosopher," replied Charles. "When I follow her advice, and accept her wisdom, I am not far out of the way. I tell you, Squire, it is a good thing for a man to find his mate early."

"But do you think the Doctor is going to abandon Fanny?" said the anxious and thrifty old gentleman.

"No, I don't," said Charles. "Dr. Parker improves every day, and you can see it. If he moved on with an indifferent air, and not above a commonplace method, I should despair of him. But it requires a good deal of a 
storm to clear his sky, and I am sure he keeps up all the storm that is necessary."

"Did you ever hear anybody say he was in love with Peter Ilsley's wife before Peter married her?" said the Squire, hesitatingly, as if dreading the answer.

"Good heavens! no," said Charles. "I never heard of such a thing, and never thought of it."

" Well, I don't know as he was," said the Squire, trying to shelter himself behind an assumed ignorance, and hoping to lead Charles's mind entirely away from the idea that such a thing was possible, after having relieved his own feeble fears of drawing out a denial from Charles himself. "I should be sorry to suppose he sought a wife in that circle before turning his attention to my family. The IVrights are a very old family in this town, I suppose you know, Charles."

"O yes," said Charles, laughing; "and so are the Bells, five generations of millers in one mill. Clara showed me an old teaspoon, the other day, that Peter Bell brought over in the Arbella, the first ship for Naumkeag."

The Squire now became garrulous and cheerful. He had escaped from the heated air of excitement and passion, and had found relief in the healthy and bracing atmosphere of a sensible young man, who had mind enough to keep his professional business in capital order, and heart enough to present his dearest relations in all their blessedness and strength. He grew very talkative over the events of his own family, how the law had been their favorite study for generations, and how highly respectable they had been, even under adverse circumstances. They had always been a very steady family, free from weak ambition and eccentricities of all sorts. "We have been very proper people always," said he; and he added with an air of triumph, seeing that Charles was preparing to close the office and go home, "No member of our family" 
was ever guilty of such a breach of etiquette as to live in the same house with his lady-love before marriage."

Charles thought that the Squire was coming down to pretty small talk, and he felt amused and quite upset by the trivial condition into which the venerable old lawyer had brought his mind, by plunging into an untried sea of annoyances; and he added, with a half-sheepish air, as if he had been caught in an act of petty meanness: "I cannot leave Mrs. Bell and Clara ; they could not possibly get on without me. Perhaps it is n't just the thing, however." And then the old Squire and the young one closed the office, and strolled along together in the moonlight towards their respective homes; the old one to rejoice in the respectability which he had inherited, and the young one to rejoice in the prospect before him of establishing his own family respectability for himself. And yet, thought he, pucrile respectability often weighs more in this world than mature and masculine wisdom unaided by station. The old Squire reached his home and his nightly repose; the young Squire reached his home to enjoy that radiant hour which, in the stillness of night, ends the lover's day.

The old man's repose was unbroken through the night, and his troubles were wellnigh forgotten when morning came; and when he considered what the nature of the difficulties was, he was glarl cnough to take Charles's advice and leave Dr. Parker and Fanny to work out their own problem, while he undertook to prepare a paper, at the request of Mr. Howe and John Thomas, on the Smaller Animals of the Farm.

\section{SQUIRE WRIGHT'S ESSAY.}

Shcip. - In discussing the smaller animals of the farm, Mr. President, I shall begin with sheep, whose relations to the agri- 
culture of this country I have studied with some degree of care, and whose management I have observed both on my own farm and in that section of the West where, as you know, I have passed a year or two of my life. I cannot expect, in the brief time allowed me, to consider the relation and care of these animals with any degree of minuteness; but I shall cucleavor to present some views which may guide you in your choice of this branch of husbandry, and of the animals which compose it. It is not every farm which is adapted to sheep of any lind ; it is not every section in which sheep can be profitably fed; it is not erery kind and degree of labor that can be applied to the care of sheep with hope and promise of reward; it is not every climate that is suited to their habits and growth. It is uscless to introduce sheep-husbandry in this camtry upon a small farm so located as to be suited to market gardening and the dairy. In those regions where the winters are long and colel sheep cannot be profitably fed for their wool alone, and rarely for their meat and their increase. When labor is lear, wool-growing is seldom remumerative. The milder latitude's and the broad grazing-lands, where the sheep require no lousing, and where large flocks have plenty of room to roam, admit of sheep-husbandry as a foremost inclustry. And the sheep which are best adapted to this form of husbandry are those which should be selected for the business of growing wool and mutton. True, in England, where labor is cheap, heary mutton-sheep can be fed to a profit; so also can this be done in Canada and in some of the rich pastures of the Midclle States. Not, howerer, as I think, in New Englund, where special cultivation and the dairy should occupy the most attention, nor along the northern line of the Lnited States. For ourselves, we should remember that in attempting to decide what flocks are suitable, if we would feed sheep at all, we should bear in mind the circumstances of soil and climate by which we are surrounded. In this region our pastures are not luxuriant. Our climate is severe. Neither the grazing of summer nor the usual quality of food in winter is conducive to large animal growth.

A friend of mine has said, one great object of English agri- 
culture, on the contrary, is to furnish animal food for the population of the kinglom at as cheap a rate as possible, and to no

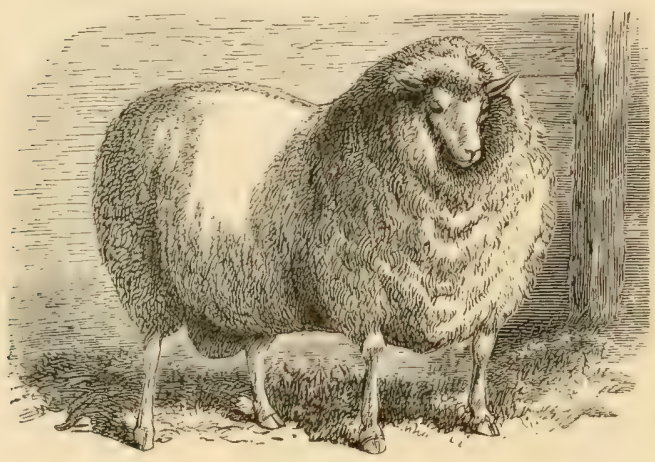

COTSIVULD R.M.I.

one branch of animal breeding for this purpose has the English farmer applied himself with more skill and success than to the production of mutton. Various breeds of sheep, each adapted to the locality in which

it is found, are scattered over the kingdom, supplying food of a most nutritious and economical quality to all classes of the inhabitants. Mutton is said to be the cheapest food that the farmer there can produce. 'The domestic consumption is very great. Every edible portion of the animal finds a ready market. The hind-quarters and middle constitute a luxury for the rich, and

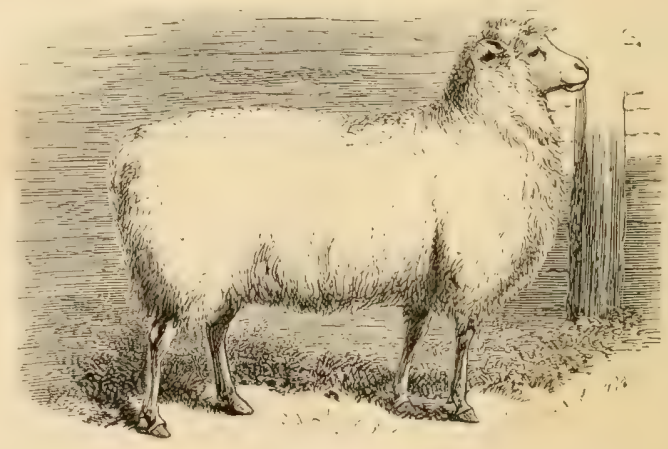

COTSWOLD EWE. the fore-quarters supply the poor with food at the most reasonable prices. In order to meet the demand which now exists there, great care has been taken in the selection of animals for breeding purposes, and Mr. John Ellman with his South Downs, and Mr. Bakewell 
and Mr. Cully with their Leicesters, are looked upon as the benefactors of England; while every farmer who cultivates his turnips and improves his pastures for the feeding of sheep finds that his labor meets with an ample reward.

The soil and climate and agricultural system of England is admirably adapted to this business. The mild and humid atmosphere and the equability of the temperature encourage the growth of the animal, and enable it to arrive at early maturity ; at the same time the fleece has a tendency to increase in length and coarseness. The luxuriant pastures also afford suitable food for animals whose heavy carcasses require abundant nourishment. The ease with which root crops, especially turnips, are raised on English soil, combined with the possibility of feeding such crops on the land during the mild winters of that island, enables the English farmer to support his sheep with great economy during the cold season. All this produces a sheep which, when brought to the stall, is in conclition to take on fat rapidly, and to remunerate the feeder.

Of the best of English sheep, Oxford Downs are sent to market at fourteen months old, weighing eighty pounds, and shearing from seven to ten pounds of wool. Shropshire Downs are said to dress from twenty-five to thirty-pounds per quarter, and to shear from five and one half to seven pounds of wool ; and they are highly recommended as strong, healthy, and heavy animals.

Cotswolds, at two years old, are made to weigh thirty-five pounds to the quarter; and it is said that a ram of this breed has sheared seventeen pounds of good coarse wool. South Down wethers, at two years old, weigh from eighty-five to one hundred and twenty-five pounds, making more internal fat than others, and on this account being favorites with the butcher. The average weight of their fleeces is in England three pounds; in this country it is said to be four. Leicesters, at two years old, weigh from twenty-five to thirty-five pounds to the quarter, and yield about seven pounds of wool. So much for the English breeds, which can also be fed in Canada, where labor is worth but little and grain less, and in the United States, where 
there are luxuriant pastures and no winters. In harder climates and with harder fare a different class of sheep is found to be profitable. Throughout Scotland, and in Westmoreland, Lan-

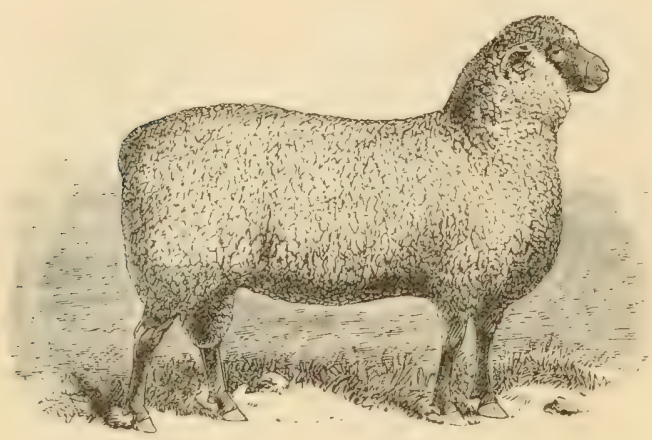

SOUTIIDOWN RAM.

cashire, and Northumber land, the blackfaced heath sheep abound; in Wales a small, short, knotty sheep; and on the continent of Europe the various small finewoolled breeds are to be found. Among these the Spanish merino stands foremost, - a sheep which for centuries furnished the looms of Spain with the finest wool, and which have improved all the other breeds on the continent of Europe into which their blood has been introduced, and have given high value to the Saxonies and French especially. These sheep have been largely introduced into America from the early part of

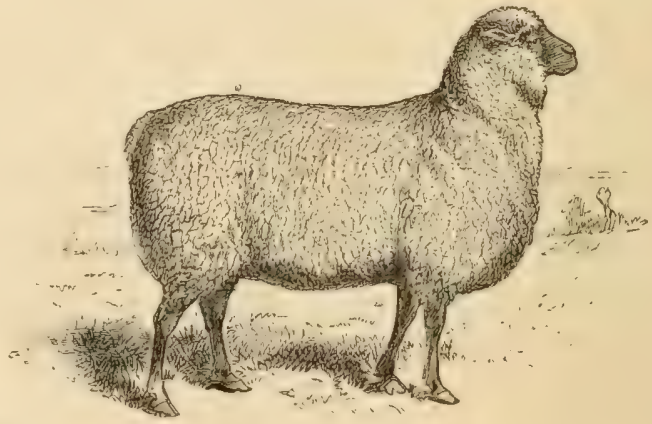

SOTTHDOWX EWE. the present century to the year $\mathbf{r} \mathbf{S I}_{\mathbf{I}}$, and they have laid the foundation of all the great flocks in the wool-growing sections of the country. To the American wool-grower they have been a mine of wealth. 
The Hon. John Lowell grives a marvillous account of their value in his clay, and the breeters of Vermont can tell a fabulous tale of their worth in ours. They are small consumers of food, lirge producurs of wool, and easy producers of mutton. 'They are well adapted to short pastures and broad ranges; and they can thrive in large flocks either in summer in the open air, or confined to the sheep-cote in winter. They have been bred in Vermont to a very great profit for the sake of their blood ; and they hare multiplied into the great profitable flocks of (Ihio, Texas, and California. They stand foremost in the primary work of the sheep, the production of wool : and they stand next to the foremost in the secontiary work of the sheep, the production of mutton.

If you would combine these two interests, the merino is the sheep which can best enable you to do it. There is a large quantity of mutton brought to market of a rery high quality and good flatror, which comes from the fine-wool regions of New Encland and the West. The carcasses weigh from fifty to sixty pounds, are not loaded with a great weight of extemial fat, but carry much tallow, and furnish meat of fine grain and well marbled. The best of these sheep are grade-merinos, usually wethers, whose wool has paid well for their keeping until they have arrived at maturity. They compare well with the mountain sheep of Scotland, - the farorite of the Fnglish epicure, who sencls his own over-fattened mutton for the market, for those who have a less clelicate palate than himself. The class of sheep of which I am speaking are not only profitable to the producer for their wool, but also for their meat, grown with a small amount of food. The production of these grades has been highly recommunded by such authorities as John Johnson and Mr. Randall of New York, especially when crossed with the South Down and some of the small-boned, coarse, and middle-woolled sheep, and they have been much admired in Massachusetts, Maine, New Hampshire, and Vermont. It is grades like these which constitute the great flocks sent to the market annually from the Northwest.

In feeding all breeds of sheep great care should be taken to 
keep them constantly in a thrifty condition. A good pasture in summer is essential, - a pasture adapted to the breed you have selected: a luxuriant one for coarse, heavy sheep; a shorter

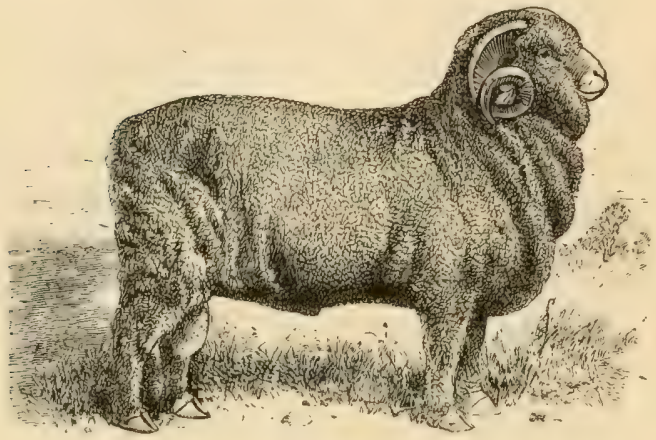

MERINO RAM. one for merinos and theirgrades. A sheep once out of condition is with difficulty restored. And whether it be by a poor pasture in summer, or by poor feeding in the winter that the thrift of the animal is suspended, a check is produced in the growth of the wool which destroys its quality as a firm and uniform fibre. The ewes especially should be well fed throughout the year. As the pastures begin to decline in the autumn they should be turned upon fall feed, and when winter opens they should be supplied with good hay, a few turnips, and a small supply of oats three or four times a week until

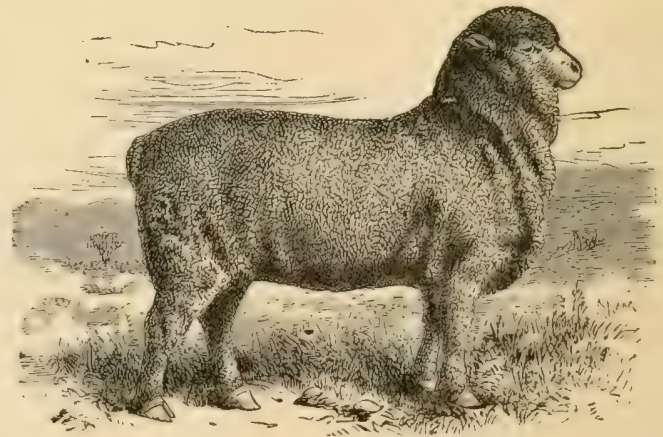

MERINO EWE.

spring comes

on and the pastures are again ready for them. Sheep are very fond of the coarser grasses, and they devour clover, pea-vines, meadow hay, and barley straw with great avidity, and should be 
supplied with such food as this, even while being most carefully fed, whether for wool or the shambles. They should be fed regularly. If you are feeding for mutton, the following suggestions by John Johnson of New York will be found to be valuable. He says: "I generally buy my sheep in October. Then I have good pasture to put them on, and they gain a good deal before winter sets in. For the last twenty-three years I have fed straw for the first two or two and a half months, with a pound of oil-cake, meal, or grain to each sheep. When I begin feeding hay, if it is good early-cut clover, I generally reduce the quantity of meal or grain one half; but that depends on the condition of the sheep. If they are not pretty fat, I continue the full feed of meal or grain with their clover, and on both they fatten wonderfully fast. I have fed buckwheat, a pound to each per day, - half in the morning and half at four in the afternoon, with wheat and barley straw."

In laying the foundation of your flocks, you will of course select the best animals, both male and female, whatever your selected breed may be; and the lambs had better be dropped from the middle of April to the middle of May, as at this season the weather is mild enough to encourage their growth, and it is early enough to supply you with good lambs should you desire to furnish them to the market. Ewes in the spring should be most carefully treated, handled gently and without noise, and kept in a well-lighted, clean, well-ventilated room. If the days are mild they can be turned out for a few hours; but at night and in storms they should be sheltered. The young lamb should also be cared for most tenderly, wrapped in warm blankets if chilled, and fed with cow's milk if the ewe's supply is small. And if the ewe disowns the lamb, they should be confined in a pen together until the unnatural mother returns to her senses and her duty.

Washing and shearing are a part of the early summer work with the flocks. Washing should not be undertaken before the middle of June. The wool should be thoroughly wet in washing, left to soak a little while, then dipped and squeezed, and the washing finished under a fall of water. In shearing great 
care should be observed not to injure the she p by ough handling, and not to wound it with the shears.

Wean your lambs at four months old, and give them a good pasture or fall feed to keep them growing till you can house and nourish them carefully in the winter.

In winter sheep should be provided with comfortable and well-ventilated quarters. A barn cellar opening to the south and provided with doors to be closed in excessively cold and stormy wather forms an admirable sheep-cote. In this cellar they should be divided into Hocks of one hundred each of merinos, and from twenty-five to fifty if of the coarser breeds. 'They should be well littered with straw and kept perfectly dry: The pens should be supplied with an abundance of fresh air, foul air and dampness being fertile causes of much of the disease and mortality which visit our flocks. For feeding purposes varius racks have been constructed, and I shall leave to each of you the sulection, only adrising that the simplest are the best.

Sheep are liable to many diseases, and to parasitic torments. Ticks can be destroyed by washing in tobacco-water. Grub in the herr can be prevented by ploughing furrows in the pastures, into which the sheep can run their noses when they are altacked, in the early part of July, by the fly which lays the egess of the grub in their nostrils. Smearing their noses with tar at this season will repel the fly. Colic can be cured by an ounce of Epsom salts dissolved in warm water, with a teaspoonful of essence of peppermint for a full-grown animal, and half that dose to a lamb. Malignant catarrh may be prevented by a plentiful supply of fresh air, and cured by nothing. The scab can be cured with a mixture of tar, sulphur, and lard in the proportion of one pound of lard, half a pound of sulphur, and a quarter of a pound of melted tar. Rub this mixture into the head and along the back and sides. If foot-rot gets into your flocks, take the advice of the best treatise on sheep husbandry you can find, and follow these instructions laid down by Mr. Randall, who says: "I had a flock of sheep a few years since that were in the second season of the disease. They had been 
but little looked to during the summer, and as cold weather wats setting in many of them were quite lame. . . . I bought a quantity of bluc vitriol, made the necessary arrangements, and took the chair as principal operator. Never were the feet of a flock more thoroughly pured. Into a large washing-tub, in which the sheep could stand convinienty, I poured a saturated solution of blue vitriol and water, as hot as could be endured by the hind, even for a moment. The liquid was about four inches deep. . . . The sheep, when pared, were compelled to stand in the tub about ten minutes. The cure was perfect. .... Many years after the above took place I treated a flock of diseased lambs in the same way, except that they were put into a larger tub which would hold five of them, so that each stood in the liquid from twenty to twenty-five minutes. And again the cure was complete."

I cannot pretend to have exhausted this subject, but I have given you such information as will enable you to select and care for your flocks properly, as I think, and may possibly lead you to a more elaborate investigation of this important topic. Sheep husbandry has always held an important place in the agriculture of every nation, and is surrounded with the most agreeable associations of rural life. To the shepherd and his flocks the genius of the poet has always paid tribute; and the industry to which they are devoted has always been regarded with the greatest interest and care. And so I commend it to your patient consideration.

The Squire was cordially thanked for his essay, and the subject was discussed until a late hour by the Club. Before the adjournment the "learned author" was requested to continue his investigations into the smaller animals of the farm; a request he was ready to grant, as a duty to the Club, and as an occupation to his mind which would attract his attention from more perplexing topics. 


\section{THIRTY-THIRD MEETING.}

THE SITALEER ANIMALS OF THE FARM (Continued).

JOHN THOMAS AND HULDAH DISCUSS THE DOCTOR, MARGARET, AND FANNY. - THE OLD SEXTON APPEARS. - DR. PARKER AND FANNY MAKE AN EVENING CALL. - THE WEDDING OVER. - LIFE IS FULL OF PROMISE.

JOHN THOMAS and Huldah his wife sat dreamily and cosily in their little sitting-room, as they called it, before a smouldering and flickering fire, which tempered the chill of an April evening to their blood, now thinned a little by the weight of years and toil. The day had been long and busy. John had devoted it to his early garden, which the instructions of the Club had taught him to value highly; and he had allowed the pleasing stimulus of the newly upturned soil and of the promises held forth by the first planted seeds of spring, to beguile him into longer and more exhausting toil than he had realized until the day was over and the work was done. Huldah, too, had been diligently occupied in the annual process of cleaning those sacred rooms which were seldom opened, and with which she became familiar when she let in upon them the light and air of spring, and piously prepared their ancient furniture for another year's repose. John had a few notices to write as Chairman of the Board of Selectmen, to which exalted position he had been heartily and unanimously restored by his townsmen since the death of Peter Ilsley; but his fingers were too stiff with toil, and he prefurred to settle down into that sturdy languor which is the swect solace of overwrought strength. Huldah might have 
done a little knitting, but her winter's stint in this line was finished, and her mind was so completely occupied with the memories which her devotion to the old heirlooms had awakened, that she failed to rouse her weary powers up to the point of any useful occupation. And so they sat, and mused, and nodded, while all around the house, in field and forest, the drowsy hum of awakened life filled the evening air with its sleepy music. The conversation of the placid couple was entirely in accord with these surrounding influences, and it ran on for an hour or more in its subduing and monotonous strain, until late in the evening, when it was broken by a clumsy and clattering knock on the door. John Thomas himself responded to the summons, and let in a tall, gaunt, and solemn specimen of humanity, known to everybody in Jotham as the village sexton. He strode slowly in, with a length which was quite astonishing even when reduced by his habitual stoop in the shoulders and bend in the knee, and quietly seated himself before the fire, with a sort of modest familiarity and awkward self-confidence, which grew out of a long-continued exercise of his sad and solemn duty in almost every family in the town. He was not an old man, and he had never been known as a young one. Upon his subdued and solemn visage, on which was written a cheerful resignation, which never relaxed into levity and was never beclouded by passion, could be read the imprint of his gloomy occupation. No man was ever more thoroughly adapted to his work than he. His form was entirely in harmony with the quaint architecture of the old meeting-house over which he presided on Sunday; and his somewhat drawling and plaintive voice chimed admirably with the old bell which had, for more than a century and a half, called the worshippers together, and tolled out its dismal requiem as the funeral procession wound its way to the graveyard, and proclaimed with the punctuality of the curfew that the hour of nine 
had come. Without austerity he preserved the sanctity of the ancient edifice, and without a tearful demonstration performed well his painful part in the house of mourning. His entire fitness everybody recognized. At church he

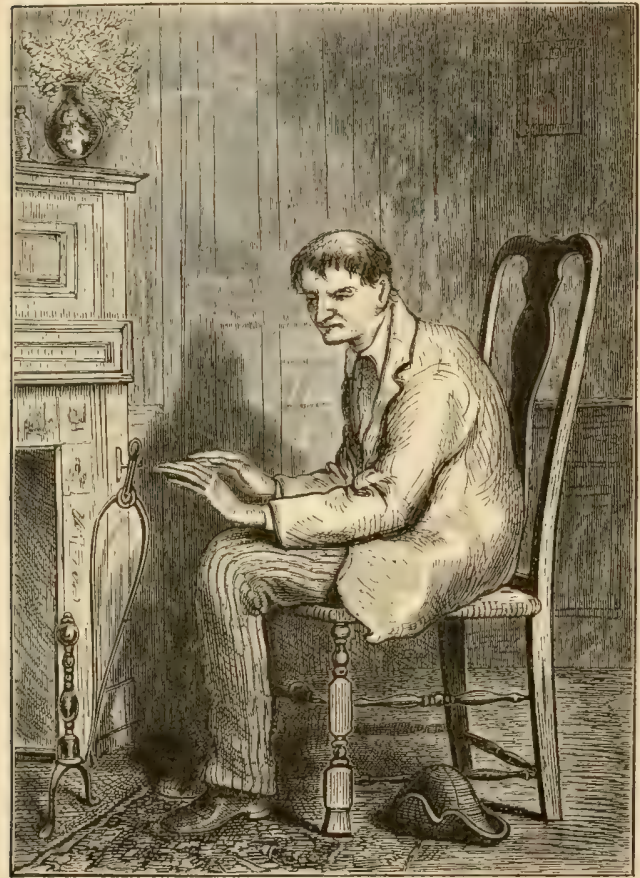

THE OLD SEXTON.

was more than sexton ; at funerals he was by no means an undertaker ; but in spite of the sadness of his occupation and the poverty and lowliness of his life, he managed to secure such a peculiar hold upon the people that they submitted the sacred ashes of their friends into his hands with a feeling of tender confidence ; they opened their doors to him at all hours, as if he had been a member of the domestic circle; they bestowed their alms upon him, as if they were contributing to a sacred cause ; and they classed him with the minister and the lawyer and the doctor, as among the most important personages in the village. Made up as he was of simplicity and shrewdness, he had won from the Rev. Mr. Howe and his predecessor, with whom he had also scrved, the high eulogium of being as "wise as a serpent and harmless as a dove." Had he not been the 
sexton he would probably have amounted to but little; but he was the sexton, and so as the companion of the minister he counted a great deal. When, therefore, this important official seated himself before the fire, and, resting his wrists on his knces, presented his great open palms to the genial warmth of the embers, all the while moving his features up and down with curious and impressive method, Deacon Thomas prepared his mind for some kind of important business, he knew not what.

"We had heard the nine-o'clock bell, and were just starting for bed as you came in," said Huldah to the sexton. "You must ha' come right from the meeting-house here."

"So I did," drawled the sexton. "Every night, for thirty years, in fair weather and foul, I ve travelled up this road and rung that bell. Not a night have I missed. Sometimes I 've been kind o' tired, and kind o' sick, and sometimes the folks have n't been well, but I've always rung it. One of the nights, grandsir died; but I rang the bell. I've rung that bell, and tolled it a good many times, Deacon, taking Sundays, and funerals, and noonings, and nights."

"Yes; and have done it well, too," said the deacon. "But does this business pay?" added the thrifty ecclesiastic.

"Well," said the sexton, "there's the rides on the hearse, - not so bad on a fine summer afternoon; and there's the steady work of it. The folks have been very good, and I'm much obleeged to them ; yes, I be ; I 'm sure I be ; I know I be; I 'm very much obleeged to 'em. And as for the business, Deacon, I suppose, taking it all together, the ringing, the tolling, and the meetin'-house, and the funerals, - 't is rather more pleasurable than profitable. Howsoever, I 've stood it for thirty year, and got along; and the Parson says, every time he meets me, the ravens 
always have been and always will be fed; and I s'pose he means me as one of 'em."

"O," said Huldah, "what a multitude has passed away since you began, - old and young, - the fathers and mothers, and the old folks, and the little children! there's more gone than there is here, John, a good many."

"That 's just as true as preachin'," replied the sexton; "and I 've told Parson Howe so many a time. But this is nothing here nor there, Deacon. I jist come over to tell you, Deacon, that Dr. Parker's going to set a monument up in Peter Ilsley's lot, and he wants the line rum between his 'n and your'n. I thought I'd better tell ye, now, for the Doctor's dreadful particular, you know. Wants everything done jes' so."

" Not a very handy season just now for it," said Deacon Thomas; "but I s'pose it must be done. Tell the Doctor I 'll do it to-morrow afternoon."

"I'm much obleeged to ye, Deacon; yes, I be; I'm sure I be; I know I be; I'm very much obleeged to ye. You know I've got to get a new cow this spring; and the Doctor's real kind about it; and so I want to be real kind to him. You could n't lend a hand toward it, could ye, Deacon?"

John Thomas was ready as usual to do his share, and Huldah encouraged him; and with this substantial assurance of regard from the kind-hearted couple, the sexton rose up in all his longitude, and moved slowly towards the door, declaring as he went: "I'm much obleeged to ye, Deacon; yes, I be; I'm sure I be; I know I be; I'm very much oblecged to ye. Parson Howe always said you and Huldah was the salt of the earth. Dr. Parker said so once; and he don't flatter nobody. Good night, Deacon. Good night, Miss Thomas. I kind o' think Dr. Parker's going to change his situation; but I don't know exactly. Good night, all" 
The sexton was gone; and as he took his steady, awkward gait along the loncly road which led to his home, "the grand old farmer and his wife" turned their thoughts to the curious fact that Dr. Parker was groing to erect a monument over the spot where Peter and Margaret Ilsley and their family were buried.

"What upon airth do you suppose he is going to do that for ?" asked Huldah.

"I hardly know," replied John; "but the Doctor is queer, anyway. He is getting ready to adopt Margaret, and I do solemnly believe he is bound to marry the young ITiclow Ransom, the Squire's Fanny, if he can only muster courage enough."

"Adopting Margaret, marrying Fanny, - why John Thomas, what are you a-talking about?" exclaimed Huldah." He 's no more fit to take care of a family than a wild critter."

"O Huldah, you do not know about that," said John. "Dr. Parker is as steady as a clock now, and has been for months. I think he has found out that Fanny is smart enough for him; and he acts as if he was glad of it. I have seen many a man in my day who was glad to put himself under the rule of his wife, after he had run his rig and found out that he could not rule himself. Such kind make the best of husbands they say. Dr. Parker is odd, I know; but he is sensible, and he is too honorable and manly to let his appetites and passions control him, when he feels that they will do it at the expense of those whom he ought to protect and love. His habits may be bad sometimes, but his mind and heart are good, and I am ready to bet the best cow $I$ have got in my barn that if Dr. Parker marries Fanny he will never allow himself to insult her or hurt her feelings. He is too good a fellow for that, or he has not got his old mother's blood in him, bless her old soul!" 
"She was a good woman, a real good old woman, and bright as a pin," said Huldah. "And the old doctor, his father, - was there ever such a noble old man born? But, John, who in the world is at the door now ?"

John listened, and heard a livelier knocking than the sexton's, and became aware that more than one person sought admission to his house, at an hour of the night which usually found himself and his neighbors in Jotham deep in the business for which nights in the country seem to have been specially created. He was far from being a timid man, but it must be confessed that he felt a little uneasy at such a demonstration around his house at such an hour. And it was with something more vivid than mere curiosity and courtesy that he took a candle in his hand to respond to ine call. He thought of burglars and lost travellers and beggars and accidents as he traversed the long wide entry leading to the front door, a great space of darkness in which his little light seemed like a wandering star in the firmament of the heavens; but he did not think of his friends and daily companions, and it was with unutterable astonishment mingled with alarm that he found Dr. Parker and Fanny standing on the doorstep waiting for admission, while he heard the hard breathing of a horse which was dimly visible in the darkness, standing by the little gate which opened into the yard.

"How are you, Uncle John?" said the Doctor, " and how is Aunt Huldah? Fanny and I were driving up this way home, and seeing your light we thought we would make you an evening call. A little late, I know, but better late than never, you know. I think we'll walk in, Uncle John, if you please, for Fanny and I are rather chilled with our ride through the evening air not yet as warm as midsummer." And Dr. Parker almost elbowed his way into the house, followed by Fanny, and running on with unusually voluble talk even for him, while John 
silently submitted to their entrance and lishted them into the little sitting-room, wondering, with an uprising pity, whether 1)r. Parker had forgotten his good purposes for a time and had prepared an hour of horror for himself and his fair companion. He managed, howerer, to lead the way, and ushered the unexpected visitors into the presence of Huldah, who was as amazed as he was at the unseasonable call.

"Bless my soul! Where under the canopy did you come from ?" asked John, as he and his wife provided the visitors with comfortable seats beside the fading fire, and received them with their accustomed hearty hospitality.

"Bless your heart, Fanny dear, how beautiful you do look! But what in the name o' natur are you and the Doctor running round at this time of night for?" exclaimed Huldah, as she hovered about Fanny and unpinned her shawl and smoothed her down into her motherly ideas of comfort.

"Now, my dear old friends, don't be alarmed," said Dr. Parker, who realized in a moment all the doubts and fears which had filled John's mind, and who now rejoiced that he had a chance to show his friends the difference between the wildness of unnatural excitement, and the joy and exaltation which spring from a happy heart. "Don't be alarmed. But listen. You both know how I have been tossed about from my boyhood up, and what an unlucky track I have travelled, considering how narrow my sphere has been. I know what temptation is, and what weakness is ; and feeling how poor a thing man is when he endeavors to resist the one and overcome the other alone, I have made up my mind to fight a single-handed fight no longer. So here we are, Fanny and I, man and wife, bound to help each other through the world. I did n't want a wedding and a fuss and a party and all that; nor did Fanny. Great weddings and heaps of flowers and music and dan- 
cing belong to the young and incxperienced; a quiet marriage to those who have passed through trial and trouble and disappointment on their way to the altar, at whose foot they are to lay down all their sorrows, and find at last their surest peace. And so we have been married by Parson Snow of Chilton, just over beyond the pond, and are on our way to our home, where I hope and pray we shall be as happy as you have been in yours. And that is all."

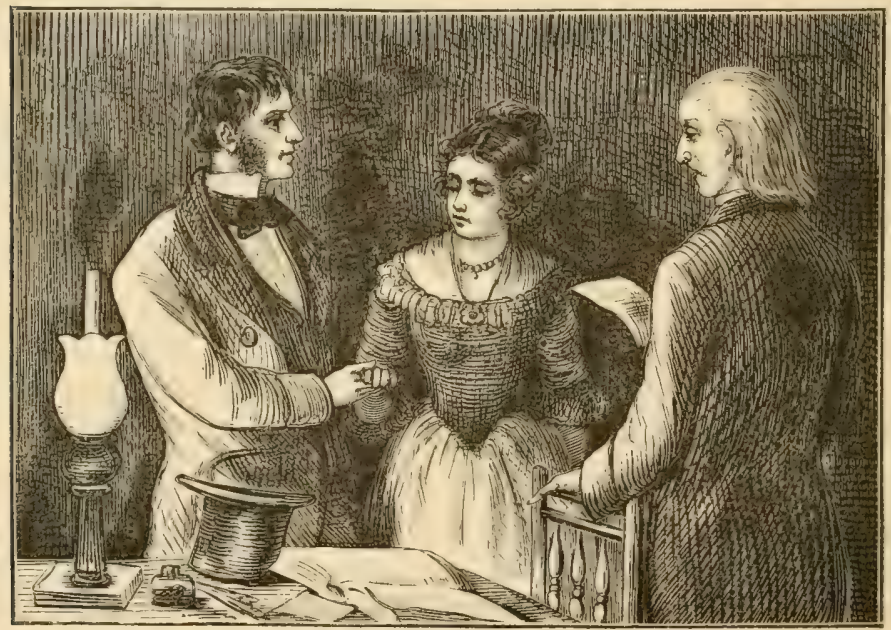

DR. PARKER'S WEDDING.

The Doctor rose to a height of unwonted refinement and glow as he made this statement; and Fanny's radiant beauty was tempered with an expression of sweetness and fervor which had not before been brought out by any of the experiences of her life. John looked a little suspicious, and Huldah a little anxious. But there was no mistaking the lofty purpose of Dr. Parker, or the luxuriant existence which had come round to Fanny. John and Huldah sat there and looked upon them at last with true confidence 
and profound admiration. The bygone days passed rapidly in review before them, - their own calm and placid existence; the fine memory of the old doctor; the laughing childhood of Fanny; their own griets and losses; the sweet little faces of those who fainted and fell in the morning of life, - and their hearts uverflowed with a tender solicitude for these friends, who seemed to have stopped by the way to receive their blessing.

"Does the old Squire know all about this?" asked John, suddenly possessed by a suspicious spasm, and a little anxious about what answer he would get.

"Know it? WVhy, yes, certainly, all about it ; agreed to it; understood it; advised it; thought the plan appropriate and admirable; the dear, generous old father that he is and has always been to me," replied Fanny. She knew nothing about the thrifty fears and misgivings which her father had expressed during the interview at the office, when discussing the daguerreotype; $O$ blissful unconsciousness of a sordid motive for a high-toned and generous sentiment!

"How is your mother? and how is the boy?" asked Huldah, with a shy and half-doubtful expression.

"O Aunt Huldah, they are well and happy," said Fanny. "Mother hates to have me leave the old house, and she longs to keep the boy; but I think she had better not, and Dr. Parker agrees with me. Grandmothers are not apt to bring out the manly qualities of boys, I think. And then the boy has been my little teacher so long, Aunt Huldah, that I cannot bear to part from him. He has unfolded to me many and many a page of human life. Children do to us mothers, you know."

"Yes," said Dr. Parker, "and so I hope little Margaret will be my teacher, too. I suppose you know, Aunt Huldah, I have adopted her?"

"Well, now, this is great doings!" exclaimed Mrs. Thomas, somewhat sharply. "Adopted Margaret? Why, 
you are a-going to set up housekeeping with all the fixtures ready made. Lord a' mercy! IVell, I guess on the whole you had better take her. She's a child I don't understand; good enough, 'most too good; but I don't understand her, and she don't understand me. And as for Dr. Parker, she thinks the world of him. But she's kind o' handy, too. However, that don't signify. I suppose I had better let her go. She really is n't fit for the common ways. Her mother, you know, was a good deal set up. And I declare, Fanny, you and the Doctor and the boy and Margaret ought to have a bright and happy home when you all get together. And may God bless you in it!" And the kindhearted woman had literally talked herself out of all her selfish impulses, and into a warm and maternal appreciation of the peace and happiness which Fanny and the Doctor had gathered about themselves in the new house. And she rejoiced with them to the full extent of her large and tender heart.

"But, my dear Doctor," said Mrs. Thomas, "what do you think Parson Howe will say when he finds that you have not asked him to tie the knot? Don't you think he'll be kind of disappointed? You know how much he likes you and Fanny."

"O," said the Doctor, "Mrs. Howe is too ill to have a wedding in her house ; the Squire," - and here Dr. Parker moved away to a remote corner of the room accompanied by Mrs. Thomas, and leaving John and Fanny engaged in their talk before the fire, - " the Squire had a superstitious feeling against a second wedding for Fanny in his house; and how could Fanny stand up there with all the memories of the past around her, and the boy looking curiously on, and repeat a ceremony which had once been attended by all the bright angels of her dawning life, and irradiated with the glowing colors of a young girl's morning? O, Aunt Huldah, Fanny could not have done 
that." And IIuldah saw in the Doctor's face, as he said this, a gentle and tender expression of love, and kindness, and purity, and honest purpose, which with a woman's instinct she fully unclerstood, and for which, with a woman's heart, she thanked God. Then it was that Dr. Parker took Fanny by the hand to journey with her along the way of life, and to leave behind him the load which but for her he would have borne in misery to the end. And they went forth to their own home, with the sincere blessing, and the sweet and simple, and life-long harmony of the farmer and his wife, who had known no division, resting upon their heads.

"He is queer, but he is safe now," said Huldah, when the newly married couple were gone.

"And she has found a new life, I hope," said John.

The morning dawned upon Jotham, and upon the new home of Dr. and Mrs. Parker it shone with peculiar brightness. The announcement of the marriage created hardly a ripple of excitement in the community where Dr. Parker was so well known and where Fanny was so much admired. Mr. Hopkins felt assured that it was a good alliance for both. "The Doctor is a very successful man," said he, "and has a long list of valuable correspondents." Sam Barker merely remarked, "You don't say so!" and in five minutes the wedded life of Dr. Parker seemed to have existed for years. William Jones was highly pleased with the "new order of things," and he felt confident that Dr. Parker, as he now had a new wife, would soon want a new horse, a want which he felt sure he would be called on to supply. Charles Ingalls and Clara Bell felt a strong personal interest in the event; and they assured themselves that a refined and cultivated and well-ordered home would now be added to those already existing in Jotham, and that they not only retained the Doctor and Fanny in their list of friends, but they had increased that list by a charming 
domestic organization in which they could find wisdom for their heads and sympathy for their hearts. But the calm repose of Jotham was not ruffled, and "the family of Dr. Parker" was soon an accepted fact among all the other families of the town. Margaret and the boy had their places assigned them; Fanny became a matron; and of the Doctor himself it was said that he had sown all his wild oats, and had become not only a corner-stone, but a vitalizing force in a well-behaved and Christian community. The people felt, with Huldah, that he was saved; and, realizing that popular sentiment, he behaved like a man and never forgot his obligation. It may not have been either morality or religion which rescued him from the dangers by which he was surrounded; but saved he was, and if it was by an honorable sense of his obligations to her whom he had sworn to protect and love, let us thank God that woman has it in her power to stretch forth her hand patiently and tenderly and powerfully, and save him who, but for her, might be left to perish. And let woman rejoice in her power and her prerogative.

John Thomas was of course deeply interested in the affairs of Dr. Parker; but he could not forget his farm and his club. From the former he drew his subsistence, and from the latter he received mental food enough to keep himself in that condition of intellectual activity which belongs to an enterprising and progressive New England farmer. The Club was, moreover, to him the arena in which his faculties found room for recreation and exercise; and it was in obedience to a natural inclination, therefore, that he arranged for the next meeting and enlisted Squire Wright in the work of continuing his investigations into the smaller animals of the farm. When the Club assembled once more in the hospitable mansion of Mr. Hopkins, and had been called to order by that now venerable gentleman, the Squire drew forth his paper and read a concise essay upon Swine. 


\section{SQUIRE WRIGHT ON SIVINE}

I need not apologize, (ientlemen, for selecting this subject at a time like this; for you must all be aware that we have now traversed nearly all the paths of investigation which agriculture offers, and the choice of topics for us is small. I am not one of those who believe that swine are a necessary part of every system of farming; but I do recognize their importance, and I am fully aware that they are entitled to careful consideration. Not only do they constitute a most important portion of the animal economy of the farm, but they hold, more than any other of our clumb companions, a curious and interesting relation to man, whose servants they are. Originally the most cleanly and energetic of animals, they have been brought by their contact with man to a state of degradation which renders their name a synonyme of ererything low and filthy and brutish. Evidently occupying a valuable position in the economy of Oriental farming, if we may believe that a drove of five thousand perished miserably in the waters to which they were driven by their madness, they were condemned as an unhealthy and poisonous nuisance. In his natural estate considered to be game worthy of royal steel, in his domesticated state the swine is considered to be worthy of the lowest consideration. The favorite food of many people on the earth, his very name is a forbidden word among them. A very observant traveller in Portugal writes: "No Portuguese of any class will name that shocking animal, the pig. If he must be allucled to - and it is necessary sometimes, seeing that the Portuguese are very fond of him cooked - he is called the fat animal cevada, and if a Portuguese is driven into a corner and absolutely forced to employ the word, he will use the diminutive 'porquito,' little pig, and even that under his breath, and with the phrase, "by your leave.' I have been amused by reading the translation into Portuguese of a French sarant's account of a fossil bone care, in which had been found, among other remains, abundant bones of swine. The Portuguese translator ingeniously eluded all direct mention of the animal, and as often as science clearly 
demanded the plain word 'pig, he would have recourse to some ingenious paraphrase, such as "a familiar animal which we still employ as food." And he gives an accuunt of the connection of this domestic outcast with the superstitions of the country, which lets light in upon the mental condition of the Portuguese and the physical condition of their pigs. He says: "With an agricultural population, pig-fattening is necessarily an important matter. No Portuguese, high or low, rich or poor, old or young, is, I am inclined to beliere, quite happy who does not possess a pig in process of fattening. Autumn comes round,

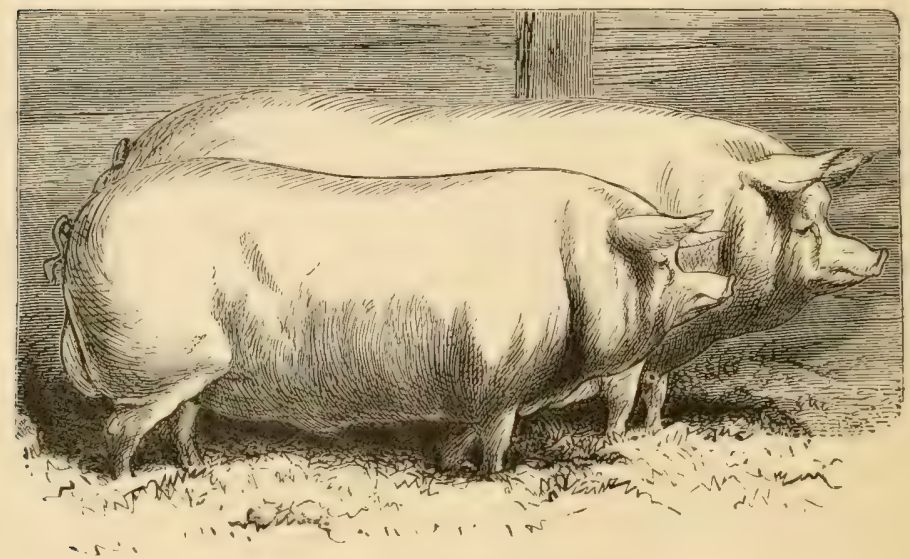

CHFSTER COUNTY SWINE.

the pigs get fatter, but not rapidly. The breeds of Yorkshire and Berkshire are unknown. The Portuguese animal has the length of leg, the leanness and nearly the speed of the English greyhound. He will not be hurried into presentable bacon; his fattening is a slow and precarious process. Nevertheless, fat or lean, the last new moon before the winter quarter must be fatal to him. A fortnight more might make a respectable Martinmas pig of him, but the popular belief is that if he is not killed before the hunter's moon has waned salt will not pickle him, nor wood-smoke cure him. It would be curious to specu- 
late how much the nation loses every year through this superstition alone."

"Nobody who knows anything would kill a pig, except on the full of the moon, unless he wanted his pork to shrink to nothing in the pot," interposed Sam Barker.

But pigs we must have, and good ones, continued Squire Wright; and I can only urge great care in the selection of such breeds as are hardy, thrifty, and easily grown and fattened. Pork-raising is not very profitable here, anyway, brought as we are into competition with the Western producel; but inasmuch

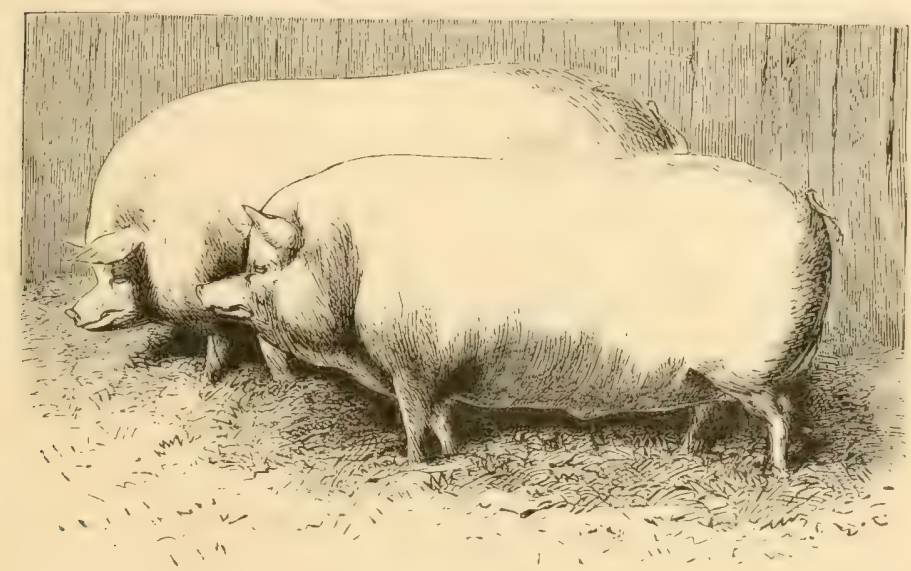

SUFFOLK SWINE.

as a pig will consume much which but for him would be wasted, and is skilful in working over the manure-heap, we must cxercise some discretion in the choice and some judgment in the feeding of him. The best breeds are undoubtedly the Chester Whites, Suffolks, Yorkshires, and Berkshires. The Essex is also a good breed, but objectionable on account of color, although he makes a fine cross with other breeds, especially with the Suffolk. For the purpose of crossing, however, nothing can excel the Chester White. Like a Shorthorn bull, he 
improves every herd into which he pours his blood. Select what breed you will, pigs are difficult animals to raise, no matter how careful you may be. The young are very delicate. The sow is very apt to disown or devour her progeny; and no skill of man has yet been able to strengthen the one or harmonize the other. Warmth, gentle treatment, cleanliness, and good food may possibly help you out, but even these will too. often fail.

In orcler to raise young pigs well and keep them growing, you must have a plentiful supply of milk. The sty depends very much upon the dairy for its success. With milk give them oat-meal, corn-meal, and shorts mixed in equal quantities, and boil the mess before feeding it. A little green food, such as grass, weeds, and small potatoes, will help them along very much. Give no whole grain unless it be now and then a little corn as they grow older, and never allow them to cease growing and fattening if you can avoid it. A pig once stopped in his growth is not easily started. And when you find your pigs humpbacked and rough from starvation, bad feeding, or cold, take my advice; sell out, and start again. Feed what they will eat, and no more. You can destroy a pig's appetite by an excessive supply of food, and a pig with a poor appetite is the most useless and restless of animals.

"In the summer season," we are told by Mr. Mapes, "hogs and pigs should most certainly have access to a good field of clover, both as a matter of economy and of health, as they will keep in good condition and grow rapidly thereon with but little or no other feed. Thus by a rigid economy, both in winter and summer, hogs may be kept as a matter of profit as well as any other class of stock."

In constructing the piggery, every man may consult his own taste, being careful to have his building well drained, well ventilated, dry, warm, and economical. An expensive piggery is a reproach to every practical farmer who erects it. And as for troughs, those are the best which the pigs can neither eat up nor get into.

Swine, like all other animals, are liable to diseases, and with 
them, as with all their associates in the domestic economy, an ounce of prevention is worth a pound of cure. Sulphur and charcoal given from time to time are great preventives of disease. And strange as it may seem to you, consiclering the utterly reckless manner in which a pig will devote himself to a mud-hole, when he becomes accustomed to it, his tendencies are towards the most scrupulous neatness, and his health is vastly benefited by allowing him to gratify his taste in this respect.

I might enlarge upon the various points I have presented to you on this important and interesting subject; but, after all, the pig will have his own way, and never thrives so well as when quietly encouraged in the hands of an accommodating master.

Squire Wright continued his remarks in a conversational way, and was joined by many members of the Club, who succeeded in prolonging the session to a late hour, and in making an interesting discussion out of a very troublesome and often disappointing portion of the animal economy of the farm. The Jews, the Egyptians, the Mohammedans, the Chinese, and the English, the Mosaic law and the status of the Saxon swineherds, all came into the debate, until the hog himself was pretty effectually thrust out.

At the close of the exercises Mr. Hopkins endeavored to detain Dr. Parker and a few of his friends for a little fireside talk, but it could not be done. The parlor was cheerful and attractive enough, but the Doctor had stronger attractions elsewhere; and as he went, the rest followed.

"He is less angular than he was," remarked Mr. Howe.

"Yes," said Mr. Hopkins ; " he 'll get his corners rubbed off, I doubt not."

And so the Club departed, and the village was soon wrapped in slumber. 


\section{THIRTY-FOURTH MEETING.}

THE SMALLER ANIIALS OF THE FARM (Continued).

SQUIRE WRIGHT'S INTELLECTUAL OPERATIONS - HE DISCOURSES OF POULTRY.

SQUiRE IVRIGHT was one of those determined and indefatigable gentleman who, having work on hand, are never quite easy until it is finished. He could turn his mind, it is true, to collateral matters for a short time; but it returned swiftly and eagerly to the object on which it was engaged, - as swiftly and eagerly as the bird returns to its nest at nightfall, and forgets the idle warblers which had tempted it away. Usually calm and thoughtful in his demeanor, he became, under the pressure of duty, restless and roving and uncompanionable. When he labored, he labored alone; and when he was preparing for labor, he avoided his fellow-men. His powers of perception and observation were keener than his powers of thought; and it was in the hours of darkness, therefore, and in the seclusion of his library, or under the excitement of a public occasion in which his mind rose above the temptations of surrounding objects, that he could perform his best work. Dr. Bowditch, correcting the proof-sheets of his translation of Laplace, and accurately computing the great mathematical calculations of the divine astronomer, in the chatty circle of his family, he could not understand. Mental application with him meant solitary confinement; and it mattered little whether he was engaged on an argument before a jury, or a speech at the Sunday school, or a paper for the Club, he was annoyingly devoted to the business 
before him. In fact, he did not even leave his work easily and gracefully, and betake himself to the recreation of his family or the village. IIe often related the astonishment with which he saw the great Judge Story, whom he was visiting as an old friend, leave his commentaries on the Constitution, and in an instant unbend to the domestic amusements for which his home was so remarkable, and by which it was made so attractive. Squire IVright felt that this capacity for work and play combined was really the moving force for great accomplishment; but he also felt keenly that it was not a characteristic of his own. And he was half ashamed that he was so poor a companion, when he was encleavoring to make himself a useful member of society. And so because he had a little work to do for the Club, he seemed to be unmindful of one half of the events which were transpiring about him, and indifferent to the other half. Fanny's marriage he took as a matter of course, and he saw her and the boy leave his own home and take up their residence with Dr. Parker, with an apparent indifference which seemed almost unfeeling; and he never appeared to realize the fact that he and Mrs. Wright alone made a very small and very quiet family circle, and one quite in contrast to that to which they had recently been accustomed. He had profound respect for Mrs. Howe, and a deep interest in her welfare; but when he learned from the minister, whom he also loved, that the health of his wife was rapidly declining, he remarked, to the consternation of the minister, that the weather had been excessively bad for chickens during the entire spring. He so far forgot himself that he inquired of Mr. Hopkins when his ship Althea, which foundered at sea twenty years before, would probably return from her Canton voyage. When he was told that William Jones had lost his favorite horse, he only replied, "There are as good fish in the sea as ever were caught." And when Charles Ingalls 
reminded him that Sam Barker was in danger of losing his farm, unless his cause was vigorously and skilfully defended in the courts, he quietly reminded Charles that "Sam never did know anything about hens." This was a little too much for the equanimity of the young lawyer, even : and deeply alarmed that the overshadowing peculiarities of the Squire might indicate approaching mental decay, he quietly informed him that there was no good reason why he should be utterly lost in a little essay about the livestock of a farm, and he even went so far as to call his attention to the fable of the mountain and the mouse.

"Yes, yes," said the Squire, "but it is my way and always was. I suppose it is just about as hard for the mountain to bring forth a mouse as a mastodon; and that the groaning and convulsion is as great in one case as in the other. Who was it that reminded us the other day of Mr. Emerson's wise saying, 'It is as easy for the strong man to be strong as it is for the weak man to be weak'? The job for the Club is n't much, I know; but it is a job for all that, and I have got it on hand. I never could do two things at the same time, Charles; and I think old age strengthens one's weakness and weakens one's strength. This second childhood is a great deal more tender than the first."

Charles felt the force of what the old Squire had said, and he was touched with remorse for his apparent thoughtlessness. Squire Wright, however, was as placid and peaceful as possible about it, and started off in search of John Thomas, to inform him that he was now ready for the next meeting of the Club; in fact, anxious for it, that he might free his mind of the burden which the Club had placed upon it.

The meeting of the Club was called as usual at the house of Mr. Hopkins, and it was but the work of a moment for the old gentleman, now growing more and more indisposed 
to wander away into matters of supererogation, to call it to order, and to ammounce Squire IVright as the speaker upon the Smaller Animals of the Farm.

\section{SQUIRE WRIGHT'S ESSAY ON POULTRY.}

Mr. President and Gentlemen, - I propose to devote myself this evening to the subject of Poultry, and to end with this my first investigation into the smaller animals of the farm. Perhaps dogs and cats and goats might come in for a share of our consideration; but as they belong, like donkeys, to the

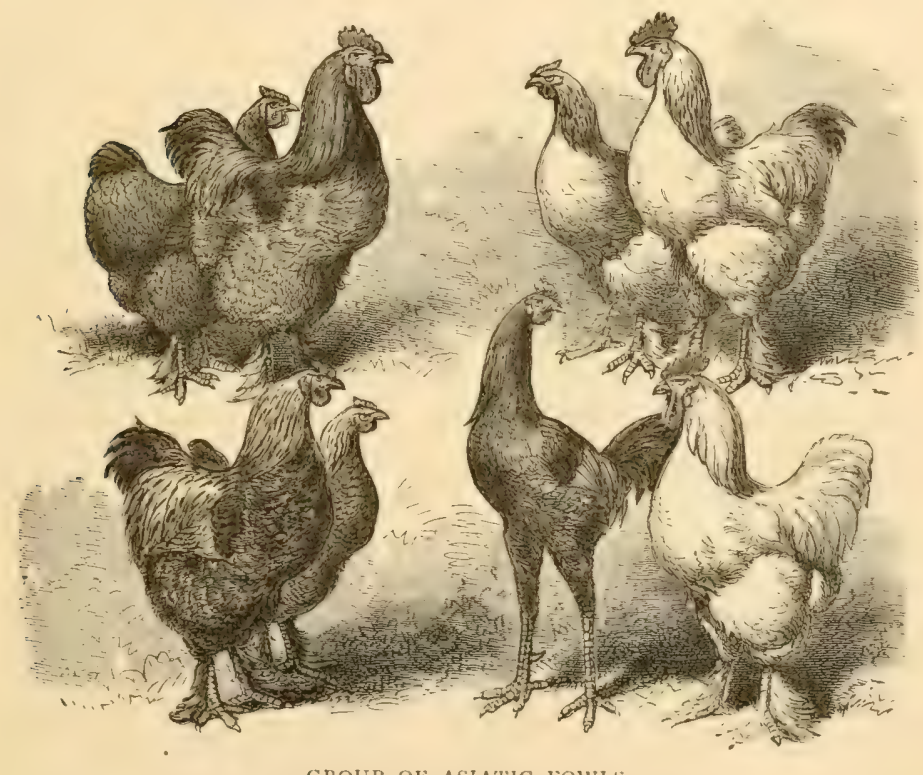

GROUP OF ASIATIC FOIVLS.

unusual affairs of rural life, and are companions of either extreme poverty or extreme riches, I shall content myself with discoursing upon Poultry alone as the only remaining important branch of my subject. 
And first, of gallinaceous fowls, - domestic fowls, so called, comprising the great family of hens, with all its varieties. The cock and his whole race seem to be as old as man. He has his place in the history of Jewish civilization and the founding of Christianity; he was held in high esteem in Greece and Rome; he is found among the oldest Asiatics; and he carried his prolific and profitable family into Britain when Casar led his legions and his game cocks thither for conquest and sport combined. Of the origin of the cock little is known; and there is much speculation still going on with regard to the source from whence sprang the many varieties which are now found in almost every quarter of the globe. For myself, I have no doubt that, springing from a common origin, our domestic fowls have been so influenced by breeding and locality as to have been clivided at last into what might appear to be distinct races, but what in reality are only different families of the same race. The Asiatic fowls and the French fowls are widely different, I know; but so are the Shorthorn and the Brittany cattle. And as in the latter case I would not doubt a common origin, neither would I in the former.

But whatever may have been the origin, the varieties are now so great that it is difficult to decide upon the best; indeed, it is impossible to become familiar with them all, and to thoroughly understand their different characteristics and merits.

Of the Asiatics, I have no doubt that the Light Brahmas are the best. They are quiet, hardy, and thrifty; they bear confinement well ; and when properly fed are almost as prolific in eggs as the small varieties brought from the Mediterranean. They are clumsy sitters and not good hatchers; but if you confine them to eleven eggs to a sitting, and give them a roomy nest, they will do pretty well. Their eggs are of good size and heavy. They can be hatched with safety in early spring, and can be rapidly fed into a size and condition requisite for marketable spring chickens.

I wish I could say all this for the other Asiatic fowls; but, so far as my observation goes, I cannot. The Dark Brahmas. are indolent, careless of their nests, lay but few eggs, and are 
filled with a constant desire to sit. The Buff Cochins are large, clumsy, and indifferent to the object for which a hen was created. The Partridge Cochins are very apt to become misshapen, with hump backs and wry tails. They make an excellent table bird, so far as the quality of the meat is concerned; but they require great care lest they degenerate, and they neither lay nor sit as an ambitious hen should. The I3lack and White Cochins have their alvocates, but I cloubt whether in attributes or accomplishments they equal the I, ight Brahmas, which combine in themselves all known Asiatic excellences.

Of the smaller varieties, I think they may be divided into English, French, and Mediterranean. Of these, I place the English first, because, while they are somewhat difficult to breed, they stand deservedly high for the table, and many of them for the production of eggs. The Dorkings, white and gray, are both valuable, though somewhat tender, and for the fancier not easy to breed to a feather. The English Games are all splendid birds, and although, like all ( ames, inclined to be wild and pugnacious, they are admirable birds to breed, and most admirable to cross. Their flesh is of the finest quality. In this class I will place the Dominiques, which are highly prized by those who breed them, and the Plymouth Rocks, an artificial breed made up probably of the Black Malay and the Tominique, and distinguished for the irregularity with which they breed, the zeal with which they strip each other of their feathers, and the readiness with which they take every disease known to the poultry world. When successfully bred, however, they rank among the best of all fowls for the table. 'The Bolton Grays are compact, solid, small, handsome, and good layers.

The introduction of French fowls will undoubtedly be of great advantage to breeders of poultry in this country. The Creve-Cœurs are very attractive; and the Houdans, said now to be the farorite breed in France, are rapidly becoming acclimated, and are hardy, prolific, solid birds. For crossing with larger fowls they are very valuable. In this class may be included the Hamburgs, the Polands, the Golden Topknots, and 
the Russian and Turkish fowls, - all furnishing an opportunity to gratify every variety of taste.

The fecundity of the Mediterranean fowls is well known and remarkable. Of these, the White Leghorns stand high, and represent undoubtedly that large class of hens which have for years been brought from Southern Europe, and have been prized for their great production of eggs. They lay well, and breed well. The Brown Leghorns, a beautiful and lively breed, are good layers, but they breed irregularly, and are too restless for comfort or convenience. The Black Spanish has long been known and recognized as among the best of our pure-bred fowls. Fowls have recently been brought from Sicily which hold high rank among those which I have already mentioned.

The Frizzles, Silkies, and Bantams, bred, as they are, more for taste than utility, I leave to the fancier alone.

But when you leave the breeds, and clevote yourself to the Dunghill fowl, the work of poultry peace and prosperity has begun. I have known many a successful raiser of poultry to be led into the difficulties and trials of a fancy-breeder bent on the exact production of a feather, simply to learn that his day of trouble had come. This Dunghill fowl comes of a judicious crossing of breeds, and may consequently be of every shape and color; a cross of the Brown Leghorn and Light Brahma producing an excellent variety, a cross of Houdan and Light Brahma producing another, of Creve-Cour and Light Brahma another, and a good, strong, solid cock of mixed breed with a good, solid hen of similar breed, another. In fact, the mixed fowls seem to be the farmers' fowl, especially, being good for the table, the market, laying, and hatching. I find one little record of this mode of producing fowls which may be interesting. Mr. Coons, a farmer in Rensselaer County, who is very curious in the breed of his fowls, began about twenty years ago with the pure Canton or Malay breed; but, finding them rather poor layers and unprofitable sitters, he first crossed them with the Dominique cock, and then introduced white cocks with yellow legs; and afterwarls, by selection, keeping in view the yellow legs, small combs and gills, and the small tail and peculiar 
form to the breed, he has succeederl in retaining those characteristics, and has reduced them to the size of our common fowls ancl of a pure white color. Mr. Cuons informed me that they were now good layers, good sitters, and, notwithstanding he had been breeding "in and in " for the last ten years, but always selecting the best, I must confess I have never seen a more healthy looking yard of fowls. There were about sixty in the yard, and my attention was first arrested by their pure white color, yellow bilis and legs, small tails of the hens and short plumes of the cocks.

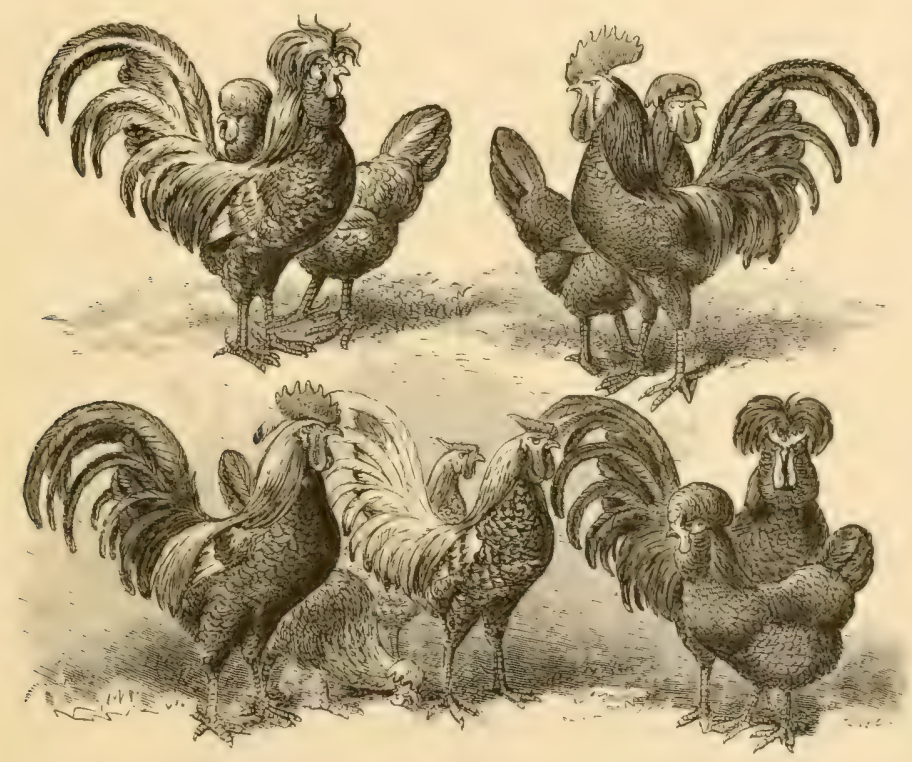

GROUP OF FRENCH AND ENGLISH FOWLS.

Haring provided yourself with hens, the next business is to provide them a place to live in. Every observer knows that the sunny sidle of a barn, or a woodshed, is the farorite resort of fowls, and that, left to rum at large and find their own retreat, they will, if supplied with an abundance of proper food, almost always do well. But in these days of gardens and tower-beds 
it is impossible to give fowls this amount of freedom, and we are obliged to provide some form of a building devoted to their accommodation; and a hen-house has become as common as a stable or a cow-barn. In erecting this structure be careful not to make it too expensive. For the gratification of the taste the hen-house may be made to vie with a pagoda in the extravagance of its erection and outfit; but for the purposes of the farm a simple and economical building will be sufficient for all practical uses, and will often afford more real comfort to the fowls than a more costly structure. A house twelve or fifteen feet wide, with the roof sloping one way, and having on its lower side, which should open to the south, windows constructed like the glazed frames of a hotbed, and with a length sufficient for the accommodation required, is the best form so far as my observation goes. This building may be divided into rooms about fifteen feet in length, if more than one house is necessary, and each room may be supplied with roosts and laying-boxes to suit the taste of the owner. The simplest laying-boxes are the best, and the most conrenient are those which can easily be removed after being used for a time and cleaned with hot water and lime. Beneath the roosts keep a bed of sand about three inches deep, into which the droppings of the hens may fall, and in which the hens themselves may wallow. This room should be supplied with proper feed-boxes, one for corn and wheat screenings, one for daily mixture of shorts and hot water, and one for crushed bones or oyster-shells, with which the fowls should always be supplied. There should also be in this room a vessel containing clean water, and a box of slacked lime or ashes in which the fowls can dust themselves. The room should be whitewashed, and the roosts should be washed from time to time with whale oil soap and water. Each room, or the house, if it is single, should be provided with a yard well enclosed by a wire or tall picket fence, and into this yard the fowls should be allowed to run freely. When the hens desire to sit, they should be removed from this house and furnished with accommodations elsewhere. Movable sitting-boxes are useful, which can be placed in quict and secluded parts of the barn or outbuildings. 
lood and water should be placed within easy reach of sitting hens.

Cracked com is the best and most economical food for fowls, but they should never he kept on any one kind of food ; oats, kitchen scraps, buckwheat, bonnyclabber, sunflower-seeds, and other changes should be made. Never feed all they will eat, but stop when they cease to be greedy for food. Lime, burned oyster-shells, and shells of their own eggs will assist them in forming new shells. Give chickens plenty of room and ploughed ground to scratch in. If you do not want the hens in the ploughed land, fasten the coop near it and let the chickens run. But it is better, after the first week or two, to let them all run, calling them to the house at least once a clay to make them feel at home there.

The average cost of keeping fowls of all kinds, with corn at \$ I a bushel, and small grain in proportion, will be not far from $\$$ I.25 per year.

Millet, boiled potatoes, cabbage-leaves, or bits of turnips and animal food should be given the fowls from time to time through the winter.

Sitting hens should be allowed to cover eleven or thirteen eggs, and no more. They will sit three weeks, at the end of which time the eggs should hatch, if they are to hatch at all. For about twenty-four hours after birth the chickens cannot only do well enough without any extraneous nourishment, but will b. fir more likely to thrive subsequently, if let alone, than if crammed or incited to eat prematurely. More chickens are destroyed by over-feeding than are lost by the want of it. It is, however, well to turn them in among other chickens that already: feed themselves; they will, in such cases, generally follow the example of the rest and pick away at whatever is around.

A roomy, boarded coop in a dry, sunny spot is the best position for them cluring the first month; after which it may be left open during the day, for the hen to retire to when she pleases. In quiet, grassy places it is scarcely necessary to coop the hen at all. As to food, they may have ererything which is not absolutely poisonous ; though if wet food is giren the chicken is 
then obliged to take water, whether it requires it or not, in order to get a sufficient supply of solid food, and this is liable to bring on diseases of the crop and intestines: whereas, if the food is dry, they can supply themselves with food and water according to their pleasure. If Indian meal is well boiled, and fed not too moist, it will answer a very good purpose, particularly if the chickens are more than eight or ten days old. Pure water must be placed near them in such a manner as to enable them to drink without getting into the water, which by wetting their feathers benumbs and injures them. Meat and insect diet are almost necessary; but whatever the food the meals must be given at short intervals, - as much as they can swallow and as often as they can eat. With all their industry, they are only half clad till flesh and bone stop growing for a while, and allow down and feathers to overtake them.

Chickens should not be let out of their coops too early in the morning or while the dew is on the ground; still less should they be suffered to range over the wet grass, which is a common cause of clisease and death. They should also be guarded against sudden unfavorable changes of the weather, more particularly if attended with rain. Nearly all the diseases of gallinaceous fowls arise from cold moisture.

The period at which chickens are left to shift for themselves depends upon the disposition of the hen. Some will continue their attention to their chickens till they are nearly full grown, others will cast them off much earlier. In the latter case, an eye should be kept to them for a few days; for chickens in this half-grown state are much more liable to disease than when they were apparently tender little weaklings, crowded under their mother's wings. They should be kept in a dry, warm place; dryness is especially necessary.

Most of the diseases to which fowls are liable arise from neglect, or mismanagement, or exposure. Irregular and injudicious feeding, improper food, filthy coops, damp location, bad water, all tend to destroy the health and to bring on those diseases which are more easily prevented than cured. From indiscreet feeding arise all the cliseases which attack the alimentary organs 
and destroy the health and vigor of the young chick. Neglect of the houses, laying-boxes, sitting-boxes, and coops is pretty sure to engender lice, a trouble to which fowls are especially liable. Pip, or gapes, arises, I have no doubt, from the use of putrid and dirty water in hot weather. Now the first business is to avoid all these difficulties; the next business is to cure them. In cases of loss of appetite and incligestion, the food should be changed according to the nature of the discase and the kind of food which has induced it. To prevent lice and to destroy them, whitewash the walls and roosting-poles. Burn flour of sulphur in the house, first having driven out the fowls, the fumes of which will penetrate every crevice and destroy the pests. Clean out the old nests, and when a new one is made rub into it dry tobacco-leaves, pulverizing them between the hands. It is a good plan to mix a little flour of sulphur with Indian meal and feed the mixture to the fowls now and then. If the chickens become infested with the vermin, a little lard, in which a small quantity of sulphur has been mixed, may be carefully rubbed into the feathers on a dry, warm day, and the remedy is very efficacious. The same remedy will avail in case of the loss of feathers. For the gapes, turpentine seems to be a specific. It may be used by mixing at the rate of five or ten drops to a pint of meal in preparing dough for the chickens; or it may be applied with a feather pushed into the windpipe. Chickens troubled with this disease should have as free a run as posisible. Roup, which is another distemper caused by cold and dimpness, and which is attended with great swelling of the head and eyelicls, may be cured by keeping the fowls warm and giving them plenty of water and scalded bran. Wiash the eyes with a solution of sulphate of zinc. Prepare a mixture of pulverized charcoal and of new yeast, each three parts; of pulverized sulphur, two parts; of flour, one part; of water, sufficient to moisten the mass; mix well and make into doses of the size of a hazel-nut, and gite one three times a day. Cleanliness and warmth are especially necessary in treating this disease and in preventing it.

Turky's. - The breeding and rearing of turkeys is a most 
difficult business, inasmuch as the hen is very much disposed to steal her nest in places where she is liable to be invaded by vermin, and the young are very sensitive, and liable to be killed by wet and cold and injudicious feeding. When the hen has been left to herself, however, during her laying, and has chosen a nest at a small distance from the house, there is hardly anything to be done, for she will leave it with difficulty; and it is even prudent not to thwart her, for she generally hatches her own brood safely, and the young ones are the stronger for it.

When the chicks are hatched the hen and brood must be housed during a month or six weeks, dependent upon the state of the weather. The scorching sun and the rain are above all hurtful to them; superfluous moisture, whether external or internal, is death to them; therefore all slop victuals should be avoided. The utmost cleanliness is necessary, and a dry gravel layer is most proper. High places exposed to the east or south are those which always agree best with the young turkeys, especially when they have a separate yard.

The best food for them is eggs boiled hard and chopped fine; thick sour milk boiled, which makes a thick curd; the whey is separated by putting it into a colander or coarse sieve, and when cold rubbed fine in the hands and fed to them in small parcels and often. Indian-meal wet in the ordinary way is injurious to them until they are several weeks old. Chives cut fine and mixed with their food is eaten with great avidity. In case of the chicks appearing sickly and the feathers ruffled, indicating a chill from severity or change of weather, ground malt with a little barley-meal is allowed, and by way of medicine powdered caraway or coriander seeds. Boiled meat pulled into strings is a valuable and nutritious food for them. Water should be given them in very shallow vessels, in which they cannot wet themselves, as this would be very injurious. In orcler to prevent the mother turkey from robbing the chicks of their food, they should be fed in a separate coop and at such a distance from her as to be out of her reach.

At two periods of their lives turkeys are very apt to die, namely, about the third day after they are hatched, or when they throw 
out what is called the red-head, which they do at about six weeks old. It is a very critical period in the life of a turkey, much more so than the period of moulting; the food must therefore be increased and rendered more nutritious by addin: boiled eggs, wheaten flour, bruised hemp-seed, or a few bruised beans.

It is only when the cold comes, and when turkeys are about six months old, that they should be fed with better and more plentiful food in order to increase their size and plumpness for market. Indian-corn, ground barley, rice, and other articles used to fatten common fowls are considered best for the turkey. The most successful mode of fattening I have found from experience to be to shut up the flock in a warm, well-lighted room, and feed them on corn, with a liberal supply of boiled potatoes mixed with meal and pulverized charcoal. This latter substance appears to have a most remarkable effect in increasing the weight and improving the flavor and tenderness of this bird. In fact, I think a liberal use of charcoal is indispensable in the proper preparation of turkeys for the table or the market. Their weight when well fattened should average twelve pounds; their living and dead weight is as eighteen and twelve pounds.

Aquatic Forcls. - At the head of this class stands the goose, a bird whose habits, in a wild state, fill our imaginations with the grandest pictures of nature as he pursues his lofty flight to the awful solitudes that surround the pole, and, returning, bathes himself in the luxuriance of the tropics; a bird whose domestic history is a strange commingling of useful service and bad ways, of ancient renown and modern inferiority. No man ought to keep geese who has near neighbors; but to show what can be done with them I will quote the following account of anserine agriculture, taken from the Maine Farmer. "I once knew," says a writer in that paper, "a couple of industrious sisters who lived near a never-failing brook or stream in Massachucetts, who kept generally through the winter thirty geese, male and female. They had erected some suitable, but not costly sheds, in which they had apartments for them to lay, sit, and hatch. Their food in the winter was meal of various kinds 
to some extent, but principally apples and roots. In the summer they had a pasture enclosed with a stone-wall or board fence which embraced the water. They kept their wings so clipped that they could not fly over such a fence. Their owners well know what we all know, that live geese-feathers are a cash article at a fair price. They picked off their feathers three times in the season. Those thirty geese wintered would raise serenty-five goslings, and of course the owners had that number to clispose of in the fall or the beginning of winter when they are sent to market and again picked, making four times they obtained feathers from those they wintered, and twice from the young ones that they had killed." While I have nothing to sily of the perspicuity and grammar of the quotation, I recommend its statement to all who have a pond or a running stream with a little waste land adjoining, which they would profitably utilize. And let me add that clipping at a proper season is an innocent and humane operation compared with the severity of plucking.

Geese will generally take pretty good care of themselves, although they require feeding twice a day if they are expected to reach a good size. In fattening, however, they must be carefully attended to. Confinement, meal, and skimmed milk will make a good green goose at two months old. Steamed potatoes, mixed with ground buckwheat or oats, will render geese cooped in a dark place fat enough in three weeks. Generally they can do best fattened in the month of November, to accomplish which they should be kept clean and well fed.

Ducks are the most sociable, garrulous, interesting, and unprofitable birds which the farmer can feed. They hold the most noisy assemblies, and keep up the most restless activity of any known living beings, not excepting man. 'They are carnis'orous as well as granivorous and graminivorous; and will eat flesh, garbage, flies, insects, fish, corn, and peas, with equal relish. 'They are prolific and careless layers. They will do well when provided with a creek or small pond, and they will do well without it. Their parades are inimitable, and their repose is as solemn and profound as night itself. The best 
agricultural ducks are undoubtedly the Rouen and the Aylesbury.

A duck should be allowed to sit upon from nine to eleven eggs as soon as she has laid her litter. At this time she should be especially cared for, and furnished with food and drink. The duck is generally disposed to take good care of its egres, and often covers them with feathers in order to prevent their being chilled during her absence from the nest. Young ducks should be carefully fed with a variety of food, and should not be allowed to go to the water until they have reached considerable size and strength. The pools and streams have great temptations for them, but they are apt to be very fatal.

Ground oats and corn, mixed with boiled potatoes, with now and then a little meat chopped fine and added, is the food best calculated to fatten a duck speedily and well.

I have endeavored to set forth in concise form the most important facts and suggestions with regard to the poultry usually found on our farms, and with this I must be allowed to terminate my work for the Club. My mind is too slow, and my body too feeble, to allow me to devote my time to any service which is not absolutely necessary, and I find an unexplored path is by no means easy for me to travel with my infirmities. Old age requires a familiar and well-worn highway. I can pray for you, but I fear I cannot instruct you. And, thanking you for your attention this evening, I now take my place among the learners in the Club.

The Squire was heartily congratulated upon his essays relating to the smaller animals of the farm, and he was especially thanked for his elaborate views upon poultry, a mere sketch of which it has been possible to give here. He answered the many questions put to him at the close of his reading with patience and intelligence; and, notwithstanding his humility, he seemed to be highly gratified with the evidence of belief in his knowledge and wisclom manifested by the inquiring members about him.

Before the adjournment of the Club, a vote was passed 
548 THE FARM-YARD CLUB OF FOTHAM.

requesting William Jones to prepare an exhaustive essay upon the Horse, as the final investigation of the Club for the season, and as completing the matters of legitimate agriculture. This being accomplished, the members bade Mr. Hopkins good night, and returned to their homes. 


\title{
THIRTY-FIFTH MEFTING.
}

\author{
THE HORSE.
}

MRS. HOWE'S DEATH. - MR. HOWE'S TRIALS AND SUBMISSION. - WILLIAM JONES TELLS ABOUT HORSES.

MRS. HOWE was known in Jotham and in the regions round about as the most charming and exemplary of ministers' wives. She was born in affluence, was descended from a long line of cultivated and prosperous ancestors, had inherited the sagacity and commonsense which secure success and are confirmed to the condition of inherited faculties by it, was possessed of a delicate and sensitive organization and that keen sensibililty which always grows luxuriantly on a moral soil

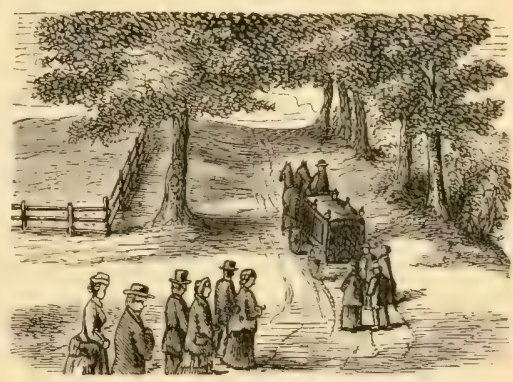

FUNERAL PROCESSION. which has not been chilled and hardened by the frosts of adversity. It was said of her in her childhood that she was intended to adorn the mansion of wealth and distinction; but she came under the influence of the handsome young minister while she was yet a young girl, and before she had learned the difference between the self-sacrificing demands of cultivated poverty and the burdensome cares of luxury and ease. Stepping suddenly from the position of a petted and admired school-girl, with a home where 
every comfort and indulgence was affectionately lavished upon the only daughter of the house, into the duties and responsibilities of a Puritan parish minister's economical home, she entered at once upon her work; and nowhere within all the circuit of that association of clergymen to which Mr. Howe belonged could there be found the equal of his beautiful wife in all Christian virtues and graces. She was so much beloved by his less fortunate brethren, that his house was their favorite place of resort; and there it was that they found that refinement and taste which were too often denied them in their own households. Her heart warmed constantly towards the people of her husband's flock, who, high and low, rich and poor, young and old, felt that there was one spot at least in which they could all find a home. In partaking of their simple and humble ways of life, she seemed to forget the more elaborate customs into which she was born, without laying aside the delicacy of thought and feeling and expression which the associations of her childhood and youth had cultivated. From a thoughtless girl she became at once a Christian woman; and to the deference and respectful admiration with which she was treated by all the villagers before her marriage were added the love and confidence and respect of a delighted parish, when she became the wife of their beloved pastor. That they were proud of her was manifest. Her hospitality was especially charming to them ; and as they gathered in her well-warmed and cheerfully lighted room at the sociable evening parties which she was fond of calling together, they evidently felt that their powers were invigorated, and that their thoughts and feelings and manners were refined and purified. They were put upon their good behavior without awkward or painful restraint; and it was more than half suspected that she cxerted a more powerful influence upon the community by her example and presence than did Mr. Howe, armed with 
all the power of the church. Dr. Parker always spoke of her as the flower of her family, who were his father's devoted and useful friends. Squire Wright was alway's reacly to listen respectfully to her opinion. Peter Ilsley, so long as he lived, took off his hat in her presence. Mrs. Thomas always warmed and glowed and expanded under her influence. William Jones invariably put his best foot foremost in Mrs. Howe's parlor. Mr. Hopkins loved her for her father's sake, who was his old commercial friend. Charles Ingalls and Clara Bell looked admiringly on her gentle and dignified manners, and learned a lesson of deportment which they never forgot in the elevated and conspicuous paths which they travelled in after life. When she entered, the slang of the grocery was hushed. With a people known among themselves as "Uncle Joe," and "Aunt Betsy," and "Ma'am Jess," and "Cap'n Phin," and "Sally Bliss," she was spoken of respectfully as Mrs. Howe, and without exception she received this mark of deference from all. That she had faults, who that is human can doubt? But they were faults which indicated a kind and chivalrous spirit, and were free from meanness and deception. If she was roused to indignation, all her friends knew that it was over some wrong towards the feeble and defenccless. If she expressed too strongly her approval and regard, they understood that it was for encouragement, and not for flattery. If she became stubborn and dogmatical, it was under the influence of strong conviction, or a generous impulse to sustain a friend. If she was imperious, the sudden impulse could be traced to a firm and honest faith, attended by a consciousness of power. And these somewhat defiant faults were tolerated, perhaps almost admired, by her friends, who saw in them the natural and necessary absence of dishonesty, and jealousy, and suspicion, and hardness of heart.

For twenty years Mrs. Howe had lived in Jotham and 
had impressed herself upon the community. Her children were growing up about her; and so accustomed were her daily companions to her commanding power, that neither her children, nor her husband, nor her friends observed that an unusual feebleness was coming upon her, and that the divine light of premature decay was beginning to irradiate her spiritual face. Mr. Howe knew how delicate she had always been, but he also knew how strong she had been through the inspiration of a determined spirit, which no obstacle could daunt. Her children knew that she was not strong as Mrs. Thomas, the substantial and motherly, was; but they had a feeling that she was superior to all infirmities, and that her slender cord was not to be broken. They had observed with anxiety that often during the winter months the cold seemed to oppress her, and that her voice failed her when she attempted her customary reading aloud in her family circle. She drooped too, - but their eyes were blinded to that by the overconfidence of love. The warm days of spring came on, and she fainted and languished in their enfeebling heat, but nobody was quite strong in the spring. And it was with overwhelming grief that Mr. Howe received from Dr. Parker the sad and distressing announcement of her sudden and hopeless decline.

"O my Father," said he, "let this cup pass away from me; nevertheless, not my will but thine be done."

And then he who had led so many mourners through the dark valley of sorrow prepared himself to walk alone in its bitter experience. To him the task was hard indeed. He had a great and sustaining faith, it is true; but he felt that life without her who had filled his soul with pride and strength, and whose companionship had always lifted him above the ordinary affairs and associations of his daily life with the common people about him, would be a blasted and withered existence, worse by far 
than death itself. He concealed his anxiety and maintained his cheerfulness, even when she was compelled to withdraw from her daily duties, and rest and wait patiently in her own room. To the broken-hearted minister the opening spring was an agony. He saw the mild days come and gro; he knew that the flowers and buds were coming forth, and that the air was laden with their perfume; and he walked through the radiance of this season of hope and promise as he would have traversed the shadowy regions of a bewildering dream. He was faithfully attentive to all his duties; taught his children as their mother had taught them ; cheered the broken-hearted, as he had done when she was by his side; and ministered to his people with the same courage as when his wife and children sat before him, and inspired him to his sacred service. But the weight was terrible. The new hope which filled his soul as each morning dawned upon him led him only to deeper and deeper despair as each day declined. The strong and ruddy faces of his people seemed to mock him, until at last he felt withdrawn from all the common affairs of life, and, unmindful of children and friends, he entered with her whom he had loved so long into a patient and cheerful and exalted journey, which he knew would at last bring them both to rest in peace. He felt that the ordinary pleasures of life for him were over. $\mathrm{He}$ knew that his sun was to be darkened in mid heaven; that the light on the hills had faded; that the joy of his home was passing away; and that over all his landscape was settling down a cold gray twilight, which nothing but the opening gates of another world could warm and irradiate. For themselves the mysterious journey was begun ; and it ended not until their separation was over and their joy was complete. When Mr. Howe realized that he was to be left alone in his work, and that his way through life was erclong to be solitary, he felt that his pride was 
gone and his glory was quenched, and that not until the "shining shore" was revealed to him, as it would soon be to her, would he return to that full measure of happiness which he had thus far enjoyed as a husband and father, and a well-poised and useful parish minister, supported in his work by her whom Heaven has sent to man to cherish his gentlest virtues and to quicken his strongest faculties.

And so it was. Mrs. Howe died, and Mr. Howe was left alone. It was on the morning of a bright and still summer day that she passed away. Her last night on earth had been spent with him to whom she had been faithfully and tenderly devoted through all her life of love, in a communion whose memory was never to pass away from him who was to bear the anguish of parting. It was a night of sweet stillness and spiritual glory to them both. There was no agony there; but as the hours rolled away the beauty of her who was approaching heaven grew brighter and brighter, and the faith of him whom she supported by her divine influence in this hour of trial grew stronger and stronger. For her children, whom she was to see no more, she left the fervent outpouring of a dying mother's heart. For her people she left her example and her prayers. To her husband she gave the radiant faith of a Christian, the tender and gentle endearments which she hoped would soothe his sorrow, and the assurance that they should meet again in that eternal home to which she led the way. And so as the morning opened in all its freshness and beauty she fell asleep, to wake in heaven.

In all that followed the minister bore himself with a degree of cheerful resignation which was more touching than the wildest grief. Not a tear was seen to fall from his eye; but over all his countenance there fell a soft and holy light, as he seemed to walk with her spirit and to be 
led by her invisible hand. To his children he became, through the constant memory of her life, father and mother combined. To his people he presented the best and purest of his service, and that support and consolation which come from the sad experience of life. To himself he was a heartbroken man, the bitterness of whose solitude was known to himself alone, and whose daily companion was an angel in heaven.

To return patiently and cheerfully to his work was a recognized obligation with Mr. Howe; and he was found moving among his people as usual. But can they who are engaged in the ordinary business of life, and whose minds are led away from their sorrows by their duties, tell or imagrine the heroic resignation and composure required by him who, in the stillness of the country, and with the intensified life which belongs to a parish minister, is compelled to perform the services of his church before a congregation, every one of whom reminds him of his loss, and whose spiritual needs sharpen his sensibilities to a painful realization of his own? Who can tell the weary and wearing work which falls upon him who, while bearing his own burdens, is compelled to "rejoice with those who do rejoice, and weep with those who weep"? To be led into the depths of life with a mind worn by trial, and a heart broken by grief; to sympathize with the joyful and to console the suffering, when every excited sentiment and thought tears open one's own wounds, - this is the intensity of the burden which falls upon the minister of God who would faithfully perform his duty in joy and sorrow alike. And this, the keenest trial, fell upon Mr. Howe. The affairs of his sympathizing people went on as usual. The meeting-house was thronged on Sunday; the eldest daughter of Sam Barker had arranged to be married, and the wedding could not be postponed; the young wife of William Ferson died suddenly, and the grief-stricken hus- 
band must be consoled; the child soon followed the mother, and another wound must be healed; the schools were to be visited; the daily trials and troubles of the flock were to be relieved. And this work was faithfully done, while to the side of the mourning minister and his family came Mr. Hopkins with his generous courtesy, and Dr. Parker with his cheering ways, learned at the bedside of his patients, and Squire Wright with his worldly philosophy, and Fanny Parker with her fresh and inspiring energy, and John Thomas with his hearty good-will, and Mrs. Thomas with her matronly comfort, and Charles Ingalls with a manly and honest courage, and Clara Bell with her sweet and vitalizing beauty; and over the kindly group, to the eye of the minister, hovered the spirit of her whose memory was cherished in silence and whose influence was felt more and more as the days went on.

During the illness of Mrs. Howe the Club continued its deliberations, and it was from the kind and sympathizing associations of its meetings that Mr. Howe found much relief and comfort during those trying weeks. To William Jones had been assigned the duty of preparing an essay upon the Horse, and he had turned his attention to the work with such assiduity and skill that he had cheered as well as enlightened his companions. He had formed an intimate acquaintance with a young student of medicine in an adjoining town, and had learned from him that he was preparing a paper upon the selection and care of horses ; and to this student Mr. Jones applied for aid in his undertaking. The essay which he read, occupying two evenings, was the concluding work of the Club for the season, and so far as any record can be found, forever. Mr. Jones, having familiarized himself with the contents of the paper which the young student had prepared, presented himself at the Club in most elaborate attire, with his hair brought to glossy curls by the skill and toil of the barber, and his 
linen perfumed with an abundance of home-made cologne; and read as follows to his admiring audience :-

\section{WILLIAM JONES ON THE HORSE.*}

I shall not occupy your time on the discussion of the origin of the horse, or his relations to state and society, upon which so many of our enthusiastic writers are fond of dwelling. I

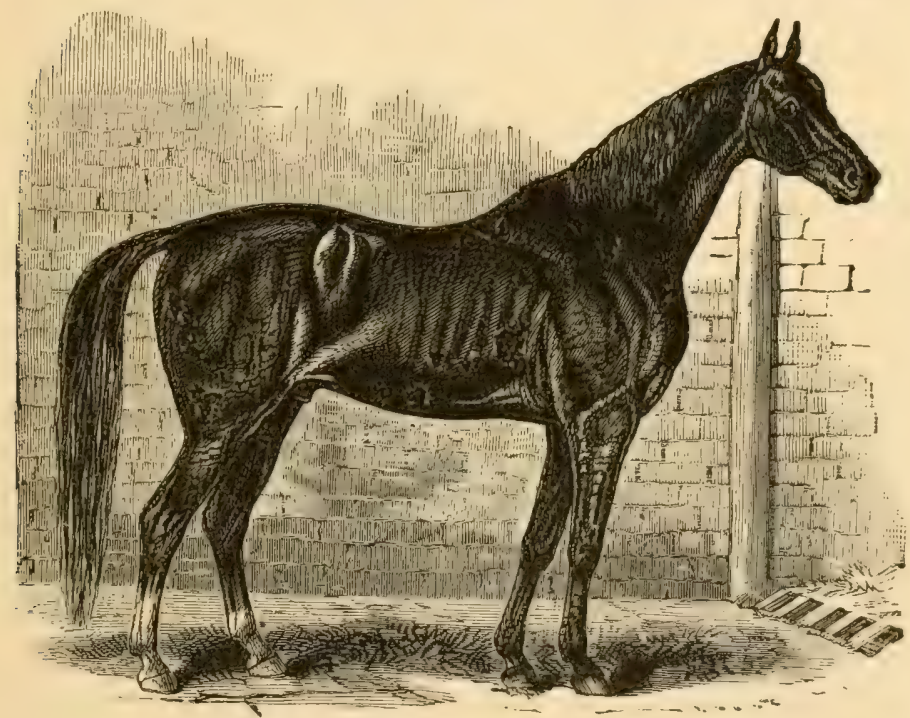

AMERICAN TROTTING HORSE.

shall proceed at once to describe what I consider a good horse, and then discuss how he can be bred, and how he should be fed and cared for.

A good horse, an animal fit for all work, - the track, the farm,

* This essay was evidently published at a later day in that part of "The Perfect IIorse," written by the author of this work under the head of "Agriculture and the Horse." As read by Mr. Jones, many years ago, it varied somewhat from that which is now presented; but it is thought better to give it in the form most suited to these times. No doubt the young medical student and the author are one and the same person. 
and the business wagon, - is a horse weighing a little over ten hundred pounds in good road condition; fifteen hands and two inches high (for I find that this height and weight usually go together); with a head not too fine, wide between the eyes and erect above them; with a good-sized, steady, and lively ear; with every bony process sharp and prominent, - even the processes of the first cervical vertebra behind the ears; with a calm and well-set eye, and lips which indicate determination rather than delicacy; a Websterian head, with a neck well muscled, well arched, strong and elastic, with active motion and a throttle loose and open; with withers not sharp and thin, but solid and strong; with a shoulder set loosely on, broad and deep at the base; with a strong arm, sinewy leg, short canon-bone, firm and not too long or elastic a pastern, and a firm foot; with a deep chest, without a prominent and bulging breastbone; with a round barrel ribbed well back towards the hips, but not so far back as to interfere with the action of the hindquarters; with a short back and a slight elevation of the rump just behind the coupling; with a long and strong quarter well muscled insicle and outside; with a hind-leg so set on that the action shall be free and open, and with the fore-leg so set on that the toes shall not turn out and be liable to brush the knees at speed, and that they shall not turn in too much and be subject to paddling. 'The color should be bay with black points as the best; and the temperament should be calm, collected, fearless, defiant, with a brain quick to learn and strong to remember. This horse, known usually as the "American Trotting Horse," is an animal after his own kind, and I venture to say unequalled by any other horse on earth, in all that makes such an animal truly valuable in every kind of service. It takes true equine genius tn make a trotting horse. His mechanism must be as well balanced and symmetrical as a locomotive. Propelled as he is by one quarter at a time, his progress is the result of nerve and strength and decision, unknown and utterly ignored in that leaping, bounding motion where one end follows the other, as is the case of the running horse of the English turf. He must be solid in his foot, strong in his limb, firm in his back, free 
and easy in his stride, and, above all things, calm and collected amidst all the trials of the track and the roud which tend to throw him off his balance, and reduce him to the level of the hare and the fox and the greyhound and the English race-horse, running helter-skelter in a natural manner, without the exercise of any faculties except those with which nature endows the coward when he flies from danger or conflict. The American trotter requires bones and muscles and brains; and when he stands high on the list he has them all. For compactness of form and ease of motion, for strength, endurance, and sagacity, he is unequalled. Now we have this animal as the natural product of our farms. I know not how it las come to pass, but it is a fact that the farmer's horse in the whole northern section of the United States is peculiar to himself, and is, moreover, peculiarly an American institution. He may be and undoubtedly is, on one side or the other, descended from the thoroughbred, for anything which can be said to the contrary; but the further he is removed from that rather equivocal class of animals the more truly does he become a trotter. I look upon him as one result of that social and civil equality which, in our own country, makes one man's time as valuable as another's, and which authorizes the farmer's boy to take the road from the squire, or the parson, or the dealer whenever his colt can do it. Every man in this country who can keep a horse wants a good one, and when he has got him he wants to avail himself of his horse's powers to make the distance between the mill or the meeting-house and his own home as short as possible. We all drive on the road; and this, combined undoubtedly with certain fortunate aptitudes of climate and soil, has given the United States its valuable races of trotters.

I wish it to be thoroughly understood, Mr. President, that I fully recognize the value of those old horse progenitors who brought into our country many years ago the bone and muscle and nerve and wind and capacity of the English thoroughbred of that day. I am mindful of the old Messenger and of what he and his sons have done; and I cannot, moreover, forget 
that his fame as the ancestor of trotters was established, not in Buck's County, Pennsylvania, where he stood two seasons after his arrival in this country, in 1780 , but on Long Island and various other points in New York State, whence his stock was distributed throughout the best breeding sections of New England and the Northwest. As the sire of Miller's Damsel (the dam of American Eclipse) and of Sir Harry, out of mares of acknowledged and recorded pedigrees, he won a fine reputa. tion; but it was as the sire of Mambrino, - whose dam had no pedigree except that she was by Sourkrout and of Hambletonian, whose dam was by Messenger himself, but whose granddam was "unknown," - that he won his distinction as the ancestor of some of the most remarkable trotters on earth. And how as generations went on and that "unknown" blood worked in, did the speed of this family increase! From Mambrino sprang Abdallah, dam Amazonia (by Messenger, dam unknown) and Mambrino Paymaster, dam unknown. From Abdallah, with his unknown grandmother, we have, two or three generations removed, each with his unknown dam, Rysdyk's Hambletonian, with his famous sons Dexter, George Wilkes, and Mountain Boy. From Mambrino Paymaster, with his unknown dam, we have Mambrino Chief, dam also unknown, though said to be of Messenger descent; and from Mambrino Chief we have Lady Thorne, and Mambrino Pilot, and Mambrino Patchen, and Ericsson, and Brignoli, and Ashland, in whose pedigrees will be found as many unknown dams as there are sires and grandsires. And as $I$ trace the blood of the old imported Messenger horse into Maine and Vermont, where all the mares were "unknown," what a tribe of our earliest and best trotters rises before my vision! Ripton, the gallant "white-legged pony," the favorite of Hiram Woodruff, the resolute and plucky and triumphant, rivalling Dutchman as a three-miler, and defeating Lady Suffolk, a little Eastern horse of Messenger and Morgan breed; and Daniel D. Tompkins, a wonderful little horse ; and General Taylor, "a very famous trotter and sticker"; and Independence, the delight of my boyhood; and Fanny Pullen, the dam of Trustee, 
the twenty-miler; and Shepard Knapp, and Mac, and True John, and Green Mountain Maid, an! (Bray Vermont, and Sontag, and Ithan Allen (dam a Messenger mare), the best balanced horse ever seen on a track, the evenest gaited horse from the walk onward ever bred, and the most striking illustration of the enervating influence of high feed and rapid work in eanly life ever linuwn in horse annals. These horses, far removed fiom the original thoroughbred, and fortunate in the strain of blood which they do possess, springing from families in which an admixture of various breeds is undoubtedly to be found; members of a list honorable and illustrious, commencing with Topgallant, and Whalebone, and I)utchman, and Confidence, and Washington, and Rattler, and Lady Suffolk, with their "unknown" strains, and ending in our day with Flora Temple, and (ioldsmith Maid, and Dexter, and American Girl, and Lucy, and Bonner's P'ocahontas (the Iaates mare), the queen of mares, with their great record and their defiance of time and space, these horses, I say, illustrate what I mean by that power of the American trotter which is to be obtained by removal, step by step, from the form and gait of the thoroughbred.

liut not everywhere does this removal accomplish the object which the breeder of horses in America has in view. Old Nessenger did not leave behind him the same results in Pennsylvania that he did in New York and New England. He met nowhere in that more southern region the blood which it was necessary to mingle with his own in order to produce the genuine American horse. Who can tell that his fame as the ancestor of a long line of trotters is not due as much to the fortunate locality in which his lot was cast as to his own intrinsic merit? Who can tell that Diomed, and his two famous sires, Sir Henry and Duroc, would not have been rivals of Messenger and his more famous sons Mambrino and Hambletonian, had the two families exchanged residences, and Miessenger had gnne into Kentuck: among the thoroughbreds of that State, while Duroc had cast his lot among the "unknown" mares of the North?

However this may be, Sir, we have the American horse all 
along the northern line, from Eastport to Detroit; ay, still farther West, - a fortunate combination of various bloods, invigorated by the sharp air of our Northern hills; refreshed from our cold Northern streams; fed into hard bone and vigorous muscle by our short and sweet Northern pastures; and caluable of carrying his sturdy forces and implanting them, for a generation at least, among the heavier bones and softer mu-cles of more luxuriant valleys, milder skies, and warmer springs. That he gets somewhat of his power from his native soil and climate there can be no cloubt. But how has he converted that stilted gait of the thoroughbred into the swinging stride and powerful knee-action of the trotter? What has changed the narrow and confined shoulder of the thoroughbred, with its short humerus attached and the necessarily advanced position of the fore-leg so near the point of the shoulder, that a line falling from thence touches the toe, - to loose shoulderblade and long humerus, long from the elbow to the shoulder, so that a line falling from this point touches the ground far in front of the foot, and to that massive and muscular base which wins for the good trotter that common exclamation, "What $a$ " rousing shoulder!" What has cut down those sharp, thin withers of the thoroughbred, and filled in the space above the top of the shoulder-blades with such a mass of strong muscle? What has strengthened that lower jaw, so that the horse and his driver may be made one through the bit and rein? What has dropped the points of the hips below that level of the rump, whe:e they stand usually with the thoroughbred? What has judiciously cooled the ardor, and increased the patience, and enlarged the sagacity of the thoroughbred? What has incased the untiring channels of true blood in a new frame of proportions hitherto unknown to them, until they were subjected to the influence of American companions and American wants and American institutions? Probably no single cause, but many combined. 'The habit of driving, to which I have allucied, has undoubtedly done much towards bringing about this result. But this alone is not sufficient. And. I am constrained to believe that we owe much of the shape and stricle 
which distinguish our best trotters to a larger or smaller infusion of canalian blood, derived from the carly importations of Norman horses into Canada, which have been improved in size and quality by the soil and climate of their new home. In very many of our good trotters this is manifest. All the descendiants of IIenry Clay (whose sire was I ong Island Black Hawk and whose dam was Surry, a mare of great speed from Canada), especially the get of Cassius M. Clay (a son of Hemry), have the thick jowl and heavy ear and romed muscle and thick sinews and coarse-grained foot of the family fom which their mother sprang. How the Morrills show it, even when browht down to Voung Morrill, and through him and that wonderful Stere-French mare to Fearnaught and his sons! How apparent it was in Hiram Drew! Sometimes there is enough to malie them faint, and sometimes enough to send them along. So Pilot, "a genuine Cannuck," came over into the States and stimed up the thorough-blood to the extent of Pilot, Jr., and his rousing son, John Morgan, and rushingr daughter the dam of Mambrino Pilot. So from a Cimadian mare, Rysdyk's Hambletonian got Bruno and the brother of Bruno, and their full sister Brunette. So " a small pacing ('annuck" brought forth "Gift, a chestnut gelding by Mambrino Pilot," who, "at four years old received five forfeits, and challenged, through 'The Spirit of the 'Times, any colt of the same age to trot to harness or to wagon, for a thousand dollars, without being accepted." So Old Morrill received and transmitted that tremendous stride which his family will never lose until they are swamped by the daisy-cutters of Virginia or the English turf. So that wonclerful little incarnation of equine genius, Justin Morgan, son of True Briton and the Great Unknown mare, improved and elevated the cold horse-blond of Termont (uncloubtedly largely filled by French infusion at the time of his arrival there) up to the courage and endurance and style of Sherman and Green Mountain, and at last to the speed of Bliack Hawk and Ethan Allen and Lady Sutton and General Knox and Lancet and General Lyon and Honest Allen and Gilbreth Knox. And so the thousands of hardy, medium-sized, enduring 
horses in the service of the family, in the stage-coach, on livery, on the track, and in the road go whirling on with their Norman stride and their thoroughbred wind and courage.

Hence, then, our American horse; and, taking him as he is, I have an idea that we can so direct his breeding as to preserve to oursclves all his best qualities and even enlarge and improve them. I am aware that the breeding of horses is difficult and doubtful business. The horse holds a position in the scale of being which makes him peculiarly sensitive to all surrounding influences, from his embryo life upwards. The fact that but a few generations are necessary to change almost his entire structure, in order to conform to a change of climate and soil, is sufficient evidence of the ease with which his race may be modified by the accidents about him or by the designs of his mastcr. Suffolk pigs, short-horned cattle, terrier pups, can be bred to order. Not so the horse. He is a bundle of forces, moral and physical, either class of which may be listorted by influences almost beyond our control. A calm, courageous, docile, intelligent mare, bearing a colt sired by a stallion equally well balanced with herself, may be subjected to sudden fright; she may fall into bad hands, and be lashed to madness while pregnant; she may have her attention fixed on some ignoble companion; and the character of her offspring be so different from her own, or that of its sire, that she is ashamed of it (or ought to be), and her owner despises it. Every man knows that there are some families of horses which are easily broken to harness, in fact, have a natural gift in that direction, and take kindly to the strap and the shaft; and that other families are rebellious and violent and almost untamable. That this quality is inheriter there can be no doubt; and, if you doubt it, take the English thoroughlored, with his inheritance of strong passions and impetuosity on the turf, and his days of idleness, in which his sins grow apace, and compare him in all points of submission, docility, and usefulness with the American horse of all work, the heir of every accomplishment which can make a horse useful at the plough or the cart, or on the track or road. Now these qualities may easily be transmitted or they 
may easily be destroyed. A rough master may upset ai! the virtues of generations, and unexpectedly find himself the owner of a colt inspired with all the wildness and savacery of his remote ancestors. It is a good deal to ask, I know; but if a man means to raise up a good-tempered and civilized family of horses he must be good-tempered and civilized himself.

And then the unexpected physical variations; who can account for them? You can generally be pretty sure of breeding a pig which will weigh a given number of pounds at a given age. You can generally breed a Shorthon cow with certain specified lines, a desired color, a wished-for aptitude to fatten, and any number of such inglorious qualities which make up a good beef-producer; but to breed that delicate organization which makes a good milch cow, and that nice adjustment of nerves and reins and bones and muscles which makes a really valuable horse is not so easy. Even thoroughbreds vary to a degree entirely unaccountable. The size varies, the color varies, the form varies, the power varies in a family bred even from one sire and one dim. The success which hat attended the efforts of the best breeders is so small as to be truly discouraging. The great English horse Fclipse, bred as he was to hundreds of the best mares of his time, got only three hundred and forty-four winners; and half of these never grot heyond a single race. Matchem, another great and victorious horse on the English turf, got but three hundred and fifty winners. And King Herod - the third king of the race-course and the stud - got only four hundred and ninety-seven winners, but few of which made any mark beyond their first effort. What will the most enthusiastic friend of any trotting stallion known within the last thirty years tell us of the trotting quality of his stock? Old Black Hawk stood for mares almost from the day when, a four-year-old colt, he trotted down from I)over, N. H., to the hour when he died in the comfortable stable of David Hill of Bridport, Vt., for whom he had earned a fortune : and yet you could count his trotting sons and daughters on your fingers. So, too, of Ethan Allen, and General Knox, and the Drew horse, and the Eaton horse, and Old Witherell, and Lam- 
bert, and Rysdyk's Hambletonian, and Young Morrill, and a host of others, known and unknown; while some unheard-of stallion has sent his single offspring to the track, "but that one a lion."

And yet with all this variety and this uncertainty of obtaining what you desire, let no man doubt that he can breed a good horse, and do it profitably, if he will but exercise judgment and skill, - not a bay horse always, nor a black one, nor a chestnut one, but a good one. In endeavoring to do this, do not select parents who have a bad ancestry. Never hope to get from a sire which you do not like, and a dam which you do not like, offspring which you do like. Do not try to breed out an unsounchess; you may not live long enough to do it. Never breed from an immature horse. Very young horses are always doubtful sires. Old horses, if good themselves, have seldom any reason to be ashamed of their offspring. Never breed from kickers, or biters, or sullen horses, or from half-broken horses. If either sicle is slow, let it be the mare. It is by the male that the race is to be improved. And always expect to get more good females than males; for this is the rule in breeding almost all animals.

William Jones paused here, before proceeding to discuss the care and management of horses from their youth mpward. The comments upon his remarks thus far had occupied so much time that it was deemed prudent to defer the reading of the rest of his essay until the next meeting. And so at a late hour the Club adjourned.

As the members went out, Charles Ingalls joined Mr. Howe and accompanied him to his gate, not daring to ask after Mrs. Howe, but hoping that the sympathy with which his heart was overflowing might be instinctively felt by his friend, and assure him that he was not forgotten. The minister could not speak. 


\section{THIRTY-SIXTH MEETING.}

\section{THE HORSE.}

WILLIAM JONES FINISHES READING THE ESSAY OF THE YOUNG MEDICAL STUDENT. - REMARKS ABOU'T BOYS. - FEEDING, STABLING, DRIVING. - THE LAST MEETING OF THE CLUB.

TiIE duty of calling the Club together for what proved to be the last time devolved upon John Thomas alone. Mr. Howe, who had been his associate in this work for so many years, and who had never failed to be present both at the preliminary arrangements and at the meetings which followed, could not separate himself from that companionship to which he clung more and more closely as time went on, and the end drew nigh; nor could he increase the burden he already bore with the additional trial of bidding farewell to an assembly around which clustered some of the pleasantest memories of his life, and where he had found so many kindly associations, which he now felt would be interrupted and perhaps broken. He was approaching a sharp turn in the highway of life; he knew it; and his heart sunk within him.

But the Club met on the call of Mr. Thomas, and Mr. William Jones, having got himself up with more odoriferous elaboration than on any former occasion, drew forth the remainder of the essay of his young medical friend, and proceeded to read an essay on

COLTS, AND HOW TO MANAGE THEM; WITH A FEW REMARKS ON BOYS.

When a colt is born into a family, especially if his lot is cast in pleasant places and he has a goodly heritage, the foremost 
danger is that he will be spoiled in early life. It really seems as if all the owners of horses endeavored to ascertain how in the most expeditious manner to ruin them. The natural tendency of a horse, young or old, is to preserve himself in a sound and healthy condition. The wear and tear of a life of hard work, and the injurious effects of a life of luxury and ease are

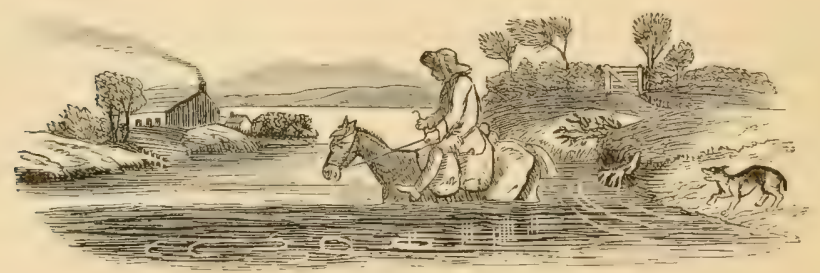

THE HORSE AND IIS RIDER, - AFTER BEWICK.

about equally destructive to him ; and the price he is obliged to pay for his intimacy with man, and the care and attention he receires at his hands, is the loss, in a large or a small degree, of the robust health and elastic animal spirits, and the abounding and joyous and painless power of motion, with which nature enclows him. A colt is a happy thing in the beginning, - happier than a child; a horse is intended to be a happy thing through life, - happier than a man. But the folly and misfortune which sadden and weaken the master bear heavily also upon his dumb and patient servant. The two travel a hard road together, and both are obliged to pay the penalty which should in justice fall upon one. If this is one of the inevitable consequences of the decree which gives man dominion over the fowls of the air and the beasts of the field, I suppose men and animals must silently and patiently submit and obey. But it may not be so. If, for the gratification of ambition or pride, or for high service to his race, or for immortal renown, man is willing to subordinate and sacrifice all his own physical powers, and is determined that his body shall obey the commands of his imperious spirit, inspired and consumed in the great flame, so must it be; but let him spare his servant who obeys him, - his dumb beast who has trusted in him. 
It is a good thing to remember that a horse has certiin natural faculties, without which he would not be a horse, and which it is important to preserve. Man is so wise, as well as tyrannical, that he finds it difficult to believe that he is not to remodel and reconstruct everything which is provided for his use and comfort before it is fit for his imperial service; and so he merldles with everybody and everything. It is much easier for him to comprehend his own handiwork than the Lord's. His boy stands before him, a bright, strong, attractive lasl, full of capacity and promise; a combination of faculties, good and bad, each striving for the ascendency; a fresh and glowing creation from the hand of God, intended to rejoice his father and bless mankind. It is only necessary for that father to know where to encourage him, where to suppress him, and where to let him alone ; to distinguish between his healthy powers, which a superabundance of youth and strength may sometimes make offensive, and those unhealthy deformities which, eren while quiet and slumbering, are disgusting and discouraging. But this is no easy task. Where there should be peace and mutual confidence, a contest begins ; and before it ends the boy has lost his self-respect, his lore, his confidence in his fellow-men; his virtues are cliscouraged, his vices rage. Or it may be that in rooting up the tares the wheat has been pulled up along with them; or his good points may have been distorted into subserviency and inefficiency, while his bad ones may have learned how to play the hypocrite, and rule. Where, too, there should be a manly and dignified intercourse, there is too often an effeminate and enervating intimacy. The boy may be softened into abject dependence upon those who should inspire and encourage his most manly self-reliance. That apron-string business, - how many a brave fellow has it sent mewling through life, like a milk sop! His father has made a good boy of him, but not the boy he was intended to be. The problem has been solved, but not in the right way. And, in the trials which follow, he wonders where those qualities are which he fult moving within him in his youth; and the father wonders why he is so little satisfied with the work of his own hands. No; do not 
bother the boys. Do not meddle with them too much. Make them way-wise early. Do not pet them into weakness, or check them into madness. And, when they go forth in life, let them have manliness enough to meet their fellow-men in a manly way, generosity enough to warm a generous feeling in the breasts of their associates, charity enough to forgive the faults of their race, and humanity enough to lnow that it is better and more useful to encourage the virtues than to expose the vices of society, and more honorable to set a good example than to pronounce a good precept.

But, to the colts. They, like the boys, may be spoiled by meddling. Not that I would leave them to run wild, - a rough and shaggy and half-savage drove, - but I would not so thoroughly domesticate them as to obliterate every trace of that headlong and impulsive temperament which makes a colt a colt. I have seen many a colt, especially when he was "the one ewe lamb," so petted that he was more like a house-dog than anything else. He had become so much the intimate companion of the family, that, as he grew up, he forgot to be in any way the servant. An appeal to his progressive faculties, which are the clominant ficulties of a horse, was received with a sort of blank astonishment, instead of as a signal for more vigorous exertion. He had lost all that independence and courage which Virgil saw and admired when he spoke of his "leading the way," and "braving the torrent," and "daring the unknown arch that spans the waves." You may suppose that a good gait and strong powers of endurance are not to be destroyed in any such way as this; but I assure you that even while they may possibly remain, the knowledge how to use them may be lost. Every experienced man knows that a horse will be one thing in the hands of one driver, and another thing in the hands of another. Hiram Woodruff could give new strength to The Koan the instant he took the reins; and Ripton and Dexter were inspired with new energy by his touch. Now, what shall we say to all this? Why, that a horse knows what he is doing, and with whom he is dealing; and that, having learned his lesson, it becomes as much a part of him as his second nature. If, 
therefore, you expect to get a horse, let the colt retain in its full vigor the fire that warms his blood. You must not humanize him entirely. Meet him half-way. Let him unclerstand that there is as much horse in you as you expect there will be man in him. Let your intercourse with him be calm and goodnatured, but prompt, energetic, decided, with a sort of carcless firmness, colored with tenderness and youthful activity.

A colt should neither be petted to death, nor conquered and subdued to death. He should be familiarized with the harness when so young that he may imagine the straps to be a part of himself. He should never know what it is to be broken. He should find himself engaged in business, he hardly knows how ; and he should be gradually introduced to his work with an unruffled temper, and an acquiescent but unsubdued spirit. When you conquer a young horse by violence you can never tell where the conquest is going to end. It may be in obedience; it may be in madness. Colts should be broken, then, at two years old, gently, easily, good-maturedly, - never with a harsh bit, but with a well-covered snaffle. The ordinary bitting apparatus is unnecessiry and should seldom be used. When a colt has well learned his lesson at two years old, he needs no more education until he is four or five. He will not forset what he has learned. And in this way you avoid all violence in training; you do not interfere with the colt's spirit ; you d not expose him to strains and wrenches; and you give him a chance to harden his muscles by free exercise in the open air, just at a time when his bones are becoming well knit, and his nervous poiver strong and enduring.

As a colt may be spoiled by over-handling, so may he be ruined by over-feeding. Dr. Buckingham of Boston, in an admirable address read before the Massachusetts Medical Society, after speaking of the reckless manner in which the lives of young children are trifled with by. the use of "artificial food," when they should be confined as nearly as possible to the nourishment which nature proviles for them, says: "There the baby of the lower animals has the advantage. He is fed on natural food only, from the beginning, because his father and mother 
don't know enough to kill him. Mam, the reasoning being, is defeated by the animals who exercise instinct only. They never, for amusement or curiosity, experiment upon the stomachs and lives of their children, with the desire of seeing how much indigestion they will bear with impunity. I am not alone in the belief that the excessive mortality at an early period of infancy is, very much of it, caused by attempts to substitute for natural food that which will save time and trouble to the mother, and by attempts to force growth!" With Dr. Buckingham's views of the proper food for the young of animals we must all agree; but if he were as familiar with the attempts to force growth in our stables as he is in our nurseries, I am afraid he would hesitate before drawing an unqualified illustration from the former for the benefit of the latter. I agree that the father and mother of the colt "don't know enough to kill him"; but the owner does, oftentimes, know just enough. And the same destruction which the physician witnesses with distress and shame in his practice the farmer may, with equal distress and shame, see in his stables, in a less fatal form, it is true, but in a form none the less clisastrous. You cannot easily kill a colt, I know, by injudicious feeding; but you can inflict injuries upon him that are worse than death, and give him a prolonged life of weakness and suffering and uselessness. A dyspeptic man in the counting-room or the pulpit or the court-room made a dyspeptic by the injudicious food of his chilclhood or by his own mature thoughtlessness - is an object of cleep compassion, it is true; but how much more compassion should we feel for the animal, which, without human aspiration and ambition to bear him above the pains of his existence, has been fed into a weakened stomach, and an exaggerated carcass, and nerveless limbs, and tender feet, and unsound joints, and cribbing, and torpor, and untimely death! And this we see continually among the favorite colts. Give me the boys whose health and strength are derived from natural food in inf.uncy and simple food in youth. Give me the colts whose dams have been generous, and whose owners have been judicious. If a colt is born late in the season, say in August or September, 
which is the best time of the year for him, there is no trouble about the first winter. A box-stall and grood food for the mare, who is to nurse her colt until the following spring approar hes, will take the young animal over the first trying season, and will prepare it for weaning and the first summer's rum at grass. Lut if the colt is to be weaned as usual, when he comes to the ham in autumn, we must then exercise skill and judgment in tramsforming him from his infant life to the days of his childhood. A little milk from the cow once a day for a few diass, and a pint of oats, with rowen or fine hay, a mixture of herd's-grass and redtop, will carry him over the trials of separation from his dam. But all this must cease as soon as prosible; and that diet of good hay and roots which is to serve him until he is put upon the road must be commenced. Many a colt has been ruined by heavy feed the first winter. It is pleasant to see his glossy coat and lively head and mature neck and well-dereloped form under a good suplly of oats, with just a little cracked corn. Iut all this pleasure will ranish if you look carefully at those knees which tremble a little after exercise ; and it will still more thoroughly vanish if you will examine him after his summer's run at grass, and wonder why he looks no better, and has not grown more. "It has been a bad season for colts," you say. But no. 'The season has been good enough for those young things which were wintered well in a box and a barn-yard, had simple food, were kept healthy and thriving, and went out in the spring a little ragged, it is true, and not over fat, but as hardy as cold air and good appetites could make them. The season has been good enough for these.

I have said good hay and roots, and by roots I do not mean carots, the most unsatisfactory root that horse, young or old, can eat, producing an unhealthy state of the skin and kidneys, overloading the cellular tissues with fat, and making a horse as washy as a lather-brush; but I mean Swedish turnips, ruta-bagas, - the king of roots for all young animals which are making bone and muscle, and for all old ones which are being stalled. I have long since abandoned carrots. Having become dissatisfied with them, both for my colts and my driving-horses, I 
looked about for a substitute; and, learning from a report on "Farming in Ireland," that in the early spring, when the farmers there begin to plough, they also begin to feed Sivedes to their horses which are to draw the plough, I took the hint. I do not ask others to follow my example; but I am under everlasting obligations to the Irishman for his, and to the observer who recorded it. I have seen many colts that have never eaten a mouthful of grain until four years old, and many a horse which has wintered always on hay and turnips, and wintered well. I know nothing which will restore a colt in early winter, if he comes to the barn out of condition, and begins to droop and stark as soon as he is confined to the stable, so readily and effectually as Swedes. You can drive your old horses in winter, when fed on them, an occasional drive, as well as when fed on corn. You can preserve their legs in good conclition, and their health in a sound state, year after year, on this food, and you may be sure that while you can bring a colt to a working age with hay and turnips better than with anything else, you can also secure to yourself a good, hard, lively winter horse, and to the horse himself a longer and a more useful and comfortable life. Turnips are economically raised; they make bone and muscle ; they keep the digestive organs in good condition; they impart vigor to the nervous system. If you are told that your colt or horse will not eat them, let me tell you that an animal that will learn anything will soon learn to like them. Hay and turnips and good pasturage for colts; hay and turnips for the winter food of resting horses. And if you do not believe that heavy food during the first winter will injure a colt, ay, cluring the first three winters of his life, go and buy one that has been this fed, and in this way pay for your knowledge as many another man has paid for his. Breed a good colt, and have him facle out of your hands about the fourth winter if not the first summer, on account of your stuffing process. Go and ask Ethan Allen, and hundreds of his clescendants, who went through the enervating process; go and ask the fat and favorite colts who are passing their hotbed lives in the good-looking stables which are multiplying everywhere; go and ask the 
thousands of English thoroughbreds, who are hobbling about, ruined by forced growth and forced efforts and hot food, cre their lives had fairly begrun ; and see what answer you will wet. They will all tell you that all the musle a horse makes after he is four years old is worth vastly more than what he makes before that time; that all the fat a colt loakls upon himself lefore he is four years old, and perhaps five, is an injury to him; that the life is shortened, and the powers are weakened, by early feed and early work; that the breeter of a good horse must be patient; that if you will feed for carly maturity, and drive for early speed, you must expect to lose a large part of the ultimate value of the horse, - a few yeits of life. a few seconds of speed on the track. Precocity is a poor thing; that alone endures which ripens slowly. The wisclom of human maturity is the best wisdom, - that maturity which comes from the steady and legitimate development of all humm powers. The speed and endurance are the greatest which are not called for until the horse is in full possession of all his faculties. An American man, dependent on himself for all that he is and is to be, fit for all the duties which may devolve upon him, will not grow up in a day. An American horse of all work, destined to toil like a locomotive, and expected to travel like one, wants time to develop, himself for his tremendous service. It takes a great while to make a man, a trotting-horse, and an Ayrshire cow. Spruce wood, Shorthorn beef, Western corn-fed horse-flesh, all grow apace; but they do not stand high in the scale, and they do not endure well unto the end.

\section{STABLES, AND HOW TO CONSTRUCT THEII.}

But the folly of bad breecling is no greater than the folly of bad stabling. The practice of providing warm and tightly built stables for young colts is as injurious to them as forcing their growth by heavy feed. A colt requires fresh air, and if he is furnished with an opportunity, he will be sure to use it. His lungs are the largest part of his internal organs, and he will provide for them if there is any way to do it. Give him the best 
and warmest box in the world, and he will leave it for the invigorating influences of the northern blasts in winter, and for the cooling and indurating effects of a coating of snow and hail. He seems to understand by instinct that if he confines himself to the elaborate, well-finished, model stable, his energies will wilt and facle. He seems to feel that a glossy, shining coat is to him a sort of white wall of a whited sepulchre, - pleasing without, but within full of all equine disabilities; and so he only asks for room to stretch his growing limbs, and a roof sufficient to shield him from the storm, undisturbed if he should see a star through the crevice above him, and feel the fresh breeze whistling through a crack by his sicle. He wants a well-ventilated stable, and a chance to get out of it whenever he has a desire to do so. And above all things let him stand on the ground, if possible, while in his box; and, at any rate, in a yard into which his box opens. A floor, especially a wooden floor, is bad enough for a mature working-horse; but to a colt it is almost destruction if he is compelled to stand continually upon it. There is no doubt that we ruin thousands of horses' feet in this country by our plank floors. 'The wood when dry is a non-concluctor of heat, and tends to keep the horse's foot above its natural temperature, and to remove from it all its natural moisture; and when wet it has a tending to rise above the surrounding temperature by fermentation. Wet or dry, therefore, wood, whether in the form of a plank floor or of sawclust beclling, is very injurious to the horse's foot. And so true is this, that we should always proride brick floors for all that portion of the stall which is occupied by the horse's fore-feet, a practice which, with the aid of an ointment composed of honey one part, tar one part, and lard five parts, simmered together, applied every other night around the coronet, and in the heel and frog, has protected all who follow it from soretoed horses, and will produce a foot which every farrier will admire as soon as he puts his buttrice into it. For the feet, then, of the colt and bridle-horse, furnish the earth as a standing-place; for the feet of the working-horse furnish a brick or stone floor. By such a floor alone can you secure to your colt 
a really good foot; and in this way alone, moreover, can you be sure of giving him a good lege, a well-shaped ankic, and a firm and substantial knee. I know not how it is; but the misshapen ankles and knees which come out of hot stables and wooden floors, among the colts which have wintered there, constitute the peculiar phenomena of the business of rearing these animals. But so it is; and I urge upon you all, whether you like horses or not, whether you fear them or trust them, to give them the solid ground to stand on, whenerer it is practicable, in their youth, and anything but wood in their days of maturity and toil.

So important do I think this matter of floors, that I pass by all the feeding arrangements of the stall, whether for hay or grain, as of secondary consideration. I think it a poor plan, however, to compel a colt to put his head through a hole in order to get at his food, or to thrust it under a low beam, or to drag his hay through a narrow rack. A feell-box so constructed as not to furnish an opportunity for cribbing and biting, elevated not much above the stall floor, and easily cleaned, is the best contrivance I have seen.

I take it for granted that no man will compel his colt to stand on a manure-heap, unless he wishes to injure his feet, and that the stall will be kept as clean as time and circumstances will allow.

But you will say to me, - those of you who are especially anxious to place the horse in as unfavorable a light as possible and to cool the enthusiasm of his friends, - that in spite of all your care and attention the animal will be sick and unsound. I know it. But let me tell you that he need not be sick half as much as he is, nor unsound half as often, if proper measures are taken to preserve his health and to prevent and cure his unsoundness.

\section{DISEASES: HOW PREVENTED AND CURED.}

With regard to the health, it is easier to preserve it than it is to restore it. The natural condition of the horse is one of 
robust health, of good digestion, of strong respiratory organs, of calm and even circulation. He has no especial tendency to those diseases which torment the human race and lurk in our swamps, and cellars, and water-springs, and crowded habitations, and thronged cities. A few epidemics peculiar to himself, and one or two inflammatory disorders, constitute the great bulk of his ailments. And yet the loss of horses by disease is enormous. What the precise character of the disease is, its symptoms, its local complications, its premonitions, the exact time and extent of convalescence, it is difficult to ascertain ; for the horse has no story to tell. He is dumb under suffering, and can point out to no man the locality of his distress. How keen his agony is no one can understand, for he bears with apparent insensibility crushing accidents which would paralyze his master, or leave him writhing in unspeakable agony. The effect also of remedial agents upon the horse is a matter extremely difficult to investigate. We apply them; relief comes; and we are too glad to trace it to our own efforts. But the veil is still drawn, and the mystery is as impenetrable as ever. I do not for a moment mean to doubt that soap and aloes, single or combined, that opium and saltpetre and rosin and ginger and yellow-bark and carbonate of ammonia and salprunella and oil of juniper and camphor and mustard and oil of turpentine and calomel and digitalis and belladonna and colombo and cassia and rhubarb, will cure anasarca and fevers of various kinds, and perhaps check glanders and farcy, because I am told so every day by those whose business it is to administer all those powerful medicinal agents. But I do know that in the human subject, such a pharmacopoeia has lost its ancient charm; and an intelligent assistance of nature is now considered as important as the heroic treatment adopted by our ancestors. And I think I know one thing more, and that is, that oftentimes the difficulties created by medicine itself are as hard to overcome as the disease it is proposed to remove by their use. Some physicians declare that medicines usually substitute one disease for another; and, as Nature cannot well do two things at the same time, we may turn her 
attention from what is ummanargeable to what is easily controlled. I think there is something in this; for I can reaclily understand that the condition of the body produced by mercury and iodide of potassium and opium and digitalis and quinine is as much a clisease as rheumatism or colic or palpitation of the heart or fever and ague. This a man can undoubtedly bear, if he can only more about his busine'ss or his pleasure. But a horse camnot. He must be "pretty" well," or his machine will not work. He is, moreover, very easily affected by medicine. His system feels it more readily than does that of a man. I gave a horse some small doses of antimony many years ago, for a glossy coat, and he was nearly a year recorering from the evidently prostrating influence of the drug. So I am of the opinion that we should aroid dosing our horses as much as possible. I should recommend early attention to the first appearance of illness, with care, warmth, shelter, starvation, and cold water. No sooner loes a horse show signs of sickness than his work should be stopped, his food reduced, he should have repose, and if feverish he should be wrapped in a wet sheet covered well with blankets. Do not try to work a sick horse; believe in season that he is really sick. Do not try to persuade yourself that he will get along; but nurse him promptly and well in a well-ventilated stable.

For the health of the horse improve the stables; and give the young horses new and better food, more sweet hay and less sour grain. In all the stables, public and private, give them better air, broader stalls, cleaner feed-boxes, better floors, and fewer stenches. Do not insult a respectable animal who has come down from the country to do his share of the work of the world, and has brought with him the memory of the sweet hills and clear skies, by immuring him in one of those crimped, rickety, rotten, stinking, slovenly, damp dungeons, where a dumb beast would lose his breath and his courage, beneath an oppressive weight of miasmas and hideous, gloomy, nasty confusion. Stop this, or pray that the horses may die ere the evil days come.

Cnsoundness. - But I shall be reminded, I am aware, of that 
unfortunate tendency of almost every horse, however well he may be cared for, to become more or less unsound. I know this is so. The horse has, partly by an inheritance of defects which are very apt to attend a delicate organization, and partly from the abuse to which he is subjected from his youth upwards, a liability to break down in many points where it would seem as if nature should have guarded and strengthened him with peculiar care. That he becomes sparined, and ring-boned, and curbed, and splinted, and broken-winded, and sore-toed, I will not deny. But all these evils seem to me to grow out of man's determination to spoil his horse; for when we remember that the horse's foot is the strongest structure of the kind in all the animal kingdom, and that his back is the most ingeniously pracked and contrived, and his fore-leg the best constructed to receive a blow, and his pasterns the finest combination of elasticity and strength, and his lungs the largest and most capacious, we can understand what long generations of hardship and misuse he must have passed through to bring upon each one of these important and naturally powerful organs a peculiar disposition to break down. If you were to examine a horse for the first time, you would say, "That foot cannot fail, no matter how hard the road; that pastern will not give out; that back-joint will not yield to the hardest strains even; those lungs will endure through all long and severe driving on the road or track!" And the fact that they do fail, and have so long failed, that they are liable to congenital malformation, is merely a proof that no machine can be subjected to such strain as falls upon the horse, without breaking; no animal organization could possibly endure it without serious, almost incalculable injury. It is useless, therefore, to close our eyes to this natural and artificial defect in the horse; and, bearing in mind that he has been brought to this condition by his hard service for man, it seems to me that, instead of condemning him for his weakness, we ought to help him out of his trouble.

I would not set aside a horse for unsoundness until I was satisfied that he was beyond remedy, and had become useless. Promptly and energetically would I attack the disease, nor 
would I allow my hopes to deceive me or to lead me away from quick and decided action. It is neither wise nor humane to shut your eyes to the first approach of the local difficulty; or to delay attending to it when cliscovered, in the hope that somehow the horse will find his way out. I hardly know any calamity, large or small, in which delay is so tempting and hope so strong, as the misfortunes which befall our farorite horses, and that special colt so full of promise.

Lameness, and how to prevent it. - If your horse is lame, realize the fact as quickly as possible, and attend to it. Locate the lameness where it manifestly is, or where it is most likely to be, even if there is a hopelessness about it ; and allow no friend or surgeon to flatter you with the suggestion that the trouble is temporary, trivial, confined to some comparatively unimportant point, and in your horse at least is not what it would be in every other horse about you. If the lameness is "forward," you may, in nine cases out of ten, infer that the trouble is in the foot, unless you can fund some manifest enlargement of the bones or sinews. Shoulders are seldom lame. It is the foot which is most exposed; it is the foot which is most affected by the action of the shoulder and leg above it, so that many wise observers have insisted upon it that any foot will stand if only rightly maniged by the muscles which move it; and it is the foot whose diseases are most difficult to cure. There is no lameness so perplexing, annoying, and discouraging. It puts an end rery effectually to a horse's fast work, and enrolls his mame amongst the slow movers on the farm or in the family carriage. Rest, cold water, the tar-ointment which I have already described, a cool brick floor, with perhaps a blister or two, will almost always relieve the early stages of the disease, and give the horse comfort and ability to discharge well the strvices of a quiet life. But laminitis and navicular disease do not surrender so easily, and are as troublesome as the gout when they find their way into the luxurious horse-circles, those circles in which they are most usually found.

So, too, of ring-bone and spavin. More conspicuous than diseases of the foot, they are more easily managed. I would 
never resign a promising young horse on account of the appearance of these diseases, and I would never neglect one until they were past relief. I have seen many a young horse fired and blistered as soon as the sparin showed itself, given a year's run at grass and in a winter yard, and come out fit for a long life of work, slow or fast. I am aware that the loss of six months or a year in the working-time of a horse is a serious matter for most men who use horses. But even to such as work them simply for what they can earn, this remedy is cheaper than the ultimate loss of the animal altogether; and to those who are breeding and preparing them for the market, it must be economy to take hold of these defects in season, and treat them promptly and summarily. Hardly a local disease can be named which will not yield to this summary process and rest. If there is a check to be put to cribbing, for instance, that most mysterious and unaccountable of all diseases of horses, a diseased habit which is often acquired, and which I have scen inherited, it is by instantly remoring every object which can be seized with the tecth, and by regulating the food. So, too, of swelled legs, scritches, corns, false-quarter, thrush, and other difficulties which arise from neglecting either the general condition of the horse, or from injuclicious use. Into the intricacy of veterinary practice I do not propose to enter; nor do I intend to give an elaborate description of diseases for the gratification of curiosity, or the teaching of science. I can only suggest the fundamental principles of dealing with the ills to which the horse is heir, - principles which, if adopted, will insure economy to the master and comfort to the animal, and the neglect of which may lead to an endless train of expensive surgical experiments and complicated and incurable disorders.

The paper of the young medical student was finished, and William Jones opened a general discussion on the modes of managing, driving, and selling horses, relating many interesting aneclotes of their sagacity and intelligence, and alluding gently to the variety of ways in which they can be disposed of, and the pleasing mystery which 
hangs around every new member of this inscrutalle family: Every gentleman present had his favorite, and could tell also of his accomplishments and value.

I suppose the debate was prolonged to an unusually late hour on account of the interest feit in the subject; but more, I am sure, from a painful consciousness that in all probability the Club would not assemble again. No man there acknowledged this, and no man entered upon a formal farewell. But they all lingered, and they somehow remembered those who had been with them, and now were not. Mr. Hopkins relieved his mind by rejoicing in the opening summer; Dr. Parker still told of his "Sorrel Jim"; Squire Wright contemplated Charles Ingalls with a sort of longing interest; John Thomas took the recordbook uncler his arm and departed. They all followed, and as they went, their thoughts turned tenderly to the minister, and the clouds which hung over his home. 


\section{SINCE THE ADJOURNMENT.}

TREE PLANTING. - MR. HOPKINS'S WILL.

JOHN THOMAS AND HULDAH TELL THEIR STORY OF MR. HOWE AND THEMSELVES. - WILLIAM JONES STILL DRIVES. - DR. PARKER MORALIZES. - I TAKE MY RECORD AND DEPART.

IT is many years since the Farm-Yard Club of Jotham adjourned and closed its record. A careful examination of the books and papers kept by the Rev. Mr. Howe, the Secretary, from which I have selected the discussions here presented, in a form somewhat modified in order to conform to the views and experience of our own day, has revealed nothing to me since the essay of the young medical student upon "The Horse," read by the sweetscented IVilliam Jones, on that soft mild evening of opening summer. I have every reason to believe that occasional meetings of members of the Club and others were held during the following winter, sometimes at the private dwellings of those who were hospitably inclined, now and then in the parlor of Mr. Hopkins, and on two or three evenings in the school-house or the vestry. In fact, I learn from tradition that the custom established by the Club remained for a long time, and that even at this day informal assemblies for deliberation and debate are quite common in the town; and that the effects of this long-continued public instruction are manifest to every lecturer who has the good fortune to address a Jotham audience. It is, indeed, true that the impression produced upon the "common and general mind" of the town by the institution founded and conducted by Mr. 
Hopkins and his contemporaries is visible still ; and that many bright young men, the fruit of this impression, have carried the names with which we are now familiar into almost every corner of the globe, for useful and influential purposes. But meanwhile the members have nearly all passed away, and the appearance of the village has considerably changed. A long time had clapsed since I had visited it, when, coming into possession of Mr. Howe's papers, I found it necessary to take a survey of the once familiar old spot, in order to do justice to the work which Mr. Iowe imposed upon me when he intrusted these papers to my care and keeping, to be dealt with according to my best judgment. I found there indeed

"The pleasant fields traversed so oft, In life's morning march, when my bosom was young."

I found the lake nestling as peacefully among the bills as it did when my childhood's eye rested upon it, and I found the wooded shores unaltered. The avenue of maples still invited the loiterer and the traveller, with its shade deepened and made more venerable by time. The farmhouses, with their sentinel elms grown grander and more majestic, reposed still upon the hillsides and along the valleys. Nature was the same; but I could see that during all these long years man had not been idle. The old meeting-house had been remodelled and modernized. The square pews were gone. The sounding-board had vanished. An organ filled the place once occupied by the primitive orchestra. The deacon-seats had been removed, and the deacons were reduced to the level of the congregation. And the pulpit had been brought down to the modest condition of an ordinary lecture platform. The old bare and bleak graveyard had become a cemetery, beautified and adorned with well-grown trees and shrubs. The grocery, standing where it stood years ago, had an 
unusually thriving appearance with its newly painted walls. To the front of Mr. Hopkins's old mansion, for after all his plans he had never built a new one, now converted into a summer boarding-house, had been added an ample piazza. A stylish residence occupied the spot where Peter Ilsley's house once stood. The roadsides and the Common were adomed with shade trees of every variety. And a rather commonplace New England village, with which I was familiar in my childhood, had been converted into a delightful spot, whose square and thoroughfares were as pleasing to the eye as had formerly been the swelling hills, the luxuriant valleys, and the green lanes, rejoicing in all their natural beauty.

My first impulse was to stroll among the scenes which had been impressed upon my eye so slightly in my earliest childhood, that, even though recognized now, they had all the charm of a revelation, which has been made more charming still by the haze and halo of a well-remembered dream. I had seen a great deal of the world since I had walked along the little roadside path through the maples; and when I entered upon it, on this delightful summer afternoon, the sunlight streaming through the branches, and the heavy shadows stretching across the street, filled my mind with a strange mingling of the pictures of early infancy in the freshness of the country, and ardent youth wandering beneath the solemn arches of the sacred cathedral. The first breath was of nature, and brought me back to my home; the second breath was of art, and carried me along the great halls in which man has deposited the work of his divine genius. I was surprised and delighted to find how much of the surrounding scene was familiar to me. The turns in the path, the projecting stones in the walls, the fecble flower by the wayside, the foot-worn root which was but half hidden in the earth, the rounded top of the hill on the right hand, the little grove of twinkling birches 
which crowned the hill on the left, the open ficlels and the decaying orchards, scemed not to have changed, but bore still the features of old friends, to remind me of those who, older and dearer, had now passed away. I met but few persons; and those whom I did meet. I did not know. And yet I saw in more than one youthful passer-by a glance which I had certainly secn somewhere, perhaps in a former generation. A turn in the road brought me into the view of a homestead which was filled with a thonsand sweet associations, - a strong and lind father, a gentle, quict mother, little children my former playmates, - the fresh and healthy and cheerful home of John Thomas and Huldah his wife, and of their children John and Susan. John and IInldah were old to me when I first knew them ; they were old to me now. And when I entered the house through the front door, which stood open, as it had always done on the long, warm summer days, and found the old people there, they were the same to me, and I was the same to them, that we were when we parted more years ago than I dare tell.

"Why, my little dear," exclaimed Huldah, when she realized who I was, "how you have grown! Your poor, dear father! and so he's clead; and your mother, dead too! and here are John and I spared or forgotten, mercy knows which. I'll call John. I guess he's taking a little nap somewheres. He and I had our golden wedding last night, and the young folks kept us up pretty late, and John can't stand quite what he could once. I do so wish you had been here; your sir and your marm were both at our wedding fifty years ago. But sit down; do, now, my little dear; you must be awful hot and tired."

John was soon aroused, and he came in to refresh his memory, and to get myself and my father and my grandfather gloriously mixed in his allusions to my family. He was the same sensible and practical farmer that he was 
years ago; and having added to his agricultural experience that of a faithful public servant in town and county and State, he had a great deal to say for himself that was interesting and instructive. After a good deal of circumlocution, I brought him to the affairs of the Club, in which he had formerly been so much engaged, and informed him of the work I had undertaken. The record he had seen, as kept by Mr. Howe, and he considered it substantially correct. Of the members, both he and Huldah had much to say.

"O, poor dear Mr. Howe," said Huldah; "he waited and waited after Mrs. Howe died, cheerful enough and good as man could be, but kind o' lost for twenty-five years. And then he died; and glad enough he was to go. I have heard about a great many last words, but I do think that Mr. Howe's were the best of all. 'I want to be with God,' said he, when one of his daughters asked him in his last moments if he wanted anything; and then full of this great faith he went to heaven. He was a good man; and he loved Mrs. Howe; and he had a hard time; and he set us all a good example; and he was so sensible; but he was terribly broken down by Mrs. Howe's death, and never was really himself until he knew he was going to dic, and then he was just the same Mr. Howe who was settled here a young man, and good as a saint, just before John and I were married."

"I suppose Mr. Hopkins died long ago ?" said I.

"O yes," replied John. "He died long before Mr. Howe. In fact, he left a great deal of the work he wanted done after he was gone in Mr. Howe's hands. Mr. Hopkins thought a great deal of Jotham, you know; and he did a great deal for us in his will. His two boys were a little wild, and a little unlucky, so he provided well for them, all in trust, and then he looked after his native town. He left a fund for a library, and made the minister and the 
selectmen trustees; and provided money enough for a goot fire-proof buileling, whenever the: trustees might think such a building necessary; for he said he thought the library ousht to grow to the size of the building before it was erected. And he was very particular about the books; they were to be what he called standard; the best volumes of history and biography, especially of our own country; accepted literature; novels, only when the world had passed judgment upon them, and classed them with the best products of the human mind. He rather liked novelreading; but he detested a mere extravagant and overwrought story, with more incident than philosophy. So I heard him say. He left a fund to keep the village sidewalks, and the grounds around the church, and the Common paths and fence in order; for he said the law provided for the highways only in a town, and he knew the people would keep them in good condition if the ornamental part was well taken care of. And then he left a fund for the planting of trees, and the foundation of a "Village Improvement Association " in this town. On this last matter he was very earnest and enthusiastic. In that portion of his will making provision for this association, he alludes to a work of the same kind just starting in Connecticut, and he inserts the following passage, which, it is supposed, Charles Ingalls wrote for him, when he practised law here with Squire Wright. I happen to have a copy here in my desk :-

"'For, whatever may be man's outward circumstances, however hardening and depressing may be the incidents of his life, he has an instinctive love of beauty which insi-ts on being gratified. He knows that this is his distinguishing characteristic, which separates him from the beasts that perish, an element of his mind and heart which leads him from nature up to nature's God. To him the sunrise means glory as well as daylight ; the lone and lofty mountains elevate him to the con- 
templation of Almighty power, even while they are a shelter for the wild goats; the dewy pastures, where the cattle graze and recline in the long shadows, lull him to the sweets of evening repose; the sparkling stream, where "the wild asses quench their thirst," soothe and sing him to happiness and rest; the majestic and commanding tree, whose wide-spread branches shelter the panting animals from the blaze of the noonticle sun, is a picture of power and strength and varying.loveliness which is to him a source of never-ending cielight. When his eye surveys the swelling landscape, the emotions which belong to him, as a child of the Creator of all, inspire and elevate him above the earth on which he treads, and distinguish him from that other orcler of animal existence to which all scenery is alike; whose sensibilities no ugliness of nature or of art offends, which no starry heavens delight, and no homely surrounding disturbs; whose vision is blind, both to the graces and the deformities of even its own kind; which nibbles the daisy and the June grass with equal satisfaction; and whose eye is not moistened with the tears of joy or sorrow. It is man alone who knows that

\section{"A thing of beauty is a joy forever,"}

and who, because he is a man, endeavors to beautify and cultivate himself and his abode on earth. His religion and love and all his affections and aspirations seek expression in some form of beauty; and so the poet, and the architect, and the artist, and the gardener, in song and picture, and temple and lanclscape, provide for him the divine language. It is as an animal, that he is contented with a cave; as a man, that he organizes the refinement of a home. And although, as Plato tells us, "the groves were the first temples of the gods," still man erects his chapel, and loves it and adorns it, and lingers around it as the home of his spiritual life, the sacred spot where he can hold communion with his God. Here in the presence of the Father he reaches his highest sense of the beautiful, and inspired with piety and love he elevates both altar and priest into his highest region of the sublime. This is man's sense of beauty, his divine characteristic, his angel which attends him in 
his most sacred hours, his inspired power which elevates him into a higher order of beings, and gives his own works a signif cance which l)ivinity alone could bestow. And it is this sense: of beauty which, secking expression in music, and pretry, and art, and adornment, makes society cheerful and fills our homes with delight." ",

"He had begun, some years before his death, a plantation of trees about his house, and he always insisted that such a plantation should suit the building it is to surround and the landscape it is to occupy. He kept open spaces among his trees for their benefit, and to gratify his eye; was opposed to planting trees in straight lines unless it was necessary; seemed to feel towards his trees as he did towards his old friends, and declared that the towns of New England should be made so attractive by ornamental trees that the young men would be slow to leave them, and having left would be quick to return. He was fond of rehearsing the history of representative trees, the Charter Oak, the IVashington Elm at Cambridge, the Frye Elm at North Andover, hung with the story of Lovewell's fight, the oak at White Lady's, the sturdy old tree from which the stern-post of the frigate Constitution was cut. And in leaving a fund to endow an association for the purpose of beautifying his native town, he felt that he was not only erecting a monument to his own memory, but was paying a tribute to the memory of the fathers, who gave him the home he loved so well. And now see how Jotham has improved under the advice and assistance of this one good man."

"You referred just now to Charles Ingalls, who studied law with Squire Vright," said I. "Is he still in town?"

"O no," replied John Thomas; "the young Squire, as we called him, married Clara Bell, the miller's daughter, so many years ago that I have forgotten when it was: I should say a year or two after Dr. Parker married the 
old Squire's daughter Fanny; and then he left town for some great Western city. We were all distressed to have him leave. Mr. Howe was terribly cast down about it. Mr. Hopkins absolutely mourned outright. Squire Wright shut up his office for nearly a month after he left. I never did miss anybody in my life as I did this young lawyer. His leaving was bad enough for us men; but I believe the women mourned over the loss of Clara as much as we did over the loss of Charles. We used to talk them over when any of us got together, and I remember how the old men of that time always wound up with saying, 'He'll be a great man yet.' And I have been told, for I haven't read the newspapers much lately, and I should think you must have been out of the country not to have heard of it, that he has done well. I heard a gentleman say the other day to our minister, that if there was a man in this country who had been true to the best interests of the people, had accepted the best and most humane theories of the times, had frowned upon the wrong and upheld the right, had been an honest and capable lawyer, and at the same time a progressive jurist, a wise politician, and a powerful statesman, that man was Charles Ingalls, who taught school, and commenced the practice of his profession, in this town. I suppose from what the man said, Charles must have been in Congress, and a great judge somewhere. We have had hard times in the country since he went West; but I am sure he has done his duty wherever he has been. He was equal to any question we ever had here. I am sure he must have been equal to whatever he has had before him, wherever he is. I am told he is well off. Of Clara I heard the gentleman say, 'As for Mrs. Ingalls, she is simply splendid."

I was obliged to acknowledge that I had been out of the country a great while longer than I ought to have 
been, considering the necessities of the times, and that my knowledge of the controlling men was very poor; and I realized the truth of what Hawthorne says in the "Marble Faun," of Kenyon and Hilda, when they entered hand in hand on the journey of life: "And now that life had so much human promise in it, they resolved to go back to their own land; because the years, after all, have a kind of emptiness, when we spend too many of them on a foreign shore." I felt ashamed of myself that I knew more about Thiers and Castelar than I did about the American jurist and statesman, Charles Ingalls. I remembered, however, that I had seen men who were proud of such ignorance, - and Americans, too.

John Thomas was anxious by this time that I should take a look at his farm. "For more than seventy-five years, man and boy," he said, "have I lived on this spot; for more than fifty years have I carried on this farm; and it is just as good now as it ever was. I am not ashamed to show my barns and orchards and cattle and crops to any man, no more than my father was before me. And John, I've settled him on a good piece of land over yonder against the hill, and he is a first-rate farmer. And Susan, she married Mr. Howe's oldest son; and I've settled them on a nice little farm down by the pond, and they get a good living. So I have nothing to complain of. I am so glad the children took to the land, and did n't wander away from home."

I learned from John Thomas that Squire Wright and his estimable wife had departed, having never fully recovered from the effects of the Western miasmas to which they were exposed on that unfortunate journey, and leaving the estate and the professional business to Charles, their indifferent son, who was lounging along the path which the old Squire had travelled with so much vigor, and satisfying himself with a frequent recital of the rela- 
tions which existed between his father and the distinguished men of his time. Fanny, too, I was distressed to hear, had followed her parents, and had left Dr. Parker to toil on alone for a short period, until Margaret and "The 13oy," having reached years of discretion, had bound themselves by the great bond which unites all loving hearts, and had taken the domestic economy of the Doctor into their own hands. I say I was distressed to hear of Fanny's death, because I remembered how, as a little child, I was dazzled with her beauty, and charmed into a dreamy ecstasy by her rich and glowing voice. I was indeed distressed, and began to feel that nothing was left of Jotham for me but its new generation, its trees and its necrology, when William Jones entered, a cheery, well-preserved, and well-got-up old man, and finding out who I was, invited me to drive behind a good horse. "Your father liked a good horse," said he, " and knew a good one as soon as he put his eye on him."

The road we travelled led along the shore of the lake, and never, in all my wanderings, have my eyes fallen upon a more fascinating scene. On either hand dark hemlock groves, and sloping pastures studded with towering oaks, looking out upon the sparkling waters of the lake; and before me, in the distance, the blue mountains which bounded the far-off horizon, beneath the declining sun. William Jones was in a peculiarly talkative mood as we drove on, and supplied me with a great mass of the personal incidents of Jotham, which had been omitted by the less gossiping John Thomas, in the stronger sketch which he had given me. As we proceeded, the road seemed to dawn upon me, and erelong a very vivid picture of my childhood and its associations rose before me, evidently excited by scenes along the way which must have been well known to my eyes in a former day. I seemed to remember with great vividness a drive just like this, in 
which I was accompanied by my father and mother, whose long-vanished faces had never been so distinct before me as at this hour. I passed the very place by the roadside where my father alighted to gather a flower for my mother, then as delicate as the flower itself; and I recognized the spot, and saw her as I had not seen her for many a long year. Turning away from the shore, the road brought us to the fine old mansion once occupied by Squire IVright, and now in the possession of Charles, his son and heir, who stood, as we approached, beneath the shade of the towering trees which embowered the house, and leaning orer the gate, saluted William Jones, as an idle man will always salute a passer-by who is known to be engaged in the business of selling and exchanging horses. As William Jones drew up, and the drowsy conversation commenced between these two gentlemen, I turned my eye in the direction of the lane leading to the lake, and was seized with a desire to enjoy its quiet footpath, as I was sure I had enjoyed it once before; and to enjoy it now, unmolested and alone. Bidding Mr. Jones good evening, and touching my hat to the stranger at the gate, I entered the lane and wandered on, - that picturesque and dreamy path which Dr. Parker and Fanny traversed on that eventful and silent and fervid summer evening a quarter of a century ago, when love was revealed to them, and the way of life was opened. I knew the lane, its overshadowing trees, its little brooklet trickling modestly along the wayside, and creeping at last under the loose, misshapen wall, to be lost in the meadow beyond. Its hiding-places and its vistas from the highway to the lake were all peopled to my mind with the sighing youths and maidens who had paced that path before me. As they had reached the shore of the lake whose tinkling waters had listened to so many ardent declarations in the eventide, so had I. The beauty of the spot was enchant- 
ing. Upon a dead twig overhanging the water a robin was pouring forth his evening song. Upon a stone near by sat a squirrel, who had just taken his farewell sip of the waves, and, bounding away at my approach, found his nest in the top of a lofty forest oak, from which, as he entered, he chattered to me his saucy and defiant good night. In the depths of the wood a partridge was drumming his last summons for the day to his mate. The whippoorwill was still lashing out his evening song there; and still the sound of the plashing oars, and the voices of the rowers, came across the placid waters. When I reached the spot, I found that I was not there alone.

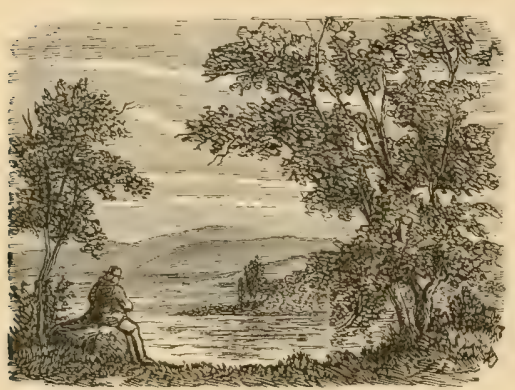

DR. PARKER AT THE LAKE. Sitting upon the bank, and surveying the scene, was an old man, who seemed to be so absorbed in thought that, not until I stood by his side, was he aware of my presence. He arose with a slight air of surprise, and addressed me with a manner in which I discovered just enough of a brusque and patronizing tone to lead me to suspect what might be his professional calling.

"A charming evening, sir," remarked he.

"Most delightful!" I replied. "I have seen nothing finer since I was brought here by my parents, a little child, many, many years ago."

"The spot is familiar to you, then, I suppose?" said the old man.

"Not exactly," replied I. "And yet I recall it with a vividness which I can hardly understand. I know well the story of this lane and the shore. One of my father's old friends, a bright, accomplished, and energetic gentle- 
man, as I am told, often resorted hither for meditation ; and they do say he lost his heart here, too."

"Your father was - " said he, looking eagerly for the reply.

"My father was Henry Sullivan, who left this town long ago, and died at sea," I answered.

"Died at sea," said the old man, "because your sweet mother had died on shore before him. And are you the boy Henry whose name was the last word uttered by her dying lips ?"

"I am Henry Sullivan," said I; "the chronicler of the Farm-Yard Club of Jotham, and of the personal adventures of this town, as I have gathered them from record and tradition. And I shall indeed congratulate myself if I have met here Dr. Parker, the old friend of my father and mother, whose name I have heard repeated so often in my family, and have found, with many an affectionate reference, in the papers my parents left behind them. But if you are that old friend, I beg you to excuse the allusion to your name, and to an incident in your life which I just now carelessly made, and which may have brought painful memories to your mind."

The old man's heart was deeply moved, and he did not readily regain self-possession enough to reply, or even to recognize my presence. When, however, he was able to control his feelings, he beckoned me to place myself beside him on his rustic seat, which he had fixed there, and laying aside all those peculiarities which a long professional life as a physician had given him, he poured forth in the kindest and gentlest and tenderest way the story of his life. He rehearsed the trials of his petted childhood, the obedient affection of his mother, the pride of his father, the enervating flattery which surrounded him, his education abroad until he had nearly lost his national characteristics, his weakened moral sense, his surrender to tempta- 
tion, his jealous sensibility, his vanity, and his ignorance of the motives and feelings of his fellow-men. It was curious and interesting to see how, through all his errors and wanderings, he had preserved his conscience and his sense of honor. It was sweet to see his chiicllike nature returning to assert itself, as fresh and pure as it was in the beginning. He begged me to learn at once the value of obedience and humility. "Individuality I admire," said he; "but men ruin themselves by cultivating their eccentricities, and expecting the whole world to be obedient to them. I know how hard it is to resist a wayward impulse, a sudden determination to force the current of life about you into your own channel; and I know, too, the misery which follows such attempts, even when they are successful. If the story could be told of the overwhelming remorse which darkens the private hours of him who has gratified his revenge, or achieved a mean ambition, the victims of these wrongs would ask for no keener punishment for those who have injured them. I have known many a life ruined mentally and physically by the blasting heat of violent resentment. I have known many a life to be made cheerful and happy and strong by a magnanimous and generous desire to forgive, forget, and obey. I am an old man now, grateful for the blessings which have been showered upon me; but conscious that my work is but half accomplished, and that my talent has been hid, because I could not accept, with a generous appreciation, the work of those about me, and because I would not look with a forgiving eye upon the weaknesses and follies of my fellow-men. I have no doubt that, in a larger sphere of action, I might have learned my own shortcomings, and have been humble; but a larger sphere I would not seek, because I was too proud to have my defects and faults exposed. Beware, then, my friend of an intense self-consciousness. It does not belong to the truly great powers 
of the mind, or the great qualities of the heart. But the wise and useful and fortunate man is he who, while bravely and manfully asserting his own opinion, is receptive of the opinions and knowledge of others. Next to the selfrighteousness of the Pharisee stands the self-conceit of the fool. And if you look the world over for the highest achievements of genius, you will find them where man has forgiven his enemies and denied himself. I think a man can be neither a good poet, nor a good orator, nor a good statesman, nor a good husband, nor a good father, nor a good citizen, without reverence; and no man can have that characteristic who "thinketh of himself more highly than he ought to think.' The world is full of brilliant failures, because of our conceit. It is full of sad successes, because the Lord will dwell with the humble and the lowly and the unfortunate. Pride and wisdom seldom go together. Self-conceit, and that love which is the foundation of all power, and unlocks the gate of heaven, do not dwell in the same breast. $O$, if Fanny could only come back to this spot, where we began life together - "

And here the old man broke down entirely. He never finished that sentence, but I knew what his remorse was, and I listened with affection and pity, as he rehearsed, far into the night, his experiences in Jotham, and spoke tenderly of Clara Bell, and generously of Charles Ingalls, whom he called "the wise and honest and obedient," and reverently of $\mathrm{Mr}$. and Mrs. Howe, and admiringly of Mr. Hopkins, and respectfully of John Thomas and his wife Huldah, the kind-hearted and Christian, and proudly of his intimacy with the intelligent and accomplished scholars of the land, and sadly of his own mistakes and faults. His voice faltered when he spoke of Mrs. Ilsley, and told how blessed to him was the companionship of Margaret and her husband, "The Boy."

The early morning moon was just shining over the hills 
as we rose to go, paving a silver pathway across the lake. The dew lay heavy on the grass, as the old man leaned upon my arm and pursued his way home. When daylight came, I left Jotham with my record of the Club, my notes, and a new friendship cemented by sacred memories and the best impulses of the mind and heart, and feeling that my work as the Chronicler of the Club was finished.

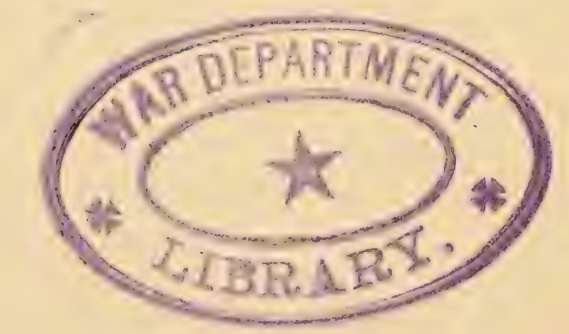




\section{AGRICULTURAL INDEX.}

Agriculture, when profitable, 20.

Animals, points of beef-producing, 47 .

Apples, the cultivation of, 440 .

"when and how to gather, 443 .

" best varieties of, 444 .

Ashes as a fertilizer, I46.

Asparagus, the cultivation of, 393 .

Barley, 3 I 8.

Barn, a plan of constructing, Io.

Beans, the cultivation of, 398 .

Beets, the cultivation of, 399 .

Blackberries, the cultivation of, 427 .

Bones as a fertilizer, 146.

Breeds, foreign, not all valuable, 36 .

Brown hay, I9I.

Butter-making, Io6.

Cabbages, the cultivation of, 384 .

Calves, Ayrshire mode of raising, 60.

Carrots, the cultivation of, 269.

" effect of, on animals, 269.

" modes of raising, 400 .

Cattle, statistics of, 30 .

" value of pure-bred, 33 .

" how to feed, 75.

" what food to give them, 76 .

Cauliflower, the cultivation of, 385 .

Celery, the cultivation of, 393 .

Cheese-making, 107.

Chess, what it is, 318 .

Chickens, care of, 542 .

Clover, 174.

Colts, how to break and manage them, 567 .

Composting, 122.

Corn, essay on, 284.

" soil for, 285 .

" preparation of soil for, 285.

Corn crop, record of, 287.

Cows, points of, for the dairy, 45 .

" difficulty of breeding for the dairy, 49 .

"mature slowly, 63 .
Cranberries, the cultivation of, $4 \mathrm{I} 2$. " mode of gathering, 415 .

Cucumbers, the cultivation of, 375 .

Currants, the cultivation of, 427 .

Dairy, importance of, 32.

Decomposing manure, 124 .

Diseases of cattle, 72.

Drainage, 158 .

" applicable to certain lands, I 59.

" of bog-meadows, I63.

Drain-tiles, 165.

" how to lay them, 166.

Ducks, the breeding and rearing of, 546.

Feeding, when profitable, 66.

Fertilizers, I 2 I. " artificial, I52.

Flowers, the cultivation of, 428 .

Fodder-corn, value of, 80 .

Food for young dairy animals, 60 .

" uniform for cattle, 64 .

“ for cows, Horsfall's, 90.

"6 the steaming of, $9 \mathrm{I}$.

Fowls, Asiatic, 536.

“ English, 537.

"French, 537.

" common varieties, 538 .

" proper food for, 54I.

" diseases of, 542 .

Fruit-culture, 437 .

Fruit, profit of, $43^{8}$.

Garget caused by improper feeding, 62 .

Geese, the feeding and care of, 545 .

Gooseberries, the cultivation of, 427 .

Grapes, the cultivation of, 467 .

"what vines to choose, 468 .

" how to set the vines, 469 .

" how to prune the vines, 470 .

" how to keep them, 473 .

"best varieties of, 474 . 
Grass, best time to cut, I75.

" best varieties of, 174 .

" most nutritive condition of, 176 .

Grass-seed, best time to sow, I78.

" "how to sow, 185 .

Green crops ploughed in for manure, I5I.

Hay, how to make it, 193.

Hay crop, value of, 177 .

Harrows, 483 .

Hen-house, plan of, 540.

Herds-grass, I 74 .

Horse, description of a good one, 558 .

" American trotter, what he is, $55^{8}$.

"A American trotter, how bred, 560.

" Old Messenger and his de. scent, 560 .

"Mambrino and his descent, 560.

"Abdallah and his descent, 560.

" list of trotters, and what they are, $56 \mathrm{I}$.

" the effect of French blood on speed, 563 .

" celebrated instance of the value of French blood, 563 .

" how to breed and preserve his moral qualities, 564 .

" his physical qualities hard to reproduce, 565 .

" how to treat him when young, 570.

" how to spoil a young one by feeding, 572 .

" how his stable should be built, 576.

" how his diseases can be prevented and cured, 578 .

" how his unsoundness should

Horse-hoes, 483. be dealt with, 580 .

Hotbeds, how to prepare them, 373 .

Hungarian-grass, the cultivation of, I 86.

Implements of husbandry, 489 .

Lambs, when to wean, 512.

Lettuce, the cultivation of, 394 .

Lime as a fertilizer, 149.

Mangolds, the cultivation of, 396 .

Manure, experiments with, 150.

Medicine for cattle, 65 .
Melons, the cultivation of, 396 .

Milk-mirror, value of, 104.

Mowing-machines, 487 .

Muck, when and where to be used, I23.

Oat-meal as food for calves, $6 \mathrm{I}$.

Oats as a crop, 3 Io.

" best food for horses, 3II.

"where they grow best, 3I3.

" time to sow, 3I4.

Onions, the cultivation of, 382 .

Orchards, when to plant, 438 .

" how to set, $44 \mathrm{I}$.

Organs, fat-producing, 57.

milk-secreting, 58 .

Parsnips as a crop, 400.

the cultivation of, $27 \mathrm{I}$.

Pasture, a good specimen of a, 238.

Pasture-lands, 220.

Pastures, how to restore them, 221 .

" when to plough them, 223.

" how to fertilize, 224.

" how to manage them, 233.

Peaches, the cultivation of, 453 .

Pears, " 449.

" best varieties, 448 .

Peas, the cultivation of, 397 .

Ploughs, 478

" how to construct them, 48r.

Potatoes, soil for, 337.

" manure for, 338 .

" how to raise them, 343 .

"6 the best for seed, 343 .

Poultry, 535 .

Raspberries, the cultivation of, 427 .

Redtop, I 74

Rhubarb, the cultivation of, 397 .

Root crops, 252.

Rowen for calves, $6 \mathrm{I}$.

Ruta-bagas, the cultivation of, 255 .

Rye, 319.

Sand, use of, for composting, 123.

Sheep husbandry, 505 .

"various breeds of, 508.

" how to feed, 5 Io.

" diseases of, $5^{12}$.

Soiling, value of, 93 .

Soils, the mixing of, 125 .

Squashes, the cultivation of, 395 .

Steaming food, value of, $9 \mathrm{I}$.

Strawberries, the cultivation of, 425 .

Swedish turnips, essay on, 267.

Swine, 527 . 
Swine, best breeds of, 529 .

" how to house and feed, 530 .

Tomatoes, the cultivation of, 396 .

Top-dressing, experiments in, I 49 .

T'urnips for calves, 61 .

" for horses, 78 .

" the cultivation of, 77 .
Turnips, essay on, 399.

Wheat, essay on, 314.

" soil for, 315 .

" manure for, 315.

" how to destroy its parasites, 3 I6.

" when to be sown, 316 . smut of, 317 .

THE END.

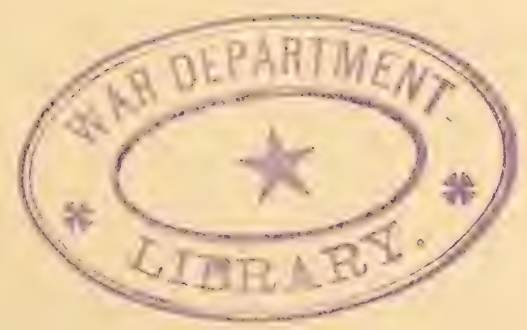











\section{LIBRARY OF CONGRESS

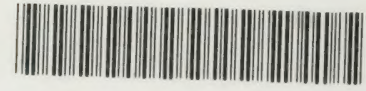 00027740716}

